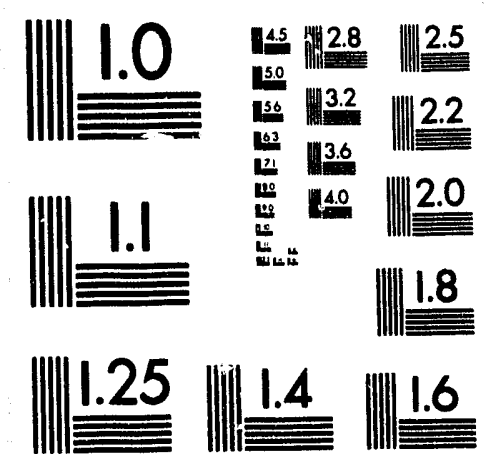



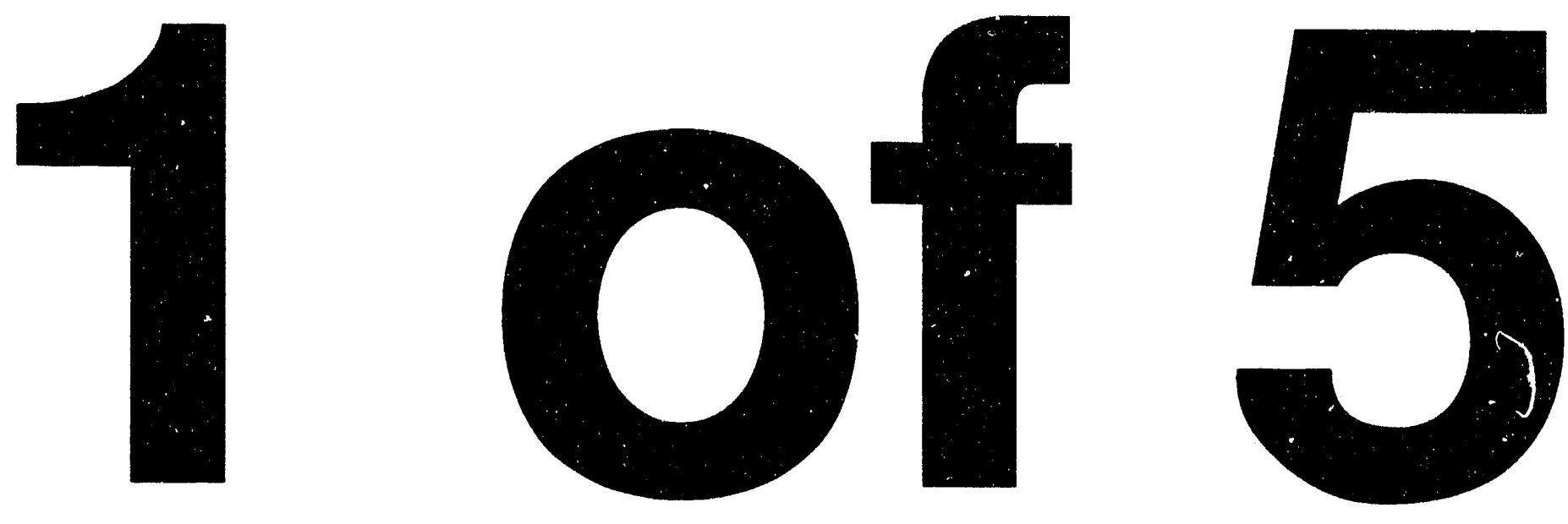


\title{
NATIONAL IMPACTS OF THE WEATHERIZATION ASSISTANCE PROGRAM IN SINGLE-FAMELY AND SMALL MULTIFAMILY DWELLINGS
}

\author{
Marilyn A. Brown \\ Linda G. Berry \\ Richard A. Balzer \\ Ellen Faby
}

May, 1993

\author{
Prepared for the \\ Weatherization Assistance Programs Division \\ U. S. Department of Energy
}

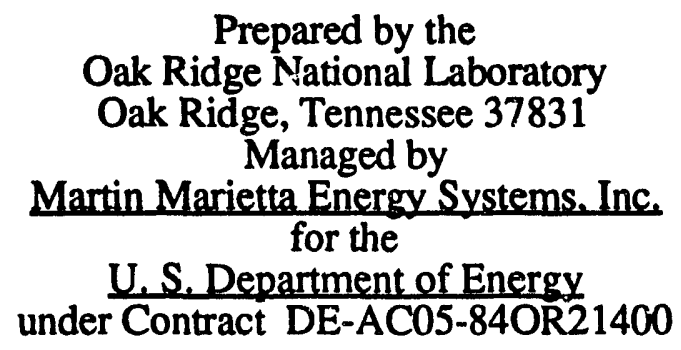




\section{National Impacts of the Weatherization Assistance Program in Single-Family and Small Multifamily Dwellings: Program Year 1989 At a Glance}

\section{REPRESENTATIVE NATIONAL_SAMPLE}

Number of Agencies

Number of Weatherized Dwellings with Agency Data ${ }^{a}$

Number of Utilities Providing Data

Number of Weatherized Dwellings with Utility Data ${ }^{b}$
368 (of 400 in original sample)

14,971 (of 18,748 in original sample)

543 (of 926 contacted)

4,796 (of 13,162 gas or electrically heated dwellings)

\section{ENERGY SAVINGS}

\section{Eirst-year_Savings}

Gas (50.6\% of weatherized homes)

Electricity ( $9.5 \%$ of weatherized homes)

All fuels ( $100 \%$ of weatherized homes)

\section{High Gas Savings}

Cold climate region

Single-family detached dwellings

10 exemplary agencies $c$

Low Gas Savings

Hot climate region

Mobile homes

20-year Savings

All fuels

\section{VALUE OF BENEEUTS}

Gas Savings

Electricity Savings

Savings of All Fuels

Nonenergy Benefits

\section{COST FEFECTIVENESS}

Program B/C Ratiod

Installation $B / C$ Ratio

Societal B/C Ratiof

Cost per MBtu of conserved gas

Cost per kWh of conserved electricity

\section{Savings Per Dreelling}

17.3 MBtu

6.2 MBtu (site)

$18.9 \mathrm{MBtu}$ (source)

17.6 MBtu (source)

23.5 MBtu

18.4 MBtu

34.7 MBtu

9.1 MBtu

12.0 MBtu

69.7 million MBtu's or 12 million barrels of oil
$10.9 \%$

$12.0 \%$

$13.0 \%$

$12.2 \%$

$13.5 \%$

$17.7 \%$

$14.1 \%$

$23.7 \%$

$19.9 \%$
$33.4 \%$

$33.4 \%$

$15.4 \%$

$16.9 \%$
$18.3 \%$

$35.9 \%$

$18.2 \%$
$24.9 \%$
Eirst_year

\$101/dwelling

\$128/dwelling

$\$ 116 /$ dwelling

$\$ 816 /$ dwelling

Gas Heated

1.06

1.58

1.61
Electrically Heated

1.13

1.69

2.33
20 years

$\$ 1,605 /$ dwelling $\$ 1,728 /$ dwelling $\$ 1,690 /$ dwelling \$976/dwelling

All Euels

1.61

1.72
$\$ 4.60$ (vs average weighted retail price of $\$ 5.90$ )g

$\$ 0.04$ (vs average weighted retail price of $\$ 0.069$ )g

a Agency data included information on household demographics, weatherization procedures, measures installed, and costs.

b Utility data were used if they included at least four meter readings pre- and post-weatherization and passed a number of other data quality checks. Ninety percent of the dwellings with complete utility data had gas heat. Complete data also were available on 3,226 gas-heated control dwellings and 429 electrically heated control dwellings.

c A geographically dispersed set of 10 exemplary agencies was sampled for analysis in the second phase of the Single-Family Study.

d The program benefit/cost ratio compares the discounted value of energy savings to total program costs with an assumed lifetime of 20 years and a discount rate of $4.7 \%$.

e The installation benefit/cost ratio compares the discounted value of energy savings to installation-related costs with an assumed lifetime of 20 years and a discount rate of $4.7 \%$.

f The societal benefit/cost ratio compares the discounted value of both energy and nonenergy benefits (such as employment and environmental impacts) to total program costs with an assumed lifetime of 20 years and a discount rate of $4.7 \%$.

$g$ Fuel prices were developed by weighting average State prices according to the proportions of PY 1989 weatherized dwellings located in each State. 


\section{TABLE OF CONTENTS}

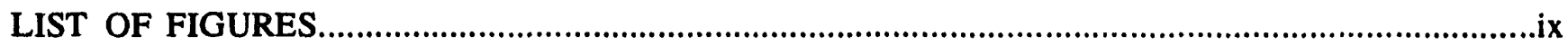

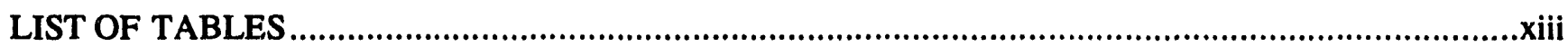

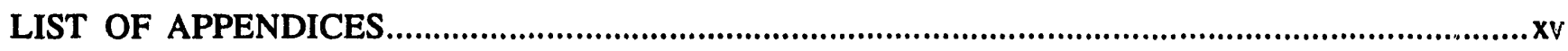

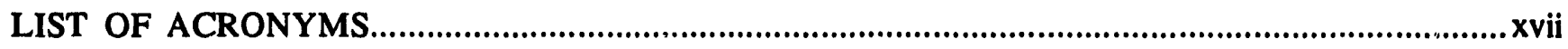

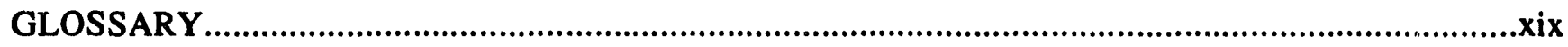

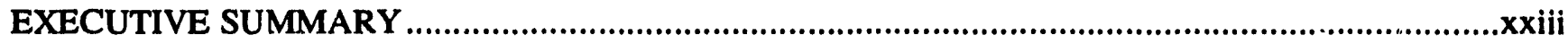

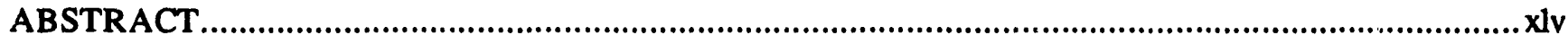

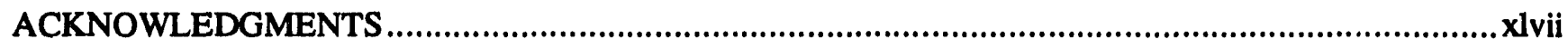

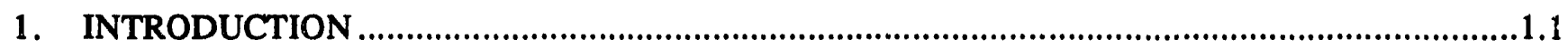

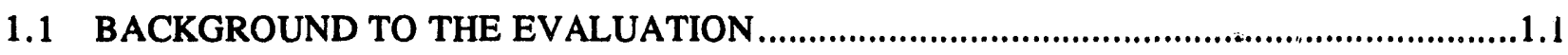

1.2 OVERVIEW OF THE WEATHERIZATION ASSISTANCE PROGRAM...............................

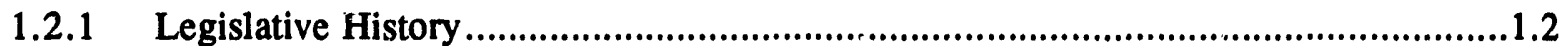

$1.2 .2 \quad$ Roles and Responsibilities....................................................................................

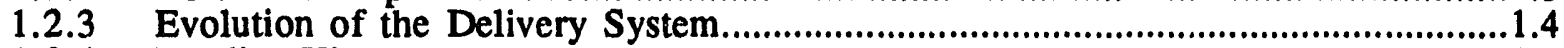

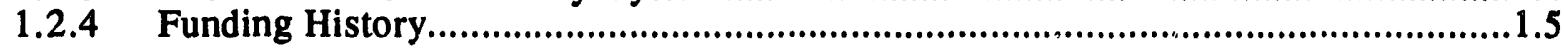

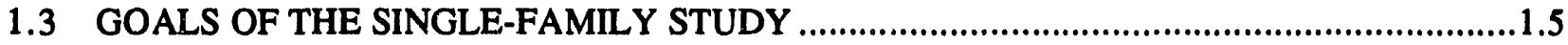

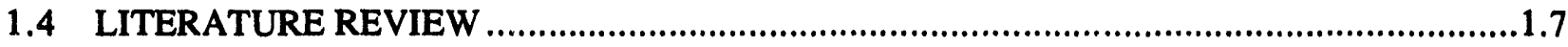

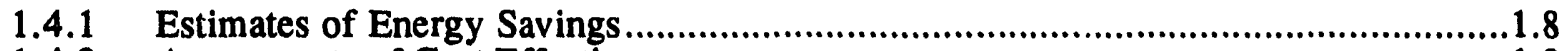

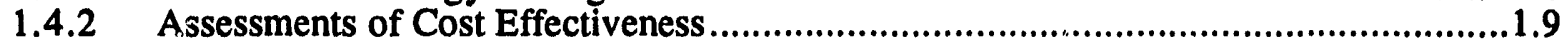

1.4.3 Identification of Promising Opportunities............................................................1.10

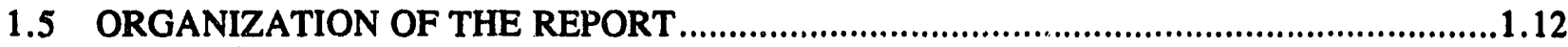

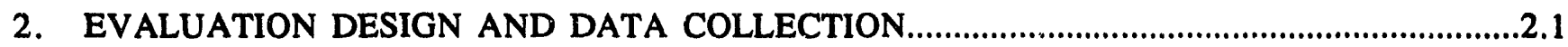

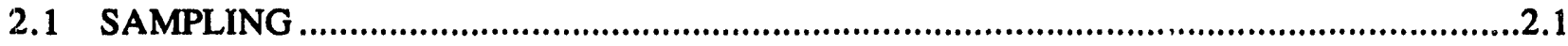

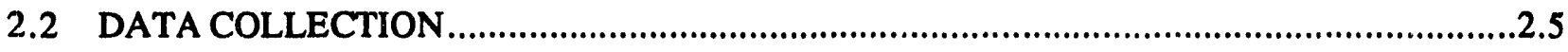

2.2.1 Dwelling-Specific Data from Agency Records .....................................................

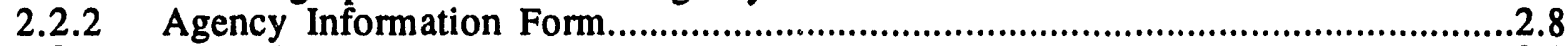

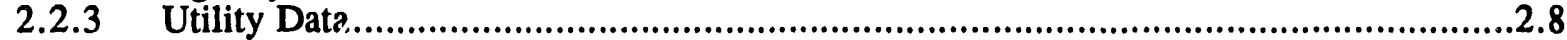

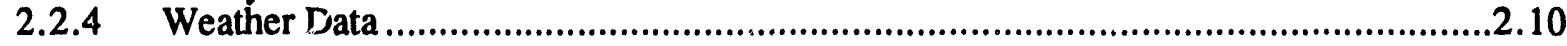

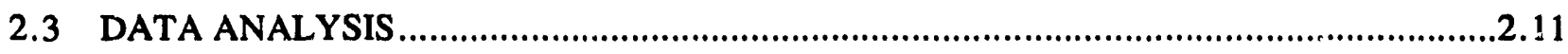

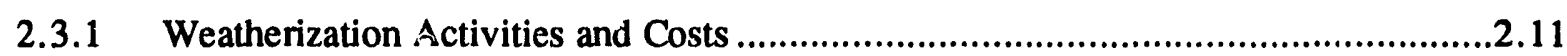

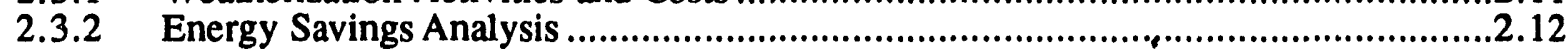

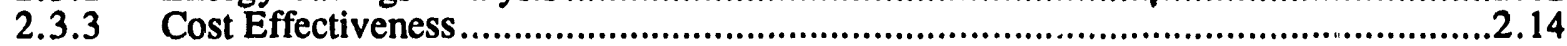

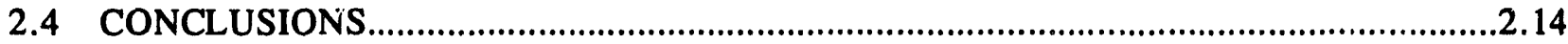


3. DWELLING AND OCCUPANT CHARACTERISTICS OF WEATHERIZED

HOMES AND THE ELIGIBLE POPULATION ………..............................................................

3.1 CHARACTERISTICS OF THE SAMPLE OF WEATHERIZED DWELLINGS .......................1

3.1.1 Sample of Dwellings with Dwelling-Specific Data ............................................3.2

3.1.2 Sample of Dwellings with Energy-Consumption Data ..........................................

3.1.3 Sample with Agency Cost Information..............................................................

3.2 DWELLING AND OCCUPANT CHARACTERISTICS OF

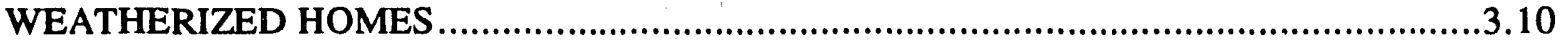

3.2.1 Differences Across Climate Regions...............................................................10

3.2.2 Differences by Primary Heating Fuel ...........................................................

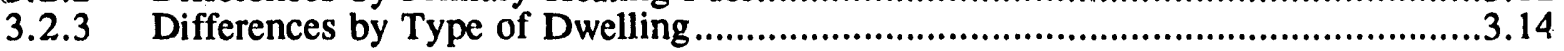

3.3 Program PARTICIPANTS VERSUS THE ELIGIBLE POPULATION ..................................16

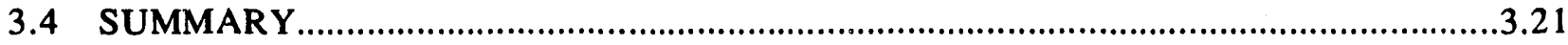

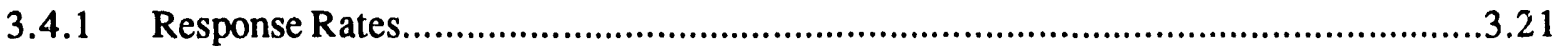

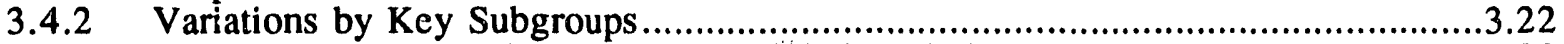

3.4.3 Comparisons of Weatherized and Eligible Populations................................................2.23

4. DESCRIPTION OF WEATHERIZATION ACTIVITIES ...........................................................

4.1 WEATHERIZATION MEASURES INSTALLED ...........................................................

4.1.1 Frequency of Installation of Different Measures ....................................................4.1

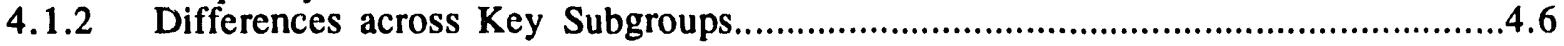

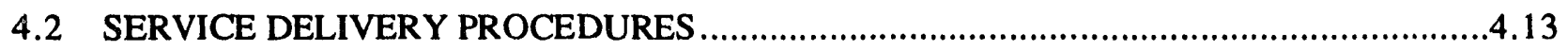

4.2.1 Frequency of Use of Different Service Delivery Procedures...............................4.14

4.2.2 Differences across Key Subgroups.............................................................16

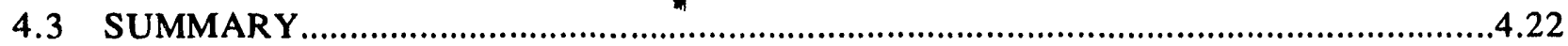

4.3.1 Differences Across Climate Regions...............................................................22

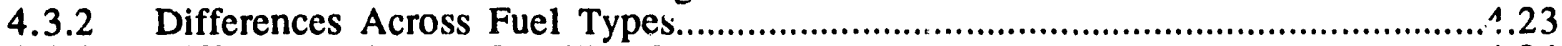

4.3.3 Differences Across Dwelling Types................................................................24

4.3.4 Differences Across Agency Sizes ...............................................................25

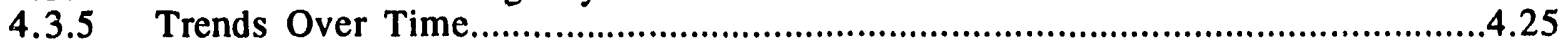

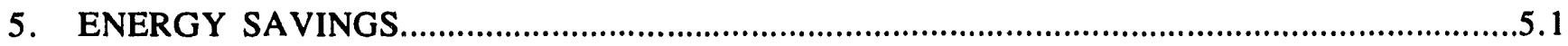

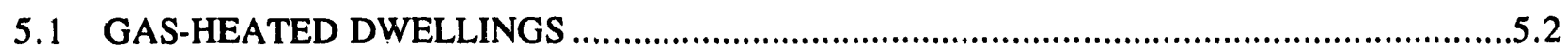

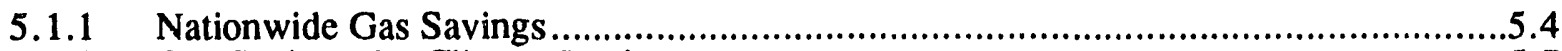

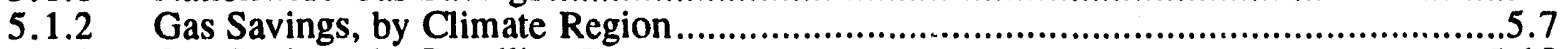

5.1.3 Gas Savings, by Dwelling Type .....................................................................

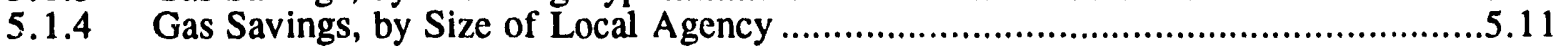

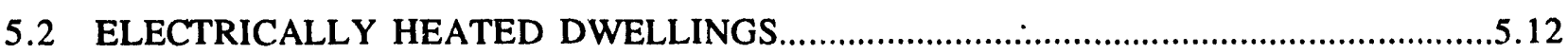

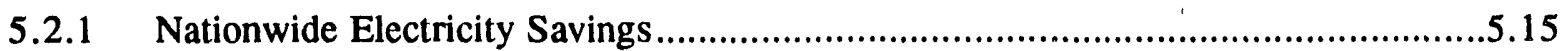

5.2.2 Electricity Savings, by Climate Region .............................................................

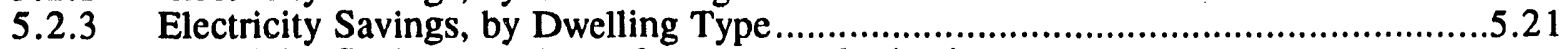

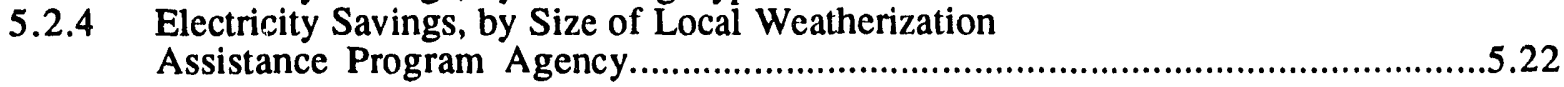




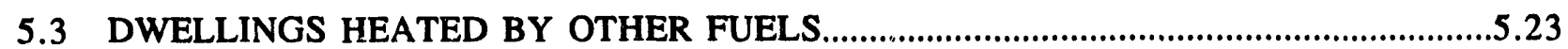

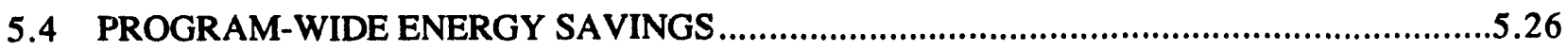

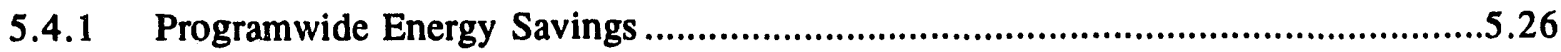

5.5 COMPARISONS WITH OTHER WEATHERIZATION EVALUATIONS ........................5.27

5.5.1 Comparison with the 1981 Program..............................................................5.27

5.5.2 Comparison with Utility Programs .................................................................5.29

5.5.3 Comparison with State Weatherization Programs .............................................5.30

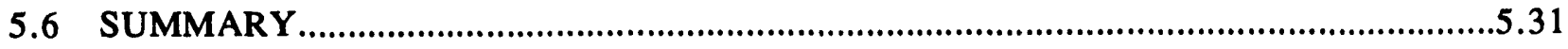

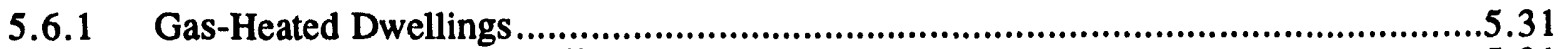

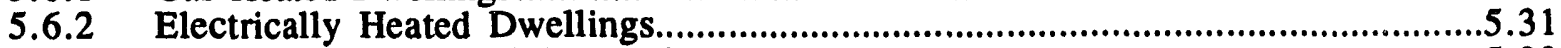

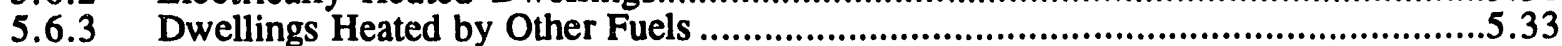

5.6.4 Programwide Energy Savings .......................................................................5.33

5.6.5 Opportunities for the Future …......................................................................5.34

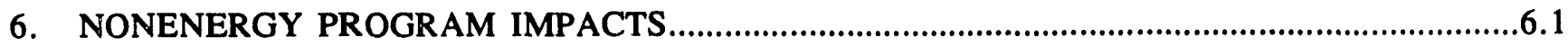

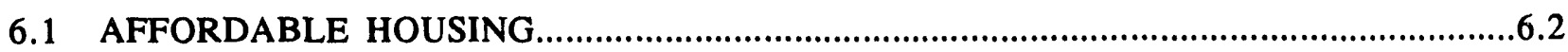

6.1.1 Property Values and the Longevity of Structures ..........................................6.2

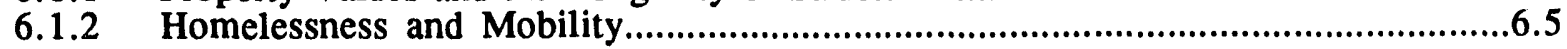

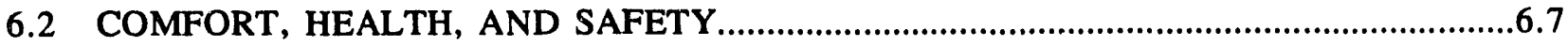

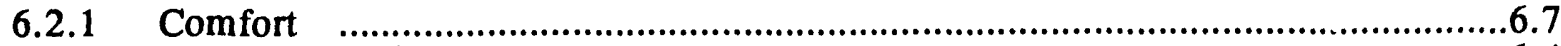

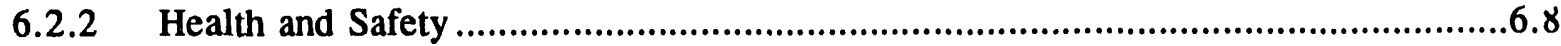

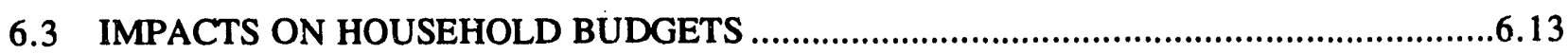

6.3.1 Energy Affordability and Increased Nonenergy Expenditures...........................6.13

6.3.2 Reduced Utility Arrearages and Terminations...............................................6.14

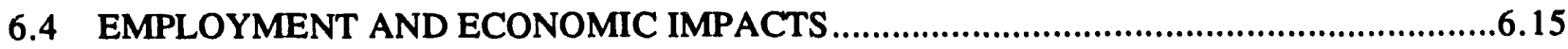

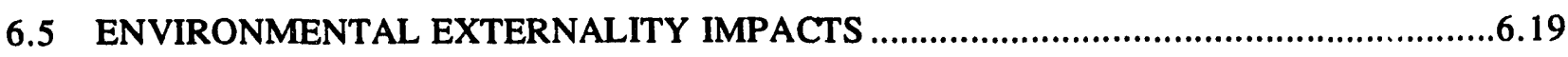

6.5.1 Environmental Impacts of Energy Production and Consumption.........................6.19

6.5.2 Environmental Impacts of Weatherization Materials Production............................6.21

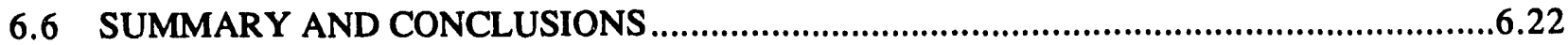

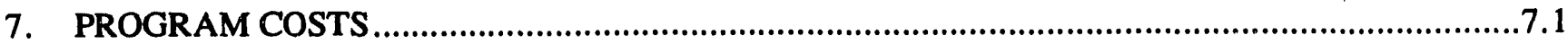

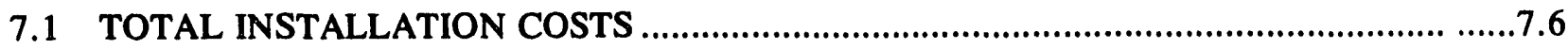

7.1.1 Programwide Total Installation Costs ................................................................6

7.1.2 Differences by Climate Region, Fuel Type, Dwelling Type,

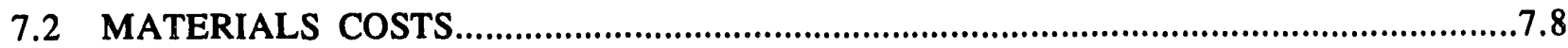

7.2.1 Programwide Materials Costs .........................................................................

7.2.2 Measure-Specific Materials Costs for All Weatherized Homes ................................7.9

Measure-Specific Materials Costs Only for Homes with the
Measure Installed.............................................................................................. 


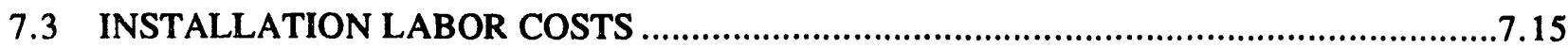

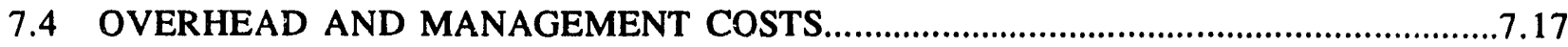

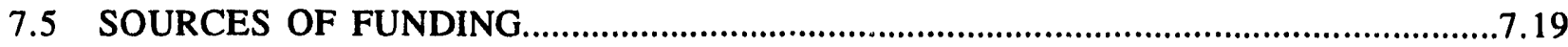

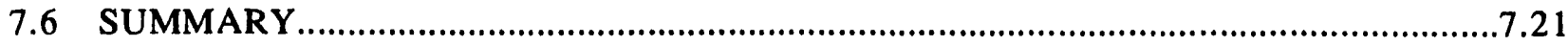

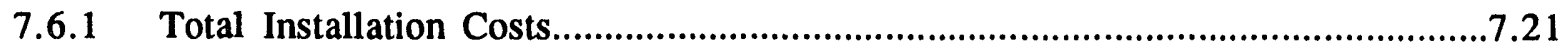

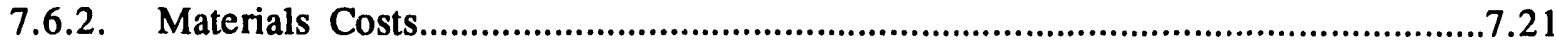

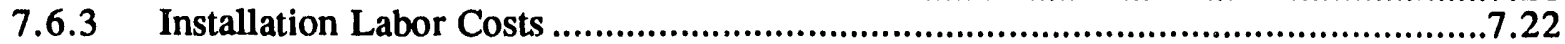

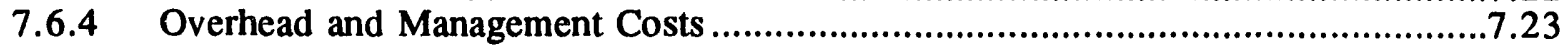

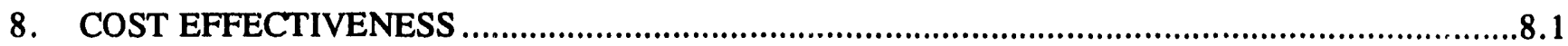

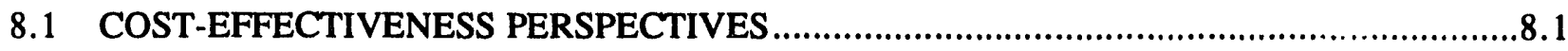

8.2 COST EFFECTIVENESS IN GAS-HEATED DWELLINGS ................................................

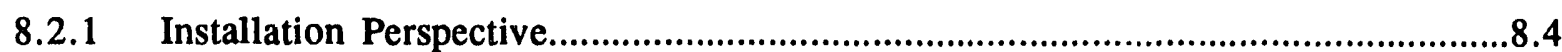

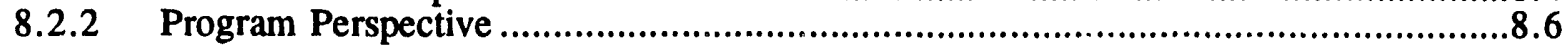

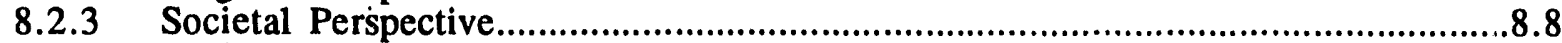

8.2.4 Excluding Utility Funding and Structural Measures Costs....................................8.10

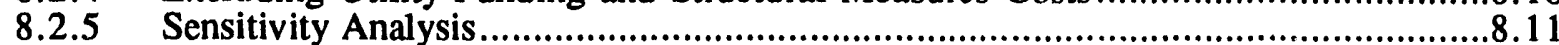

8.3 COST EFFECTIVENESS IN ELEC, ,RICALLY HEATED DWELLINGS............................8.14

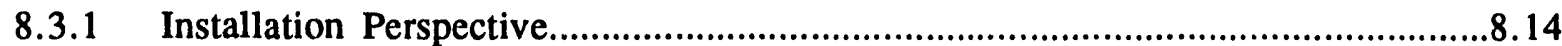

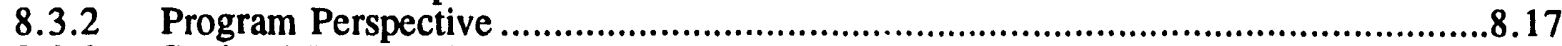

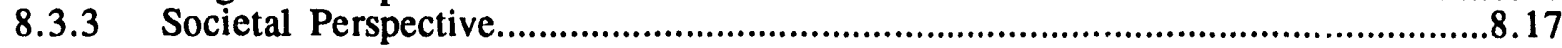

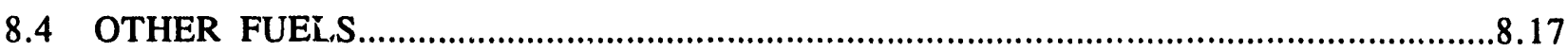

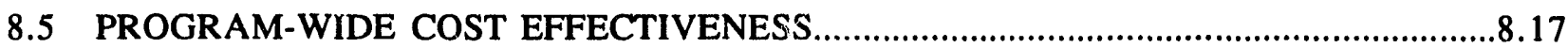

8.6 COMPARISONS WITH PREVIOUS COST EFFECTIVENESS RESULTS............................8.18

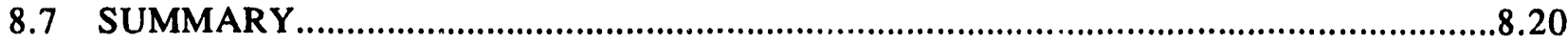

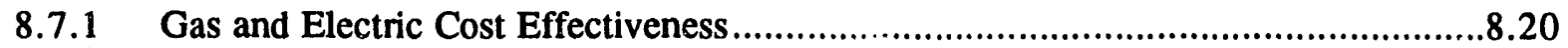

8.7.2 Program-Wide Cost Effectiveness........................................................................

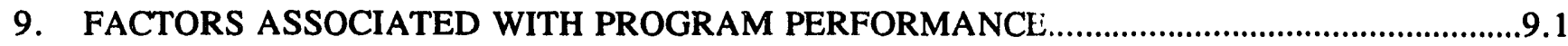

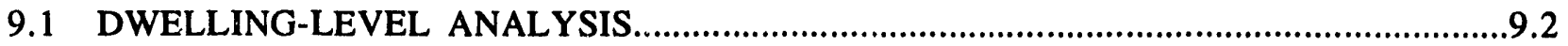

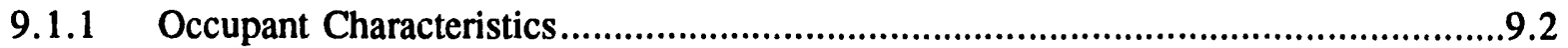

9.1.2 Dwelling Characteristics....................................................................................9.3

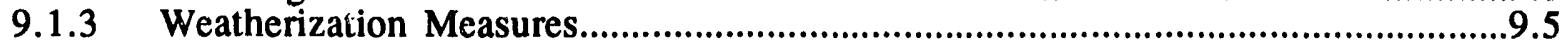

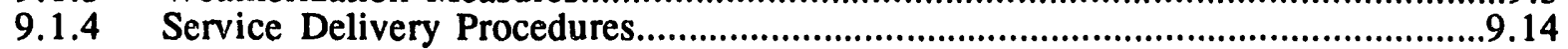

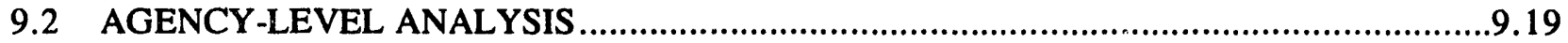

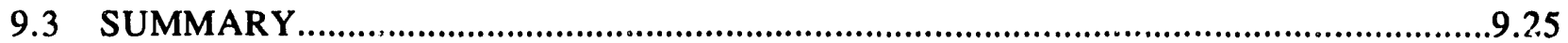

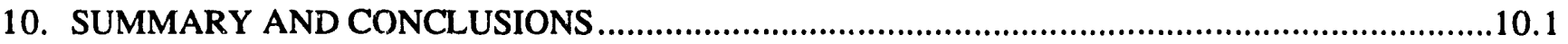

10.1 DESCRIPTION AND CHARACTERIZATION OF THE SAMPLE ..................................10.1

10.1.1 Characteristics of Weatherized Dwellings and Key Subgroups...............................10.1

10.1.2 Comparison of Weatherized and Eligible Populations ...........................................10.2 
10.2 DESCRIPTION OF WEATHERIZATION ACTIVITIES .......................................10.3

10.2.1 National Program Trends Over Time ...........................................................10.3

10.2.2 Differences Across Regions, Heating Fuels, and Housing Types.........................10.5

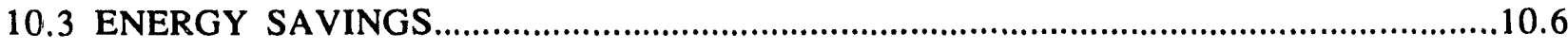

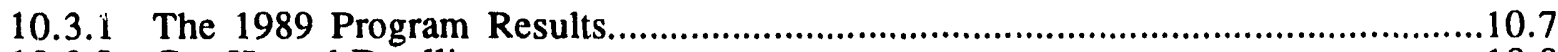

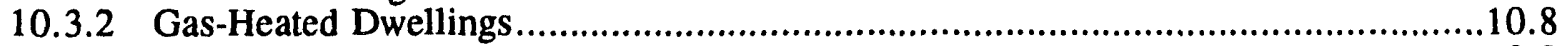

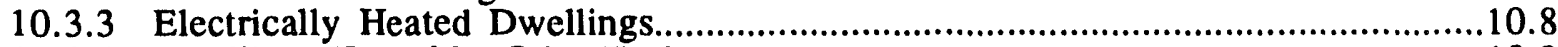

10.3.4 Dwellings Heated by Other Fuels ..........................................................10.9

10.3.5 Trends and Comparisons .....................................................................10.10

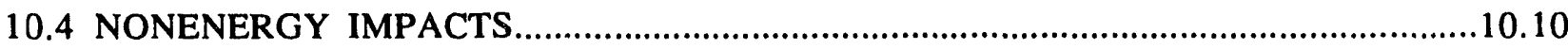

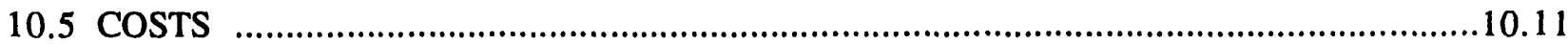

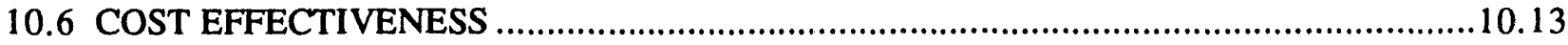

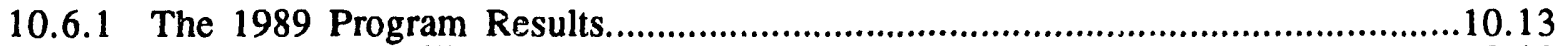

10.6.2 Gas-Heated Dwellings........................................................................10.13

10.6.3 Electrically Heated Dwellings...................................................................10.14

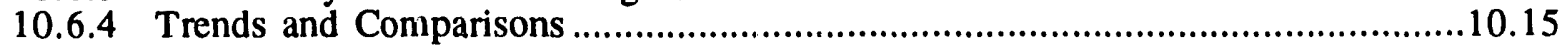

10.7 FACTORS ASSOCIATED WITH PERFORMANCE.............................................10.15

10.8 CONCLUSIONS AND RECOMMENDATIONS ................................................10.17

10.8.1 Diversity and the Need for Technology Transfer ........................................10.18

10.8.2 Targeted Research and Technology Transfer................................................10.20

10.8.3 Recordkeeping and Future Evaluations.................................................10.21

11. REFERENCES 


\section{LIST OF FIGURES}

Fig. 1.1 Full-Scale Weatherization: Funding Sources, PY 1978-PY 1989..................................1.6

Fig. 1.2 Single-Family Study Goals, by Phase.

Fig. 2.1 Climate Regions for the Single-Family Study

Fig. 2.2 Distribution of the Original Sample of Agencies and Dwellings, by Climate Region..........2.3

Fig. 2.3 Distribution of the Original Sample of Agencies and Dwellings, by Agency Size..............2.4

Fig. 2.4 Timing of Data Collection in the Single-Family Study..............................................2.6

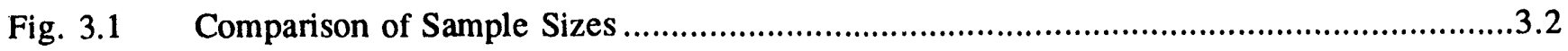

Fig. 3.2 Distribution of Agencies and Weatherized Dwellings with Dwelling-Specific

Data, by Climate Region (unweighted).

Fig. 3.3 Distribution of Agencies and Weatherized Dwellings with Dwelling-Specific

Data, by Agency Size (unweighted) .....................................................................3.3

Fig. 3.4 Distribution of Weatherized Dwellings, by Climate Region................................................3.4

Fig. 3.5 Distribution of Weatherized Dwellings, by Primary Heating Fuel ....................................3.5

Fig. 3.6 Distribution of Weatherized Dwellings, ty Dwelling Type...............................................3.6

Fig. 3.7 Distribution of Agencies and Weatherized Dwellings with Energy-Consumption

Data, by Climate Region (unweighted) ..................................................................

Fig. 3.8 Distribution of Agencies and Weatherized Dwellings with Energy-Consumption Data, by Agency Size (unweighted).

Fig. 3.9 Distribution of Program-Participant Homes and Program-Eligible Homes, by Climate Region..

Fig. 3.10 Age of Dwelling of Program-Participant Homes and Program-Eligible Homes in the U.S.

Fig. 3.11 Square Footage of Program-Participant Homes and Program-Eligible Homes in the U.S.

Fig. 3.12 Income Distribution of Program-Participant and Program-Eligible

Households in the U.S.

Fig. 4.1 Types of Weatherization Measures Installed in PY 1989 ..........................................4.2

Fig. 4.2 Frequency of Installation of Weatherization Measures ..............................................4.3

Fig. 4.3 Installation Rates for Selected Weatherization Measures: 1981 and $1989 \ldots \ldots \ldots \ldots \ldots \ldots \ldots \ldots . . . .6 .6$

Fig. 4.4 Frequency of Use of Selected Service Delivery Procedures......................................4.15

Fig. 5.1a Distribution of Gross Gas Savings for Gas-Heated Weatherized and Control Dwellings (unweighted) ..........................................................................5.6

Fig. 5.1b Distribution of Percent Gross Gas Savings for Gas-Heated Weatherized and Control Dwellings (unweighted) ......................................................................5.6

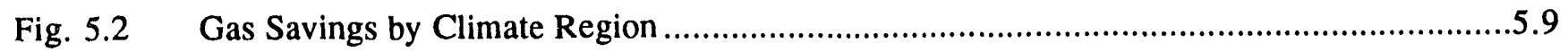

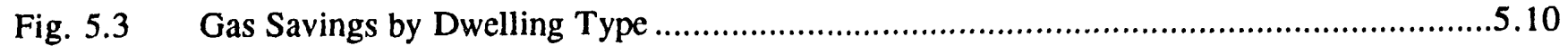

Fig. 5.4 Gas Savings by Size of Local Weatherization Assistance Program Agency ...................5.11

Fig. 5.5 Model Electricity Consumption Profiles for the Three Versions of PRISM: Heating Only, Heating-and-Cooling, and Cooling Only 
Fig. 5.6 Distribution of Electricity Savings for Electrically Heated Weatherized and

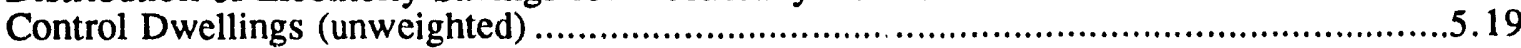

Fig. 5.6 Distribution of Percent Electricity Savings for Electrically Heated Weatherized and Control Dwellings (unweighted) ........................................................................5.21

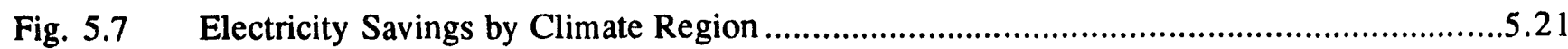

Fig. 5.8 Electricity Savings by Dwelling Type ............................................................5.22

Fig. 5.9 Electricity Savings by Size of Local Weatherization Assistance Program Agency ............5.23

Fig. 5.10 Weatherization Assistance Program Gas Savings Vs Utility

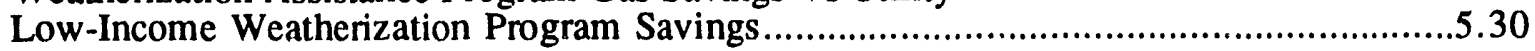

Fig. 5.11 Weatherization Assistance Program Gas Savings Vs

State Weatherization Program Savings

Fig. 6.1 Frequency of Incidental Repairs and Other Weatherization Work (Percent of Dwellings).

Fig. 6.2 Improving Substandard Housing Through Weatherization: An Example from the Blue Mountain Community Action Agency ....................................................6.4

Fig. 6.3 Annualized Rates of Occupancy Change: Pre- Versus Post-Weatherization .....................6.6

Fig. 6.4 Frequency of Health and Safety Measures (Percent of Dwellings)................................6.8

Fig. $6.5 \quad$ Value of Deaths Due to Fires Prevented by Weatherization .......................................6.11

Fig. 6.6 Value of Property Loss Due to Fires Prevented by Weatherization ...............................6.12

Fig. 7.1 Local Program Agency Direct Financial Support for Weatherization and Other Energy Programs........................................................................................

Fig. 7.2 National Distribution of Total Installation Costs (weighted) ......................................

Fig. 7.3 Total Installation Costs (in 1989 dollars) ............................................................7.7

Fig. 7.4 Average Material Costs (in 1989 dollars), by Climate Region........................................7.11

Fig. 7.5 Average Material Costs (in 1989 dollars), by Type of Heating Fuel ..............................7.11

Fig. 7.6 Average Material Costs (in 1989 dollars), by Dwelling Type.......................................7.12

Fig. 7.7 Average Material Costs (in 1989 dollars), by Size of Local Weatherization Agency ........7.12

Fig. 7.8 Average Cost of Materials in Dwellings Receiving the Measure, by Climate Region..........7.14

Fig. 7.9 Average Cost of Materials in Dwellings Receiving the Measure, by Fuel Type.................7.14

Fig. 7.10 Average Cost of Materials in Dwellings Receiving the Measure, by Dwelling Type..........7.15

Fig. 7.11 Average Cost of Material's in Dwellings Receiving the Measure, by Agency Size ..............7.16

Fig. 8.1 Assumptions, Evaluation I $\iota_{\perp}$, $u t s$, and Indicators for Cost-Effectiveness Analysis................8.1

Fig. 8.2 Three Approaches Used to Calculate Cost Effectiveness...............................................8.2

Fig. 8.3 Installation Benefits and Costs by Climate Region for Gas-Heated Dwellings ..................8.4

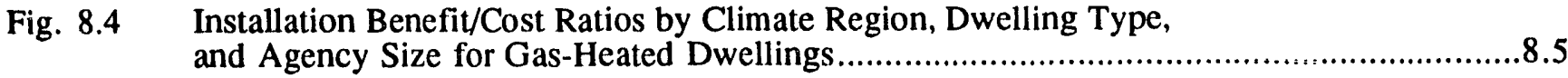

Fig. 8.5 Installation Perspective: Energy Benefits vs. Installation Costs for Gas-Heated Dwellings.................................................................................

Fig. 8.6 Program Benefits and Costs by Climate Region for Gas-Heated Dwellings.....................8.7 
Fig. 8.7 Program Benefit/Cost Ratios by Climate Region, Dwelling Type, and Agency

Size for Gas-heated Dwellings....

Fig. 8.8 Program Perspective: Energy Benefits Only vs. Installation Costs

for Gas-Heated Dwellings.

Fig. 8.9 Societal Benefits and Costs by Climate Region for Gas-Heated Dwellings .

Fig. 8.10 Societal Benefit/Cost Ratios by Climate Region, Dwelling Type, and Agency Size for Gas-Heated Dwellings.

Fig. 8.11 Societal Perspective: Energy, Employment, and Environmental Benefits vs. Total Costs for Gas-Heated Dwellings

Fig. 8.12 Distribution of Program Benefit/Cost Ratios with Input Distributions for Assumptions ....

Fig. 8.13 Distribution of Societal Benefit/Cost Ratios with Input Distributions for Assumptions

Fig. 8.14 Sensitivity of Program Perspective Results to Choice of Discount Rates. .8 .15

Fig. 8.15 Sensitivity of Benefit/Cost Ratios to Assumed Discount Rates and Measure Lifetimes.

Fig. 8.16 Societal Benefit/Cost Ratios by Climate Region, Dwelling Type, and Agency Size for Electrically Heated Dwellings ..

Fig. 8.17 Cost of Conserved Energy for the Weatherization Assistance Program and Low-Income Utility Programs in Gas-Heated Dwellings

Fig. 8.18 Cost of Conserved Energy for the PY 1989 Weatherization Assistance Program vs. Low-Income Utility Programs in Gas Heated Dwellings.

Fig. 9.1 Gas Savings of Dwellings With Different Dwelling Characteristics..................................9.4

Fig. 9.2 Gross Energy Savings of High Versus Low Energy Users...........................................9.6

Fig. 9.3 Gas Savings of Dwellings that Received Air Leakage Control Measures ............................9.8

Fig. 9.4 Gâs Savings of Dwellings that Received Insulation....................................................9.9

Fig. 9.5 Gas Savings of Dwellings that Received Water Heater Measures ...................................9.10

Fig. 9.6 Gas Savings of Dwellings that Received Window and Door Measures............................9.11

Fig. 9.7 Gas Savings of Dwellings that Received Space-Heating System Measures.........................9.12

Fig. 9.8 Gas Savings of Dwellings that Received Mobile Home Measures....................................9.13

Fig. 9.9 Gas Savings of Dwellings that Based on Client Selection, Investment Criteria, and Measure Selection........................................................................15

Fig. 9.10a Gas Savings of Dwellings that Used Particular Diagnostic Procedures ............................9.17

Fig. 9.10b Gas Savings of Dwellings that Used Particular Diagnostic Procedures ...........................9.17

Fig. 9.11 Gas Savings of Dwellings that Used Client Education Procedures...................................9.18

Fig. 9.12 Gas Savings of Dwellings with Different Levels of Weatherization Costs..........................9.19

Fig. 9.13 Average Energy Savings of 97 Local Weatherization Agencies....................................9.20

Fig. 9.14 Average Percent Gas Savings of 97 Local Weatherization Agencies ..............................9.20

Fig. 9.15 Average Benefit/Cost Ratio of 97 Local Weatherization Agencies...................................9.21 
Fig. 10.1 Income Distribution of Program Participants and Eligible Households ..........................10.3

Fig. 10.2 Installation Rates for Selected Weatherization Measures: 1981 and 1989 ....................10.4

Fig. 10.3 Average Material Costs (in 1989 dollars), by Climate Region.....................................10.12

Fig. 10.4 Societal Perspective: Energy and Nonenergy Benefits vs. Total Costs for Gas-Heated Dwellings.................................................................................10.14

Fig. 10.5 Energy Saved by High vs. Low Energy Users in the Three Climate Regions ................10.16 


\section{LIST OF TABLES}

Table 2.1 Nonequivalent Comparison Group Design..

$.2 . \dot{3}$

Table 3.1 Dwelling and Occupant Characteristics of Weatherized Homes, by Climate Region (weighted).

Table 3.2 Dwelling and Occupant Characteristics of Weatherized Homes, by Primary Heating Fuel (weighted)....

Table 3.3 Dwelling and Occupant Characteristics of Weatherized Homes, by Dwelling Type (weighted).

Table 3.4 Dwelling and Occupant Characteristics of RECS Sample of Program-Eligible Homes, by Climate Region

Table 4.1 Installation of Weatherization Measures, by Climate Region (weighted)....

Table 4.2 Installation of Weatherization Measures, by Primary Heating Fuel (weighted)........

Table 4.3 Installation of Weatherization Measures, by Dwelling Type (weighted) .4 .11

Table 4.4 Installation of Weatherization Measures by Size of Local Agency (weighted)

Table 4.5 Selected Service Delivery Procedures, by Climate Region (weighted).

Table 4.6 Selected Service Delivery Procedures, by Primary Heating Fuel (weighted).

Table 4.7 Selected Service Delivery Procedures, by Dwelling Type (weighted).

Table 4.8 Selected Service Delivery Procedures by Size of Local Agency (weighted)

Table 5.1 Average First-Year Gas Savings for Gas-Heated Weatherized and Control Dwellings (in ccf/year).

Table 5.2 Average First-Year Gas Savings tor Gas-Heated Weatherized and Control Dwellings (in ccf/year), by Climate Region.

Table 5.3 Average First-Year Electricity Savings for Electrically Heated Weatherized and Control Dwellings (in $\mathrm{kWh} / \mathrm{year}$ )

Table 5.4 Average First-Year Electricity Savings for Electrically Heated Weatherized and Control Dwellings (in kWh/year), by Climate Region..............................................5.20

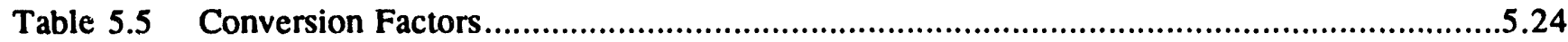

Table 5.6 Energy Saved by Dwellings Heated by Other Fuels...................................................5.25

Table 5.7 First and 20-Years Energy Savings of Housing Units Weatherized in PY 1989...............5.27

Table 5.8 Energy Savings by Primary Heating Fuel: An Earlier Evaluation (1981) and the Current Evaluation (1989) ...............................................................................5.28

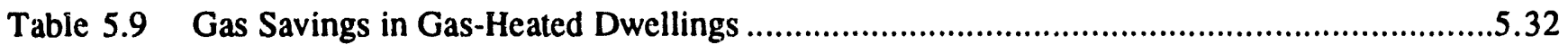

Table 5.10 Electricity Savings in Electrically Heated Dwellings...............................................33

Table 6.1 Taxes Generated from Employment in the Weatherization Assistance Program...............6.17

Table 6.2 Indirect Employment Impacts of the Weatherization Assistance Program........................6.18

Table 6.3 Avoided Costs of Unemployment Benefits for Direct and Indirect Employment.............6.19

Table 6.4 Environmental Benefits of the Weatherization Assistance Program.................................6.20

Table 6.5 Net Present Value of Nonenergy Impacts of the Weatherization Assistance Program 
Table 7.1 Cost Categories Used in Typical Local Agency Expenditure Reports to the State. 7.2

Table 7.2 Cost Categories Used in This Study

Table 7.3 Contractor Labor Costs Higher Because Include Profit, Overhead, and More Space-Heating Work.

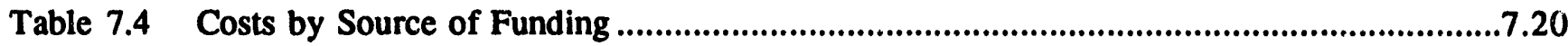

Table 7.5 Cosis for Dwellings with Mixed Funding by Coverage of DOE Guidelines........................7.2n

Table 8.1 Benefit/Cost Ratios Using Installation Costs Only for Gas-Heated Dwellings Weatherized in 1989 Program Year.

Table 8.2 Benefit/Cost Ratios Using Total Costs for Gas-Heated Dwellings

Weatherized in 1989 Program Year

Table 8.3 Sensitivity of Benefit/Cost Ratios of Discount Rates and Lifetimes..................................8.16

Table 9.1 Factors Distinguishing High from Low Energy Savers:

Occupant and Dwelling Characteristics ...........................................................................9.3

Table 9.2 Factors Distinguishing High from Low Energy Savers:

Weatherization Measures

Table 9.3 Factors Associated with High Gas and Electricity Savings:

Service Delivery Procedures

Table 9.5 Regression Analysis of Average Agency Gas Savings Per Weatherized Dwelling .............9.22

Table 9.6 Regression Analysis of Average Agency Percent Gas Savings ....................................9.23

Table 9.7 Regression Analysis of Average Agency Percent Cost Effectiveness................................9.24

Table 10.1 1st and 20-Year Energy Savings of Housing Units Weatherized in PY 1989....................10.7

Table 10.2 Gas Savings in Gas-Heated Dwellings ................................................................10.8

Table 10.3 Electricity Savings in Electrically Heated Dwellings ...................................................10.9

Table 10.4 Net Present Value of Nonenergy Impacts of the Weatherization Assistance Program......10.11

Table 10.5 Energy Savings and Cost Effectiveness of the Weatherization Assistance Program .........10.18 


\section{LIST OF APPENDICES ${ }^{\star}$}

APPENDIX B-1 DEVELOPMENT OF THE REPRESENTATIVE SAMPLE

APPENDIX B-2 EXAMPLES OF LETTERS USED FOR DATA COLLECTION

APPENDIX B-3 EXAMPLES OF DATA COLLECTION FORMS

APPENDIX B-4 PROCEDURES FOR MATCHING WEATHER STATIONS TO HOUSING UNITS

APPENDIX B-5 SAMPLE WEIGHTING PROCEDURES

APPENDIX C SUPPLEMENTAL TABLES FOR CHAPTER 3

APPENDIX C-1 WEIGHTING FACTORS

APPENDIX E SUPPLEMENTAL TABLES FOR CHAPTER 5

APPENDIX F-1 SUPPLEMENTAL TABLES FOR CHAPTER 6

APPENDIX F-2 WEIGHTED ANNUAL DOLLAR VALUE OF ENERGY SAVINGS FOR ALL FUEL TYPES

APPENDIX G SUPPLEMENTAL TABLES FOR CHAPTER 7

APPENDIX H-1 BENEFIT/COST ANALYSIS BASED ON WEIGHTED ESTIMATES OF THE LIFETIMES OF MEASURES

APPENDIX H-2 COST-EFFECTIVENESS RESULTS FOR ELECTRICALLY HEATED DWELLINGS

APPENDIX I SUPPLEMENTAL TABLES FOR CHAPTER 9

* Appendices are keyed to the chapter numbers; that is, Appendix B is associated with Chapter 2, Appendix C with Chapter 3, etc. There is no Appendix A or D because Chapters 1 and 4 do not have appendices. 


\section{LIST OF ACRONYMS}

\begin{tabular}{|c|c|}
\hline $\mathrm{AC}$ & Air conditioning \\
\hline APN:" & Average Program Management Costs \\
\hline CAA & Community Action Agency \\
\hline CAP & Community Action Program \\
\hline CCE & Cost of Conserved Energy \\
\hline CCF & One hundred cubic feet of natural gas \\
\hline CDD & Cooling Degree Day \\
\hline CSA & Community Services Agency \\
\hline CMFERT & Collaborative Manufactured Building Facility for Energy Research and Training \\
\hline DOE & U.S. Department of Energy \\
\hline DSM & Demand Side Management \\
\hline ECM & Energy Conservation Measure \\
\hline EIA & Energy Information Administration \\
\hline FTE & Full-Time Equivalent \\
\hline HDD & Heating Degree Day \\
\hline HUD & U.S. Department of Housing and Urban Development \\
\hline kWh & Kilowatt hour of electricity \\
\hline LIHEAP & Low-Income Home Energy Assistance Program \\
\hline MBtu & One Million British Thermal Units \\
\hline NAC & Normalized Annual Consumption \\
\hline NCDC & National Climatic Data Center \\
\hline $\mathrm{NO}_{\mathrm{x}}$ & Nitrous oxides \\
\hline ORNL & Oak Ridge National Laboratory \\
\hline Post-NAC & Post-weatherization Normalized Annual Consumption \\
\hline PMC & Program Management Costs \\
\hline Pre-NAC & Pre-weatherization Nornalized Annual Consumption \\
\hline PRISM & Princeton Scorekecping Method \\
\hline PVE & Petroleum Violation Escrow \\
\hline PY & Program Year \\
\hline RECS & Residential Energy Consumption Survey \\
\hline $\mathrm{SO}_{2}$ & Sulphur dioxide \\
\hline TIC & Total Installation Costs \\
\hline TPC & Total Program Costs \\
\hline T\&TA & Training and Technical Assistance \\
\hline WAP & Weatherization Assistance Program \\
\hline
\end{tabular}




\section{GLOSSARY}

Air Leakage:

\author{
Air Leakage Control \\ Measures:
}

Air Sealing:

Attic Insulation:

Blower Door:

Clean and Tune:

Cold Region:

Community Action Agency:

Community Services

Administration:

Component Retrofit:

Contractor:

Control Dwelling:
The loss of conditioned air through air paths in the dwelling's structure.

Techniques which aim to reduce the escape of conditioned air to areas not intended to be conditioned. Common measures include caulking/weath:erstripping, air sealing, and distribution system work.

A systematic process of tightening a dwelling's structure to reduce heat loss through warm air leakage sites. Uses a variety of materials such as insulation, caulk, foam, vapor barriers, and weatherstripping. Air leakage site identification is aided by the use of blower doors and infrared scanning because not all leakage sites are obvious to the unaided eye.

The use of an insulator in the attic to reduce transference of heated or cooled air from the conditioned rooms to the attic. Usually, involves installing fiberglass batts or blown cellulose insulation. Attic insulation may be added for the first time to a structure or may be applied on top of existing attic insulation.

A door- or window-mounted calibrated and variable speed fan that blows air into (pressurizes) or sucks air out of (depressurizes) a house. It has an adjustable frame, usually plastic or fabric, around the fan so that it can fit snugly into most doorways. Gauges that measure air flow and pressure are connected to the blower door, which is used to locate air leakage sites as well as to quantify the level of air leakage.

A procedure performed on a heating system (usually natural gas or fuel oil), which is generally preceded by a combustion efficiency test. The clean and tune can involve a variety of activities to upgrade the efficiency and safe operation of the heating system, including pilot or burner adjustment; adjustment of ventilation or combustion; checking and resetting controls; and check relief valves, safety valves, or thermocouples.

For the purposes of this study, includes the States of Idaho, Montana, Wyoming, North Dakota, South Dakota, Minnesota, Michigan, Wisconsin, Maine, Vermont, and New Hampshire.

The most prominent type of subgrantee or local weatherization agency.

The government agency with the original charge of low-income weatherization.

Updating components of the heating system, cooling system, or water heating system for energy efficiency and health and safety reasons.

A private firm hired by a local agency to deliver Weatherization Program services. Contractors tend to be used for heating system, cooling system, and water heating system work.

A dwelling which was qualified for the DOE Program but was waiting to receive weatherization in the spring of 1991 . 


\section{Cool Seal:}

Crew:

Dwelling-specific Data:

Elderly Person:

Eligible Dwelling-Unit:

Fuel-Oil Study:

Grantee:

Gross Energy Savings:

High-density Multifamily

Study:

Hot Region:

Incidental Repairs:

Installation-Related Overhead:

Large Agency:

Low-Income Home Energy Assistance Program:
Primarily a mobile home measure which seeks to reduce cooling load by reducing heat transference through the roof of the structure.

In-house workers for local agencies who install weatherization measures.

Refers to the database which contains data on dwelling and occupant characteristics, measures installed, costs, and service delivery procedures for each dwelling in the representative national sample. These data come from local agency records.

An irdividual who is 60 years of age or more.

A dwelling unit which is occupied by: (1) a family whose income is less than the $125 \%$ of poverty guideline set by the Director of the Office of Management and Budget; (2) by a family member who has received cash assistance payments under title IV or XVI of the Social Security Act; or (3) a family member who qualifies under other applicable State law at any time in the past twelve months.

Component study of the National Weatherization Evaluation which focuses on dwellings that are heated primarily with fuel oil and that are located in the Northeast.

The State or other entity named in the Notification of Grant Award as the recipient of Program funding. Also called State Agency.

Calculated by subtracting the post-NAC from the pre-NAC for each dwelling and summing across dwellings to obtain an average. Gross savings are calculated for both weatherized and control dwellings.

Component study of the National Weatherization Evaluation which focuses on high-density multifamily dwellings (five or more units).

For the purposes of this study, includes the States of Arkansas, Louisiana. Tennessee, Mississippi, Alabama, Georgia, South Carolina, North Carolina, Florida, Arizona, New Mexico, Texas, Oklahoma, and the southern California region.

Structural repairs necessary for effective application of weatherization measures. Common incidental repairs include window, door, and roof repair.

Common expenses associated with weatherization field work, such as vehicles, travel time, equipment, field supervision, insurance, training, and contractor profit.

A local agency which weatherized 400 or more homes in PY 1989.

(LIHEAP) The federal program administered by the U.S. Department of Health and Human Services, which assists low-income households with their home energy costs. 
Medium Agency:

Moderate Region:

Net Energy Savings:

Normalized Annual

Consumption (NAC):

Petroleum Violation Escrow:

Post-NAC:

Pre-NAC:

Program Management Cost:

Program Year:

Rim/Band Joint Insulation:

Single-Family Study:

Small Agency:

Weatherized Dwelling:

Window Film:
A local agency which weatherized more than 100 and less than 400 homes in PY 1989.

For the purposes of this study, includes the states of Washington, Oregon, Nevada, Northem California, Utah, Colorado, Nebraska, Kansas, Illinois, Indiana, Iowa, Ohio, Kentucky, Missouri, West Virginia, Virginia, Delaware, Maryland, Pennsylvania, New Jersey, New York, Massachusetts, Connecticut, and Rhode Island.

Calculated by subtracting the average gross savings for control homes from the average gross savings for weatherized homes.

A weather-adjusted index of consumption which indicates what annual energy consumption would be under typical weather conditions (based on a ten-year average).

(PVE) Funding source for State and local weatherization agencies. Funded by court fines and penalties from energy manufacturers and distributors for unfair business practices.

Normalized Annual Consumption for the year after weatherization. The post-NAC period in this evaluation is typically defined as April 1, 1990 through March 31, 1991.

Normalized Annual Consumption for the year before weatherization. The pre-NAC period in this evaluation is typically defined as April 1, 1988 through March 31, 1989.

Includes costs associated with intake and eligibility checks; audits and assessments; final inspections; contractor/crew management; program administration; and program evaluation.

Generally defined as April 1 - March 31 of a given year.

The use of an insulator to reduce energy transference at the intersection of walls, floors, ceilings, or other dwelling structures.

Component study of the National Weatherization Evaluation which focuses on single family dwellings and small multifamily dwellings (2-4 units) and is based on a representative national sample.

A local agency which weatherized 100 or less homes in PY 1989.

A dwelling which was weatherized by the DOE Program in the 1989 Program Year with DOE funds (entirely or in part) or with funds from other sources that were used according to DOE regulations.

A film that reduces excessive warming of a dwelling due to direct sunlight. Film, as opposed to window shades, is transparent. 


\section{EXECUTIVE SUMMARY}

\section{INTRODUCTION}

\section{Background}

Since 1976, the U.S. I partment of Energy (DOE) has operated one of the largest energy conservation programs in the nat.on - the low-income Weatherization Assistance Program. The Program strives to increase the energy efficiency of dwellings occupied by low-income persons in order to reduce their energy consumption, lower their fuel bills, increase the comfort of their homes, and safeguard their health. It targets vulnerable groups including the elderly, people with disabilities, and families with children.

The most recent national evaluation of the impacts of the Program was completed in 1984 based on energy consumption data for households weatherized in 1981. DOE Program regulations and operations have changed substantially since then: new funding sources, management principles, diagnostic procedures, and weatherization technologies have been incorporated. Many of these new features have been studied in isolation or at a local level; however, no recent evaluation has assessed their combined, nationwide impacts to date or their potential for the future.

In 1990, DOE initiated such an evaluation. This evaluation is comprised of three "impact" studies (the Single-Family Study, High-Density Multifamily Study, and Fuel-Oil Study) and two "policy" studies. ${ }^{1}$ Altogether, these five studies will provide a comprehensive national assessment of the Weatherization Assistance Program as it existed in the 1989 Program Year (PY 1989).

This report presents the results of the first phase of the Single-Family Study. It evaluates the energy savings and cost effectiveness of the Program as it has been applied to the largest portion of its client base - low-income households that occupy single-family dwellings, mobile homes, and small (2- to 4-unit) multifamily dwellings. ${ }^{2}$ It is based upon a representative national sample that covers the full range of conditions under which the program was implemented in PY 1989.

\section{Goals of the Study}

Phase one of the Single-Family Study has two principal goals:

1 The two policy studies address additional aspects of the program, but are not designed to provide estimates of energy savings or cost effectiveness. They include:

- a characterization of the WAP network's capabilities, technologies, procedures, staff, and innovations; and

- a profile of low-income weatherization resources, the weatherized population, and the WAP-eligible population that remains to be served.

2 Using households below $125 \%$ of the poverty line as the eligible population and excluding public housing, data from the 1987 Residential Energy Consumption Survey indicate that 83\% of the WAP-eligible population resides in single-family or small multifamily dwellings (Energy Information Administration, 1989). In the 1990 RECS, the proportion was very similar, 84\% (Response Analysis Corporation, 1993). 
- estimate the energy saved nationwide by the Program during the first year after participation in PY 1989; and

- assess program cost effectiveness.

In addition, it has three secondary goals:

- assess nonenergy impacts, such as employment and environmental externalities;

- analyze factors that influence energy savings and cost effectiveness; and

- identify promising weatherization opportunities for the future.

Each of these secondary goals will be a major focus of the second phase of the Single-Family Study, which will involve a process evaluation of high-performing local weatherization agencies and the collection and analysis of on-site field data on dwelling and occupant characteristics. The third phase of the Single-Family Study will look at the persistence of energy savings two and three years after weatherization in PY 1989.

\section{EVALUATION DESIGN}

The evaluation design for the Single-Family Study consists of a treatment group of dwellings weatherized in PY 1989 and a control group of applicants for weatherization services. The details of this design were developed with the assistance of two working groups, and thus reflect the experience and knowledge of evaluation and weatherization experts. ${ }^{3}$

\section{Sampling Design}

A representative sample of weatherized and control dwellings was used to estimate national and regional program impacts. Because of the difficulty and expense of obtaining data from large numbers of utilities and local weatherization agencies, a two-stage, cluster sampling technique was used to select the representative national sample. A sample of 400 local weatherization agencies was selected in the first stage. The second stage produced a sample of 18,748 weatherized dwellings $(13,162$ that heated primarily with gas or electricity and 5,586 that heated primarily with other fuels), ${ }^{4}$ and 11,795 gas- or electrically heated control homes. The sample was restricted to dwellings weatherized entirely, or in part, with DOE funds or with funds from other sources that were used according to DOE weatherization regulations.

\section{Data Collection}

3 See the Acknowledgments for a list of working group members.

4 Gas- and electrically heated dwellings were oversampled in order to ensure reliable energy-savings estimates. Natural gas was the primary heating fuel for $51 \%$ of dwellings weatherized by the WAP during PY 1989, and electricity was the primary heating fuel for $10 \%$. 


\section{Data Collection}

Four types of data were collected for the sampled dwellings:

- dwelling-specific data on dwelling and occupant characteristics, weatherization measures installed, and material and labor costs;

- agency-level cost data on overhead and management costs;

- utility data on fuel consumption; and

- weather data.

Dwelling-specific and agency-level data were requested from each of the 400 agencies selected for the sample of weatherized homes. The cooperation of agency directors resulted in minimal sample attrition: data were received on 14,971 weatherized dwellings, or $80 \%$ of the original sample of 18,748 homes.

Fuel-consumption data were requested from the 926 utilities which provided gas and/or electricity to those weatherized and control dwellings that heated primarily with gas or electricity. No effort was made to gather fuel consumption records for dwellings that heated primarily with other fuels such as fuel oil, kerosene, propane, wood, or coal. Despite extensive follow-up activities, attrition was significant: utilities provided complete data for only 4,796 (or $36 \%$ ) of the 13,162 weatherized dwellings that heated primarily with gas or electricity, and 3,776 (or $32 \%$ ) of the 11,795 control dwellings.

Data on average daily temperatures for weather stations in proximity to the local weatherization agencies were obtained from the National Climatic Data Center.

\section{Data Analysis}

The representative national sample was designed to be large enough to provide estimates of national program energy savings for PY 1989 that were within 10\% of the mean at the $90 \%$ confidence level. In addition, estimates of energy savings were to be sufficiently precise to enable comparisons across the following key subgroups:

- climate region (cold, moderate, and hot - see Figure A.6);

- primary heating fuel (gas, electric, and other);

- housing type (single-family, small multifamily, mobile homes); and

- agency size (small, medium, and large). ${ }^{5}$

These same subgroups are used to examine dwelling and occupant characteristics, weatherization activities and costs, and cost effectiveness.

5 Small agencies weatherized 100 or fewer dwellings in PY 1989, medium-sized agencies weatherized more than 100 and less than 400 dwellings, and large agencies weatherized 400 or more dwellings during that year. 
Altogether, the evaluation design provides for:

- the most comprehensive evaluation of the Weatherization Assistant Program ever conducted (involving thousands of dwellings and hundreds of local weatherization agencies and utilities);

- understanding of the program across key subgroups (climate regions, primary heating fuels, dwelling types, and agency size);

- implementation of innovative approaches to weatherization program evaluation (e.g., retention of dwellings with occupancy changes and use of a new weather normalization model for electrically heated and cooled dwellings);

- a detailed description of the Program's weatherization activities;

- a primary data analysis of energy savings and cost effectiveness of the Program as applied to gas- and electrically heated homes;

- the inclusion of some non-energy benefits in the cost-effectiveness analysis; and

- the involvement of representatives of all the Program's major stakeholders in the evaluation's design and implementation.

\section{DESCRIPTION AND CHARACTERIZATION OF THE SAMPLE}

\section{Description of the Sample}

Figure A.1 shows a comparison of the original sample sizes and the data received from local agencies and utilities. With the high response rate from local weatherization agencies, the database of dwelling-specific information provides a robust basis for generating highly accurate statistics about the activities of the Program. The low response rates from gas and electric utilities, however, prevent reliable energy-savings and cost effectiveness estimates for a few key subgroups and introduce possible response biases. Nevertheless, the data are sufficient to generate reliable savings and cost effectiveness estimates for the Program as a whole and for each of the climate regions.

\section{Characteristics of Weatherized Dwellings}

The analysis of weatherized dwellings underscores the existence of great diversity in the types of occupants and single-family and small multifamily buildings that received DOE weatherization services during PY 1989. The dominant markets are clear: most weatherized dwellings are singlefamily detached $(64 \%)$, owner-occupied $(66 \%)$, are located in the moderate climate region (59\%), have central heating systems (68\%), and heat with natural gas (51\%). On the other hand, the PY 1989 
\# of agencies/dwellings in original sample

\# of agencies/dwellings with dwelling-specific data

\# of agencies/dwellings with energy-consumption data (weatherized dwellings)

\# of agencies/dwellings with energy-consumption data (control dwellings)

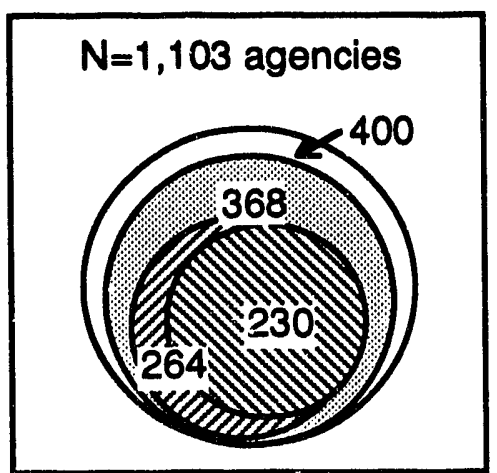

Local Agencies

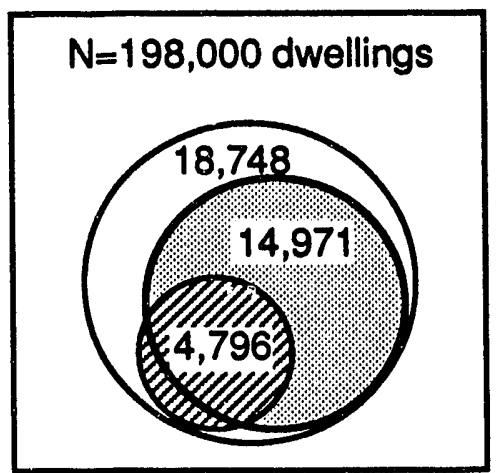

Weatherized Dwellings
$N=49,500$ dwellings

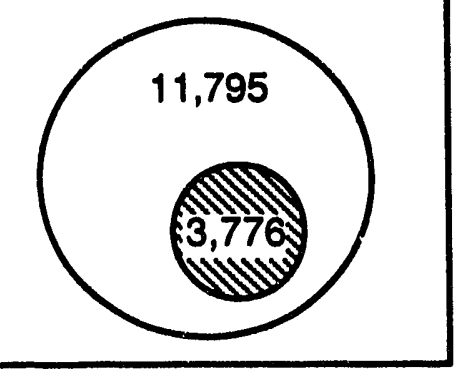

Control Group Dwellings

Fig. A.1 Comparison of Sample Sizes.

weatherized dwellings also include mobile homes (20\%), dwellings that heat primarily with non-utility fuels such as liquid propane gas (13\%) and wood (6\%), and households with elderly occupants (36\%) and persons with disabilities (24\%).

There are significant geographic differences in the demographic and housing characteristics of the Program's clients. Key differences by climate region are:

- Cold Climate: highest household incomes, highest incidence of central heating and owner-occupancy.

- Moderate Climate: predominantly heated by natural gas, highest percentage of small multifamily homes.

- Hot Climate: highest percentage of mobile homes, smaller and newer homes, relatively few central heating systems, more supplemental fuels, high percentage of homes with elderly or handicapped occupants.

Similarly, dwelling and occupant traits vary markedly across primary heating fuels.

- Dwellings Heated by Natural Gas: vast majority have central heating systems, older homes than average, many small multifamily dwellings, few mobile homes. 
- Dwellings Heated by Electricity: relatively few central heating systems, more air conditioning equipment, newer than average.

- Dwellings Heated by "Other" Fuels: about half have central heating systems, high percentage use supplemental heating fucls, many mobile homes.

Dwelling and occupant traits also vary by type of dwelling.

- Single-family Detached Dwellings: largest household sizes, highest incidence of slderly and handicapped occupants, more reliance on supplemental fuels.

- Single-family Attached Dwellings: high incidence of central heating, limited use of supplemental fuels, oldest dwellings, highest income occupants.

- Mobile Homes: smallest and newest dwellings, greatest home ownership, limited gas heat.

- Small Multifamily Dwellings: heat primarily with natural gas, largest dwellings, lowest level of home ownership, fewest elderly.

These differences are key to understanding the performance, challenges, and opportunities of the Program.

\section{Comparison of Weatherized and Eligible Populations}

Definitions of income eligibility for the Program vary among the States, but generally range from $125 \%$ to $150 \%$ of the federal poverty level. ${ }^{6}$ Program participants and the eligible population have somewhat different profiles when eligibility is defined as $125 \%$ of poverty. Because the Program tends to serve the needier part of the low-income sector, these differences are more pronounced when eligibility is defined as $150 \%$ of poverty.

Participants in PY 1989 typically had a lower average income than the Program-eligible population (Fig. A.2) They also resided in smaller and older homes. In addition, weatherized dwellings had fewer electric heating systems and relied more on non-utility fucls, such as fuel oil, propane, kerosene, wood, and coal, than the eligible population. These findings characterize a program that directs its resources towards the more economically disadvantaged portion of the lowincome population.

Participants in PY 1989 were more concentrated in the cold and moderate climate regions than the eligible population, reflecting the higher funding levels of States with colder climates. The weatherized dwellings also included higher proportions of mobile homes and lower proportions of single-family attached and small multifamily dwellings than the eligible population. This is the case

6 Some States use $125 \%$ of the federal poverty level as the Program cligibility threshold, while others use $150 \%$ of the poverty level. Other definitions, such as $60 \%$ of the State's median income, also may be used. Because of the varying State definitions, the Program-eligible population actually has a mean income that is somewhere between $125 \%$ and $150 \%$ of the poverty level. 


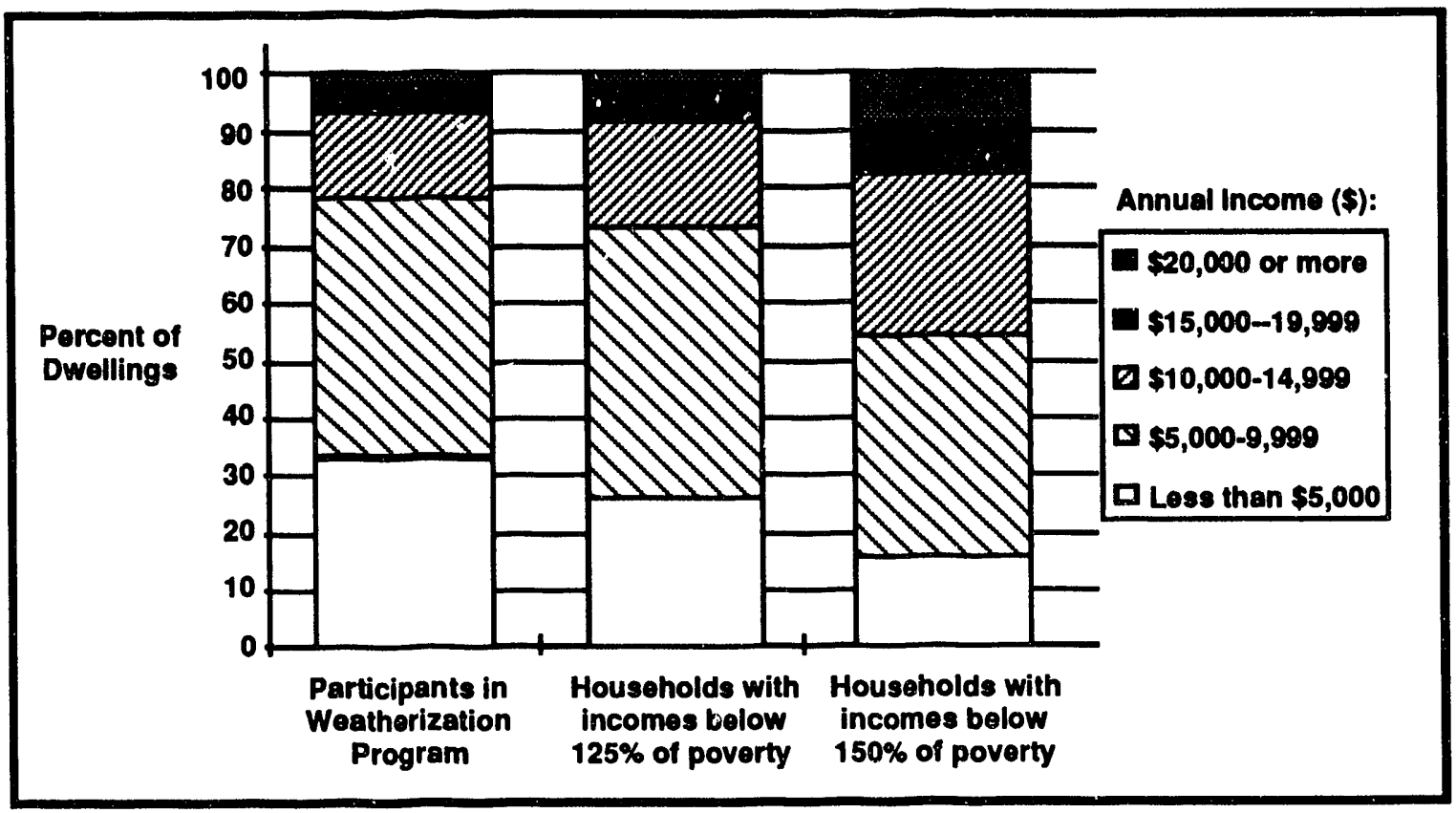

Fig. A.2 Income Distribution of Program Participants and Eligible Households.

even though (1) mobile homes are most prevalent in the hot region (which receives disproportionately less funding relative to its low-income population), and (2) single-family attached and small multifamily dwellings are most prevalent in the moderate and cold climate regions (which receive disproportionately more funding). Thus, there appears to be a programwide tendency to serve mobile homes at higher rates, and small multifamily and attached single-family dwellings at lower rates than their proportions in the eligible pupulation.

In general, the average proportion of dwellings with an elderly occupant is about the same in the two populations. Weatherization agencies located in the hot climate region, however, served a disproportionately large number of elderly clients.

\section{DESCRIPTION OF WEATHERIZATION ACTIVITIES}

\section{National Program Trends over Time}

The cost effectiveness of the Program depends upon selecting the most appropriate measures for each participating house and installing them properly so that each dollar spent on weatherization generates the maximum energy savings. In the early years of the Program, emergency and temporary measures were emphasized, including caulking, weatherstripping, and low-cost/no-cost measures such as plastic window sheets. By the time of the Energy Information Administration's evaluation of the 1981 weatherization program, the emphasis had changed to more permanent and effective building envelope measures, such as storm windows and attic insulation. By 1989, spaceheating system measures (such as tune-ups and component retrofits, which were not part of the 1981 
Program) were installed in $30 \%$ of the weatherized dwellings (Fig. A.3). In PY 1989, another new measure - blower dcor-assisted air sealing - was used in $18 \%$ of weatherization jobs. Storm windows, on the other hand, were installed in a majority of weatherized dwellings in 1981, but were installed in only $36 \%$ of the dwellings weatherized in PY 1989. Insulation was installed in $62 \%$ of the dwellings weatherized in PY 1989 (down slightly from 81\% in 1981), but in PY 1989 it included much more sidewall, floor, and duct insulation as opposed to just attic insulation. These trends are consistent with a growing body of research emphasizing the cost effectiveness of fumace retrofits, blower door diagnostics, and insulation; and questioning the ability of storm windows to save energy cost effectively.

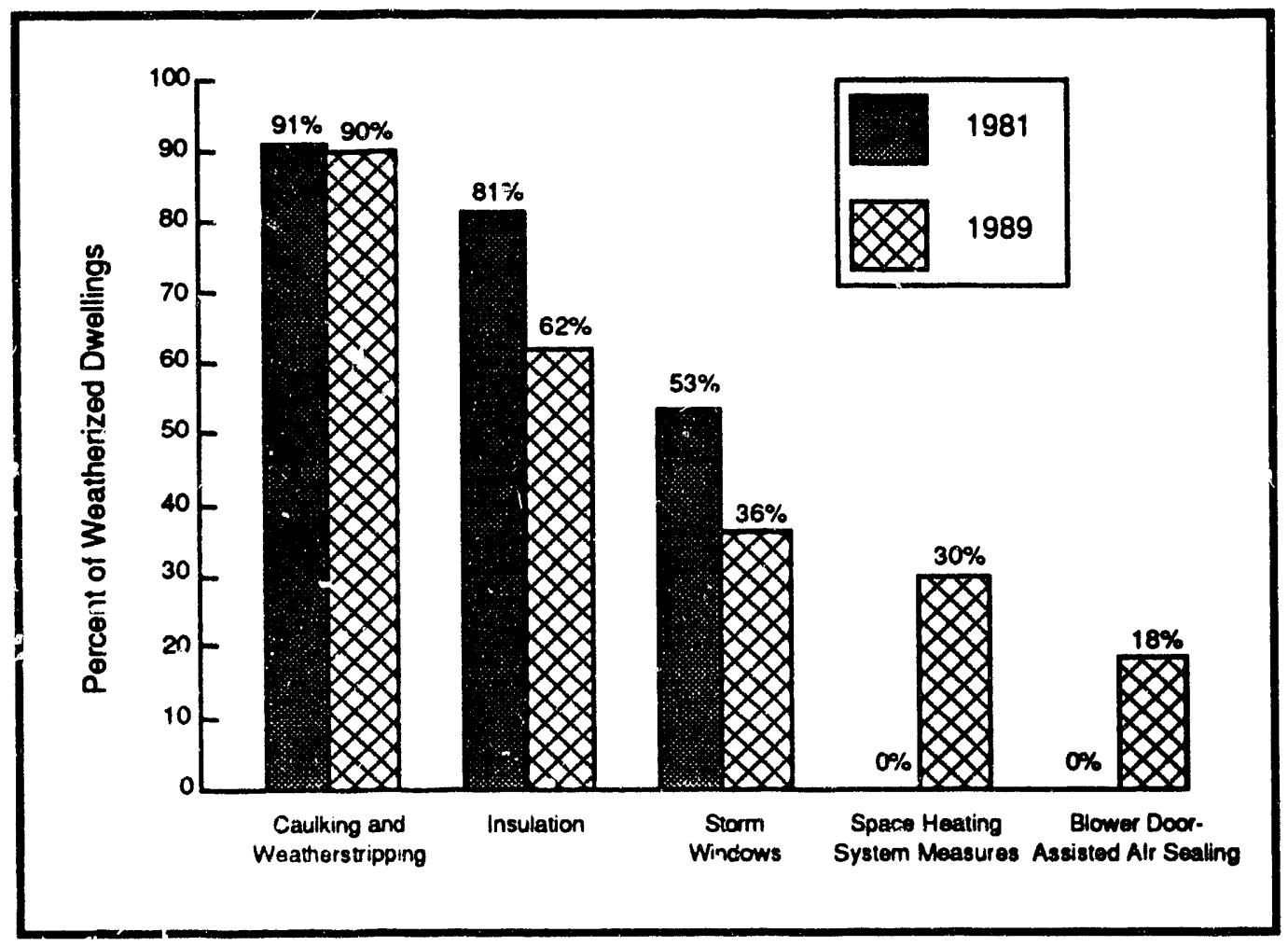

Fig. A.3 Installation Rates for Selected Weatherization Measures: 1981 and 1989.

The diversity ind complexity of weatherization procedures has increased dramatically over the past decade. While many agencies still select their clients on a first come-first served basis, others target clients with greater-than-average potential for cost-effective energy savings. Similarly, investment criteria have been developed that deviate from uniform expenditures per house to allow larger investments in dwellings that offer greater energy-savings opportunities. Program implementers now have a large menu of diagnostic tools to help guide their weatherization. In addition, the Program pis:ulits the use of a variety of methods for selecting weatherization measures, 
which allow measures to be better targeted to the specific needs of individual dwellings than occurs when priority or prescribed lists are used. Recognizing the impact of occupant behavior upon energy consumption, client education has become an integral part of many State and local weatherization programs. Finally, quality control has gone beyond visual inspections during monitoring visits, to include sophisticated measurement and diagnostic procedures.

Despite the increased use of more sophisticated measures and diagnostic techniques, many advanced measures and service delivery techniques are still not practiced very widely. For example, in 1989, few weatherized dwellings received high-density wall insulation (2\%), an integrated envelope/heating system audit $(8 \%)$, or distribution system diagnostics to find leakage areas for air sealing $(8 \%)$.

\section{Differences Across Regions, Heating Fuels, and Housing Types}

There was great diversity in the weatherization measures installed and the procedures used during the 1989 Program. Differences across climate regions are particularly pronounced.

- Cold climate region: high installatic'n rates for insulation, water heating, and space heating measures; low installation rates for storm and replacement windows and doors; most frequent use of integrated audits and blower door testing; more space heating diagnostics.

- Moderate climate region: high installation rates for storm windows, space-heating measures, and air leakage control; most heating system diagnostics and dissemination of energy literature.

- Hot climate region: low installation rates for wall insulation and space- and water-heating measures; high installation rates for replacement windows and doors; least frequent use of integrated audits, blower door testing, and snase heating diagnostics.

Local weatherization agencies in the cold climate region emphasize many of the measures and procedures that recent literature suggests will produce the best results (such as integrated audits, insulation, space heating and water-heating measures). In contra.t, housing rehabilitation measures, which cannot be expected to significantly lower energy usage, are emphasized most by agencies in the hot region, reflecting the more dilapidated condition of the South's housing stock.

Differences in measures installed and procedures used by fucl type were less dramatic, but still significant.

- Gas-heated dwellings: high installation rates for insulation, space- and water-heating measures; low instailation rates for mobile home measures; and most frequent use of distritutic: system diagnostics and air sealing, heating system efficiency tests, and initegrated sudits.

- Electrically heated dwellings: high installation rates for storm windows; low installation rates for other types of weatherization measures; infrequent use of space-heating diagnostics and integrated audits; and greatest emphasis on client education. 
- Dwellings heated by "other" fuels: high installation rates for mobile home measures; low installation rate for water-heater measures; and most frequent use of blower door testing for envelope diagnostics and as a cost-effectiveness guide.

In part, these differences reflect the fact that measures and procedures are in some cases appropriate for certain fuel types but not for others. For example, the most common heating system measures and diagnostics are not applicable to electric heating systems. Profiles of weatherization measures and procedures also differ across primary heating fuels because reliance on these fuels differs geographically (e.g., the hot region relies more on "other fuels") and by housing type (e.g., mobile homes are rarely heated by natural gas).

Finally, differences across dwelling types are also apparent.

- Single-family detached homes: high installation rates for insulation, storm windows and doors, and air leakage control; low installation rates for space-heating measures; and most blower door testing.

- Mobile homes: high installation rates for storm windows, underpinning/skirting, and cool seals on roofs; and low installation rates for insulation.

- Single-family attached dwellings: high installation rates for space-heating system improvements, storm windows, and attic insulation; and low installation rates for wall insulation.

- Small multifamily dwellings: high installation rates for water-heater measures and storm windows and doors; greater use of heating system diagnostics, distribution system diagnostics, and integrated audits; and less blower door testing.

Like the cold climate region and gas-heated dwellings, two dwelling types had a high concentration of advanced diagnostic procedures: single-family detached homes and small multifamily dwellings.

The above profiles indicate that there are systematic variations in the diagnostics and measures used to weatherize different types of dwellings. These differences are key to understanding the performance of the Program in its various submarkets.

\section{ENERGY SAVINGS}

For both gas- and electrically heated dwellings, the estimation of heating and cooling energy savings involved several steps. First, normalized annual consumption (NAC), which is the amount of energy that would have been consumed in a year with typical weather, was estimated for a preweatherization year (pre-NAC), and a post-weatherization year (post-NAC), for each dwelling with complete consumption data. ${ }^{6}$ Gross savings were estimated by subtracting the average post-NAC from the average pre-NAC for weatherized homes. Net savings were estimated by subtracting the average gross savings for control homes from the average gross savings for weatherized homes. The

6 The Princeton Scorekeeping Method (PRISM) was used to calculate Normalized Annual Consumption. 
gross or net percentage savings were calculated by dividing the average gross or net savings by the average pre-NAC.

The energy saved by weatherizing fuel-oil heated homes was based on the results of the FuelOil Study. The energy saved in homes heated by other fuels was based on the analysis of gas-heated homes, with a correction for their different geographic distributions.

\section{The 1989 Program Results}

Estimates of programwide energy savings are summarized in Table A.1. On average, each dwelling weatherized in PY 1989 saved an estimated 17.6 MBtu's during its first year after weatherization, ${ }^{7}$ resulting in a $13.5 \%$ reduction in total energy use, an $18.2 \%$ reduction in the energy used for space heating, and an annual decrease of $\$ 116$ in the low-income participant's energy burden.

\section{Table A.1 1st and 20-Year Energy Savings of Housing Units} Weatherized in PY 1989

\begin{tabular}{|c|c|c|c|c|}
\hline \multirow[b]{2}{*}{ Woros Prinass } & \multirow{2}{*}{ We No Unitss } & \multirow{2}{*}{$\begin{array}{l}\text { First Y lear } \\
\text { Energy Savings } \\
\text { per Dwelling }\end{array}$} & \multicolumn{2}{|c|}{ Erogranuwide } \\
\hline & & & (in Mirstitu's) & 20. Y ear Total \\
\hline Haturalsos & 100,188 & 17.3 & $1,733,000$ & $34,670,000$ \\
\hline Electricity?. & $\begin{array}{l}18,810 \\
18,810\end{array}$ & $\begin{array}{r}6.2 \\
18.9\end{array}$ & $\begin{array}{l}117,000 \\
356,000\end{array}$ & $\begin{array}{l}2,340,000 \\
7,120,000\end{array}$ \\
\hline Other ruels. & 79,002 & 17.7 & $1,398,000$ & $27,960,000$ \\
\hline We Tothl & $\begin{array}{l}198,000 \\
198,000\end{array}$ & $\begin{array}{l}16.4 \\
17.6\end{array}$ & $\begin{array}{l}3,248,000 \\
3,487,000\end{array}$ & $\begin{array}{l}64,960,000 \\
69,740,000\end{array}$ \\
\hline
\end{tabular}

Nationwide, the 1989 Program resulted in annual energy savings of 3,487,000 MBtu's. At an equivalence of 5.8 MBtu's per barrel of oil, this represents 601,000 barrels of oil during 1990-91, or 1,650 barrels of oil per day. Over the 20-year lifetime of the weatherization measures installed in PY $1989,^{8}$ it is estimated that the savings from this one year of weatherization will amount to

7 MBtu refers to one million British thermal units.

8 The assumption of an average lifetime of 20 years for all weatherization measures installed in PY 1989 was based on an analysis of: (1) the frequency of installation of various packages of measures, (2) the average 
$69,740,000 \mathrm{MBtu}$ 's, or 12 million barrels of oil. This is approximately equal to the amount of oil that was added to the emergency Strategic Petroleum Reserve in 1992.

\section{Gas-Heated Dwellings}

Gas-heated dwellings account for $90 \%$ of the 4,299 weatherized dwellings for which fuel consumption records were available, and represent half of the dwellings weatherized by the Program in PY 1989. Thus, their performance dominates the outcome of this evaluation.

This study's weighted estimate of net savings in gas-heated homes is $173 \mathrm{ccf}$ 's or $17.3 \mathrm{MBtu}$ 's. This represents $13.0 \%$ of pre-weatherization gas consumption (Table A.2). The savings are higher when calculated as a percentage of the gas used for space-heating purposes during the year preceding weatherization. Using this as the denominator for estimating percent net savings, the Program saved an average of $18.3 \%$ of the gas used for space heating.

Table A.2 Gas Savings in Gas-Heated Dwellings

\begin{tabular}{|c|c|c|c|c|}
\hline & Cold Region & $\begin{array}{l}\text { Moderate } \\
\text { Region }\end{array}$ & Hot Region & Program-wide \\
\hline Number of Dwellings & 1,040 & 2,243 & 590 & 3,873 \\
\hline First year Gross Savings (in & 166 & 137 & 102 & 135 \\
\hline Firstovear Net savings (in & 235 & 182 & 91 & 173 \\
\hline Net Savings as Percent of Total & $17.7 \%$ & $12.4 \%$ & $10.9 \%$ & $13.0 \%$ \\
\hline $\begin{array}{l}\text { Net Sayings as Percent of Gas } \\
\text { Used for Space Heating }\end{array}$ & $24.9 \%$ & $17.5 \%$ & $15.4 \%$ & $18.3 \%$ \\
\hline
\end{tabular}

Net gas savings are highest in the cold region (235 ccf's), somewhat lower in the moderate region (182 ccfs), and much lower in the hot region $(91 \mathrm{ccf} s)$. Because pre-weatherization gas use is highest in the moderate climate region, net savings as a percent of total gas use for this region $(12.4 \%)$ is much less than in the cold region (17.7\%). Due to the low level of gas use in the hot region, percent net savings for this region (10.9\%) is only slightly less than in the moderate region. Variations in savings by dwelling type are large and significant for gas-heated dwellings: singlefamily detached dwellings (the dominant dwelling type served by the Program) saved over 50\% more than mobile homes.

lifetime of the energy conservation measures included in each package, and (3) the measured gas savings of each package. 


\section{Electrically Heated Dwellings}

Electrically heated dwellings represent $10 \%$ of the dwellings weatherized by the Program during 1989. Thus, they account for a small, but significant fraction of the Program's clients.

The weighted net savings estimate for the Program nationwide is $1,830 \mathrm{kWh} /$ year or 6.2 MBtu's/year (at the site) (Table A.3). ${ }^{9}$ This represents a $12.2 \%$ reduction in total electricity, a $29.7 \%$ reduction in electricity used for space heating and air conditioning, and a $35.9 \%$ reduction in electricity used for space heating.

Table A.3 Electricity Savings in Electrically Heated Dwellings

\begin{tabular}{|c|c|c|c|c|}
\hline & Cold Region & $\begin{array}{l}\text { Moderate: } \\
\text { Region }\end{array}$ & Hot Region & Progranivide \\
\hline Number of bwellings & 35 & 260 & 131 & 426 \\
\hline Rist gevar Giross Savings (in. & 1,933 & 939 & 307 & 867 \\
\hline 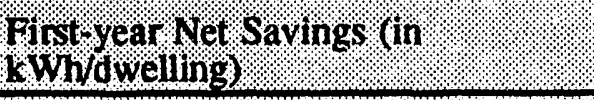 & 2,686 & 2,479 & 595 & 1,830 \\
\hline Net Savings as rercent of Total: & $14.4 \%$ & $14.9 \%$ & $5.4 \%$ & $12.2 \%$ \\
\hline $\begin{array}{l}\text { Nef Savings os percent of } 1 \text { ' } \\
\text { Electricity Used for Space } \text { Heating }\end{array}$ & $42.4 \%$ & $43.8 \%$ & $15.9 \%$ & $35.9 \%$ \\
\hline
\end{tabular}

The energy saved by electrically heated homes varies markedly across key subgroups. Percent net savings range from $5.4 \%$ in the hot region to $14.9 \%$ in the moderate region. As with gasheated homes, single-family detached and small multifamily dwellings saved more electricity after weatherization than mobile homes.

\section{Dwellings Heated by Other Fuels}

An indirect estimation approach was used to estimate the energy saved by dwellings heated by fuels other than natural gas and electricity. The approach emphasized the similarity between gasheated homes and dwellings heated primarily by these other fucls, but recognized that the two types of dwellings have different regional distributions. It also incorporated the results of the National Weatherization Evaluation's Fuel-Oil Study. The resuit is an estimate of 17.7 MBtu's saved per weatherized dwelling heated with other fuels. This value is slightly more than the estimated energy savings for gas-heated homes (17.3 MBtu's per year), because of the high savings of the fuel-oil heated homes located in the nine northeastem states (22.4 MBtu's per year).

9 Additional energy savings occur at the source of electricity generation, because energy (e.g., coal or gas) is typically consumed to produce electricity. 
The estimated energy saved by different types of "other" fuels suggests that fuel oil has contributed more than any of the others. It is the most common "other" fuel among homes weatherized in PY 1989, and it is used primarily in the cold and moderate regions. Liquid propane gas is the next most common "other" fuel, but because it is used primarily in the hot region, it contributes much less to the Program's total energy savings.

\section{Trends and Comparisons}

The estimated Program savings in PY 1989 are higher than the estimate of 13.8 MBtu's per dwelling resulting from EIA's evaluation of the 1981 Program (Peabody, 1984). In addition to the general increase in savings over time, our findings differ in other ways from the earlier evaluation. Peabody (1984) found very little variation in energy savings by climate region, reporting only slightly lower savings in warmer climates. The Single-Family Study documents much higher savings in the moderate and cold regions compared with the hot region. Peabody (1984) found lower savings for electrically heated dwellings than for dwellings heated by natural gas, but our results show comparability, particularly when considering percent savings. Finally, our estimate of energy savings for homes heating primarily with fuel oil is the highest of any fuel type, while fuel-oil energy savings were more like the average in the assessment of the earlier program.

The estimated savings of the 1989 Program compare favorably with the results of evaluations of utility-operated low-income weatherization programs and evaluations of individual State weatherization programs.

\section{NONENERGY IMPACTS}

The various nonenergy impacts of low-income weatherization programs are numerous. However, much of the research addressing these benefits has been qualitative in nature, presenting only anecdotal evidence. A consensus on how to quantify the value of many nonenergy benefits has not been reached.

Table A.4 lists the nonenergy benefits that were monetized in this study. Additional benefits that have not been assigned a dollar value include: thermal comfort improvements, indoor air quality, benefits of increased nonenergy expenditures, and savings associated with fewer residential moves. Thus, the dollar value used here for nonenergy benefits (\$976) is conservative. 
Table A.4 Net Present Value of Nonenergy Impacts of the Weatherization Assistance Program

\begin{tabular}{|c|c|}
\hline Type of Nonenergy Impact & $\begin{array}{l}\text { Net Present Value of the } \\
\text { Impact per Dwelling } \\
\quad(1989 \text { \$) }\end{array}$ \\
\hline $\begin{array}{l}\text { Enhinced Property Value and Extended Lifetime of } \\
\text { Dwelling }\end{array}$ & $\$ 126$ \\
\hline Reduced Fires: & $\$ 3$ \\
\hline Reduced Arrearages. & $\$ 32$ \\
\hline Federal Taxes Generated from Direct Employment & $\$ 55$ \\
\hline Income Generated from Indirect Employment & $\$ 506$ \\
\hline Avoided Costs of Unemployment Benefits & $\$ 82$ \\
\hline Environmental Externalities & $\$ 172^{\mathrm{a}}$ \\
\hline Total Net Present Value of Nonenergy Impacts & $\$ 976$ \\
\hline \multicolumn{2}{|c|}{$\begin{array}{l}\text { The net present value of the environmental benefits was calculated assuming a } 4.7 \% \text { discount } \\
\text { rate and a } 20 \text {-year lifetime. The other nonenergy benefits occur only in the year (1989) in } \\
\text { which weatherization occurred and, therefore, do not require discounting. }\end{array}$} \\
\hline
\end{tabular}

The methods used here to estimate the value of nonenergy impacts varied. Estimates of environmental benefits relied on a literature review and on information from this study about the proportions of weatherized dwellings using various fuel types and about the average savings by fuel type. The analysis of environmental impacts was limited to the costs associated with $\mathrm{SO}_{2}, \mathrm{NO}_{\mathrm{X}}$, and $\mathrm{CO}_{2}$. Estimates of employment benefits combined a literature review with data from this study on the number of employees directly supported by DOE's weatherization program, the skill level of workers, and managers' judgments concerning the structure of the job market for weatherization workers. Direct and indirect, but not induced, employment benefits are included in the estimate. Data from this study on weatherization expenditures for home repairs are used to quantify the benefits associated with maintaining or enhancing property values and extending the lifetime of dwellings. Our estimate of reductions in arrearages is based on a litcrature review and data on payment histories that were collected on the dwellings included in this study. 


\section{costs}

In PY 1989, the programwide average total installation cost (i.e., materials and on-site labor) per dwelling was $\$ 1,050$. Expenditures for individual dwellings, however, often varied substantially from this average. In particular:

- Eighty-five percent of dwellings had total installation expenditures of less than $\$ 1,500$, with $45 \%$ of dwellings in the $\$ 600$ to $\$ 1,200$ range. About $8 \%$ had expenditures of less than $\$ 300$ and about $9 \%$ had expenditures of more than $\$ 1,800$.

- There were no significant differences by climate region in total materials costs, but differences in labor costs and total installed costs were significant. The largest installation expenditures were in the moderate and cold climate regions, while the hot region spent about $10 \%$ less.

- Total installation costs, total materials costs, and labor costs differed significantly by fuel type with the highest expenditures for dwellings that heat with other fuels.

- Total installation costs, total materials costs, and labor costs differed significantly by dwelling type with the highest total installation expenditures for single-family attached and single-family detached dwellings, and the highest materials costs for multifamily.

Although total materials costs did not vary significantly by climate region, the proportion of the expenditures invested in various types of measures did differ significantly (Fig. A.4). In the cold region, investments were highest for insulation. In the moderate region, the highest expenditures

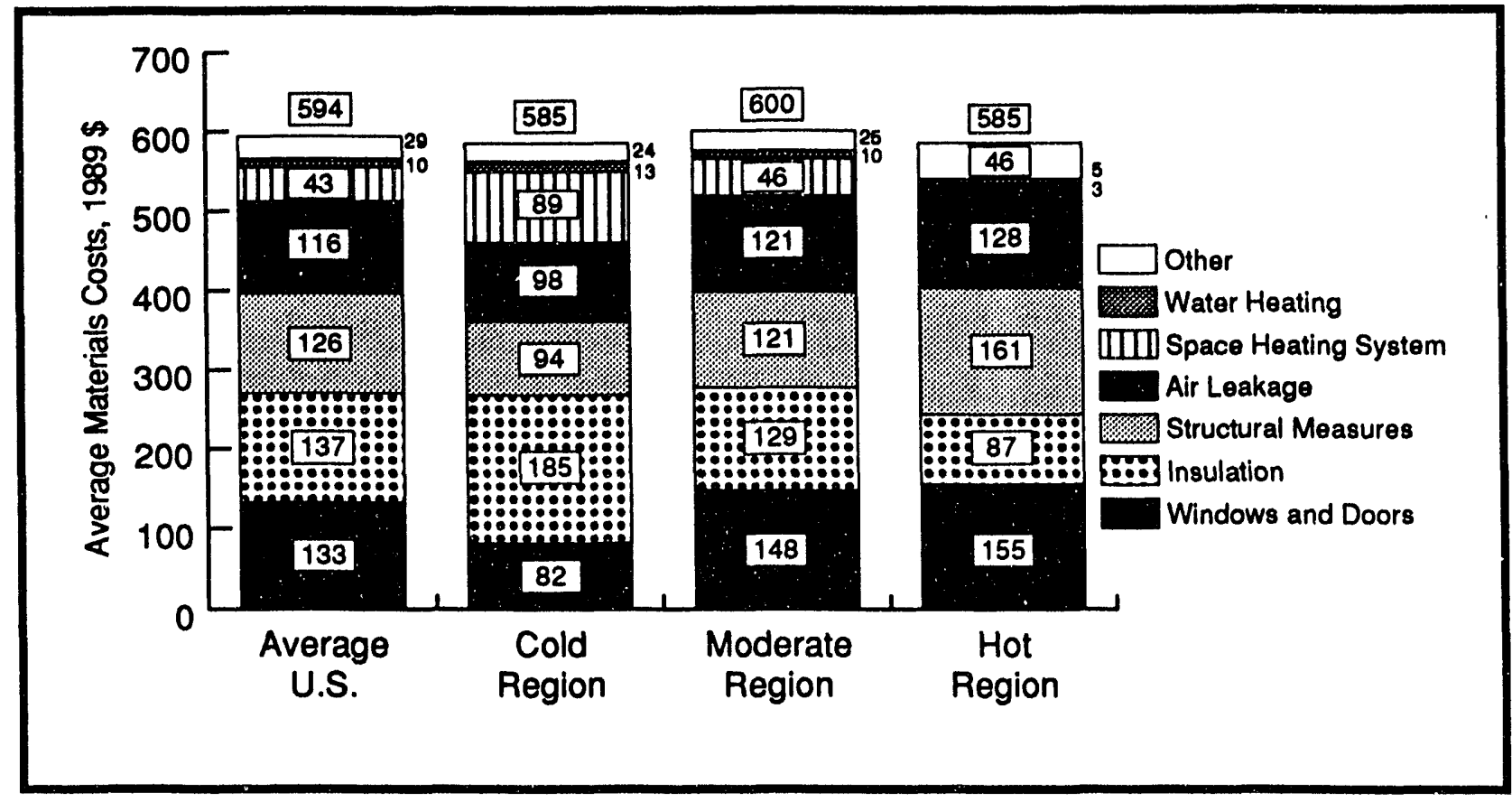

Fig. A.4 Average Material Costs (in 1989 dollars), by Climate Region. 
were for windows and doors. In the hot region, structural repairs had the highest investment level, and windows and doors consumed nearly as high an amount. Thus, the cold region puts more resources into the measures most likely to save energy. Differences in materials costs by fuel type also were significant with the most being spent on homes heated with other fuels.

Labor cost data were collected and calculated with different methods for crew-only, contractor-only, and mixed (crew and contractor) weatherization jobs. This was necessary because the way agencies track costs for crew and contractor labor differs. Among the representative dwellings that could be classified by labor type, approximately one-third fell into each of the three types: crew-only, 33\%; contractor-only, 38\%; and mixed crew and contractor, $29 \%$. Generally, agencies tend to use one labor type on all, or at least most, of their weatherization jobs. Nationally, labor costs averaged about $\$ 433$ per dwelling out of a total installation cost of $\$ 1,050$.

Previous studies suggest that management and overhead costs (all costs other than materials and on-site-installation labor) range from $\$ 300$ to $\$ 600$ per house. In spite of the magnitude of management and overhead costs, most previous evaluations of weatherization programs have not reported them and have not included them in their cost-effectiveness calculations. In part, this reflects the difficulty of obtaining accurate information on management and overhead costs. An estimate of management and overhead costs $(\$ 500)$, consistent with findings of previous studies, was developed and used in this evaluation.

\section{COST EFFECTIVENESS}

The cost effectiveness of the Program was examined from many perspectives, but only three are presented in detail, by subgroup. With the installation perspective, which follows the usual procedure in previous low-income weatherization program evaluations, the only benefit valued is energy savings and the only costs included are installation expenditures (i.e., on-site-installation labor and materials costs). With the program perspective, the only benefit valued is energy savings, while costs include installation and management and overhead costs (i.e., the "worst" case). With the societal perspective, benefits include both energy and nonenergy benefits, and costs include installation and management and overhead costs. Net energy savings (rather than gross energy savings) are used in all the cost-effectiveness calculations, because we consider this a better indicator of program impacts. In addition, the same baseline assumptions are used (4.7\% discount rate and 20 year lifetime of measures), although sensitivity analyses are conducted using alternatives. 


\section{T:1e 1989 Program Results}

All of the perspectives that were examined show the 1989 national program to be cost effective. Benefit/cost $(\mathrm{b} / \mathrm{c})$ ratios range from 1.09 (for the program perspective) to 1.72 (for the societal perspective). With the installation perspective, the $b / c$ ratio is 1.61 . Thus, the value of the energy saved by the Program slightly exceeds the cost of operating the Program. When nonenergy benefits are also included, the Program returns $\$ 1.72$ for every $\$ 1.00$ invested.

\section{Gas-Heated Dwellings}

For gas-heated dwellings, the national Program was cost effective from all three perspectives, with b/c ratios ranging from 1.06 to 1.61 . Fig. A.5 presents the results for the societal perspective. The cold and moderate regions had higher $b / c$ ratios than the national average, while the hot region had $\mathrm{b} / \mathrm{c}$ ratios of less than 1.00 with the installation and program perspectives, and of 1.17 with the societal perspective. Only single-family detached homes (which account for $63 \%$ of weatherized homes) had b/c ratios above 1.00 with the program perspective. All dwelling types had b/c ratios of 1.23 or higher with the other two perspectives. Large and medium-sized agencies had cost-effective results with all three perspectives, while small agencies fell below 1.00 with the program perspective.

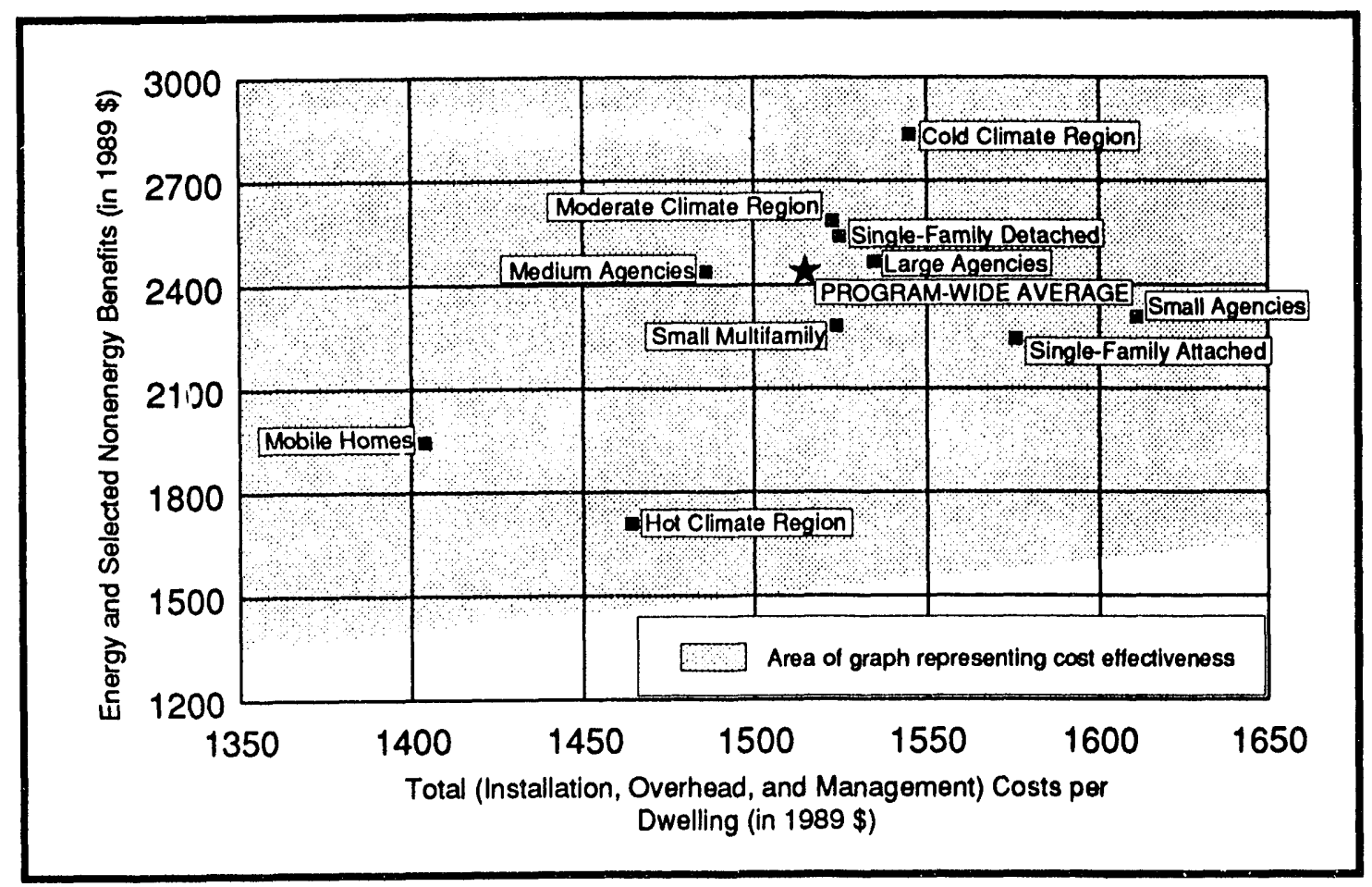

Fig. A.5 Societal Perspective: Energy and Nonenergy Benefits vs. Total Costs for Gas-Heated Dwellings. 


\section{Electrically Heated Dwellings}

Because electricity prices are higher than gas prices, energy savings in electrically heated dwellings are worth more. Therefore, cost-effectiveness results were consistently more favorable. The national benefit/cost ratio was 1.13 with the program perspective, and higher with the other two perspectives. The results by climate region show that the Program was cost effective in the cold and moderate regions, but not in the hot region. All climate regions had b/c ratios of 1.17 or higher with the societal perspective. Comparisons by dwelling type indicate that weatherizations of single-family detached and small multifamily dwellings were cost-effective, while those of mobile homes were not. From the societal perspective, the weatherization of electrically heated dwellings was highly cost effective, with a national benefit/cost ratio of 2.33. All of the subgroups showed cost-effective results with this perspective.

\section{Trends and Comparisons}

The results of cost-effectiveness analyses in previous evaluations suggest that for gas-heated dwellings the 1989 Program improved upon the average performance of similar programs. Schlegel and Pigg (1990), in their review of nine evaluations of cold climate programs serving gas-heated dwellings, reported costs of conserved energy (CCE) that, when recalculated with our baseline assumptions (4.7\% discount rate, 20-year lifetime, only on-site installation labor and materials costs), averaged $\$ 6.08 / \mathrm{MBtu}$, with a range of $\$ 2.69$ to $\$ 17.33$. Cohen, et al. (1990), in their review of 12 evaluations of cold climate programs serving gas-heated dwellings, reported a median CCE recalculated with our assumptions, of $\$ 5.07 / \mathrm{MBtu}$. Thus, our cold climate region results for gasheated dwellings ( $\$ 3.50$ per $\mathrm{MBtu}$ ) compare favorably to the results of previous studies, as do the national results ( $\$ 4.60$ per MBtu). Comparisons with utility low-income programs (for gas-heated dwellings) also show the 1989 Program to be more cost effective. The results for electrically heated dwellings indicated a national CCE $(\$ 0.04$ per $\mathrm{kWh})$ that was lower than the average national price of $\$ 0.07$ per $\mathrm{kWh}$.

\section{FACTORS ASSOCIATED WITH PERFoRMANCE}

The analysis of factors associated with energy savings was multifaceted: (1) it examined the savings of individual dwellings and the average savings of different agencies; (2) it examined absolute savings as well as percent savings and benefit/cost ratios; (3) it employed both bivariate and multivariate analytic techniques; and (4) it examined the predictors of performance in each of three climate regions and nationwide. The different approaches produced a consistent portrayal of the major predictors of energy savings.

The analysis indicates that energy savings per dwelling are largest in the Program's dominant submarkets, where weatherization activity is concentrated. These include: 
- cold and moderate climate regions; and

- single-family detached homes.

Partly because of small sample sizes, few additional predictors of electricity savings were identified. These include high electricity consumption prior to weatherization and the installation of first-time attic insulation. In contrast, numerous factors were significantly associated with gas savings.

Certain service delivery procedures correspond with higher-than-average gas savings, including:

- weatherization of households with high gas consumption (Fig. A.6);

- integrated envelope/heating system audit;

- distribution system diagnostics; and

- heating system efficiency tests.

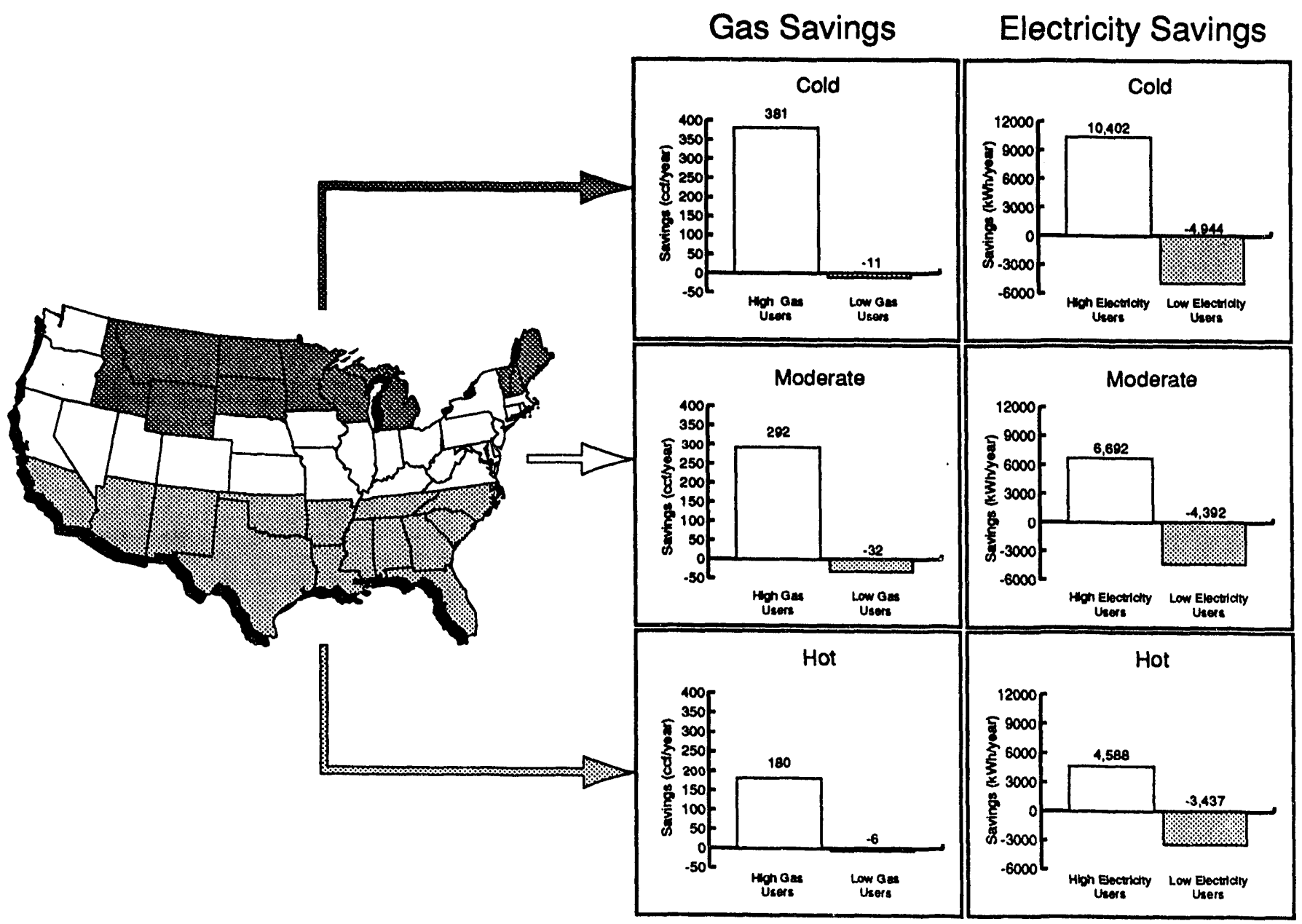

Fig. A.6 Energy Saved by High vs. Low Energy Users in the Three Climate Regions. 
In contrast, the energy-savings benefits of blower-door assisted air sealing and client education were not discernible.

Certain weatherization measures correspond with higher-than-average gas savings, including:

- distribution system air leakage control;

- air sealing without blower doors;

- attic insulation (particularly first-time);

- wall insulation (particularly high density);

- floor insulation;

- water heater tank insulation, pipe insulation and temperature reduction;

- furnace replacements; and

- mobile home underpinning/skirting.

Many of these findings are consistent with the results of previous research. The two findings that are least substantiated by other research are the apparent key role of distribution system diagnostics and air leakage control, and the questionable energy-savings benefits of blower-door assisted air sealing.

Clearly, more analysis is needed to test these findings before employing them as a basis for policy and program recommendations. The results reported here are "correlational" in nature and cannot identify "causes" of high energy savings. More definitive information on factors influencing savings will result from the Single-Family Study's on-site field work (i.e., phase two).

\section{CONCLUSIONS}

During PY 1989, the Weatherization Assistance Program weatherized 198,000 single-family or small multifamily homes. On average, each weatherized dwelling saved an estimated 17.7 MBtu's during its first year after weatherization, resulting in an annual decrease, in 1989 dollars, of $\$ 116$ in the low-income participant's energy burden. Nationwide, the 1989 Program resulted in annual energy savings of 3,487,000 MBtu's. At an equivalence of 5.8 MBtu's per barrel of oil, this represents 601,000 barrels of oil during 1990-91, or 1,650 barrels of oil per day. Over the 20-year lifetime of the weatherization measures installed in PY 1989, it is estimated that the savings from this one year of weatherization will amount to $69,740,000$ MBtu's, or 12 million barrels of oil. This is approximately equal to the amount of oil that was added to the emergency Strategic Petroleum Reserve in 1992.

Total costs (including materials, installation-related labor, installation-related overhead, and program management) averaged $\$ 1,550$ per weatherized dwelling in PY 1989. From the societal perspective, which includes both energy and nonenergy benefits and total costs for all single-family and small multifamily dwellings, the Program in PY 1989 was cost effective, with a benefit/cost ratio of 1.72. Table A.5 presents some of these key statistics. 
Table A : Energy Savings and Cost Efrectiveness of the Weathrrization Assistance Program

\begin{tabular}{|c|c|}
\hline Indicator & Program-Wide Value \\
\hline $\begin{array}{c}\text { First-Year Energy Savings per Dwelling } \\
\text { (in Million Btu's) }\end{array}$ & $\begin{array}{c}16.4 \text { (site) } \\
17.6 \text { (source) } \\
\end{array}$ \\
\hline Energy Savings as a Percent of Total Energy Use & $13.5 \%$ \\
\hline Energy Savings as a Percen 1 of Energy Used for Space Heating & $18.2 \%$ \\
\hline First-Year Dollars Saved per Dwelling ${ }^{2}$ & $\$ 116$ \\
\hline Installation-Related Coscs per Dwelling & $\$ 1,050$ \\
\hline Total Weatherization Costs per Dwelling & $\$ 1,550$ \\
\hline Program Ben fit in Ratio ${ }^{3}$ & 1.09 \\
\hline Installation BenefivCost Ratio 4 & 1.61 \\
\hline Societal Benefit/Cost Ratin ${ }^{5}$ & 1.72 \\
\hline Cost per Million Btu's of Conserved Natural Gas ${ }^{6}$ & $\$ 4.60$ \\
\hline Cost per $k$ Wh of Conserved Electricity ${ }^{7}$ & $\$ 0.04$ \\
\hline $\begin{array}{c}\text { Number of Sirgle-Family and Small Multifamily Dwellings } \\
\text { Weatherized in PY } 1989\end{array}$ & 198,000 \\
\hline
\end{tabular}

Based o: energy consumption one year after weatherization in 1989-90.

2 Estimated at an average cost of $\$ 6.89$ per MBtu's.

3 Based on energy-savings benefits and total weatherization costs.

4 Based on energy-savings benefits and installation-related costs.

5 Based on energy-savings, employment, environmental and other nonenergy benefits and total weatherization costs.

6 The weighted average retail price for natural gas is $\$ 5.90$ per MBtu.

7 The weighted average retail price for electricity is $\$ 0.07$ per $\mathrm{kWh}$.

The Program proved nost cost effective in the submarkets (including cold and moderate climate regione and single-family detached homes) where weatherization activity is concentrated. The hot climate region and mobile homes, on the other hand, represent submarkets where program improvements are needed. Service delivery procedures that curre ipond with higher-than-average energy savings include high priority for high energy users and i.ttegrated envelope/heating system audits. Weatherization, measures associated with higher-than-average savings include heating system replacements and attic, wall, and floor insulation. More widespread adoption of these measures and procedures represent sorne of the many promising opportunities for the future. 


\begin{abstract}
Introduction. In 1990, the U. S. Department of Energy (DOE) initiated a national evaluation of its low-income Weatherization Assistance Program. This report, which is one of five parts of that evaluation, evaluates the energy savings and cost effectiveness of the Program as it has been applied to the largest portion of its client base - low-income households occupying single-family dwellings, mobile homes, and small (2- to 4-unit) multifamily dwellings. The study is based upon a representative national sample (of 368 agencies, 14,971 weatherized dwellings and 11,795 control dwellings) that covers the full range of conditions under which the program was implemented in the 1989 Program Year (PY 1989).
\end{abstract}

Data collection. Dwelling-specific and agency-level data on dwelling characteristics, measures installed, costs, and service delivery procedures were collected from the sampled agencies. Fuelconsumption data were requested from the 926 utilities which provided gas and/or electricity to the sampled dwellings that heated primarily with gas or electricity. Estimates of fuel-oil savings from a companion Fuel-Oil Study were incorporated into the analysis. No effort was made to gather fuel consumption records for dwellings thai heated primarily with other fuels such as kerosene, liquified propane gas, wood, or coal.

Energy savings. Energy savings were calculated by applying the Princeton Scorekeeping Method (PRISM), which is a weather normalization procedure, to gas and electric consumption records for a year before and a year after weatherization. For gas-heated dwellings, national net savings averaged $17.3 \mathrm{MBtu}$, or $13 \%$ of total gas usage, and $18 \%$ of gas used for space heating. For electrically heated dwellings, national net savings averaged $1,830 \mathrm{kWh}$, or $18.9 \mathrm{MB}$ (u's/year. This represents a $12 \%$ reduction in total electricity, and a $36 \%$ reduction in electricity used for space heating. For all fuel types, the national estimate of annual savings was $17.6 \mathrm{MBtu}$ 's per weatherized dwelling resulting in a $13.5 \%$ reduction in total energy use, an $18.2 \%$ reduction in the energy used for space heating, and an annual decrease of $\$ 116$ in the low-income participant's energy burden.

During PY 1989, the Weatherization Assistance Program weatherized 198,000 single-family or small multifamily homes, resulting in a total savings of 3,487,000 MBtu's during the first year. At an equivalence of 5.8 MBtu's per barrel of oil, the Progra n saved 601,000 barrels of oil during 1990. Over the 20-year lifetime of the weatherization measures, the anticipated savings amount to $69,740,000$ MBtu's, or 12 million barrels of oil.

Cost effectiveness. From the socictal perspective, which includes both energy and nonenergy (e.g., employment and environmental) benefits and both installation and noninstallation (i.e., overhead and management) costs for the gas-heated dwellings, the Program in PY 1989 was cost effective, with a national benefit/cost ratio of 1.61 . Because electricity prices are higher than gas prices, energy savings benefits in electrically heated dwellings are worth more than those in gasheated dwellings. Cost-effectiveness results, therefore, were generally more favorable for the electrically heated dwellings, with a national benefit/cost ratio of 2.33. For all fuel types combined, the benefit/cost ratio was 1.61 .

Factors influencing savings and cost effectiveness. The analysis indicates that energy savings and cost effectiveness are highest in the Program's dominant submarkets (including cold and moderate climate regions and single-family detached homes), where DOE Weatherization activity is concentrated. Service delivery procedures that correspond with higher-than-average gas savings include the weatherization of high energy users and the use of integrated envelope/heating system audits. Weatherization measures associated with higher-than-average savings include heating system replacements and attic, wall, and floor insulation. 


\section{ACKNOWLEDGMENTS}

Members of the National Weatherization Evaluation's working groups helped design this study, guide its implementation, and interpret its findings. The authors are grateful for their contributions and would like to acknowledge them individually:

\section{Jeff Ackermann \\ Colorado Department of Local Affairs \\ Don Bamett \\ Missouri Department of Natural \\ Resources

\author{
Mary Ann Bernald \\ Edison Electric Institute \\ Jeff Brown \\ Energy Division, North Carolina \\ Department of Commerce
}

Dale Canning

Salt Lake Community Action Agency

David Carroll

Response Analysis Corporation

Mert Dahn

State of Arizona

Department of Commerce, Energy Office

\section{Margaret Fels \\ Princeton University Center for \\ Energy and Environmental \\ Studies}

Michael Foley

National Association of Regulatory

Utility Commissioners

Michael Gan'ey,

National Rural Electric

Cooperaive Association

Richard Cierardi

New York State Dept. of State

Division of Economic Opportunity
Sharon Gill

U.S. Department of Energy, Chicago Support Office

Larry Goldberg

Sequoia Technical Services

Miriam Goldberg

U.S. Department of Energy, Energy Information

Administration

Judy Gregory

Center for Neighborhood

Development

Al Guyant

Public Services Commission of Wisconsin

Martha Hewett

Center for Energy and the Urban Environment

Bion Howard

Alliance to Save Energy

Larry Kinney

Synertech Systems Corporation

Judith Lankau

Orange and Rockland Utilities

Leon Litow

U.S. Department of Health and Human Services

Ron Marabate

Michigan Department of Labor

Bureau of Community Services

Jane Marden

American Gas Association
Phil Mihlmester

Aspen Systems Corporation

John Mitchell

Consolidated Edison Company, Inc.

Barry Moline

American Public Power Association

John Nelson

Wisconsin Gas Company

Karl Pnazek

Director, Community Action

Program Services

Meg Power

National Community Action

Foundation

Bill Prindle

Alliance to Save Energy

Ken Rauseo

The Commonwealth of Massachusetts

Jeffrey Schlegel

Wisconsin Energy Conservation Corporation

Ken Tohinaka

Vermont Energy Investment Corp.

We: lel Thompson

U.S. Department of Energy

Marjorie J. Witherspoon

National Association of State

Community Services Programs 
Darrell Beschen (the original DOE Project Manager for this study) helped define the overall goals of this study and contributed significantly to the study's completion. Jeanne Van Vlandren (the current DOE Project Manager for this study and the new Weatherization Program Director) offered valuable help with interpreting and presenting the evaluation's findings. Mary Fowler, Jim Gardner, and Frank Stewart (DOE sponsors of this research) also provided useful feedback and guidance.

Research staff at Oak Ridge National Laboratory and several subcontractors (particularly Aspen Systems Corporation) also contributed to the completion of this report. In particular, graphics support was provided by:

- Mark Beyer

- Ed Lapsa

- Steve Steinbach

Data collection, entry, and screening was conducted by:

- Robin Noe

- Charlotte Franchuk

- Debbie Martin

- Mellissa McCoy

The collection of bill waivers was organized and implemented by:

- Paige Tolson

Valuable comments on various drafts of this report were provided by:

- Don Jones

- Bill Levins

- Mike MacDonald

- Mark Ternes

- Dennis White

Don Jones, in particular, provided valuable assistance with the analysis of employment impacts.

David Carroll, of Response Analysis Corporation, provided information on the eligible population based on RECS data.

Tommy Wright designed and wrote the sample weighting methodology that is presented in Appendix B-5, and offered valuable advice on its implementation. Finally, Sherry Surdam and Paulette Bivens contributed to the typing and layout of the report.

This study could not have been completed without the cooperation of local and State weatherization program mangers and the DOE Regional Support Offices, who took time away from their busy schedules to provide data and other assistance to the National Weatherization Evaluation. The input received from all of these individuals is greatly appreciated. 


\section{INTRODUCTION}

\subsection{BACKGROUND TO THE EVALUATION}

This report evaluates the energy savings and cost effectiveness of the U.S. Department of Energy's (DOE) Weatherization Assistance Program (the Program), as it has been applied to the largest portion of its client base - low-income households occupying single-family and small multifamily homes. The most recent national evaluation of the Program's performance was completed in 1984 based on energy consumption data for households weatherized in 1981 (Peabody, 1984). More recently, several States have evaluated their programs to determine their effectiveness. However, most of these State evaluations have assessed cold-climate programs, resulting in an incomplete assessment of overall program performance and uneven information about factors influencing cost effectiveness. As a result, DOE determined that a more timely and comprehensive national level evaluation of the Program was needed to provide policy makers and Program implementers with the up-to-date, credible, and reliable information required for effective decision making.

With assistance from Oak Ridge National Laboratory (ORNL), a National Evaluation of the Program was designed. The evaluation is comprised of three "impact" studies and two "policy" studies (Beschen and Brown, 1991). The three impact studies focus on the energy savings and cost effectiveness of the Program in key DOE Weatherization markets:

- single-family and small multifamily dwellings using gas or electricity for heating - the Single-Family Study (Berry, Brown, Wright, and White, 1991);

- high-density multifamily buildings using gas, electricity, or fuel-oil for heating - the Multifamily Study (MacDonald, Brown, Temes, and Sharp, 1991); and

- fuel-oil heated single-family homes in nine northeastern States - the Fuel-Oil Study (Ternes, Levins, and Brown, 1992).

Two supporting studies address additional aspects of the Program, but are not designed to provide estimates of energy savings or cost effectiveness. They include:

- a characterization of the DOE Weatherization network's capabilities, technologies, procedures, staff, and innovations (Mihlmester, Koehler, Beyer, Brown, and Beschen, 1992); and

- a profile of low-income weatherization resources, the weatherized population, and the Program-eligible population that remains to be served (Power, Eisenberg, Michels, Witherspoon, and Brown, 1992).

Altogether, these five studies will provide a comprehensive evaluation of the Weatherization Assistance Program. The Single-Family Study, the subject of this report, is a critical part of this coordinated evaluation effort. Its focus on single-family dwellings, mobile homes, and dwellings in 
small (2 to 4-unit) multifamily buildings covers $83 \%$ of the income-eligible population. ${ }^{1}$ As a result, it is the largest of the national evaluation's five studies. It is based upon a representative national sample that covers the full range of conditions under which the Program was implemented in the 1989 Program Year (PY). ${ }^{2}$

This chapter begins with an overview of the Program, to provide the reader with the background necessary for understanding the evaluation's results. It then provides a brief review of the literature, again for background purposes. Next the goals of the evaluation are presented. The chapter ends with an overview of the remaining chapters that comprise this report.

\subsection{OVERVIEW OF THE WEATHERIZATION ASSISTANCE PROGRAM}

\subsubsection{Leglslative History}

Federal efforts to weatherize the homes of low-income persons began on an ad hoc, emergency basis after the 1973 oll embargo. A formal program was established, under the Community Services Administration (CSA), in 1975. DOE became involved in 1976, with passage of Public Law 94-385. In 1977 and 1978, DOE administered a grant program which paralleled and supplemented the CSA program; DOE monies provided for purchase of materials and CSA was responsible for labor. In 1979, DOE became the sole Federal agency responsible for operating a low-income

The Weatherization Assistance Program is authorized by the Energy Conservation in Existing Buildings Act of 1976, as amended, 42 U.S.C. 6851 et seg. The following quotation from 42 U.S.C. 6861 (c) describes the Congressional intent of the Program:

"to increase the energy efficiency of dwellings owned or occupied by low-income persons, reduce their total residential energy expenditures, and improve their health and safety, especially low-income persons who are particularly vulnerable such as the elderly, the handicapped, and children."

The intent of the program is also noted in Federal regulations, which are in 10 CFR Part 440, "Weatherization Assistance for Low-Income Persons."

weatherization assistance program. In 1982 Low-Income Home Energy Assistance Program (LIHEAP) funds became available for weatherization, and in 1986 Petroleum Violation Escrow (PVE) funds were first applied to weatherization. However, the majority of funds from both of these sources have been spent under the rules and regulations of the DOE Weatherization Assistance Program (Power, et al., 1992).

The goals of the Weatherization Assistance Program are to decrease national energy consumption and to reduce the impact of high fuel costs on low-income households, particularly

1 Using households below $125 \%$ of the poverty line as the eligible population and excluding public housing, data from the 1987 Residential Energy Consumption Survey indicate that 83\% of the WAP-eligible population resides in single-family or small multifamily dwellings. In the 1990 RECS, the proportion was nearly the same, $84 \%$.

2 The 1989 Program Year typically covered the period from April 1, 1989 through March 31, 1990. In a few states, however, the 1989 Program Year started on July 1, 1989 and ended on June 30, 1990. 
those of the elderly and the handicapped. The energy burden on low-income households is significant: the average low-income family spends $25 \%$ of its income on home energy compared to 7\% for the average family (Vine and Reyes, 1987). Homes occupied by low-income households have less insulation, fewer storm windows, and older and less efficient heating and cooling equipment, incica:ing a greater than average need for energy-efficiency improvements. This need is corrobo, ated by their higher than average levels of energy consumption per square foot of occupied space (Co.'en and Goldman, 1991). At the same time, low-income households have limited financial resources to invest in the conservation measures that would reduce their energy requirements.

\subsubsection{Role:s and Responsibilitles}

The Weatherization Assistance Program is a formula grant program which operates in a decentralized fashion - from Federal to State government to local weatherization agency. There are 51 State grantees (each of the States and the District of Columbia) and approximately 1,103 local weatherization agencies (or subgrantees). Each local agency veatherizes the dwellings of incomequalified households in its service territory, which typically is composed of several rural counties, a medium to large city, or part of a metropolitan area.

The Headquarters office of DOE has responsibility for overall management and nationwide coordination of the Program including such functions as establishing policy, promulgating regulations and guidance, collecting data, monitoring field offices, evaluating progress, providing national level training and technical assistance, and allocating appropriated funds.

Ten field offices of DOE exercise day-to-day oversight and coordination among the States in their respective regions. They review and approve State plans and applications and make grant awards. Field offices monitor States for progress against goals established in State plans and for compliance with statutory and regulatory requirements. They provide training and technical assistance and facilitate the flow of information on new technologies and innovations among States and between States and the Fcderal govemment.

State Grantees are responsible for developing plans and implementing programs that reflect their particular needs and circumstances (climate, housing stock, etc.). Each State is entitled to its formula share of the annual Program appropriation, based on $\mathrm{JOE}$ review ard approval of its State application and plan.' States select local agencies to serve areas within the State and enter into grant or contät :greements with the subgrantern. States are responsible for monitoring and oversight of subgri lees, for trainıng and providing technical assistance to them, for maintaining records, and for reporting to DUE un yrogress in meeting the goals established in their DOE approved plans. The plurality of State Weatherization agencies are located within human services departments of State

3 The formula takes into account the number of low-income households, the percentage of total residential energy used for space heating and cooling, and the number of heating and cooling degree days in the State. 
government; State community and economic development departments house most of the remaining agencies (Mihlmester, et al., 1992).

Subgrantees, or local agencies, are selected by the State grantees. They are responsible for receiving and prioritizing applications and installing the energy conservation measures appropriate to each dwelling unit, for maintaining required records, and for reporting progress to the State. During 1989, 81\% of the Program's local agencies were Community Action Agencies (CAA) and the remainder were local government agencies, community-based organizations, or other nonprofit entities (Mihlmester, et al., 1992).

\subsubsection{Evolution of the Delivery System}

The DOE program began as a hybrid effort which supplemented and paralleled the CSA program by providing grants for the purchase of materials to be installed by voluntary labor with

minimal training. The emphasis was on temporary, quick fix, and/or low-cost measures. Installation standards varied widely.

Subsequent to the early, quick fix/voluntary labor stage, the delivery mechanism evolved through several stages. At first there was a mixture of voluntary and hired labor, with an emphasis on general heat waste and infiltration measures, storm windows and doors, and increasingly on insulation. There was insufficient emphasis on installation standards and on the use of labor saving and/or diagnostic tools and techniques. The development of permanent, trained and experienced staff was just beginning.

As the shift toward professional labor accelerated, more attention was paid at all levels to selection of the right measures, to labor saving and diagnostic techniques, and to proper installation. Today the emphasis is on permanent, cost-effective measures installed by a trained, professional staff and augmented by client education.

Through the early 1980's, there has also been a steady increase in the amount of weatherization work which has been subcontracted to professional contractors by local agencies. Subcontracted work may involve total substitution of contract labor for local agency crews; in other instances it applies only to certain specialized work, such as furnace replacement or retrofits.

In recognition of improved State and local capabilities, several changes were introduced into the Program through amendments to the statute and reguation, beginning in 1984. These changes had the effect of allowing the States more flexibility to design and implement programs liv meet their individual needs. The changes include: provisions which allow States to develop alternative inergy audits (in place of the single nationwide audit procedure previously prescribed); the addition of heating and cooling system measures; an increase in the expenditure level per home; and a shift (with respect to both the $\$ 1600$ maximum expenditure per home and to the 60/40 ratio of labor to materials costs) from a dollar limit per home to a statewide average. 
Finally, the evolution of the system at the State and local levels has led to changes in the DOE role. Monitoring practices and training and technical assistance activities have changed to meet the evolving needs of a more stable, skilled, and sophisticated system. Training and technical assistance delivery involves: identification of State staff and resource needs through monitoring of weatherization activities and day-to-day contact; identification, evaluation, and documentation of new technologies; production of training materials; training conferences and workshops at all levels national, regional, and State; and the sharing and transferring of innovative and successful experiences.

\subsubsection{Funding History}

Throughout the United States, it is estimated that full-scale weatherization programs spent $\$ 4.4$ billion between 1978 and 1989 on improving the energy efficiency of low-income housing (Power, et al., 1992). ${ }^{4}$ DOE-appropriated funds constituted a majority of this funding between 1978 and 1985, but was just 27\% of the funding spent in PY 1989. As Fig. 1.1 illustrates, PVE funds have dominated the funding of low-income weatherization in recent years, LIHEAP funds have become important, and utility resources also have grown over the past decade.

Despite the slight decline in DOE Program funding since 1985, the vast majority of lowincome full-scale weatherization funds continue to be spent in programs administered under DOE Program rules. (In PY 1989, this figure was 76.5\%.) Thus, there has been a marked increase in the capacity of the Program to leverage and use effectively other resources in addition to DOE appropriations. For example, in PY 1989, local agencies received 69\% of their support for energy programs from sources other than the DOE Program. This included $\$ 44$ million from utility companies (Mihlmester, et. al, 1992, p. 65).

\subsection{GOALS OF THE SINGLE-FAMILY STUDY}

The Single-Family Study is being conducted in three parts. The results of the first part are presented in this volume. The second and third parts will be completed over the next year. The goals of the three parts of the Study are summarized in Figure 1.2.

4 Full-scale weatherization refers here to conservation programs for low-income households that are offered at no charge and include all of the following:

(1) an evaluation of the unit's requirements according to a formal, written energy audit or evaluation procedure;

(2) the availability of a comprehensive package of major and minor energy measures from which to choose; and

(3) installation of at least one or more of the following major measures: attic/ceiling insulation, floor insulation, wall insulation, heating or water heating system maintenance, repair or replacement, window replacement or storm windows (Power, et al., 1992, pp. 3-4). 


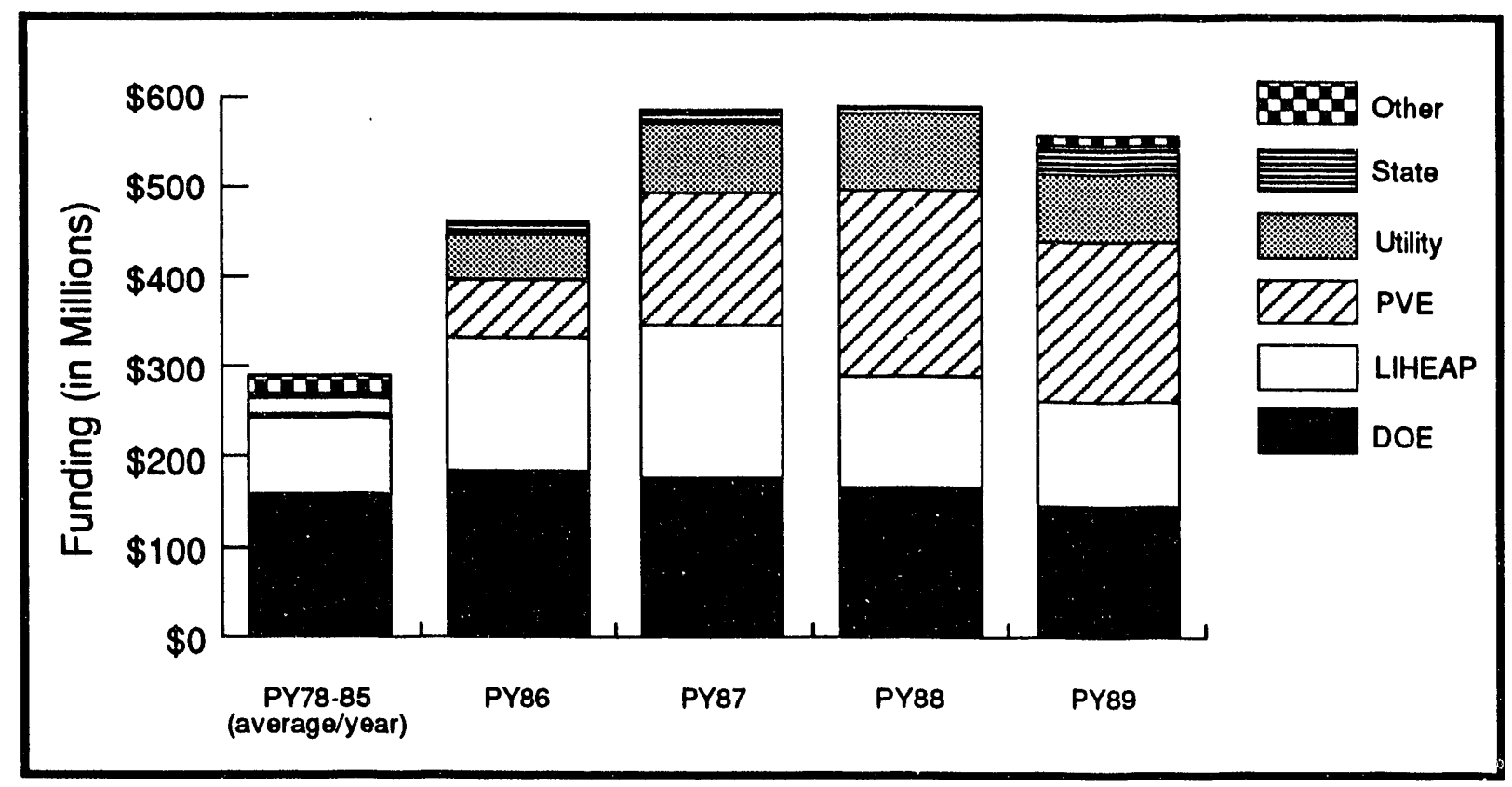

Fig. 1.1 Full-Scale Weatherization: Funding Sources, PY 1978-PY 1989. (Source: Power, et al., 1992).

\begin{tabular}{|c|c|c|c|c|}
\hline $\begin{array}{l}\text { Estimate } \\
\text { Energy } \\
\text { Savings }\end{array}$ & $\begin{array}{l}\text { Assess } \\
\text { Nonenergy } \\
\text { Impacts }\end{array}$ & $\begin{array}{l}\text { Assess } \\
\text { Cost- } \\
\text { Effectiveness }\end{array}$ & $\begin{array}{c}\text { Analyze } \\
\text { Sontributing } \\
\text { Factors }\end{array}$ & $\begin{array}{l}\text { Define } \\
\text { Promising } \\
\text { Opportunities }\end{array}$ \\
\hline
\end{tabular}

Phase

10

2

3
○

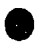

$\mathbf{O}=$ minor focus

○

$\mathbf{0}$

O

○

$=$ major focus

Fig. 1.2 Single-Family Study Goals, by Phase. 
Phase one of the Single-Family Study has two principal goals:

- estimate the energy saved nationwide by the Program during the first year after participation in PY 1989; and

- $\quad$ assess Program cost effectiveness.

In particular, the first phase estimates the energy saved during the first postretrofit year for housing units weatherized in PY 1989. Phase one also analyzes Program cost effectiveness for PY 1989.

The first phase of the Single-Family Study has three secondary goals:

- assess nonenergy impacts, such as comfort, safety, and housing affordability;

- analyze factors that influence energy savings, nonenergy impacts, and cost eff ctiveness; and

- identify promising Program opportunities for the future.

These secondary goals are also a major focus of the second phase of the Single-Family Study. In particular, the second phase of the study will involve a process evaluation of a set of highperforming local weatherization agencies and the collection and analysis of on-site field data on dwelling unit, occupant, and weatherization characteristics. Energy-savings results from phase one will be used to guide the selection of high-performing local agencies and a subsample of weatherized and control group housing units. The on-site data will help identify factors that account for variations in energy savings and benefit/cost results, particularly for housing units with especially high or low savings. This information will be used to interpret the energy savings and benefit/cost results, to quantify the nonenergy impacts of the Program, and to identify promising opportunities.

The third phase of the Single-Family Study will look at the persistence of energy savings over time. Three years of postretrofit energy consumption (Program Years 1990-1992) will be analyzed to assess long-term savings and the influence of household mobility.

In sum, the Single-Family Study covers significant issues and focuses on producing useful and practical information for program planning, implementation and management that can be obtained for reasonable costs. Understanding how the Program is operating establishes the groundwork for planning future efforts.

\subsection{LITERATURE REVIEW}

Previous evaluations of low-income weatherization programs offer an important context within which the results of this evaluation should be interpreted. While there has been only one previous nationwide evaluation of the energy savings and cost effectiveness of the Weatherization Assistance Program (Peabody, 1984), there have been numerous evaluations of weatherization programs implemented by individual States and utilities. In addition, several publications review 
these State and utility evaluations and summarize their findings (CSR, Inc. and Meridian Corporation, 1989; Schlegel and Pigg, 1990; Cohen, Goldman, and Harris, 1990). These reviews and the prior nationwide evaluation are the focus of the following literature review. Our review is organized into three sections: estimates of energy savings, assessments of cost effectiveness, and identification of promising opportunities.

\subsubsection{Estimates of Energy Savings}

The national Weatherization Assistance Program evaluation conducted by the Energy Information Administration examined a random sample of 965 single-family homes weatherized in 1981 (Peabody, 1984). The homes were drawn from 111 counties located in 24 States and the District of Columbia. The focus was on energy savings during the year following weatherization. The study presented three types of energy savings estimates for the Program (p. 20):

- 13.1 to $13.7 \%$ of a home's heating energy;

- 10.4 to $10.9 \%$ of the home's main heating fuel; and

- 9.1 to $9.7 \%$ of the home's total energy consumption (including electricity, natural gas, fuel oil, kerosene, and liquid propane gas).

The study showed substantial variation in energy savings across homes. In particular, 50\% of weatherized homes reduced their home heating energy consumption by $10 \%$ or more, while $23 \%$ of the homes used more energy for space heating the year after weatherization compared with the year before. This wide range of energy savings is typical of weatherization programs (Brown and White, 1991).

The applicability of these findings to today's Program is questionable, given the number of changes that have occurred over the past decade in DOE Weatherization procedures and the "stateof-the-art." In addition, the validity of the 1984 study is compromised by the lack of a control group and the use of unconventional and unclear weather normalization and space heat estimation procedures. Further, the limited sample size could not produce robust estimates of energy savings for specific climate zones or types of housing and heating fuel.

Each of the three reviews of State and utility weatherization evaluations presents estimates of the energy savings of low-income weatherization programs. The study by CSR, Inc. and Meridian Corporation (1989) analyzed 14 State program and reported average gross savings of $14.9 \%$. The generalizability of these findings to the nation as a whole is hampered by the lack of existing evaluations of weatherization programs operating in the South. Seven evaluations of other comprehensive weatherization programs reported higher average gross savings of $17.7 \%$. The nonProgram evaluations include four studies of weatherization programs that involve more intensive and costly weatherization measures than is typical of the Program. 
Cohen, Goldman, and Harris (1990) reviewed twelve evaluations of State low-income weatherization programs, mostly involving gas-heated homes located in colder climates. The median savings of the space heat fuel (after normalizing for long-term heating degree-days) for these studies is $12 \%$, with a range of $7-14 \%$. Many of these twelve studies evaluate weatherization activities in the early to mid 1980's. Results from several recent demonstration projects produce more encouraging results. For example, demonstration programs conducted in the late 1980's in Michigan, Minnesota, and Virginia generated savings of 17 to $18 \%$.

Schlegel and Pigg (1990) reviewed nine evaluations of DOE-funded low-income weatherization programs operating in the States of Michigan, Minnesota, Ohio, and Wisconsin. Most of the buildings evaluated in each of the studies were heated by natural gas, and the majority of the studies focused on single-family residences with no occupancy changes over the study period. The period of weatherization varied from 1982 to 1988 . The average energy savings of these programs (based on total fuel consumption) was $16.9 \%$, ranging from 6.4 to $23.4 \%$.

In sum, evaluations to date indicate that DOE low-income weatherization programs operating in cold climates have reduced energy consumption by 12 to $17 \%$ during the first year after weatherization and that energy savings have increased slightly over time. In addition, a number of recent demonstration projects indicate that the Program has the potential to offer much greater savings (25\% to $40 \%)$.

These conclusions, however, are based on a small number of program evaluations that have focused on single-family homes located in moderate or cold climates. Few of the studies reviewed above have addressed weatherization savings in mild or hot climates, and none include estimates of air conditioning savings. All of the studies focus on weatherization activities prior to 1989 and exclude dwellings where there was a change of occupant. Few of the studies employed control groups, and none examined the persistence of energy savings beyond the initial post-weatherization year.

\subsubsection{Assessments of Cost Effectiveness}

The nationwide weatherization evaluation conducted in 1984 did not estimate the cost effectiveness of the Weatherization Assistance Program. Only the materials costs of weatherization were analyzed, and these were simply compared with the average savings. It was found that greater expenditures on weatherization materials were associated with higher energy savings (Peabody, 1984, p. 28). If the average materials cost of $\$ 400$ (1981-\$) is doubled to approximate the total labor and materials costs, the simple payback of the 1981 program is approximately 5.6 years (CSR, Inc. and Meridian Corporation, 1989, p. 18). This measure (the period of time it takes for the energy savings resulting from weatherization to pay for the cost of weatherization) can then be compared with the results of other studies. 
The 14 State weatherization program evaluations reviewed by CSR, Inc. and Meridian Corporation (1989) tended to limit the estimate of costs to the sum of installation labor and materials, excluding any associated management or overhead costs. Using this definition, the average cost of these programs (in current dollars) was $\$ 1,209$ per household, and the average simple payback war 10.3 years.

The review of 12 State evaluations by Cohen, Goldman, and Harris (1990) found the median retrofit costs to be $\$ 1,080$ (in 1989 dollars), which includes installation labor and materials, but not administrative costs. Cost effectiveness is evaluated in terms of the cost of conserved energy (CCE), which is found by dividing the annualized cost of the retrofit by the annual energy savings, using a discount rate of $7 \%$ and a retrofit lifetime of 15 to 20 years. With these assumptions, the median cost of conserved energy is $\$ 6.80 / \mathrm{MBtu}$, as compared to a national average cost of $\$ 6.00 / \mathrm{MBtu}$ for gas. As with energy savings, cost effectiveness has improved over time, and three recent demonstration projects have performed particularly well, with CCEs between $\$ 3.60 / \mathrm{MBtu}$ and $\$ 5.90 / \mathrm{MBtu}$.

In comparing the results of nine low-income weatherization program evaluations, Schlegel and Pigg (1990) attempted to determine total program costs (installation labor and materials plus management and overhead cosis). Thus, the average total program cost estimated by the Schlegel and Pigg (1990) study (\$2,119, with a range of $\$ 1,450$ to $\$ 3,461)$ is higher than the average costs reported by CSR, Inc. and Meridian Corporation (1989). This average exceeds the DOE-mandated average maximum of $\$ 1,600$ per dwelling because of additional funding sources. Cost effectiveness was assessed by estimating the cost of conserved energy (calculated using a real discount rate of $5 \%$ and a measure lifetime of 15 years). The result is an average CCE of $\$ 9.55$, with a range of $\$ 4.22$ to $\$ 27.44$.

In sum, weatherization program evaluations do not always analyze cost effectiveness; those that do assess cost effectiveness use a variety of different indicators, making it difficult to compare results across studies. Based on the studies reviewed above, it would appear that State low-income weatherization programs have a simple payback period of approximately 10 years and a cost of conserved energy of approximately $\$ 6 / \mathrm{MBtu}$ to $\$ 10 / \mathrm{MBtu}$. The treatment of costs also varies widely, particularly the treatment of management and overhead costs, which are frequentiy excluded. Benefits tend to be limited to energy savings; none of the studies reviewed above included nonenergy benefits in analyzing the cost effectiveness of low-income weatherization. In addition, the same caveats about the measurement of energy savings noted in the previous section apply to the estimation of cost effectiveness.

\subsubsection{Identification of Promising Opportunities}

The national evaluation of the 1981 Weatherization Assistance Program offered a few conclusions that suggested promising opportunitics. For instance, it concluded that insulation, storm 
window:s, and storm doors are important measures for producing energy savings. However, the cost effectiveness of these measures was not examined. Because of the dated and limited nature of the evaluation, no prornising opportunities emerge from it that are relevant for today's low-income weatherization programs. In contrast, the more recent reviews do recommend future opportunities and directions for the Program.

CSR, Inc. and Meridian Corporation (1989) conclude the following:

- Water heater measures are the most cost effective. Furnace repairs, tune-ups, and retrofits also yield cost-effective results. The least cost-effective measures are storm windows and attic insulation.

- Weatherization applied to gas-heated homes tends to be more cost effective than weatherization applied to homes heated with electricity.

- Weatherization of both single-family and multifamily homes is approximately twice as cost $e_{i}^{f} f e c t i v e$ as weatherization of mobile homes.

- Directed approaches to prioritizing weatherization measures help to maximize the energy S'ivings derived from given expsnditure levels.

Cohen, Goldman, and Haris (1990) conclude the following:

- Retrofit savings and cost effec:iveness of the low-income weatherization program could be improved nationally if techniques from the more advanced State programs and demonstration projects are adopted by weatherization agencies in other States. Examples of recommended techniques include blower door guided infiltration reduction and highdensity blown cellulose wall insulation.

Schlege' and Pigg (1990) estimate that the near-term potential energy savings for the programs they reviewed range from 22 to $39 \%$ of initial energy consumption. They recommend four strategies for increasing cost effectiveness, three of which also can lead to increased energy saving::

- Programs can address a wider range of energy conservation measures, including such "soft" measures as client education.

- Programs can target the most cost-effective measures by using advanced diagnostic and audit techniques.

- Programs can reduce the cost of installing measures, by increasing the efficiency of program delivery systems.

- Programs can target high energy users, reflecting the strong correlation between preweatherization energy consumption and energy savings.

Despite the valuable background information provided by prior weatherization evaluations, many questions remain unanswered. This report seeks to add substantially to the base of knowledge established to date by providing recent and reliable estinates of the Program's average energy savings and cost effectiveness and by analyzing viriations across climate regions, types of heating fuels and 
dwellings, and other key subgroups. Several methodological innovations are implemented in the Single-Family Study that enable a fuller analysis of Program impacts than has been conducted to date. These include the use of waiting lists of Program-eligible households to provide a control group, the inclusion of dwellings regardless of whether or not there has been an occupancy change, the estimation of air conditioning savings in hot and moderate climate regions, the inclusion of some nonenergy benefits, and the inclusion of both program management and installation-related overhead in the estimation of program cost.

\subsection{ORGANIZATION OF THE REPORT}

This report begins by describing the research design (Chapter 2) and the dwelling and occupant characteristics of weatherized dwellings (Chapter 3). Chapter 4 describes the nature of the weatherization activities undertaken in PY 1989, and Chapter 5 estimates the energy savings that have resulted. Attention then turns to a discussion of nonenergy program impacts (Chapter 6 ), program costs (Chapter 7), and program cost effectiveness (Chapter 8). The next chapter identifies factors that have influenced energy savings (Chapter 9). The report ends with a discussion of its conclusions (Chapter 10) and a list of references (Chapter 11). 


\section{EVALUATION DESIGN AND DATA COLLECTION}

As explained in Chapter 1, the primary goals of the Single-Family Study are to estimate DOE Weatherization Assistance Program energy savings and cost effectiveness based on a nationally representative sample of single-family and small multifamily homes weatherized in the 1989 program year, and to analyze the factors influencing these outcomes.

The basic evaluation design for obtaining energy savings estimates is, according to the classic typology of research designs written by Campbell and Stanley (1971), a type of quasi-experimental design - the nonequivalent comparison group design (Table 2.1). ${ }^{1}$ The evaluation design consists of a treatment group of dwellings weatherized in PY 1989 and a control group of applicants for weatherization services (whose dwellings had not yet been weatherized by the end of March 1991). Although this design lacks the random assignment of dwellings to treatment and control groups that characterizes a true experimental design, there is little reason to expect that the comparison group of later participants differs from the earlier participants in ways that would significantly affect their energy use.

Table 2.1 Nonequivalent Comparison Group Design

\begin{tabular}{|c|c|c|c|}
\hline & Pre-weatherization & $\begin{array}{l}\text { Participation } \\
\text { in PY } 1989\end{array}$ & $\begin{array}{l}\text { Post-weatherization } \\
\text { period }\end{array}$ \\
\hline Participants in PY 1989 . & $\mathbf{O}$ & $\mathbf{X}$ & 0 \\
\hline Nonparticipants in PY 1989 & 0 & - & 0 \\
\hline
\end{tabular}

$0=$ Observation

$\mathbf{X}=$ Participation

$-=$ No data

Implementing this study required careful sampling, extensive data collection, and the application of a variety of data analysis techniques. In this chapter, overviews of sample design and selection procedures, data collection instruments and procedures, and data analysis techniques are presented.

\subsection{SAMPLING}

The major goal of our sampling process was to obtain a representative national sample of single-family and small (2- to 4-unit) multifamily housing units weatherized by local agencies in PY

1 In Campbell and Stanley's (1971) terminology, "nonequivalent" simply means that statistical equivalence cannot be assuimed because random assignment to treatment and control groups was not implemented. 
1989. This national sample was drawn from the mainstream of the Program. Because the Program implementors and weatherization installers could not have been aware that the houses they weatherized in PY 1989 eventually would be in this study's sample, this evaluation covers the gamut of conditions under which the Program was implemented. Unlike many studies of weatherization, it does not focus on closely monitored situations where the installers' awareness of the study may produce atypical results. Instead, this study includes a cross section of the entire Program's operations, including homes weatherized under a full range of conditions and with a large variety of techniques.

Because this study is designed to estimate the impacts of the DOE weatherization program (and not the impact of other programs that fund weatherization), the sample was restricted to dwellings weatherized entirely, or in part, with DOE funds or with funds from other sources (such as Oil Overcharge or Stripper-Well) that were used according to DOE Program regulations. Thus, dwellings weatherized entirely with Low-Income Home Energy Assistance Program (LIHEAP) funds were not included in the sample if they were not administered according to DOE regulations.

The national sample was designed to be large enough to provide estimates of national program energy savings for PY 1989 that were within 10\% of the mean at the $90 \%$ confidence level. In addition, estimates of energy savings for the three climate regions shown in Fig. 2.1, were to be obtained at the same precision. Estimates for smaller geographic regions, and for specific fuel types and dwelling types, within the three regions, were expected to have less precision. The sample also was designed to yield descriptive data on the Program's installation of weatherization measures; on weatherization materials, labor, administrative and overhead costs; and on dwelling and occupant characteristics. Energy savings were estimated with primary data only for dwellings that heat primarily with gas or electricity. Data on weatherization measures, costs, occupant and dwelling characteristics were, however, collected and analyzed for all fuel types.

Because of the difficulty and expense of obtaining data from large numbers of utilities and local agencies, a cluster sampling technique was the most practical approach. Thus, a two-stage sampling strategy was used, with a sample of 400 local agencies selected in the first stage, and a sample of 18,748 of the dwellings they weatherized and of 11,795 control homes awaiting services selected in the second stage. The distribution of the original samples of agencies, weatherized dwellings, and control dwellings by climate region and agency size are shown in Figs. 2.2 and 2.3.

Five major steps were involved in developing our samples of local agencies and dwellings. The first step was designing the overall sampling process and defining the required sample sizes. This step depended upon an enumeration and characterization of the Program population of 1,103 local agencies and of the 198,000 single-family and small multifamily dwellings they weatherized in PY 1989, an understanding of the typical variation in energy savings among weatherized homes and 


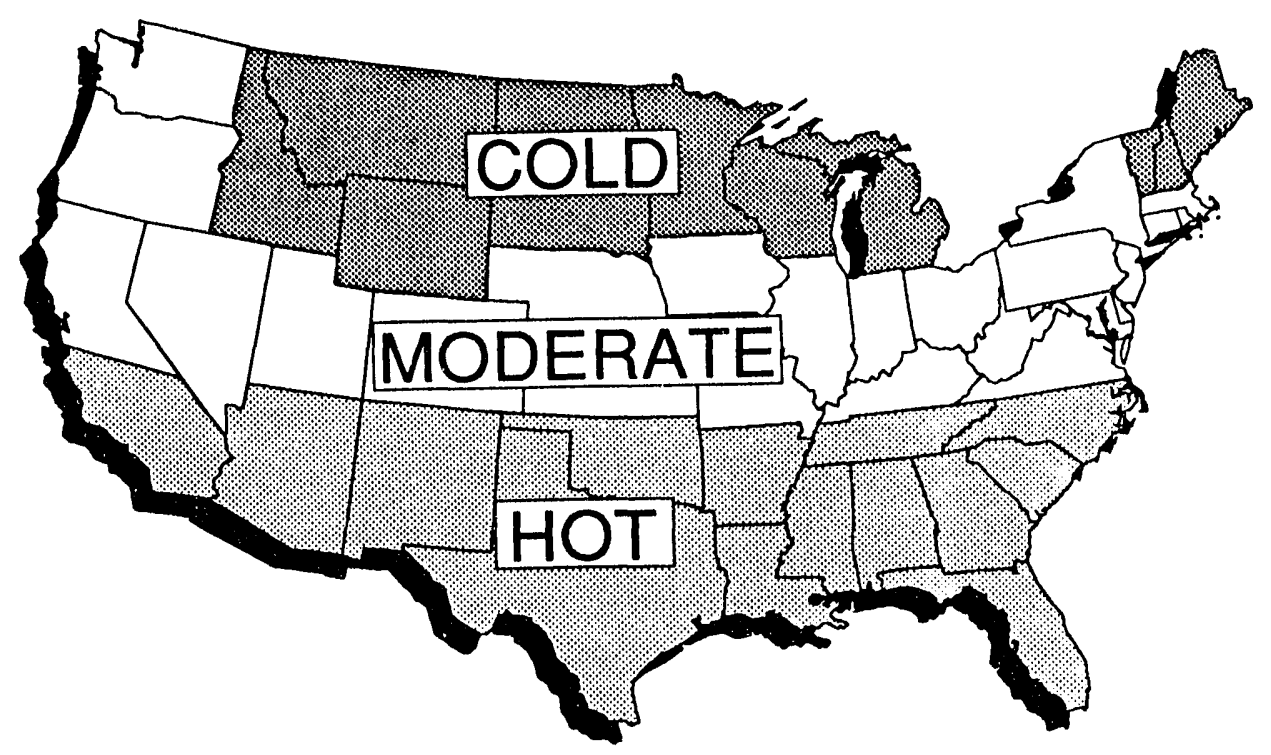

Very cold with little or no cooling

$\square$ Cold with moderate cooling

Hot with substantial cooling

Fig. 2.1 Climate Regions for the Single-Family St wdy

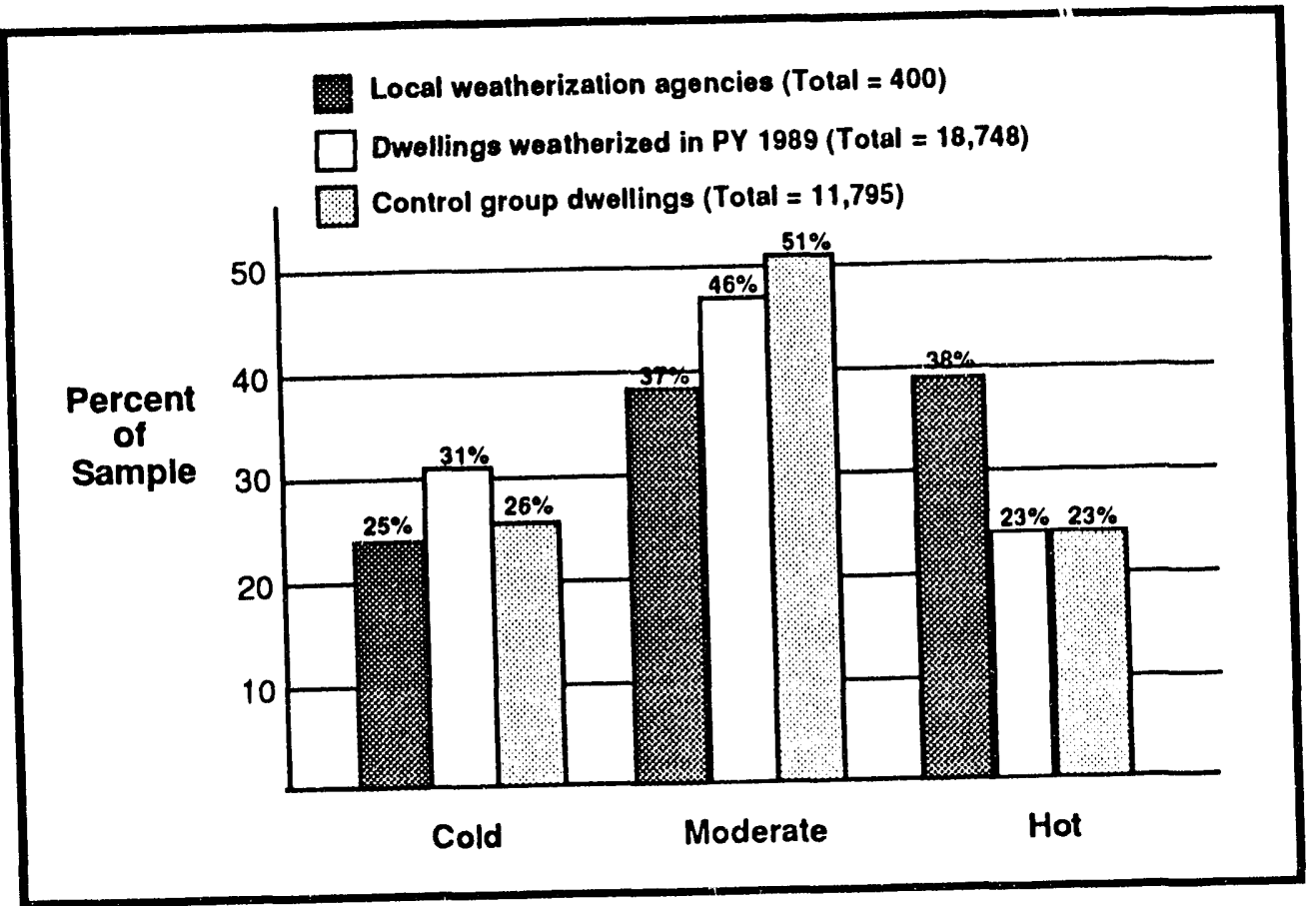

Fig. 2.2 Distribution of the Original Sample of Agencies and Dwellings, by Climate Region 


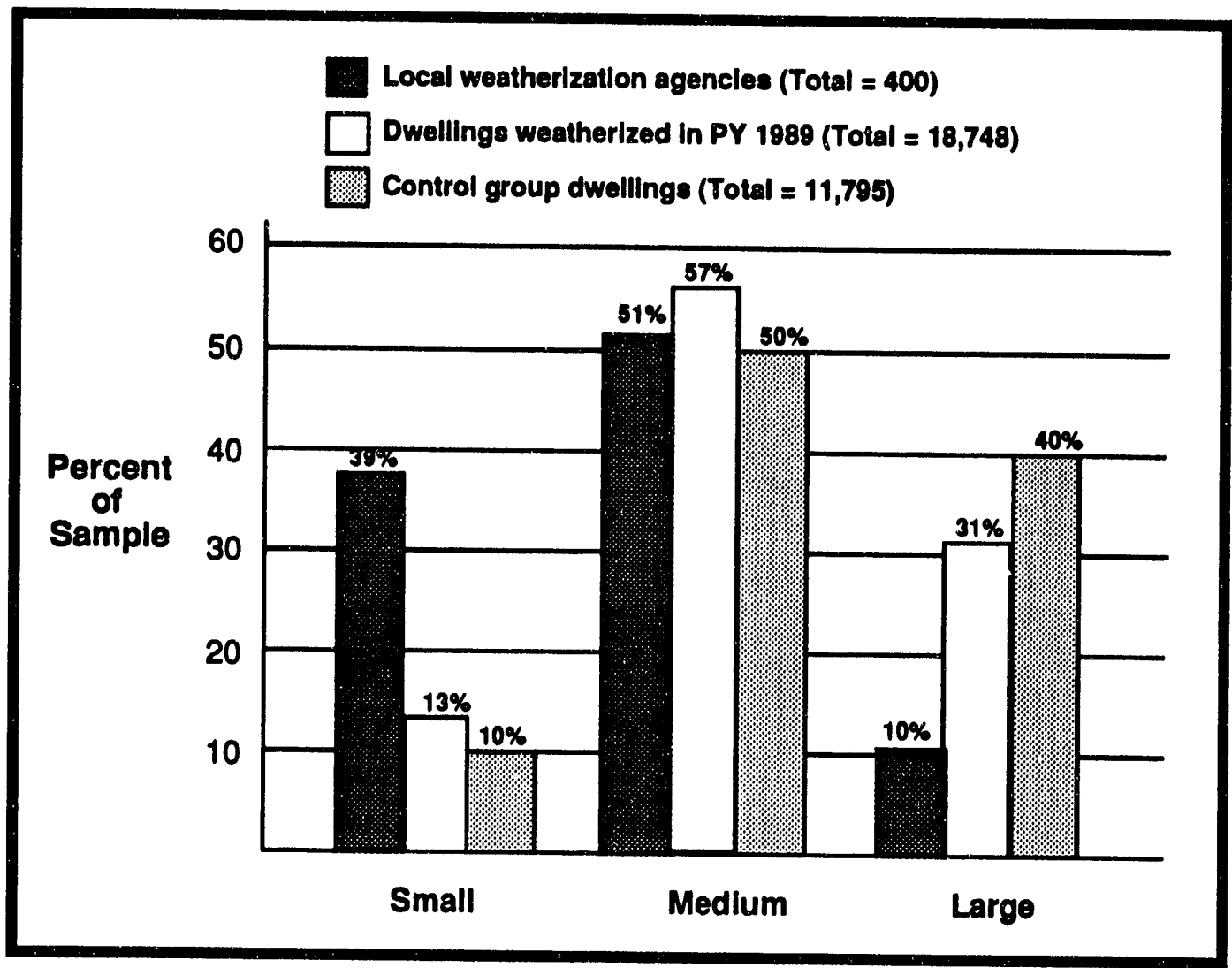

Fig. 2.3 Distribution of the Original Sample of Agencies and Dwellings, by Agency Size

among local agencies, and the detailed statistical calculations presented in the Appendices of the experimental plan (see Berry, Brown, Wright and White, 1991). The second step was to construct a sampling frame that was stratified by local agency size and geographic region. The third step was to draw a random sample of local agencies from the sampling frame stratified by size and geographic region. The fourth step was to randomly select a sample of dwellings from lists of dwellings weatherized in PY 1989 entirely, or in part, with DOE funds or funds used according to DOE regulations (dwellings meeting these criteria will be called "weatherized dwellings" in the rest of the report). These lists of weatherized dwellings were obtained from the local agencies selected in step three. The fifth step was to obtain a control group from the waiting lists of the same local agencies selected in step three. ${ }^{2}$

2 Each of these five major steps is discussed in more detail in Appendix B-1. Additional details about the selection and weighting of the national sample are given in Appendices B-2 through B-5. 


\subsection{DATA COLLECTION}

This study necessitated the collection and management of several large data sets, which required an extensive and complicated effort. The data collection effort began with the identification and classification of the 1,103 local agencies operating in the continental United States. The local agencies were classified by geographic location and by size, which was defined as the number of dwellings weatherized in PY 1989. Contact names, addresses, and telephone numbers also were obtained for this data base, which was used for sampling, informational mailings, data requests, mail surveys, and telephone follow-up activities.

The next step in the data collection effort was to contact the local agencies. Information packages, explaining the purposes and plans for the National Evaluation of the Weatherization Assistance Program, were sent to all 1,103 agencies by each State's program director in September 1990 (Appendix B-2). All of the agencies also received a mail survey in October 1990 as part of the Network Characterization Study (Mihlmester, et al., 1992). The 400 agencies selected (from the population of 1,103 ) for our national sample were contacted again by mail beginning in December 1990, informed of their inclusion in this study, and asked to provide lists of the dwellings they weatherized in PY 1989 (Appendix B-2). The collection of the lists of weatherized dwellings continued through April 1991 (Fig. 2.4).

As the lists of weatherized dwellings were received from the local agencies, they were entered into a data base, and a sample of weatherized dwellings was selected at random from the lists. Sampling rates varied by fuel type and agency size as is explained in Appendix B-1. There were four major components of the data collection effort for these sample dwellings which are described in the sections that follow: (1) dwelling-specific data on dwelling and occupant characteristics, weatherization measures installed, and material and labor costs; (2) agency level cost data on overhead and management costs; (3) utility data on fuel consumption; and (4) weather data. The timing of the data collection efforts is summarized in Fig. 2.4.

\subsubsection{Dwelling-Specific Data from Agency Records}

Most local agencies keep extensive records on the dwellings that they weatherize, but these records differ from agency to agency. Thus, the first step in developing the Dwelling-Specific Form was to understand what information was available in agency records. Agencies were asked to supply examples of their recordkeeping systems so that the common elements of their systems could be identified. Items were generally included in the Dwelling-Specific Form only if a large majority of agencies ( $80 \%$ or more) had the item in their records. A few items, such as utility names and utility 


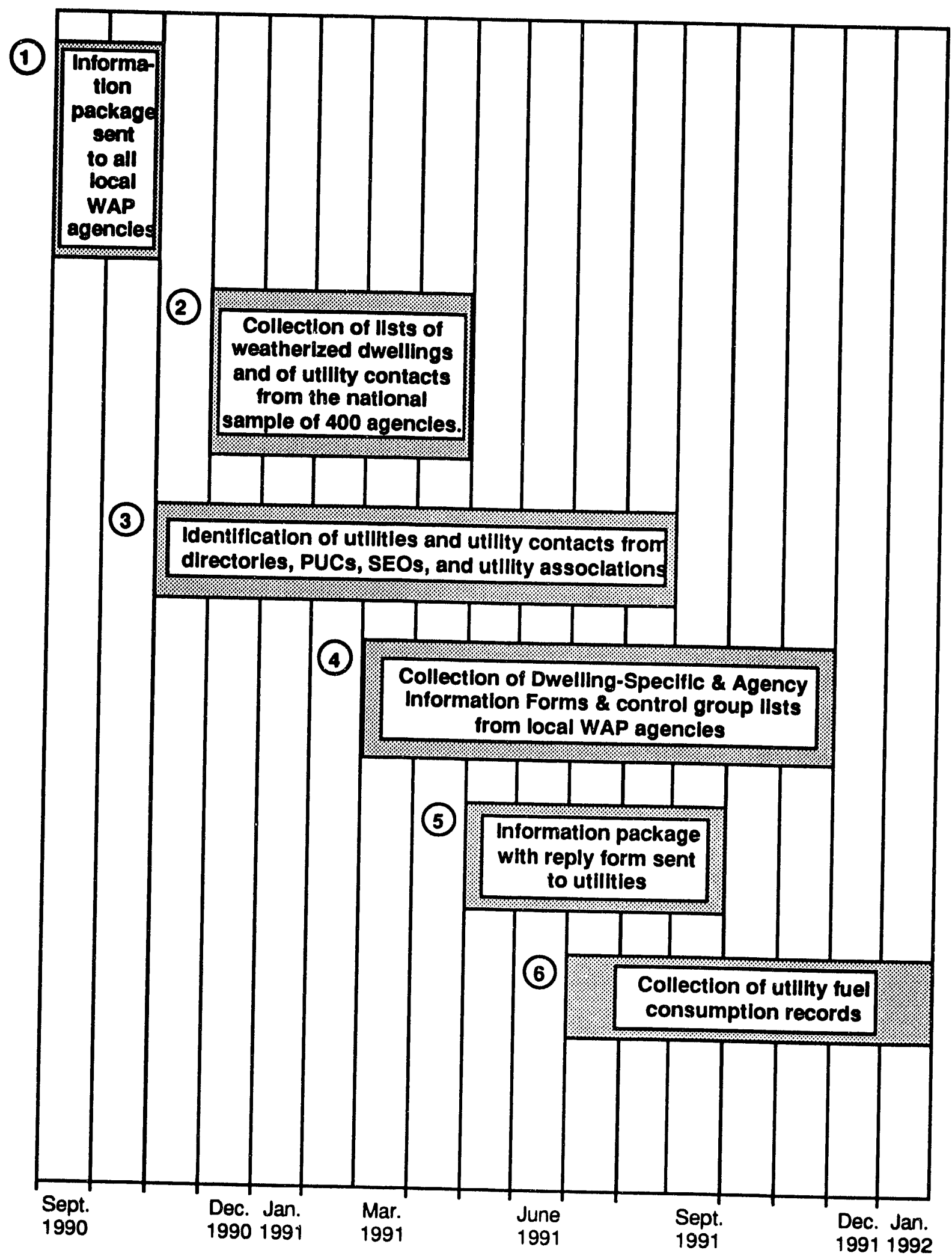

Fig. 2.4 Timing of Data Collection in the Single-Family Study. 
account numbers, were included on the form even though we knew that many agencies did not have this information. This was done because the value of having the utility information, even for a minority of dwellings, was high.

After selecting the data items on dwellings that were most useful for the study's purposes and most available in agency records, a test version of the Dwelling-Specific Form was developed. This test version was pre-tested with six agencies. Feedback from these agencies was used to refine the instrument. The final version of the Dwelling-Specific Form (Appendix B-3) asks for information on dwelling and occupant characteristics, weatherization measures, and material and labor costs for dwellings weatherized in PY 1989.

For each of the 400 agencies, a data request package was mailed in March through June of 1991. Each data request package contained one Dwelling-Specific Form for each dwelling in the sample served by that agency. The package also contained one Agency Information Form (Appendix B-3), a cover letter from the DOE director of the Program (Appendix B-2), and a set of instructions. Small agencies were asked to complete data forms for only a few dwellings, while the largest agencies were asked to complete several hundred forms.

The data request packages were sent out in successive waves of mailings that were spaced about one to two weeks apart. Mailings were conducted in these successive waves both because of the sheer volume of the effort, and because it was desirable to spread out the return of data and the accompanying workload over several months. Mailings requesting agency cost data and utility data (Sections 2.2.2 and 2.2.3) also were implemented in successive waves in a similar pattern.

Extensive follow-up activities were conducted to minimize sample attrition. These actions included several reminder letters and numerous telephone calls. In cases of persistent nonresponse, the State manager of the program was contacted and asked to encourage a response (Appendix B-2). By November 1991, the collection of Dwelling-Specific Forms ended. At that time, 368 out of the original sample of $\mathbf{4 0 0}$ agencies had responded. Data entry was completed in December, and analysis began in January 1992.

The 32 agencies that did not respond were dropped from the sample because of lack of cooperation, insufficient funding or manpower, or other such reasons. Dwelling-Specific Form information was requested for 18,748 dwellings and data were returned for 14,971 dwellings. Attrition occurred for the following reasons:

- local agency did not return any forms (3\% of dwellings),

- local agency did not return some of the forms (3\% of dwellings),

- dwelling did not meet study criteria ${ }^{3}$ ( $10 \%$ of dwellings).

3 Some dwellings that were initially classified as single-family or small multifamily were later identified by the local agency as a large multifamily unit. When this occurred the dwelling was dropped from the sample. In 


\subsubsection{Agency Information Form}

The Agency Information Form (Appendix B-3) asked for information on overhead and program management costs. Because overhead and program management costs are not tracked on a house-by-house basis, they must be collected for the agency as a whole, and then used to calculate an average per house cost. Separate agency cost-related questions were developed for crew-based vs. contractor-based jobs, because these two types of jobs use different methods of reporting overhead and program management costs. The Agency Information Form was mailed out to each agency at the same time as their set of Dwelling-Specific Forms. This mailing (Appendix B-2) also asked for a list of dwellings awaiting weatherization services that could be used as a control group. Typically, agency waiting lists average about one-fourth of annual production. Thus, the population of control homes on waiting lists was estimated to be about 49,500 .

\subsubsection{Utility Data}

Primary data on fuel consumption were collected only for dwellings that heat primarily with gas or electricity. No effort was made to gather fuel consumption records for dwellings that heat primarily with other fuels (such as wood, coal, fuel oil, kerosene, and propane). These fuel consumption records are often nonexistent, the cost of trying to collect whatever records might be available would be extremely high, and the uscfulness and reliability of the information would be low. Because of these problems, a separate metering effort was undertaken for homes heated primarily with fuel oil (i.e., the Fuel-Oil Study). Fuel oil is second only to natural gas in its frequency of use among homes participating in DOE's 1989 Weatherization Program.

The first step in collecting electric and gas consumption data was to identify the utilities that served the sample dwellings, and to locate the appropriate contact person within the utility. Utility directories were consulted and extensive telephone work was conducted. Telephone contacts included State Public Utility Commissions, State energy offices, utilities, utility associations, and local governments. In addition, the local agencies were asked to provide utility contacts in the mailings they received beginning in December 1990. Information about the utilities serving specific dwellings also was collected as part of the Dwelling-Specific Form (Appendix B-3). This information was used to locate the correct utility for specific dwellings.

Beginning in April 1991, a preliminary mailing was sent to 1,500 utilities that had been tentatively identified as serving the dwellings in the study. The purpose of this preliminary mailing was to introduce the study to the utility, to ascertain any problems the utility would have in providing the data, and to continue the process of identifying the best contact person. A reply form

addition, some dwellings that were initially identified as having been weatherized in PY 1989 were actually weatherized in a different program year. These dwellings also were dropped from the sample. 
(Appendix B-2) which identified the contact person and asked for information on any potential problems in providing the data was enclosed with a request to return the form to ORNL. After the utility responses to the preliminary mailing were received and the list of contacts and addresses updated, the first wave of data request packages was sent to utility contacts in July 1991. Mailings of data requests to utilities continued in successive waves until September 1991. These data request packages explained the National Weatherization Evaluation's goals and sponsorship and asked for assistance in obtaining fuel consumption records (Appendix B-2). The data request packages also contained the list of sample dwellings that the utility served for which fuel consumption data were needed and a detailed explanation of preferred formats for machine readable data.

During July through September 1991, utility data request packages were mailed out to 926 utilities. Members of the original group of 1,500 utilities were eliminated from the mailing list if they were found to be duplicates (sometimes the same utility was listed under different names, or at different locations or branch offices), or if they were not gas or electricity providers for the study's sampled dwellings. In all of the climate regions, gas records were requested for gas-heated dwellings and electric consumption records for electrically heated dwellings. Additionally, in the moderate and hot climate regions, electric consumption records were requested for gas-heated homes if we knew (from the Dwelling-Specific Forms) that the dwelling had air conditioning.

Extensive follow-up efforts were conducted to maximize the utility response rate. These actions included several reminder letters and telephone calls. In cases of persistent nonresponse, a letter from DOE was mailed to the utility's Vice President, or CEO/General Manager and a letter, cosigned by two Working Group members representing utility regulators, was sent to the Chair of the Public Utilities Commission in their State (Appendix B-2).

Most local weatherization agencies collect bill waivers from their clients as part of the process of applying for services. Most of the utilities believed that an example of an agency's bill waiver provided sufficient authorization for the release of the fuel consumption records for this study. Some utilities, however, would not provide fuel consumption records unless they had a signed bill waiver in their possession from each customer in the sample. If a utility required such waivers, mailings were sent to local agencies that had these bill waivers on their application forms (to obtain xeroxes for the utilities). If an agency did not have bill waivers in their files, a bill waiver request was sent to individual householders. The bill waivers that were returned to ORNL were, then, forwarded to the utilities that required them.

As a result of the extensive follow-up efforts (including several thousand letters and telephone calls) to obtain utility billing records, 689 of the 926 utilities (74\%) responded to our data request. However, some of the information they provided was incomplete. ${ }^{4}$ The information received is much

4 Because most utilities keep between one and two years of billing histories on-line in their computer systems, obtaining recent information is relatively easy. Earlier data could often be obtained only from microfiche or from 
more complete for the post-weatherization years (1990-1991) than for the pre-weatherization years (1988-1989).

For the initial sample of 926 utilities consumption records were requested on 24,957 dwellings. Of the total dwellings, 13,162 were weatherized homes and 11,795 were control homes. Among the 689 utilities that responded to our data request, records had been requested for 17,991 dwellings. Out of these 17,991 dwellings, some data were received on 14,198 and reasonably complete data were received on 11,882 . Thus, out of the 24,957 dwellings for which records were requested attrition occurred for the following reasons:

- utility did not respond,

- utility required bill waivers which could not be obtained,

- utility could not locate the dwelling in their customer records, and

- records were too incomplete to be useful.

\subsubsection{Weather Data}

Weather data were obtained from all the primary and secondary weather stations in the continental U.S. for which the National Climatic Data Center (NCDC) keeps records. The NCDC data on average daily temperature, which are required to run PRISM, are quite complete and generally of high quality.

Although many analysts limit their studies to primary weather stations (of which there are 267), our analysis used data from both primary and secondary weather stations to ensure greater accuracy. The procedure for matching dwellings with weather stations involved identifying the geographic locations of the agency that weatherized the dwellings and of the primary and secondary stations in both longitude and latitude. After the locations of all the agencies and stations were denoted, the distances from each agency to all possible weather stations were calculated. The next step was to find the closest weather station by minimizing the distance in a weighted distance equation (Appendix B-4). The weighted distance equation gave greater weight to north-south differences than to east-west differences, because they have larger effects on temperature. If data were not available from the nearest secondary weather station, the default was to the nearest primary station. Procedures for missing data also were developed and applied (Appendix B-4).

paper records. Utilities were often unable, or unwilling, to do the very labor intensive job of retrieving earlier data. The expense of paying workers to assemble the data was frequently raised as an issue by the nonresponding utilities. This study did not include a provision for paying for the data. Future studies may need to consider paying utilities for the data requested, to reduce nonresponse rates. A few utilities informed us that they require payment, as a standard policy, before providing any records. 


\subsection{DATA ANALYSIS}

Data obtained from each of the four major components of the data collection effort (Dwelling-Specific Forms, Agency Information Forms, utility fuel consumption records, and weather data) were developed into clean data sets. Standard agency and dwelling identification numbers were assigned so that information from the various data sets could be merged as needed. In Chapter 3 , sample attrition for the data from the Dwelling-Specific Forms, Agency Information Forms, and utility fuel consumption records is analyzed. Sample attrition was not a significant problem for weather data, although some procedures for imputing missing data are described in Appendix B-4.

In Chapters $4,5,7$, and 8 , differences in weatherization activities, energy savings, costs, and cost effectiveness are consistently tabulated by the same key subgroups:

- climate region (cold, moderate, and hot);

- primary heating fuel (gas, electric, and other);

- dwelling type (single-family, small multifamily, and mobile homes); and

- size of local agency (small, medium, and large). ${ }^{5}$

These key subgroups were emphasized because they significantly correlate with program performance measures.

In reporting variations by key subgroups, weighted results are used in every chapter except Chapter 3 (which describes the sample in both unweighted and weighted terms). The weighting procedure is described in Appendix B-5. The methods used to analyze the data on weatherization activities and costs, on energy savings and on cost-effectiveness are discussed below.

\subsubsection{Weatherization Activities and Costs}

The initial analysis of the data obtained from the Dwelling-Specific and the Agency Information Forms, which is presented in Chapters 4 and 7 , is descriptive in nature. Simple tabulations and cross-tabulations are used to characterize the national distribution of weatherization activities and costs. Differences by key subgroups such as climate region, fuel type, etc. also are presented.

Weatherization activities are reported in the six broad categories used in the Dwelling-Specific Form (Appendix B-3): air leakage control, insulation, water hea measures, windows and doors, space heating measures, and mobile home measures. The percentages of dwellings that had measures of each type installed are reported by key subgroups.

5 Recall that small agencies weatherized 100 or fewer dwellings in PY 1989, medium-sized agencies weatherized more than 100 and less than 400 dwellings, and large agencies weatherized 400 or more dwellings during that year. 
For specific dwellings, efforts were made to collect the materials costs for each of these six categories as well. However, the materials costs data for these six categories is often missing, with only the total materials costs reported. This led to some complications in the analysis of costs, with respect to the treatment of zeroes and missing values, which are discussed in Chapter 7.

Analysis of the agency cost data obtained from the Agency Information Form was difficult because much of the information was missing or obviously incorrect. A subset of 137 agencies that provided complete and logically consistent data was assembled and analyzed for this part of the study.

\subsubsection{Energy Savings Analysis}

The major goal of this study was to estimate the national energy savings of the Weatherization Assistance Program. In general, a dwelling's energy use will vary from year to year for a variety of reasons including changes in weather, appliance stock and usage, thermal integrity of the house, and energy-related behavior of the occupants. Weatherization is only one of many factors that may cause changes in energy consumption. For individual dwellings, it is difficult (and beyond the scope of this study) to identify the contribution of weatherization alone to changes in consumption. By averaging across large numbers of weatherized and control group dwellings, however, it should be possible to estimate an average effect of weatherization.

In this study, the influence of weather on consumption was removed by applying a weather normalization procedure - the Princeton Scorekeeping Method (PRISM) (Fels, 1986). Other factors which cause variations in energy consumption, such as changes in occupant behavior and appliance stocks, were assumed to cancel out because large enough groups were being examined to produce similar effects in both the treatment and control samples.

For dwellings that heat primarily with gas or electricity, PRISM was applied to utility consumption records for the year before and the year after a retrofit installation, together with average daily temperatures from a nearby weather station for the same time periods, to determine a weather-adjusted index of consumption labeled normalized annual consumption (NAC). Analogous to an automobile miles-per-gallon rating based on a standard driving cycle, the NAC index indicates what energy consumption would be under typical weather conditions. The gross energy savings are then derived from the differences in the NAC for pre- and post-weatherization periods. An energy conservation effect is thus neither masked by a cold winter nor exaggerated by a warm one.

To estimate the savings attributable to the Program from changes in consumption that would have occurred without the Program, the PRISM method also was applied to a control group of houses. Both gross savings and net savings are presented in Chapter 5. Gross savings are based on the PRISM results for the treatment group alone. Net savings are obtained by comparing changes in control group consumption to those of the treatment group. Because control group consumption 
may increase or decrease during the study period, net savings may be either higher or lower than gross savings.

Some data (Dwelling-Specific Forms) were collected on all weatherized dwellings in the sample regardless of the fuel used for heating. For example, information on the dwelling and occupant characteristics, weatherization measures installed, and the costs of the measures was obtained from agency records for all weatherized dwellings in the sample. This approach made it possible to characterize the entire population of single-family and small multifamuj owellings weatherized in PY 1989 on several important variables. This information was analyzed to produce indirect estimates of energy savings. The indirect estimates were inferred from existing studies (where available) and developed from a comparison of dwellings using other fuels to gas and electrically heated dwellings. Thus, the single-family and small multifamily housing units, for which Dwelling-Specific Forms were returned, were included in the national estimate of energy savings regardless of the fuel type used. Their esti, ited savings were weighted according to the proportions of weatherized dwellings using each fuel type.

A somewhat atypical ane riethodologically interesting feature of this study is that housing units were not dropped from the analysis because of occupancy changes. Most evaluations of weathierization impacts remove housing units with occupancy changes from the sample because of the large fluctu: ions in energy consumption that may result. If a new family moves into a housing unit, consumption may double or be cut in half even with no change $i_{i}$, the unit's energy-efficiency characteristics. There are, however, several reasons to retain units with occupancy changes:

- a primary purpose of the Program is to increase the energy efficiency of the low-income housing stock, and this occurs with or without occupancy changes;

- low-income housing units have especially high occupant turnover rates, and an extremely high attrition might result if all housing units with occupancy changes were eliminated (high attrition could be especially damaging to the phase three persistence analysis);

- housing units with occupancy changes and housing units without occupancy changes may have different energy-related characteristics, because movers tend to differ from stayers (e.g., they belong to different age groups or neighborhoods); and

- there is some evidence that examining only stayers may misrepresent energy savings because of attrition bias (Blasnick, 1989).

In this study, housing units with and without occupancy changes are included; in addition, we examine the impact of household tumover on savings.

Although utility billing data are the best source of information on gas and electricity consumption, there are some important complicating factors that must be considered in their use. First, the time periods separating meter readings are of variable length (e.g., some may be monthly and some bimonthly); thus, different households will have different beginning and ending dates for a meter-reading (billing) cycle. Because calendar months rareiy correspond to the cycle months, no, 
monthly summary data can be used. Instead, daily weather data must be matched to the days for which consumption data are obtained, and each household's weather-adjusted estimates of consumption must be computed separately.

A second complication is that different utilities keep records in different formats (some hardcopy and some computerized); therefore, records must be reformatted into a standaĩ system. Inaccurate or missing billing data may result from meters' not being read when scheduled, from estimated readings, or from changes in utility accounting procedures. Errors like these were handled by eliminating housing units with inadequate billing histories from the data base. Chapter 3 contains an analysis of patterns of attrition in the utility consumption data.

\subsubsection{Cost Effectiveness}

Analysis of cost effectiveness requires using the estimates of program-induced ene-gy savings (Chapter 5), data on fuel prices, and data on other program benefits and costs. To the extent that nonenerg impacts can be estimated in monetary terms, these also can be incorporated into the costeffectiveness analysis. The monetization of nonenergy impacts is discussed in Chapter 6 , costs in Chapter 7, and cost-effectiveness results in Chapter 8.

The cost effectiveness of a retrofit investment can be determined with a variety of approaches. Although a basic comparison between measured energy savings and the costs of achieving them is always involved, a number of other inputs are usually needed as well. Key assumptions include the expected lifetime of the housing unit and of the retrofit measures, a discount rate that reflects the time value of money, and estimated fuel price escalation rates. Because there is significant uncertainty in these key assumptions, sensitivity analysis was used to estimate a range of cost effectiveness under varying conditions (Chapter 8). The baseline assumptions were a $4.7 \%$ real discount rate, 20 year measure lifetimes, and 1989 fuel prices. The fuel prices were obtained from published sources (Energy Information Administration, 1991a and 1991b); weighted fuel price values were calculated based on the distribution of weatherized dwellings by State.

In Chapter 8, cost-effectiveness indicators are calculated with standard formulas. In particular, estimates of benefit/cost ratios and of the cost of conserved energy are presented. These cost-effectiveness indicators are reported by climate region, housing type, fuel type, and size of local agency.

\subsection{CONCLUSIONS}

The evaluation design and data collection processes described in this chapter provide for:

- the most comprehensive evaluation of the Weatherization Assistance Program ever conducted (involving thousands of dwellings and hundreds of local agencies); 
- understanding of the Program across key subgroups (climate, primary heating fuels, dwelling types, and agency size);

- implementation of innovative approaches to weatherization program evaluation (e.g., retention of dwellings with occupancy changes and use of a new weather normalization model for electrically heated and cooled dwellings);

- a detailed description of the Program's weatherization activities;

- a primary data analysis of energy savings and cost effectiveness of the Program as applied to gas- and electrically heated homes;

- the inclusion of some non-energy benefits in the cost-effectiveness analysis; and

- the involvement of representatives of all the Program's major stakeholders in the evaluation's design and implementation. 


\section{DWELLING AND OCCUPANT CHARACTERISTICS OF WEATHERIZED HOMES AND THE ELIGIBLE POPULATION}

This chapter describes the dwelling and occupant characteristics of homes weatherized by the Weatherization Assistance Program during PY 1989. It begins by analyzing the respondents in the sample by climate region, agency size, type of primary heating fuel, and dwelling type. This characterization is used in an assessment of nonresponse bias and in the development of sample weights. These weights are used in the rest of this chapter and in all subsequent chapters to convert sample statistics into estimates of totals and means for the population of weatherized homes (Section 3.1). Attention then turns to the dwelling and occupant characteristics of homes weatherized during PY 1989 (Section 3.2). Next, characteristics of weatherized dwellings are compared with those of the Program-eligible population (Section 3.3). This comparison is based on an analysis of data from the 1990 Residential Energy Consumption Survey (RECS). The chapter ends with a summary of its key findings (Section 3.4).

\subsection{CHARACTERISTICS OF THE SAMPLE OF WEATHERIZED DWELLINGS}

The original sample contained 400 local weatherization agencies, 18,748 weatherized dwellings, and 11,795 control group homes. Dwelling-specific data were solicited from local apency records for the entire sample of weatherized dwellings. Dwelling-specific data were not requested for the control group, since such data would not be available in agency files. Energy-consumption data were solicited from utilities for those sampled dwellings that heated primarily with gas or electricity. Gas and electric utilities were asked to provide energy-consumption data for the entire original sample of control group dwellings, since all of them were presumed to have gas or electric heat.

Dwelling-specific data were received from $368(92 \%)$ of the original sample of agencies, on 14,971 (80\%) of the sample of dwellings they weatherized in PY 1989 (Fig. 3.1). Complete energyconsumption data' were provided for 4,796 of the sample of weatherized dwellings (drawn from the clients of 264 different agencies) and 3,776 of the sample of control dwellings (drawn from the clients waiting to be served by 230 different agencies). Dwelling-specific data are available for $85 \%$ of the weatherized dwellings for which complete energy-consumption data were provided. These samples are described in more detail in the sections below.

1 A dwelling was considered to have "complete" energy-consumption data if it had at least four consumption values for the primary heating fuel during both the pre- and post-weatherization years and including one or more winter months during both years. 


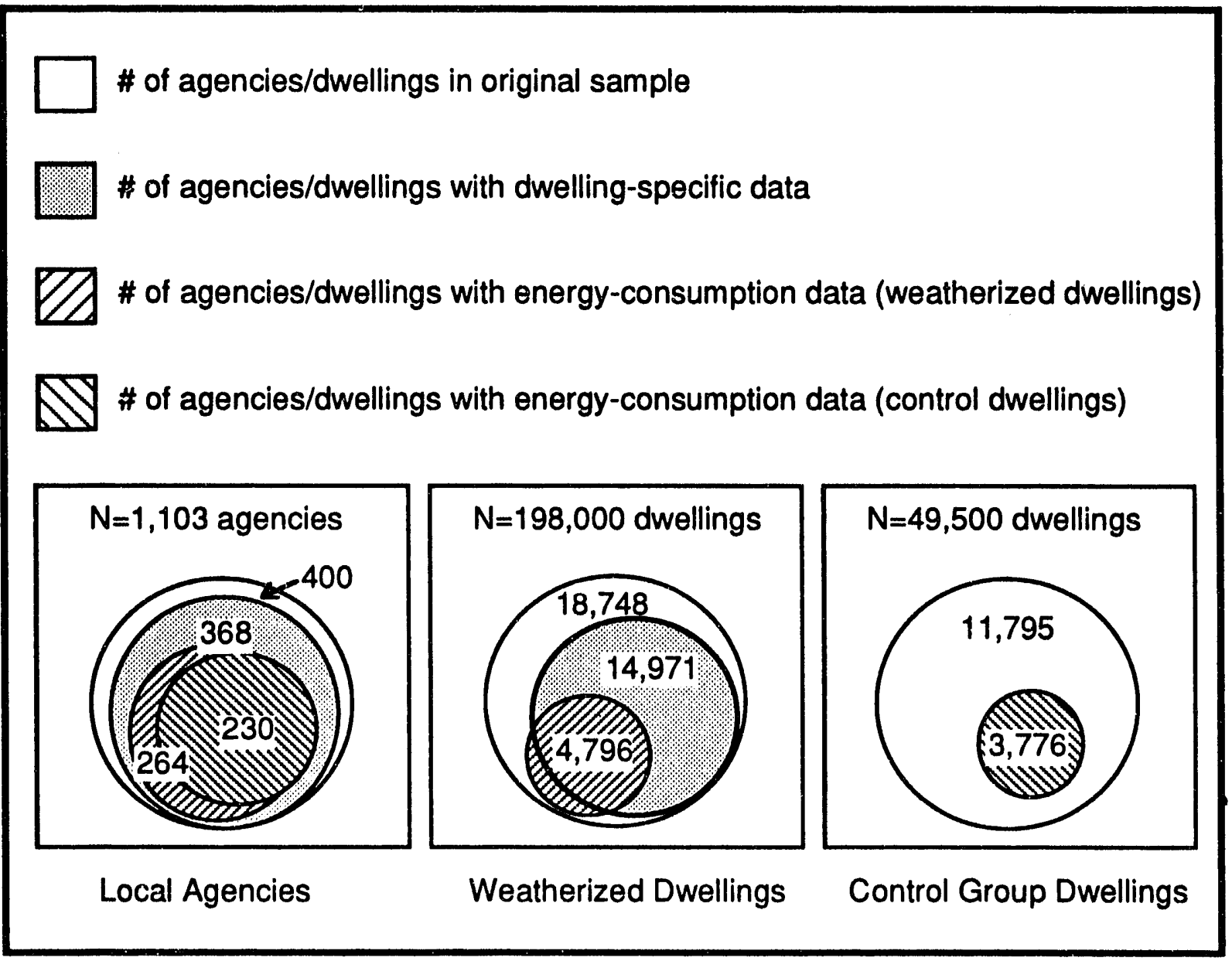

Fig. 3.1 Comparison of Sample Sizes

\subsubsection{Sample of Dwellings with Dwelling-Specific Data}

There is little difference between the geographic distributions of the sample with dwellingspecific data (Fig. 3.2) and the original sample of agencies and dwellings (see Fig. 2.2 on page 2.3). This is due to the excellent response of the local agencies to our request for dwelling-specific data. The distribution of responding agencies, by climate region, is very similar to that of the original sample. The only notable difference between the samples of dwellings is the slightly lower response rate in the hot climate region, which provided $20 \%$ of the sample with dwelling-specific data compared with $23 \%$ of the original sample.

The original sample (see Fig. 2.3 on page 2.4) and the sample with dwelling-specific data also are distributed similarly by agency size (Fig. 3.3). The only notable difference is the slightly lower response rate of smaller agencies. However, those smaller agencies that did respond provided information on a higher percentage of the sampled dwellings, so the distribution of weatherized dwellings with dwelling-specific data, by agency size, is essentially equivalent to that of the original sample. 


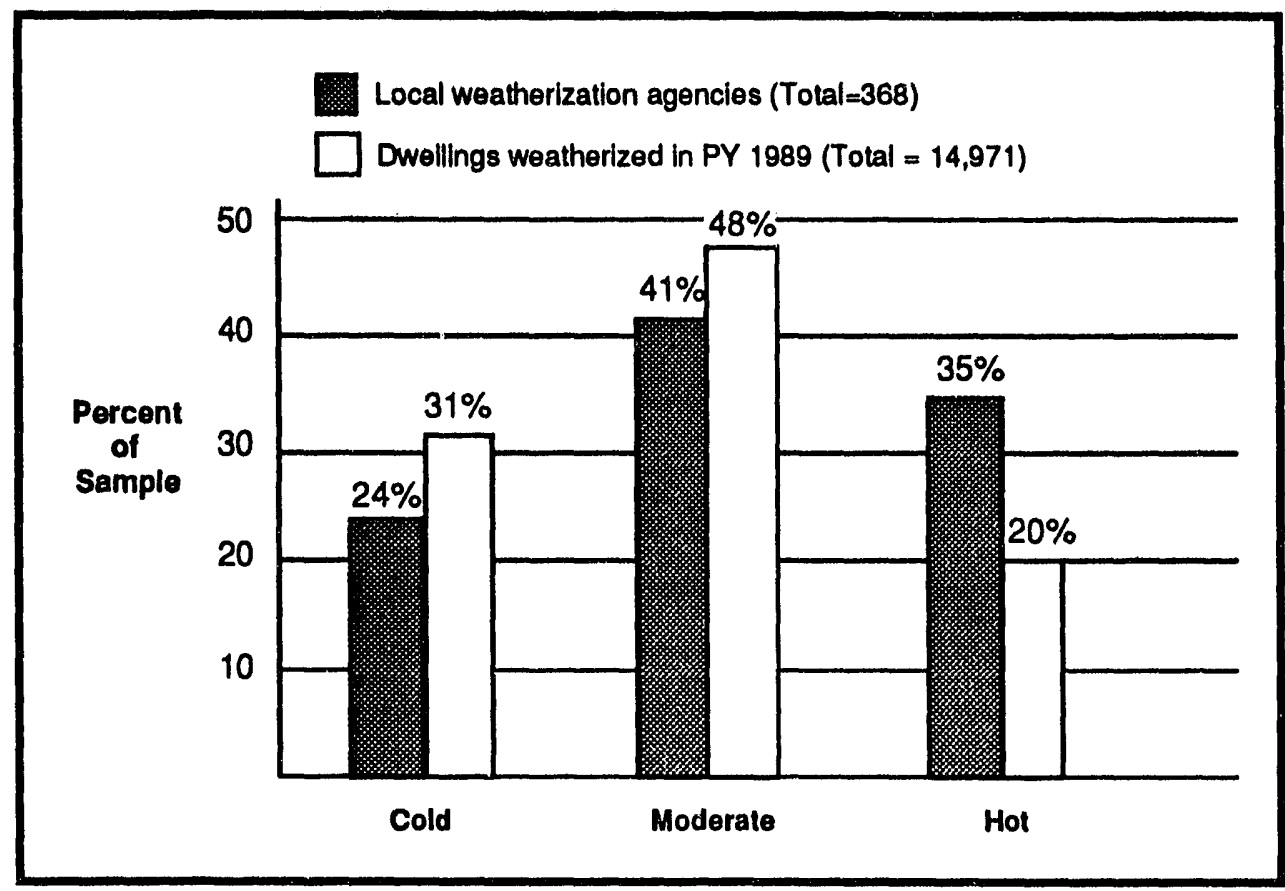

Fig. 3.2 Distribution of Agencies and Weatherized Dwellings with Dwelling-Specific Data, by Climate Region (unweighted)

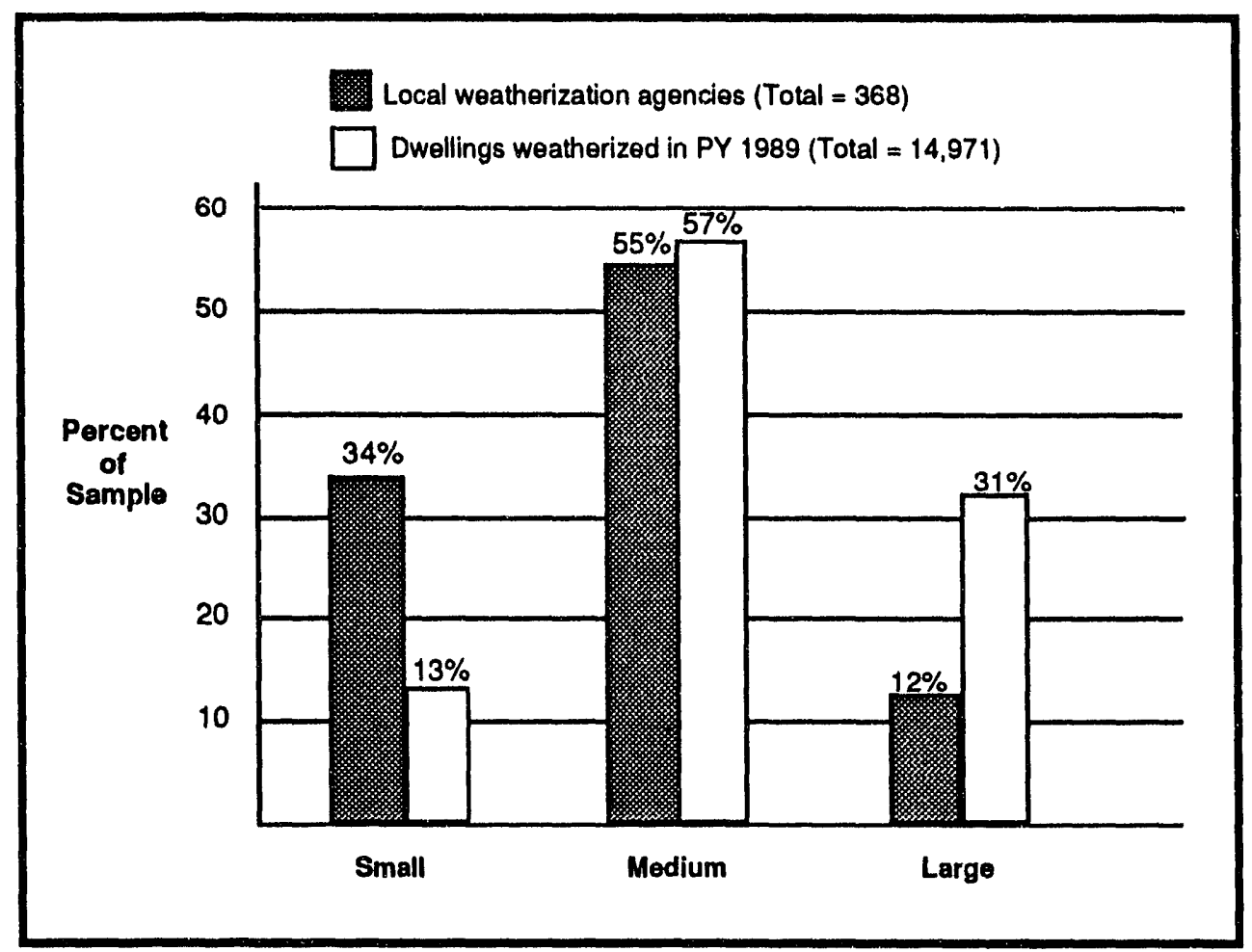

Fig. 3.3 Distribution of Agencies and Weatherized Dwellings with Dwelling-Specific Data, by Agency Size (unweighted) 
The distributions summarized in Figs. 3.2 and 3.3 are the basis for the development of weights that are used throughout the rest of the report to correct for nonresponse biases. Appendix C-1 presents the actual weights that are used in the analysis of dwelling-specific data. Both of the minor nonresponse biases noted above are correctable with these weights.

Figure 3.4 presents the distribution of the sample of weatherized dwellings (with dwellingspecific data) by climate region. Both unweighted and weighted percentages are shown. The weighted percentages are unbiased estimates of the distribution of PY 1989 weatherized dwellings across the three climate regions. They document the dominance of the moderate climate region, in terms of weatherized homes (with 58.5\% of the total in PY 1989). The cold region is a larger percentage of the unweighted sample compared to the weighted sample because it had the highest response rate of the three climate regions. Identical sampling fractions were used across the three regions.

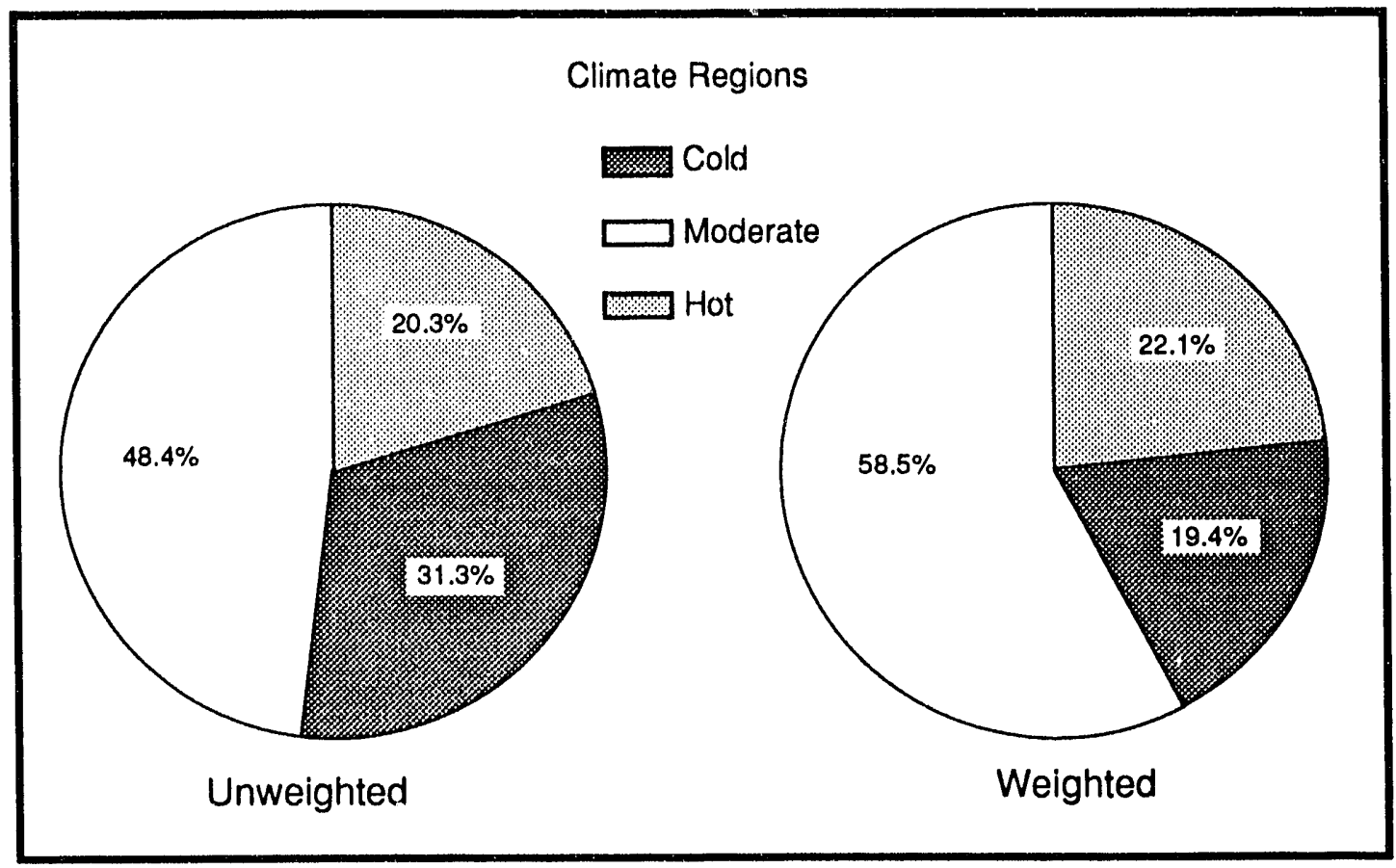

Fig. 3.4 Distribution of Weatherized Dwellings, by Climate Region

Figure 3.5 presents the distribution of the sample of weatherized dwellings (with dwellingspecific data) by primary heating fuel. Both unweighted and weighted percentages are shown. The unweighted percentages show the dominance of gas heat in the sample of weatherized dwellings for which dwelling-specific data are available. Both gas and electrically heated homes were sampled at higher rates than homes heated by other fucls to ensure adequate sample sizes for the analysis of energy savings. The weighted percentages are unbiased estimates of the types of primary heating fuel used by homes weatherized in PY 1989. Based on these numbers, gas and electricity represent 
just $60 \%$ of the population of weatherized homes. Thus, $40 \%$ of the homes weatherized in PY 1989 were heated with other fuels. Fuel oil (16\%) and liquid propane gas (13\%) are the most prominent among these, but wood (6\%), kerosene (3\%) and coal (1.4\%) were also used.

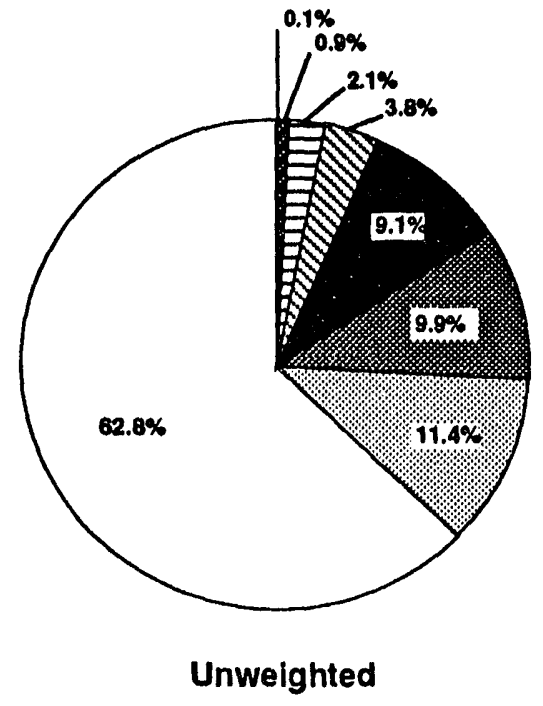

Primary Heating Fuel:

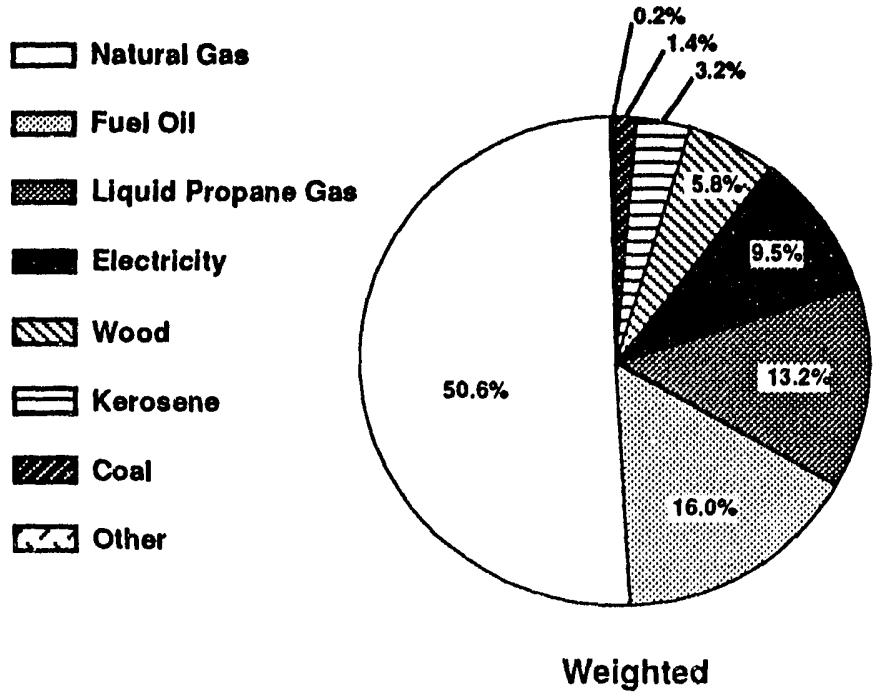

Fig. 3.5 Distribution of Weatherized Dwellings, by Primary Heating Fuel

A similar analysis of the sample of weatherized dwellings by type of dwelling is presented in Fig. 3.6. ${ }^{2}$ The unweighted percentages illustrate the dominance of single-family detached dwellings in the sample. The weighted percentages shown on the right side of the figure indicate that among the population of homes weatherized by the Program during PY $1989,64 \%$ are single-family detached, $3 \%$ are single-family attached, $20 \%$ are mobile homes, and $13 \%$ are small multifamily dwellings. These percentages do not vary markedly from the unweighted values, since the sampling fractions did not differ by housing type. The slightly higher weighted percentage for mobile homes (20\% compared with an unweighted value of $19 \%$ ) is due to the fact that mobile homes were underrepresented in the original sample because they have a lower than average incidence of gas and electric heating.

2 Our definitions of single-family and small (2- to 4-unit) multifamily dwelling units follow those used by the Residential Energy Consumption Survey (RECS) (Energy Information Administration, 1989): "[A] singlefamily housing unit [is] a structure that provides living space for one household or family. The structure may be detached, attached on one side (semidetached), or attached on two sides. Attached houses are considered singlefamily houses as long as the house itself is not divided into more than one housing unit and has an independent outside entrance. A single-family house is contained within walls that go from the basement (or ground floor, if there is no basement) to the roof." 


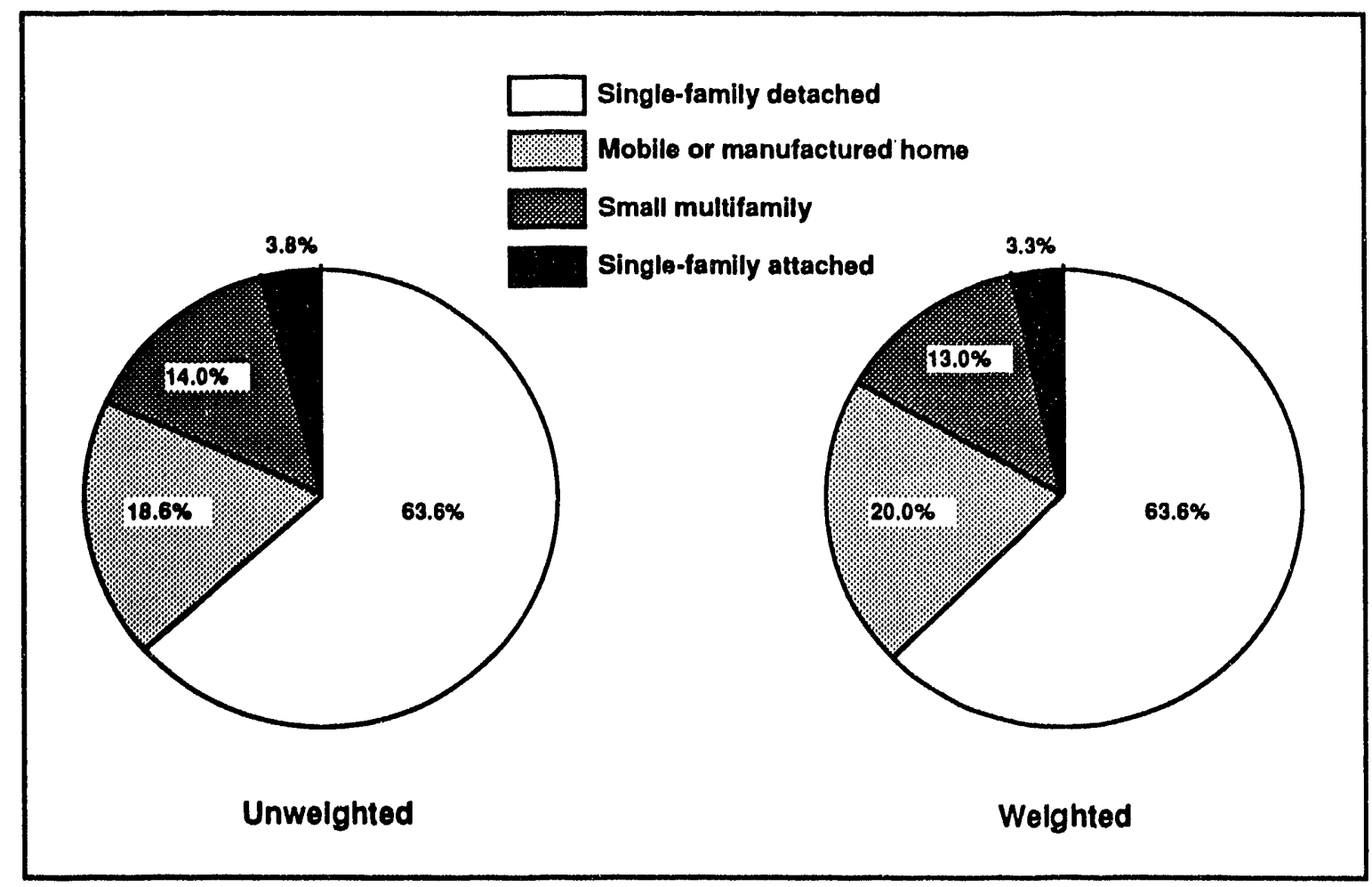

Fig. 3.6 Distribution of Weatherized Dwellings, by Dwelling Type

In Section 3.3, the fuel-type and housing-type characteristics of weatherized homes are compared with the eligible population. Significant differences exist.

\subsubsection{Sample of Dwellings with Energy-Consumption Data}

Energy-consumption data were requested from utility companies for the sample of 13,162 weatherized dwellings that heat primarily with gas or electricity. Information on energy consumption was also sought for the entire control group sample of 11,795 dwellings.

Utilities provided complete data for only 4,796 (or $36 \%$ ) of the original sample of weatherized dwellings and 3,776 (or 32\%) of the sample of control dwellings. This sample of 4,796 weatherized homes was served by 264 different local agencies, and the control sample of 3,776 homes by 230 of these agencies. Comparing these sample sizes with the target of $6,500 \mathrm{dwellings}$ weatherized by a sample of 365 local agencies indicates a significant shortfall. Thus, it will not be possible to achieve the anticipated levels of confidence and precision when estimating the energy savings of specific subgroups of dwellings. However, based on our planning assumptions the sample should be sufficient to estimate the energy saved by the program as a whole with a relative error of $10 \%$ and a $90 \%$ confidence level.

The significant nonresponse rates on the part of gas and electric utilities cause several notable biases in the composition of the sample with complete energy consumption data. Because response 
rates were highest in the moderate climate region and lowest in the hot region, there is a geographic bias. This bias can be assessed by comparing Fig. 3.7 with Fig. 2.2 on page 2.3. While $23 \%$ of the original sample of PY 1989 weatrerized dwellings were located in the hot zone, only $14 \%$ of the representative sample of weatherized dwellings with energy-consumption data reside in that zonc. S.nilerly, while $23 \%$ of the original sample of centrol dwellings were located in the hot zone, only $13 \%$ o: the representative sample of control dwellings with energy-consumption data are located there.

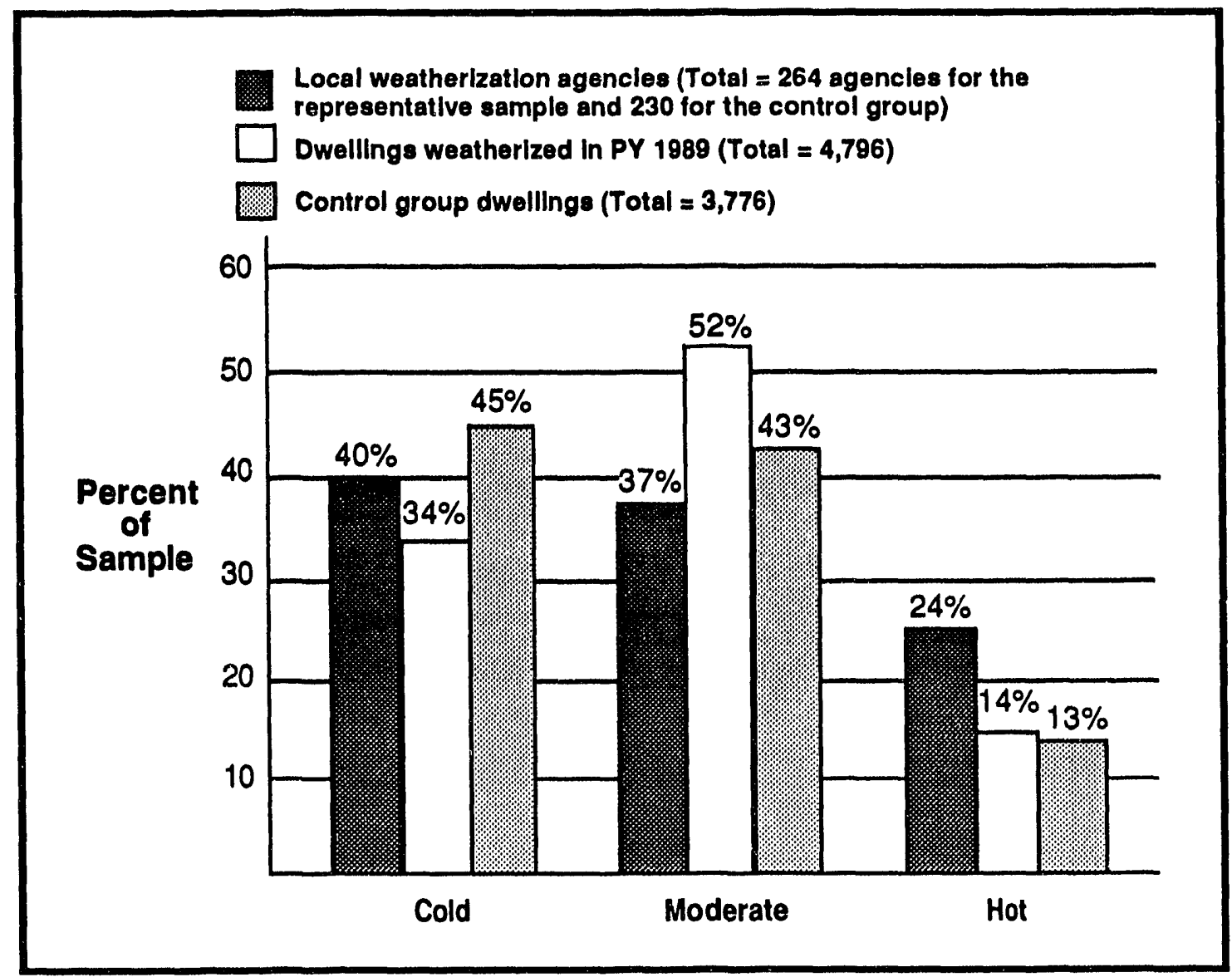

Fig. 3.7 Distribution of Agencies and Weatherized Dwellings with Energy-Consumption Data, by Climate Region (unweighted).

There is also a bias in the size of the local agencies that weatherized the sample of dwellings for which romplete energy consumption data are available. This bias can be seen by comparing Fig. $3 . \%$ with Fig. 2.3 on page 2.4 . While $31 \%$ of the original sample of PY 1989 weatherized dwellings were wuatiserized by large agencies, $34 \%$ of the representative sample of weatherized dwellings with energy-consumption data were weatherized by agencies of this size. In contrast, both the small and medium-sized agencies are under-represented. A similar pattern holds for the control dwellings. 


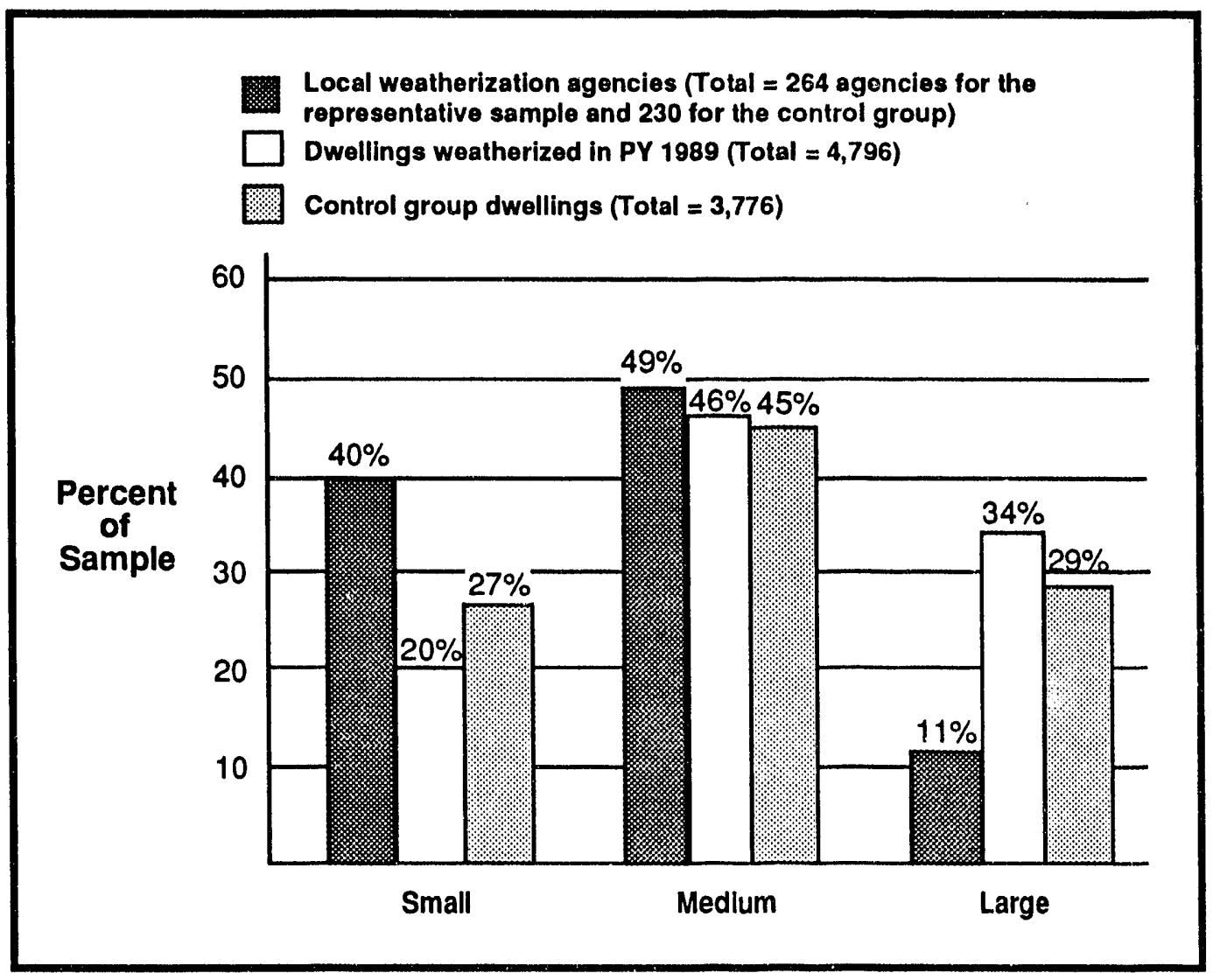

Fig. 3.8 Distribution of Agencies and Weatherized Dwellings with Energy-Consumption Data, by Agency Size (unweighted)

Thus, the lower than anticipated utility response rates has resulted in samples of dwellings that do not proportionately represent the populations from which they were drawn. However, the same biases that afflict the representative sample of weatherized dwellings also impact the control dwellings, facilitating comparisons between the weatherized and control dwellings. Further, a set of weights was developed to adjust for biases in climate region distributions. These weights (described in further detail in Chapter 5) are used to reduce the bias associated with estimates of energy savings and other weatherization statistics.

The vast majority of both the weatherized and control dwellings with energy consumption data are gas-heated ( $90 \%$ and $84 \%$, respectively). Because of the relatively smali number of representative weatherized dwellings with electric heat for which consumption data are available $(\mathrm{N}=497)$, the precision of the energy-savings estimates for this fuel type is consicicrably less th: that for natural gas. 


\subsubsection{Sample with Agency Cost Information}

Three-quarters of the sampled agencies (298 out of 400) returned an Agency Information Form; however, many of these forms were too incomplete to be usable or contained obviously inaccurate and inconsistent information. The first three questions on the form (Appendix B-3), for example, ask for: (1) total program costs (TPC) in PY 1989, (2) total installation costs (TIC, which is the sum of all materials, labor and installation overhead costs), and (3) total program management costs (PMC, which includes any costs that are not installation costs). Logically, the sum of installation costs and program management costs should equal the total program costs (TIC + PMC = TPC). On many of the data forms, however, the values reported for installation costs and management costs did not sum to the total program costs.

In addition, there were frequent errors in calculating an average per house program management cost (APMC). To obtain an APMC, the total program management cost in PY 1989 should be divided by the number of houses weatherized in PY 1989. In this case too, the values reported on the Agency Information Form often did not have the correct numerical relationships. In particular, the values that appeared to have been used within the Agency Information Form for the number of houses weatherized often did not agree with data on the number of houses weatherized obtained from other sources (i.e., the Network Characterization Survey and the lists of dwellings provided by the agency).

Because of the frequency and pervasiveness of the reporting and computational errors on the Agency Information Form, many of the values reported for APMC were not credible. Specifically, values for APMC ranged from a low of $\$ 12$ per house to a high of $\$ 1,868$ per house. Previous studies (Kushler and Witte, 1985; Kushler, Witte, and Stanley, 1987; McKenzie and Pheneger, 1983; Randolph and Greeley, 1990; Schlegel, 1991) suggest that average values of between $\$ 300$ and $\$ 500$ per house are typical. The values of less than $\$ 300$ that appear in the Agency Information Form data probably do not include some significant management cost categories, and the values above $\$ 500$ probably include some installation costs.

For the reasons discussed above, much of the cost information reported on the Agency Information Form was seriously flawed. A subset of credible data was developed by applying logical checks (such as TIC + PMC $=$ TPC) and a believable value criterion (not less than $\$ 100$ or more than $\$ 1000$ for APMC). The number of forms returned with what appeared to be credible and consistent data was 137.

The 137 agencies that returned credible and consistent data were not distributed across the climate regions in the same proportions as the total sample. While the proportions of the agencies with good data to the total sample were similar in the cold and moderate regions (33 out of 99, and 64 out of 151, respectively), there was a noticeably smaller proportion in the hot region (40 out of 
150). The agencies with good data also were not distributed evenly by agency size. Larger agencies were more likely to return consistent data, as shown by the fact that agencies with good data weatherized an average of 287 dwellings while the average for the total sample was 172 . The larger agencies probably were able to report more consistent cost data because they were more likely to have computerized recordkeeping, and staff with accounting skills.

Although the subset of 137 agencies that reported reliable data on the Agency Information Form is not representative of the total sampie of local agencies, the APMC estimated from the agencies with good data falls within the range estimated by prior studies (Chapter 7). An analysis of variations in APMC by key subgroups was planned for this study, but the limited number of accurate values and their unrepresentative distribution could not support much analysis of this type. Therefore, only average values for the agencies with good data are reported and used for the costeffectiveness analysis (Chapter 8). The absence of Agency Information Form data on overhead and management costs does not, however, result in the removal of any agencies or dwellings from any other part of the analysis.

\subsection{DWELLING AND OCCUPANT CHARACTERISTICS OF WEATHERIZED HOMES}

This section characterizes the population of dwellings that the Program weatherized in PY 1989 and compares dwelling and occupant characteristics across key subgroups. Only weighted values are reported, because the goal is to describe the population of weatherized dwellings and key subgroups. The analysis of different subgroups lays the foundation for explaining variations in en rgy savings, weatherization costs, and cost effecliveness (Chapters 5, 7, and 8).

\subsubsection{Differences Across Climate Regions}

Table 3.1 presents the dwelling and occupant characteristics of the population of weatherized dwellings, and compares these characteristics across the three climate regions. Each of these characteristics differs significantly by climate region, underscoring the importance of conducting a region-by-region analysis of the performance of the Program.

Based on the weighted statistics shown in Fig. 3.1, 64\% of the dwellings weatherized by the Program in 1989 were single-family detached, and 66\% were owner-occupied. Both of these characteristics are most prevalent in the hot region ( $74 \%$ and $83 \%$, respectively). Mobile homes are estimated to be $20 \%$ of the weatherized dwellings; they are also most prevalent in the hot region (22\%). Small multifamily dwellings make up $13 \%$ of weatherized homes and are most common in the moderate climate region $(17 \%)$, where only $58 \%$ of the weatherized dwellings are owneroccupied. 
Table 3.1 Dwelling and Occupant Characteristics of Weatherized Homes, by Climate Region (weighted)

\begin{tabular}{|c|c|c|c|c|}
\hline & $\begin{array}{c}\text { Total } \\
\text { Sample } \\
(\mathrm{N}=14,97: 1) \\
\end{array}$ & $\begin{array}{l}\text { Cold } \\
\text { Climate Region } \\
(\mathrm{N}=4,690)\end{array}$ & $\begin{array}{l}\text { Moderate } \\
\text { Climate Region } \\
(\mathrm{N}=7,238)\end{array}$ & $\begin{array}{l}\text { Hot } \\
\text { Climate Region } \\
(\mathrm{N}=3,043)\end{array}$ \\
\hline $\begin{array}{l}\text { Type of Housing***1 } \\
\text { Single-family detached } \\
\text { Single-family attached } \\
\text { Mobile home } \\
\text { Small multifamily }\end{array}$ & $\begin{array}{r}63.6 \\
3.3 \\
20.0 \\
13.0 \\
100.0 \\
\end{array}$ & $\begin{array}{r}66.5 \\
0.5 \\
20.9 \\
12.1 \\
100.1 \\
\end{array}$ & $\begin{array}{r}58.7 \\
5.2 \\
18.7 \\
17.4 \\
100.0 \\
\end{array}$ & $\begin{array}{r}74.5 \\
0.5 \\
22.9 \\
2.1 \\
100.1 \\
\end{array}$ \\
\hline $\begin{array}{l}\text { Primary Heating Fuel***l } \\
\text { Natural Gas } \\
\text { Electricity } \\
\text { Other }\end{array}$ & $\begin{array}{r}50.6 \\
9.5 \\
39.9 \\
100.0 \\
\end{array}$ & $\begin{array}{r}46.4 \\
7.5 \\
46.0 \\
100.0 \\
\end{array}$ & $\begin{array}{r}56.1 \\
8.5 \\
35.4 \\
100.0 \\
\end{array}$ & $\begin{array}{r}39.7 \\
14.0 \\
46.3 \\
100.0 \\
\end{array}$ \\
\hline Supplemental Heating Fuel***1 & 30.3 & 23.7 & 30.3 & 38.4 \\
\hline Central Heating System***t & 67.9 & 82.8 & 77.4 & 24.0 \\
\hline $\begin{array}{l}\text { Air-Conditioning Equipment } \\
\text { (Central, Wall, or Window)***1 }\end{array}$ & 27.9 & 15.7 & 20.6 & 54.5 \\
\hline Square Footage*** & 1,083 & 1,181 & 1,083 & 987 \\
\hline Age of Housing (in Years)** & 41.7 & 44.9 & 44.0 & 32.9 \\
\hline Owner-Occupied $* * * 1$ & 65.8 & 67.3 & 58.7 & 83.2 \\
\hline Number of Occupants*** & 2.81 & 3.00 & 2.80 & 2.67 \\
\hline Elderly Occupant***1 & 35.8 & 28.0 & 28.5 & 57.3 \\
\hline Handicapped Occupant***1 & 24.3 & 20.1 & 21.1 & 36.2 \\
\hline $\begin{array}{l}\text { A verage Income } \\
\text { (in } \$-1989)^{* * *}\end{array}$ & 7,343 & 7,864 & 7,578 & 6,388 \\
\hline
\end{tabular}

** and $* * *$ indicate that differences across climate regions are significant at the 0.01 or 0.001 level, respectively. Chi-square tests are used for all variables designated with a "l", and F-tests based on analysis of variance are used for the remaining variables.

1 Measured as the percent of dwellings with the characteristic.

Half $(51 \%)$ of the dwellings weatherized in 1989 were heated primarily by natural gas; this fuel heats a significantly higher percentage of the homes weatherized in the moderate region. Electric heat, on the other hand, is used as a primary heating fuel by only $10 \%$ of the weatherized dwellings. It is most prevalent in the hot region where it accounts for $14 \%$ of weatherized homes. Other fucls represent nearly $40 \%$ of the homes weatherized by the DOE Program nationwide; they account for higher percentages in the cold and hot regions than in the moderate region. In the cold 
region, fuel oil is the dominant other fuel. In the hot region, liquid propane gas, kerosene, and wood are commonly used.

Supplemental heating fuels are used in about $30 \%$ of the homes weatherized by the Program. The incidence of supplemental heat is lowest in the cold climate region. This can be explained, in part, by the high percentage of central heating systems in that region (83\%). Despite the prevalence oi central heating systems in the total population of weatherized dwellings, only $24 \%$ of the dwellings weatherized in the hot region have central heating systems.

Nationally, less than one-third (28\%) of the weatherized dwellings have some form of airconditioning (AC) equipment - either a central AC system (7\%), a wall or window unit (19\%), or both $(2 \%)$. More than half of the homes in the hot region, but only $16 \%$ of the homes in the cold region, have $\mathrm{AC}$ equipment.

Weatherized homes average 1,083 square feet, nationwide. They are smallest in the hot region. The average weatherized house was built in 1947, but again this varies by climate region. Weatherized divellings are newest in the hot region and oldest in the cold and moderate regions.

The average number of occupants in a weatherized dwelling is 2.8 . Thirty-six percent of the time, weatherized dwellings are occupied by at least one elderly person, and $24 \%$ of the time, there is a handicapped occupant. Weatherized dwellings in the hot region have the smallest households and the highest percentages of elderly (57\%) and handicapped (36\%) occupants. Thus, this region performed most effectively in meeting the Program's legislated goal of targeting its services to the elderly and handicapped.

The average income of households who participated in the PY 1989 Program, was \$7,343. This average is significantly lower in the hot region $(\$ 6,388)$ compared with the cold region $(\$ 7,864)$.

In sum, dwelling and occupant characteristics of homes weatherized by the Program in PY 1989 vary markedly across climate regions. In Section 3.3 we provide a profile of the eligible population and identify several dissimilarities with the weatherized population.

\subsubsection{Differences by Primary Heating Fuel}

Table 3.2 profiles the dwelling and occupant characteristics of weatherized dwellings by primary heating fuel - natural gas, electricity, and other. As with th climate region distinctions discussed above, the statistics indicate marked and significant differences. 
Table 3.2 Dwelling and Occupant Characteristics of Weatherized Homes, by Primary Heating Fuel (weighted)

\begin{tabular}{|c|c|c|c|}
\hline 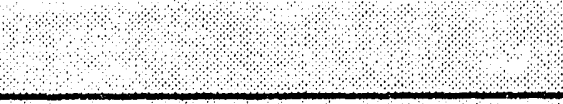 & $\begin{array}{l}\text { Natural Gas } \\
(\mathrm{N}=9,161)\end{array}$ & $\begin{array}{l}\text { Electricjty } \\
(\mathrm{N}=1,325)\end{array}$ & $(\mathrm{N}=4,113)$ \\
\hline $\begin{array}{l}\text { Type of Housing }{ }^{* * * 1} \\
\text { Single-family detached } \\
\text { Single-family attached } \\
\text { Mobile home } \\
\text { Small multifamily }\end{array}$ & $\begin{array}{r}66.7 \\
4.0 \\
10.7 \\
18.7 \\
99.9 \\
\end{array}$ & $\begin{array}{r}57.2 \\
1.6 \\
29.4 \\
11.8 \\
100.1 \\
\end{array}$ & $\begin{array}{r}61.2 \\
2.8 \\
29.8 \\
6.1 \\
100.0\end{array}$ \\
\hline $\begin{array}{l}\text { Climate Region***1 } \\
\text { Cold } \\
\text { Moderate } \\
\text { Hot }\end{array}$ & $\begin{array}{l}17.8 \\
64.9 \\
17.3 \\
99.9 \\
\end{array}$ & $\begin{array}{r}15.3 \\
52.3 \\
32.3 \\
100.0 \\
\end{array}$ & $\begin{array}{r}22.4 \\
51.9 \\
25.7 \\
100.0 \\
\end{array}$ \\
\hline Supplemental Heating Fuel $* * * 1$ & 25.9 & 32.2 & 35.2 \\
\hline Central Heating System $* * * 1$ & 80.9 & 37.0 & 58.4 \\
\hline $\begin{array}{l}\text { Air Conditioning Equipment } \\
\text { (Central, Wall, or Window)**. }\end{array}$ & 30.5 & 40.5 & 21.9 \\
\hline Square Foolage*** & 1,136 & 1,016 & 1,037 \\
\hline Age of Housing (in Years)** & 44.9 & 28.9 & 40.5 \\
\hline Owner-Occupied $* * * 1$ & 60.0 & 65.4 & 73.4 \\
\hline Number of Occupants*** & 2.81 & 2.87 & 2.80 \\
\hline Elderly Occupant***1 & 30.0 & 34.1 & 40.9 \\
\hline Handic $\mu$ ped Occupant $* * * 1$ & 22.0 & 26.1 & 26.7 \\
\hline Average Income (in $\$-1989)^{* *}$ * & 7,324 & 7,304 & 7,378 \\
\hline
\end{tabular}

$* *$ and $* * *$ indicate that differences across climate regions are significant at the 0.01 or 0.001 level, respectively. Chi-square tests are used for all variables designated with a "l", and F-tests based on analysis of variance are used for the remaining variables.

1 Measured as the percent of dwellings with the characteristic.

* Missing Observations $=372$ dwellings.

Recall that weatherized dwellings heated with natural gas are most prevalent in the cold and moderate climate regions. This accounts for some of their unique dwelling and occupant characteristics. For instance, the vast majority of weatherized homes with gas heat have central heating systems (80\%), and they tend to be older than other homes (44 years old); both traits are consistent with their geugraphic distritution. Gas heat is common among small multifamily 
dwellings weatherized by the Program, but it is uncommon among weatherized mobile homes. Only $60 \%$ of weatherized homes with gas heat are owner-occupied, and a smaller than average percentage have elderly or handicapped occupants.

Electrically heated homes weatherized by the Program tend to be located in the hot region, which explains many of their characteristics. For instance, they have relatively few central heating systems, more air-conditioning equipment, and are newer than weatherized homes heated by other fuels. A high proportion of electrically heated weatherized dwellings are mobile homes (29\%), and fewer than average are single-family (57\%). Their households are slightly larger (averaging 2.9 occupants) and have higher incomes than homes heated with natural gas or other fuels.

Weatherized homes heated by fuels other than natural gas and electricity (primarily fuel oil, liquid propane gas, and wood) provide a third distinct profile. A high percentage of these dwellings $(22 \%)$ are located in the cold climate region, which accounts for the relative absence of airconditioning equipment (only $21 \%$ of these homes have central AC systems or a wall or window air conditioner). Only half $(58 \%)$ of these dwellings have central heating systems. A relatively high percentage of these dwellings are mobile homes (29\%), and a relatively low percentage are small multifamily dwellings. This distribution of housing types is consistent with their high rate of owneroccupancy $(73 \%)$. Finally, many of these households have elderly $(40 \%)$ or handicapped $(26 \%)$ occupants.

In sum, dwelling and occupant characteristics of homes weatherized by the Program in PY 1989 vary markedly by type of heating fuel. These differences suggest that the potential for energy savings also differs by fuel type. In particular, the cluster of characteristics of electrically heated homes (e.g., southern locations and newer homes) suggests a lower potential for space-heat savings and a higher potential for cooling savings relative to homes heated by gas or other fuels.

\subsubsection{Differences by Type of Dwelling}

Table 3.3 profiles the dwelling and occupant characteristics of weatherized homes by dwelling type - single-family detached, nobile homes, single-family attached, and small multifamily. As with the climate region and fucl distinctions discussed above, the statistics indicate substantial differences. 
Table 3.3 Dwelling and Occupant Characteristics of Weatherized Homes, by Dwelling Type (weighted)

\begin{tabular}{|c|c|c|c|c|}
\hline & $\begin{array}{l}\text { Single family' } \\
\text { Detached } \\
(\mathrm{N}=9,445)\end{array}$ & "yobile- & Single famills & $\begin{array}{l}\text { smailt } \\
\text { Muitifamily. } \\
\text { (N=2.074). }\end{array}$ \\
\hline 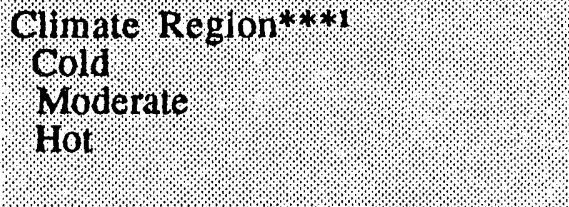 & $\begin{array}{r}20.3 \\
54.1 \\
25.5 \\
100.0\end{array}$ & $\begin{array}{r}20.3 \\
54.8 \\
24.9 \\
100.0\end{array}$ & $\begin{array}{r}3.2 \\
93.5 \\
3.3 \\
100.0\end{array}$ & $\begin{array}{r}18.0 \\
78.5 \\
3.5 \\
100.0\end{array}$ \\
\hline 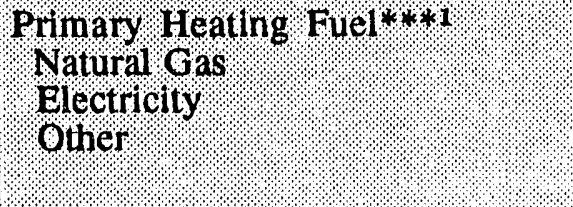 & $\begin{array}{r}53.2 \\
8.6 \\
38.2 \\
100.0\end{array}$ & $\begin{array}{r}27.0 \\
14.0 \\
59.0 \\
100.0\end{array}$ & $\begin{array}{r}62.7 \\
4.7 \\
33.6 \\
100.0\end{array}$ & $\begin{array}{r}72.7 \\
8.6 \\
18.7 \\
100.0\end{array}$ \\
\hline Supplemental Heating Fuel***1 & 31.3 & 30.1 & 14.1 & 27.2 \\
\hline Central Heating System ${ }^{*} *^{* 1}$. & 62.8 & 12.9 & 92.9 & 77.4 \\
\hline $\begin{array}{l}\text { Ait Conditioning Equipment. } \\
\text { (Central. Wall, or Window)***1 }\end{array}$ & 28.6 & 32.7 & 27.6 & 17.2 \\
\hline Square Footage*t: & 1,149 & 804 & 1,078 & 1,210 \\
\hline Age of Housing (in Years)** & 46.1 & 16.9 & 55.5 & 54.3 \\
\hline Owner Occupied***t/ & 72.5 & 77.9 & 50.6 & 18.1 \\
\hline Number of Occupants***. & 2.8 & 2.8 & 2.8 & 2.7 \\
\hline Elderly Occupani***i & 40.2 & 26.8 & 29.6 & 21.2 \\
\hline Handicapped Occupant***1 & 26.3 & 24.7 & 20.0 & 14.4 \\
\hline Average Income (in \$-1989)*** & 7,420 & 7,134 & 7,386 & 7,265 \\
\hline
\end{tabular}

** and *** indicate that differences across climate regions are significant at the 0.01 or 0.001 level, respectively. Chi-square tests are used for all variables designated with a "1", and F-tests based on analysis of variance are used for the remaining variables.

1 Measured as the percent of dwellings with the characteristic.

* Missing Observations $=122$ dwellings 
Single-family detached dwellings are most similar to the "average" weatherized home, because they domisate the population. They have the largest houschold sizes and the highest incidence of elderly and handicapped occupants. Only $63 \%$ of them have central heating systems, and they rely on supplemental heating fuels more than any other dwelling type.

Mobile homes have the least square footage, the greatest home ownership, and are the newest of the four types of weatherized dwellings. Slightly more than a quarter of them heat with natural gas, while $59 \%$ heat with fucls other than gas or electricity.

Only $3 \%$ of weatherized homes are single-family altached dwellings. Almost all of these homes have central heating systems (92\%), and few have supplemental heating fuels. Single-family attached dwellings are the oldest of the dwelling types, and their occupants have among the highest incomes.

Small multifamily dwcllings heat primarily with natural gas $(72 \%)$. They have the largest square footage and the lowest incidence of air conditioning equipment of any type of dwelling; the lack of air conditioning equipment is related to their almost exclusive location in the moderate and cold regions. Small multifamily dwellings also have the lowest level of home ownership (18\%), which is consistent with the fact that only $21 \%$ of them have an elderly occupant.

In sum, different dwelling types have markedly different dwelling and occupant characteristics. The distinct constellation of characteristics associated with each type must be considered in explaining the performance of the Program.

\subsection{PROGRAM PARTICIPANTS VERSUS THE ELIGIBLE POPULATION}

The population of Program participants (i.e., PY 1989 weatherized dwellings) was described in Section 3.2. In this section, the characteristics of these participants are compared to those of the population of income-eligible dwellings Characteristics of the population of income-eligible dwellings (Figures 3.9 through 3.12, Table 3.4 and Tables C.3 through C.5) were provided by Response Analysis Corporation, based on the DOE Energy Information Administration's 1990 Residential Energy Consumption Survey (RECS) data tapes.

In analyzing the RECS data, the eligible population could be defined as all households below $125 \%$ or below $150 \%$ of the federal poverty guidelines. Definitions of income eligibility vary among the States. Some States use $125 \%$ of the poverty level, while others use $150 \%$ of the poverty level. Other definitions, such as $60 \%$ of the State's median income also may be used. Because of the varying State definitions, the Program-eligible population actually has a mean income that is somewhere between $125 \%$ and $150 \%$ of the poverty level. Most of the comparisons in this section are between the participants and houscholds at $125 \%$ of poverty. (This is the definition being used unless it is otherwise noted.) The differences shown by these comparisons would be more pronounced if the eligible population were defined as houscholds at $150 \%$ of poverty. Althoughi 
Alaska and Hawaii are included in the RECS, they were excluded from this analysis to make the geographic coverage the same as for this study (which covers only the continental U.S.). Similarly, high-density multifamily dwellings were excluded from the RECS data to be consistent with this study.

As Figure 3.9 shows, the Program-participant population is more concentrated in the cold and moderate climate regions than is the eligible population. In the hot climate region, the Programparticipant population is a much smaller percentage than the eligible population. These regional differences reflect the Program funding formula, mentioned in Chapter 1, which gives more funds to areas with colder weather.

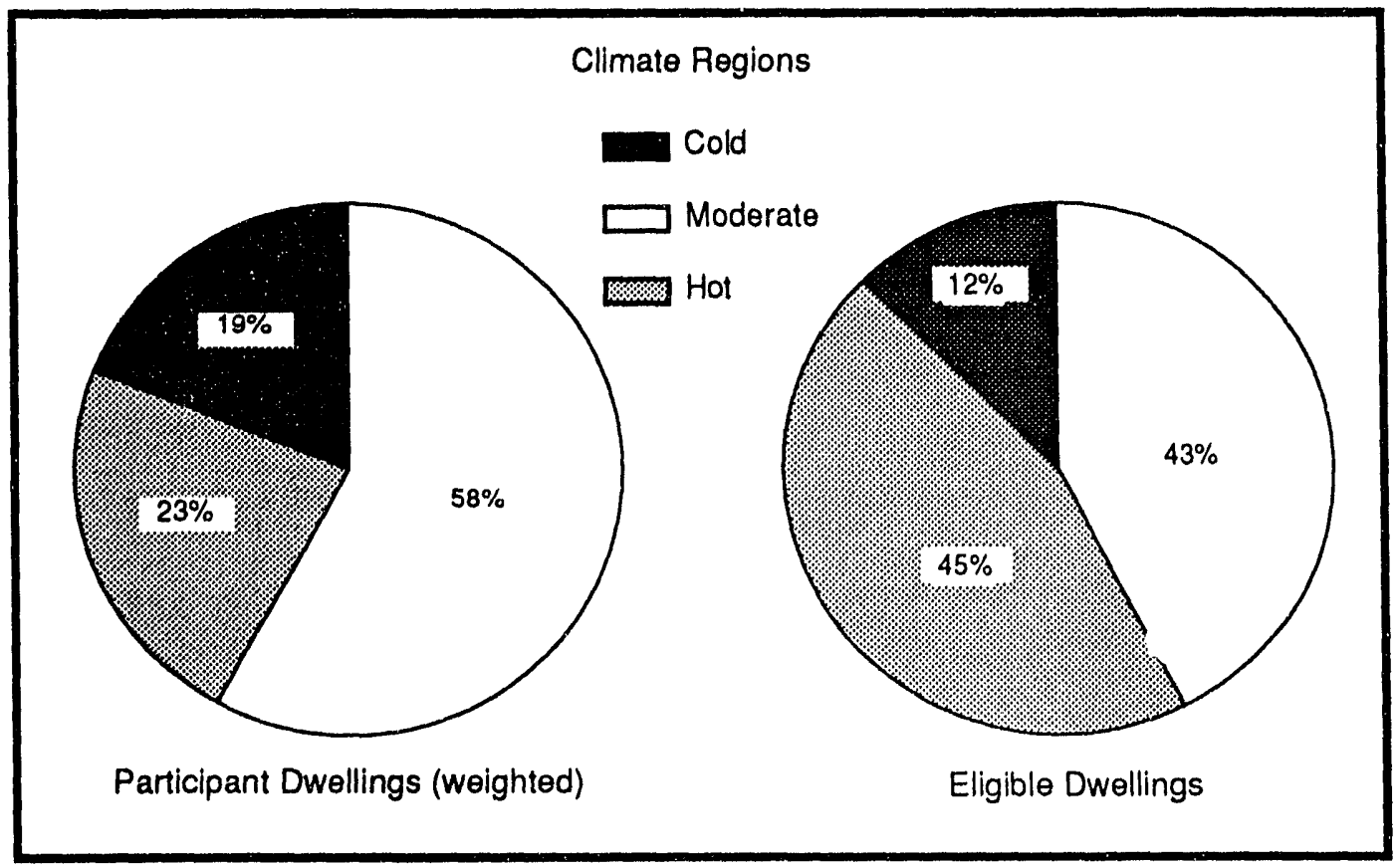

Fig. 3.9 Distribution of Program-Participant Homes and Program-Eligible Homes, by Climate Region

By comparing the results in Table 3.1 to those in Table 3.4, one can see that the population of weatherized dwellings differs in other ways from the population of cligibles. First, the Programparticipant population includes a higher percentage (20\%) of mobile homes and a lower percentage of single-family attached (3\%) and multifamily dwellings (13\%) than the eligible population (12\%, $6 \%$, and $18 \%$, respectively). This is the case even though the Program-participant population is underrepresented in the hot region, where mobile homes are most common, and overrepresented in the moderate climate regions where small multifamily and single-family attached dwellings (such as row houses) are most prevalent. Thus, there appears to be a program-wide tendency to serve mobile homes at higher rates, and small multifamily and attached single-family dwellings at lower rates than their proportions in the eligible population. Perhaps this occurs because of associated characteristics, 
Table 3.4 Dwelling and Occupant Characteristics of RECS Sample of Program-Eligible Homes by Climate Region ${ }^{2}$

\begin{tabular}{|c|c|c|c|c|}
\hline & Sample & Climate Region & Glingite Region & Climate Region \\
\hline 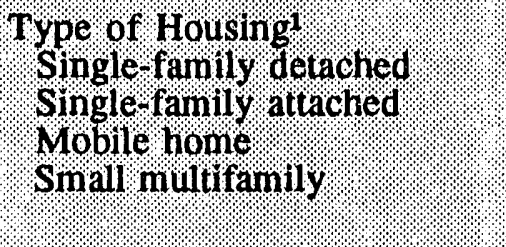 & $\begin{array}{r}63.4 \\
6.4 \\
12.1 \\
18.1 \\
100.0\end{array}$ & $\begin{array}{r}65.9 \\
4.9 \\
12.8 \\
16.4 \\
100.0\end{array}$ & $\begin{array}{r}51.8 \\
10.7 \\
10.6 \\
26.9 \\
100.0\end{array}$ & $\begin{array}{r}73.8 \\
2.8 \\
13.3 \\
10.1 \\
100.0\end{array}$ \\
\hline 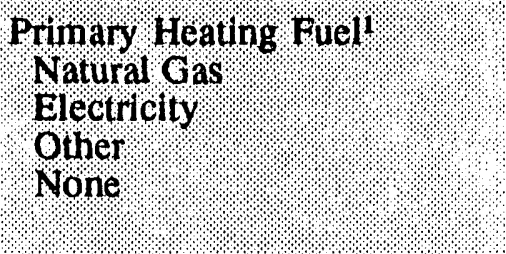 & $\begin{array}{r}53.2 \\
16.1 \\
30.5 \\
0.2 \\
100.0\end{array}$ & $\begin{array}{r}52.0 \\
7.6 \\
40.3 \\
0.0 \\
99.9\end{array}$ & $\begin{array}{r}52.6 \\
15.1 \\
31.8 \\
0.5 \\
100.0\end{array}$ & $\begin{array}{r}54.1 \\
19.5 \\
26.5 \\
0.0 \\
100.1\end{array}$ \\
\hline Supplemental Heating Fuel'1 & 33.8 & 37.4 & 34.2 & 32.5 \\
\hline Central Heating System ${ }^{3}$ & 56.6 & 72.5 & 68.3 & 41.2 \\
\hline $\begin{array}{l}\text { Air-Conditioning Equipment } \\
\text { (Central, Wall, or Window) }\end{array}$ & 51.2 & 29.3 & 42.6 & 65.3 \\
\hline Square Footage (Heated) & 1,234 & 1,339 & 1,335 & 1,110 \\
\hline Age of Housing (in Years) & 38.9 & 44.9 & 43.2 & 33.1 \\
\hline Owner-Occupiedt & 56.6 & 65.8 & 50.5 & 60.0 \\
\hline Number of Occupants & 2.9 & 2.7 & 2.9 & 3.0 \\
\hline Elderly Occupant' & 34.1 & 31.8 & 31.8 & 36.9 \\
\hline Average lncome (in \$-1989) & 7,893 & 7,344 & 7,977 & 7,963 \\
\hline Number of Observations & 783 & 109 & 360 & 314 \\
\hline
\end{tabular}

1 Measured as the percent of dwellings with the characteristic.

2 The figures in this table were provided by Response Analysis Corporation from the 1990 Residential Energy Consumption Survey (RECS). Eligibility for the Weatherizat on Assistance Program was defined as $125 \%$ of the federal poveriy income guidelines. 
such as higher proportions of homeowners and lower incomes among mobile home residents or because there are more renters among small multifamily/attached single-family residents. Such associated characteristics could produce variations in client receptiveness to outreach and screening procedures, resulting in differential rates of program participation. Alternatively, program managers may target mobile homes because they are often clustered in "parks," which facilitates outreach. Similarly, the DOE requirement that at least two of the houscholds occupying 3- and 4-unit rental buildings must be eligible before the entire building can be weatherized may be an outreach barrier. The reasons for the over-representation of mobile homes and the underrepresentation of small multifamily/attached single-family dwellings among the Program-participant population cannot be discerned conclusively from this statistical analysis.

Secondly, the weatherized population uses lower proportions of electricity (10\%) and higher proportions of other fuels $(40 \%)$ as the primary heating fuel than the Program-eligible population (16\% and $31 \%$ respectively). The differences in primary heating fuel are especially large in the hot climate region, where $46 \%$ of the Program-participant population heats primarily with other fuels as compared to $27 \%$ of the eligible population (Tables 3.1 and 3.4 ). This underrepresentation of electricity as a primary heating fuel may relate to its concentration in newer homes, its greater use in hot climates, and its lower prevalence among mobile homes, which are more likely to heat with other fuels.

Differences in the average size and age of dwellings are not large, with the Programparticipant population occupying slightly smaller, older homes than the Program-eligible population (Tables 3.1 and 3.4). Distributions of the age of dwcllings and their square footage (Figures 3.10 and 3.11) also show that slightly more of the Program-participant population is concentrated in the oldest and smallest dwellings. The slightly higher concentration of the Program-participant population in dwellings built after 1980 may reflect its higher concentration in mobile homes (which tend to be newer, because their housing market share has increased in recent years, and because they have shorter expected lifetimes than site-built dwellings).

The number of occupants shows little variation between the two populations, except for the slightly larger houscholds among the Program-eligible population in the hot climate region. The hot climate region had a much higher percentage of dwellings with elderly occupants (57\%) among the Program-participant population than among the Program-cligible population (37\%). Thus, agencies located in the hot climate region are particularly effective at reaching out to elderly clients, which is a legislated goal of the Weatherization Assistance Program. For the Program as a whole, the average percentage of dwellings with an elderly occupant was about the same for the two populations (36\% participant vs. $34 \%$ eligible). Thus, elderly houscholds are slightly underrepresented among weatherization participants in the moderate and cold regions. 


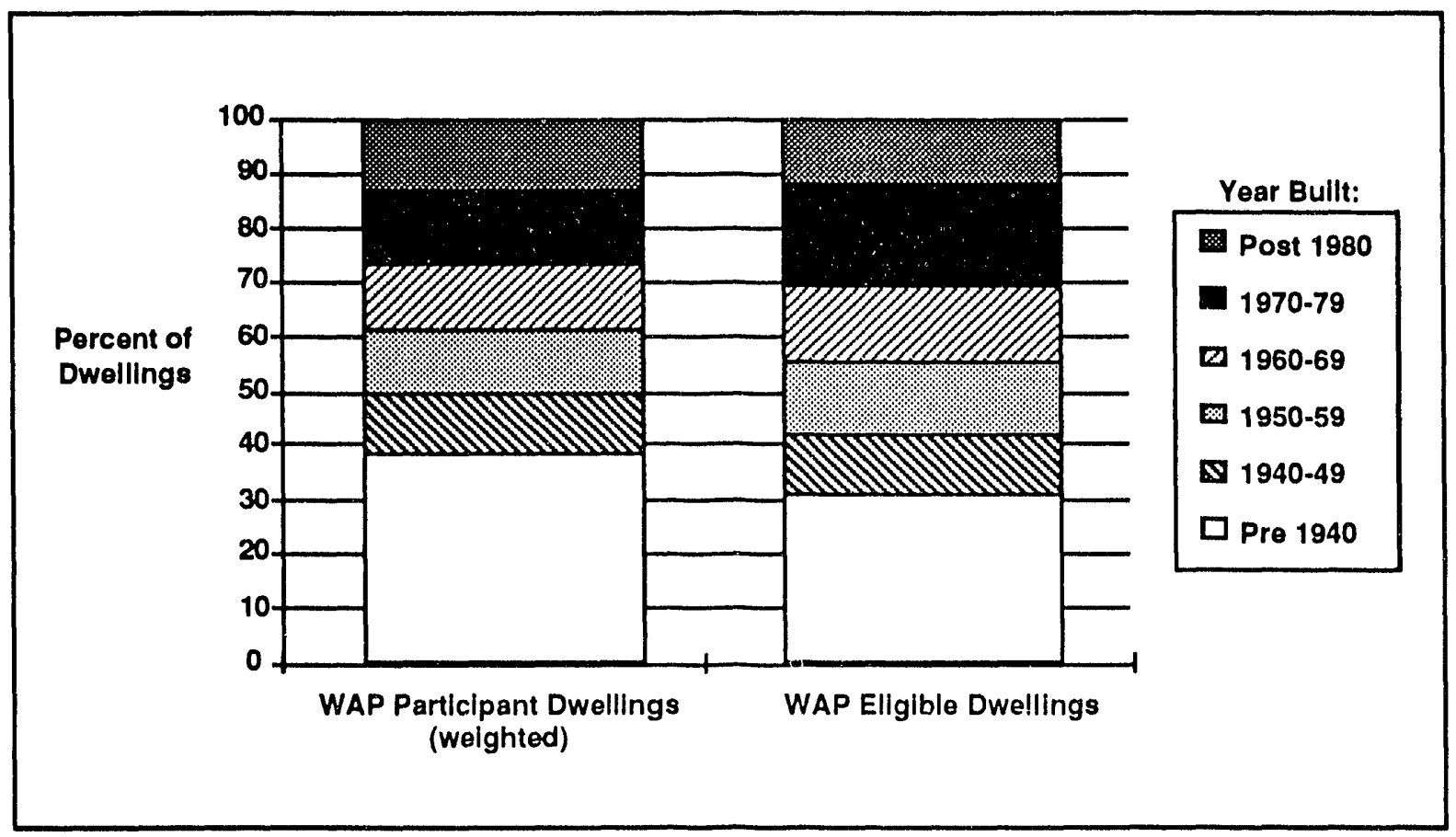

Fig. 3.10 Age of Dwelling of Program-Participant Homes and Program-Eligible Homes in the U.S.

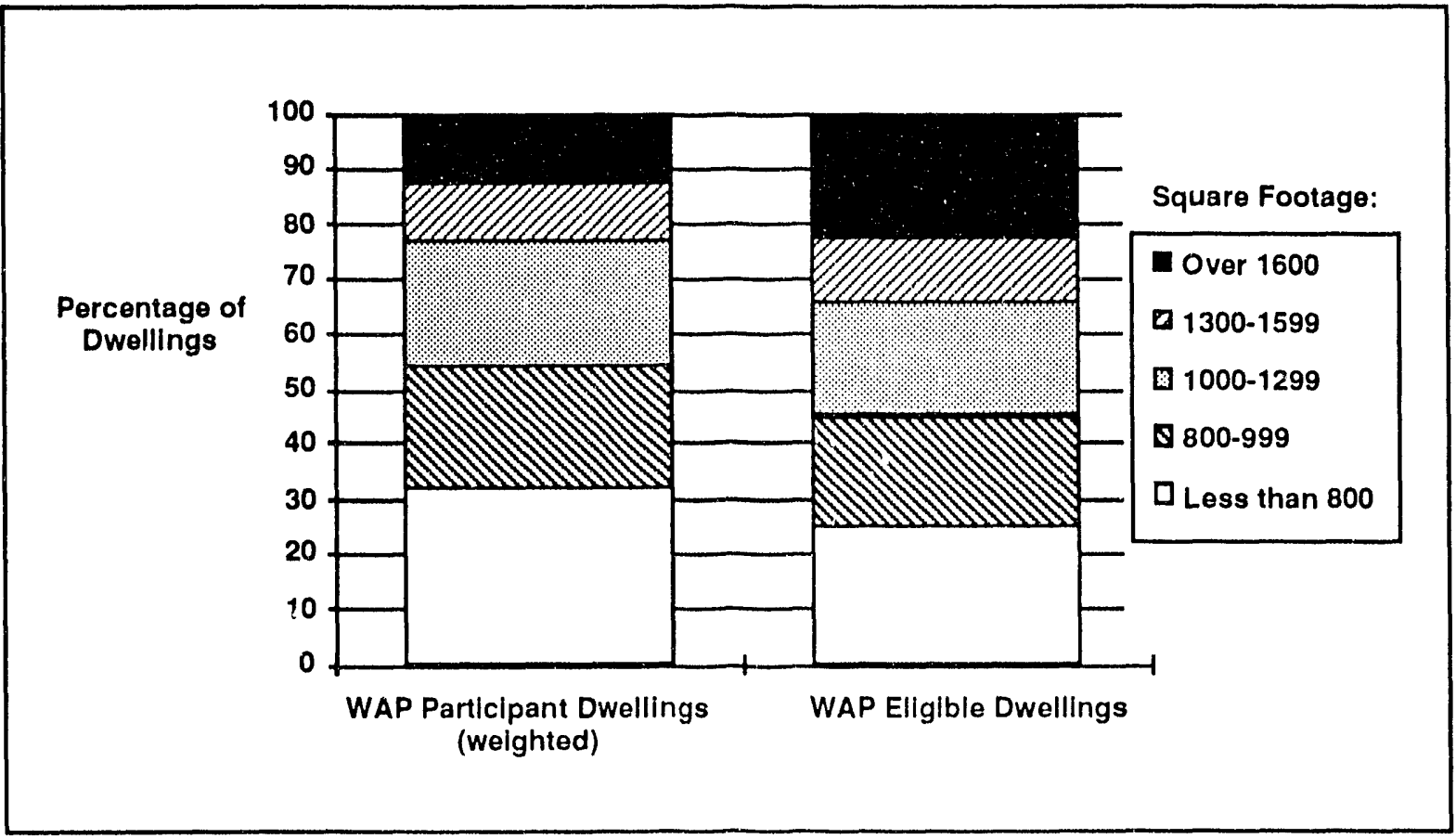

Fig. 3.11 Square Footage of Program-Participant Homes and Program-Eligible Homes in the U.S. 
Information on the percentage of dwellings with a handicapped occupant that appears in Table 3.1 could not be included in Table 3.4 because RECS does not collect information on this variable. Differences in definitions and data quality may cause comparisons of results on the central heating system, supplemental heating fucl, and air-conditioning equipment variables to be misleading. RECS definitions for central heating system categories differ from those used on the Dwelling-Specific Form in ways that could not be clearly reconciled. The RECs data showed higher usage of supplemental heating fuels and higher penetrations of air conditioning equipment than results from the 1 welling-Specific Form (Tables 3.1 and 3.4). These differences, however, may be largely due to differences in the data collection procedures. Agency files sometimes lacked information on the use of supplemental fuels and on the presence/absence of air conditioning equipment. Since the RECS was conducted on-site, it certainly has a more complete accounting of the penetration of supplemental fuels and air conditioning equipment. Although the greater frequency of missing values in the Dwelling-Specific data may lead to biased cstimates of the total penetrations for these variables, this does not affect this sludy's ability to identify correlations between the presence of supplemental fuels or air-conditioning equipment and other variables, such as electricity savings and cost effectiveness.

The Program-participant population generally (with the exception of the cold climate region) has a lower average income than the Program-eligible population (Tables 3.1 and 3.4). This difference is especially marked in the hot climate region. Figure 3.12 shows that higher proportions of the Program-participant population (33\%) earn less than $\$ 5,000$ annually than is true for the Program-eligible population (25\%) (when eligibility is defined as $125 \%$ of poverty). When eligibility is defined as $150 \%$ of poverty, the differences are even greater. These differences suggest that the Program is targeting the needier part of the low-income sector. This finding is consistent with other differences discussed above, such as the greater concentration of the Program-participant population in mobile homes (the least expensive housing option), and in older, smaller dwellings.

\subsection{SUMMARY}

\subsubsection{Response Rates}

Local agencies were very responsive to DOE's requests for dwelling specifir data, resulting in a response rate of $80 \%$. Response rate bias was minimal and easily correctable through the use of sample weights. As a result, the database of dwelling-specific information provides a robust basis for generating highl: accurate statistics about the activities and characteristics of the network of local agencies, and fo analyzing factors leading to successful program performance. 


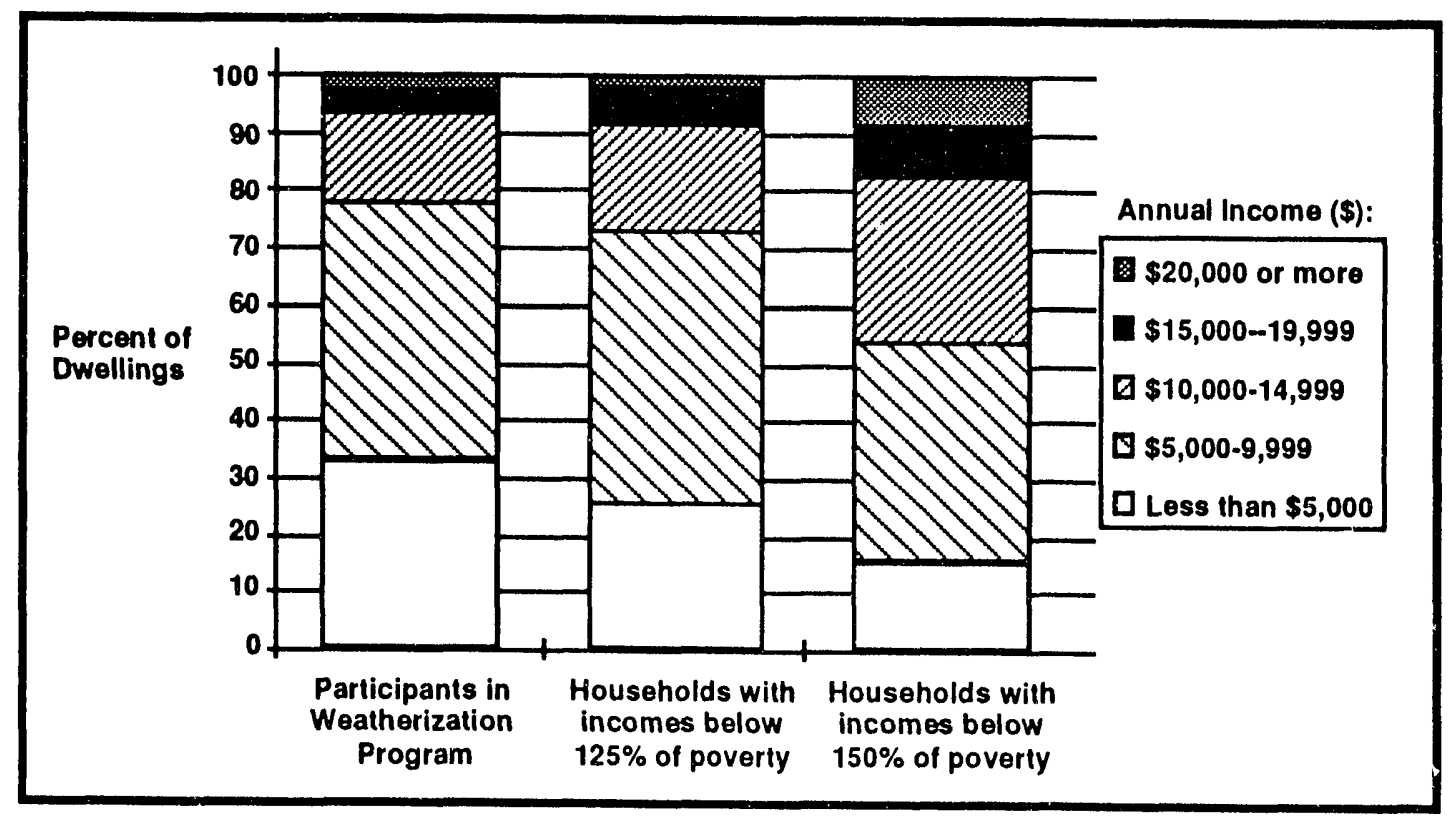

Fig. 3.12 Income Distribution of Program-Participant and Program-Eligible Households in the U.S.

Gas and electric utilities, on the other hand, were less responsive to DOE's request for the energy-consumption data. Complete information was provided for $36 \%$ of the weatherized dwellings and $32 \%$ of the control group dwellings. Thus, the oversampling of gas and electrically heated dwellings (that was part of the original experimental plan) was wise. The lower than anticipated response rate from utilities prevented reliable energy-savings and cost-effectiveness estimates for a few key subgroups. However, the data are sufficient to generate reliable savings and costeffectiveness estimates for the program as a whole and for each of the climate regions.

\subsubsection{Variations by Key Subgroups}

The analysis of weatherized dwellings underscores the existence of great diversity in the types of occupants and single-family and small multifamily buildings that received weatherization services during PY 1989. The dominant markets are clear: most weatherizrd dwellings are single-family detached (64\%), owner-occupied (66\%), and are located in the moderate climate region (58\%); and the plurality heat with natural gas $(51 \%)$, and have central heating systems $(68 \%)$. On the other hand, the PY 1989 weatherized dwellings also include mobile homes (20\%), dwellings that heat primarily with noncommercial fuels such as wood $(6 \%)$ and coal (1\%), and houscholds with elderly (36\%) and handicapped $(24 \%)$ occupants. 
There are significant geographic differences in the Program's clients. Specifically, weatherized homes in the cold climate region have the highest household incomes and the highest incidence of central heating and owner-occupancy. Weatherized homes in the moderate climate region have a preponderance of gas heat and a high percentage of small multifamily homes. In the hot climate region, weatherized dwellings are dramatically different - they are smaller and newer, use more supplemental heating fuels, rarely have central heating systems, typically have air conditioning equipment, and house more elderly and handicapped occupants.

Similarly, dwelling and occupant traits vary markedly by type of primary heating fuel. For example, weatherized dwellings that heat primarily with natural gas are most prevalent in the cold and moderate climate regions. The vast majority have central heating systems, and they tend to be older than other homes. Gas heat is common among small multifamily dwellings weatherized by the Weatherization Assistance Program, but it is uncommon among weatherized mobile homes. Only $60 \%$ of weatherized homes with gas heat are owner-occupied, and a smaller than average percentage have elderly or handicapped occupants.

Finally, different types of dwellings have different structural and occupant traits. To illustrate, consider the differences between mobile homes (with only 804 square feet of heated living space, $78 \%$ home ownership, and where $59 \%$ heat primarily with fucls other than natural gas or electricity) and small multifamily dwellings (with 1,210 square feet of heated living space, only $18 \%$ home ownership, and where $73 \%$ heat primarily with natural gas).

These differences are key to understanding the performance, challenges, and opportunities of the Program.

\subsubsection{Comparisons of Weatherized and Eligible Populations}

There are notable differences between the Program participants in PY 1989 and the Programeligible population. The Program participants were more concentrated in the cold and moderate climate regions than the Program-eligible population, reflecting the higher funding levels of colder climate regions. The weatherized dwellings also included higher proportions of mobile homes and lower proportions of single-family attached and small multifamily dwellings than the eligible population. This is the case even though (1) mobile homes are most prevalent in the hot region (which receives disproportionately less funding relative to its low-income population), and (2) singlefamily attached and small multifamily dwellings are most prevalent in the moderate and cold climate regions (which receive disproportionately more funding). Thus, there appears to be a programwide tendency to serve mobile homes at higher rates, and small multifamily and attached single-family divellings at lower rates than their proportions in the eligible population.

Another significant difference is that weatherized dwellings had fewer electric heating systems and relied more on other primary heating fuels (i.c., fuel oil, propane, kerosene, wood, and coal) than 
the eligible population. In the hot climate region, for instance, nearly half of the weatherized dwellings heated primarily with other fuels as compared to about a quarter of the eligible population. The over-representation of other fuels may relate to the prevalence of mobile homes in this region's weatherized sample, which predominantly heat with fuels other than gas or electricity.

In general, the average proportion of dwellings with an elderly occupant is about the same in the two populations. Weatherization agencies located in the hot climate region, however, served a disproportionately large number of elderly clients. Program participants in PY 1989 typically had a lower average income than the eligible population (Fig. 3.12), and resided in smaller, older homes. This suggests that the DOE Weatherization Assistance Program is serving the needier part of the lowincome sector. 


\section{DESCRIPTION OF WEATHERIZATION ACTIVITIES}

This chapter characterizes the nature of the weatherization activities that were undertaken by the Weatherization Assistance Program during PY 1989. It begins by describing the weatherization measures that were installed in the 198,000 participating homes (Section 4.1). Attention then turns to the service delivery procedures used during PY 1989, including client selection and investment criteria, use of diagnostics, selection of measures, client education, and quality control (Section 4.2). In both sections, we examine differences across climate regions, fuel types, types of dwellings, and agency sizes. A summary of findings is provided in Section 4.3.

\subsection{WEATHERIZATION MEASURES INSTALLED}

The cost effectiveness of any weatherization program depends upon selecting appropriate measures for each house and installing them properly, so that each dollar spent on weatherization generates the maximum energy savings. In the early years of the Program, emergency and temporary measures were emphasized, including caulking, weatherstripping, and low-cost/no-cost measures such as plastic window sheets. By the time of the EIA evaluation of the 1981 Program (Peabody, 1984), the emphasis had changed to more permanent and effective building envelope measures, such as storm windows and doors and insulation. In 1984, regulations were passed to allow Program funds to be spent on heat exchangers, thermostat control systems, water heater efficiency modifications, and pipe and boiler insulation. In 1985, replacement furnaces and boilers were approved, and the Secretary of Energy was allowed to add weatherization measures to the Program without a rulemaking procedure. Thus, the Program in 1989 allowed States great flexibility with respect to the weatherization measures that could be installed with Program funds, particularly in cold climates. Regulations passed in 1993 amend the Program to allow States to spend Program funds on cooling efficiency modifications, giving greater flexibility to programs operating in hot climates. The newly approved measures include replacement air-conditioners, evaporative coolers, ventilation equipment, screening, window films, and shading devices. This section describes the weatherization measures that were actually installed in PY 1989.

\subsubsection{Frequency of Installation of Different Measures}

Local agencies offer numerous different weatherizatic- measures to their clients. Based on weighted data from the representative samp. of dwcllings, Fig. 4.1 shows the six most commonly installed types of measures. Less common categories of measures include space cooling system improvements (e.g., tune-ups, component retrofits, and the installation of fans), lighting (e.g., compact fluorescents), and appliance measures (e.g., refrigerator replacements). None of these 


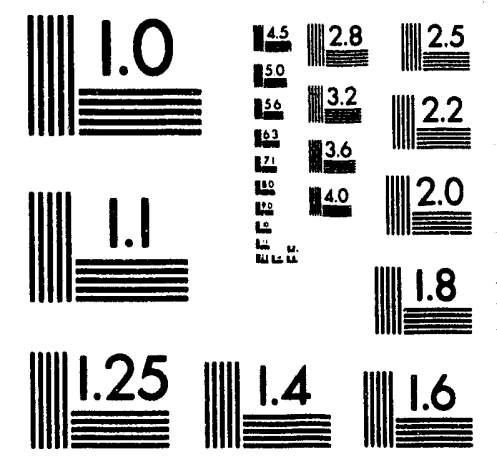



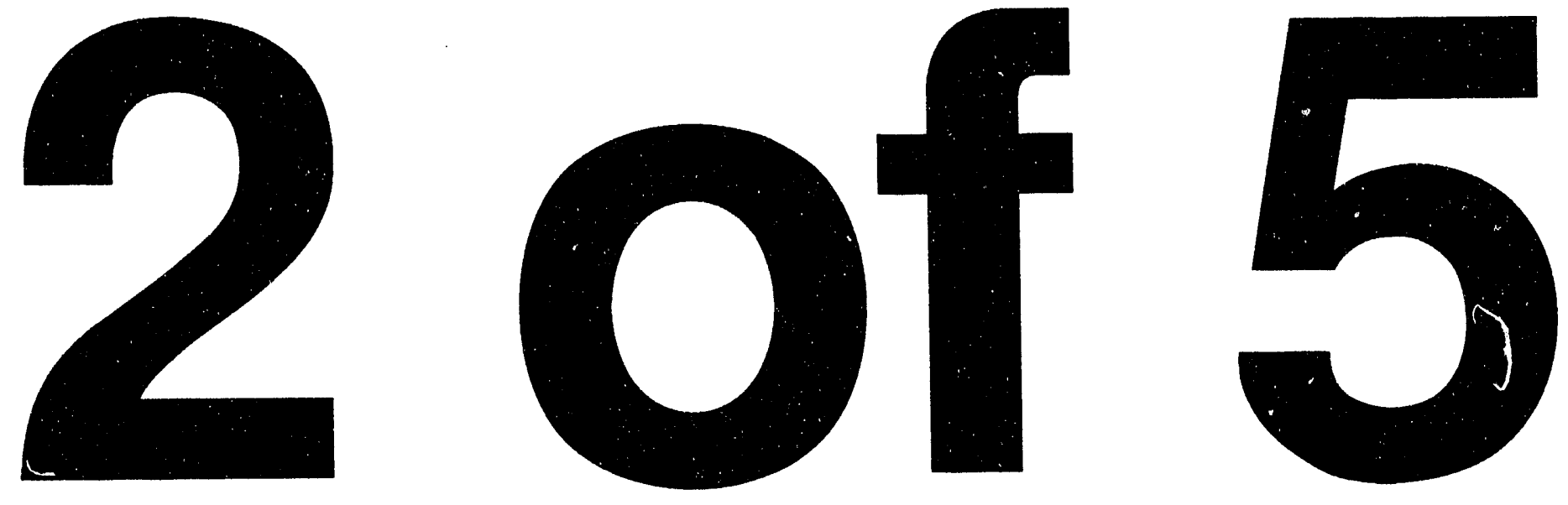
measures were installed in more than 2\% of the dwellings weatherized by the Program in PY 1989 [see Mihlmester, et al. (1992) for statistics on these].
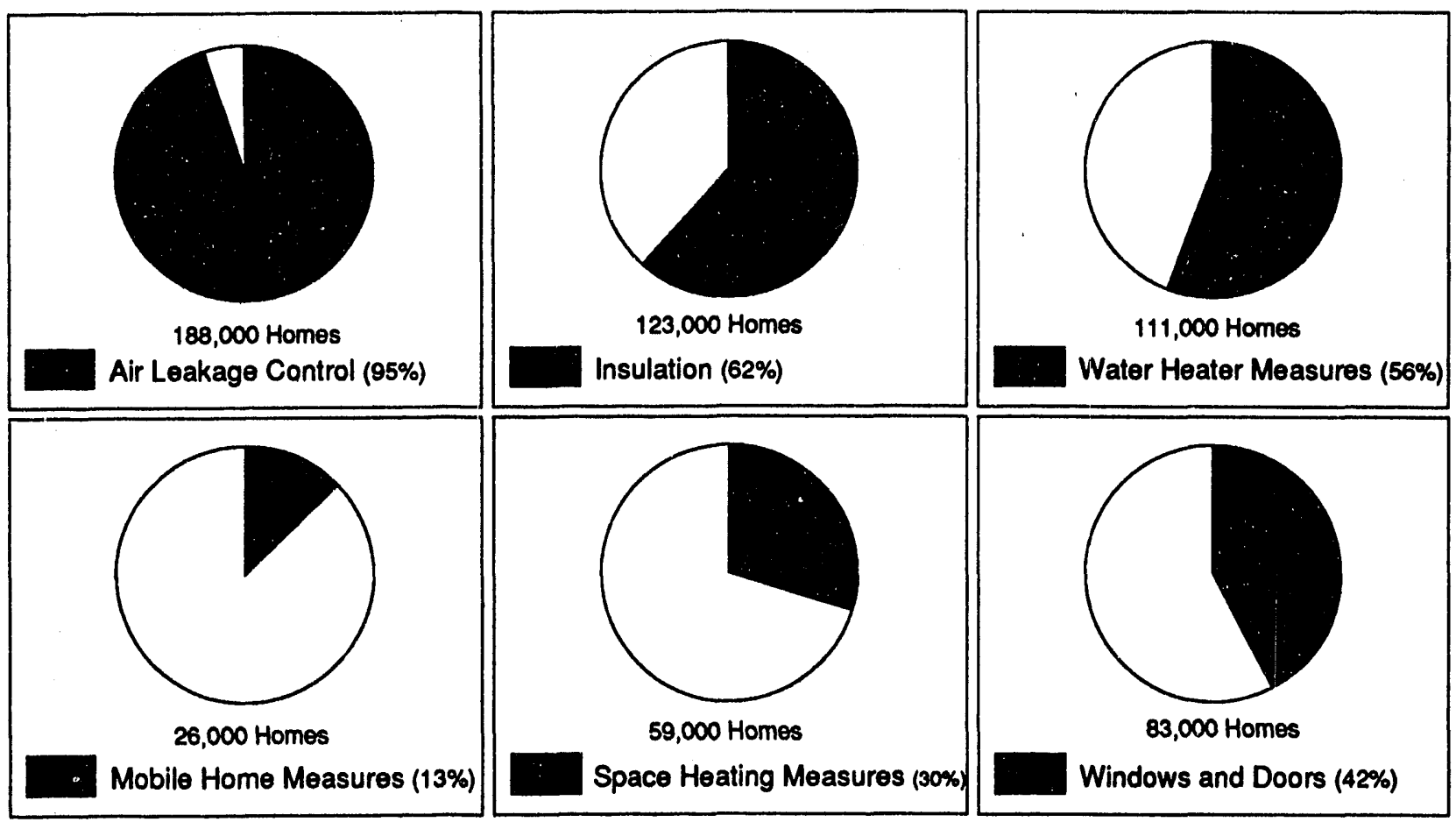

Each pie represents the population of 198,000 single-family and small multifamily dwellings weatherized in PY 1989.

Fig. 4.1 Types of Weatherization Measures Installed in PY 1989.

Air leakage control was the most common type of weatherization measure installed in PY 1989. It is estimated that 188,000 (i.e., $95 \%$ ) of the 198,000 weatherized homes received one or more measures aimed at reducing air infiltration. General caulking and weatherstripping around windows and doors is by far the most common of these measures.

Insulation was the next most common type of energy conservation measure installed by the Program in PY 1989. It was installed in 123,000 (i.e., 62\%) of the 198,000 homes. Attic insulation was either installed for the first time $(27 \%)$ or added to existing insulation (19\%) in the majority of these 123,000 homes (Fig. 4.2). More than $10 \%$ of the weatherized homes received one or more of each of the following: conventional wall insulation, rim or band joint insulation, and floor insulation. High density wall insulation, foundation or perimeter insulation, and attic hatch or access door insulation were each installed in $2 \%$ of the weatherized homes. Duct and crawlspace insulation was added to about $1 \%$ of them. 


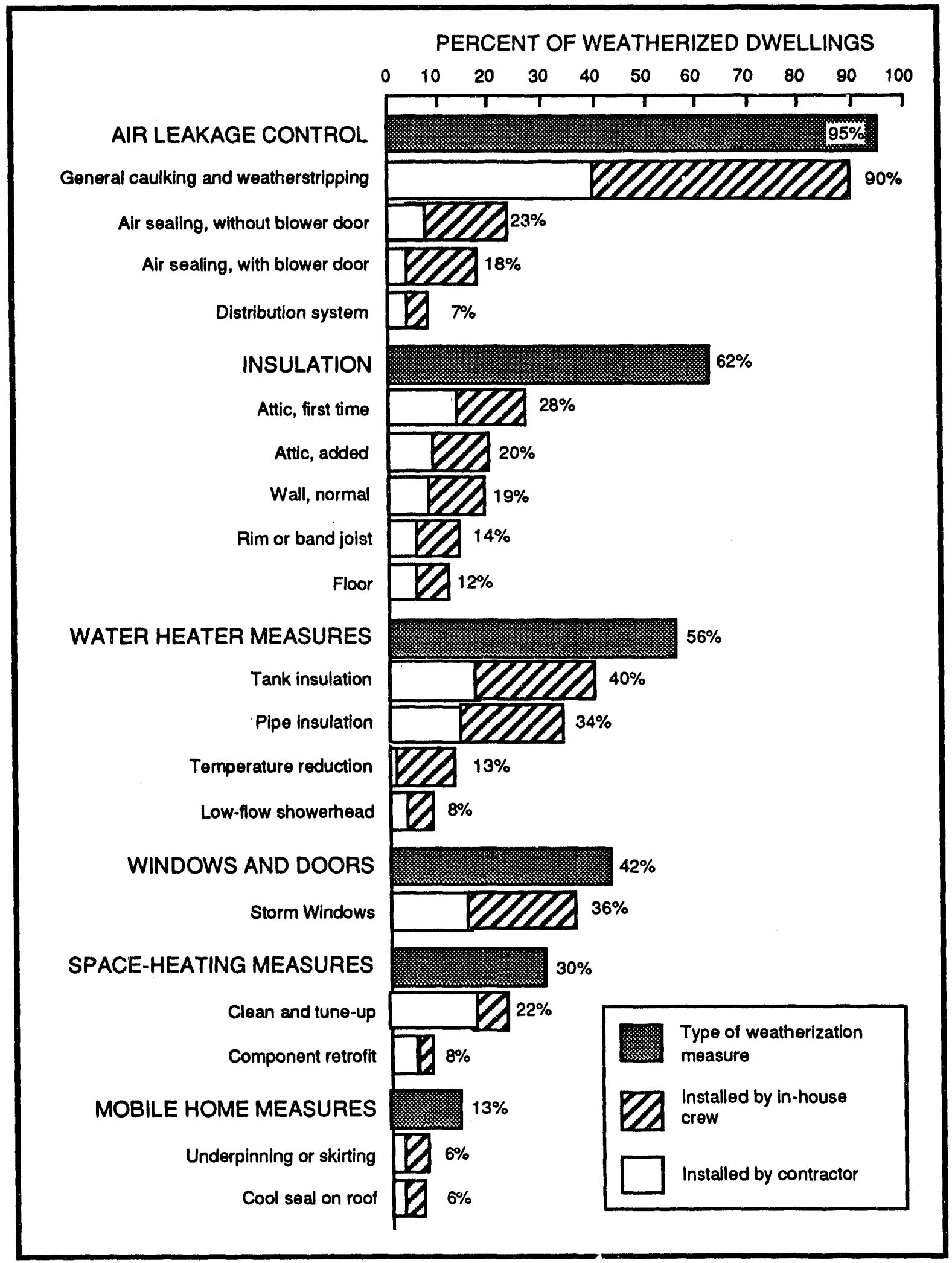

Fig. 4.2 Frequency of Installation of Weatherization Measures. 
Comparing the installation rates for attic and wall insulation to the penetration of these measures (based on the 1990 Residential Energy Consumption Survey) suggests that very different proportions of the potential are being captured. ${ }^{1}$ RECS shows that $66 \%$ of low-income dwellings have attic insulation (defined as at least some attic insulation), suggesting that $34 \%$ have no insulation. Therefore, the $27 \%$ installation rate of first-time attic insulation by the Program is close to the potential shown by the RECS. On the other hand, the national Program installation rate for wall insulation of $19 \%$ is far below the potential suggested by RECS (46\% of dwellings lack wall insulation). This shortfall is especially large in the hot climate region where only $1 \%$ of dwellings received wall insulation from the Program.

Energy-efficiency improvements to water-heating systems were made in 111,000 homes (i.e., 56\%). Most of these retrofits involved water heater wraps (40\%) or hot water pipe insulation (34\%). In addition, water temperatures were reduced and low-flow showerheads were added to $13 \%$ and $8 \%$ of the 198,000 homes, respectively. RECS data show that $74 \%$ of low-income dwellings lack water heater wraps, indicating that the Program is not capturing the full potential savings from this measure.

Energy-efficiency improvements to windows or doors were made to 84,000 homes (i.e., $42 \%$ ) in PY 1989. By far, the majority of these improvements involved the addition of storm windows, which were added to $36 \%$ of the weatherized homes (Fig. 4.2). This installation rate is capturing a significant proportion of the potential for the addition of storm windows. RECS data indicate that $43 \%$ of low-income dwellings have storms on all windows, while $57 \%$ do not. Storm doors were added to only $4 \%$ of the 198,000 weatherized homes, and window films or shades were added to only $2 \%$ of them. The statistics on replacement windows and doors (discussed in Chapter 6 and presented in Figure 6.1 and Table F.1) indicate that replacements are at least as common as the addition of storms. Doors were replaced on $38 \%$ of the homes weatherized in PY 1989, and windows were replaced almost as often (37\%). Altogether, storm windows were added or entire windows were replaced on $61 \%$ of the weatherized homes.

Thirty percent (i.e., 59,000) of the 198,000 homes weatherized in PY 1989 had energyefficiency improvements made to their space-heating systems. Most of these improvements involved tune-ups, during which the heating systems were cleaned, controls adjusted, and filters replaced. Heating system component retrofits were completed in $8 \%$ of the weatherized homes. These retrofits include a variety of efficiency improvements such as vent dampers, replacement burners, and electrical or mechanical furnace ignition systems which replace standing gas pilot lights. The addition of a set-back thermostat and the replacement of an entire heating system occurred much less often.

1 The RECS statistics reported in this chapter were provided by Response Analysis Corporation. 
Finally, mobile home measures were installed by local agencies in 26,000 (i.e., 13\%) of the 198,000 homes in PY 1989. The most common of these measures, underpinning or skirting, was added to $6 \%$ of the weatherized units. Since $20 \%$ of the dwelling units weatherized in PY 1989 were mobile homes, approximately one-third of these received either underpinning or skirting. Skirting refers to the addition of material to border the bottom of a dwelling to prevent air infiltration. Underpinning refers to work done to the underbelly of a mobile home, which sometimes included repairing the bellyboard to enable foundation insulation to be added. Other mobile home measures include cool seals on roofs, which were added to $6 \%$ of the weatherized homes (Fig. 4.2), and vapor barriers, which were added to $4 \%$ of the weatherized homes.

On average, approximately 55 to $65 \%$ of the weatherization measures shown in Fig. 4.2 were installed by employees of local agencies, called "in-house crews." The reliance on crews versus contractors, however, varies by type of measure. Storm windows and general caulking and weatherstripping, for instance, were most often installed by crews. In contrast, space-heating system measures were installed by contractors in $71 \%$ of the cases. This pattern is consistent with the profile of local agency staff provided by Mihlmester, et al. (1992, p. 41). Local agencies employ very few engineers. The Mihlmester, et al. (1992) survey of 920 local agencies identified only 20.3 full-time equivalent (FTE) engineer empiuyees, or 0.02 per agency. Envelope crew and crew chiefs, in contrast, account for $34 \%$ of total FTEs, or 3.17 FTEs per local agency.

Fig. 4.3 compares the installation rates for selected weatherization mieasures between 1981 (based on Peabody, 1984, p. 21) and PY 1989. The comparisons are made only for single-family detached dwellings since that was the focus of the Peabody (1984) study. The three most dramatic changes were in the installation rates of space heating system measures, blower door-assisted air sealing, and storm windows. The 19\$1 Program did not use blower doors or install any space heating system measures, while by PY 1989 these had become established features of the Program. In contrast,

\section{Blower Doors}

Blower doors are variable-speed fans equipped with a frame and shroud that permit them to fit inside a variety of door frames. Instrumentation includes pressure gauges that enable the operator to determine the flow of air through the fan as well as the pressure the fan induces on a dwelling. Since leakier houses require higher fan speeds to induce a given pressure difference, blower doors can measure the relative leakiness of a house. When used as a diagnostic instrument, they can also reveal the locus of many leaks, thus providing a clear larget for air sealing. When the job is partially or fully complete, blower doors also provide technicians with fast feedback on the effectiveness of their work, a fact that contributes to increased practical wisdom on the part of the technicians and the overall professionalization and efficiency of the weatherization process itself.

the PY 1981 Program installed storm windows in a majority of homes, while by PY 1989 this rate had declined to $36 \%$. These trends are consistent with a growing body of research emphasizing the cost effectiveness of blower doors (see sidebar) and furnace tune-ups and retrofits and questioning the cost effectiveness of storm windows (CSR, Inc. and Meridian Curporation, 1989; Cohen, Goldman, and Harris, 1990). Caulking and weatherstripping were more prominent in 1989 than in 1981, 
although in both years air leakage measures were used in more than $90 \%$ of the weatherized homes. Finally, insulation was installed in $62 \%$ of the dwellings weatherized in 1989 (down from $81 \%$ in 1981), but the 1989 Program included much more sidewall and duct insulation than the 1981 Program.

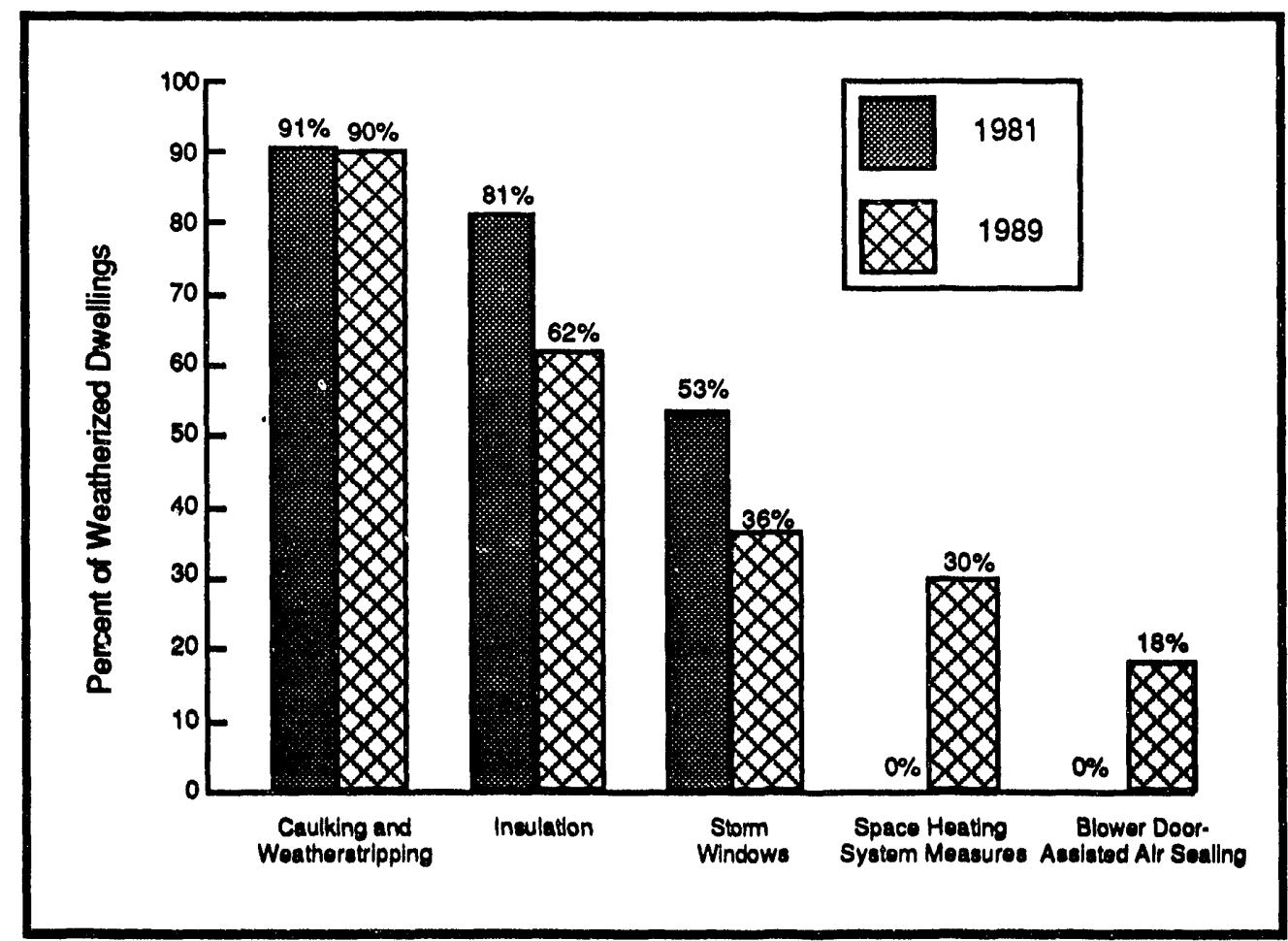

Fig. 4.3 Installation Rates for Selected Weatherization Measures: 1981 and 1989.

Another interesting comparison is between DOE weatherization and utility "full-scale" weatherization programs operating in 1989. Power et al. $(1992, \mathrm{pp} .18-23)$ found that relative to DOE weatherization, utilities invested less and installed fewer energy-conservation measures in the dwelling units they weatherized.

\subsubsection{Differences across Key Subgroups}

The package of energy-efficiency measures installed during a particular weatherization job typically is determined by an audit or some other prioritization procedure (see Section 4.2). Inputs to these procedures often include factors such as the dwelling's prior level of energy consumption, type of heating system, and structural characteristics. Most of these factors differ by climate region, primary heating fuel, and type of dwelling. As a result, we would expect installation rates for specific measures to vary significantly across the program's major subgroups. This is shown to be the case in the following tables and paragraphs. 
Differences Across Climate Regions. Table 4.1 shows dramatic differences across climate regions. In the cold climate region, insulation, water heater, and space heating system measures are installed at notably higher rates than for the program as a whole. In addition, air sealing with the

Table 4.1 Instailation of Weatherization Measures, by Climate Region (weighted percentages) ${ }^{1}$

\begin{tabular}{|c|c|c|c|c|}
\hline & $\begin{array}{l}\text {. Totall: } \\
\text { Sample: } \\
(\mathrm{N}=14.971)\end{array}$ & $\begin{array}{c}\text { Cold } \\
\text { Climate Region } \\
(\mathrm{N}=4,690)\end{array}$ & $\begin{array}{l}\text { Moderate } \\
(\mathrm{N}=7238\end{array}$ & Climate Region. \\
\hline 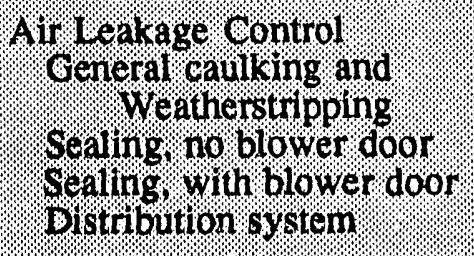 & $\begin{array}{r}95.2 \\
90.1 \\
22.9 \\
18.3 \\
6.8\end{array}$ & $\begin{array}{r}95.3 \\
81.3 \\
24.2 \\
35.5 \\
6.5\end{array}$ & $\begin{array}{r}96.9 \\
93.1 \\
28.7 \\
19.0 \\
8.6\end{array}$ & $\begin{array}{r}90.5 \\
90.1 \\
6.1 \\
1.4 \\
2.2\end{array}$ \\
\hline Insuiction & $\begin{array}{l}61.9 \\
28.0 \\
19.9 \\
19.3 \\
13.7 \\
12.3\end{array}$ & $\begin{array}{l}74.2 \\
20.3 \\
32.5 \\
24.9 \\
22.1 \\
15.7\end{array}$ & $\begin{array}{l}63.6 \\
28.7 \\
19.5 \\
24.3 \\
16.1 \\
13.0\end{array}$ & $\begin{array}{r}46.4 \\
32.8 \\
10.2 \\
1.1 \\
0.2 \\
7.2\end{array}$ \\
\hline 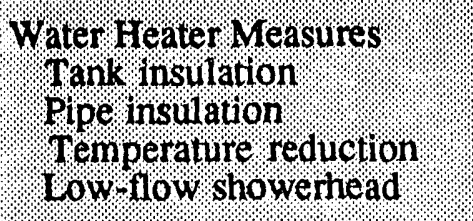 & $\begin{array}{r}56.0 \\
40.1 \\
34.1 \\
12.7 \\
8.4\end{array}$ & $\begin{array}{l}65.8 \\
48.7 \\
44.6 \\
11.2 \\
16.9\end{array}$ & $\begin{array}{r}62.9 \\
44.8 \\
39.6 \\
17.2 \\
6.8\end{array}$ & $\begin{array}{r}29.2 \\
20.2 \\
10.5 \\
2.0 \\
5.4\end{array}$ \\
\hline Windours and Doors. & $\begin{array}{l}42.3 \\
36.3\end{array}$ & $\begin{array}{l}35.4 \\
26.9\end{array}$ & $\begin{array}{l}45.3 \\
39.5\end{array}$ & $\begin{array}{l}40.2 \\
36.2\end{array}$ \\
\hline $\begin{array}{l}\text { Space Heating System } \\
\text { = coan and tune up } \\
\text { Coment retrofit }\end{array}$ & $\begin{array}{r}29.8 \\
22.2 \\
8.0\end{array}$ & $\begin{array}{r}35.5 \\
21.3 \\
5.3\end{array}$ & $\begin{array}{l}37.7 \\
30.4 \\
11.7\end{array}$ & $\begin{array}{l}3.7 \\
1.4 \\
0.5\end{array}$ \\
\hline $\begin{array}{l}\text { Moblle Home Measures } \\
\text { : Underpinning or skirting } \\
\text { Cool seal on roof }\end{array}$ & $\begin{array}{r}13.0 \\
6.3 \\
5.6\end{array}$ & $\begin{array}{r}10.5 \\
2.1 \\
4.5\end{array}$ & $\begin{array}{r}10.0 \\
3.5 \\
4.7\end{array}$ & $\begin{array}{r}23.2 \\
17.6 \\
9.0\end{array}$ \\
\hline
\end{tabular}

1 Values in the table are the percent of dwellings in which a measure was installed. All of the weatherization measures differ significantly across climate regions, at the 0.001 level, based on Chi-square tests. The table is limited to measures that were installed in at least $5 \%$ of the homes weatherized during PY 1989. 
assistance of blower doors was used to control air leakage in more than one-third of the cold region's weatherized homes compared with $18 \%$ nationwide. In contrast, mobile home measures were installed in only $11 \%$ of the weatherized homes located in the cold region (vs $13 \%$ nationwide and $23 \%$ in the hot climate region). This is despite the fact that $21 \%$ of the dwellings weatherized in the cold region were mobile homes, which is slightly higher than the nationwide average. Storm windows and doors and replacement windows and doors also were installed infrequently in this region relative to the nationwide rates.

In the moderate climate region, all of the major types of weatherization measures except for mobile home measures were installed at higher than average rates, particularly water heater measures, storm windows, and space heating system measures. Air leakage control was installed in $97 \%$ of the jobs in this region, a slightly higher percentage than in the other two regions. However, the use of air sealing emphasizing bypasses with blower door testing is notably less common in the moderate climate region than in the cold region.

The hot region is the most distinct of the three climate regions in terms of installation rates. Very few space heating system measures were installed in PY 1989 (i.e., in 2\% of the dwellings), and water heater measures were installed in only $29 \%$ of the weatherized dwellings, compared with nearly twice that rate $(56 \%)$ nationwide. Insulation and air leakage control measures also were installed relatively less often in the hot region. Wall insulation, in particular, was installed in only $1 \%$ of the homes in this region, compared with $25 \%$ and $24 \%$ in the cold and moderate regions, respectively. On the other hand, mobile home measures were installed in one quarter of the weatherized homes. This far exceeds the installation rate of the other regions, even when the hot region's greater than average proportion of weatherized mobile homes is taken into account. The hot region installed storm windows and doors at approximately the nationwide average, but it installed many more replacement doors (58\%) and windows (46\%) than the other two regions (see Table F.1).

Differences Across Heating Fuels. Table 4.2 documents installation rates for three types of heating fuels. Differences across fuel types are important because of this study's need to extrapolate energy savings from measured fuel use (for natural gas and electricity) to other fuels. To the extent that the weatherization jobs are different for dwellings heated by "other" fucls, the savings based on gas and electric dwellings must be adjusted to reflect the entire program's energy savings in singlefamily and small multifamily dwellings.

Weatherized dwellings heated primarily with natural gas have significantly higher than average rates of installation for four of the six types of weatherization measures shown in Table 4.2. Installation rates for insulation, water heater measures, and space heating system measures are particularly high. Window and door treatments are slightly less common in gas-heated weatherized homes, and mobile home measures are significantly less common. The latter is consistent with the fact that few mobile homes heat with natural gas. 
The profile for weatherized dwellings heated primarily by electricity is very different from the profile provided above. Rates for all but one of the major categories of weatherization measures shown in Table 4.2 are lower for these dwellings than for the program as a whole. Because many space heating measures are not applicable to electric heating systems, there is less potential for their use. Thus, electrically heated dwellings cannot use what is commonly believed to be one of the more

Table 4.2 Installation of Weatherization Measures, by Primary Heating Fuel (weighted percentages) ${ }^{1}$

\begin{tabular}{|c|c|c|c|}
\hline & $\begin{array}{l}\text { Natural Gas } \\
(\mathrm{N}=9,161)\end{array}$ & $\begin{array}{l}\text { Electricity } \\
(N=1,325)\end{array}$ & $(\mathrm{N}=4,113)$ \\
\hline $\begin{array}{l}\text { Air Leakage Control } \\
\text { General caulking and weatherstripping } \\
\text { Sealing, no Blower door } \\
\text { Sealing, with blower door } \\
\text { Distribution systen }\end{array}$ & $\begin{array}{r}96.4 \\
91.4 \\
26.8 \\
20.0 \\
7.7\end{array}$ & $\begin{array}{r}89.2 \\
84.9 \\
16.8 \\
17.4 \\
2.6\end{array}$ & $\begin{array}{r}95.3 \\
90.1 \\
19.3 \\
16.5 \\
6.6\end{array}$ \\
\hline $\begin{array}{l}\text { Insulation } \text { Atic insulation, first time } \\
\text { Attic insulation, added } \\
\text { Wail insulation, normal : } \\
\text { Rim/band oint ins. } \\
\text { Floor insulation }\end{array}$ & $\begin{array}{l}67.2 \\
32.1 \\
19.8 \\
25.3 \\
16.1 \\
10.3\end{array}$ & $\begin{array}{r}49.4 \\
13.7 \\
22.8 \\
8.8 \\
5.3 \\
16.4\end{array}$ & $\begin{array}{l}58.2 \\
25.9 \\
19.5 \\
14.0 \\
12.6 \\
13.7\end{array}$ \\
\hline $\begin{array}{l}\text { Water Heater Measures } \\
\text { Tank insulation } \\
\text { Pipe insulation } \\
\text { Temperature reduction } \\
\text { Low flow showerhead }\end{array}$ & $\begin{array}{r}63.3 \\
48.1 \\
38.0 \\
16.2 \\
7.6\end{array}$ & $\begin{array}{r}52.3 \\
37.5 \\
28.0 \\
8.4 \\
7.9\end{array}$ & $\begin{array}{r}49.9 \\
30.7 \\
30.6 \\
9.2 \\
9.6\end{array}$ \\
\hline $\begin{array}{l}\text { Windows and Doors } \\
\text { Storn window(s) }\end{array}$ & $\begin{array}{l}39.6 \\
33.8\end{array}$ & $\begin{array}{l}39.3 \\
34.2\end{array}$ & $\begin{array}{l}46.3 \\
40.0\end{array}$ \\
\hline $\begin{array}{l}\text { Space Heating System } \\
\text { Clean and tune-up. } \\
\text { Component retrofit }\end{array}$ & $\begin{array}{l}36.0 \\
28.4 \\
10.4\end{array}$ & $\begin{array}{l}7.9 \\
4.2 \\
1.9\end{array}$ & $\begin{array}{r}27.1 \\
18.6 \\
6.3\end{array}$ \\
\hline $\begin{array}{l}\text { Mobile Home Measures } \\
\text { " Conderpinning or skirting }\end{array}$ & $\begin{array}{l}6.4 \\
2.6 \\
2.6\end{array}$ & $\begin{array}{r}19.1 \\
10.4 \\
8.0\end{array}$ & $\begin{array}{r}19.9 \\
10.1 \\
8.9\end{array}$ \\
\hline
\end{tabular}

1 Values in the table are the percent of dwellings in which a measure was installed. All of the weatherization measures differ significantly across fuel types, at the 0.001 level, based on Chisquare tests. The table is limited to measures that were installed in at least $5 \%$ of the homes weatherized during PY 1989. There are 372 missing observations. 
cost-effective measures. The one major category of measure that is installed in greater frequency in electrically heated homes is mobile home measures, which were installed in $19 \%$ of the weatherized dwellings heated by electricity. This is consistent with the fact that a relatively high proportion of mobile homes are electrically heated. Within the major category of insulation, added attic insulation and floor insulation also were installed at slightly higher rates in these dwellings. The low installation rate for first-time attic insulation reflects the relative newness of the electrically heated housing stock, which has more attic insulation in place when the weatherization crews arrive.

Installation rates for dwellings heated with "other" fuels are generally close to the nationwide averages, and are more similar to the rates for gas-heated, than for electrically heated dwellings. Modest differences include: a slightly higher than average rate of installation of mobile home measures and storm windows and doors, and a slightly lower than average rate of installation of water heater measures.

Differences Across Dwelling Types. Table 4.3 shows the diversity of weatherization measures installed in different types of dwellings. Many of these differences reflect the Program's objective of installing measures that reflect the most cost-effective opportunities available for a particular dwelling.

Single-family detached homes have higher than average installation rates for insulation and air leakage control. Rates of attic insulation are particularly high. Based on the installation rate for attic insulation/first time, we can deduce that more than one-third of the single-family detached homes weatherized in PY 1989 were without attic insulation prior to participation in the program. In contrast, single-family detached homes have the lowest installation rates for space heating measures.

More than half of the mobile homes weatherized in PY 1989 had one or more specific mobile home measures installed (e.g., skirting or cool seal on roof), distinguishing this dwelling type from single-family and small multifamily dwellings. Mobile homes also had a relatively high installation rate for storm windows. On the other hand, insulation was installed in fewer than one-fifth of the weatherized mobile homes compared with a programwide average of $62 \%$. When insulation was installed in mobile homes, it was most often used to insulate the floors.

Single-family attached hcines are distinguished by the high rate of space heating system improvements $(62 \%)$ and storm h'indows $(57 \%)$ provided by the Program. Wall insulation is uncommon in these dwellings, but attic insulation is added for the first time to $40 \%$ of them (compared with $28 \%$ programwide).

Small multifamily dwellings offer yet one more distinct profile of weatherization activities. Water-heater measures are installed with greatest frequency in these dwellings, particularly pipe insulation. Storm windows and doors also are installed at notably higher than average rates in small multifamily dwellings. 
Table 4.3 Installation of Weatherization Measures, by Dwelling Type (weighted percentages) ${ }^{1}$

\begin{tabular}{|c|c|c|c|c|}
\hline & $\begin{array}{l}\text { Single-family } \\
\text { Detached } \\
(\mathrm{N}=9,445)\end{array}$ & $\begin{array}{l}\text { Mobile } \\
\text { Home } \\
(\mathrm{N}=2,760)\end{array}$ & $\begin{array}{l}\text { Single-family } \\
\text { Attached } \\
(\mathrm{N}=570)\end{array}$ & $\begin{array}{l}\text { Small } \\
\text { Muitifamily } \\
(\mathrm{N}=2,074)\end{array}$ \\
\hline 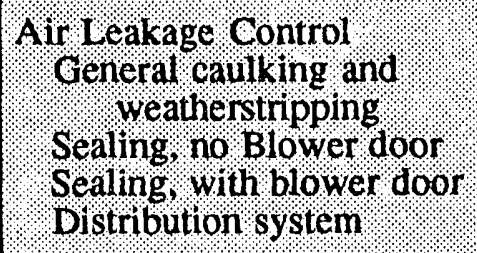 & $\begin{array}{r}96.8 \\
92.3 \\
23.0 \\
20.0 \\
6.2\end{array}$ & $\begin{array}{r}91.4 \\
86.7 \\
20.9 \\
16.3 \\
8.1\end{array}$ & $\begin{array}{r}97.6 \\
84.7 \\
29.1 \\
10.9 \\
5.7\end{array}$ & $\begin{array}{r}94.5 \\
87.9 \\
24.0 \\
14.5 \\
7.5\end{array}$ \\
\hline 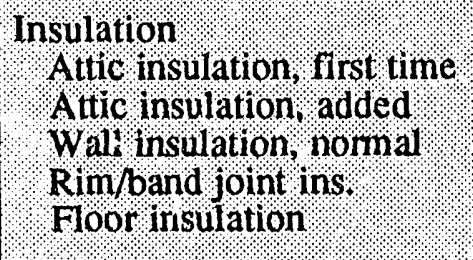 & $\begin{array}{l}75.3 \\
36.0 \\
27.0 \\
24.4 \\
16.8 \\
13.3\end{array}$ & $\begin{array}{r}20.1 \\
2.4 \\
3.2 \\
1.5 \\
1.2 \\
13.4\end{array}$ & $\begin{array}{r}58.5 \\
39.9 \\
13.2 \\
1.9 \\
15.8 \\
4.7\end{array}$ & $\begin{array}{r}61.0 \\
23.3 \\
13.1 \\
25.9 \\
17.2 \\
7.4\end{array}$ \\
\hline $\begin{array}{l}\text { Water Heater Measures } \\
\text { Tank insulation } \\
\text { Pipe insulation } \\
\text { Temperature reduction } \\
\text { Low-flow showerhead }\end{array}$ & $\begin{array}{r}58.5 \\
41.6 \\
36.6 \\
13.0 \\
7.6\end{array}$ & $\begin{array}{l}47.9 \\
32.9 \\
20.5 \\
10.0 \\
11.1\end{array}$ & $\begin{array}{r}53.0 \\
45.7 \\
25.3 \\
3.4 \\
2.8\end{array}$ & $\begin{array}{r}65.1 \\
43.4 \\
45.9 \\
17.2 \\
9.7\end{array}$ \\
\hline $\begin{array}{l}\text { Windows and Doors } \\
\text { Storn window(s) }\end{array}$ & $\begin{array}{l}38.2 \\
32.2\end{array}$ & $\begin{array}{l}49.8 \\
43.7\end{array}$ & $\begin{array}{l}58.5 \\
56.6\end{array}$ & $\begin{array}{l}47.5 \\
41.0\end{array}$ \\
\hline $\begin{array}{l}\text { Space Heating System } \\
\text { Clean ond tune-up } \\
\text { Component retrofit }\end{array}$ & $\begin{array}{r}28.2 \\
20.8 \\
8.4\end{array}$ & $\begin{array}{r}29.6 \\
22.3 \\
5.6\end{array}$ & $\begin{array}{l}61.6 \\
54.0 \\
18.9\end{array}$ & $\begin{array}{r}30.5 \\
21.8 \\
6.5\end{array}$ \\
\hline $\begin{array}{l}\text { Mobile Home Measures } \\
\text { Underpinning or skinting } \\
\text { Cool seal on roof }\end{array}$ & $\begin{array}{l}2.8 \\
1.9 \\
0.3\end{array}$ & $\begin{array}{l}55.8 \\
25.6 \\
27.1\end{array}$ & $\begin{array}{l}0.3 \\
0.0 \\
0.0\end{array}$ & $\begin{array}{l}0.2 \\
0.2 \\
0.0\end{array}$ \\
\hline
\end{tabular}

1 Values in the table are the percent of dwellings in which a measure was installed. All of the weatherization measures differ significantly across dwelling types, based on Chi-square tests. The table is limited to measures that were installed in at least $5 \%$ of the homes weatherized during PY 1989. There are 122 missing observations.

Differences Across Agency Sizes. Small, medium, and large agencies are distinct in terms of the frequency with which they install different weatherization measures (Table 4.4). 
Table 4.4 Installation of Weatherization Measures, by Size of Local Agency (weighted percentages) ${ }^{1}$

\begin{tabular}{|c|c|c|c|}
\hline & $\begin{array}{c}\text { Small } \\
(\mathrm{N}=1,870)\end{array}$ & $\underset{(N=8,494)}{\text { Medium }}$ & $\begin{array}{c}\text { Large } \\
(\mathrm{N}=4,607)\end{array}$ \\
\hline $\begin{array}{l}\text { A ir Leakage Control } \\
\text { General caulking and weatherstripping } \\
\text { Sealing, no blower door } \\
\text { Sealing, with blower door } \\
\text { Distribution system }\end{array}$ & $\begin{array}{r}93.4 \\
92.0 \\
21.7 \\
10.5 \\
7.0\end{array}$ & $\begin{array}{r}95.5 \\
90.9 \\
23.9 \\
17.6 \\
7.2\end{array}$ & $\begin{array}{r}95.4 \\
86.3 \\
20.5 \\
26.5 \\
5.2\end{array}$ \\
\hline $\begin{array}{l}\text { Insulation } \\
\text { Attic insulation, first time } \\
\text { Attic insulation, added } \\
\text { Wall insulation, normal } \\
\text { Rim/band joint ins. } \\
\text { Floor insulation }\end{array}$ & $\begin{array}{r}59.5 \\
32.4 \\
18.2 \\
12.0 \\
4.7 \\
13.3\end{array}$ & $\begin{array}{l}61.2 \\
26.1 \\
20.6 \\
19.8 \\
13.8 \\
13.6\end{array}$ & $\begin{array}{r}65.7 \\
30.1 \\
19.0 \\
22.7 \\
19.8 \\
7.5\end{array}$ \\
\hline $\begin{array}{l}\text { Water Heater Measures } \\
\text { Tank insulation } \\
\text { Pipe insulation } \\
\text { Temperature reduction } \\
\text { Low-flow showerhead }\end{array}$ & $\begin{array}{r}45.1 \\
32.0 \\
20.7 \\
11.9 \\
3.3\end{array}$ & $\begin{array}{r}56.8 \\
40.5 \\
33.3 \\
12.4 \\
9.9\end{array}$ & $\begin{array}{r}65.3 \\
44.8 \\
46.2 \\
13.8 \\
7.7\end{array}$ \\
\hline $\begin{array}{l}\text { Windows and Doors } \\
\text { Stom window(s) }\end{array}$ & $\begin{array}{l}42.3 \\
37.4\end{array}$ & $\begin{array}{l}42.8 \\
36.2\end{array}$ & $\begin{array}{l}40.5 \\
35.6\end{array}$ \\
\hline $\begin{array}{l}\text { Space Heating System } \\
\text { Clean and tune-up } \\
\text { Component retrofit }\end{array}$ & $\begin{array}{r}19.6 \\
14.4 \\
4.0\end{array}$ & $\begin{array}{r}29.7 \\
21.8 \\
6.7\end{array}$ & $\begin{array}{l}37.1 \\
28.9 \\
14.2\end{array}$ \\
\hline $\begin{array}{l}\text { Mobile Home Measures } \\
\text { Underpinning or skirting } \\
\text { Cool seal on roof }\end{array}$ & $\begin{array}{r}17.6 \\
10.4 \\
7.4\end{array}$ & $\begin{array}{r}14.2 \\
7.0 \\
6.3\end{array}$ & $\begin{array}{l}6.0 \\
1.4 \\
2.1\end{array}$ \\
\hline
\end{tabular}

1 Values in the table are the percent of dwellings in which a measure was installed. All of the weatherization measures differ significantly across agency sizes, at the 0.001 level, based on Chisquare tests. The table is limited to measures that were installed in at least $5 \%$ of the homes weatherized during PY 1989.

Since the hot climate region has a high proportion of those agencies that weatherized 100 or fewer dwellings during PY 1989, the installation pattems of these two subgroups (hot climate region and small agencies) are similar. Small agencies tend to rely on more traditional measures - general caulking and weatherstripping, storm windows, and attic insulation, which is added typically for the first time. The air sealing conducted by small agencies is rarely assisted by blower doors, and space 
heating measures, water heater wraps, and wall and rim/band joint insulation are relatively uncommon. Mobile home measures were installed in $18 \%$ of the dwellings weatherized by small agencies in PY 1989 - a rate that is three times higher than large agencies. This reflects the more rural territory served by small agencies, and the greater incidence of mobile homes among the rural poor.

Large agencies (those that weatherized 400 or more dwellings during PY 1989) have many of the opposite characteristics. Their air sealing is often assisted by blower doors (in $27 \%$ of the homes they weatherized), and space heating measures, water heater measures, and wall and rim/band joint insulation are installed at relatively high rates. Mobile home measures are rarely installed. This profile of measures reflects the more urban northern nature of the housing stock served by large agencies.

Medium-sized agencies tend to install weatherization measures at rates that are typical of the Program as a whole, ranging somewhere between the installation rates of small and large agencies. This is not surprising since medium-sized agencies account for more than half of the dwellings weatherized in PY 1989.

\subsection{SERVICE DELIVERY PROCEDURES}

The diversity and complexity of weatherization procedures has increased dramatically over the past decade. While many agencies still select their clients on a first come-first served basis, others target those clients with greater-than-average potential for cost-effective energy savings based on indicators such as pre-weatherization energy use. Similarly, investment critcria have been developed that deviate from uniform expenditures per house to allow larger investments in dwellings that offer greater energy-savings opportunities. Program implementers now have a large menu of diagnostic tools to help guide their weatherization choices. In addition, the Program permits the use of a variety of home energy audit procedures for selecting weatherization measures and services. These allow measures to be better targeted to the specific needs of an individual dwelling than occurs when priority or prescribed lists are used. Because of the impact of occupant behavior upon energy consumption, client education has become an integral part of many state and local Weatherization Assistance Programs. Finally, quality control has gone beyond visual inspections during monitoring visits, to include sophisticated measurement and diagnostic procedures.

Because of the newness of many of these service delivery procedures, their impact on energy savings and cost effectiveness is unclear. Nevertheless, many experts believe that these newer, more advanced practices can improve program performance (Schlegel and Pigg, 1990; CSR, Inc. and Meridian Corporation, 1989; Cohen, Goldman, and Harris, 1990; Greeley, Randolph, and Hill, 1992). The following sections examine the extent to which various service delivery procedures were employed by the Program during PY 1989. 


\subsubsection{Frequency of Use of Different Service Delivery Procedures}

The Single-Family Study's Dwelling-Specific Form requested detailed information about the service delivery procedures used for each of the sampled weatherized dwellings (see Appendix B-3). In addition, the survey of local agencies conducted by Mihlmester, et al. (1992) provides a great deal of agency-specific data about service delivery approaches. Information on a selection of service delivery procedures was abstracted from these two data sources for use in this section's description of weatherization procedures and in later analyses of factors influencing energy savings and cost effectiveness (Chapters 9 and 10). These selected procedures are liste $f$ in Fig. 4.4.2 These procedures were judged likely to be able to discriminate between high and low performance. In particular, it is hypothesized that the use of a priority or prescribed list to select weatherization measures is associated with low energy savings and cost effectiveness, since the needs of specific dwellings may be overlooked when applying the standardized guidance of a single list. All of the other procedures shown in Fig. 4.4 are expected to be associated with high energy savings and cost effectiveness.

Highly innovative or uncommon procedures such as infrared scanning and smoke sticks are not discussed in this section because they are not employed with sufficient frequency for the SingleFamily Study to identify a statistical impact upon performance. However, numerous innovative procedures are described in Mihlmester, et al. (1992, chapter 6), and some of these are revisited in the second part of this study when we profile the procedures used to weatherize high-performing dwellings.

During PY 1989, a majority of local agencies used at least one method of distributing weatherization resources across eligible clients to maximize the energy saved per invested dollar (Mihlmester, et al., 1992, Fig. 6.2, p. 75). Nearly one-quarter (23\%) of the dwellings weatherized in PY 1989 were selected based on estimated savings or energy use (energy use being a typical indicator of potential energy savings). The level of investment in 51\% of the PY 1989 weatherized dwellings was based on estimated energy savings per dollar spent; for $36 \%$ of the weatherized dwellings, investment level was based on energy use or estimated savings. Such procedures were rarely used by the Program during the early 1980's.

2 Data for the three client selection and investment criteria and the two client education methods shown in Fig. 4.4 were derived from the Mihlmester et al. (1992) data base. A particular dwelling unit was assigned a value of " 1 " for a particular procedure if the local WAP agency indicated that it used the procedure in $50 \%$ or more of the dwellings it weatherized during PY 1989. Otherwise the assigned value was " 0. " 


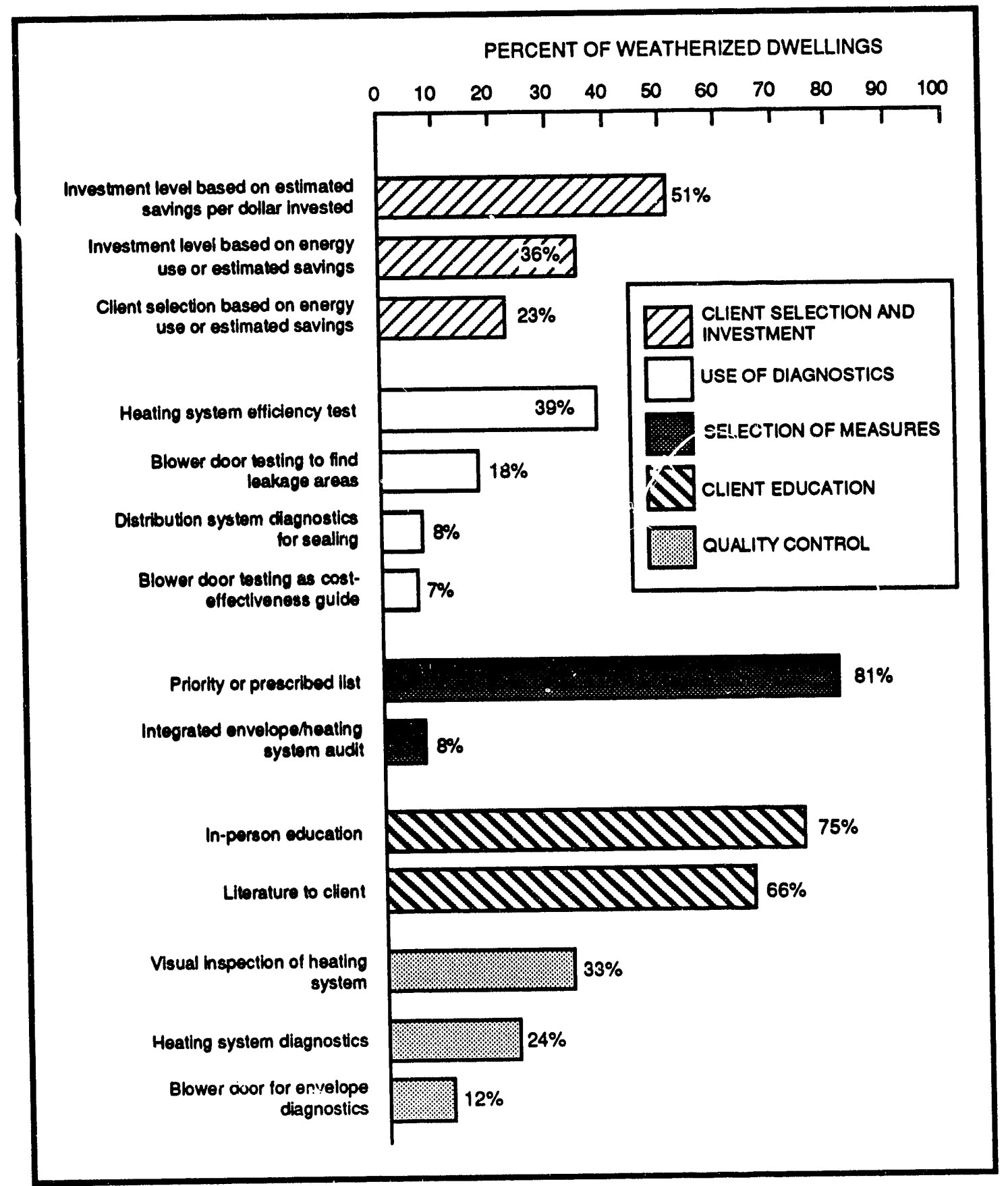

Fig. 4.4 Frequency of Use of Selected Service Delivery Procedures.

A variety of diagnostic proceduses were used by the Program in PY 1989 to guide the weatherization wo-k. Heating system efficiency tests were conducted in $39 \%$ of the weatherized dwellings. Blower door testing was done in $18 \%$ of the weatherized dwellings to find leakage areas, and in $7 \%$ of the dwellings to estimate when further air leakage control ceased to be cost-effective. Distribution system diagnostics were conducted in $8 \%$ of the dwellings to find leakage areas for sealing. 
Priority or prescribed lists were still the dominant method of selecting weatherization measures in PY 1989, although less so than in 1981. The vast majority of dwellings weatherized in PY $1989(81 \%)$ had measures installed based on such prescribed recommendations. Of the local agencies surveyed by Mihlmester, $c \mathfrak{a l}$ al. (1992, Fig. 6.2, p. 75), 28\% indicated that in PY 1989 they used an integrated audit to select measures - that is, they used a single audit approach to select envelope and space heating system measures, thereby accounting for the interdependencies of these two types of energy-saving measures. On a house-by-house basis, however, the Single-Family Study's data indicate that during PY 1989 , only $8 \%$ of the weatherized homes were subjected to an integrated audit.

Client education has become a mainstay of the Program. In 1981, the Program was only beginning to recognize the critical role of occupant behavior and the potential for client education to save energy. By PY 1989, the vast majority of participants in the Program were provided with either in-person education (75\%) or literature on how to conserve energy and reduce utility bills (66\%). Some agencies have extensive client education programs involving additional activities such as video

tapes and workshops. Most agencies, however, limit their education to a one-on-one discussion with the client of energy-saving opportunities, accompanied by a pamphlet, flyer, or other literature.

Some of the same diagnostics that have become important means of directing the installation of weatherization measures also are now used as quality control methods to judge the caliber of the completed job. Nearly one-quarter of the dwellings weatherized during PY 1989 were subjected to heating system diagnostics as a quality control indicator. Tweive percent were blower door tested to diagnose the level of air leakage after weatherization. In addition, visual inspections of heating systems were common ( $33 \%$ of dwellings).

\subsubsection{Differences Across Key Subgroups}

The service delivery procedures used by local agencies during PY 1989 varied markedly across climate regions (Table 4.5), primary heating fuels (Table 4.6), types of dwellings (Table 4.7), and agency size (Table 4.8).

Differences Across Climate Regions. The cold climate zone used the most rigorous methods for selecting clients, determining investment levels, and selecting measures. For instance, $43 \%$ of their clients were selected based on energy use or estimated savings, and more than one-quarter of the weatherized dwellings underwent an integrated envelope/heating system audit. Homes weatherized in the cold region also often underwent heating system efficiency tests, reflecting this region's focus on space heating retrofits. Blower door testing was used more often in this climate than in the other two climate regions to identify leakage areas (37\% of the homes), as a cost-effectiveness guide (18\%), and 
in monitoring the completed work (17\%). In-person education was provided to $78 \%$ of this region's PY 1989 clients, but only 54\% were provided literature on energy-efficiency measures.

Table 4.5 Selected Service Delivery Procedures, by Climate Region (weighted percentages) ${ }^{1}$

\begin{tabular}{|c|c|c|c|c|}
\hline , & Total Sample & $\begin{array}{l}\text { Cold } \\
\text { Climate Region } \\
(\mathrm{N}=4,690)\end{array}$ & $\begin{array}{l}\text { Moderate } \\
\text { Climate Region } \\
(\mathrm{N}=7,238)\end{array}$ & $\begin{array}{l}\text { Hot } \\
\text { Climate Region } \\
(\mathrm{N}=3,043)\end{array}$ \\
\hline $\begin{array}{l}\text { Cient Selection and Investment } \\
\text { Investment level based on } \\
\text { estimated savings per } \\
\text { dollar invested } \\
\text { Investment level based on } \\
\text { energy use or estimated } \\
\text { cavings } \\
\text { elient selection based on } \\
\text { savings use or estimated }\end{array}$ & $\begin{array}{l}51.3 \\
36.4 \\
23.3\end{array}$ & $\begin{array}{l}56.2 \\
37.7 \\
42.6\end{array}$ & $\begin{array}{l}49.4 \\
31.4 \\
15.0\end{array}$ & $\begin{array}{l}51.8 \\
49.7 \\
28.7\end{array}$ \\
\hline $\begin{array}{l}\text { Use of Diagnostics } \\
\text { Heating system } \\
\text { efficiency test } \\
\text { Blower door testing to } \\
\text { find leakage areas } \\
\text { Distribution system } \\
\text { diagnostics for sealing } \\
\text { Blower door testing as } \\
\text { cost-effectiveness guide }\end{array}$ & $\begin{array}{r}39.3 \\
18.2 \\
7.9 \\
7.7\end{array}$ & $\begin{array}{r}40.0 \\
37.1 \\
7.4 \\
18.3\end{array}$ & $\begin{array}{r}53.8 \\
18.4 \\
9.1 \\
7.0\end{array}$ & $\begin{array}{l}0.6 \\
1.1 \\
5.2 \\
0.0\end{array}$ \\
\hline $\begin{array}{l}\text { Selection of Measures } \\
\text { Priority or prescribed list } \\
\text { Integrated envelope/heating } \\
\text { system audit }\end{array}$ & $\begin{array}{r}81.3 \\
8.3\end{array}$ & $\begin{array}{l}67.2 \\
28.2\end{array}$ & $\begin{array}{r}80.7 \\
4.5\end{array}$ & $\begin{array}{r}95.1 \\
0.8\end{array}$ \\
\hline $\begin{array}{l}\text { Client Education } \\
\text { In-person education } \\
\text { Literature to client }\end{array}$ & $\begin{array}{l}75.0 \\
65.9\end{array}$ & $\begin{array}{l}77.9 \\
53.7\end{array}$ & $\begin{array}{l}71.9 \\
72.5\end{array}$ & $\begin{array}{l}80.8 \\
59.7\end{array}$ \\
\hline $\begin{array}{l}\text { Quality Control } \\
\text { Visual inspection of } \\
\text { heating system } \\
\text { Heating system diagnostics } \\
\text { Blower door for envelope } \\
\text { diagnostics }\end{array}$ & $\begin{array}{l}33.0 \\
24.3 \\
11.8\end{array}$ & $\begin{array}{l}32.8 \\
17.2 \\
17.2\end{array}$ & $\begin{array}{l}43.9 \\
35.9 \\
13.4\end{array}$ & $\begin{array}{l}4.4 \\
0.0 \\
2.9\end{array}$ \\
\hline
\end{tabular}

1 Values in the table are the percent of dwellings in which a measure was installed. All service delivery procedures differ significantly across climate regions, at the 0.001 level, based on Chisquare tests. This table is limited to measures that were installed in at least $5 \%$ of the homes weatherized during PY 1989. 
Table 4.6 Selected Service Delivery Procedures, by Primary Heating Fuel (weighted percentages) ${ }^{1}$

\begin{tabular}{|c|c|c|c|}
\hline & $\begin{array}{l}\text { Natural Gas } \\
(\mathrm{N}=9,161)\end{array}$ & $\begin{array}{l}\text { Electricity } \\
(N=1,325)\end{array}$ & $\begin{array}{c}\text { Other } \\
(\mathrm{N}=4,113)\end{array}$ \\
\hline 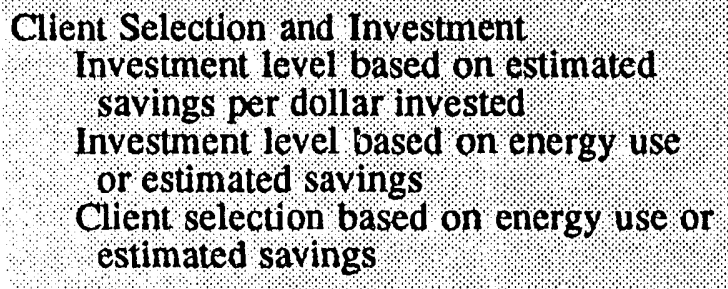 & $\begin{array}{l}52.6 \\
29.7 \\
20.4\end{array}$ & $\begin{array}{l}50.6 \\
42.7 \\
28.9\end{array}$ & $\begin{array}{l}49.8 \\
42.9 \\
25.7\end{array}$ \\
\hline $\begin{array}{l}\text { Use of Diagnostics } \\
\text { Heating system efficiency test : } \\
\text { Blower door testing to find leakage } \\
\text { areas } \\
\text { Distribution system diagnostics for } \\
\text { sealing } \\
\text { Blower door testing as cost? } \\
\text { effectiveness guide }\end{array}$ & $\begin{array}{r}47.1 \\
19.4 \\
8.7 \\
8.4\end{array}$ & $\begin{array}{r}13.0 \\
18.4 \\
5.2 \\
5.8\end{array}$ & $\begin{array}{r}35.9 \\
16.6 \\
7.3 \\
7.2\end{array}$ \\
\hline $\begin{array}{l}\text { Selection of Measures } \\
\text { Priority or prescribed list } \\
\text { Integrated envelope/heating } \\
\text { system audit }\end{array}$ & $\begin{array}{r}76.8 \\
8.8\end{array}$ & $\begin{array}{r}87.0 \\
4.6\end{array}$ & $\begin{array}{r}85.4 \\
8.3\end{array}$ \\
\hline $\begin{array}{l}\text { Client Education } \\
\text { In-person education } \\
\text { Literature to client }\end{array}$ & $\begin{array}{l}69.5 \\
66.4\end{array}$ & $\begin{array}{l}80.5 \\
66.5\end{array}$ & $\begin{array}{l}80.6 \\
65.1\end{array}$ \\
\hline $\begin{array}{l}\text { Quality Control } \\
\text { Visual inspection of heating system } \\
\text { Heating system diagnostics } \\
\text { Blower door for envelope diagnostics }\end{array}$ & $\begin{array}{l}41.1 \\
31.4 \\
12.2\end{array}$ & $\begin{array}{r}16.0 \\
8.5 \\
12.1\end{array}$ & $\begin{array}{l}26.7 \\
19.2 \\
11.1\end{array}$ \\
\hline
\end{tabular}

1 Values in the table are the percent of dwellings in which a measure was installed. All service delivery procedures differ significantly across fuel types, at the 0.001 level, based on Chi-square tests. This table is limited to measures that were installed in at least $5 \%$ of the homes weatherized during PY 1989. There are 372 missing observations. 
Table 4.7 Selected Service Delivery Procedures, by Dwelling Type (weighted percentages)'

\begin{tabular}{|c|c|c|c|c|}
\hline & $\begin{array}{l}\text { Single family } \\
\text { Detached } \\
\mathrm{N}=9+945)\end{array}$ & $\begin{array}{l}\text { Mobile } \\
(\mathrm{N}=2,760)\end{array}$ & $\begin{array}{l}\text { Single family } \\
\text { Attached } \\
(\mathrm{N}=570)\end{array}$ & $\begin{array}{c}\text { Small } \\
\text { Multifamily } \\
(\mathrm{N}=2,074)\end{array}$ \\
\hline 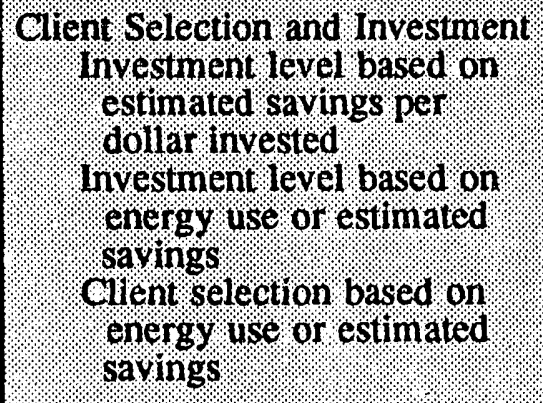 & $\begin{array}{l}51.0 \\
33.3 \\
23.0\end{array}$ & $\begin{array}{l}45.4 \\
43.5 \\
26.6\end{array}$ & $\begin{array}{l}51.9 \\
17.3 \\
30.9\end{array}$ & $\begin{array}{l}61.7 \\
45.0 \\
17.3\end{array}$ \\
\hline Use of biagnostics & $\begin{array}{r}38.9 \\
20.2 \\
7.3 \\
8.2\end{array}$ & $\begin{array}{r}34.6 \\
15.5 \\
9.1 \\
5.8\end{array}$ & $\begin{array}{r}25.2 \\
12.2 \\
3.9 \\
8.0\end{array}$ & $\begin{array}{r}53.4 \\
13.8 \\
9.6 \\
7.5\end{array}$ \\
\hline $\begin{array}{l}\text { Selection of Measures } \\
\text { Prionty or prescribed list } \\
\text { Integrated envelope/heating } \\
\text { system audit }\end{array}$ & $\begin{array}{r}82.0 \\
8.9\end{array}$ & $\begin{array}{r}83.6 \\
6.2\end{array}$ & $\begin{array}{r}83.3 \\
2.8\end{array}$ & $\begin{array}{r}74.3 \\
9.4\end{array}$ \\
\hline $\begin{array}{l}\text { Glient Education } \\
\text { in person education } \\
\text { Literature to client }\end{array}$ & $\begin{array}{l}73.2 \\
66.7\end{array}$ & $\begin{array}{l}79.7 \\
64.7\end{array}$ & $\begin{array}{l}71.2 \\
24.4\end{array}$ & $\begin{array}{l}76.7 \\
75.0\end{array}$ \\
\hline $\begin{array}{l}\text { Quality Control } \\
\text { Visual inspection of } \\
\text { heating system } \\
\text { Beating system diagnostics } \\
\text { diagnor door for envelope }\end{array}$ & $\begin{array}{l}33.3 \\
25.0 \\
13.3\end{array}$ & $\begin{array}{l}32.4 \\
21.3 \\
11.7\end{array}$ & $\begin{array}{r}24.0 \\
17.5 \\
6.7\end{array}$ & $\begin{array}{r}36.2 \\
28.8 \\
5.9\end{array}$ \\
\hline
\end{tabular}

1 Values in the table are the percent of dwellings in which a measure was installed. All service delivery procedures differ significantly across dwelling types, at the 0.001 level, based on Chisquare tests. This table is limited to measures that were installed in at least $5 \%$ of the homes weatherized during PY 1989 . There are 122 missing observations. 
Table 4.8 Selected Service Delivery Procedures, by Size of Local Agency (weighted percentages) ${ }^{1}$

\begin{tabular}{|c|c|c|c|}
\hline & $(\mathrm{N}=1,870)$ & $\begin{array}{l}\text { Medium } \\
(\mathrm{N}=8,494)\end{array}$ & $\begin{array}{c}\text { Large } \\
(\mathrm{N}=4,607)\end{array}$ \\
\hline $\begin{array}{l}\text { Client Selection and laves nent } \\
\text { Investment level based. } \text {. estimated } \\
\text { savings per dollar invested } \\
\text { Investment level based on energy use } \\
\text { or estimated savings } \\
\text { Client selection based on energy use or } \\
\text { estimated savings }\end{array}$ & $\begin{array}{l}42.8 \\
45.9 \\
30.3\end{array}$ & $\begin{array}{l}50.3 \\
34.9 \\
22.6\end{array}$ & $\begin{array}{l}59.2 \\
34.8 \\
20.9\end{array}$ \\
\hline $\begin{array}{l}\text { Use of Diagnostics } \\
\text { Heating system efficiency test } \\
\text { Blower door testing to find leakage } \\
\text { areas } \\
\text { Distribution system diagnostics for } \\
\text { sealing } \\
\text { Blower door testing as cost- } \\
\text { effectiveness guide }\end{array}$ & $\begin{array}{r}26.2 \\
11.9 \\
6.8 \\
3.4\end{array}$ & $\begin{array}{r}38.2 \\
18.0 \\
6.1 \\
7.3\end{array}$ & $\begin{array}{l}51.8 \\
23.3 \\
13.8 \\
11.7\end{array}$ \\
\hline $\begin{array}{l}\text { Selection of Measures } \\
\text { Priority or prescribed list } \\
\text { Integrated envelope/heating } \\
\text { system audit }\end{array}$ & $\begin{array}{r}86.9 \\
8.2\end{array}$ & $\begin{array}{r}81.9 \\
7.4\end{array}$ & $\begin{array}{l}74.9 \\
10.6\end{array}$ \\
\hline $\begin{array}{l}\text { Client Education } \\
\text { In-person education } \\
\text { Literature to client }\end{array}$ & $\begin{array}{l}79.4 \\
47.9\end{array}$ & $\begin{array}{l}72.7 \\
70.9\end{array}$ & $\begin{array}{l}79.3 \\
62.4\end{array}$ \\
\hline $\begin{array}{l}\text { Quality Control } \\
\text { Visual inspection of heating system } \\
\text { Heating system diagnostics } \\
\text { Blower door for envelope diagnostics }\end{array}$ & $\begin{array}{r}28.3 \\
18.9 \\
9.9\end{array}$ & $\begin{array}{l}30.2 \\
19.7 \\
10.3\end{array}$ & $\begin{array}{l}44.3 \\
41.4 \\
17.3\end{array}$ \\
\hline
\end{tabular}

1 Values in the table are the percent of dwellings in which a measure was installed. All service delivery procedures differ significantly across agency sizes, at the 0.001 level, based on Chi-square tests. This table is limited to measures that were installed in at least $5 \%$ of the homes weatherized during PY 1989.

In the moderate climate region, only $15 \%$ of the PY 1989 weatherized dwellings were selected according to an estimation of energy use or savings. Similarly, integrated audits were used in $4 \%$ of the dwellings. In contrast, the region's weatherized dwellings often benefited from the use of space heating efficiency tests both as a diagnostic procedure at the time of weatherization (54\%) and later 
as a quality control measure. This reflects the region's emphasis on space heating system measures. Blower door testing was used less often in this region than in the cold region, despite the moderate climate region's high rates of installation of air leakage control measures (97\%). Clients in the moderate climate region were most likely to receive energy-efficiency literature from their local weatherization agency.

In the hot region, client selection and investment levels often were based upon energy use or estimated savings. However, measures were selected almost exclusively according to priority or prescribed lists and not individual audits of dwellings. Similarly, few sophisticated diagnostic procedures were used, either as part of the weatherization or subsequently as part of the quality control. The relative absence of heating system diagnostics parallels this region's low level of space heating retrofits. In-person energy education was provided to $81 \%$ of the hot region's PY 1989 clients, but in-person literature was given to only $60 \%$ of the clients.

Difierences Across Heating Fuels. The frequency of use of several service delivery procedures differs markedly by primary heating fuel (Table 4.6). Not surprisingly, heating system diagnostics were rarely used in electrically heated homes during PY 1989, since most of these diagnostic procedures are not applicable to electric furnaces. Gas-heated homes, in contrast, exhibited the most frequent use of heating system diagnostics and integrated audits.

Differences Across Dwelling Types. Differences across dwelling types are also apparent (Table 4.7). In particular, heating system diagnostic procedures were used most frequently in weatherizing small multifamily dwellings: more than half of their heating systems were efficiency tested during the weatherization job, and nearly one-third underwent some form of heating system diagnostic as a quality control measure. The prevalence of these procedures can be partially explained by the slightly higher than average installation of heating system measures in 2- to 4-unit muitifamily dwellings. It also reflects the fact that small multifamily dwellings typically have centralized heating systems that serve all the units in the building. Thus, one furnace efficiency test acts as a diagnostic tool for multiple units. This dwelling type also received more energy literature at the time of weatherization than any of the cther dwelling types. Blower door testing, on the other hand, was relatively infrequent.

Differences Across Agency Sizes. Small and large agencies are distinct from the national average in their reliance on different service delivery procedures (Table 4.8). Medium-sized agencies, on the other hand, tend to follow the national average in their service delivery practices. The only notable departure from this typicality is their greater reliance on providing literature to clients to support their energy education efforts.

Small agencies rarely use blower door testing to find leakage areas, as a cost-effectiveness guide, or for quality control. The size of their weatherization budgets is probably an important 
obstacle to their purchasing expensive equipment such as blower doors. Perhaps because they perform space heating system measures with relative infrequency, they also have lower-than-average use of heating system efficiency tests, heating system diagnostics, and integrated audits. In contrast, for $87 \%$ of the dwellings they weatherized in PY 1989, they used a priority or prescribed list to select weatherization measures. The nationwide average is $81 \%$.

Large agencies make the most extensive use of blower door testing - to find leakage areas, as a cost-effectiveness guide, and for quality control. They also employ space heating system diagnostics with great frequency, including distribution system diagnostics (14\% of homes), heating system efficiency tests (52\%), heating system diagnostics (41\%), and an integrated audit (11\%).

\subsection{SUMMARY}

This chapter underscores the diversity of weatherization procedures used by each of the Program's major subgroups and the advances that have occurred over the past decade. Some of the more distinguishing features of the weatherization measures installed and the procedures used by major subgroups are summarized in Sections 4.3.1 through 4.3.3. Program trends over time are summarized in Section 4.3.4.

\subsubsection{Differences Across Climate Regions}

The findings by climate subgroup indicate that there are dramatic differences across climate regions.

- Cold climate region

- high installation rates for insulation, water heating, and space heating measures.

- low installation rates for mobile home measures, storm windows and doors, and replacement windows and doors.

- most frequent use of integrated audits and blower door testing.

- more space heating diagnostics.

- Moderate climate region

- high installation rates for storm windows, space heating measures, and air leakage control.

- most space heating diagnostics.

- most frequent dissemination of energy literature.

- Hot climate region

- low installation rates for wall insulation and space- and water-heating measures.

- high installation rates for mobile home measures and replacement windows and doors.

- least frequent use of integrated audits, blower door testing, and space heating diagnostics. 
These findings show that the cold climate region implements at higher rates the measures and procedures that recent literature suggests will produce the best results (such as advanced air sealing guided by blower door testing, space heating and water heating measures). The cold climate rision used the most rigorous methods for selecting clients, determining investment levels, and selecting measures. Homes weatherized in the cold region also often underwent heating system efficiency tests, reflecting this region's focus on space heating retrofits. Blower door testing was used more often in this climate than in the other two climate regions to identify leakage areas, as a cost-effectiveness guide, and in monitoring the completed work.

The moderate region implements more advanced measures than the hot region and fewer than the cold. Blower door testing was used less often than in the cold region, despite the region's high rates of installation of air leakage control measures.

The hot region is the most distinct of the three climate regions in terms of measure installation rates. Very few space heating system and water heater measures were installed. Insulation (especially wall insulation) and air leakage control also were installed relatively less often in the hot region. In contrast, housing rehabilitation measures, which cannot be expected to significantly lower energy usage, are emphasized most by agencies in the hot region, reflecting the more dilapidated condition of the South's housing stock. In the hot region, measures were selected almost exclusively according to priority or prescribed lists and not individual audits of dwellings. Similarly, few sophisticated diagnostic procedures were used, either as part of the weatherization or subsequently as part of the quality control. The relative absence of heating system diagnostics parallels this region's low level of space heating retrofits.

\subsubsection{Differences Across Fuel Types}

Differences across fuel types are important because of this study's need to extrapolate energy savings from measured fuel use (for natural gas and electricity) to other fuels. Differences by fuel type were less dramatic than those by climate region, but still significant. The following differences are relative to the nationwide averages.

- Gas-heated dwellings

- high installation rates for insulation, space- and water-heating measures.

- low installation rates for mobile home measures.

- most frequent use of space-heating diagnostics and integrated audits.

- Electrically heated dwellings

- high installation rates for mobile home measures.

- low installation rates for other types of weatherization measures.

- infrequent use of space-heating diagnostics and integrated audits.

- greatest emphasis on client education.

- Dwellings heated by "other" fuels 
- high installation rate for storm windows.

- low installation rate for water heater measures.

- most frequent use of blower door testing for envelope diagnostics and as a costeffectiveness guide.

Weatherized dwellings heated primarily with natural gas have significantly higher than average installation rates for insulation, water heater, and space heating system measures, heating system diagnostics, and integrated audits. Some of these differences reflect the predominance of gas heat in many of the northern States. Window and door treatments are slightly less common in gasheated weatherized homes, and mobile home measures are significantly less common. The latter is consistent with the fact that few mobile homes heat with natural gas. Homes heated with electricity and with other fuels, in contrast, are more likely to have less cffective measures, such as storm windows and mobile home measures, installed. In addition, heating system diagnostics were rarely used in electrically heated homes because many of these diagnostic procedures are not applicable to electric heating systems. Installation rates for dwellings heated with "other" fucls are generally close to the national averages, and are more similar to the rates for gas-heated, than for electrically heated dwellings.

\subsubsection{Differences Across Dwelling Types}

Some differences across dwelling types are also apparent. The following differences are relative to the nationwide averages.

- Single-family detached homes

- high installation rates for insulation, windows and doors, and air leakage control.

- low installation rates for space-heating measures.

- Mobile Homes

- high installation rates for mobile home measures and storm windows.

- low installation rates for insulation.

- Single-family attached dwellings

- high installation rates for space-heating system improvements and storm windows.

- high installation rates for attic insulation.

- low rates for wall insulation.

- Small multifamily dwellings

- high installation rates for water-heater measures and storm windows and doors.

- more heating system diagnostics.

- less blower door testing

- frequent dissemination of encrgy literature.

Unlike the cold climate region and gas-heated dwellings, no single dwelling type had a higher concentration of the measures generally believed to be most effective. The only important 
concentration of an advanced technique was in weatherizing small multifamily dwellings where heating system diagnostic procedures were used most frequently.

\subsubsection{Differences Across Agency Sizes}

The findings by agency size indicate that small and large agencies are distinct in their reliance on different service delivery procedures, while medium-sized agencies tend to be more typical in comparison to national averages. The following differences are relative to the nationwide ?'erages.

\section{- Small agencies}

- high installation rates for general caulking and weatherstripping, storm windows, and first-time attic insulation.

- low installation rates for air sealing assisted by blower doors, space heating measures, water-heater wraps, and wall and rim/band joint insulation.

- frequent installation of mobile home measures, reflecting the rural and southern location of many small agencies.

- infrequent use of blower door testing to find leakage areas, as a cost-effectiveness guide, or for quality control.

- infrequent use of heating system efficiency tests, heating system diagnostics, and integrated audits.

- reliance on priority or prescribed lists to select weatherization measures.

- Medium-sized agencies

- installation rates that are typical of the national Program.

- extensive use of literature to support their energy education efforts.

- Large agencies

- high installation rates for space-heating measures, water-heater measures, and wall and $\mathrm{rim} / \mathrm{band}$ joint insulation.

- infrequent installation of mobile home measures, reflecting the typically urban nature of the clients served by large agencies.

- greater use of blower door testing.

- frequent use of space-heating system diagnostics and integrated audits.

\subsubsection{Trends over Time}

In the examination of trends over time, the two most dramatic changes were in the installation rates of space heating system measures, blower door-assisted air sealing, and storm windows. The 1981 Program did not install any space heating system measures, while by PY 1989 these had become an established feature of the Program. Another new feature, blower door-assisted air sealing, was used in $16 \%$ of the weatherization jobs in PY 1989. In contrast, the PY 1981 Program installed storm windows in a majority of homes, while by PY 1989 this rate had declined to 38\%. These three trends are consistent with a growing body of research emphasizing the cost effectiveness of blower door diagnostics and furnace tune-ups and retrofits and questioning the cost effectiveness of storm windows (CSR, Inc. and Meridian Corporation, 1989; Cohen, Goldman, and Harris, 1990; Greeley, Randolph, and Hill, 1992). Caulking and weatherstripping were slightly more prominent in 1989 
than in 1981. In general, insulation was slightly less prominent in 1989 than in 1981, but the use of wall insulation was greater in 1989.

Another interesting comparison is between DOE weatherization and utility "full-scale" weatherization programs operating in 1989. Relative to DOE, utilities invested less and installed fewer energy-conservation measures in the dwelling units they weatherized (Power et al., 1992).

The diversity and complexity of weatherization procedures has increased dramatically over the past decade. While many agencies still select their clients on a first come-first served basis, others target clients with high savings potential based on pre-weatherization energy use. Investment criteria have been developed that deviaie from uniform expenditures per house to allow larger investments in dwellings that offer greater energy-savings opportunities. Program implementers now have a large menu of diagnostic tools to help guide their weatherization. Similarly, the Program permits the use of a variety of methods for selecting weatherization materials and services. This allows measures to be better targeted to the specific needs of an individual dwelling than occurs when priority or prescribed lists are used. Recognizing the impact of occupant behavior upon energy consumption, client education has become an integral part of many state and local Weatherization Assistance Programs. Finally, quality control has gone beyond visual inspections during monitoring visits, to include sophisticated measurement and diagnostic procedures.

Because of the newness of many of these service delivery procedures, their impact on energy savings and cost effectiveness is unclear. Nevertheless, many experts believe that these newer, more advanced practices can improve program performance (Schlegel and Pigg, 1990; CSR, Inc. and Meridian Corporation, 1989; Cohen, Goldman, and Harris, 1990; Greeley, Randolph, and Hill, 1992).

The Greeley et al. (1992) study of the Virginia programindicates that the incorporation of advanced practices (including high density blown cellulose wall insulation and advanced air sealing techniques focusing on attics, basements/crawlspaces, bypasses, ducts and registers, heating system safety inspections, and furmace cleaning and tuning) significantly improves program energy savings. This study suggests that the advanced techniques currently used in Northem and Midwestern States can also be highly effective in milder climates, where we have shown that these techniques were rarely used in PY 1989.

In the following chapters of this report, energy savings and cost effectiveness for the PY 1989 Program will be examined by climate region, fuel type (Chapter 5) and by packages of weatherization measures installed (Chapters 9 and 10). An effort will be made to examine some of the same relationships investigated in previous research. 


\section{ENERGY SAVINGS}

This chapter presents the results of the analysis of energy savings for the first year after weatherization in the 1989 Program Year. The primary goal of this chapter is to provide a reliable and accurate estimate of the amount of primary heating fuel saved by the Weatherization Assistance Program during PY 1989. A secondary goal is to characterize the variation of energy savings across climate regions, heating futis, types of dwellings, and size of agency. Analysis of these key subgroups provides insight into factors influencing savings, a subject that is pursued further in Chapter 9.

For bott gas- and electrically heated dwellings, the estimation of energy savings involves several steps. First, the energy consumption of individual dwellings is weather-normalized, so that the consumption pattems of a dwelling can be compared across time periods that experienced different weather conditions. In particular, normalized annual consumption (NAC) is calculated with PRISM for the pie-weatherization year (pre-NAC) and the post-weatherization year (post-NAC) for each dwelling with complete consumption data.' The units for NAC are ccf for gas-heated dwellings and $\mathrm{kWh}$ for electrically heated dweilings.

Second, the difference between energy use before and after weatherization is istimated for both weatherized and control homes. In particular, gross savings are calculated by suttracting the post-N.AC from the pre-NAC for each dwelling and summing across dwellings. The gross percentage savings are calculated by dividing the average gross savings by the average pre-NAC and multiplying by 100 . Because the gross savings are calculated for individual dwellings while gross percentage savings are tased on averages, the former are subjected to statistical tests (e.g., of differences "ross subgroups;, but the latter are not.

Third, the estimates of gross savings are adjusted to take into account changes in energy consumption that would have occurred in the absence of the Weatherization Assistance Program. In particular, the uet savings per weatherized dwelling are calculated by subtracting the average gross savings for control homes from the average gross savings for weatherized homes. The net percentage savings are calculated by dividing the average net savings by the average pre-NAC and multiplying by 100 .

The first two sections of this chapter (Sections 5.1 and 5.2) present gross and net energy savings for gas- and electrically heated dwellings. In both of these sections variations in gross energy savings by key subgroups (climate region, type of dwelling, and size of agency) also are examined. The third section presents indirect estimates of energy savings for dwellings that heat with other fuels

1 Normalized annual consumption (NAC) is the amount of energy that would have occurred in a year with typical weather. defined as the 10-ycar average. The pre-NAC period is generally defined as April 1, 1988 through March 31, 1989 and post-NAC as April 1, 1990 througi Niarch 3i, i991. 
(primarily fuel oil, liquid propane gas, wood, and kerosene) (Section 5.3). Section 5.4 develops estimates of programwide energy savings. Section 5.5 compares the chapter's results with prior evaluations of the Program and with utility low-income weatherization programs. The chapter ends with a summary of its findings (Section 5.6).

Although energy savings are the most easily quantified program benefits, other benefits may be of comparable importance, including the preservation of affordable housing, health and safety improvements, employment impacts, and environmental benefits. These nonenergy benefits are discussed in Chapter 6. Program costs and cost effectiveness are discussed in Chapters 7 and 8.

\subsection{GAS-HEATED DWELLINGS}

Gas-heated dwellings account for $90 \%$ of the 4,299 weatherized dwellings for which complete fuel consumption records were available. The use of natural gas as a primary heating fuel characterizes approximately half (51\%) of the dwellings weatherized by the Program during PY 1989 (see Fig. 3.4). Thus, the overall performance of the Program is highly dependent upon the Program's ability to reduce the energy consumed in gas-heated homes.

Gas utilities across the country also provided complete gas consumption data for 3,226 gasheated control dwellings. ${ }^{2}$ Some of these complete records had errors due either to problems with the submitted data or errors introduced in the data entry process.

Therefore, an elaborate screening process was developed to identify potential data errors. The ecreening process identified invalid or duplicated dates as well as fuel consumption that was outside of reasonable ranges. Problems associated with household turnover were also resolved, where possible. In particular, periods with zero consumption values that occurred as the result of a temporary vacancy were set to missing values. By identifying and correcting such data quality problems, loss of data was minimized.

Next, the heating-only version of PRISM was applied to t': data. A second set of screens then was used to identify potential data errors based on the PRISM parameters. These data errors were corrected, where possible, and the corrected data were reanalyzed with PRISM. As a final step, the following criteria wrre applied to these results to identify poor-fitting PRISM models:*

1. coefficient of determination $\left(R^{2}\right)$ of NAC less than 0.2 and covariance of NAC greater than 0.3

2. minim $/ \mathrm{m}$ and maximum values of pre- or post-weatherization NAC, which varied by clima.e region:

2 Incomplete gas billing records were provided for approximately 6,500 additional weatherized and control dwellings. In most of these cases, some or all of the pre-weatherization period was missing. In other cases, most of the winter of either the pre- or post-weatherization period was missing.

See Keynoids and Fels (1988) for a điscussion of $R^{2}$ criteria and other indicators of the reliability of PRISM. 
- cold climate region - less than $400 \mathrm{ccf}$ or greater than $6,000 \mathrm{ccf}$

- moderate climate region - less than $200 \mathrm{ccf}$ or greater than $6,000 \mathrm{ccf}$

- hot climate region - less than 100 ccf or greater than $3,000 \operatorname{ccf}^{3}$

Any dwelling that had one or more of the above characteristics was eliminated from the analysis of gas savings. ${ }^{4}$

The application of these indicators of poor-fitting PRISM models caused the sample of weatherized gas-heated dwellings to decrease by $10 \%$ : from 4,299 to 3,882 dwellings. The sample of control dwellings declined by $18 \%$ : from 3,226 to 2,635 . These reduced samples have excellent overall modeling results. The mean PRISM parameters are presented in Table E. 3 in Appendix E. For both the pre- and post-weatherization year and for both the weatherized and control dwellings, the average coefficient of detcrmination $\left(R^{2}\right)$ of NAC for the four different groups ranges from 0.83 to 0.85 . These values compare favorably with other evaluations (Fels, 1986). The reference temperatures for the models average 63.3 degrees Fahrenheit. Finally, the temperature-dependent gas use (which includes gas use for space heat as well as the temperature-dependent portion of water heating) is estimated to be $76 \%$ of total gas consumption. The credibility of these values supports our use of the PRISM-generated Normalized Annual Consumption to estimate savings.

Once the weather normalization was completed and gross savings were estimated for each dwelling, weights were applied to the individual results to obtain unbiased estimates of savings for the nation and its key subgroups. In particular, the weights correct for the slight under-representation of the hot climate region and small agencies in the sample of homes with gas consumption data. Sample weights were calculated for the weatherized dwellings based on the sample of 3,882 dwellings with good-fitting PRISM models. A different set of sample weights were calculated for the control dwellings based on the sample of 2,635 dwellings with good-fitting PRISM models. As shown in Table E.1 in Appendix E, weighting factors (N/n) were calculated for 15 strata of local agencies five different climate regions and threc agency size categories. ${ }^{5}$ Weighting factors $(M / r)$ then were calculated for each local agency, reflecting the extent that gas consumption data were available for each agency's weatherized and control dwellings (see Table E.2).

The product of these two weighting factors $(\mathrm{N} / \mathrm{n} \times \mathrm{M} / \mathrm{r})$ produces the weight that is assigned to the weatherized (or control) dwellings for each agency Dwellings associated with agencies that had

3 The abbreviation "ccf" refers to 100 cubic feet of natural gas.

4 The first screen eliminated dwellings that had significant variability in gas use across meter-reading periods, and where the variability was unrelated to heating degree days. This situation suggests any of a number of aberrations that invalidate the weather-normalization procedure, such as extended vacations during winter, extensive use of supplemental heating fuels, or substantial gas use for purposes other than space heating. The second screen eliminated dwellings that had too little gas use, suggesting that they did not heat with gas, or too much gas use, suggesting a multifamily building without individual metering or some other anomaly.

5 Recall that 60 strata were used for weighting the dwelling-specific data, because the sample sizes were so much larger. 
weights greater than 1,000 were removed from further analysis because of the wide fluctuations that such extremely large weights would create. The weights were then recalculated, and the final sample size was reduced by less than $1 \%$ to 3,873 weatherized dwellings and 2,611 control dwellings.

\subsubsection{Nationwide Gas Savings}

Whole-House Gas Savings. The weighted results provide an unbiased estimate of nationwide, whole-house gas savings (Table 5.1). The weighted gross savings of v'eatherized dwellings is $135 \mathrm{ccf} /$ year or $10.1 \%$ of pre-NAC gas consumption. These statistics are almost identical to the unweighted estimates (Table 5.1). The closeness of the weighted and unweighted estimates of gross savings is indicative of the small amount of attrition bias in the gas consumption data.

Table 5.1 Average First-Year Gas Savings for Gas-Heated Weatherized and Control Dwellings (in ccf/year) ${ }^{\mathrm{a}}$

\begin{tabular}{|c|c|c|c|c|c|c|c|}
\hline & & PresAC & Post-NAC & Gross & $\begin{array}{l}\text { Percent } \\
\text { gross. }\end{array}$ & savings & percento \\
\hline \multirow{2}{*}{ werghted } & $\begin{array}{l}\text { weatherized } \\
\text { owellings } \\
n=3,873\end{array}$ & $\begin{array}{l}1,348 \\
(12)\end{array}$ & $\begin{array}{l}1,484 \\
(11)\end{array}$ & $\begin{array}{c}136 * * * \\
(7)\end{array}$ & $10.1 \%$ & $\begin{array}{c}167 * * * \\
(10)\end{array}$ & $12.4 \%$ \\
\hline & $\begin{array}{l}\text { Control } \\
\text { Dwellings } \\
\mathrm{n}=2,611\end{array}$ & $\begin{array}{c}1,121 \\
(8)\end{array}$ & $\begin{array}{l}1,152 \\
(10)\end{array}$ & $\begin{array}{r}-31 \\
(7)\end{array}$ & $-2.8 \%$ & & \\
\hline \multirow{2}{*}{ (velghted) } & $\begin{array}{l}\text { Weatherized } \\
\text { Dwellings } \\
n=3,873\end{array}$ & $\begin{array}{l}1,334 \\
(83)\end{array}$ & $\begin{array}{l}1,199 \\
(81)\end{array}$ & $\begin{array}{c}135 * * * \\
(13)\end{array}$ & $10.1 \%$ & $\begin{array}{c}173 * * * \\
(18)\end{array}$ & $13.0 \%$ \\
\hline & $\begin{array}{l}\text { Control } \\
\text { Dwellings } \\
n=2,611\end{array}$ & $\begin{array}{l}1,127 \\
(37)\end{array}$ & $\begin{array}{l}1,164 \\
(38)\end{array}$ & $\begin{array}{c}-37 * * * \\
(14)\end{array}$ & $-3.3 \%$ & & \\
\hline \multicolumn{8}{|c|}{$\begin{array}{l}\text { a Numbers in parentheses are standard errors of the estimates. } \\
\text { b Percent net savings is calculated as the net savings divided by the average pre-NAC, and } \\
\text { multiplied by } 100 \text {. }\end{array}$} \\
\hline
\end{tabular}

The weighted estimate of net savings provides an assessment of the amount c: energy saved by the Program in a typical single-family or small multifamily home. (Recall that net savings are a 
better estimate of Program saving because they account for changes in consumption that would have occurred in the absence of the Program.) The weighted net savings that results from subtracting the weighted gross savings of the control group from that of the weatherized group is $173 \mathrm{ccf} / \mathrm{year}$ or $13.0 \%$ of pre-weatherization consumption.

The standard error of the weighted estimate of gross savings is $13 \mathrm{ccf} /$ year. Thus, the relative error (defined as the standard error divided by the mean) is only $10 \%$, which is the targeted value for the evaluation (Berry, et al., 1991) and indicates an acceptable level of precision. The standard error around the weighted net savings of $173 \mathrm{ccf} / \mathrm{year}$ is $18 \mathrm{ccf} / \mathrm{year}$, also resulting in a relative error of about $10 \%$.

These standard errors enable the calculation of a $90 \%$ confidence interval around the estimates of savings. In particular, the $90 \%$ confidence interval around the estimated net savings of $173 \mathrm{ccf} / \mathrm{year}$ is 151 to $195 \mathrm{ccf} / \mathrm{year}$.

Gas-Heat Savings. Energy savings from weatherization programs are often described in terms of the amount of space heat energy consumption that was reduced. Nearly all of the weatherization measures installed by the Program are aimed at reducing space heating requirements. Water-heater measures are the only notable exception, and they account for a small fraction of total weatherization costs.

Based on data collected during the 1987 Residential Energy Consumption Survey (Energy Information Administration, 1989, Tables 15 and 28), low-income households nationwide (defined as $125 \%$ of the poverty level) with gas heat consume $71 \%$ of their gas for space-heating purposes. ${ }^{6}$ Applying this average to the results shown in Table 5.1, the average weatherized home with gas heat is estimated to have consumed $947 \mathrm{ccf}$ of gas (i.e., $71 \%$ of $1,334 \mathrm{ccf} / \mathrm{year}$ ) for space-heating purposes during the year preceding weatherization. Thus, the average net savings of $173 \mathrm{ccf} / \mathrm{year}$ is estimated to be $18.3 \%$ of the gas used for space heating.

Variability of Gas Savings. There is a great deal of variability in the gross gas savings of weatherized and control dwellings. Nevertheless, there is a discernible difference between the distributions of energy savings for weatherized and control dwellings. Consider the distribution of gross gas savings for the two groups (Fig. 5.1a). For $71 \%$ of the weatherized dwellings, the Normalized Annual Consumption of gas was less during the first year after weatherization than during the preceding year. In contrast, only $48 \%$ of the control group had lower Normalized Annual Consumption of gas during 1990-91, than in 1988-89.

The distribution of percent savings for weatherized and control dwellings also shows great variability (Fig. 5.1b). Nevertheless, the percent savings of weatherized dwellings is discemibly

6 The 1990 RECS indicated that low-income households (defined as $125 \%$ of the poverty level), witi gas heat consume $70 \%$ of their gas for space heating purposes (Response Analysis Corporation, 1993). 


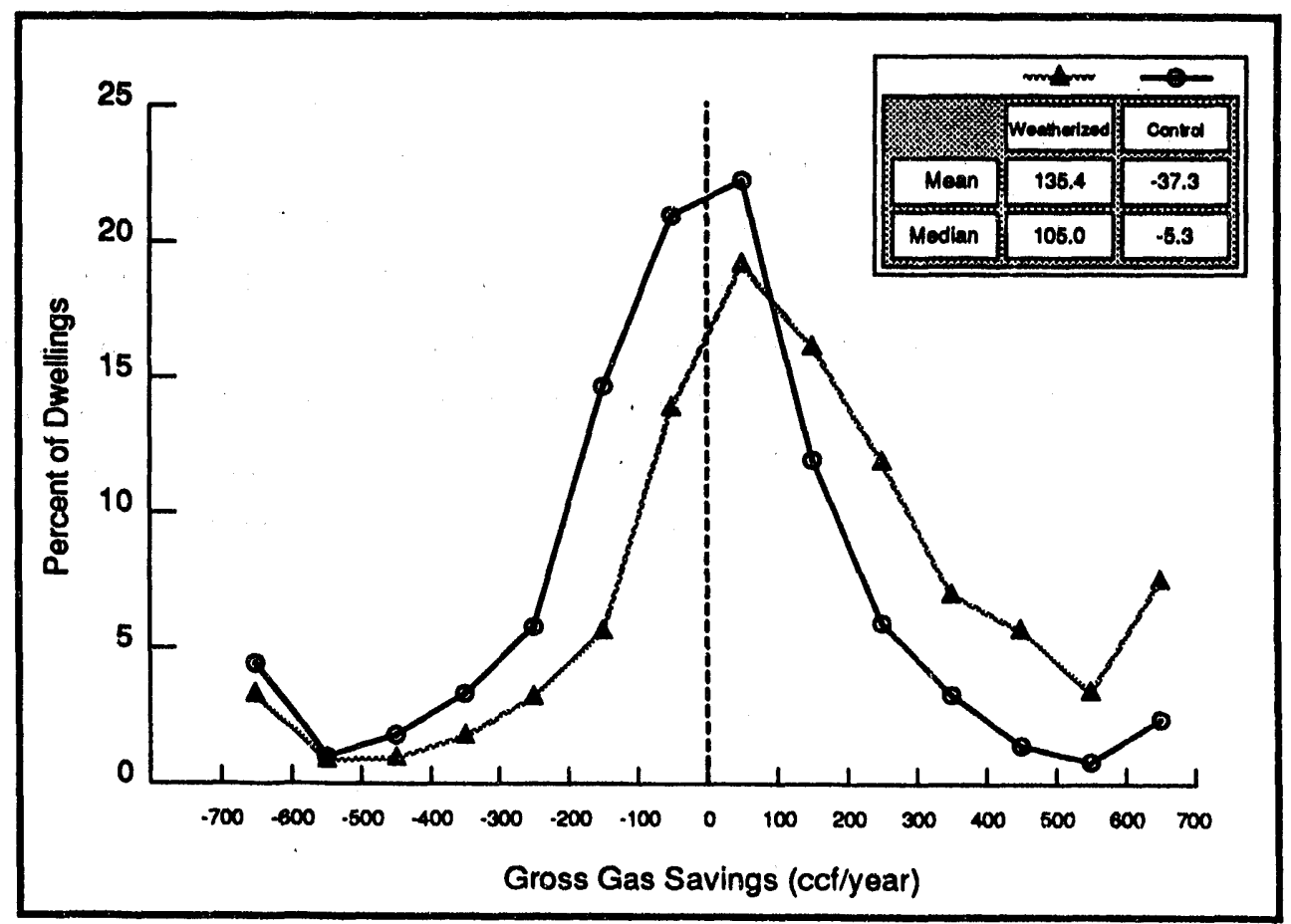

Fig. 5.1a Distribution of Gross Gas Savings for Gas-Heated Weatherized and Control Dwellings (weighted)

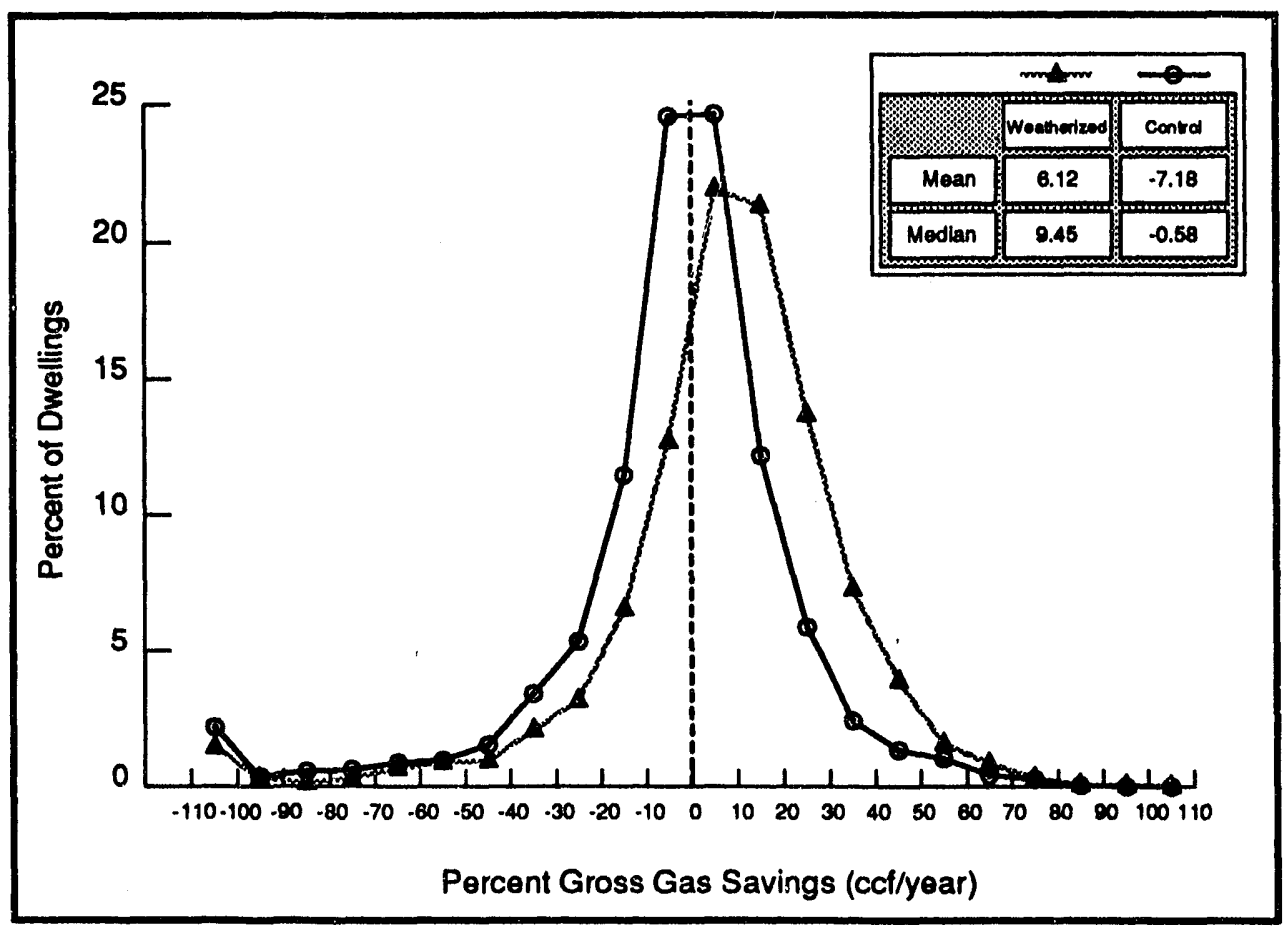

Fig. 5.1b Distribution of Percent Gross Gas Savings for Gas-Heated Weatherized and Control Dwellings (weighted) 
greater than the percent savings of control dwellings. The mean savings of weatherized dwellings is only $6.1 \%$, which is less than the percent gross savings shown in Table 5.1. Recall that Table 5.1 is based on calculating mean percent savings from the weighted mean values of pre- and postweatherization Normalized Annual Consumption (i.e., it is based on aggregate statistics). The mean percent savings shown in Fig. $5.1 \mathrm{~b}$ is based on averaging the percent savings for individual dwellings. As Fig. 5.1b shows, percent gas savings is a negatively skewed distribution. In particular, there are $\mathbf{3 0}$ weatherized dwellings (or approximately $1 \%$ of the sample) which have highly negative savings (i.e., less than $-110 \%$ ). If these dwellings were removed from the sample, the mean percent savings would increase to $9 \%$, which is close to the programwide estimate of $10 \%$.

\subsubsection{Gas Savings, by Climate Region}

The weighted gross gas savings per weatherized, gas-heated home varies substantially by climate region. As Table 5.2 shows, gross ccf's of gas saved per weatherized dwelling in the cold and moderate regions were significantly higher than in the hot region, ranging from $166 \mathrm{ccf} / \mathrm{year}$ in the cold region to $102 \mathrm{ccf} /$ year in the hot region. In the hot region, the savings are not significantly greater than zero - the variability in savings is simply too large and the sample size is too small to confirm a statistically significant reduction in consumption.

The control group analysis indicates that each region experienced a different overall trend in gas consumption among low-income households waiting to be weatherized in 1991. Therefore, the adjustments to the gross savings differ by region.

- In the cold region, control dwellings consumed $69 \mathrm{ccf} /$ year more gas in the postweatherization year (1990-91) than in the pre-weatherization year (1988-89), and this increase is statistically significant at 0.001 . Thus, the net savings in the cold region is higher than the gross savings - at $235 \mathrm{ccf} /$ year or $17.7 \%$.

- In the moderate region, control dwellings consumed $45 \mathrm{ccf} /$ year more gas in 1990-91 than in 1988-89, although this change is not statistically significant. With this adjustment, the net savings for weatherized dwellings is slightly higher (at $182 \mathrm{ccf} / \mathrm{year}$ or $12.4 \%$ ) than the gross savings for this region.

- In the hot region, control dwellings consumed essentially the same amount of gas in $1990 / 91$ as in 1988-89. The estimated net savings of the Program in this climate region is therefore only slightly lower (at $91 \mathrm{ccf} / \mathrm{year}$ or $10.9 \%$ ) than the gross savings.

These climate region differences are vividly illustrated in Fig. 5.2.

Pre-weatherization gas use is highest in the moderate climate region $(1,464 \mathrm{ccf} / \mathrm{year})$, intermediate in the cold region $(1,327)$, and lowest in the hot region (833). The fact that dwellings in the moderate region consumed more gas before weatherization than dwellings in the cold region, while their savings were substantially less, suggests that the moderate region offers considerable 


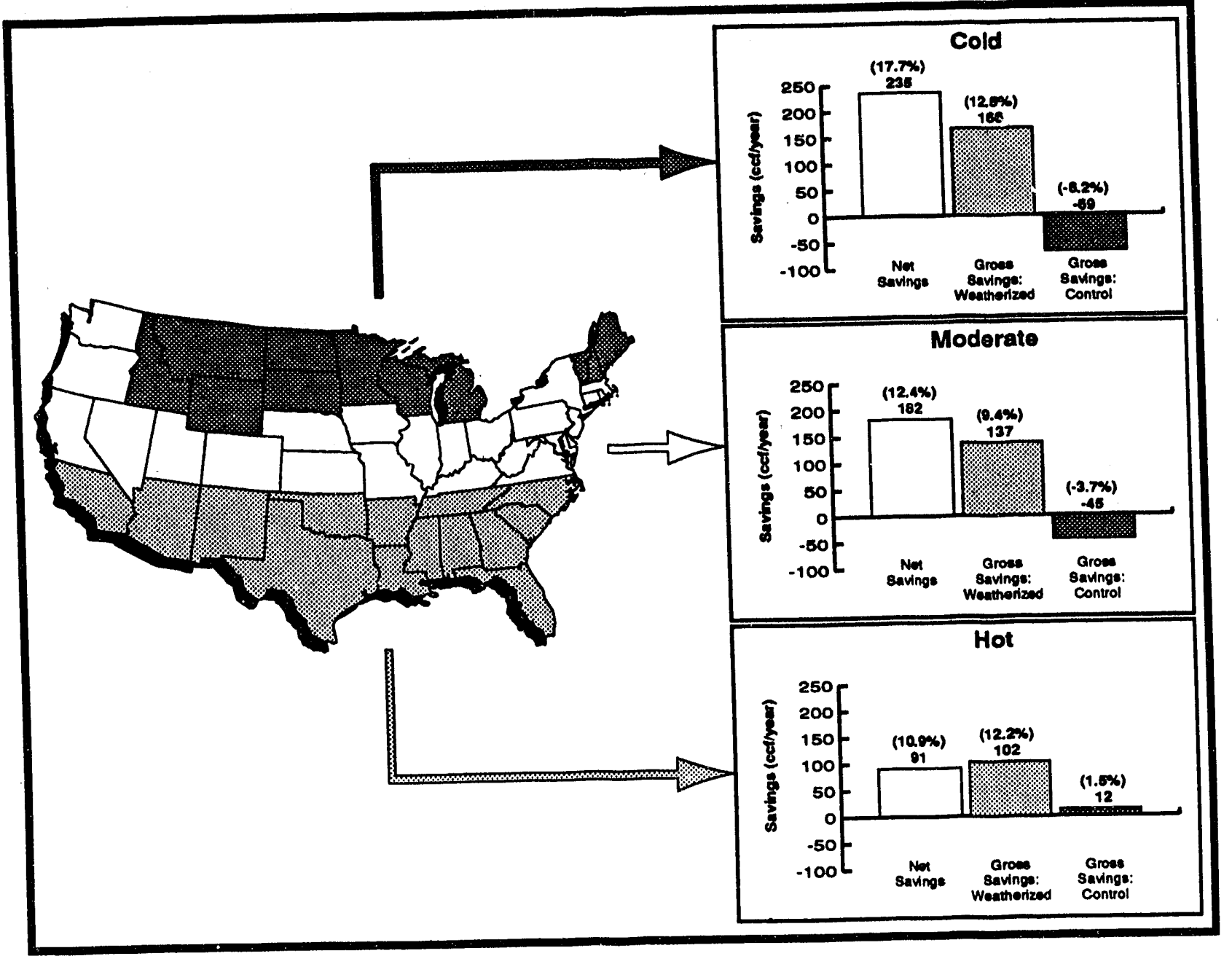

Fig. 5.2 Gas Savings by Climate Region

Reassuringly, the levels of pre-weatherization gas use for weatherized and control dwellings differ by no more than $20 \%$ in any climate region. (Weatherized dwellings consume more gas than control dwellings, before weatherization.) In the hot region there is essentially no difference. This similarity underscores the value of using a waiting list as a control group. The characteristics of the dwellings waiting for weatherization are likely to be similar to those of the weatherized homes, before participation in the Program. 


\subsubsection{Gas Savings, by Dwelling Type}

Fig. 5.3 illustrates the variations in gross and net gas savings for different types of gas-heated homes. ${ }^{7}$ Variations in savings by dwelling type are large and significant. (Based on an analysis of variance of the gross savings, these differences are significant at a 0.001 level.)

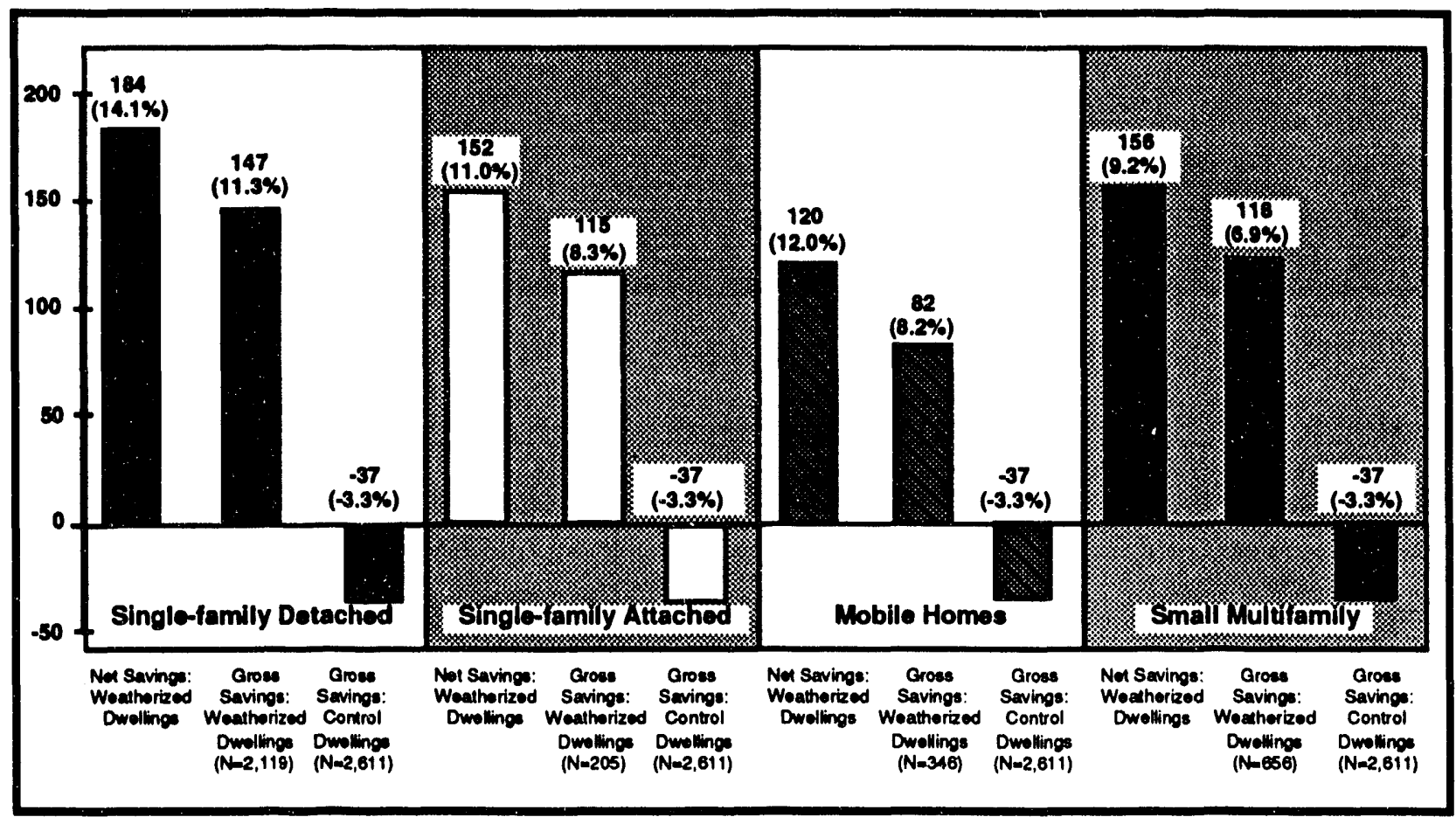

Fig. 5.3 Gas Savings by Dwelling Type

In particular, single-family detached homes weatherized in PY 1989 experienced the greatest net savings, at $184 \mathrm{ccf} /$ year. Small multifamily and single-family attached dwellings saved approximately the same amount (156 and $152 \mathrm{ccf} / \mathrm{year}$, respectively). In contrast, mobile homes saved only $120 \mathrm{ccf} / \mathrm{year}$.

As a percent of pre-weatherization gas consumption, net savings are still highest for singlefamily detached dwellings (14.1\%). However, net savings are least for small multifamily dwellings because this dwelling type has the highest pre-weatherization gas consumption.

Thus, the Program produces the greatest gas savings in those dwelling types that account for the greatest percentage of their clients - single-family detached homes dominate both the PY 1989 weatherized dwellings and the population of eligible clients (Beschen and Brown, 1991). The Program produces the least gas savings in mobile homes, but these comprise only $20 \%$ of the

7 The national control group is used as the control for each of the four dwelling types. Thus, in each case the net savings is $37 \mathrm{ccf} /$ year greater than the gross savings. Individualized control groups could not be created for each dwelling type, since the dwelling type of the control group homes is unknown. 
dwellings weatherized in PY 1989 and even less (12\%) of the eligible population nationwide. Further, only 27\% of the mobile homes weatherized in PY 1989 heated primarily with natural gas, further diminishing the impact of this submarket on Program-wide gas savings. Nonetheless, gas-heated mobile homes appear to offer an important opportunity for improvement for the Program.

\subsubsection{Gas Savings, by Size of Local Agency}

Dwellings weatherized by medium-sized local weatherization agencies experienced the greatest gross savings (148 ccf/year) and the second largest net savings (173 ccf/year) of the three size categories (Fig. 5.4). Large and small agencies had comparable gross savings (119 and $120 \mathrm{ccf} / \mathrm{dwelling}$, respectively). However the net savings of large agencies were larger than the net savings of small agencies (176 vs. $159 \mathrm{ccf} / \mathrm{year}$, respectively), because of the greater control group adjustment.

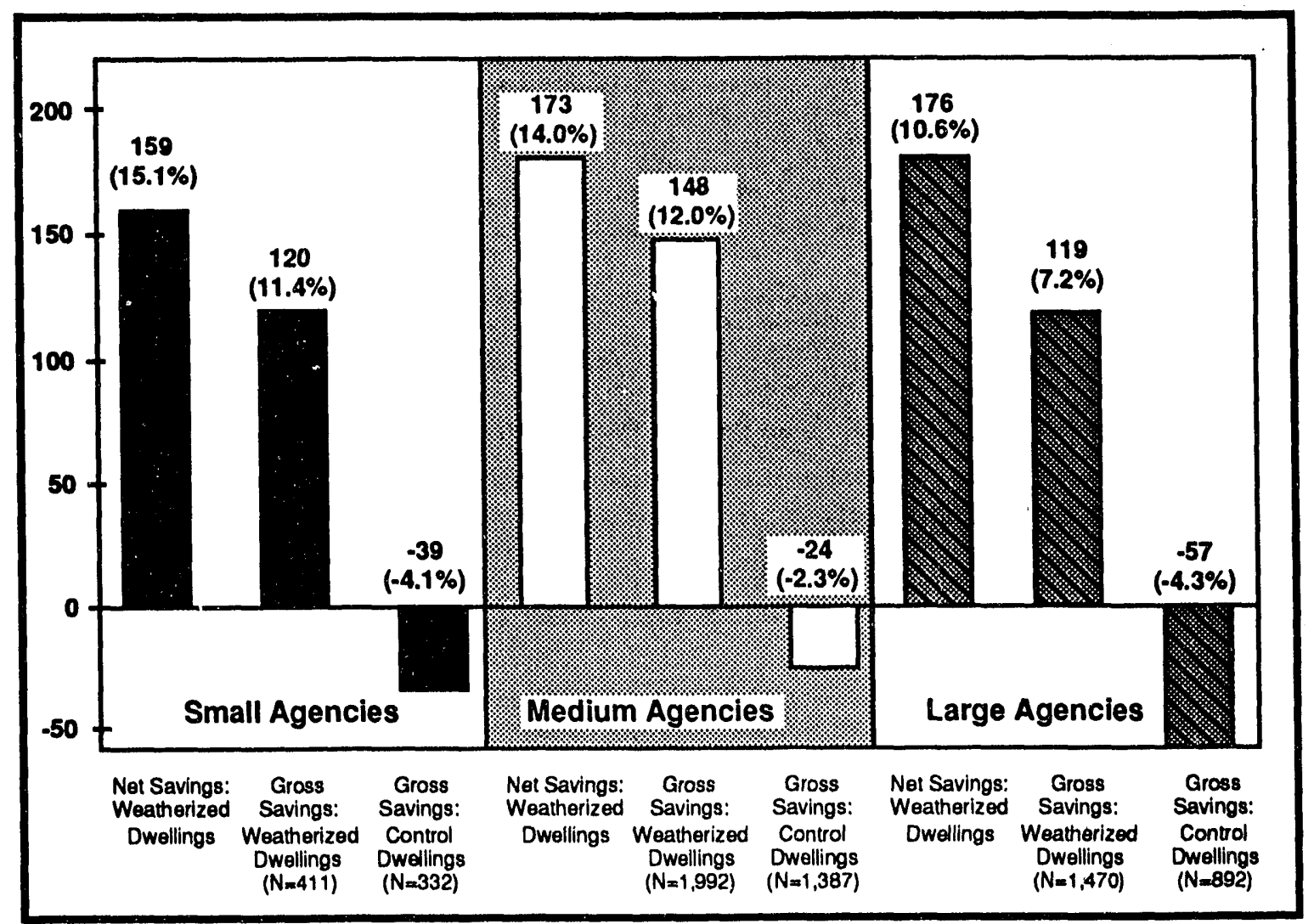

Fig. 5.4 Gas Savings by Size of Local Weatherization Assistance Program Agency

Analysis of percent savings suggests that large agencies did not perform as well as small- and medium-sized agencies. Because large agencies are located primarily in the moderate and cold climate regions, the dwellings they weatherized in PY 1989 consumed greater than average levels of 
gas before weatherization. As a result, the $176 \mathrm{ccf} / \mathrm{year}$ net savings of large agencies translates into a relatively low percentage reduction $(10.6 \%)$ in consumption. Small agencies also generated lowerthan average gross and net savings. However, they are concentrated in the hot climate region and the dwellings they weatherized therefore had low levels of gas use. As a result, their net savings were $15.1 \%$ of their pre-NAC. The percent net savings of medium-sized agencies were also relatively high.

Thus, as with different types of dwellings, the Program produces the greatest gas savings in those dwellings that are served by the dominant size of agency. Recall that medium-sized agencies (those that weatherized more than 100 and less than 400 dwellings during PY 1989) weatherized 54\% of the single-family and small multifamily homes in PY 1989.

\subsection{ELECTRICALLY HEATED DWELLINGS}

Electrically heated dwellings account for $10 \%$ of the sample of weatherized dwellings and $13 \%$ of the sample of control dwellings for which complete fuel consumption records were available. They represent $10 \%$ of the dwellings weatherized by the Program during 1989. Thus, they account for a small, but significant fraction of the Program's clients.

Electric utilities across the country provided complete electricity consumption data for 497 electrically heated dwellings weatherized in PY 1989, and for 550 electrically heated control dwellings. More than half of these dwellings are located in the moderate climate region; the cold region has the smallest proportion of them. These proportions are consistent with saturations of electric heat, by region, for the population of dwellings weatherized in PY 1989.

Electricity supports a diversified array of residential energy end uses, including home heating, air conditioning, water heating, refrigeration, and numerous other appliance uses. The existence of these multiple uses complicates the process of weather normalization and the assessment of savings.

Three versions of PRISM are available for normalizing annual electricity consumption: the Heating-Only, Heating-and-Cooling, and Cooling-Only versions (Fels, Reynolds, and Stram, 1991). Knowing the weather, appliance use, and supplemental heating of individual homes, one might be able to assign the appropriate version of PRISM to each dwelling in the sample. Information on appliance ownership is limited, however; data on air-conditioning equipment, for instance, were often missing from the Dwelling-Specific Form (Appendix B). Therefore, an alternative assignment process was used. The profile of electricity consumption for each of the approximately 1,047 dwellings was studied and assigned a version of PRISM based on the existence or absence of heating and cooling peaks.

- The Heating-Only version of PRISM was used when a dwelling exhibited a heating peak and not a cooling peak. 
- The Cooling-Only version of PRISM was used when a dwelling exhibited a cooling peak and not a heating peak.

- The Heating-and-Cooling version of PRISM was used when a dwelling exhibited both a heating and a cooling peak.*

Consumption profiles for three dwellings, one for each version of PRISM, are shown in Fig. 5.5. These dwellings illustrate the types of consumption profiles assigned to each model.

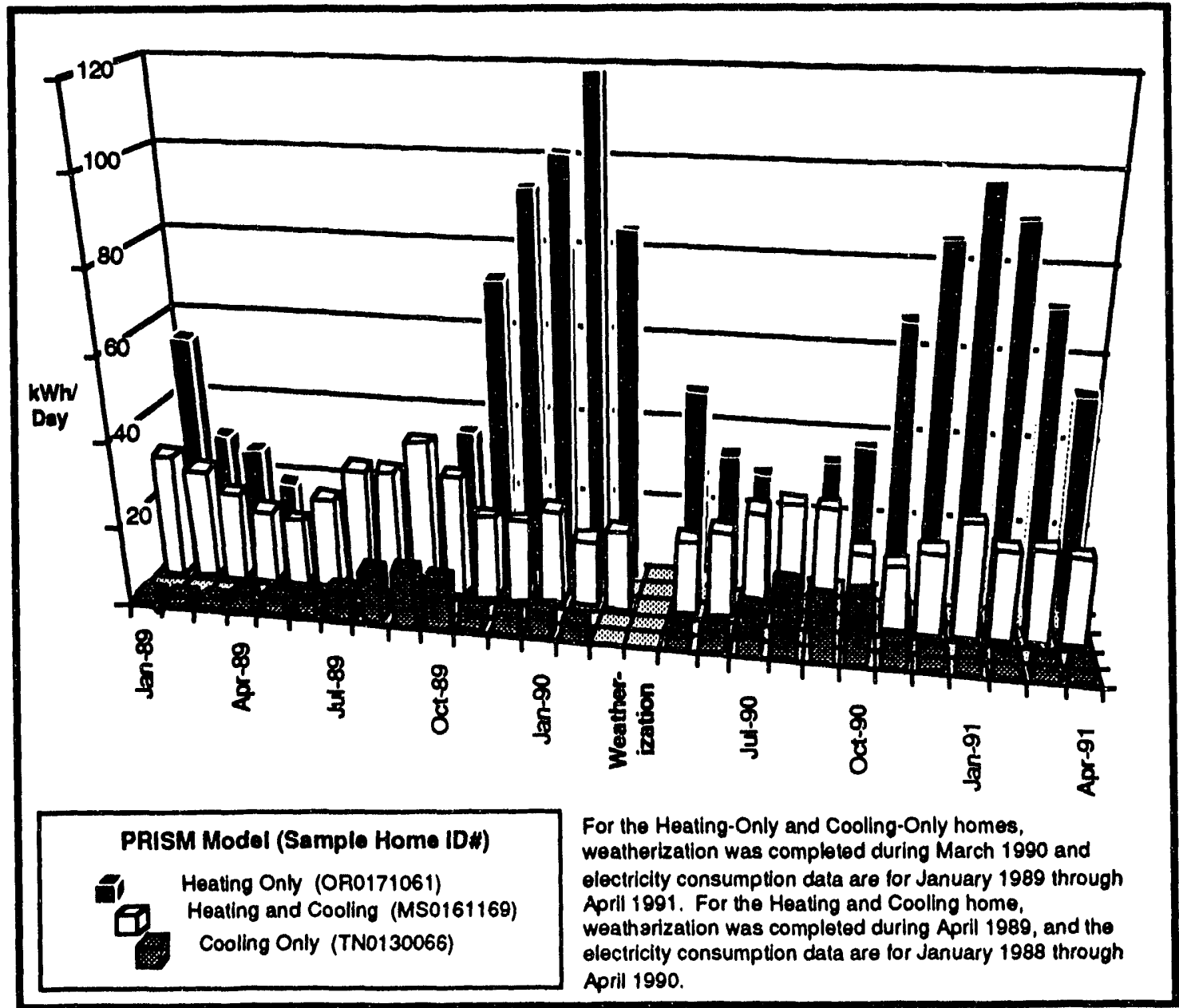

Fig. 5.5 Model Electricity Consumption Profiles for the Three Versions of PRISM: Heating Only, Heating-and-Cooling, and Cooling Only

An elaborate screening process (similar to the one used for gas-heated dwellings) was developed to identify potential errors in the electricity consumption data for all three versions of PRISM. After identifying and correcting such problems, the appropriate version of PRISM was

* An intermediate version of Heating-and-Cooling (HC) PRISM was developed solely for use in the National Weatherization Evaluation's Single-Family Study (see Fels, Reynolds, and Stram, 1991). 
applied to the data. A second set of screens was used to further identify potential errors, and any data errors found at this stage were corrected. The data were then reanalyzed with PRISM. More than half of the dwellings originally assigned to the Heating-and-Cooling version of PRISM did not have a sufficient cooling or heating load to produce meaningful results. These dwellings were then individually reassigned either to the Heating-Only or the Cooling-Only model, based on an inspection of their consumption profiles. Each dwelling was assigned the same model for both the pre-weatherization period and for the post-weatherization period, for ease of analysis.

The following criteria were applied to the final weather-normalized results to identify poorfitting PRISM models.

- coefficient of determination $\left(\mathrm{R}^{2}\right)$ less than 0.20 and covariance of NAC greater than 0.3

- minimum and maximum values of pre- or post-weatherization NAC, which varied by climate region:

- cold climate region - less than $5,000 \mathrm{kWh}$ or greatcr than $80,000 \mathrm{kWh}$

- moderate climate region - less than $3,000 \mathrm{kWh}$ or greater than $70,000 \mathrm{kWh}$

- hot climate region - less than $1,000 \mathrm{kWh}$ or greater than $60,000 \mathrm{kWh}$

Any dwelling that had one or more of the above characteristics was climinated from the analysis of electricity savings. ${ }^{8}$

Altogether, good-fitting PRISM models resulted for 918 (or $88 \%$ ) of the representative sample of 1,047 electrically heated dwellings with complete consumption data. Almost half (426) of these were weatherized dwellings and slightly more than half (492) were control dwellings. Their distribution across the three versions of PRISM is summarized below, and the resulting PRISM parameters are described in Table E.4 through E.6 in Appendix E.

Dwellings with Air Conditioning and Electric Heat. The Heating/Cooling version of PRISM provided estimates of the electricity saved by dwellings with significant electricity consumption for both heating and air conditioning. Based on the electricity consumption profiles of the sample of 1,047 electrically heated homes, the Heating-and-Cooling version of PRISM was the best model for approximately $20 \%$ of the dwellings. Good-fitting PRISM models resulted for only 52 of these dwellings, necessitating the reassignment of some dwellings to either the Heating-Only or CoolingOnly version of PRISM. The average $\mathrm{R}^{2}$ for the Heating-and-Cooling PRISM models is 0.69.

Electrically Heated Dwellings with Minimal Air Conditioning. The Heating-Only version of PRISM provided estimates of the electricity saved by electrically heated dwellings with minimal air conditioning. The Heating-Only version of PRISM was applied to a majority of the dwellings. Good-fitting PRISM models resulted for 803 of them, with an $\mathrm{R}^{2}$ averaging 0.63 .

8 The rationale for these criteria is the same as for gas-heated dwellings. Sec footnote 4 . 
desirable to employ the 15-cell weighting scheme that was used for the gas consumption data.9 Instead, weights were applied to the aggregate results for each of the three climate regions to obtain a national average. Weights were not applied to each dwelling, as was done in the analysis of gas consumption. The decision to rely primarily upon unweighted values in the analysis of key subgroups (in Sections 5.2.2 to 5.2.4) is supported by the fact that the sampled dwellings are distributed across the three climate regions in representative proportions. The slight bias is that both the weatherized and control dwellings with electricity consumption data are located disproportionately less in the cold climate region relative to the population of weatherized dwellings.

Based on the dwelling-specific data described in Table 3.2, electrically heated weatherized homes are distributed in the following proportions:

- cold climate region -0.15

- moderate climate region -0.50

- hot region -0.35 .

Weighted U.S. results are calculated by multiplying each of the mean pre-NAC and post-NAC values shown in Table 5.3 by the appropriate proportion and summing the products. The weighted gross savings is the difference between the weighted pre- and post-NAC values.

The weighted results indicate a gross electricity savings of $867 \mathrm{kWh} /$ year (or $5.8 \%$ ) nationwide, and a net savings that is more than twice as large, at $1,830 \mathrm{kWh} / y e a r$, or $12.2 \%$. The net savings are much larger than the gross savings b-cause of the behavior of the control group. In contrast to the weatherized dwellings, the average (i nweighted) gross electricity savings per control dwelling with electric heat is $-963 \mathrm{kWh} /$ year (or $-6.7 \%$ ). These control group results are also significant, indicating a discemible trend toward increased electricity consumption among lowincome households waiting for weatherization services. A similar increase in per-household electricity consumption between 1984 and 1987 was documented by EIA (Battles, 1991). The 6\% increase over this 3-year period was attributed to an increase in the use of air conditioning and an increase in the number of electrical appliances used. Our control group results suggest that the trend toward increasing electricity consumption continued through 1990.

The weighted and unweighted estimates of savings are similar because the sample of electrically heated homes with consumption data is distributed in a fairly representative fashion across the three climate regions, relative to the population of electrically heated homes weatherized in PY 1989. The weighted average gross savings is slightly higher than the unweighted average, because the sample of weatherized dwellings under-represents the PY 1989 weatherized homes located in the

9 Large weights applied to cells represented by only a handful of dwellings would have significantly decreased the precision of our estumates of savings. 
cold region. Once properly weighted, the higher savings in the cold region have more of an impact on the national statistics.

The standard error of the weighted estimate of gross electricity savings is estimated to be $268 \mathrm{kWh} /$ year. This is nearly identical to the standard error of the unweighted estimate (i.e., $239 \mathrm{kWh} /$ year). Because the weights are applied to the aggregated regional results, the weights do not add as much to the variability of the data as occurred in the weighted analysis of gas savings. The relative error (defined as the standard error divided by the mean) is $31 \%$, which greatly exceeds the targeted value of $10 \%$. It is high because of the large variability in gross electricity savings across households, and the small sample size, which reflects the relatively small population of electrically heated weatherized homes. The same standard error around the weighted net savings of $1,830 \mathrm{kWh}$ is 358 , resulting in a relative error of $19.6 \%$.

The standard error enables the calculation of a confidence interval around the savings estimates. In particular, the $90 \%$ confidence interval around the estimated net savings of $1,830 \mathrm{kWh} /$ year ranges from 1,241 to $2,419 \mathrm{kWh} /$ year.

Space-Conditioning Savings. As with the gas-heated dwellings, it is valuable to discuss the energy saved by electrically heated dwellings in terms of the amount of space heat energy consumption that was reduced. We also need to consider savings as a proportion of the amount of space heat and air conditioning energy consumption, since approximately one-tenth of the electrically heated homes appear to be best fit by the Cooling-Only version of PRISM. ${ }^{10}$

Based on data collected during the 1987 Residential Energy Consumption Survey (Energy Information Administration, 1989, Tables 17 and 29), low-income households nationwide (defined as $125 \%$ of the poverty level) with electric heat consume $34 \%$ of their electricity for space-heating purposes." Based on the results shown in Tatle 5.3, weatherized homes with electric heat consumed $5,090 \mathrm{kWh}$ of electricity (i.e., $34 \%$ of $14,972 /$ year) for space-heating purposes during the year preceding weatherization. Using this smaller value as the denominator, the net savings is estimated to be $35.9 \%$ of electricity use for space heating.

Data on the electricity consumed by low-income households for air-conditioning purposes were not available from the 1987 Residential Energy Consumption Survey. Therefore, an amount was estimated using indirect means. Based on the dwelling-specific database (see Table 3.2 on page 3.14), $44 \%$ of electrically heated weatherized dwellings have air-conditioning equipment, a higher

10 The 1990 RECS estimates that there are 13.9 million low-income (125\% of poverty) houscholds who live in mobile homes, single-family homes, or small multifamily homes. 2.3 million $(16.5 \%)$ heat with electricity, 6.9 million $(49.6 \%)$ have air conditioning equipment, and 1.5 million $(10.8 \%)$ have electric main heat and air conditioning equipment.

11 The PRISM analysis of weatherized dwellings based on the heating-only model (Table E.4) suggests that 4,538 $\mathbf{k W h} /$ year (or $30 \%$ of whole-house electricity consumption) is devoted to space-heat use. The estimate is $31 \%$ based on the 418 control dwellings described in Table E.4. The 1990 RECS shows that low-income households with eieciric ineal conisume $30 \%$ of thcir clectricity for space heating purposes. 
percentage than for homes heated with gas or other fuels. We estimate from PRISM results that each dwelling with air-conditioning equipment consumes $17 \%$ of their electricity consumption for air conditioning (this is about half the amount that they spend on space heat). ${ }^{12}$ Thus, on average, it is assumed that the electrically heated weatherized dwellings consume $7 \%(0.17$ times 0.44$)$ of their electricity on air conditioning. Adding this to the base of $34 \%$ dedicated to space heating, the total percentage used for space heating and air conditioning is estimated to be $41 \%$ (34\% plus $7 \%$ ).

Based on the results shown in Table 5.3, homes with electric heat that were weatherized is PY 1989 consumed $6,139 \mathrm{kWh}$ of electricity (i.e., $41 \%$ of $14,972 /$ year) for space-conditioning purposes during the year preceding weatherization. Using this as the denominator, net savings are estimated to be $29.8 \%$ of electricity for space conditioning.

Variability of Electricity Savings. Figure 5.6 illustrates the wide variability in the electricity saved by electrically heated homes - both in terms of absolute savings (Fig. 5.6a) and percent savings (Fig. 5.6b). It also shows a discemible difference in gross savings levels between weatherized and control dwellings. While $57 \%$ of weatherized dwellings with electric heat consumed less electricity after weatherization than before, the same is true for only $43 \%$ of control dwellings.

\subsubsection{Electricity Savings, by Climate Region}

As Table 5.4 shows, gross electricity savings are highest in the cold region $(1,933 \mathrm{kWh} / \mathrm{year})$ and lowest in the hot region ( $307 \mathrm{kWh} /$ year). Because control dwellings in the moderate region consumed significantly more electricity in the post-weatherization year than in the pre-weatherization year, the estimated net savings for weatherized dwellings in this region is quite high (at 2,479 $\mathrm{kWh}$ /year). In both the cold and hot regions, the estimated gross savings for control dwellings is negative, but the mean is not significantly different from zero.

For both the sample of weatherized and control dwellings, pre-weatherization electricity use is highest in the cold climate regions and lowest in the hot region. (This differs from the regional pattern of gas consumption, where the moderate climate region is the most energy intensive.) The percent net savings range from $5.4 \%$ in the hot region to $14.9 \%$ in the moderate region. Fig. 5.7 vividly illustrates these climate region differences.

12 The PRISM analysis of weatherized dwellings that have significant amounts of electric heating and cooling, indicates that $2,159 \mathrm{kWh} / \mathrm{year}$ (or $14 \%$ of the whole house electricity consumption) is dedicated to air conditioning. The comparable estimate based on control dwellings is $2,303 \mathrm{kWh}$ or $16 \%$. The PRISM analysis of dwellings that are best fit by the Cooling-Only model, indicates that a higher arnount of energy is used for space cooling--2,933 kWh (or 19\%) for weatherized dwellings and $2,460 \mathrm{kWh}$ (or $18 \%$; for control dwellings. Thus, the estimate of $17 \%$ used in this chapter is consistent with these results. The 1990 RECS indicates that low-income houscholds with air conditioning equipment consume $19 \%$ of their electricity for space cooling, and that households with electric heat and electric cooling consume $44 \%$ of their electricity for combined space heating and cooling. 


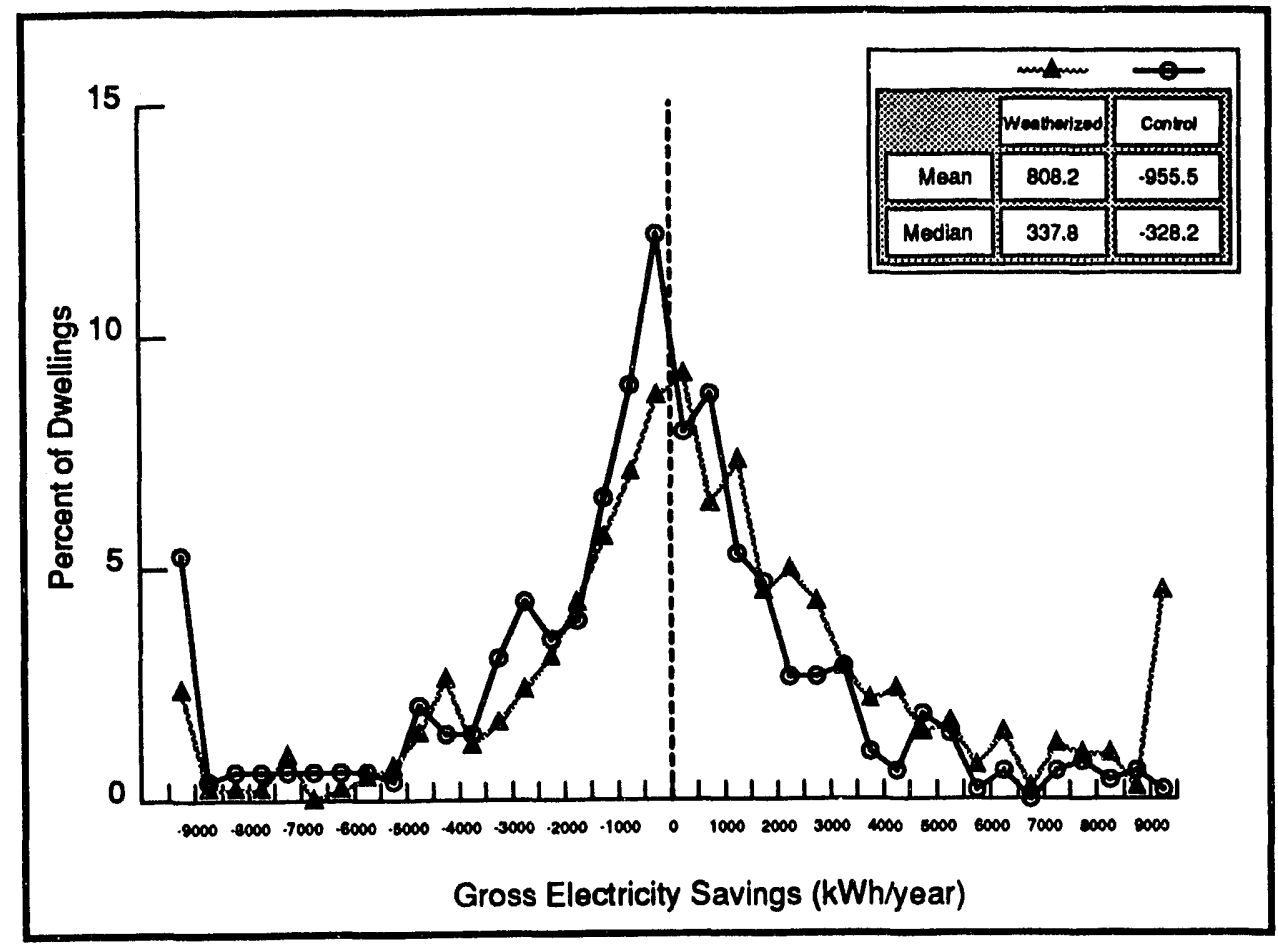

Fig. 5.6a Distribution of Electricity Savings for Electrically Heated Weatherized and Control Dwellings (unweighted)

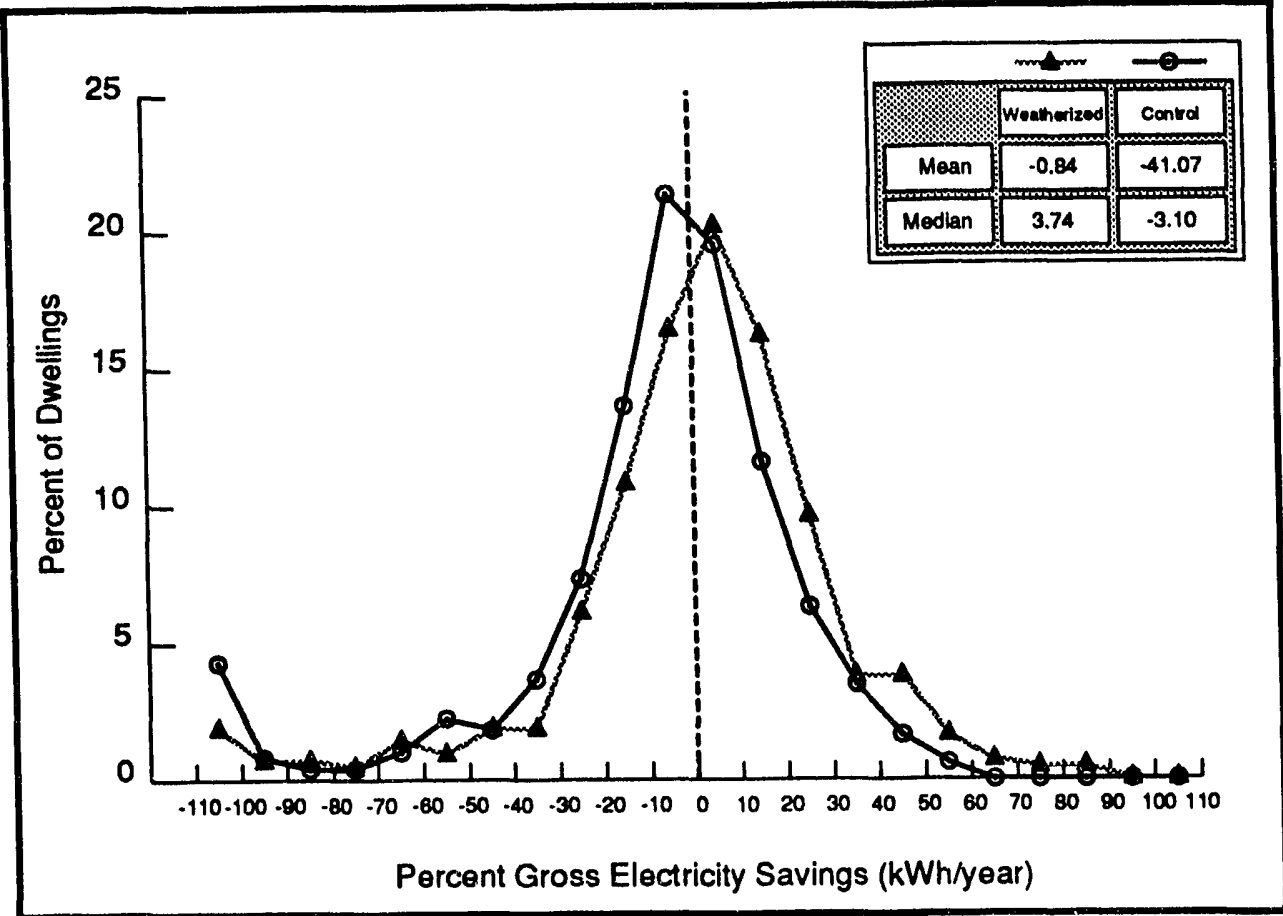

Fig. 5.6b Distribution of Percent Electricity Savings for Electrically Heated Weatherized and Control Dwellings (unweighted) 
Table 5.4 Average First-Year Electricity Savings for Electrically Heated Weatherized and Control Dwellings (in kWh/year), by Climate Regiona

\begin{tabular}{|c|c|c|c|c|c|c|c|}
\hline & & Pre-NAC & Post-NAC & $\begin{array}{l}\text { Gross } \\
\text { savings }\end{array}$ & $\begin{array}{l}\text { Percent } \\
\text { gross } \\
\text { savings }\end{array}$ & savings & 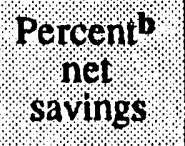 \\
\hline \multirow{2}{*}{$\begin{array}{l}\text { Coldid. } \\
\text { Climair. } \\
\text { Region. }\end{array}$} & $\begin{array}{l}\text { Weathenzed } \\
\text { owellings } \\
\text { : }=35\end{array}$ & $\begin{array}{r}18,648 \\
(1,694)\end{array}$ & $\begin{array}{r}16,715 \\
(1,509)\end{array}$ & $\begin{array}{r}1,933 \\
(1,191)\end{array}$ & $10.4 \%$ & $\begin{array}{r}2,686 \\
(1,527)\end{array}$ & $14.4 \%$ \\
\hline & $\begin{array}{l}\text { Control: } \\
\text { Dwellingss } \\
\text { n=42 }\end{array}$ & $\begin{array}{r}19,432 \\
(1,282)\end{array}$ & $\begin{array}{r}20,186 \\
(1,550)\end{array}$ & $\begin{array}{r}-753 \\
(956)\end{array}$ & $-3.9 \%$ & & \\
\hline \multirow{2}{*}{$\begin{array}{l}\text { Moderate } \\
\text { Climate. } \\
\text { Region. }\end{array}$} & $\begin{array}{l}\text { Weatherized } \\
\text { Dwellings } \\
n=260\end{array}$ & $\begin{array}{r}16,601 \\
(495)\end{array}$ & $\begin{array}{r}15,661 \\
(478)\end{array}$ & $\begin{array}{r}939 * * \\
(300)\end{array}$ & $5.7 \%$ & $\begin{array}{c}2,479 * * * \\
(483)\end{array}$ & $14.9 \%$ \\
\hline & $\begin{array}{l}\text { Control } \\
\text { Dyellings } \\
n=256\end{array}$ & $\begin{array}{r}16,317 \\
(549)\end{array}$ & $\begin{array}{r}17,857 \\
(607)\end{array}$ & $\begin{array}{c}-1,540 * * * \\
(359)\end{array}$ & $-9.4 \%$ & & \\
\hline \multirow{2}{*}{$\begin{array}{l}\text { Hot } \\
\text { Climate } \\
\text { Region }\end{array}$} & $\begin{array}{l}\text { Weatherized } \\
\text { Dwellings } \\
n=131\end{array}$ & $\begin{array}{r}11,071 \\
(636)\end{array}$ & $\begin{array}{r}10,765 \\
(529)\end{array}$ & $\begin{array}{r}307 \\
(378)\end{array}$ & $2.8 \%$ & $\begin{array}{r}595 \\
(419)\end{array}$ & $5.4 \%$ \\
\hline & $\begin{array}{l}\text { Control } \\
\text { Dwellings } \\
\mathrm{n}=194\end{array}$ & $\begin{array}{l}9,680 \\
(476)\end{array}$ & $\begin{array}{l}9,908 \\
(502)\end{array}$ & $\begin{array}{r}-228 \\
(180)\end{array}$ & $-2.4 \%$ & & \\
\hline \multicolumn{8}{|c|}{$\begin{array}{l}\text { a Numbers in parentheses are standard errors of the estimates. } \\
\text { b Percent net savings is calculated as the net savings divided by the average pre-NAC, and } \\
\text { multiplied by } 100 \text {. } \\
\text { * * and *** indicate that savings are statistically different from zero at the } 0.01 \text { and } 0.001 \text { levels, } \\
\text { respectively. }\end{array}$} \\
\hline
\end{tabular}




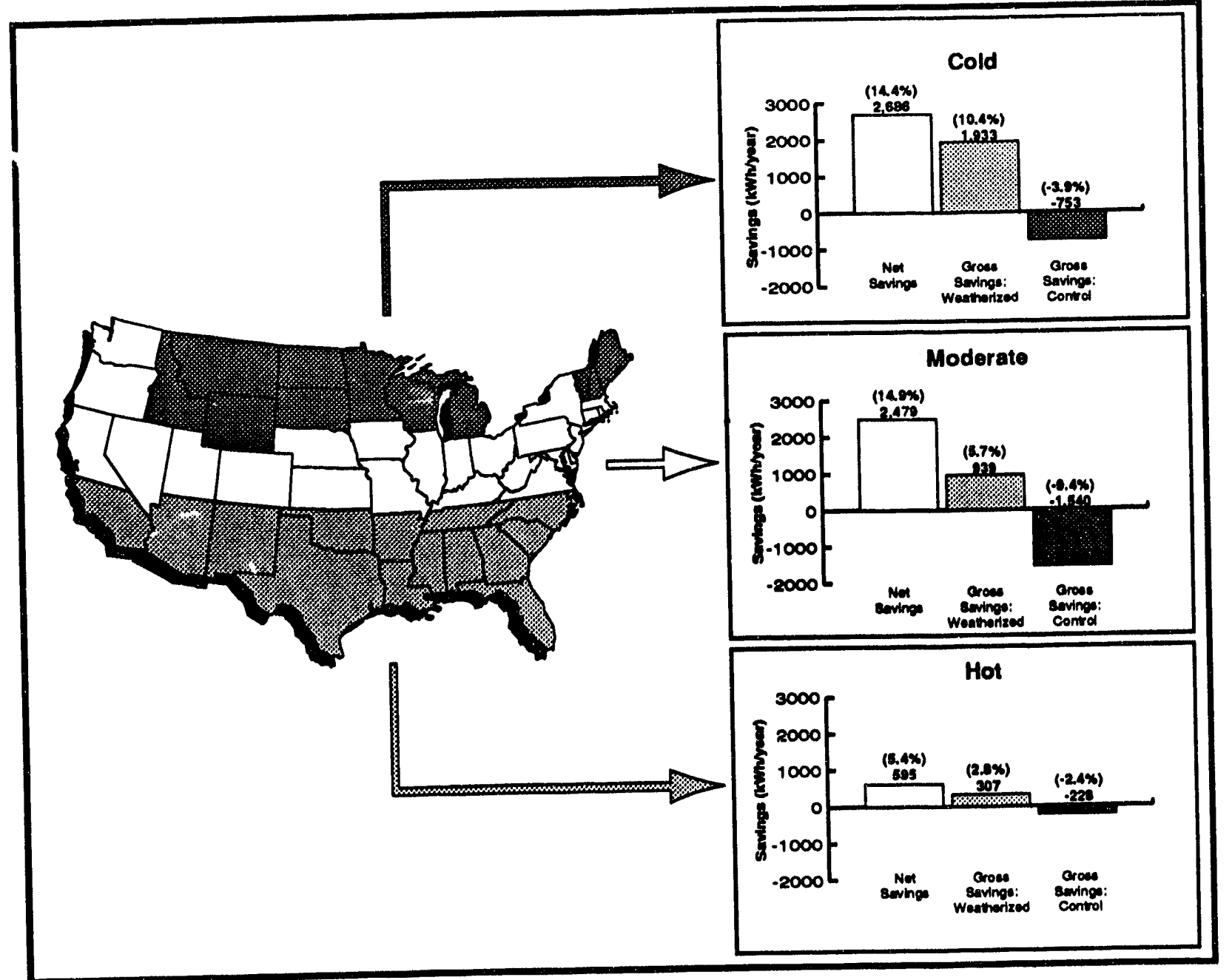

Figure 5.7 Electricity Savings by Climate Region

\subsubsection{Electricity Savings, by Dwelling Type}

Fig. 5.8 shows how electricity savings vary across different types of electrically heated dwellings. ${ }^{13}$ The differences across each type are significant. In particular, single-family detached homes and small multifamily dwellings save more electricity after weatherization than do mobile homes. The same pattern of high performance among single-family detached homes and small multifamily dwellings was found in the analysis of gas-heated homes. One difference is that the estima:cd gross savir.gs for electrically heated mobile homes is negative, although the sample size $(\mathrm{N}=48)$ is smal!

13 Savings estimates are available for only five electrically heated single-family attached weatherized dwellings. As a result, no statistics on this subgroup are provided. 


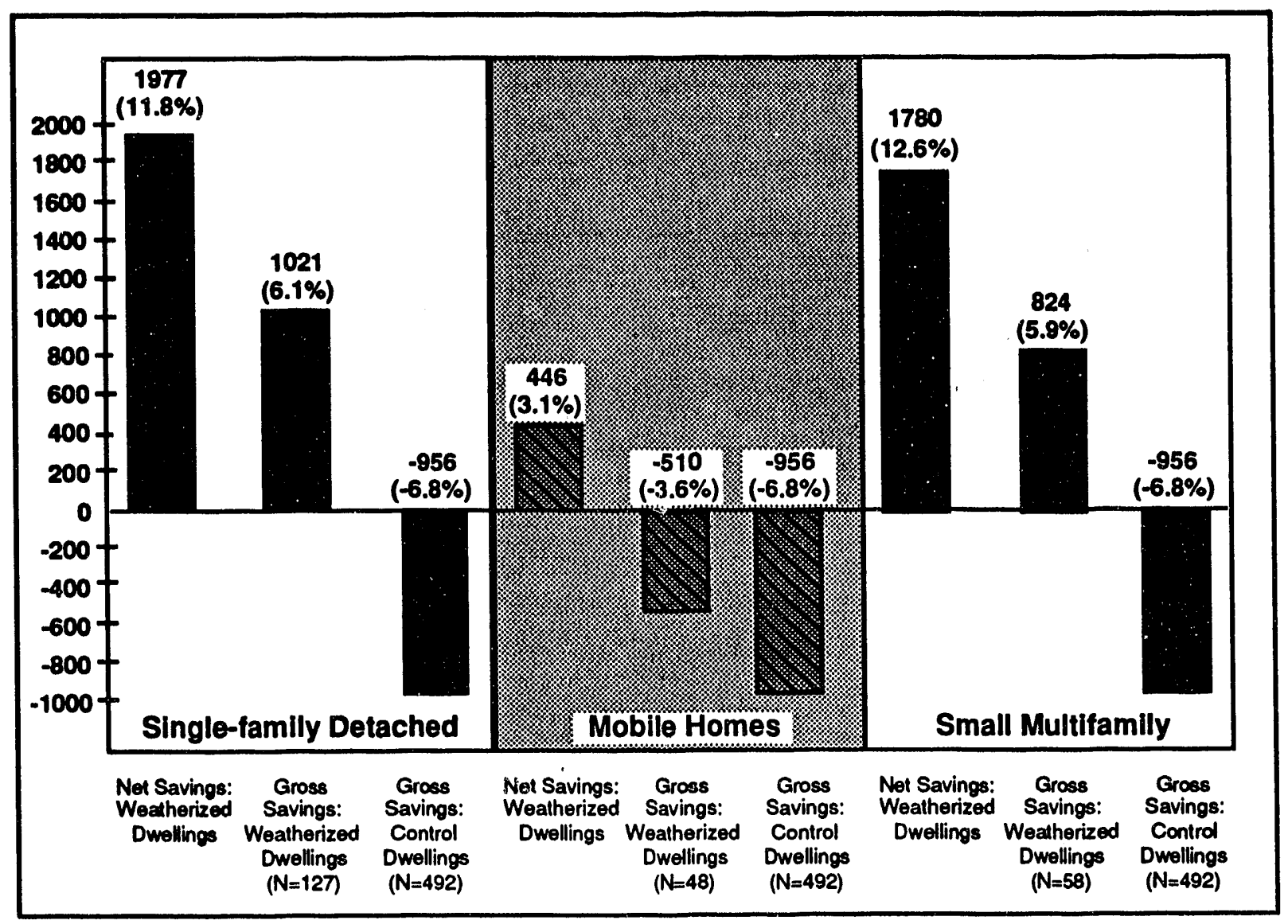

Fig. 5.8 Electricity Savings by Dwelling Type

\subsubsection{Electricity Savings, by Size of Local Weatherization Assistance Program Agency}

Large and medium-sized local agencies have slightly higher gross savings than small agencies (Fig. 5.9). They have considerably higher net savings because of the sizable increase in consumntion experienced by the control groups for the medium ind large agencies. Medium-sized and large agencies generated similarly high gross and net savings in the gas-heated dwellings they weatherized. 


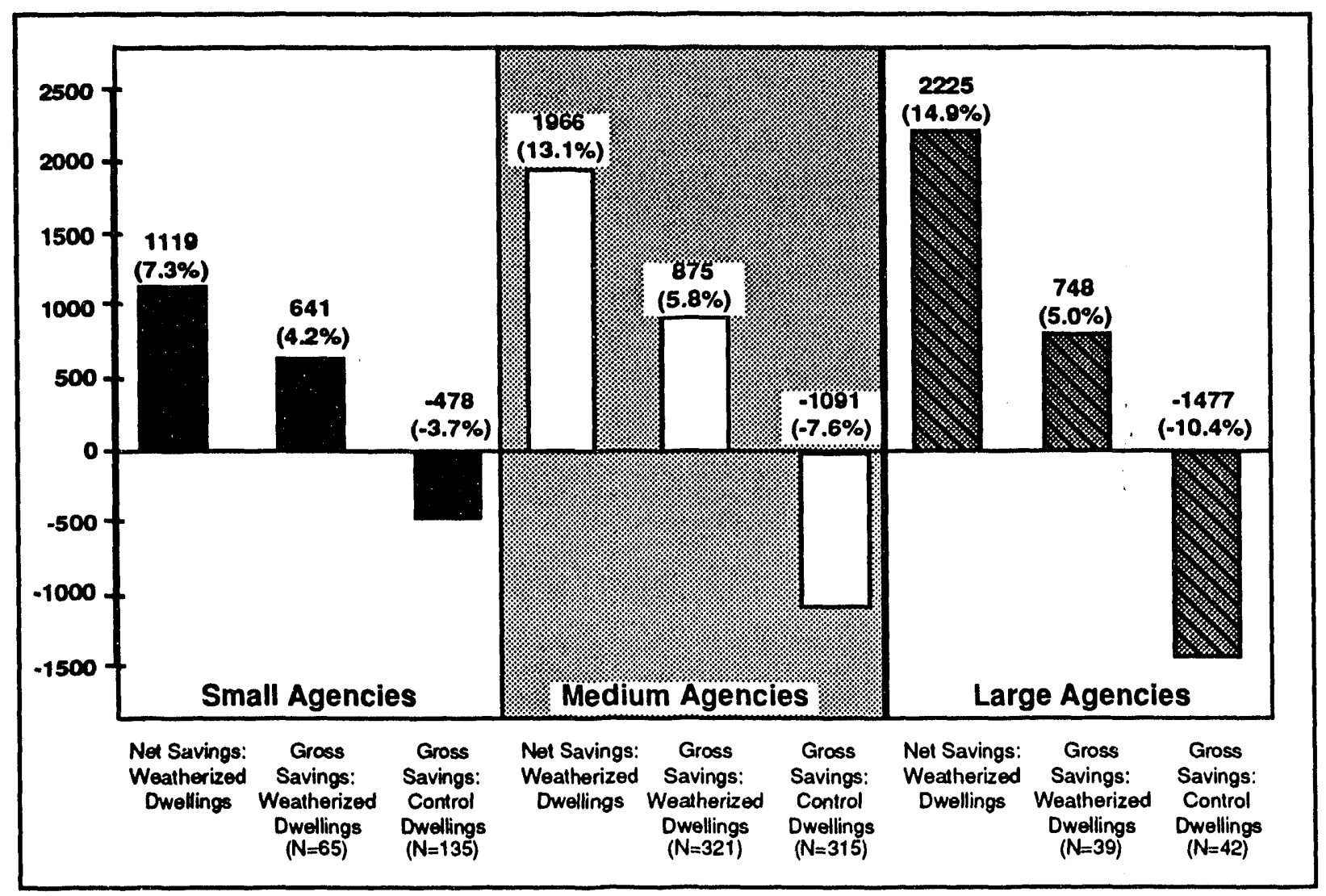

Fig. 5.9 Electricity Savings by Size of Local Weatherization Assistance Program Agency

Electricity savings as a percent of pre-weatherization electricity consumption is also high for both medium and large agencies. (Recall that this was not true of the gas-heated dwellings weatherized by large agencies, which had high pre-NAC's and hence low percent savings.) In contrast, the net savings of small agencies is only $7 \%$ of pre-weatherization electricity use.

\subsection{DWELLINGS HEATED BY OTHER FUELS}

To estimate the energy saved by homes that heat primarily with fuels other than natural gas and electricity, a common unit of energy was necessary. Table 5.5 provides conversion factors for converting natural gas, electricity, fuel oil, and barrels of petroleum into millions of Btu's (MBtu's). 
Table 5.5 Conversion Factors

\begin{tabular}{|l|c|c|c|}
\hline Fuel & Basic Units & MBtu's/Unit & Units/MBtu's \\
\hline Natural Gas & hundred cubic feet (ccf) & 0.1 & 10 \\
\hline Electricity & kilowatt hours (kWh) & 0.003412 & 293 \\
kilowatt hours (kWh) & $0.010331^{\mathrm{a}}$ & 96.8 \\
\hline Fuel Oil & gallons & 0.14 & 7.14 \\
\hline Petroleum & barrels & 5.8 & 0.172 \\
\hline
\end{tabular}

a Assumes a $33.03 \%$ conversion efficiency.

Sources: Energy Information Administration (1991).

Besides the consumption data collected in the Fuel-Oil Study, no primary consumption data were collected for dwellings that heat with "other" fuels. As a result, indirect estimates had to be made of energy savings in these dwellings. As was shown in Chapter 3, weatherized dwellings that heat with other fuels are somewhat distinct. Most noteworthy is the fact that they tend to be located disproportionately in the hot climate region. They are more likely to be mobile homes, to be owneroccupied, and to have elderly or handicapped occupants than gas- or electrically heated dwellings. Chapter 4 showed that homes heated with other fuels receive a mix of weatherization measures that resembles the national average, albeit with slightly higher rates of mobile home measures and storm windows and doors and a slightly lower than average installation rate for water heater measures.

The traits of weatherized dwellings that heat with other fuels are similar to those of gas-heated homes. Most of the differences between them can be explained by the disproportionately high representation of homes with other primary fisels in the hot climate region. In addition, there are not many gas-heated mobile homes, even in the hot region.

Our approach to estimating the energy saved by dwellings primarily heated by other fuels is two fold. First, we assume that fuel-oil heated homes located in the nine northeastem States covered by the Fuel-Oil Study save the same amount of energy as the average home in that study - 160 gallons of fuel oil per year (Ternes and Levins, 1992). Fuel-oil heated homes in the nine northeastern States account for $21 \%$ of the dwellings heated by other fuels, and $8 \%$ of the population of weatherized dwellings, in aggregate.

Second, we assume that on a climate region-by-climate region basis, dwellings heated by other fuels, including those dwellings heated by fuel oil which are located outside of the Northeast, save the same amount of energy as gas-heated dwellings. That is, we assume that the only difference between these homes and gas-heated dwellings is their geographic distribution.

Table 5.6 shows the proportion of homes located in each of the three climate regions, by type of primary heating fuel. These proportions are multiplied by the average energy savings per gas- 
heated dwelling in the respective regions; the products are then added to estimate the average energy saved per weatherized dwelling, for a particular type of primary heating fuel. The weighted average of these fuel-specific values provides an estimate of the average energy saved per weatherized dwelling that heats with other fuels - 17.7 MBtu's per year. This value is slightly higher than the estimated energy savings for gas-heated homes (17.3 MBtu's per year), because of the high savings of fuel-oil heated homes located in the nine northeastem states (22.4 MBtu's per year).

Table 5.6 Energy Saved by Dwellings Heated by Other Fuels

\begin{tabular}{|c|c|c|c|c|c|}
\hline $\begin{array}{l}\text { Type of Primary } \\
\text { Heating Fuel }\end{array}$ & $\begin{array}{l}\text { Cold } \\
\text { Region }\end{array}$ & $\begin{array}{l}\text { Moderate } \\
\text { Reglon }\end{array}$ & $\begin{array}{r}\text { Hot } \\
\text { Region } \\
\end{array}$ & $\begin{array}{l}\text { ' } \\
\text { Proportion of } \\
\text { Dwellings } \\
\text { Heated by } \\
\text { Other Fuels }\end{array}$ & $\begin{array}{l}\text { Weighted } \\
\text { Mean Energy } \\
\text { Savings per } \\
\text { Weatherized } \\
\text { Dwelling } \\
(\mathrm{MBtu} / \text { year })\end{array}$ \\
\hline & \multicolumn{3}{|c|}{ Proportion of Dwellings Located in: } & & \\
\hline Fuel Oil (Northeast) & 0.160 & 0.840 & 0 & 0.206 & 22.4 \\
\hline Fuel oil (Other States) & 0.431 & 0.408 & 0.161 & 0.196 & 19.0 \\
\hline Liquified Propane Gas & 0.221 & 0.340 & 0.439 & 0.332 & 15.4 \\
\hline Wood & 0.141 & 0.553 & 0.307 & 0.147 & 16.2 \\
\hline Kerosene & 0.134 & 0.532 & 0.334 & 0.079 & 15.9 \\
\hline Coal or Coke & 0.044 & 0.785 & 0.171 & 0.036 & 16.9 \\
\hline Other & 0.171 & 0.408 & 0.421 & 0.004 & 15.3 \\
\hline \multirow[t]{2}{*}{$\begin{array}{l}\text { Weighted Mean } \\
\text { or Total }\end{array}$} & 0.224 & 0.519 & 0.257 & 100.0 & \\
\hline & \multicolumn{3}{|c|}{$\begin{array}{l}\text { Weighted Mean Energy Savings per } \\
\text { Weatherized Dwelling (MBtu/year): }\end{array}$} & & \\
\hline $\begin{array}{l}\text { Weighted Mean } \\
\text { Value }\end{array}$ & 23.3 & 19.6 & 9.1 & & 17.7 \\
\hline
\end{tabular}


The estimated energy saved by different types of "other" fuels suggests that fuel oil has contributed more than any of the others. It is the most common "other" fuel among homes weatherized in PY 1989, and it is used primarily in the cold and moderate regions. Liquid propane gas is the next most common "other" fuel, but because it is used primarily in the hot region, it contributes much less to the Program's total energy savings.

Altogether, the energy savings of "other" fuels, per weatherized dwelling, are greatest in the cold region (averaging $22.9 \mathrm{MBtu} / \mathrm{dwelling}$ ) and least in the hot region (at $7.6 \mathrm{MBtu} / \mathrm{dwelling}$ ). It must be reiterated, however, that these are indirect estimates and they should be treated with caution.

\subsection{PROGRAMWIDE ENERGY SAVINGS}

\subsubsection{Programwlde Energy Savings}

Estimates of programwide energy savings are summarized in Table 5.7. These estimates were obtained by combining the estimated energy savings for the three types of dwellings (gas, electricity, and other) into a weighted average.

Energy savings for gas-heated homes were obtained by converting the gas savings from ccf's to equivalent MBtu's. Electricity savings in $\mathrm{kWh} /$ year were converted to MBtu's at the point of consumption ("site" or end use) and at the "source." The former value corresponds to the heat content of the kWh used by the consumer. The latter value corresponds to the energy required to generate and transmit the equivalent number of $\mathrm{kWh}$. Thus, the source value accounts for losses incurred due to generation, transmission, and distribution.

The average first-year net energy savings per dwelling weatherized in PY 1989 is estimated to be 16.4 MBtu's (site) and 17.6 MBtu's (source). This represents a $13.5 \%$ reduction in total energy use, an $18.2 \%$ reduction in the energy used for space heating, and an annual decrease of $\$ 116$ in the low-income participant's energy burden.

During PY 1989, the Weatherization Assistance Program weatherized 198,000 single-family or small multifamily homes, resulting in a total savings of 3,487,000 MBtu's during the first year following weatherization (i.e., in 1990-91). At an equivalence of 5.8 MBtu's per barrel of oil, the Program saved approximately 601,000 barrels of oil during 1990-91, or about 1,650 barrels of oil per day. Over the 20-year lifetime of the weatherization measures, the Program's savings amount to $69,740,000$ MBtu's, or 12 million barrels of oil. ${ }^{14}$

14 See Appendix H-2 for an explanation of the assumed 20-year period of energy savings. 
Table 5.7 First and 20-Year Energy Savings of Housing Units Weatherized in PY 1989

\begin{tabular}{|c|c|c|c|c|}
\hline \multirow[b]{2}{*}{$\begin{array}{l}\text { Type of Primary } \\
\text { Heating Fuel }\end{array}$} & \multirow{2}{*}{$\begin{array}{l}\text { No. Units } \\
\text { Weatherized in } \\
\text { PY } 1989\end{array}$} & \multirow{2}{*}{$\begin{array}{c}\text { First-Year } \\
\text { Energy Savings } \\
\text { per Dwelling }\end{array}$} & \multicolumn{2}{|c|}{$\begin{array}{l}\text { Programwide } \\
\text { Energy Savings }\end{array}$} \\
\hline & & & $\begin{array}{l}\text { First-Year } \\
\text { (in MBtu's) }\end{array}$ & $\begin{array}{l}\text { 20-Year Total } \\
\text { (in MBtu's) }\end{array}$ \\
\hline Natural Gas & 100,188 & 17.3 & $1,733,000$ & $34,670,000$ \\
\hline $\begin{array}{l}\text { Electricity: } \\
\text { Site } \\
\text { Source }\end{array}$ & $\begin{array}{l}18,810 \\
18,810\end{array}$ & $\begin{array}{r}6.2 \\
18.9\end{array}$ & $\begin{array}{l}117,000 \\
356,000\end{array}$ & $\begin{array}{l}2,340,000 \\
7,120,000\end{array}$ \\
\hline Other Fuels & 79,002 & 17.7 & $1,398,000$ & $27,960,000$ \\
\hline $\begin{array}{l}\text { Weighted Average } \\
\text { or Total: } \\
\text { Site } \\
\text { Source }\end{array}$ & $\begin{array}{l}198,000 \\
198,000\end{array}$ & $\begin{array}{l}16.4 \\
17.6\end{array}$ & $\begin{array}{l}3,248,000 \\
3,487,000\end{array}$ & $\begin{array}{l}64,960,000 \\
69,740,000\end{array}$ \\
\hline
\end{tabular}

\subsection{COMPARISONS WITH OTHER WEATHERIZATION EVALUATIONS}

This section compares the estimated energy savings of the 1989 Program with the savings estimated for the 1981 Program. Comparisons are then made with the energy saved by utilityoperated low-income weatherization programs and Weatherization Assistance Programs operated by a sample of States.

\subsubsection{Comparison with the 1981 Program}

Recall that the Energy Information Administration's evaluation of the 1981 Weatherization Assistance Program (Peabody, 1984) is the only previous nationwide evaluation of the Program. These previous estimates of energy savings for the 1981 Program are not dircctly comparable to the estimates presented earlier in this chapter, because of numerous methodological differences:

- the EIA study employed a different modeling approach to estimate savings ${ }^{15}$

15 The PY 1981 evaluation based its savings estimates on the difference between predicted post-weatherization consumption and actual post-weatherization consumption. The predicted consumption estimates were obtained from a regression equation with an extensive list of variables related to dwelling, energy equipment, and occupant characteristics. The process of predicting consumption was designed to statistically control for the influences of weather and other confounding factors. This process introduces many possible sources of variation which are not present in this study. In contrast, the Single-Family Study normalizes for weather with PRISM and controls for other confounding factors with a control group. Thus, it is not possible to replicate the previous evaluation's methods in this study, nor is it possible to adapt its findings to make them precisely comparable to ours. 
- the EIA study excluded units in small multifamily buildings, and included few mobile homes

- the EIA study excluded units if they experienced a change in occupancy between 1980 and 1983

- the EIA study included fewer homes from warm weather States; as a result, the average pre-NAC gas consumption of the homes in its sample is high

- the EIA study did not collect consumption data for a control group, but instead incorporated external factors in its modeling estimates of net savings.

Despite these differences, comparisons are useful since the EIA study is the only other national evaluation of the Weatherization Assistance Program conducted to date.

Table 5.8 compares the energy savings estimates for 1981 (from the EIA study) and 1989 (this evaluation). The evaluation of the 1981 Program examined 568 gas-heated homes which consumed an estimated 1,342 ccf of gas during the first year after weatherization. Through a modeling approach, Peabody estimated that this represented an average savings of $160 \mathrm{ccf} / \mathrm{year}$, or a 10.7\% reduction (Table 5.8). These values are lower than the estimates of program-induced gas

Table 5.8 Energy Savings by Primary Heating Fuel: An Earlier Evaluation (1981) and the Current Evaluation (1989)a

\begin{tabular}{|c|c|c|c|}
\hline $\begin{array}{c}\text { Primary Heating Fuel } \\
\text { (and Number of Dwellings } \\
\text { in Sample) }\end{array}$ & $\begin{array}{l}\text { Annual } \\
\text { Pre-Weatherization } \\
\text { Energy Use } \\
\text { (MBtu's) }\end{array}$ & $\begin{array}{l}\text { First-Year } \\
\text { Energy Savings } \\
\text { (MBtu's) }\end{array}$ & $\begin{array}{l}\text { Percent Energy } \\
\text { Savings }\end{array}$ \\
\hline $\begin{array}{l}\text { Natural Gas } \\
1981(N=568) \\
1989(N=3,873+2,611)\end{array}$ & $\begin{array}{l}150.2 \\
133.4\end{array}$ & $\begin{array}{l}16.0 \\
17.3\end{array}$ & $\begin{array}{l}10.7 \% \\
13.0 \%\end{array}$ \\
\hline $\begin{array}{l}\text { Electricity } \\
1981(\mathrm{~N}=43) \\
1989(\mathrm{~N}=426+492)\end{array}$ & $\begin{array}{c}61.0 \\
51.1 \text { (site) } \\
154.7 \text { (source) }\end{array}$ & $\begin{array}{c}5.2 \text { (sitc) } \\
6.2 \text { (site) } \\
18.9 \text { (source) }\end{array}$ & $\begin{array}{c}8.5 \% \\
12.2 \% \text { (site) } \\
12.2 \% \text { (source) }\end{array}$ \\
\hline $\begin{array}{l}\text { All Primary Heating Fuels } \\
1981 \\
1989\end{array}$ & $\begin{array}{c}129.0 \text { (site) }^{b} \\
121.3(\text { site })^{c} \\
131.7 \text { (source) }^{c}\end{array}$ & $\begin{array}{c}13.8 \text { (site) } \\
16.4 \text { (site) }^{c} \\
17.6 \text { (source) }^{c}\end{array}$ & $\begin{array}{l}10.7 \% \\
13.5 \% \mathrm{c} \\
13.5 \% \mathrm{c}\end{array}$ \\
\hline
\end{tabular}

a Estimates for 1981 are drawn from Peabody (1984).

b Derived from the following statistics reported by Pcabody (1984, p. 18): the 1981 Program saved 13.8 MBtu's of energy in the year following weatherization, and this is 10.4 to $10.9 \%$ of total household use of the main home heating fucl.

c Includes estimates for fuels other than natural gas and electricity that are derived indirectly. 
savings provided in the current evaluation (173 ccf/year or $13.0 \%$ savings), suggesting that the program improved during the 1980's, despite the lower levels of pre-weatherization gas use in 1989 relative to 1981 .

The evaluation of the 1981 Program also examined 43 electrically heated homes which consumed an estimated $16,349 \mathrm{kWh}$ of electricity during the first year after weatherization. Through a modeling approach, Peabody (1984) estimated that this represented an average total electricity savings of $1,524 \mathrm{kWh} /$ year per weatherized dwelling, or an $8.5 \%$ reduction. These values are lower than the estimates of program-induced electricity savings provided in the current evaluation $(1,830$ $\mathrm{kWh} /$ year or $12.2 \%$ savings), suggesting that the program improved during the 1980 's, despite the lower levels of pre-weatherization electricity use in 1989 relative to 1981 .

Based mostly on an indirect estimation approach (the exception being fuel-oil homes in nine northeastem states where savings have been monitored), dwellings heated primarily by fuels other than uatural gas and electricity are estumated to save $17.7 \mathrm{MBtu}$ 's per dwelling weatherized in 1989. Based on this estimate, and the measured savings for gas and electricity, program-wide savings estimates for 1989 are derived ('Table 5.8) The results indicate a slight increase in estimated savings, from 13.8 MBtu's to 16.4 MBtu's (at the site) and 17.6 MBtu's (at the source). At the same time, the program has experienced a reduction in the levels of pre-weatherization energy consumption of participants, which may be an artifact of the greater proportion of program participants located in the hot region in recent years compared with 1981. Since the potential for energy savings declines with lower pre-wea'herization 'se, the increased savings of the Program is particularly noteworthy.

In addition to the general increase in savings over time and decrease in levels of preweatherization energy use, our findings differ in other ways from the results of the national evaluation of the 1981 Program (Peabody, 1984). Peabody found little variation in energy savings by climate region, reporting only slightly higher savings in colder climates. The Single-Family Study documents much bigher savings in the moderate and cold regions compared with the hot region. Peabody estimated lower savings for electrically heated dwellings than for dwellings heated by natural gas, but our results show comparability, particularly if you consider percent savings. Finally, our (indirect) estimates of energy savings for homes heating primarily with fuel oil or kerosene are particularly high, while they were more average in the asse sment of the earlicr program.

\subsubsection{Comparison with Utility Programs}

This section compares our findings with the results of evaluations of utility-operated lowincome weatherization programs. Because utility evaluations have focused primarily on the cost effectiveness of weatherizing gas-heated homes, we will limit our discussion to that heating fuel.

Fig. 5.10 graphs the annual energy savings of four sets of utility-operated low-income weatherization progı ams, along with our estimates of national savings for the Program and savings for 
each of the three climate regions. It illustrates that the performance of the 1989 Program is comparable to the performance of these utility low-income programs.

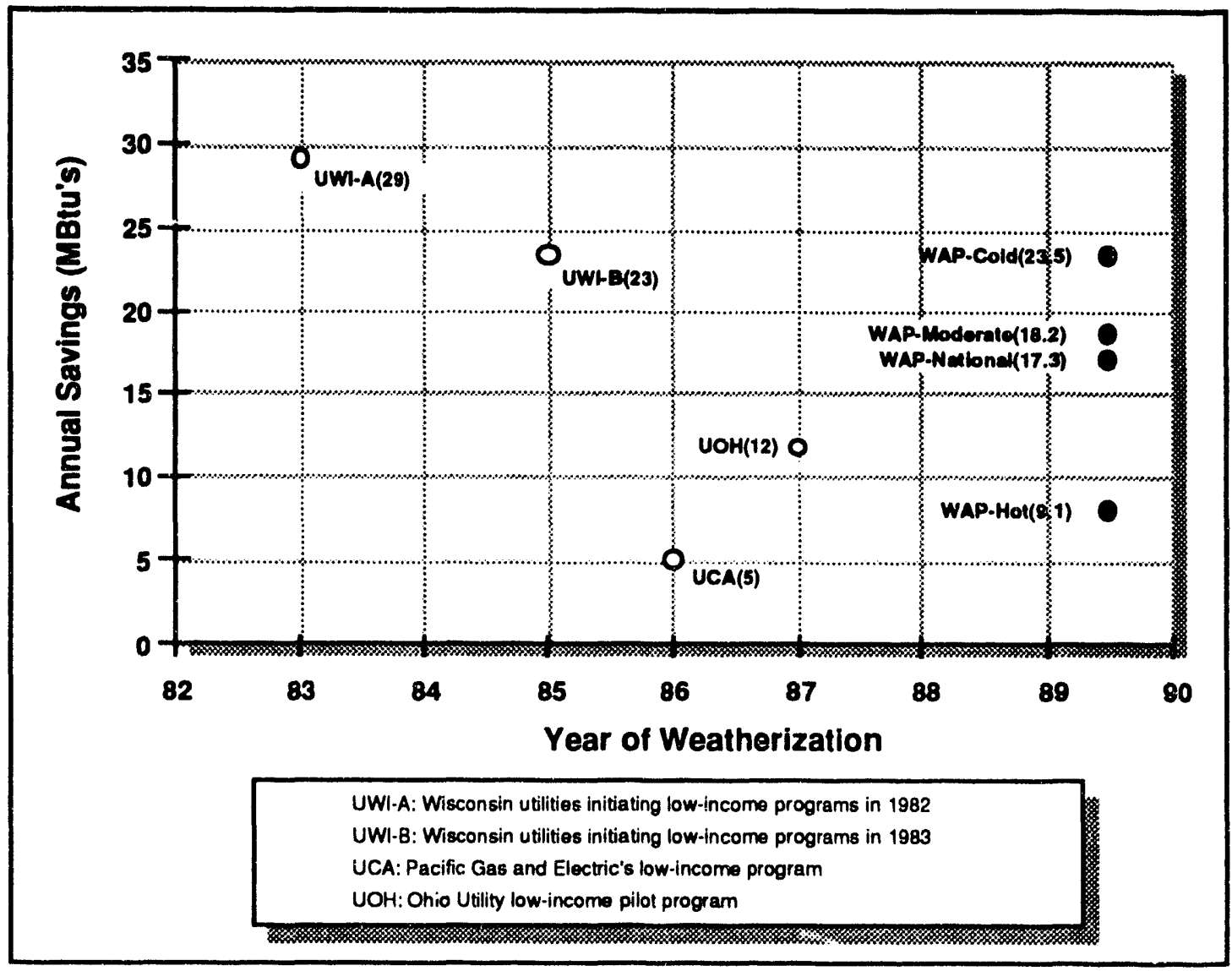

Fig. 5.10 Weatherization Assistance Program Gas Savings Vs Utility Low-Income Weatherization Program Savings

\subsubsection{Comparison with State Weatherization Programs}

Figure 5.11 compares our findings with the results of evaluations of four State Weatherization Assistance Programs. Because evaluations of State programs have focused primarily on the cost effectiveness of weatherizing gas-heated homes, we will limit our discussion to that heating fuel, as was done in the above section. ${ }^{16}$

Recall from our review of the literature in Chapter 1 that to date, no State programs in the hot region have been evaluated using measured encrgy savings. The 1988 Virginia program is the most southern program with measured energy savings, and its gas savings were only $7 \mathrm{ccf} / \mathrm{year}-22 \%$ less than the hot region produced in the 1989 Program. The 1981 Wisconsin and 1984 Michigan

16 While additional State weatherization programs have been evaluated (see Cohen and Goldman, 1991 and Schegel and Pigg, 1990, for additional references), these four program evaluations werc belicved to have particularly strong research designs. 
programs generated energy savings of 14 and $17 \mathrm{ccf} / \mathrm{year}$, respectively, which is less than the cold climate region's average savings for dwellings weatherized in 1989. Finally, the 1988 New York program had measured savings of $19 \mathrm{ccf} / \mathrm{year}$, which is close to the moderate climate region's average savings for dwellings weatherized in 1989. This region-by-region comparison suggests the possibility that low-income weatherization programs have improved measurably during the last half of the decade.

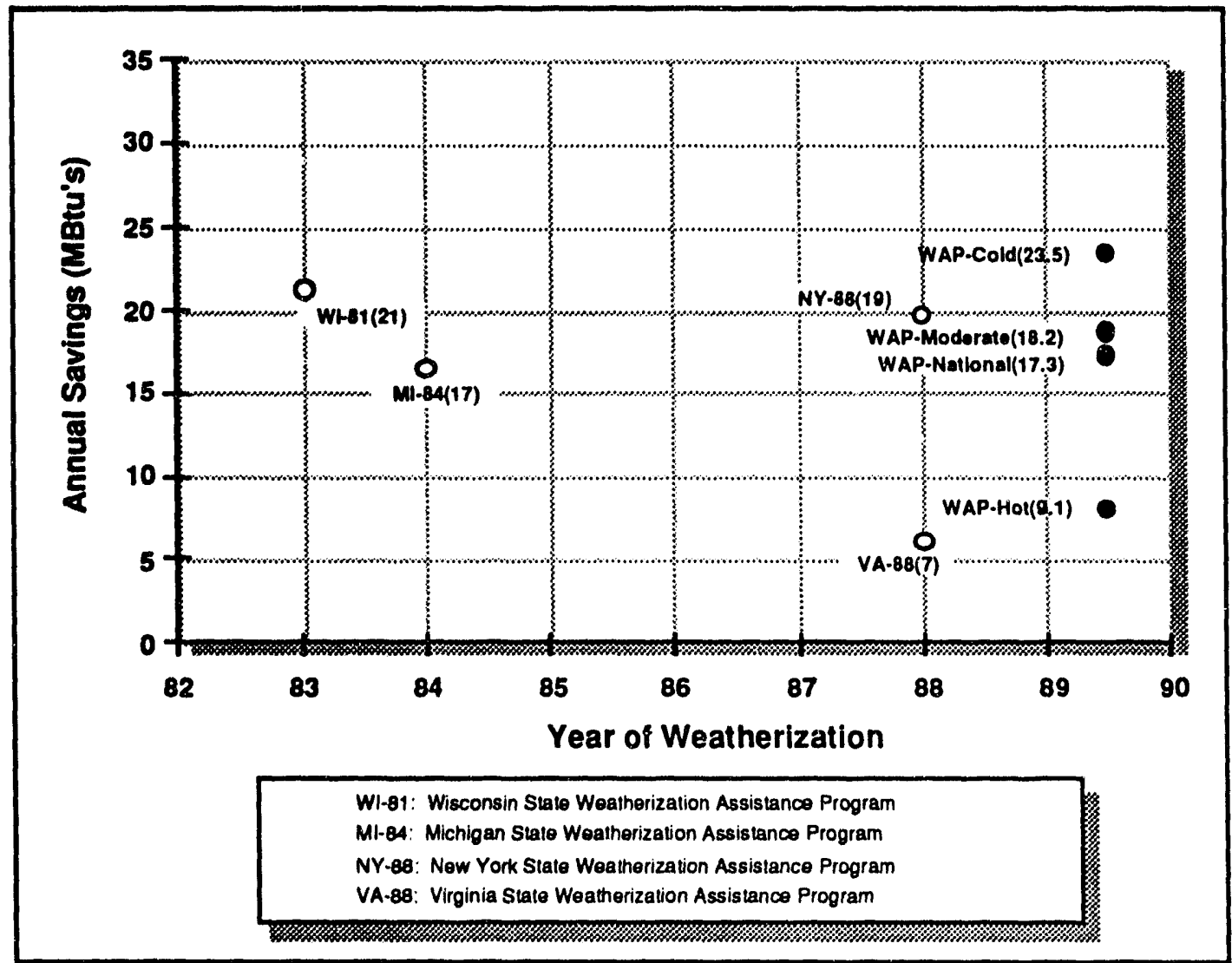

Fig. 5.11 Weatherization Assistance Program Gas Savings Vs State Weatherization Program Savings

\subsection{SUMMARY}

The Single-Family Study emphasizes the weighted estimation of nct energy savings, as the best measure of program impact. The weighting corrects for differences in sampling fractions and in response rates, and the use of a control group accounts for changes in energy consumption that would have occurred in the absence of the Program. 


\subsubsection{Gas-Heated Dwellings}

Gas-heated dwellings account for $90 \%$ of the sample dwellings for which fuel consumption records were available, and represent approximately half of the dwellings weatherized by DOE's 1989 Program. Thus, their performance dominates the outcome of the National Weatherization Evaluation. This study's weighted estimate of net savings in gas-heated homes is $173 \mathrm{ccf}$ or $13.0 \%$ of pre-weatherization gas consumption (Table 5.9). The percent savings are higher when based on the gas used for space-heating purposes during the year preceding weatherization. The average net savings of $173 \mathrm{ccf} / \mathrm{year}$ is estimated to be $18.3 \%$ of the gas used for space heating.

Table 5.9 Gas Savings in Gas-Heated Dwellings

\begin{tabular}{|c|c|c|c|c|}
\hline & Cold Region & $\begin{array}{l}\text { Moderate } \\
\text { Region }\end{array}$ & Hot Region & Program-wide \\
\hline Number of Dwellings & 1,040 & 2,243 & 590 & 3,873 \\
\hline $\begin{array}{l}\text { First-year Gross Savings (in } \\
\text { ccf/dwelling) }\end{array}$ & 166 & 137 & 102 & 135 \\
\hline $\begin{array}{l}\text { First-year Net Savings (in } \\
\text { ccf/dwelling) }\end{array}$ & 235 & 182 & 91 & 173 \\
\hline $\begin{array}{l}\text { Net Savings as Percent of Total } \\
\text { Gas Use }\end{array}$ & $17.7 \%$ & $12.4 \%$ & $10.9 \%$ & $13.0 \%$ \\
\hline $\begin{array}{l}\text { Net Savings as Percent of Gas } \\
\text { Used for Space Heating }\end{array}$ & $24.9 \%$ & $17.5 \%$ & $15.4 \%$ & $18.3 \%$ \\
\hline
\end{tabular}

Net savings are highest in the cold region (235 ccfs), nearly as high in the moderate region (182 ccf's), and much lower in the hot region (91 ccf's). Because pre-weatherization gas use is highest in the moderate climate region, net savings as a percent of total gas use for this region $(12.4 \%)$ is much less than in the cold region $(17.7 \%)$. Pre-weatherization gas use is low in the hot region, and thus the percentage saved is fairly high (10.9\%).

Variations in savings by dwelling type and size of local agency are large and significant for gas-heated dwellings. Single-family detached and small multifamily dwellings (the dominant dwelling types served by the Program) both save significantly more than mobile homes. Mediumsized and large agencies saved significantly more than small agencies.

\subsubsection{Electrically Heated Dwellings}

Electrically heated dwellings represent $10 \%$ of the dwellings weatherized by the Program during 1989. Thus, they account for a small, but significant fraction of the Program's clients.

The weighted net savings estimate in electrically heated homes for the Program nationwide is $1,830 \mathrm{kWh} /$ year (at the site) (Table 5.10 ). This represents a $12.2 \%$ reduction in total electricity, a 
$29.8 \%$ reduction in electricity used for space heating and air conditioning, and a $36.0 \%$ reduction in electricity used for space heating.

Table 5.10 Electricity Savings in Electrically Heated Dwellings

\begin{tabular}{|l|c|c|c||c|}
\hline & Cold Region & $\begin{array}{c}\text { Moderate } \\
\text { Region }\end{array}$ & Hot Region & $\begin{array}{c}\text { Program-wide } \\
\text { Average }\end{array}$ \\
\hline Number of Dwellings & 35 & 260 & 131 & 426 \\
\hline $\begin{array}{l}\text { First-year Gross Savings (in } \\
\text { kWh/dwelling) }\end{array}$ & 1,933 & 939 & 307 & 867 \\
\hline $\begin{array}{l}\text { First-year Net Savings (in } \\
\text { kWh/dwelling) }\end{array}$ & 2,686 & 2,479 & 595 & 1,830 \\
\hline $\begin{array}{l}\text { Net Savings as Percent of Total } \\
\text { Electricy Use }\end{array}$ & $14.4 \%$ & $14.9 \%$ & $5.4 \%$ & $12.2 \%$ \\
\hline $\begin{array}{l}\text { Net Savings as Percent of } \\
\text { Electricity Used for Space Heating }\end{array}$ & $42.4 \%$ & $43.8 \%$ & $15.9 \%$ & $35.9 \%$ \\
\hline
\end{tabular}

The energy saved by electrically heated homes varies markedly across key subgroups. Percent net savings range from $5.4 \%$ in the hot region to $14.9 \%$ in the moderate region. As with gasheated homes, single-family detached and small multifamily dwelling $c_{i}$ save more electricity after weatherization than any of the other dwelling types. As was found $i$ the analysis of gas-heated homes, electrically heated dwellings weatherized by medium-sized and large agencies outperform dwellings weatherized by small agencies.

\subsubsection{Dwellings Heated by Other Fuels}

An indirect estimation approach is used to estimate the energy saved by dwellings heated by fuels other than natural gas and electricity. The approach emphasizes the similarity between gasheated homes and dwellings heated primarily by these other fuels, but recognizes that the two types of dwellings have different regional distributions. It also incorporates the results of the Fuel-Oil Study of fuel-oil heated dwellings in the nine northeastern states (Ternes and Levins, 1992). The result is an estimate of $17.7 \mathrm{MBtu}$ 's saved per weatherized dwelling. This value is slightly less than the estimated energy savings for gas-heated homes (17.3 MBtu's per year), because of the high savings of fuel-oil heated homes located in the nine northeastern states (22.4 MBtu's per year).

\subsubsection{Programwide Energy Savings}

The average first-year net energy savings per dwelling weatherized in PY 1989 is estimated to be 16.4 MBtu's (at the site) and 17.6 MBtu's (at the source), representing a $13.5 \%$ reduction in preweatherization energy use and an $18.2 \%$ reduction in the energy used for space heating. 
During PY 1989, the Weatherization Assistance Program weatherized 198,000 single-family or small multifamily homes, resulting in a total savings of 3,487,000 MBtu's during the first year. At an equivalence of 5.8 MBtu's per barrel of oil, the Program saved approximately 601,000 barrels of oil during 1990-91, or about 1,650 barrels of oil per day. Over the 20-year lifetime of the weatherization measures, the energy savings from its one year of weatherization activity in PY 1989 amount to 12 million barrels of oil.

The estimated Program savings in PY 1989 are higher than the estimate of $13.8 \mathrm{MBtu}$ 's per dwelling resulting from EIA's evaluation of the 1981 Program (Peabody, 1984). In addition to the general increase in savings over time, our findings differ in other ways from the earlier evaluation. Peabody (1984) found very little variation in energy savings by climate region, reporting only slightly higher savings in colder climates. The Single-Family Study documents much higher savings in the moderate and cold regions compared with the hot region. Peabody (1984) found lower savings for electrically heated dwellings than for dwellings heated by natural gas, but our results show comparability, particularly if you consider the magnitude of energy savings at the source, when comparing types of heating fuels.

The estimated savings of the 1989 Program compare favorably with the results of evaluations of utility-operated low-income weatherization programs and evaluations of individual State weatherization programs.

\subsubsection{Opportunities for the Future}

During 1989, DOE's low-income weatherization program generated significant energy savings in those submarkets where the Program's activity historically has been concentrated -- that is, cold and moderate climate regions and single-family detached homes. Two submarkets appear to offer substantial opportunities for improvement: the hot climate region and mobile homes. Savings in both of these submarkets could probably be doubled with the implementation of state-of-the-art procedures. In addition, the fact that dwellings in the moderate region consumed more gas before weatherization than dwellings in the cold region, while their savings were substantially less, suggests that the moderate region offers considerable potential for additional savings. Since the moderate region dominates the Program, Program-wide savings could be substantially improved if this potential were to be realized.

Hot Climate Weatherization. Greely, Randolph and Hill (1992) demonstrated that lowincome homes in Virginia offer as great a potential for savings as homes in colder climates. Although Virginia is classified as a moderate climate State in the National Evaluation, it borders the hot region and, therefore, provides some indication of the potential there, especially in States such as Tennessee, Arkansas, Oklahoma and the northern parts of Georgia, Alabama and Mississippi, where 
heating loads are substantial. Demonstration studies of this type should be done in States with predominantly cooling climates (such as Florida, California, Texas, and Arizona) to determine the potential for savings there. Currently there are few published demonstration studies of the Program's potential for savings in such cooling dominated climates.

An ORNL field study in North Carolina, which is currently in draft form (Sharp, 1993), found limited savings in energy used for cooling, but a potential for space-heating savings of over 20\%. This field study compared results of current State weatherization practices (using the RetroTech audit which focuses mainly on envelope measures) with results using an advanced audit (which has now been expanded into the Wcatherization Assistance Program National Energy Audit -NEAT). In addition to more advanced measure cvaluation capabilities, the NEAT audit includes a more comprehensive set of measures than the Retro-Tech audit, with an extensive list of both heating and cooling equipment and shell measures. The total costs for the two procedures were very similar. Most of the NEAT houses received wall insulation, which was not included in the standard program and air sealing assisted by blower doors. Another difference was that NEAT houses received no storm windows, while most of the homes in the standard program did.

Like the Virginia study, the North Carolina field study showed that space-heating savings above $20 \%$ can be achicved. The pilot program Greely, et al. (1992) implemented in Virginia found that space-heating savings could be increased from $10 \%$ (for the current program) to $24 \%$ (with the improvements they implemented). In the North Carolina study, preliminary space-heating savings in houses receiving the standard State procedure averaged 20\%, while space-heating savings in houses receiving the NEAT audit averaged $28 \%$. These NEAT results demonstrate that savings improve with the use of a more comprehensive set of envelope and equipment measures to consider, and with the use of an advanced measures selection technique (audit) for each house that better prioritizes envelope and equipment measures.

Mobile Home Weatherization. Most of the mobile homes weatherized by DOE's Program were built before 1976, when HUD Thermal Standards were enacted. These Pre-HUD-Standard mobile homes use from 1.25 to 2 times the energy per square foot of comparable site-built houses (Judkoff, 1988). Their unique construction makes them difficult to weatherize effectively using the measures and techniques developed for site-constructed dwcllings.

A survey of weatherization evaluations conducted for DOE by Meridian Corporation indicated that weatherization of mobile homes was saving considerably less energy than weatherization of site-built houses (CSR, 1989). Recognizing the apparent problems with weatherizing mobile homes, DOE initiated a testing program at the Solar Energy Research Institute in 1988 to investigate cost effective ways to weatherize mobile homes. The research program tested the thermal benefits of different weatherization measures in the controlled environment of the 
Collaborative Manufactured-Building Facility for Energy Research and Training (CMFERT). The CMFERT study showed that with retrofits developed specially for mobile homes, the potential for savings in cold climates ranges from 30 to $50 \%$. The most cost-effective measures for mobile homes located in cold climates appear to be: blower-door-directed air sealing and duct repair, furnace tuneup, blown-in belly and roof insulation, and interior storm panels (Judkoff, 1991).

During 1989 and 1990, the initial results of the first phase of the CMFERT study were available, but training and information dissemination was not widespread. With the availability of more recent research, training, and literature, it is likely that many agencies today are more fully tapping the potential of mobile home weatherization to save energy in cold climates. Research still needs to be conducted to determine cost-effective mobile home weatherization strategies in hot climates. 


\section{NONENERGY PROGRAM IMPACTS}

This chapter describes the types of nonenergy impacts that result from low-income weatherization programs. Some information is presented on the magnitude of these impacts, and where feasible, these impacts are monetized (i.e., expressed in dollars) for inclusion in the costeffectiveness analysis (Chapter 8).

The impacts of low-income weatherization programs are numerous. Most of these impacts are benefits, but a few are adverse. They are grouped into five major categories below:

(1) Affordable housing

- maintaining or enhancing residential property values;

- extending the lifetime of low-income housing; and

- decreasing homelessness and mobility.

(2) Comfort, health, and safety

- improving the livability and thermal comfort of low-income homes;

- preventing fires; and

- impacting indoor air quality.

(3) Impacts on household budgets

- increasing nonenergy expenditures; and

- reducing utility arrearages and terminations.

(4) Employment and economic impacts

- increasing economic output;

- increasing earnings;

- increasing employment;

- generating federal tax revenues; and

- decreasing unemployment payments.

(5) Environmental externality impacts

- reducing the environmental impacts of energy production and consumption; and

- increasing the environmental effects of producing weatherization materials.

This chapter begins by describing the activities undertaken by the DOE Weatherization Assistance Program that contribute to preserving affordable housing nationwide (Section 6.1). Attention then turns to the comfort, health, and safety improvements that are made by local agencies in conjunction with their weatherization work (Section 6.2). In Section 6.3, impacts on household budgets through reduced energy buriens are discussed. Section 6.4 describes the employment and economic impacts of weatherization, and Section 6.5 discusses the environmental externalities associated with home weatherization. Section 6.6 combines the results of the previous sections to 
produce the dollar values for nonenergy impacts that are used in the benefit/cost analysis of Chapter 8.

Available research on the nonenergy benefits of weatherization is limited. While there is a good deal of anecdotal evidence on the substantial benefits of low-income weatherization in the areas of affordable housing, health, and safety, these anecdotes do not support the assignment of dollar values to the benefits. We searched for literature that would help us to quantify each of the nonenergy benefits, but except for environmental and employment effects, found very little that presented quantitative estimates of impacts.

We also considered how any available information on the incidence and costs of events such as fires, illnesses caused by extreme temperatures or high $\mathrm{CO}$ levels, moving to a new residence, or demolishing housing that is not repaired might be combined to estimate the value of a nonenergy benefit. In some cases, such as for reduced mobility and avoided demolitions, we were able to estimate an average avoided cost, but found that the value was less than $\$ 1$ per weatherized dwelling. Because of the uncertainty and controversy about the assumptions underlying these values, we chose to discuss them, but not monetize them. At the other extreme, four nonenergy benefits were assigned values of more than $\$ 30$ per dwelling. From smallest to largest they are: 1) reduced arrearages; 2) enhanced property values and extended lifetime of dwelling, 3) environmental benefits, and 4) employment benefits. The estimated employment benefits are the most significant ones; they are three times larger than the next largest values.

For the benefits that are assigned a dollar value in this Chapter, the methods used to estimate their value varied. Estimates of environmental benefits relied on a literature review and on information from this study about the proportions of weatherized dwellings using various fuel types and about the average savings by fuel type. Estimates of employment benefits combined a literature review with data from this study on the amount of Program employment, the skill level of workers, and managers' judgments concerning the structure of the job market for weatherization workers. Data from this study on Program expenditures on home repairs are used to quantify the benefits associated with maintaining or enhancing property values and extending the lifetime of dwellings. The monetary benefits of a reduced incidence of fires are quantified by using insurance industry data. Our estimate of reductions in arrearages is based on a literature review and data on payment histories that were collected on the dwellings included in this study.

\subsection{AFFORDABLE HOUSING}

\subsubsection{Property Values and the Longevity of Structures}

The Program network delivers a wide array of direct services to its low-income clients, in addition to energy-efficiency improvements. Recognizing that home repairs are often needed before 
weatherization measures can be installed, DOE allows the expenditure of some of its resources on housing rehabilitation. Using funds from non-DOE sources, the Program offers a vehicle for delivering additional housing rehabilitation services that improve the structural integrity of the nation's stock of affordable housing. Sources providing funds for housing rehabilitation include the Farmers Home Administration, the U.S. Department of Housing and Urban Development's Housing Rehabilitation Program and, in a few cases, utilities. The weighted national average spent on materials for structural repairs in PY 1989 was $\$ 126$ (Chapter 7). This is the amount of benefit assumed for maintaining the property value and extending the lifetime of weatherized dwellings.

Local weatherization agencies conducted some amount of housing rehabilitation in almost all $(172,000$ - or $87 \%)$ of the 198,000 dwellings they weatherized in PY 1989 . The vast majority of these rehabilitation measures involved fixing or replacing windows or doors (Fig. 6.1). Attic ventilation and incidental repairs to roofs, walls, and floors account for most of the other housing rehabilitation activities. Other, less common rehabilitation measures include fixing attic hatches, ceilings, foundations, steps, and porches, electrical repairs, and septic, plumbing, and bathroom repairs. Fig. 6.2 shows how one home served by the Program was made more livable thru weatherization.

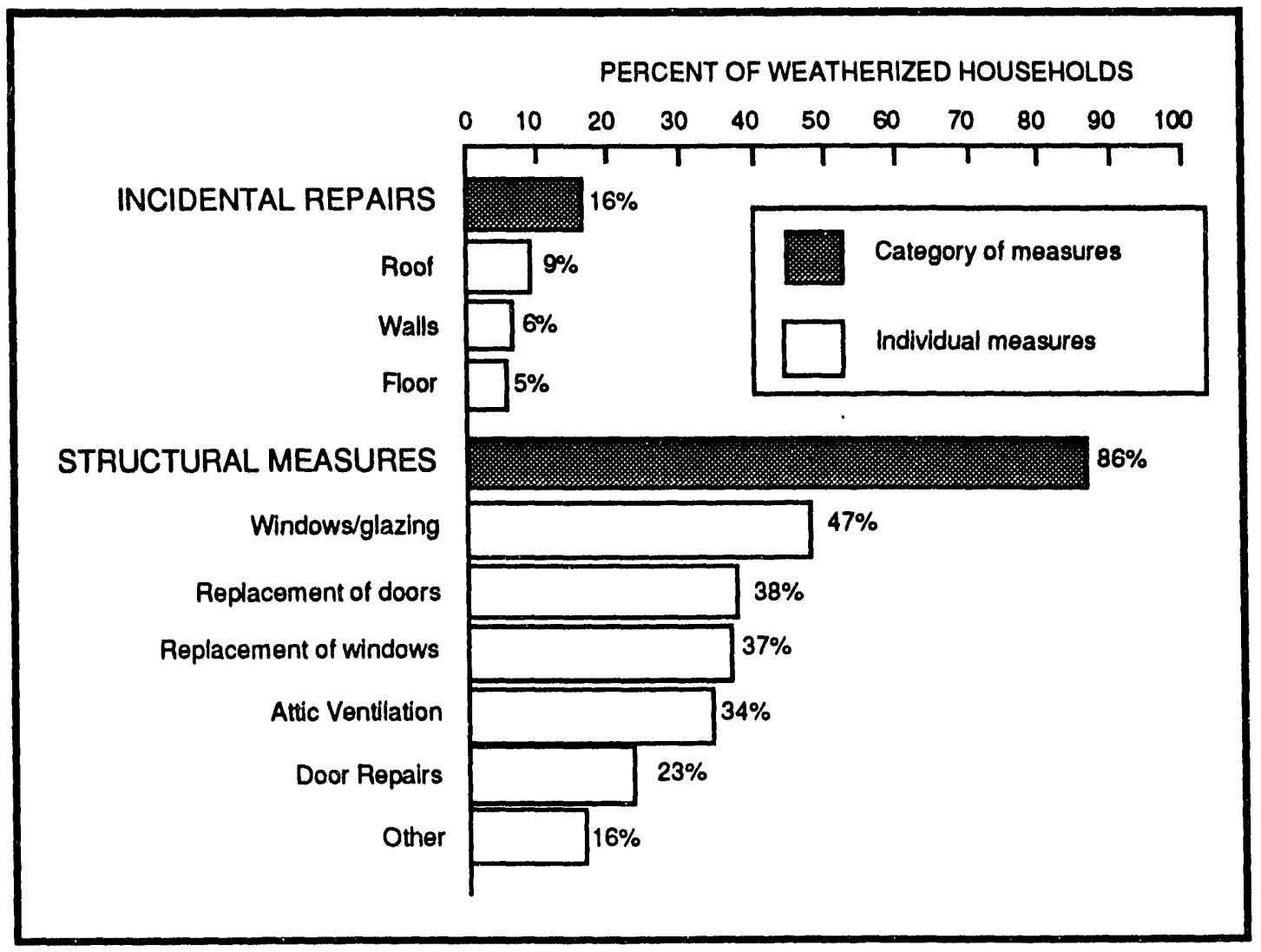

Fig. 6.1 Frequency of Incidental Repairs and Structural Repairs (Percent of Dwellings). 


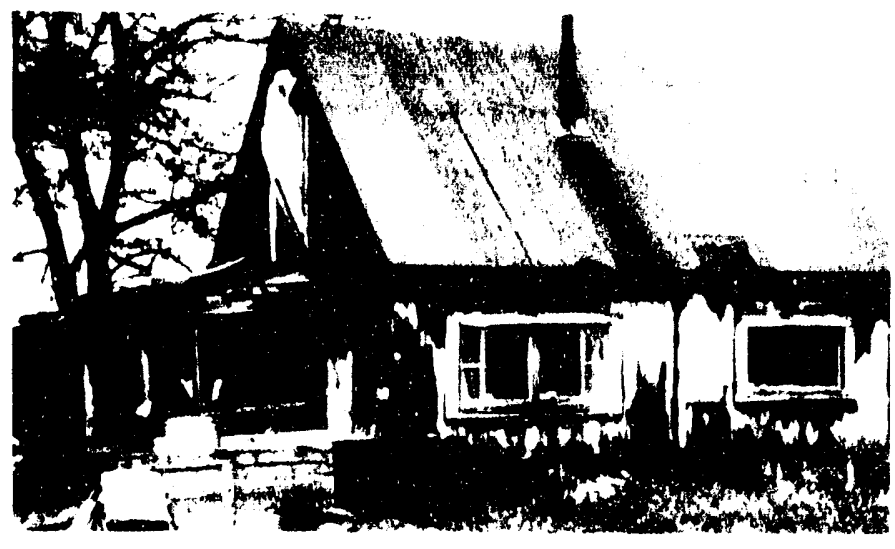

BEFORE:

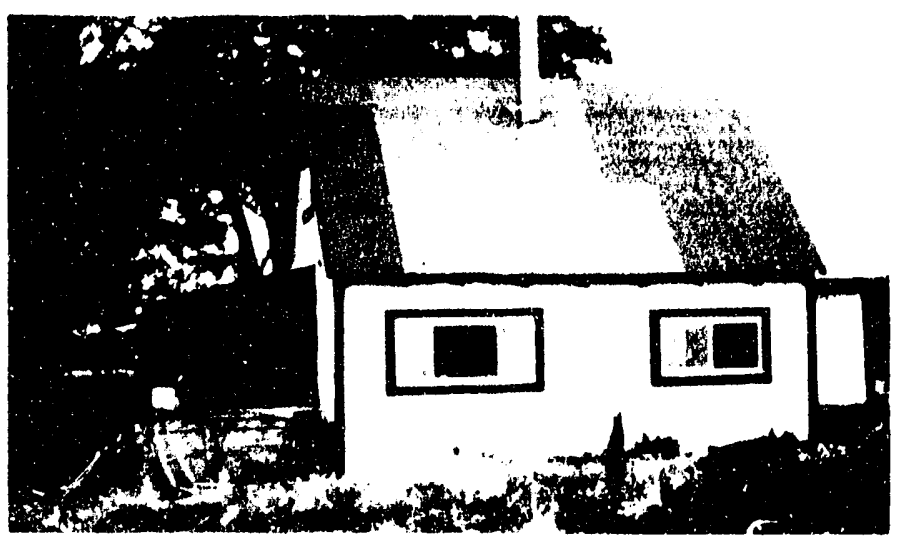

AFTER

Fig. 6.2 Improving Substandard Housing Through Weatherization: An Example from the Blue Mountain Community Action Agency.

One common concern of local Program managers is the limiled funding available for housing rehabilitation (Mihlmester. el al, 1992, p. 47). One local agency Director estimated that $10 \%$ of the eligible homes in his service area hate 10 be put on hold until they can be repatired.

The incidental repatirs and ollere structural rehabilitation work conducted by the Program during PY lege vary signilicantly adross the Program's mafor subgroups. These differences are

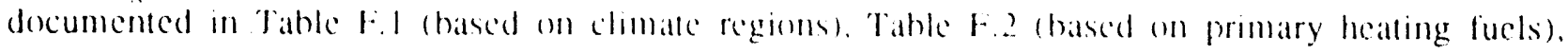
Table F.3 (hased on dwelling lypes), and Tathle Ft (based on agency size).

The installation of structural measures by lacal weatheriation agencies occurs least frequently in the cold region. The moderate chmate regun has average installation rates for these measures. Structural measures by lacal agencies are installed mos frequently in the hot region. Ninely pereent of this region's P'Y lage weatherized dwellings benefiled from some form of struclural measure.

Gas-heated homes hatd high ralles of housing rethahilitation respecially windows/glazing and allic ventilation). Electrically healed dwellings received the fewest incidental repairs and structural measures, reflecting their relatively young age. Dwellings healled by other fuels had high rates of roof repair (11\%). deor replatements $(42 \%)$. and window replatements (4t)\%), but average levels of wher structural measures.

Differences across dwelling lypes also are significant. Single-lamily detached homes had high rates of housing rehabilitation (espectally windows, doors, walls, and allic vemtilation). Mobile. homes had slighlly lower than average installation rales for housing rehabilitation measures (with the

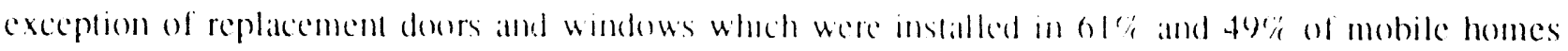


than average rates of housing rehabilitation (although relatively high rates of wall and roof repairs). Small multifamily dwellings had lower than average levels of housing rehabilitation (with the notable exception of windows and glazing, which were repaired or refurbished in more than half of these dwellings).

Incidental repairs to roofs, walls, and floors were made more frequently by small and medium-sized agencies than large agencies. Installation rates for structural measures, however, are quite similar across the agency size categories.

Housing rehabilitation improves the comfort of dwellings and helps to preserve the stock of affordable housing for low-income persons. The high rate at which some rehabilitation was performed, $87 \%$ of dwellings nationally, indicates that this is a common and important need. As one local agency Director stated, "The Weatherization Assistance Program has been an important factor for preserving older housing in [my area] and rebuilding entire neighborhoods."

\subsubsection{Homelessness and Mobility}

There is evidence that increased energy costs have exacerbated housing shortages. High energy costs mean households are less able to pay their bills - including rent or mortgage payments. A study of failures in HUD mortgages concluded that "2.5\% of the 1974-1975 mortgage failures were directly attributable to energy price increases" (Metrostudy Corporation, 1976). Dearborn and Tabor (1979), suggest that when rental owners are prohibited from passing increased energy costs on to their tenants, the pressure on landlords may contribute to deterioration of the rental housing stock and the subsequent abandonment of buildings.

Energy-efficiency improvements can abate homelessness by reducing tenant evictions and the abandonment of low-income housing. Surveys of homeless persons and emergency shelter providers have found the loss of utility service to be a minor, but consistent contributor to homelessness. Robinson (1991), for instance, found that among the dominant housing-related reasons for homelessness in Pennsylvania, utility terminations were cited as the cause $7.9 \%$ of the time. Robinson also found that utility terminations precipitate housing abandonment. Based on surveys conducted by Pennsylvania utility companies, $32 \%$ of the homes of residential electric customers were abandoned within one year after utility termination. The rate is $22 \%$ for gas terminations.

Data from this study suggest that weatherization reduces the rate of residential mobility and (by inference) the costs associated with housing turnover. The average number of occupancy changes occurring in 100 dwellings, per year, were calculated for weatherized and control dwellings based on data provided by gas and electric utility companies. These numbers are underestimates of the actual rates of occupancy change, since some utilities failec to provide information on household turnover. There is no reason, however, to expect that any such bias would differentially affect the weatherized versus the control dwellings. Therefore, we focus on the relative magnitude of 
occupancy changes in the pre-weatherization and post-weatherization periods. Fig. 6.3 presents the results.

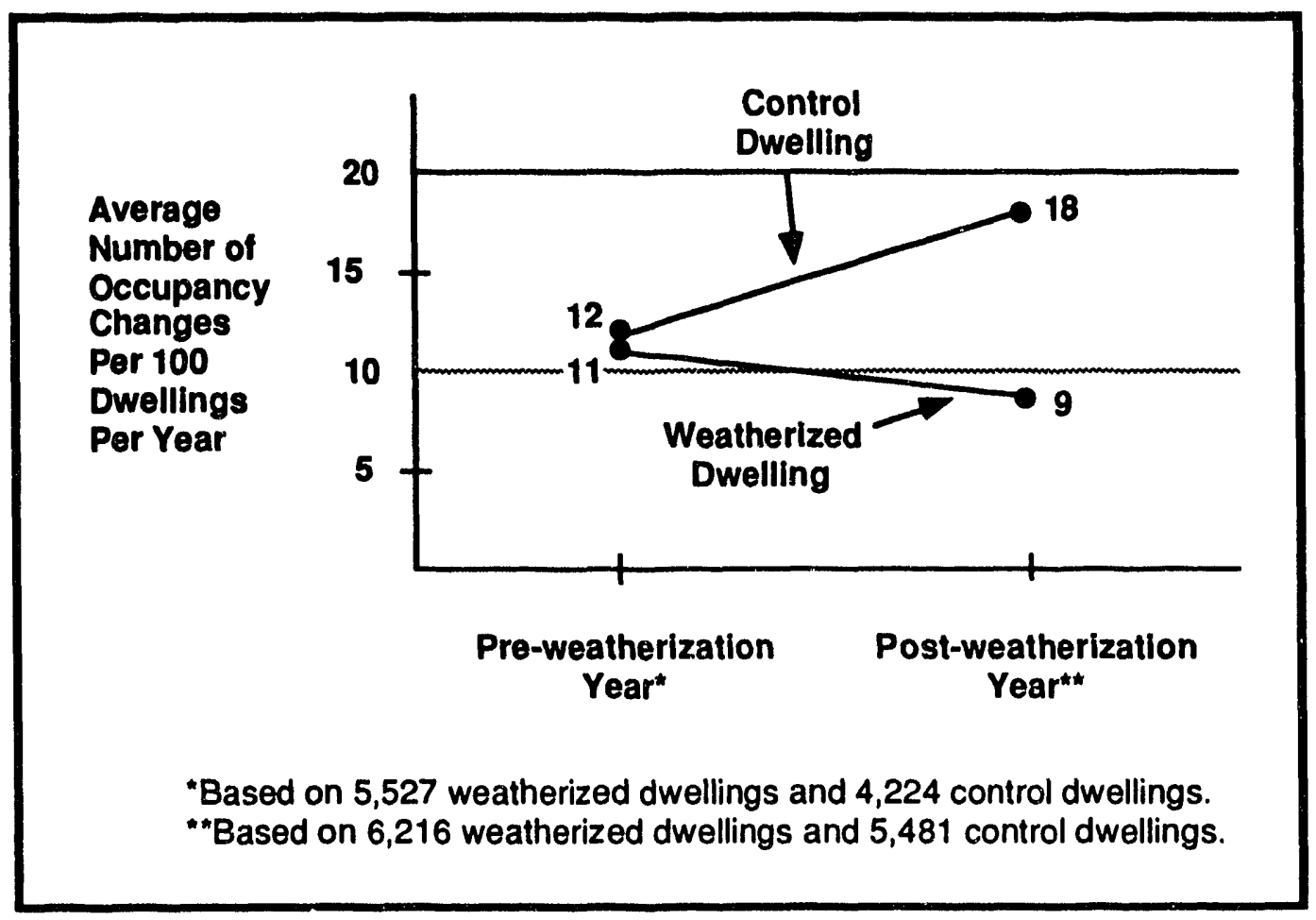

Fig. 6.3 Annualized Rates of Occupancy Change: Pre- Versus Post-Weatherization

After weatherization, dwellings experience significantly less annual tumover in occupancy than was experienced prior to weatherization (11 occupancy changes per $100 \mathrm{dwellings}$ before weatherization versus 9 occupancy changes per 100 dwellings after weatherization). Over the same period the control dwellings experienced an increase in tumover (12 occupancy changes per 100 dwellings in 1988-89 versus 18 in 1990-91). On a programwide basis (i.e., for the 198,000 dwellings weatherized by the Program in PY 1989), these statistics suggest that in the first year following weatherization the Program prevented at least 4,000 changes in occupancy. The reduction in occupant turnover is large enough to be visible by landlords, based on a survey of landlords in Wisconsin (RCG/Hagler, Bailly, Inc., 1991). Unfortunately, the resulting benefits are difficult to value. We did a rough calculation of the avoided cost of reducing mobility by 4,000 moves, but concluded that because the estimated average benefit was less than $\$ 1$ per weatherized dwelling it was not important to include this effect in our benefit/cost calculations. 


\subsection{COMFORT, HEALTH, AND SAFETY}

Enhancel comfort is a natural outcome of many weatherization measures. No DOE approved weatherization measures arc installed specifically to improve comfort; improved comfort is simply a side benefit. Certain health and saicty improvements to building envelopes (such as replacing broken doors) and space heating systems (such as correcting carbon monoxide problems) also are legitimate Program expenditures. Occasionally funds frnm non-DOE sources (including state crime and safety programs and area agencies on aging) provide additional resources to achieve health and safety goals at the same time that weatherization is being conducted.

Thie only component of this "health, safety, and comfort" category that is monetized below is the benefit of fire prevention. It is clear, however, that the other components are valuable. For instance, fewer ilinesses, due to a healthicr environment (resulting from fewer drafts or less carbon monoxir. ), and fewer injuries (c.g., from avoided accidents due to home repairs such as fixing steps), reduce the need for medicare payments, which offsets the government expenditure on weatherization.

\subsubsection{Comfort}

A great deal of anecdotal information suggests that the homes of low-income households are more conifortable as the result of weatherization and associated housing rehabilitation. Several quantitative studies corroborate this.

Gladhart and Weihl (1990) report that weatherization led to more uniform daily interior temperatures throughout the dwelling unit and that occupants made fewer thermostat adjustments to obtain comfort. Occupants also reported that their houses were warmer, less drafty, and "more comfortable" after weatherization. ${ }^{1}$ Similarly, the Fucl-Oil Study being conducted for the National Weatherization Evaluation (Ternes and Levins, 1993) has also documented improvements in perceived comfort and draftiness following veatherization.

There is growing evidence that following weatherization houscholds "take back" some of the potential for reduced energy consumption by improving the comfort of their home's interior temperatures (Weihl, Gladhart, and Krabacher, 1988). This would cause a shortfall in the actual energy savings achieved by the energy-efficiency improvements.

An analysis of interior temperatures before versus after weatherization by the Hood River Conservation Project identified a statistically significant $0.6^{\circ} \mathrm{F}$ increase. This "take back effect" was higher for low-income houscholds than for higher income households (Dinan, 1987). The Fuel-Oil Study, ou the other hand, did not detect any "lake back" effect. The study monitored pre- and post-. weatherization indoor temperatures of both weatherized dwellings and a sample of control homes.

1 The sample consisted of ten (10) low-incoine houses in Lansing, Michigan. Metering equipment was used record interior temperatures and thermusiai setings. Blower door tests were also conducted, along with an occupant survey. 
The average indoor temperatures of both groups were within $0.2^{\circ} \mathrm{F}$, in both the before and after time periods. Thus, the overwhelming evidence is that weatherization improves the perceived comfort of homes, but it may or may not lead to increased indoor temperatures during winter.

It is difficult to value the worth of improved comfort. It is likely, however, that this value is greater for alderly households than for others, given the diminished capability of their bodies' temperature-regulating systems (Schwartz and Petcrson, 1979; Brown and Rollinson, 1985).

Another possible benefit is being able to heat, and therefore occupy additional rooms as the result of weatherization. These comfort benefits are not quantified in this report, but the second part of the Single-Family Study will include interviews with occupants of both weatherized and control dwellings that should produce valuable information on comfort benefits.

\subsubsection{Health and Safety}

Health and safety measures (other than those dealing with the heating system) were installed in $53, \mathrm{C} 30$ (or $27 \%$ ) of the 198,000 single-family and small multifamily dwellings weatherized in PY 1989 (Fig. 6.4). Carbon monoxide tests were conducted in $23 \%$ of the weatherized homes, window and door locks were installed in $4 \%$, and smoke detectors in 3\%. The Program also occasionally provides fire extinguishers.

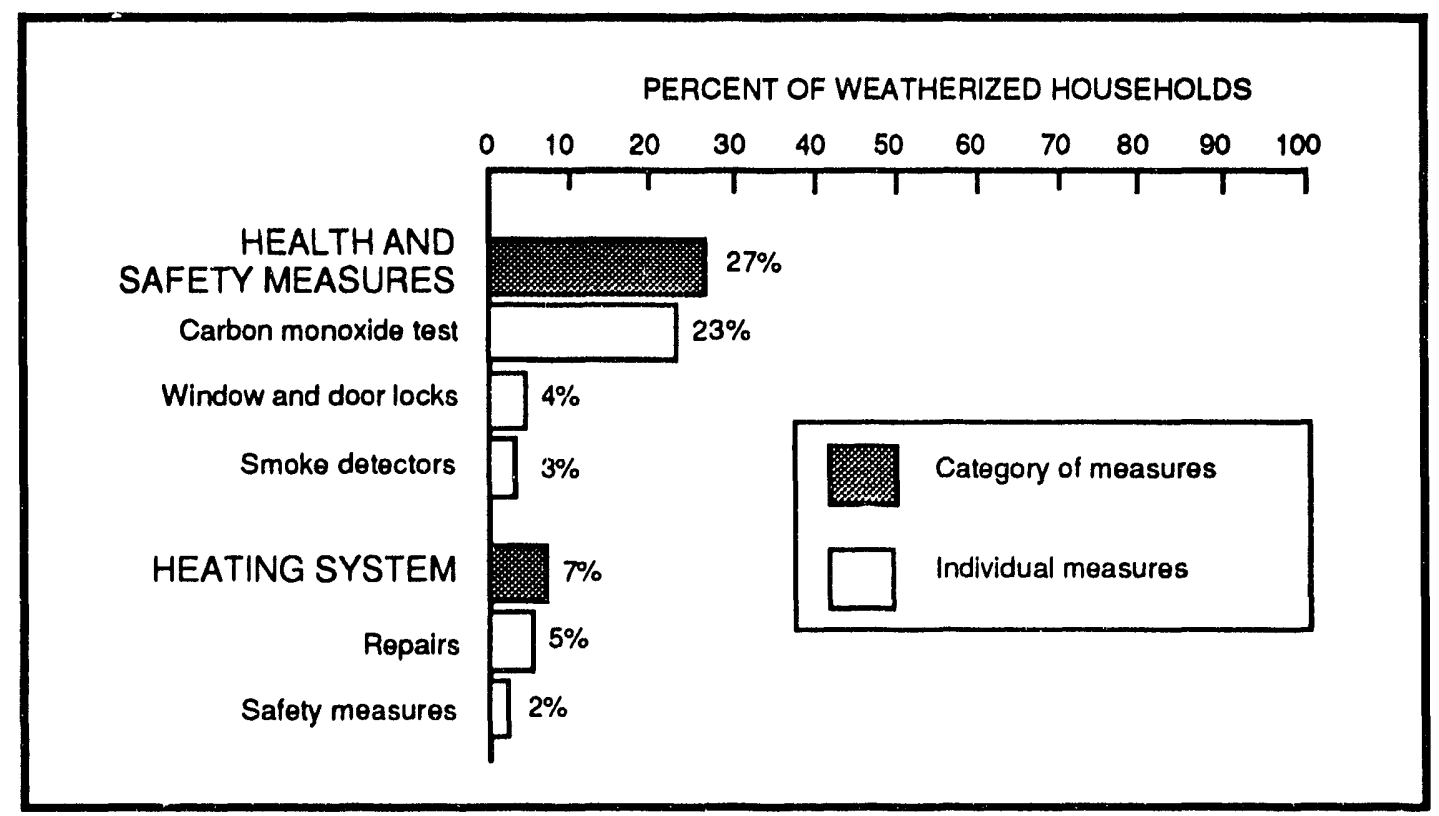

Fig. 6.4 Frequency of Health and Safety Measures (Percent of Dwellings)

Heating system repairs and safety improvements were made to 14,000 (or 7\%) of the 198,000 homes weatherized in PY 1989. Heating system repairs include the replacement of thermocouples, 
thermostats, fan switches, and furnace filters. Heating system safety measures include repairing or replacing gas valves, gas controls, leak detectors, and limit switches, as well as fixing gas leaks and carbon monoxide problems. While these safety measures are relatively uncommon, it is likely that their benefits are significant.

Each of the health and safety measures shown in Fig. 6.4 have different distributions across climate regions (Table F.1). Health and safety measures are installed at slightly lower than average rates in cold climates. In contrast, heating system repairs and safety measures are undertaken in cold climates at rates that exceed programwide averages. The moderate climate region has higher than average installation rates for health and safety measures and heating system repairs and safety measures. Health, safety, and heating system repairs were relatively uncommon features of the PY 1989 weatherized homes in the hot region.

Differences across primary heating fuels are equally marked (Table F.2). In PY 1989, gasheated homes had high rates of health and safety measures (especially carbon monoxide tests), and heating system repairs and safety measures. Electrically heated dwellings had low levels of heating system repairs. Dwellings heated by other fuels had average levels of heating system repairs and safety measures, and lower than average instaliation rates for health and safety measures.

Differences across dwelling types also are significant (Table F.3). Single-family detached homes had average installation rates for health and safety measures and heating system repairs, as did mobile homes. Single-family attached dwellings had extremely high installation rates for heating system repairs, safety measures, and carbon monoxide testing. Small multifamily dwellings had lower than average installation rates for heating system repairs and safety measures, but higher than average installation rates for window and door locks - perhaps reflecting the more urban milieu of this type of housing stock.

Large agencies conducted heating system repairs and safety measures and installed window and door locks at a higher rate than small and medium-sized agencies (Table F.4). These emphases reflect the more northern and urban nature of large weatherization agencies.

To illustrate the potential value of these health and safety measures, the following sections discuss the benefits they offer in terms of fire prevention and possible impacts on indoor air quality.

Fire Prevention. "Defects in, or mishandling of, heating equipment causes more residential fires than any known cause ..." (Insurance Information Institute,' 1990). In 1987, heating systems caused $20.5 \%$ of the residential fires, $10.1 \%$ of the deaths, and $10.0 \%$ of the injuries due to residential fires. The fire-induced death rate for elderly individuals, a group targeted in the Program, is higher than for any other age group (Insurance Information Institute, 1990).

Measures installed by the Program reduce the costs of fires in four ways. First, safety measures performed on the heating system such as fixing gas leaks, reduce the probability of fires. Second, any fires that start after weatherization are likely to cause less damage because cellulose 
insulation tends to snuff out fires, either by inhibiting their spread, or, in the case of ceilings and walls collapsing, actually putting them out. In contrast, fires in houses with uninsulated walls and ceilings tend to spread rapidly since the empty cavities help feed the fire. Third, when their primary heating system becomes more efficient and less costly to operate, low-income households may reduce use of supplemental heating systems such as space heaters and wood burning stoves, which are more likely to cause fires than central heating systems. Fourth, by reducing energy costs and therefore arrearages (see Section 6.2.1), weatherization reduces utility terminations. Loss of utility services has been shown to result in loss of life from energy-related fires. In a study of low-income households in Philadelphia, Robinson (1991) notes that a number of Philadelphians lose their lives every year in fires caused by the use of dangerous energy sources. "When electric or gas service is shut off, a number of families resort to such measures as candles, extension cords run from a neighbor's, illegal reconnections to power lines, and kerosene heaters."

The benefits of reducing the number of fires include reduced loss of life, reduced injuries from fires (and the consequent costs of hospitalization and other medical treatments), and reduced property losses. The value of these benefits is difficult to quantify, although fire prevention is clearly a benefit for at leasi some weatherized dwellings. The value of reduced injuries and medical costs is small relative to the other factors and difficult to quantify. The value of avoided deaths from fires due to heating systems and the value of preventing fire-related property damage are estimated in Figs. 6.5 and 6.6. Combining the avoided costs due to prevented deaths and avoided property losses, the total value for the Program is $\$ 643,700$ or $\$ 3.25$ per weatherized dwelling.

Indoor Air Quality. Carbon monoxide testing may be one of the more important safety offerings of the Program. A Wisconsin Gas Company manager (Nclson, 1993), reports that his utility performs carbon monoxide testing for about $1 \%$ of his utility's customers each year at an average cost of $\$ 80$ per test. These tests are performed in response to customer requests when the customer believes there may be a $\mathrm{CO}$ problem. By providing $\mathrm{CO}$ testing, the Program reduces these costs for many gas utilities, nationwide. In addition, Nelson reports that the Wisconsin Gas service area (with about 400,000 customers), experiences 4 or 5 crisis situations related to $\mathrm{CO}$ during each heating season. These crises are at least twice as likely among low-income houscholds. When such crises occur, substantial costs (perhaps in excess of $\$ 5,000$ ) are incurred for emergency service (fire trucks, ambulances, paramedics, police cars, hospitalization). In addition, reducing CO in living areas can improve the health of occupants and thereby reduce mcdical costs. 
Step 1: Estimate the elderly and non-elderly occupants of dwellings weatherized in PY 1989. The estimated number of occupants in PY 1989 weatherized dwellings:

198,000 dwellings weatherized in PY 1989

x 2.81 occupants/dwelling

$=556,400$ occupants of dwellings weatherized in PY 1989.

Estimated number of elderly occupants in weatherized dwellings:

198,000 dwellings weatherized in PY 1989

$x 0.35$ dwellings with one or more elderly occupants

$=69,300$ elderly occupants of dwellings weatherized in PY 1989.

Estimated number of non-elderly occupants in weatherized dwellings:

556,400 occupants of dwellings weatherized in PY 1989.

$-69,300$ elderly occupants of dwellings weatherized in PY 1989

$=487,100$ non-elderly occupants of dwellings weatherized in PY 1989.

Step 2: Determine appropriate fire death rates. Fire death rates are 5.2 per 100,000 elderly population (over age 64) and 1.7 per 100,000 persons in the general population. Ten percent of fire deaths are caused by residential heating equipment (Insurance Information Institute, 1990; National Safety Council, 1989).

Step 3: Estimate total number of deaths by fire due to residential heating equipment. Combining these factors:

\section{Elderly}

$5.2 / 100,000 \times 0.1 \times 69,300=0.36$ expected number of deaths of elderly persons.

Non-Elderly

$\frac{\text { Non-Elderly }}{1.7 / 100,000} \times 0.1 \times 487,000=0.83$ expected number of deaths of non-elderly persons.

Step 4: Estimate the cost of deaths by fire due to residential heating. The average lifetime cost due to a fire death is approximately $\$ 250,000$ and the average lifetime cost of an elderly person due to a fire death is approximately $\$ 24,000$ (Statistical Abstract of the U.S., 1991). If we assume that weatherization activities such as furnace repairs prevent these expected deaths from occurring, the benefit derived from reduced deaths is estimated to be:

Elderly

$0.36 \times \$ 24,000=\$ 8,640$.

Non-Elderly

$0.83 \times \$ 250,000=\$ 207,500$.

The total benefit is estimated to be $\$ 216,140$.

Fig. 6.5 Value of Deaths Due to Fires Prevented by Weatherization 
Step 1: Establish the rate at which low-income residential fires occur: $90,880,000$ occupied dwellings in U.S. $=0.0061$ fires per dwelling unit.

Assume a low-income household unit is twice as likely to have a fire than average, i.e., 0.0122 fires per dwelling unit.

As a result, 2,416 fires would be expected for the population of dwellings weatherized in PY 1989.

Step 2: Estimate rate of low-income residential fires due to heating systems.

Twenty-one percent of residential fires are caused by heating systems.

2,416 fires $\times 0.21$ fires due to heating systems $=483$ fires from heating systems would have occurred in the weatherized population if the dwellings had not been weatherized.

Step 3: Estimate the residential property loss due to a fire. Residential property loss in 1988 due to fires was $\$ 3,897$ million (U.S. Department of Commerce, Bureau of the Census, 1991).

Average loss per residential fire: $3,897,000,000=\$ 7,060 /$ fire

$$
552,000
$$

We assume that the average property loss for low-income houscholds is half the national average, i.e., $\$ 3,530$.

Step 4: Estimate the number of fires that were prevented through weatherization. If the program prevents $25 \%$ of the fires that would have occurred due to heating systems, the number of fires prevented would be 121 .

Step 5: Estimate the total avoided property loss. Avoided property loss due to weatherization would be 121 fires prevented $\times \$ 3,530$ /house $=\$ 427,000$.

Fig. 6.6 Value of Property Loss Due to Fires Prevented by Weatherization

On the other hand, weatherization can have adverse health impacts on occupants residing in dwellings located in areas with particularly high levels of radon. These occupants may (or may not) experience increased radiation as the result of weatherization. The primary method utilized to reduce exposure to these radioactive particles is increased air ventilation. Yet weatherization often significantly reduces levels of air infiltration. As a result, it can increase radiation levels within homes. In other cases, however, weatherization may reduce the amount of radon entering the living space by decreasing the amount of soil gases drawn into the house and by keeping any such gases in basement areas.

At present, indoor air quality impacts of weatherization cannot be quantified. Data on the number of low-income dwellings that might be expected to experience degraded or improved indoor 
air quality are unavailable. In addition, there is no consensus on the health risk associated with different effects on indoor air quality.

\subsection{IMPACTS ON HOUSEHOLD BUDGETS}

\subsubsection{Energy Affordability and Increased Nonenergy Expenditures}

Low-income households (defined as households earning less than $125 \%$ of the poverty level) consume $13 \%$ less and spend $15 \%$ less on energy than non-poor U.S. households (Stuntz, 1991). However, because they earn less, low-income households spend four times more on energy as a percentage of their income, than non-poor households. According to the U.S. Department of Health and Human Services (1992), the average low-income family spends $12 \%$ of its income on residential energy compared to $3 \%$ for the average U.S. family.

When fuel prices are high, low-income households may have to choose between heat and other basic necessities such as food, rent, medicine, or medical care. The inability to pay fuel bills may threaten the very survival of low-income households - economically and, at times, physically. For example, poor households may turn to cheaper, but unsafe, sources of heat such as portable kerosene heaters, which may cause deaths due to fire and asphyxiation, or suffer serious hypothermia or other health problems because of inadequate heat or cooling. Homelessness also may be increased because of the inability to pay fuel bills. The diverse negative effects of a household's inability to pay fuel bills are the crucial reasons that the federal government (through programs such as the L.IHEAP and DOE Weatherization) helps low-income households deal with high energy prices.

Because low-income households experience a constant cash flow crisis, most of the money saved through energy-efficiency improvements will be spent for other goods and services. Although the income of weatherization clients usually does not change because of weatherization, ${ }^{2}$ they are able to obtain heating/cooling comfort for less money and, thus, to spend more on other needs. Energy savings can, therefore, cause a redistribution of consumer purchases on the part of weatherized households.

This study offers some data on the impact of weatherization on the energy costs of lowincome households. The energy-savings analysis (Chapter 5) estimated that weatherization reduced natural gas consumption by $173 \mathrm{ccf}$ (or 13.0\%) and electricity consumption by $1,830 \mathrm{kWh}$ (or 12.2\%). Average 1989 gas and electricity prices were calculated by weighting State averages, published by the Energy Information Administration (1991), by the proportion of PY 1989 weatherized dwellings located in that State, and summing the products. At an average price of $\$ 0.585$ per ccf of natural gas and $\$ 0.0694$ per $\mathrm{kWh}$ of electricity, the savings per unit weatherized are

2 If the low-income household's health improves as the result of weatherization, it might experience increased earnings. 
$\$ 101 /$ year for gas-heated dwellings and $\$ 127 /$ year for electrically heated dwellings. The weighted average for the Program (including weatherized dwellings heated by "other" fuels) is \$116. Some portion of this savings on fuel bills may reduce the need for LIHEAP payments or make it possible to provide LIHEAP assistance to another household, which is a net gain.

\subsubsection{Reduced Utility Arrearages and Terminations}

Low-income households often have difficulty paying their utility bills. Some utilities have found that $30-40 \%$ of their customers with past-due bills were low-income households (Quaid and Pigg, 1991). In addition, low-income dwellings often are highly energy inefficient (Brown and Rollinson, 1985), offering a large potential for reducing fuel consumption, utility bills, and hence nonpayments through weatherization retrofits. To the extent that weatherization services (which improve the energy efficiency of low-income dwellings) reduce fuel consumption and utility bills, they may have significant impacts on the frequency of unpaid bills and the magnitude of arrearages. Utilities, and their ratepayers, bear substantial costs due to uncollectible debts. Thus, reductions in arrearages may be an important benefit of the Program.

Previous research on the customer payment impacts of wcatherization programs is limited. In all of the analyses of customer arrearages reviewed below, the analytic methodologies have been difficult to implement (White, Brown, and Tolson, 1991). First, besides the usual data needed to conduct an energy savings analysis, additional data like the amount, source, and kind of energy assistance, an accounting of financial and energy debt, among others, are needed in order to reconstruct payment histories. Second, many of the data are more private than data used in the typical energy savings analysis; consequently, customer cooperation is paramount. Third, the additional data are not maintained in readily available databases. Fourth, it has been shown that the factors that are correlated with energy savings are probably different from the factors that are correlated with reductions of arrearages (Hexter, Barnett, and Grothe, 1989). Similarly, decisions (and abilities) to pay energy bills are different from decisions to reduce energy use. Fifth, some State public utility commissions authorize a "surcharge" on the energy and demand rates in order that utilities can recover the loss due to arrearages and nonpayments. It is not clear how this policy might affect arrearages or energy use, or the utilities' diligence in recovering losses due to non-payment.

Three recent evaluations of low-income weatherization programs have identified impacts on payment behavior. In the Oregon Partners in Energy Chronic Arrearages Project, average arrearages were reduced to zero (Fogerty, et al., 1990).

A study supported by the Wisconsin Gas Company (Nelson, 1988) found that the amount of arrearages for customers receiving weatherization stabilized after the weatherization, while the amount of arrearages continued to increase in a comparison group. Post-weatherization year arrearages decreased by $\$ 56$ in the treatment group, while arrearages increased by a median of $\$ 176$ in the 
comparison group. The number of customers with new arrearages was reduced by $16 \%$ due to weatherization, and unrecovered gas charges were reduced by $56 \%$.

A study performed by the Washington State Energy Office (Quaid and Pigg, 1991) evaluated the impact of an energy services pilot program which included weatherization, energy assistance payments, 11 education sessions, and access to a utility budget plan. This study compared three groups: 1) the pilot program participants, 2) houscholds receiving only weatherization and no other services, and 3) households receiving only energy assistance payments and no other services. The pilot program group and the weatherization only group had substantial space heating savings: $25 \%$ and $17 \%$ respectively (in $\mathrm{kWh} / \mathrm{per}$ degree day). The pilot program had noticeable impac $t$ s on client payment behavior: most program clients began using a budget billing plan (81\% vs. $10 \%$ preprogram), and the amount of arrears was lower. In the pre-program year, mean arrearages were $\$ 93$, $\$ 24$, and $\$ 28$ for the program and the two comparison groups, respectively. In the post-program year, the arrearages of the three groups were $\$ 9$ for the program group vs. $\$ 18$ and $\$ 25$ for the comparison groups. Thus, all three studies suggest that low-income weatherization and education programs may have significant impacts on arrearages and payment behavior.

This study also estimated a significant reduction in arrearages. Using available data on payment histories for dwellings in our sample, we estimated that the average reduction in arrearages, for the year following weatherization, was $\$ 32$. Our estimate is somewhat lower than previous estimates, perhaps because the previous studies evaluated groups of utility customers that were targeted for weatherization because of their high arrearage levels.

\subsection{EMPLOYMENT AND ECONOMIC IMPACTS}

The employment and economic impacts of energy conservation programs can be substantial. Studies of the economic impact of demand-side and supply sector resource options have been conducted in several jurisdictions. The findings have consistently been that demand-side programs have a larger multiplier effect on local, state, and national economic activity than supply-side options.

A recent study of the economic impacts of employment benefits from investing in energyconserving technologies considered the following ways in which such investments generate economic impacts (Geller, et al., 1992):

- Direct Effect: These are the on-site jobs created by an expenditure. In the case of DOE Weatherization, the direct effect would be the jobs of the local weatherization agency employees and of the contractors paid to install weatherization measures for the local agency;

- Indirect Effect: These are the jobs supported in a wide range of industries that provide the equipment, materials, and services needed to conduct the weatherization assistance activities; and 
- Induced Effect: As the people who are directly and indirectly employed by the Program spend their weekly paychecks, they are said to "induce" other activity. This increases jobs in the industrial, retail, and service sectors that produce and distribute consumer goods and services.

When the full range of employment impacts are considered, Geller, et al. (1992) show that energy efficiency investments create more jobs than equivalent investments in energy supply sectors, which are relatively capital intensive. This corroborates a previous study which estimated that conservation and solar technologies would create 2.4 to 2.7 times more employment nationally than would the equivalent use of oil, natural gas, and electricity (Buchsbaum, et al., 1979). Similarly, integrated resource planning in Maine estimated that DSM programs would result in two to five times more jobs than a proposed power plant (The Goodman Group, 1992).

Only one study has taken a national approach to estimating the employment impacts of investment in weatherization (Oak Ridge Associated Universities, 1983). It focuses on the direct and indirect effects of weatherization investments and does not attempt to estimate the induced effect. Therefore, its results undervalue the employment benefits of weatherization. Its analysis estimates that 52 full-time equivalent (FTE) positions are supported per $\$ 1$ million (1983 dollars) spent by local weatherization agencies. Most of these jobs are direct employment by local agencies (36 FTE's), while 16 FTE's of indirect employment are created. Thus, for every employee of a local agency that is supported by the Weatherization Assistance Program, an additional 0.44 FTE employees are created indirectly as the result of jobs in supporting industrial and service sectors.

Eisl et al. (1991) also have conducted a comprehensive analysis of the jobs created by investments in weatherization, but their analysis is limited to New York State. Eisl et al. (1991) analyzed the processes producing economic impacts by identifying sector coefficients that describe the changes in the economic output of the various industrial sectors influenced by weatherization activities. The study concluded that, over the assumed 20-year lifetime of the weatherization measures installed by the New York Weatherization Program, the economic benefits included increases in employment of 95 to 122 job years per million dollars of Program cost.

The employment estimates produced by Eisl et al. (1991) are twice as high as the national estimates produced by the Oak Ridge Associated Universities study; they also are higher than the results of a majority of the 10 studies reviewed by Jones (1985). Since New York is a net energy consumer with high energy prices, the economic benefits of the Program are probably higher there than in most States. Because of our desire to be conservative in our estimates of the value of nonenergy benefits, we rely on the results of the Oak Ridge Associated Universities study to estimate the magnitude of indirect employment, rather than extrapolating from the analysis of the New York weatherization program (Eisl, et al., 1991). Results from an earlier National Weatherization Evaluation report (Mihlmester, et al., 1992) are used to estimate direct employment. 
The value of direct employment, estimated in terms of federal tax revenue creation, is $\$ 55.27$ per weatherized dwelling (Table 6.1). This value was obtained by multiplying the average per capita federal income tax paid by households making less than $\$ 20,000$ per year in $1988(\$ 1,000)$, times the estimated job years of increased direct employment and then dividing this product by the number of weatic ized homes (Table 6.1).

Table 6.1 Taxes Generated from Employment in the Weatherization Assistance Program

\begin{tabular}{|c|c|}
\hline Description or Statistic & Estimate of \\
\hline FTE Local Agency Employment Supported by the Program in PY 1989 & $13,446^{\mathrm{a}}$ \\
\hline Number of Dwellings. Weatherized by local Agencies in PY 1989 & $243,268^{b}$ \\
\hline Federal Tax Revenues Generated per PIE & $\$ 1,000^{\mathrm{c}}$ \\
\hline Gederal Tax Revenues Generated per Weatherized Dwelling. & $\$ 55.27$ \\
\hline \multicolumn{2}{|c|}{$\begin{array}{l}\text { Source: Mihlmester et al. (1992), p. } 40 \text {, for crew employment }(6,723 \text { jobs) plus an additional } \\
6,723 \text { jobs for contractors since about half of the direct weatherization labor is supplied by } \\
\text { contractors. } \\
\text { b Source: Mihlmester et al. (1992), p. } 7 \text {. This includes all funding sources. } \\
\text { c Source: U.S. Department of Commerce, Bureau of the Census, Statistical Abstract of the United } \\
\text { States } 1992 \text {, Table No. } 509 \text {. This is the average tax paid by households with adjusted gross } \\
\text { incomes of } \$ 13,000-\$ 14,999 \text {. }\end{array}$} \\
\hline
\end{tabular}

The indirect employment impacts of the Program in PY 1989 were estimated by using the Oak Ridge Associated Universities multiplier for indirect employment of 0.44 (Table 6.2). This multiplier was applied to the FTE for direct employment (13,466 jobs) to yield an additional indirect employment impact of 5,925 FTE in various supporting industries. Assuming the indirect employees earn $\$ 10$ per hour ${ }^{3}$, or $\$ 20,800$ annually, the income generated by indirect employment exceeded $\$ 123$ million per year. This produces a per weatherized dwelling benefit of $\$ 505.85$ (Table 6.2). When this is added to the tax revenue generated by direct employment (Table 6.1), the total benefit from increased direct and indirect employment is $\$ 561.12$.

Another employment-related benefit is the avoided cost of unemployment insurance payments. Table 6.3 illustrates the likely avoided costs of reducing the need for such payments. If $50 \%$ of dircet employment and $25 \%$ of indirect employment is taken from the ranks of previously unempioyed workers, over 8,000 previously unemployed workers will no longer need unemployment benefits. Thus, the arcided costs of reducing unemployment are estimated at about $\$ 82$ per dwelling.

3 Employees in industries that supply weatherization equipirent, materials and services have a wide range of hourly rates because they include high level managers and trained professionals, as well as factory workers, truck drivers, and janitors. The $\$ 10$ per hour assumption is based on the average hourly rate for direct employees of the WAP and is a conservative assumption. 
Table 6.2 Indirect Employment Impacts of the

Weatherization Assistance Program

\section{Description of Statistic}

FTE Local Direct Employment Supported by the Program in PY 1989

Multiplier to Estimate Indirect Employment

Indirect FTE Employment Supported by Program in PY 1989

Yearly Earnings Estimated at $\$ 10$ hour per employee

Income generated by Indirect Employment

Number of Dwellings Weatherized by Local Agencies in PY 1989

Estimate of Statistic

$13,446^{\mathrm{a}}$

$0.44^{b}$

5,916

$\$ 20,800$

$\$ 123,057,792$

Indirect Income Generated per Weatherized Dwelling

$243,268^{c}$

$\$ 505.85$

a Source: Mihlmester et al. (1992), p. 40, for crew employment $(6,723$ jobs) plus an additional 6,723 jobs for contractors since about half of the direct weatherization labor is supplied by contractors.

b Source: Oak Ridge Associated Universitics (1983), p. v.

c Source: Mihlmester et al., (1992), p. 7.

Table 6.3 A voided Costs of Unemployment Benefits for Direct and Indirect Employment

\begin{tabular}{|l|c|}
\hline Description of Statistic & $\begin{array}{c}\text { Estimate of } \\
\text { Statistic }\end{array}$ \\
\hline FTE Local Direct Employment Supported by the Program in PY 1989 & $13,446^{\mathrm{a}}$ \\
\hline Proportion of FTEs Coming From Persons Previously Unemployed & 0.50 \\
\hline FTE Direct Employment Previously Unemployed & 6,723 \\
\hline Indirect FTE Employment Supported by the Program in PY 1989 & 5,916 \\
\hline Prop. of Indirect FTEs Coming From Persons Previously Unemployed & 0.25 \\
\hline FTE Indirect Employment Previously Unemployed & 1,479 \\
\hline Total Direct and Indirect FTE Employment Previously Unemployed & 8,202 \\
\hline Average State and Federal Unemployment Benefits per FTE & $\$ 2,442$ \\
\hline Total State and Federal Unemployment Bencfits for 8,202 Unemployed Persons & $\$ 20,029,000$ \\
\hline Average Avoided Costs of Unemployment Benefits Per Wejilherized Dwelling & $\$ 32.33$ \\
\hline a Source: U.S. Department of Commerce, Burcau of the Census, Statistical Abstract of the \\
\hline United States 1992, Tables No. 561 and 582.
\end{tabular}


This method of valuing increases in employment does not include increases in employment that are induced by the Program through the respending of salaries and energy bill savings. At least one study has suggested that this is the largest of the three types of employment impacts (California Energy Commission, 1979). Our method also does not include increased corporate income taxes and State and local income taxes. Also ignored is the possibility that employees involved with delivering Program services have upgraded their skills and consequently their wages (Jones, 1985). An early study conducted by Urban Systems Research and Engineering (1981) concluded that the Program did not produce measurable benefits from improvement of skills. If this study were repeated today, the benefits would be greater, because of the significant amount of training being conducted within the Program network (Mihlmester, et al., 1992) and the increased skills required to deliver weatherization services. Finally, this method of valuing the employment and economic impacts does not consider the impact of removing resources from the economy through taxation to fund DOE weatherization. ${ }^{4}$

\subsection{ENVIRONMENTAL EXTERNALITY IMPACTS}

\subsubsection{Environmental Impacts of Energy Production and Consumption}

There is a growing recognition that weatherization and other energy efficiency programs constitute a pollution abatement strategy, and that evaluations of these programs should credit them for their positive environmental impacts. The enactment of Title IV of the Clean Air Act Amendments of 1990 provides both explicit and implicit incentives for utilities to use energy conservation as a means to reduce $\mathrm{SO}_{2}$ emissions for acid rain compliance (Solomon, Kruger, and Morgan, 1992). In 1991, DOE and the Commission of the European Communities signed an agreement to develop estimates of external costs associated with the production and consumption of energy from different fuel sources (Cantor and Lee, 1992). ${ }^{5}$

At the State level, a recent survey showed that 17 Public Utility Commissions have instituted or are developing rules addressing environmental externalities (ICF Integrated, 1991). These rules require electric utilities to consider the cost of environmental externalities when evaluating energy

4 A benefit/cost analysis seeks to calculate the value of benefits flowing from a public project and balance them against the costs, which generally are financed out of tax revenues, either initially or ultimately. The removal of resources from an economy via taxation will have multiplier effects on income and employment. It may be asked legitimately, should the full, multiplier effect of the tax removed from the economy to pay for a public project be accounted as the cost of the project, against which the benefits are to be compared? In practice this is not done. Most project funding comes out of general revenues, and the funding base of all projects will impose the same losses through the extraction of tax revenue. The comparison of differential benefits across projects funded from a common tax base will yield the variation which orders their social desirability. If some projects are funded by excise taxes and others by the income tax, then the difference in the social cost of the tax may cause a difference in cost of funds among projects.

5 The results of this study to date have emphasized the difficulties associated with quantifying the cost of environmenta! externalities at a national scale. Numerical results for specific sites in the U.S. will be produced, but national estimates are not anticipated. 
efficiency and other resource options as part of their integrated resource planning. Unfortunately, no national consensus has emerged regarding the value of reduced emissions.

Our review of the literature produced an estimate of the environmental externality benefits of reduced energy production, distribution, and consumption of $\$ 11.66 \mathrm{per}$ dwelling. The derivation of this figure is shown in Table 6.4 and the assumptions involved are explained below.

Table 6.4 Environmental Benefits of the Weatherization Assistance Program

\begin{tabular}{|c|c|c|c|c|}
\hline Healing Fuel & $\begin{array}{l}\text { Pounds } \mathrm{SO}_{2}^{\mathrm{a}} \text { per } \\
\mathrm{MBtu}\end{array}$ & $\begin{array}{l}\text { Environmental } \\
\text { cost per pound } \\
\qquad \mathrm{SO}_{2} \mathrm{a}\end{array}$ & $\begin{array}{c}\text { Pounds } \mathrm{NO}_{\mathrm{x}}^{\mathrm{a}} \\
\text { per MBtu }\end{array}$ & $\begin{array}{l}\text { Environmental } \\
\text { cost per pound } \\
\mathrm{NO}_{\mathrm{X}}^{\mathrm{a}}\end{array}$ \\
\hline Natural Gas & 0 & $\$ 0.43$ & 0.248 & $\$ 0.516$ \\
\hline Fuel oil/kerosene & 1.08 & $\$ 0.43$ & 0.287 & $\$ 0.516$ \\
\hline LPG & 0 & $\$ 0.43$ & 0.248 & $\$ 0.516$ \\
\hline
\end{tabular}

\begin{tabular}{|l|c|c|c|c|}
\hline Heating Fuel & $\begin{array}{c}\text { Environmental } \\
\text { cost per MBtu } \\
(\mathrm{A})\end{array}$ & $\begin{array}{c}\text { Proportion of } \\
\text { Program households } \\
\text { using fuel type } \\
(\mathrm{B})\end{array}$ & $\begin{array}{c}\text { First-year energy } \\
\text { savings (MBtu's) } \\
(\mathrm{C})\end{array}$ & $\begin{array}{c}\text { Environmental benefit } \\
\text { per weatherized } \\
\text { dwelling } \\
(\mathrm{A} * \mathrm{~B} * \mathrm{C})\end{array}$ \\
\hline $\begin{array}{l}\text { Natural Gas } \\
\text { Electricity }\end{array}$ & $\$ 0.128$ & 0.506 & 17.3 & $\$ 1.11$ \\
\hline $\begin{array}{l}\text { Fuel oil/ } \\
\text { kerosene }\end{array}$ & $\$ 0.775$ & 0.095 & 18.8 & $\$ 7.33$ \\
\hline LPG & $\$ 0.128$ & 0.192 & 19.9 & $\$ 2.96$ \\
\hline Total cost & & 0.132 & 15.4 & $\$ 0.26$ \\
\hline
\end{tabular}

a Source: Pace University, 1990.

b Source: Massachusetts Department of Public Utilitics Order 89-239.

The analysis of natural gas, fuel oil, kerosene, and liquid propane gas was limited to the costs associated with $\mathrm{SO}_{2}$ and $\mathrm{NO}_{\mathrm{x}}$. Various estimates of environmental costs of atmospheric carbon emission are available, but range from exceptionally low to exceptionally high. Because of the current lack of consensus the omission of atmospheric carbon costs was the more conservative assumption. We used estimates of pounds of $\mathrm{SO}_{2}$ and $\mathrm{NO}_{\mathrm{x}}$ per MBtu released from coal-fired, oil- 
fired, and natural gas-fired power plants, contained in Pace University's study (1990). We assumed that the emissions of these materials from dispersed sources such as home heating units using fuel oil, natural gas, kerosene, etc. are no lower than from the controlled power plants. (They are probably higher.) Also from Pace University (1990), we used estimates of damages per pound of $\mathrm{SO}_{2}$ and $\mathrm{NO}_{x}$ Theoretically, marginal control costs should be no higher than marginal damages: it would not be cost effective to pay more to control an externality than it costs in damages. However, the estimates of margina' control costs offered by Massachusetts Department of Public Utilities Order 89. 239 are six times the value of the Pace University damage estimates for $\mathrm{NO}_{\mathrm{x}}$ and nearly twice for $\mathrm{SO}_{2}$. We chose to use the more conservative damage estimates offered by the Pace University study.

For the environmental costs of electricity generation, we considered two alternative estimates, one based on a review of the literature on damages (Lapsa, 1991) and the other on control costs (Massachusetts Department of Public Utilities Order 89-239). The estimate based on control costs is lower and is the one used here.

These $d \times:$ give us estimates of the dollar value of environmental costs per MBtu of energy generated (Table 6.4). Scparate cost estimates are provided for each of four fuel types: natural gas, fuel oil/kerosene, LPG, and electricity. To estimate the environmental value of reductions in energy use permitted by DOE weatherization activities, we weighted these fuel-specific estimates by the proportion of Program savings attributable to each fucl type. The data on this distribution of savings by fuel type among weatherized houscholds is contained in Figure 3.5:

- $50.6 \%$ licated by natural gas,

- $9.5 \%$ by electricity,

- $16.0 \%$ by fuel oil and $3.2 \%$ by kerosene,

- $13.2 \%$ by LPG, and

- $7.5 \%$ by other forms, including coal, wood, and solar.

We assumed that there are no emissions from the residual $7.5 \%$.

To obtain the environmental cost estimates cited above, we multiplied these percentages by the environmental cost estimate for the respective fuef ypes and summed these weighted costs (Table 6.4). The conclusion is that the annual environmental benefits per weatherized dwelling are approximately $\$ 12$.

\subsubsection{Environmental Impacts or Weatherization Materials Production}

Expenditures by the Program will increase the production of weatherization materials, which may increase the negative impacts of pollution from certain manufacturing processes. The environmental assessment conducted by DOE in 1979 concluded that the Program increases levels of air pollution associated with the prociuction of fibcrglass insu!ation, but that these impacts are minor, 
and far less than the decreased levels of the same pollutants associated with reduced fuel consumption. DOE's (1979) review of other weatherization materials (including rock wool, cellulose, perlite, and vermiculite insulation, storm windows, caulking compounds, and weatherstripping) concluded that their increased production would not have any adverse environmental impacts.

\subsection{SUMMARY AND CONCLUSIONS}

The various impacts of low-income weatherization programs are numerous and can be grouped into five major categories:

- preservation of affordable housing;

- comfort, health, and safety impacts;

- impacts on household budgets;

- employment and economic impacts; and

- environmental externality impacts.

While numerous studie have examined the energy saved by weatherization, little research has addressed nonenergy $\mathrm{im}_{\mathrm{l}}$ dets. Much of the research that has been conducted has been qualitative, presenting only anecdotal evidence; a consensus on how to quantify the value of many nonenergy benefits has not been reached.

Table 6.5 summarizes the dollar "alues for nonenergy benefits that were developed in this chapter. Additional benefits that have not been assigned a dollar value include: thermal comfort improvements, indoor air quality, benefits of increased nonenergy expenditures, and savings assnciated with fewer esidential moves. Thus, the dollar value used here for nonenergy benefits (\$976) is an underestimate.

The methods used to estimate the value of nonenergy impacts varied. Estimates of environmental benefits rei ad on a literature review and on information from this study about the proportions of weatherized dwellings using various fuel types and about the average savings by fuel type. The analysis of environmental impacts was limited to the costs associated with $\mathrm{SO}_{2}, \mathrm{NO}_{\mathrm{x}}$, and $\mathrm{CO}_{2}$. Estimates of employment benefits combined a literature review with data from this study on the number of employees directly supported by DOE's weatherization program, the skill level of workers, and managers' judgments concerning the structure of the job market for weatherization workers. Direct and indirect, but not induced, employment benefits are included in the estimate. Data from this study on Program expenc:itures for home repairs are used to quantify the benefits associated with maintaining or enhancing property values and extending the lifetime of dwellings. Our estimate of reductions in arrearages is based on a literature review and data on payment histories that were collected on a subset of the dwellings included in this study. 
Table 6.5 Net Present Value of Nonenergy Impacts of the Weatherization Assistance Program

\begin{tabular}{|c|c|}
\hline Type of Nonenergy Impact & $\begin{array}{l}\text { Net Present Value of the } \\
\text { Impact per Dwelling } \\
(1989 \$)\end{array}$ \\
\hline $\begin{array}{l}\text { Enhanced Property Value and Extended } \\
\text { Lifetine of Dwelling }\end{array}$ & $\$ 126$ \\
\hline Reduced Fires & $\$ 3$ \\
\hline Reduced Arrearages & $\$ 32$ \\
\hline Federal Taxes Generated from Direct Employment & $\$ 55$ \\
\hline Income Generated from Indirect Employment & $\$ 506$ \\
\hline Avoided Costs of Unemployment Benefits & $\$ 82$ \\
\hline Environmental Externalities & $\$ 172^{\mathrm{a}}$ \\
\hline Total Net Present Value of Nonenergy Impacts & $\$ 976$ \\
\hline \multicolumn{2}{|c|}{$\begin{array}{l}\text { a The net present value of the environmental benclits was calculated assuming a } 4.7 \% \\
\text { discount rate and a } 20 \text {-year lifetime. The other nonenergy benefits occur only in the year } \\
\text { (1989) in which weatherization occurred and, therefore, do not require discounting. }\end{array}$} \\
\hline
\end{tabular}




\section{PROGRAM COSTS}

Local Weatherization Assistance Program agencies often receive weatherization and other energy program funds from several sources, including DOE, LIHEAP, PVE and State agencies. The amount of funding received by local agencies from various sources in PY 1989 is shown in Fig. 7.1 and is described in two earlier reports (Mihlmester, et al., 1992 and Power et al., 1992). These funds were applied to a larger number of weatherized dwellings than the ones studied in this report, including large multifamily buildings and units weatherized entirely outside of the DOE weatherization rules and procedures. The distribution of funds shown below is nevertheless indicative of the wide range of funding sources used to weatherize the dwellings studied in this report. ${ }^{1}$ The funding breakdowns in Fig. 7.1 include all $(243,268)$ houses weatherized by local agencies regardless of the funding source. The rest of the analysis in this chapter is based on a smaller subset

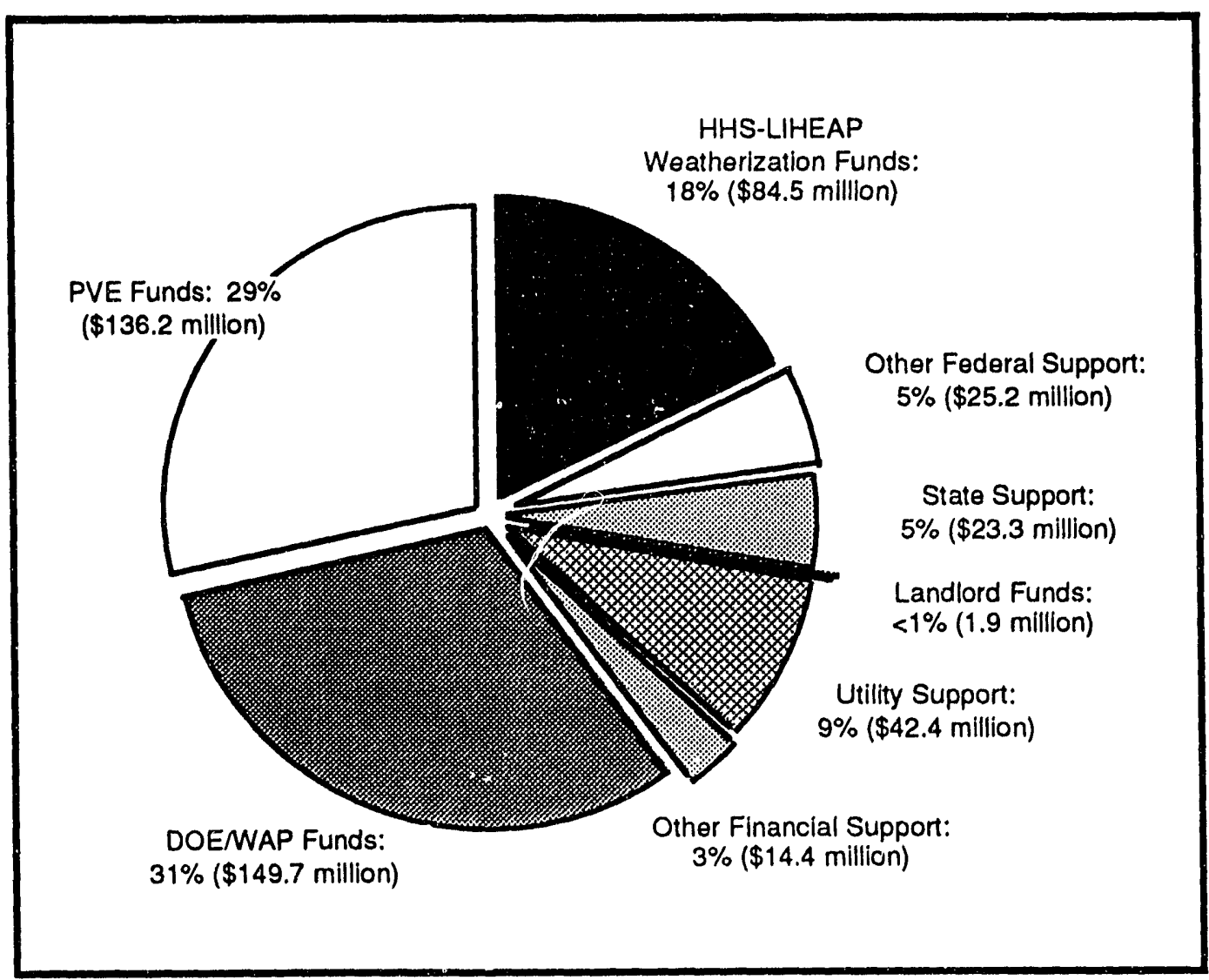

Fig. 7.1 Local Program Agency Direct Financial Support for Weatherization and Other Energy Programs. (Source: Mihlmester, et al., 1992).

i Because local WAP agency records typically do not indicate the sources of funds used to weatherize individual dwellings, we did not request such information on the Dwelling-Snecific Form (Appendix B-1). 
of homes: a stratified random sample of the 198,000 single-family and small multifamily homes weathurized entirely, or in part, with DOE funds or with funds from other sources that were used according to DOE weatherization regulations. Dwellings weatherized entirely with LIHEAP or utility funds that were administered under different rules were not included in the sample. As a result of this definition of our DOE weatherized "population," most of the homes in our sample were weatherized according to DOE rules, but some of the homes with mixed funding were not.

Data on program costs are difficult to collect and interpret because of the diversity of funding sources and the variety of recordkeeping systems used by local weatherization agencies. Different States, and local weatherization agencies within the same State, keep cost records in various formats, using a variety of cost categories. The cost categorics typically used for reporting local weatherization expenditures to the States are shown in Table 7.1. Data on total program costs and

Table 7.1 Cost Categories Used in Typical Local

Agency Expenditure Reports to the State

\author{
Administration \\ Training/Technical Assistance \\ Program Support \\ Labor \\ Materials \\ Liability Insurance \\ Total Program Costs
}

materials costs are generally the most reliable numbers and are the most comparable across agencies. ${ }^{2}$ Data on labor, administration, training and technical assistance (T\&TA), and program support costs are less consistent and comparable because the definitions, calegories, and procedures used in accounting for them are more variable. For example, agencies that usc contracted labor will not track labor costs in the same way as agencies that use in-house crew labor, or mixed crew/contractor labor. Similarly, weatherization programs housed along with several other social service programs (receiving funding from a variety of sources) may allocate and track costs for program support somewhat

2 The breakout between material and labor costs is likely to be more accurate for weatherization jobs performed by in-house crews rather than those involving contractors. Informal discussions with weatherization program managers suggest that contractor breakouts of materia! and l!!bor costs are often inconsistent and subjective. 
differently than an agency operating independently. A local Program that is part of a large Community Action Agency may, for example, pay to participate in a transportation pool that supplies vehicles, gas, and repairs for a fixed fee, while an independent local agency may purchase its own vehicles. Categories of administrative cost may aiso be tracked differently by a local weatherization agency that shares office space, reproduction equipment, telephones, etc. with five other programs than by a local weatherization agency operating alone. In general, when several programs are offered by the same agency the funding sources often overlap and the programs share functions (such as client recruitment and income eligibility verification), making it difficult to clearly and consistently assign costs to any specific program. As a result, there are substantial variations in the terminology and cost accounting systems used by local agencies.

Expenditures for weatherization materials, administration, T\&TA, and the average cost per weatherized unit are regulated by program rules. In the 1989 Program Year, the regulations required that at least $40 \%$ of the total DOE funds allocated for materials, labor, and program support be spent on materials. Both administrative and T\&TA expenditures were limited to not more than $10 \%$ of a State's grant. The limit on average DOE expenditures per weatherized dwelling unit in a State was set at $\$ 1,600$, and included materials, labor, and program support. These regulations obviously are the dominant influence on methods of defining, categorizing, and reporting various expenditures to the State.

For the purposes of this study, we chose cost categories (Table 7.2) that differed from the typical weatherization categories shown in Table 7.1. This scheme was sc'ected because it makes a logical distinction between installation costs that occur on-site for each individual house (i.e., weatherization materials and installation labor) and noninstallation costs, which we call installation-related overhead and program management (hereafter, overhead and management) costs. The Dwelling-Specific Form and the Agency Information Form (Appendix B) illustrate in detail the cost categories we used for data collection. Our cost categories are morc numerous and aie organized differently than the typical weatherization categories shown in Table 7.1. The most important general difference is that some of the functions charged to program support or to labor in the categories of Table 7.1 are placed in the overhead and management category in our scheme.

We used our cost categories (borrowed from an earlier study by Schlegel, 1991) for several reasons. First, we wished to be able to calculate installation costs on a house-by-house basis, separating them from any overhead or management costs. House-specific installation costs were needed so that house-specific cost-effectiveness indices could be calculated. Therefore, weatherization materials and installation labor costs were requested separately, on the DwellingSpecific Form, for each sample house in the study. Thus, our labor costs, unlike the catcgory of labor costs used by the Program, do not include staff labor costs allocated to performing tasks other 
Table 7.2 Cost Categories Used in This Study

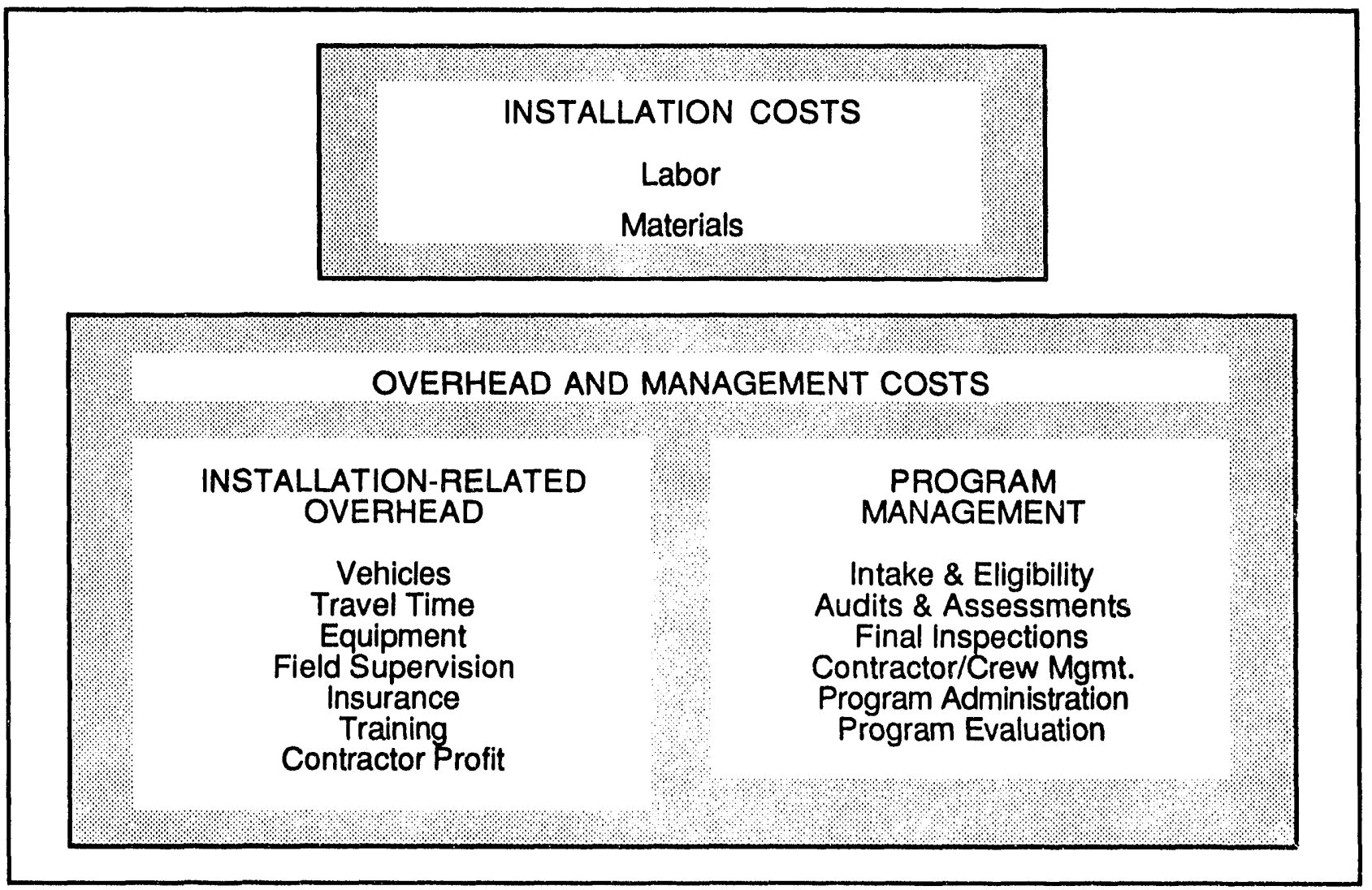

than the installation of measures. Staff travel time, or audit and inspection functions, for example, are not included in our definition of labor costs, although they may be present in the labor costs category (Table 7.1). Our category of material: costs, however, is defined the same way as the usual category (i.e., the weatherization materials installed in dwellings). This allows for comparisons with earlier studies, such as Peabody (1984), which include only weatherization materials costs. Another reason for selecting our cost categories was that we wished to be able to track costs differently for crew-based vs. contractor-based programs so that we could more closely adhere to actual variations in the expenditures by labor type. Our categories, therefore, have different components for crew and contractor work (Appendix B). ${ }^{3}$ We also hoped to obtain accurate estimates of the costs of specific individual program functions, unencumbered by the need to conform to program requirements. Lastly, we expected that our categories, which emphasize the distinction between on-site installation costs and all other costs, would be more comparable to cost accounting schemes used by low-income weatherization programs sponsored by utilities and governmental agencies other than DOE.

3 Contractor profit is part of installation-related overhead costs for contractor jobs, but is not part of crew-based program costs. 
Although there were several good reasons for using our cost categories, there also were drawbacks. The local agencies often could not map their cost accounting systems onto our categories, which led to some inconsistencies and uncertainties in our cost data. These problems are discussed in later sections.

Although our cost category definitions differ from those used by the Program, the findings on costs presented in this Chapter clearly reflect the impact of program regulations. Section 7.1, for example, describes total on-site installation costs and shows that average installation (i.e., materials and installation labor) expenditures per weatherized dwelling (for all fuel types) are $\$ 1050$. Findings in Sections 7.2 and 7.3 show that installation labor and materials expenditures, generally conform to the 60/40 rule. Overhead and management costs (all costs except installation costs) are estimated at about $\$ 500$ per house (Section 7.4 ), making the total average expenditure per house just under $\$ 1,600$.

Agencies vary in how they combine funding sources. Some use a mix of funding sources in weatherizing the same dwelling (often without tracking the funding sources used for a particular dwelling). Others use different funding sources for different parts of the program year (e.g., LIHEAP for January-June and DOE for July-December). The DOE weatherization regulations in PY 1989 were more restrictive concerning how funds could be spent than the LIHEAP rules. Since about $62 \%$ of local agencies reported receiving LIHEAP weatherization funds (Mihlmester et al., 1992), it is possible that many of the dwellings in our sample received some weatherization measures funded by LIHEAP. When LIHEAP, utility, or other funding is used in a dwelling, these funds may be used for measures (such as furnace replacements or housing rchabilitation) which would not normally be allowed in a dwelling weatherized entirely under DOE regulations. Therefore, we asked the local agencies to tell us (whenever possible), the percentage of non-DOE funds used in weatherizing a dwelling. This enables a comparison of costs for dwellings weatherized entirely with DOE funds and for dwellings weatherized partly with DOE funds and partly with other funding sources (Section 7.5).

In the next three sections of this chapter, variations in total installation costs, materials costs, and labor costs by climate region, fuel type, dwelling type, and agency size are discussed. Labor costs are reported separately for agencies that use only in-house crews, only contractors, or some combination of crew and contractor labor (Section 7.3). Findings on overhead and management costs are discussed in Section 7.4, and differences in expenditure palterns between agencies receiving only DOE funds and those with several sources of funding are reviewed in Section 7.5. Section 7.6 summarizes this Chapter's most important results. 


\subsection{TOTAL INSTALLATION COSTS}

\subsubsection{Programwide Total Installation Costs}

Total installation costs are defined as the sum of materials and installation labor costs for all labor types. The programwide average value for total installation costs for all fuel types (weighted to provide an unbiased estimate) is $\$ 1,050$. However, the total installation costs for an individual dwelling can differ substantially from this average.

The distribution of total installation costs is shown in Fig. 7.2. Eighty-five percent of dwellings had materials and labor expenditures of less than $\$ 1,500$, with $45 \%$ of dwellings in the $\$ 600$ to $\$ 1,200$ range. About $8 \%$ had installation expenditures of less than $\$ 300$ and about $9 \%$ had installation expenditures of more than $\$ 1,800$.

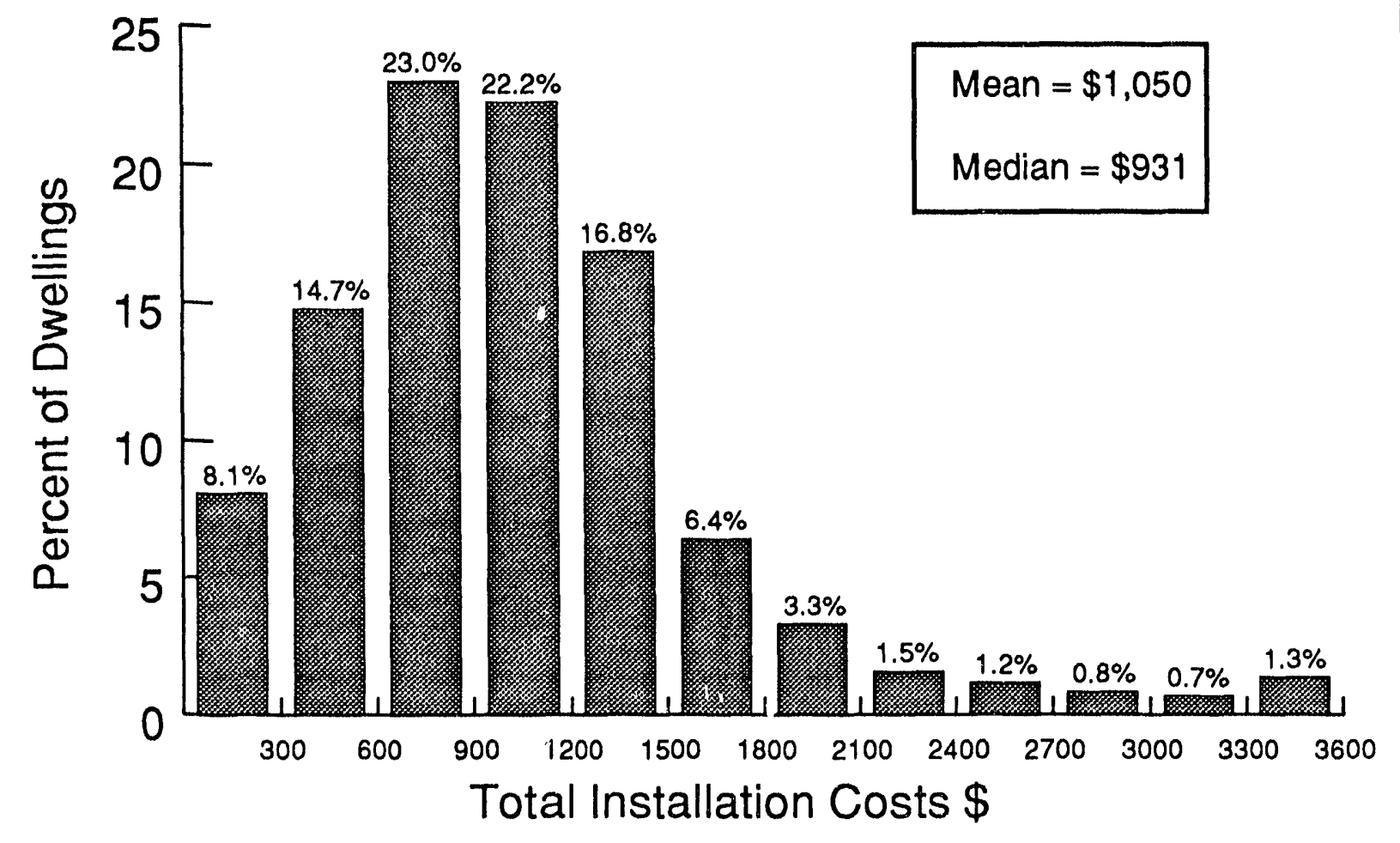

Fig. 7.2 National Distribution of Total Installation Costs (weighted).

\subsubsection{Differences by Climate Region, Fuel Type, Dwelling Type, and Agency Size}

As Fig. 7.3 shows, the total installation costs of weatherization vary by climate region, primary heating fuel, type of dwelling, and agency size. The largest installation expenditures are in the 
moderate climate region which spends an average of $\$ 1,080$ per dwelling. The cold region spends slightly less (\$4) than the moderate region, and the hot region about $\$ 111$ less Differences by primary heating fuel also are apparent, with the highest expenditures on dwellings that heat with other fuels, the next highest for electrically heated dwellings, and the lowest expenditures for gas-heated homes. Expenditures by dwelling type are highest for single-family detached and single-family attached dwellings, and lowest for mobile homes and small multifamily dwellings. Expenditures by agency size are highest for small agencies, and about \$60-100 less per house in medium and large agencies.

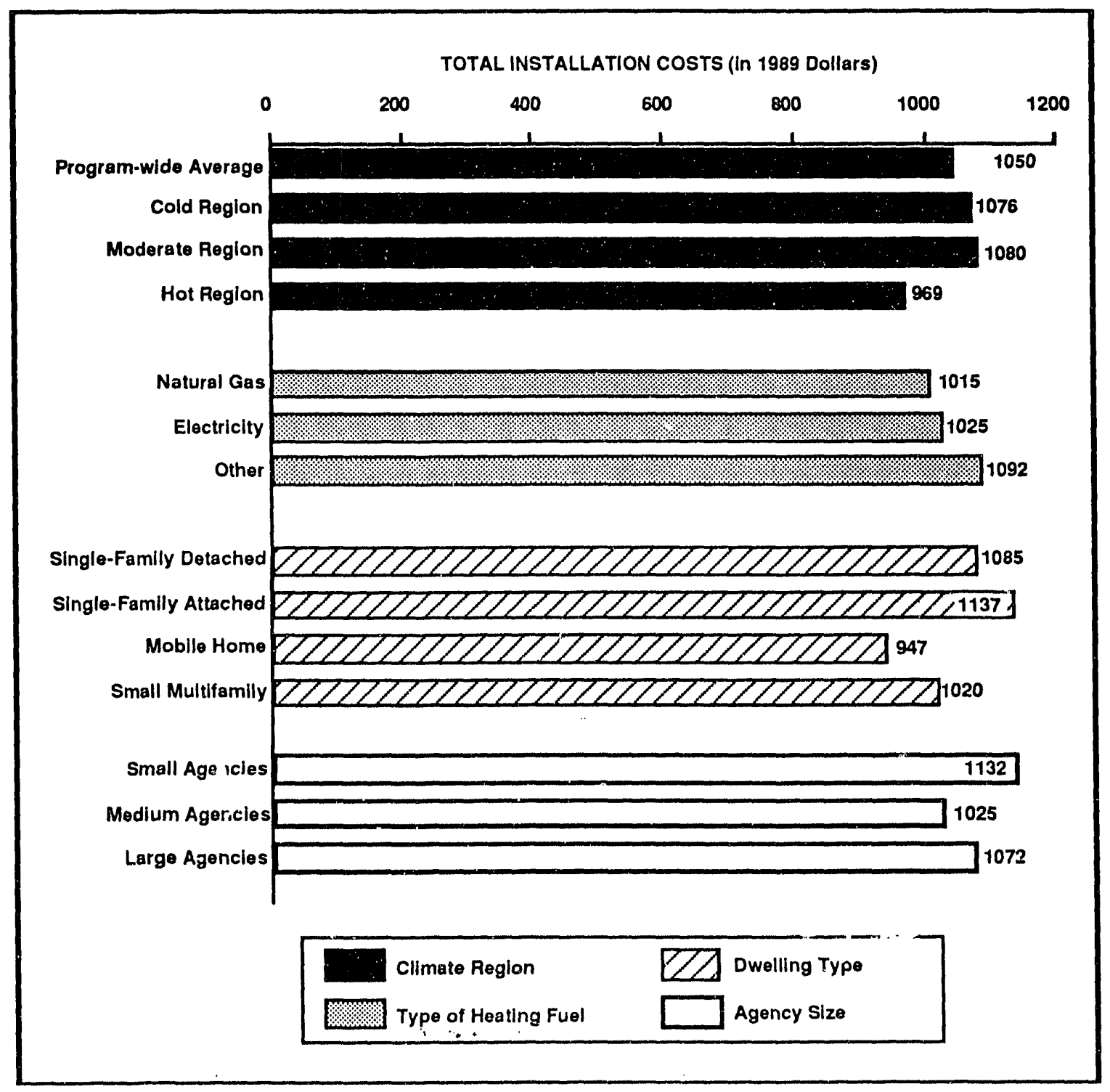

Fig. 7.3 Total Installation Costs (in 1989 dollars). 


\subsection{MATERIALS COSTS}

Interpretation of the data on materials costs presented in this section requires an understanding of how these data were collected and calculated. Materials costs data were collected in Part E of the Dwelling-Specific Form (Appendix B-3). Respondents were asked to record materials costs by type of measure (e.g., insulation, air leakage, etc.) and by type of labor (in-house crew or contractor) doing the work on that measure. They also were asked to record the total materials costs for all work done by a crew and for all work done by a contractor. Similar proportions of the 14,727 dwellings with cost data were weatherized by each of the three possible labor types: crew-only (33\%), contractor-only $(38 \%)$, and mixed crew and contractor $(29 \%)$. In mixed labor jobs, the contractor was most likely to do the space-heating work. Similarly, contractor-only jobs were more likely than crew-only jobs to include space-heating work.

Although materials costs were requested by measure type, labor costs were not because agencies do not track measure-specific labor costs. Materials costs also were sometimes not available by measure type. In many cases, responding agencies recorded only the total materials costs without providing a breakdown by type of measure. As a result, there were large numbers of zeroes and missing values in the measure-specific cost data. It also was clear that the allocation of costs to a measure-specific category was not always consistent across agencies. Storm windows, for example, might be placed in the structural measures category by some agencies and in the windows and doors category by others. Total materials costs data, on the other hand, were recorded quite completely and consistently. Therefore, more confidence can be placed in the total materials cost than in any other part of this analysis.

To help correct for inconsistencies in the measure-specific materials costs data, an extensive computer screening and checking routine was implemented. Reasonable ranges of values were defined and values outside of these ranges were set to missing. Because there were many zeroes in the measure-specific costs data, and because the combination of measures installed varies across dwellings, the number and set of dwellings with costs data (other than zero) for a measure-specific category cilanges for each category.

The presence of large numbers of zeroes in the costs data led to two separate analyses: (1) with zeroes included, and (2) with zeroes excluded. The next two sections (7.2.1 and 7.2.2) report findings with zeroes included, while the following section (7.2.3) reports results with zeroes excluded. Thus, the amount of expenditures reported in each category in Sections 7.2.1 and 7.2.2 (Figs. 7.4 to 7.7) is a function both of the average amount spent when costs are reported and of the proportion of zeroes in the category. In comparing the amount spent for space-heating measures in the hot region (\$3) vs. the amount spent in the cold region (\$89), for example, the much lower cost in the hot region occurs mainly because only $2.4 \%$ of homes in this region received space-heating 
measures, while the rest of the homes have zeroes recorded as the amount spent on space-heating. This high proportion of zeroes results in a much lower average cost for the hot region, than for the cold, where $36 \%$ of homes received space-heating measures (Fig. 7.4). Thus, the average materials costs shown in Sections 7.2.1 and 7.2.2 (Figs. 7.4 to 7.7) reflect the frequency with which specific measures are installed by various subgroups. The less frequently a measure is installed (and the more zero costs are reported) the lower the average will be. Similarly, the most frequently installed measures will have higher averages.

In contrast, if one excludes zeroes and examines costs only in those homes which received a specific measure and reported a cost value for the measure (Section 7.2.3), materials costs are usually much higher (Figs. 7.8 to 7.11 ). The values shown in Figs. 7.8 to 7.11 are based on only dwellings with non-zero materials costs reported for the specific measure.

\subsubsection{Programwide Materials Costs}

The cost of weatherization materials in PY 1989 averaged $\$ 594$ per dwelling (Fig. 7.4). When zeroes are included in the averages for materials costs, insulation (\$137), windows and doors $(\$ 133)$, structural measures $(\$ 126)$, and air leakage (\$116) account for the vast majority of the expenditures. Smaller amounts are spent on space heating and water heating measures.

\subsubsection{Measure-Specific Materials Costs for All Weatherized Homes}

Figures 7.4 to 7.7 present average materials costs (with zeroes included) by climate region, fuel type, dwelling type, and agency size. The tables on which these figures are based, and some additional detail, are presented in Appendix G (Tables G.1 to G.4).

An examination of variations in average total materials costs by climate region revealed little difference in average expenditures (Fig. 7.4). Since there are significant differences in total installation costs (Section 7.1), those differences are clearly due to variations in labor costs.

Although total materials costs did not vary much by region, the proportions of the total invested in specific measures (with zeroes included) did differ significantly (Fig. 7.4 and Table G.1). In the cold region, average expenditures for materials were higher for insulation, water heating, and space-heating measures than in the other two regions. In the moderate region, the highest materials costs were for windows and doors. In the hot region, structural measures had the highest materials costs, and windows and doors neariy as high an amount. As shown in Chapter 4, these differences indicate that the cold region puts more resources into the measures likely to save the most energy, while the hot region spends more on measures with less energy-saving potential.

The emphasis on housing rehabilitation work in the hot region occurs, in part, because of the extremely poor condition of low-income housing in the South (Table G.5). The miserable condition 
of low-income housing in the hot region is frequently emphasized by program managers from this area. They report that the funds allocated by the DOE Program are often inadequate for doing a complete job of weatherizing the homes they serve. The extremely poor condition of much of the housing in the hot region also was observed by ORNL staff during field visits to agencies in this region. Although this study did not collect quantitative data on the condition of the housing stock by region, the higher amounts spent on structural repairs in the hot region suggest that there is a greater need for housing rehabilitation there. In addition, data from the 1989 American Housing Survey (AHS) indicate that homes in the Southern Census region are more likely to be substandard than housing in the Northeastern, Midwestern, or Western regions. Because many of the States in this study's hot region also are in the Southern Census region, these AHS data (Table G.5) support the impression of both program managers and ORNL staff that the hot region has a greater need for structural repairs and housing rehabilitation.

Differences in materials costs by fuel type were significant (Fig. 7.5 and Table G.2). The most money was spent for materials in dwellings that heat primarily with other fuels -- $\$ 40$ to $\$ 80$ more than in dwellings that heat primarily with natural gas or clectricity. In dwellings heated with other fuels, the highest materials costs were for structural measures and windows and doors. The use of other fuels is concentrated in the hot region, where structural measures and window and door installations are most prevalent. For dwellings that heat primarily with natural gas, the most was spent on insulation (due, in part, to their concentration in the cold region). Electrically heated dwellings had the highest expenditures for structural measures and windows and doors (Fig. 7.5 and Table G.2).

The dwelling types of single-family detached and small multifamily had the highest average expenditures on materials. Expenditures were nearly as high for mobile homes and much lower for single-family attached dwellings (Fig. 7.6 and Table G.3). Compared to other dwelling types, singlefamily detached dwellings had the highest expenditures for insulation and the lowest for windows and doors. Mobile homes had the highest expenditures for structural measures and windows and doors, in part because of their concentration in the hot region, where installation rates for these measures are highest. Single-family attached dwellings had the highest expenditures for space heating, while small mutifamily dwellings had the highest expenditures for air leakage measures (Fig. 7.6 aid Ta':- G.3).

Small agencies had the highest average expenditure (\$638) on materials (Fig. 7.7 and Table G.4), with large and medium size agencies spending about $\$ 50$ less per house on materials. Large agencies spent the most on space heating measures, nore than twice as much as medium agencies and over four times as much as small agencies. Small agencies spent the most on windows and doors (reflecting the greater concentration of small agencies in the hot region). 


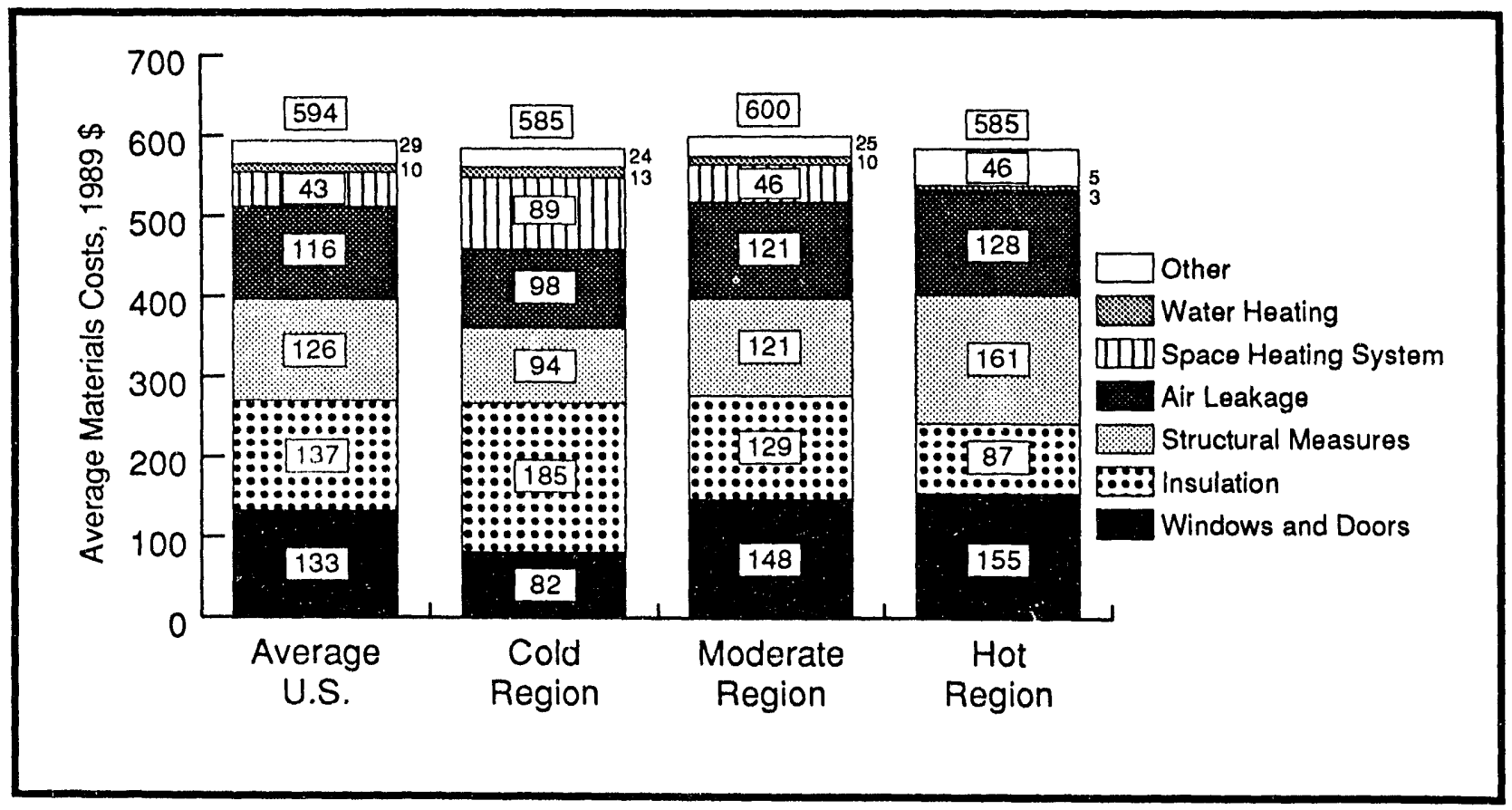

Fig. 7.4 Average Materials Costs (in 1989 dollars), by Climate Region.

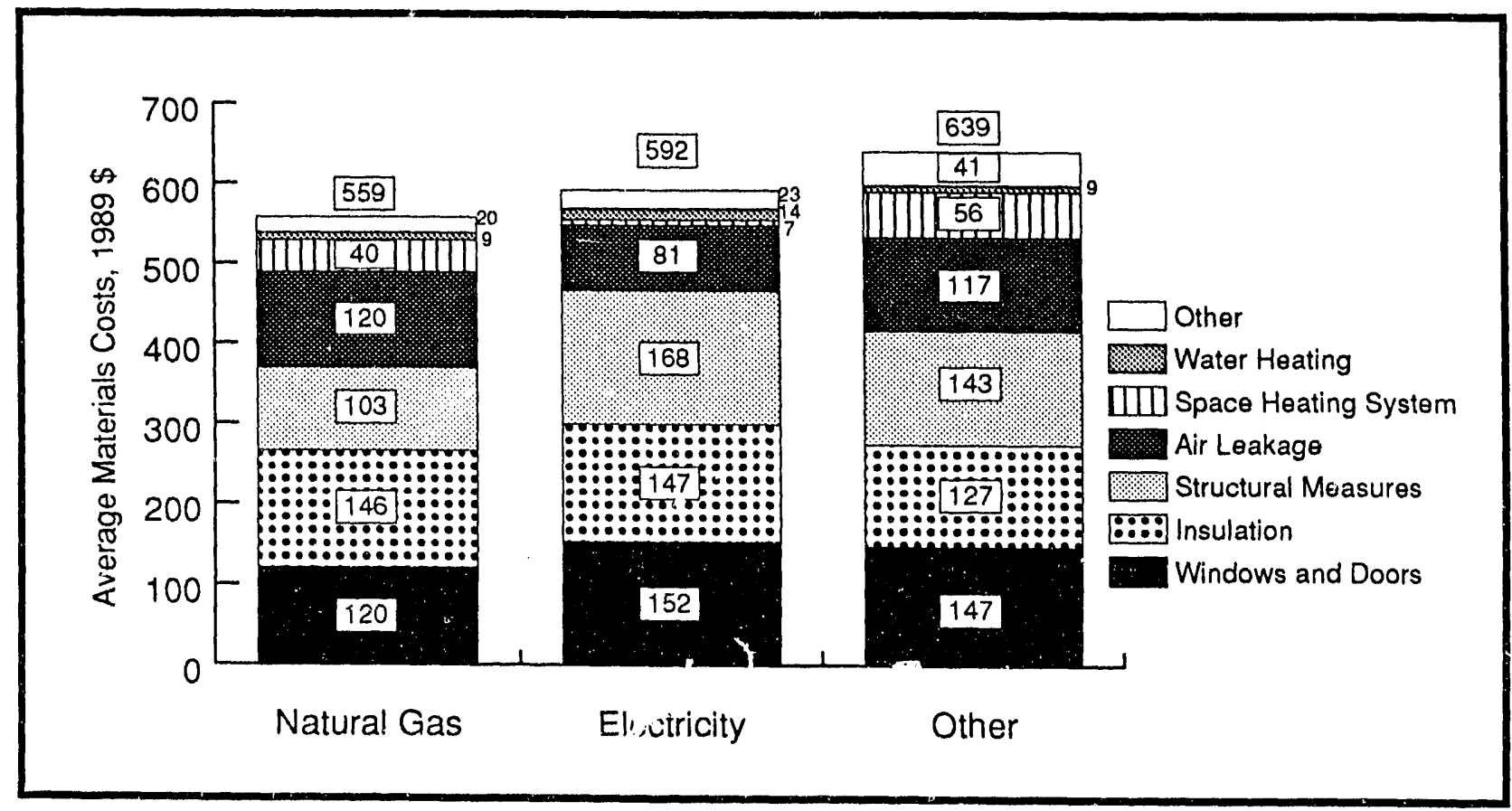

Fig. 7.5 Average Materials Costs (in 1989 dollars), by Type of Heating Fuel. 


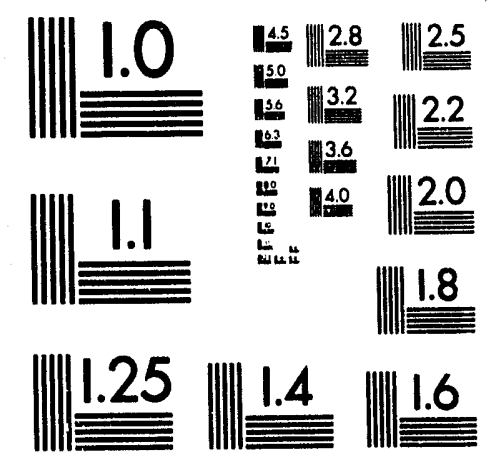



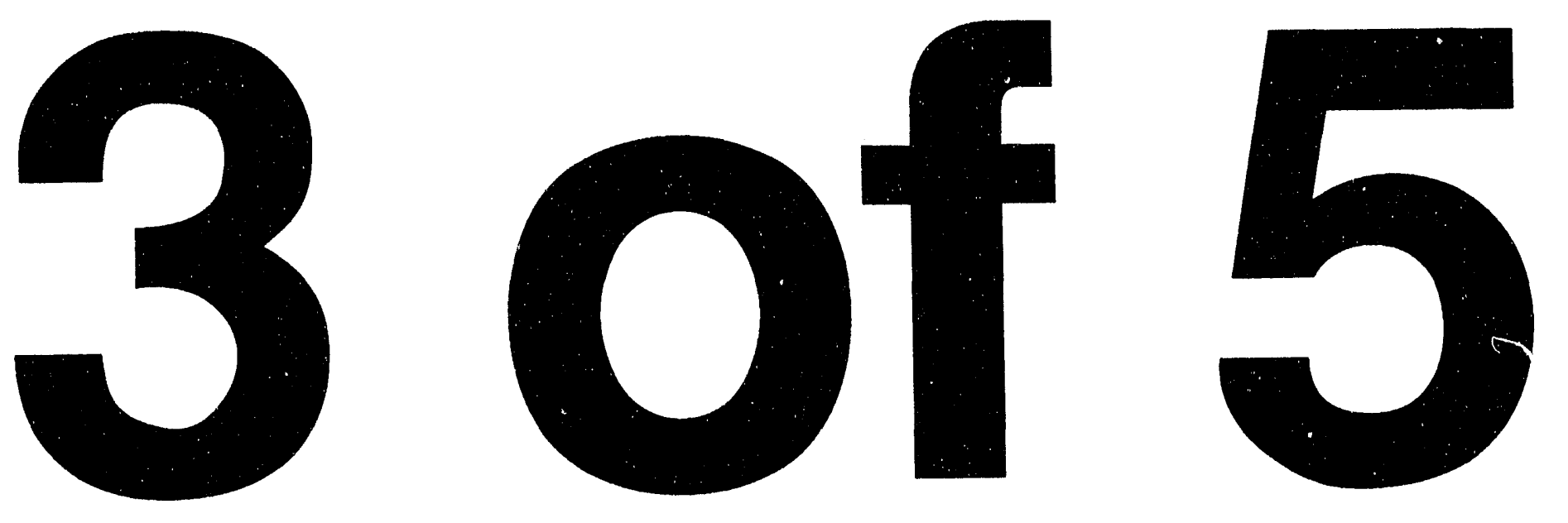


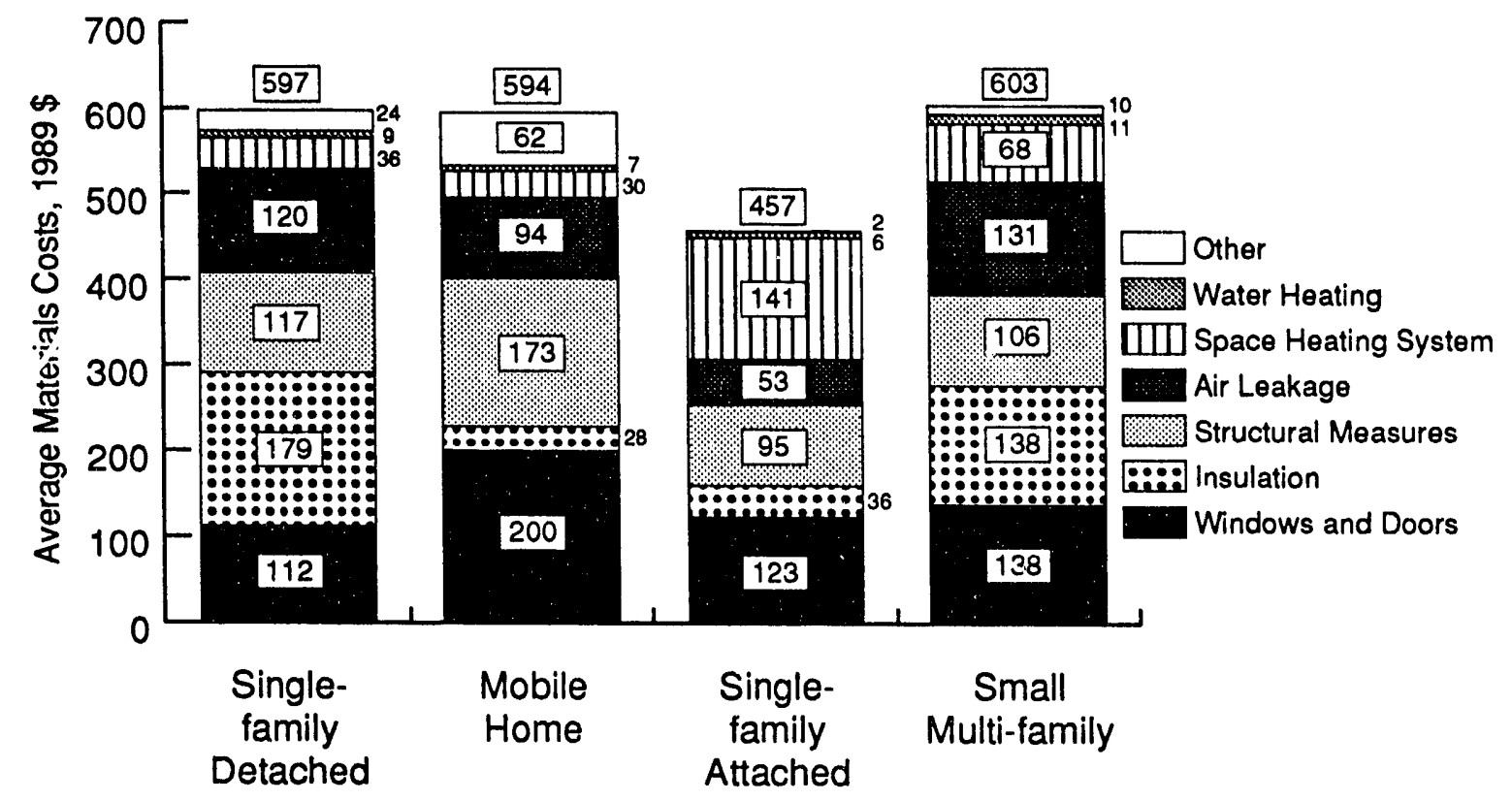

Fig. 7.6 Average Materials Costs (in 1989 dollars), by Dwelling Type.

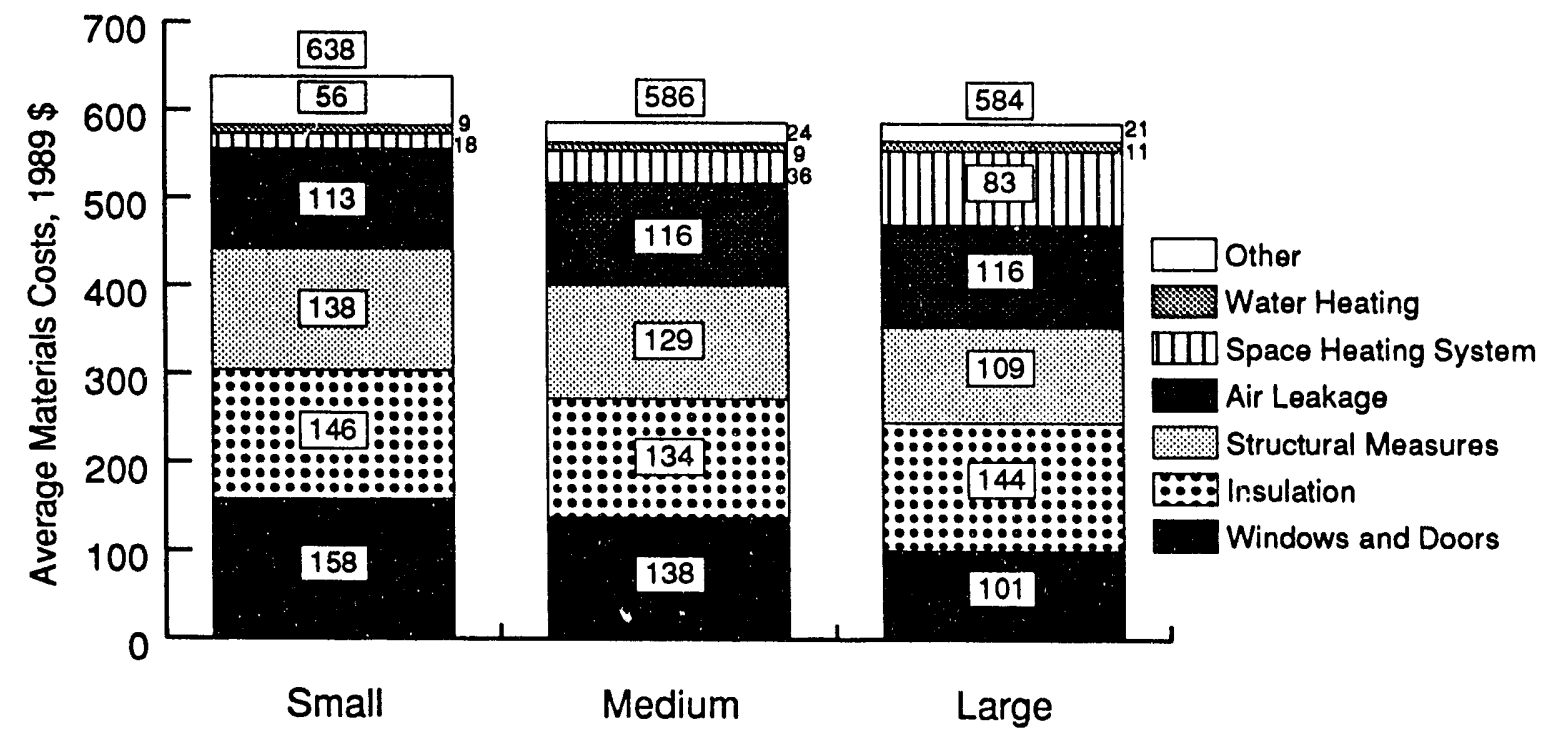

Fig. 7.7 Average Materials Costs (in 1989 dollars), by Size of Local Weatherization Agency. 


\subsubsection{Measure-Specific Materials Costs Only for Homes with the Measure Installed}

In the previous section, we examined measure-specific materials costs with the zero values included. This way of examining the materials cost data tells us the proportions of total dollars invested in various types of measures. With the zero values included, the measure-specific dollar values are a function both of the frequency with which the measure is installed (i.e., the proportion of zeroes in the category) and the costs reported.

In this section, we will address a different question about materials costs: when a measure is installed (i.e., when a non-zero dollar value is reported for the measure), what is the average materials cost? This question does not consider variations in the frequency of installation across subgroups, it only asks what is the average cost when a measure is installed in a dwelling? The amount spent on measures when zero values are excluded is usually much higher than when zeroes are included (Figures 7.8 to 7.11), showing that variations in the frequency of installation greatly reduced most of the cost values shown in Section 7.2.2.

Differences across climate regions in the avcrage materials costs when a measure is installed (Fig. 7.8) are greatest for space heating. The higher expenditures on space heating in the moderate region reflect its higher rates of installing replacement fumaces. For all measures, except insulation, average expenditures are highest in the moderate region. The cold region spends the most on insulation when it is installed, perhaps reflecting the higher incidence of wall insulation there.

Variations by fuel type (Fig. 7.9) show that expenditures are generally higher in electrically heated homes when measures are installed. The only exceptions are for space heating measures, where the most is spent in dwellings heated with other fuels; and for air leakage where the most is spent in gas-heated homes.

Expenditures by dwelling type show significant variation (Fig. 7.10) for all measures except water heating. Space heating measures cost the most in single-family attached dwellings, and a higher than average amount in small multifamily dwellings. Space-heating measure costs for single-family detached and mobile homes are significantly lower. Air leakage work is most expensive in small multifamily and single-family detached dwellings. Structural measures cost the most in single-family attached and mobile homes. Windows and doors cost the most when they are installed in mobile homes. Since mobile homes usually have a smaller living area, this suggests that complete replacement of all windows may be more common for this dwelling type. Insulation costs the most in single-family detached and small multifamily dwellings, perhaps reflecting the higher rates of installing wall insulation in these dwelling types (Table 4.3) 


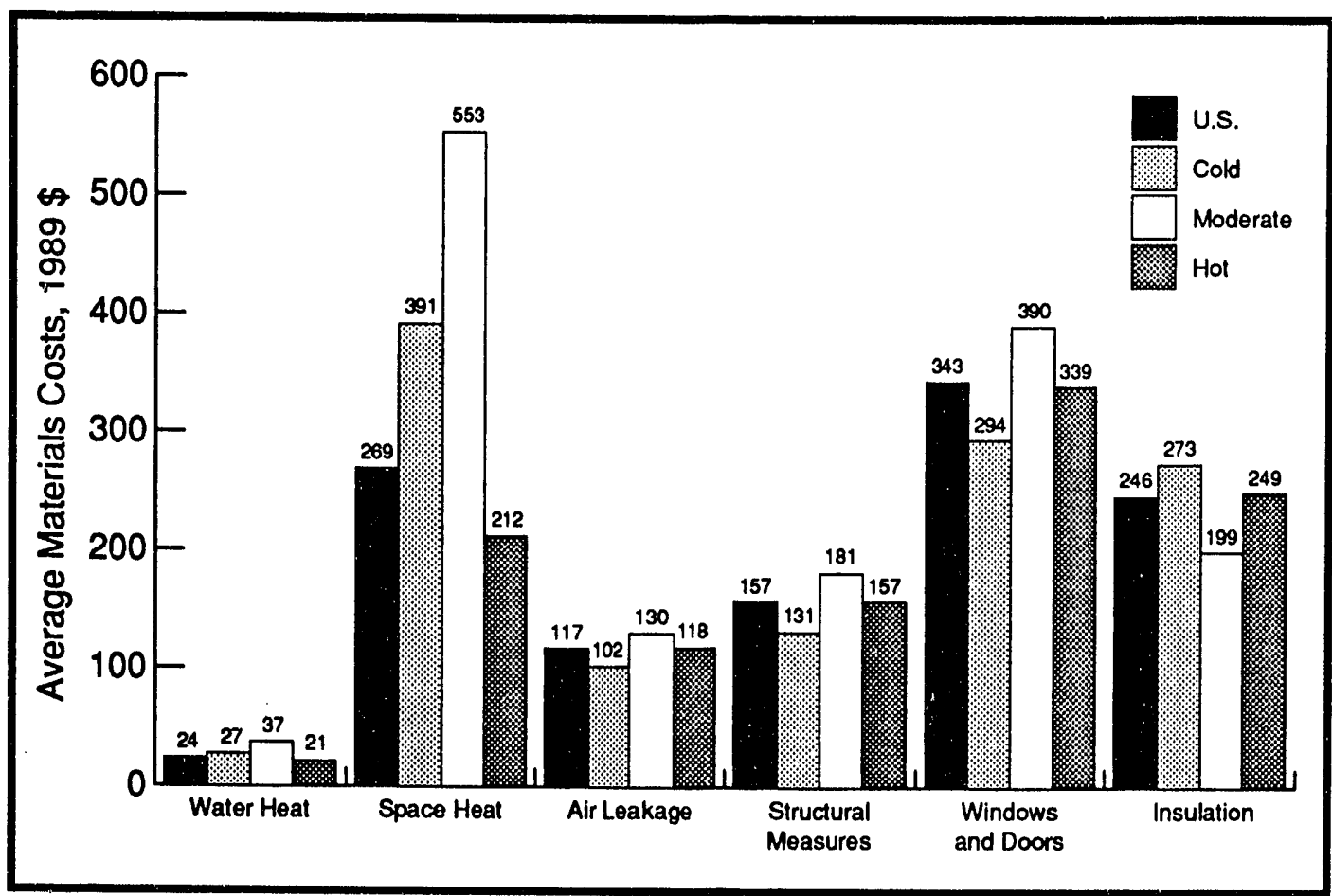

Fig. 7.8 Average Cost of Materials in Dwellings Receiving the Measure, by Climate Regiona

a No values of zero are included in these averages.

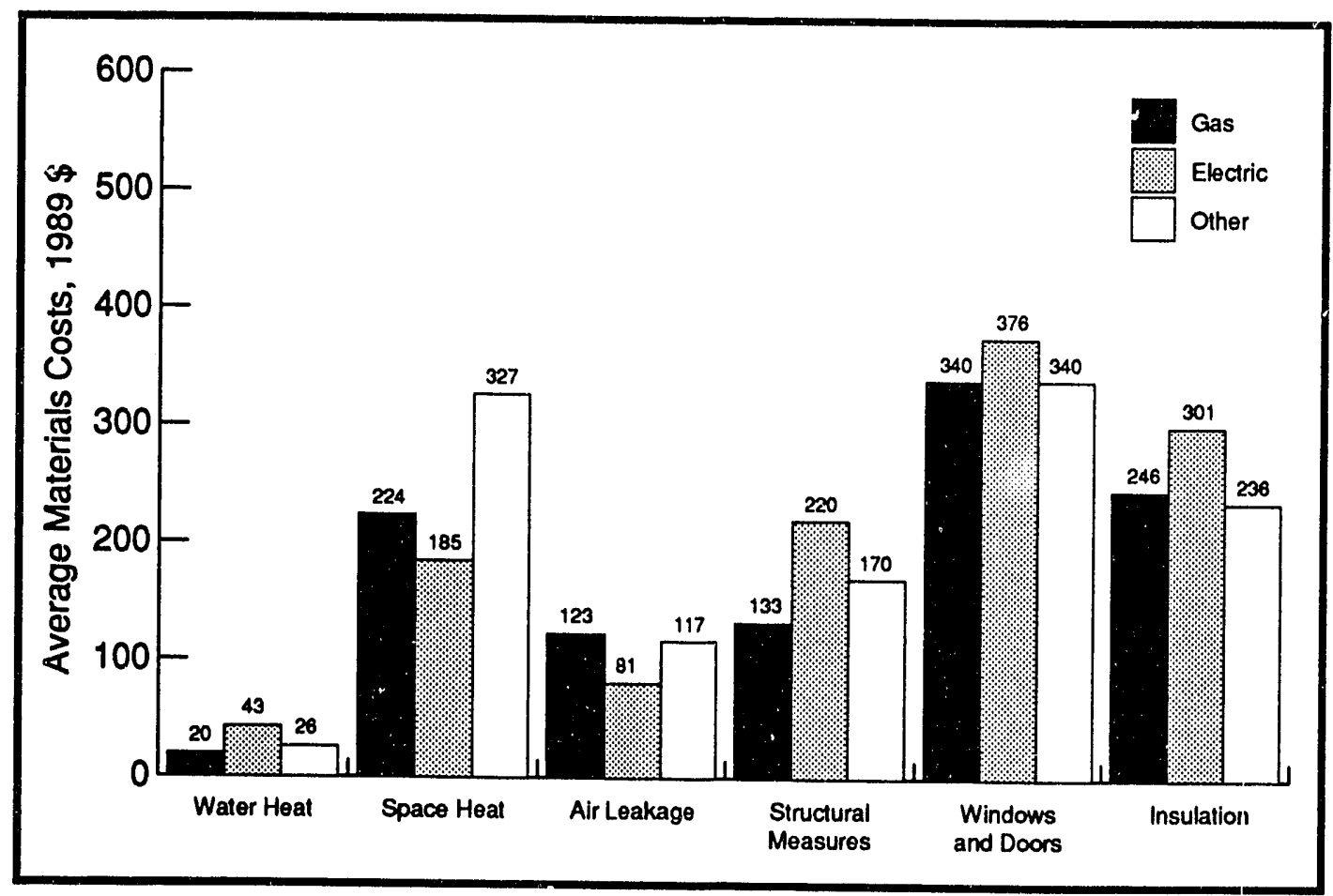

Fig. 7.9 Average Cost of Materials in Dwellings Receiving the Measure, by Fuel Type

a No values of zero are included in these averages. 


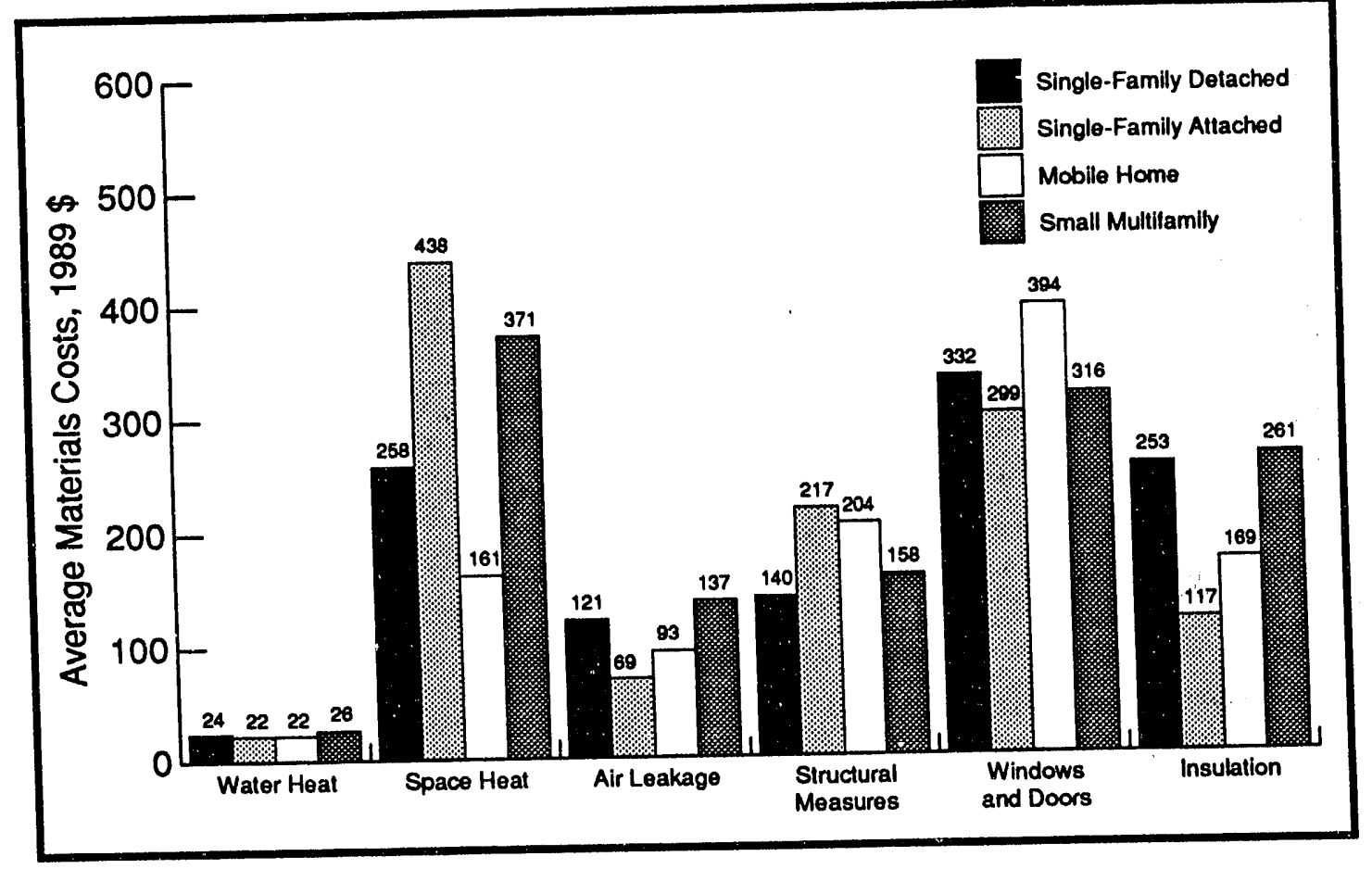

Fig. 7.10 Average Cost of Materials in Dwelling Receiving the Measure, by Dwelling Type ${ }^{a}$

a No values of zero are included in these averages.

Differences by agency size (Fig. 7.11) show that the large agencies have the lowest materials costs for all measures except water heating, air leakage, and space heating. There is little difference by agency size in costs for water heating or air leakage measures, both of which require inexpensive materials. Space heating measures, however, cost about twice as much in large agencies. This occurs mainly because the large agencies do more component retrofits and furnace replacements (Chapter 4). For most measures, small agencies have higher materials costs than either the medium or large agencies. This probably reflects the greater ability of large and medium-sized agencies to negotiate reduced prices for the purchase of large quantities of materials.

\subsection{INSTALLATION LABOR COSTS}

Labor cost data were collected and calculated with different methods for crew-only, contractor-only, and mixed (crew and contractor) weatherization jobs (Appendix B-3). This was necessary because of differences in the way agencies track costs for crew and contractor labor. Among the dwellings that could be classified by labor type, approximately one-third fell into each of 
the three types. Generally, agencies tend to use either in-house or contractor labor on all, or at least most, of their weatherization jobs.

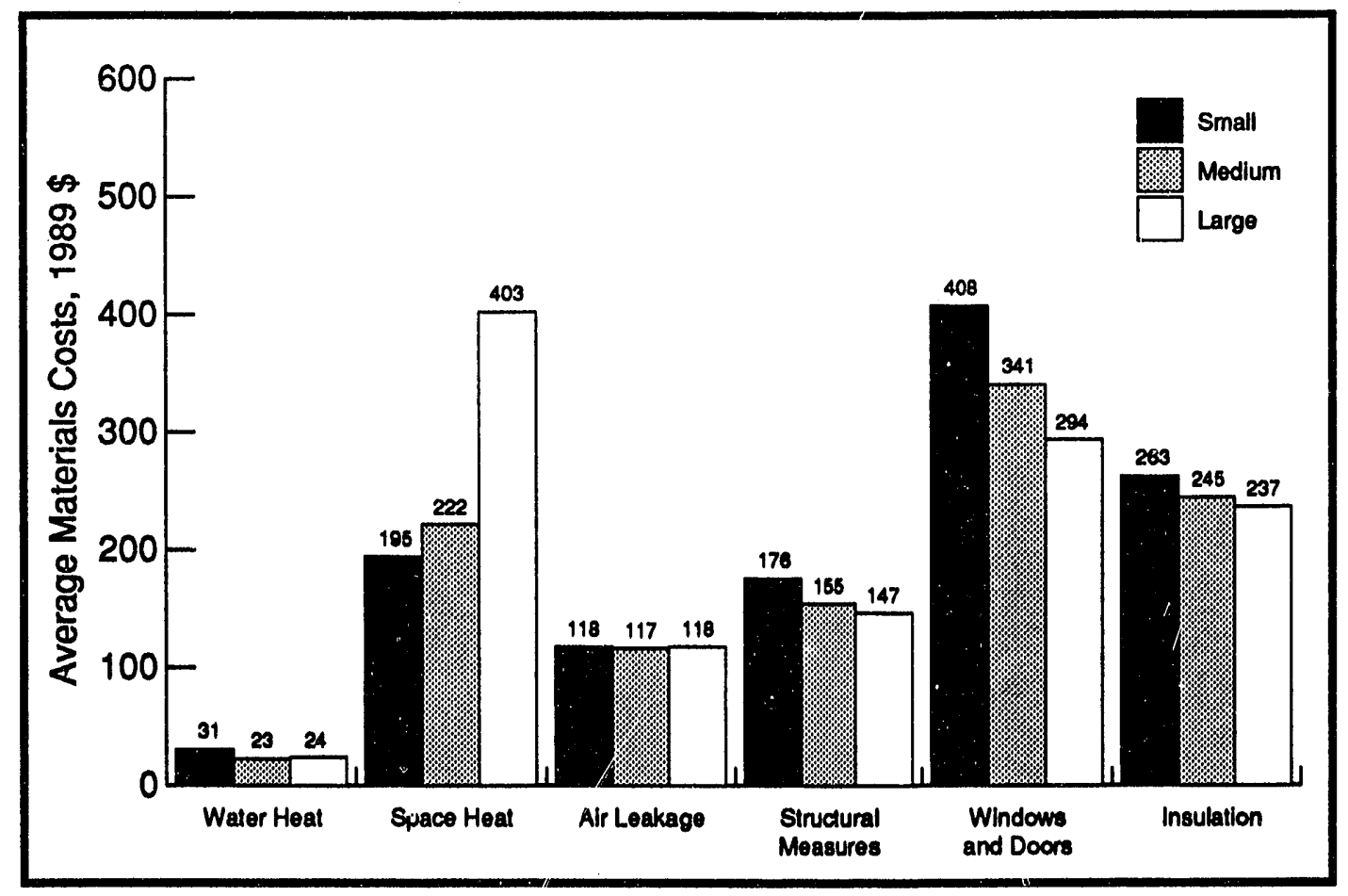

Fig. 7.11 Average Cost of Materials in Dwellings Receiving the Measure, by Agency Size ${ }^{a}$

a vo values of zero are included in these averages.

Because contractor labor costs include profit and overhead expenses that are not included in crew labor costs, one would expect the expenses repcrted for contractor jobs to be higher. As shown in Table 7.3, average total installation costs were over $\$ 300$ higher for contractor-only labor weatherization jobs than for crew-only jobs. Costs for mixed jobs exceeded those for crew-only jobs by more than $\$ 400$. These differences occur both because contractor labor costs include profit and installation overhead expenses that are not included in crew-only labor costs, and because contractors are more likely to do space-heating work.

Climate region comparisons for labor costs show that crew-only and mixed jobs cost the most in the cold climate region and the least in the hot region (Appendix G). Contractor-only jobs, however, had the highest total install:d cost $(\$ 1,303)$ in the moderate region, and averaged about $\$ 180$ less in the cold region, and about $\$ 228$ less in the hot region. The national average for labor costs (weighted by the proportions in each labor type) was $\$ 433$. 


\begin{tabular}{|c|c|c|}
\hline & $\begin{array}{l}\text { Average Total } \\
\text { Installed Cost } \\
\text { (\$/dwelling) }\end{array}$ & $\begin{array}{l}\text { Average } \\
\text { Labor Cost } \\
\text { (\$/dwelling) }\end{array}$ \\
\hline In house crew only? & $\$ 825^{a}$ & $\$ 316$ \\
\hline Contractor only. & $\$ 1,174^{b}$ & $\$ 525^{c}$ \\
\hline Mixed (crew and contractor) & $\$ 1,240^{b}$ & $\$ 532^{c}$ \\
\hline \multicolumn{3}{|c|}{$\begin{array}{l}\text { a includes materials and labor } \\
\text { b includes materials, labor, profit and installation-related overhead } \\
\text { c includes lator, profit, and installation-related overhead }\end{array}$} \\
\hline
\end{tabular}

Table 7.3 Contractor Labor Costs Higher Because Include Profit, Overhead, and More Space-Heating Work

Average labor costs (Appendix G, Table G.6) showed the same patterns as total installation costs: highest for crew only and mixed in the cold region, highest for contractor-only in the moderate region, and the lowest costs in the hot region for all labor types. Hourly rates for crew-only jobs were highest in the cold region and lowest in the hot region.

Among crew-only and contractor-only jobs, an examination of total installed costs by primary heating fuel (Appendix G, Table G.7) shows the highest expenditures for dwellings heated with other fuels. In mixed labor jobs, however, electrically heated dwellings had the highest total installation costs. Labor costs showed the same patterns as total installation costs.

Single-family detached dwellings had the highest installed costs for crew-only and mixed jobs, while single-family attached dwellings had the highest installation costs among contractor-only jobs (Appendix G, Table G.8). Labor costs showed similar patterns.

Large agencies (Appendix G, Table G.9) had the highest installed costs for crew-only and contractor-only jobs, while small agencies had the highest installed costs for mixed labor jobs. Medium-sized agencies had the highest crew labor costs, and paid the highest hourly wage. Large agencies had the highest labor costs for contractor-only jobs. For mixed labor jobs, the highest labor costs were found in small agencies.

\subsection{OVERHEAD AND MANAGEMENT COSTS}

Overhead and management costs include all costs except the expenditures for weatherization materials and for the labor required to install these materials. Installation material and labor costs were discussed above (Sections 7.2 and 7.3). As shown in Table 7.2, the total cost of a program can 
be divided into installation costs and overhead and management costs. Previous studies suggest that overhead and management costs range from $\$ 300$ to $\$ 600$ per house (Kushler and Witte, 1985; Kushler, Witte, and Stanley, 1987; McKenzic and Pheneger, 1983; Randolph and Greeley, 1990; Schlegel, 1991). In spite of the magnitude of overhead and management costs, most previous evaluations of weatherization programs have not reported them and have not included them in their cost-effectiveness calculations. In part, this reflects the difficulty of obtaining accurate information on overhead and management costs. It is particularly problematic to obtain comparable data across agencies and time, because of variations in recordkecping systems.

As was explained in Chapter 3 (Section 3.2.3), much of the information this study obtained on program management and installation overhead costs was too incomplete to be usable or contained obviously inaccurate information. Because of the frequency and pervasiveness of the reporting and computational errors on the Agency Information Forms (Appendix B), many of the values reported for average program management costs (APMC) were not credible. Specifically, values for APMC ranged from a low of $\$ 12$ per house to a high of $\$ 1,868$ per house. Values less than $\$ 300$ that appear on the Agency Information Forms probably do not include some significant program management costs, and values above $\$ 600$ probably include some direct installation (i.e., labor and materials) costs.

Out of the 298 agencies that returned Agency Information Forms, 137 provided data that fell within reasonable ranges. Although the subset of 137 agencies that reported reliable data on the Agency Information Form is not representative of the total sample of local agencies (Section 3.2.3), the APMC of $\$ 390$ estimated from the agencies with good data scems to be credible. Variations by climate region estimated from these agencies also seem to be reasonable with APMC highest in the cold region (\$435), next highest in the moderate $(\$ 410)$, and lowest in the hot $(\$ 320)$. These results should be viewed cautiously, however, because of limited sample sizes and high variability. These data also suggest that larger agencies have the highest APMC (\$430), followed by medium-sized agencies (\$407), with the lowest APMC for small agencies (\$344). Once again, however, the sample sizes are too small to produce statistically significant results.

Estimates for installation-related overhead that could be obtained from the Agency Information Form were not credible, even for the subset of agencies with good data. Although the instructions on the Agency Information Form asked that materials and labor costs be reported separately from installation-related overhead, the large magnitude of the reported average installation-related overhead ${ }^{4}$ indicated that materials and labor costs were usually mistakenly included.

4 Average installation overhead costs for the 137 agencies with the best data were reported at $\$ 895$. This is obviously much too high, and must include matcrials or labor costs in many cases. 
Results from the Fuel-Oil Study provide some assistance in interpreting the Single-Family Study's results on overhead and management costs. In the Fuel-Oil Study estimates of APMC and average installation-related overhead costs were obtained for 23 agencics in the Northeast (Ternes and Levins, 1992). Ternes and Levins (1992) initially used a form nearly identical to the Single-Family Study's Agency Information Form to collect data on costs. They found many of the same errors and inconsistencies in the data returned on their form as we did in the Single-Family Study. They tried to resolve these data problems by conducting telephone interviews with personnel at each agency. After conducting these interviews, they concluded that overhead and management costs averaged $\$ 627$ per house. This cost was estimated to include $\$ 438$ for program management, $\$ 59$ for in-house crew installation-related overhead, and $\$ 130$ for contractor installation-related overhead. An overhead and management cost of $\$ 557$ was estimated for houses in which only in-house crews performed the weatherization work, and of $\$ 651$ for contractor or mixed crew/contractor jobs.

Thus, based on results from the Fuel-Oil Study, one can conclude that the sum of APMC and installation-related overhead costs is approximately $\$ 600$, and based on the results of the SingleFamily Study one can conclude that the APMC is about $\$ 350-400$ per house. These results suggest that average program management costs are in the $\$ 350-450$ range, and that installation overhead is in the \$50-150 range. This division is obviously inexact; the sum does, however, seem to be between $\$ 400$ and $\$ 600$ per house, as is consistent with findings of previous studies (Kushler and Witte, 1985; Kushler and Witte, 1987; McKenzie and Pheneger, 1983; Randolph and Greeley, 1990; Schlegel, 1991). In the cost-effectiveness calculations (Chapter 8 ), therefore, a value of $\$ 500$ per house will be assumed for overhead and management costs. This is a lower amount than was estimated by the FuelOil Study, but we believe that the national estimate should be lower because the costs of most goods and services (and total weatherization costs) are higher in the Northeast (where the agencies Ternes and Levins studied are located) than they are in many other parts of the United States.

\subsection{SOURCES OF FUNDING}

As is shown in Table 7.4, dwellings weatherized entirely with DOE funds had average installed costs that were lower than those for dwellings weatherized with funds from multiple sources. Subcategories of costs, including materials costs, structural measures, and heating system work also had lower average expenditures for dwellings weatherized entirely with DOE funds. Except for space heating work, dwellings :veatherized with a mixture of funds that included more than 50\% DOE funds consistently had higher expenditure levels than homes with mixed funds that included less than $50 \%$ DOE funds. Also, it appears that mixed funds that include more than 50\% DOE funds tend not to be spent according to DOE guidelines. Plus, these funds are speitt quite differently than the pattern of expenditures in dwellings weatherized with only DOE funds. 
Table 7.4 Costs by Source of Funding

\begin{tabular}{|l|c|c|c|}
\hline & DOE funds only \\
$(\mathrm{N}=8688)$ & $\begin{array}{c}\text { Mixed funding } \\
\text { with 50\% or } \\
\text { more DOE } \\
(\mathrm{N}=1537)\end{array}$ & $\begin{array}{c}\text { Mixed funding } \\
\text { with less than } \\
50 \% \text { DOE } \$ \\
(\mathrm{~N}=2610)\end{array}$ \\
\hline Average total installed cost $(\$ / \mathrm{dwelling})$ & $\$ 977$ & $\$ 1,258$ & $\$ 1,167$ \\
\hline $\begin{array}{l}\text { Average materials cost }(\$ / \text { dwelling) } \\
\text { Average amount spent on } \\
\text { structural measures }\end{array}$ & $\$ 562$ & $\$ 760$ & $\$ 591$ \\
\hline \begin{tabular}{l} 
Average amount spent on heating systems \\
\hline
\end{tabular}
\end{tabular}

Among dwellings weatherized with mixed funding, some used all funds according to DOE guidelines, while others did not (Table 7.5). Dwellings with mixed funds spent entircly under DOE guidelines had lower expenditures for materials, structural measures, heating systems, and total installed costs, than dwellings with mixed funds not spent entirely under DOE guidelines. Mixed funds spent entirely under DOE guidelines were spent similarly to dwe!lings weatherized with only DOE funds (Tables 7.4 and 7.5).

Table 7.5 Costs for Dwellings with Mixed Funding by Coverage of DOE Guidelines

\begin{tabular}{|l|c|c|}
\hline \multirow{2}{*}{ Average total installed cost (\$/dwelling) } & $\begin{array}{c}\text { Mixed funds entirely } \\
\text { under DOE guidelines } \\
(\mathrm{N}=1702)\end{array}$ & $\begin{array}{c}\text { Mixed funds not entirely } \\
\text { under DOE guidelines } \\
(\mathrm{N}=2445)\end{array}$ \\
\hline $\begin{array}{l}\text { Average materials cost (\$dwelling) } \\
\text { Average amount spent on } \\
\text { structural measures }\end{array}$ & $\$ 1,077$ & $\$ 1,248$ \\
\hline Average amount spent on heating systems & $\$ 558$ & $\$ 778$ \\
\hline
\end{tabular}




\subsection{SUMMARY}

This chapter examined total installation costs, materials costs, installation labor costs, and overhead and management costs--presenting programwide averages and describing variations across climate region, fuel type, dwelling type, and agency size. Findings are summarized below.

\subsubsection{Total Installation Costs}

In PY 1989, the programwide average total installation cost (i.e., materials and on-site labor) per dwelling was $\$ 1,050$. Expenditures for individual dwellings, however, often varied substantially from this average. In particular:

- Eighty-five percent of dwellings had total installation expenditures of less than $\$ 1,500$, with $45 \%$ of dwellings in the $\$ 600$ to $\$ 1,200$ range. About $8 \%$ had expenditures of less than $\$ 300$ and about $9 \%$ had expenditures of more than $\$ 1,800$.

- There were no significant differences by climate region in total materials costs, but differences in labor costs and total installed costs were significant. The largest installation expenditures were in the moderate and cold climate regions, while the hot region spent about $10 \%$ less.

- Total installation costs, total materials costs, and labor costs differed significantly by fuel type with the highest expenditures for dwellings that heat with other fuels.

- Total installation costs, total materials costs, and labor costs differed significantly by dwelling type with the highest total installation expenditures for single-family attached and single-family detached dwellings, and the highest materials costs for small multifamily.

- Total installation costs, materials, and labor costs differed significantly by agency size with the highest expenditures by small agencies.

\subsubsection{Materials Costs}

The cost of weatherization materials in PY 1989 averaged $\$ 594$ per dwelling. When values of zero are included in the averages for materials costs, insulation (\$137), windows and doors (\$133), structural measures $(\$ 126)$, and air leakage $(\$ 116)$ account for the vast majority of these costs. Smaller amounts were spent on space heating and water heating measures.

Although total materials costs did not vary significantly by climate region, measure-specific costs did differ significantly. In the cold region, average expenditures for materials were higher for insulation, water heating, and space-heating measures. In the moderate region, the highest materials costs were for windows and doors. In the hot region, structural measures had the highest materials cost, and windows and doors nearly as high an amount. These differences indicate that the cold region puts more resources into the measures likely to save the most energy, while the hot region 
spends more on measures with less energ, saving potential. These differences also reflect a greater need for housing rehabilitation work in the hot region.

Differences in materials costs by fuel type also were significant. When zeroes were included, the most money was spent for materials in dwellings that heat primarily with other fuels. In dwellings heated with other fuels and with electricity, the highest materials costs were for structural measures and windows and doors. The use of other fucls and electricity is more common in the hot region, where structural measures and window and door installations are most prevalent. In dwellings that heat primarily with natural gas, the highest materials expenditures were for insulation.

Single-family detached and small multifamily had the highest average expenditures on materials of the four dwelling types. Expenditures with zeroes included were nearly as high for mobile homes and much lower for single-family attached dwellings. Single-family detached dwellings had the highest expenditures for insulation and the lowest for windows and doors. Mobile homes had the highest expenditures for structural measures and windows and doors, in part because of their concentration in the hot region, where installation rates for t'.ese measures are highest. Single-family attached dwellings had the highest expenditures for space heating, while small multifamily dwellings had the highest expenditures for air leakage measures.

Small agencies spent the highest amount per house on materials. Large agencies spent the most on space-heating retrofits and furnace replacements, more than twice as much as medium agencies and over four times as much as small agencies. Small agencies spent the most on windows and doors (reflecting the greater concentration of small agencies in the hot region).

When the sample was restricted to homes in which the measure was installed and in which a nonzero value for matcrial costs was reported, differences across climate regions were greatest for space-heating measures. This occurred mainly because the moderate and cold regions installed more replacement furnaces. Similarly, space-heating measures cost about twice as much in large agencies, because they did more furnace replacements than smaller agencies. For most measures, large and medium-sized agencies spent less than small agencies, probably because they were more able to negotiate reduced prices for the purchase of large quantitics. Windows and doors cost the most when they were installed in mobile homes, suggesting that storm windows and doors are most expensive in this dwelling type.

\subsubsection{Installation Labor costs}

Installation labor cost data were collected and analyzed for crew-only, contractor-only, and mixed (crew and contractor) weatherization jobs. Among the representative dwellings with cost data, approximately one-third fell into each of the three labor types. Generally, agencies tend to use either in-house or contracter labor on all, or at least most of their weatherization jobs. 
Nationally, labor costs averaged about $\$ 433$ per dwelling out of a total installation cost of $\$ 1,050$. Because labor costs for mixed labor and contractor-only jobs include profit and overhead expenses, their cosis exceed those for crew-only jobs. Labor costs showed regional patterns: highest for crew only and mixed in the cold region, highest for contractor-only in the moderate region, and the lowest costs in the hot region for all labor types.

\subsubsection{Overhead and Management Costs}

Previous siudies suggest that overhead and management costs range from $\$ 400$ to $\$ 600$ per house. In spite of the magnitude of overhead and management costs, most previous evaluations of weatherization programs have not reported them and have not included them in their costeffectiveness calculations. In part, this reflects the difficulty of obtaining accurate information on overhead and management costs. It is particularly problematic to obtain comparable data across agencies and time, because of variations in recordkeeping systems.

Much of the information this study obtained on program management and installation overhead costs was too incomplete to be usable or contained obviously inaccurate information. Because of the frequency and pervasiveness of the reporting and computational errors in the overhead and management cost data, many of the values reported for average program management costs were not credible.

Nevertheless, by creating a set of 137 agencies with consistent and credible data and using results from interviews with the 23 agencies in the Fucl-Oil Study, we concluded that overhead and management costs were approximately $\$ 500$ per house. This estimate is consistent with findings of previous studies and will be used in the cost-effectiveness calculations (Chapter 8). 


\section{COST EFFECTIVENESS}

This chapter presents the results of the analysis of Program cost effectiveness in the 1989 Program Year. Because energy savings and costs vary by key subgroups, cost-effectiveness results are pre. iented by fuel type, climate region, dwelling type, and agency size. The first section (8.1) explains the perspectives used for the cost-effectiveness calculations. Section 8.2 presents results for gas-heateä dwellings by key subgroups, Section 8.3 presents results for electrically heated dwellings, and Section 0.4 for dwellings heated with other fuels. The next section (8.5) presents programwide results for all fuel types combined. Section 8.6 compares this study's results to previous evaluation results. The final section summarizes key findings.

\subsection{COST-EfFEctiveness PERSPECTIVES}

The cost effectiveress of the Program can be determined with a variety of approaches. Although a basic comparison of the value of measured energy savings and the costs of achieving them is always involved, a number of other inputs are usually needed as well (Fig. 8.1). Key assumptions include the expected lifetime of the retrofit measures, a discount rate that reflects the time value of money, and estimated fuel price escalation rates. Once the key assumptions are chosen, a variety of cost-effectiveness indicators can be calculated with standard formulas. In this chapter, benefit/cost (b/c) ratios and costs of conserved energy (CCE) are reported. Because there is significant uncertainty in the key assumptions, a sensitivity analysis of $b / c$ ratios is presented.

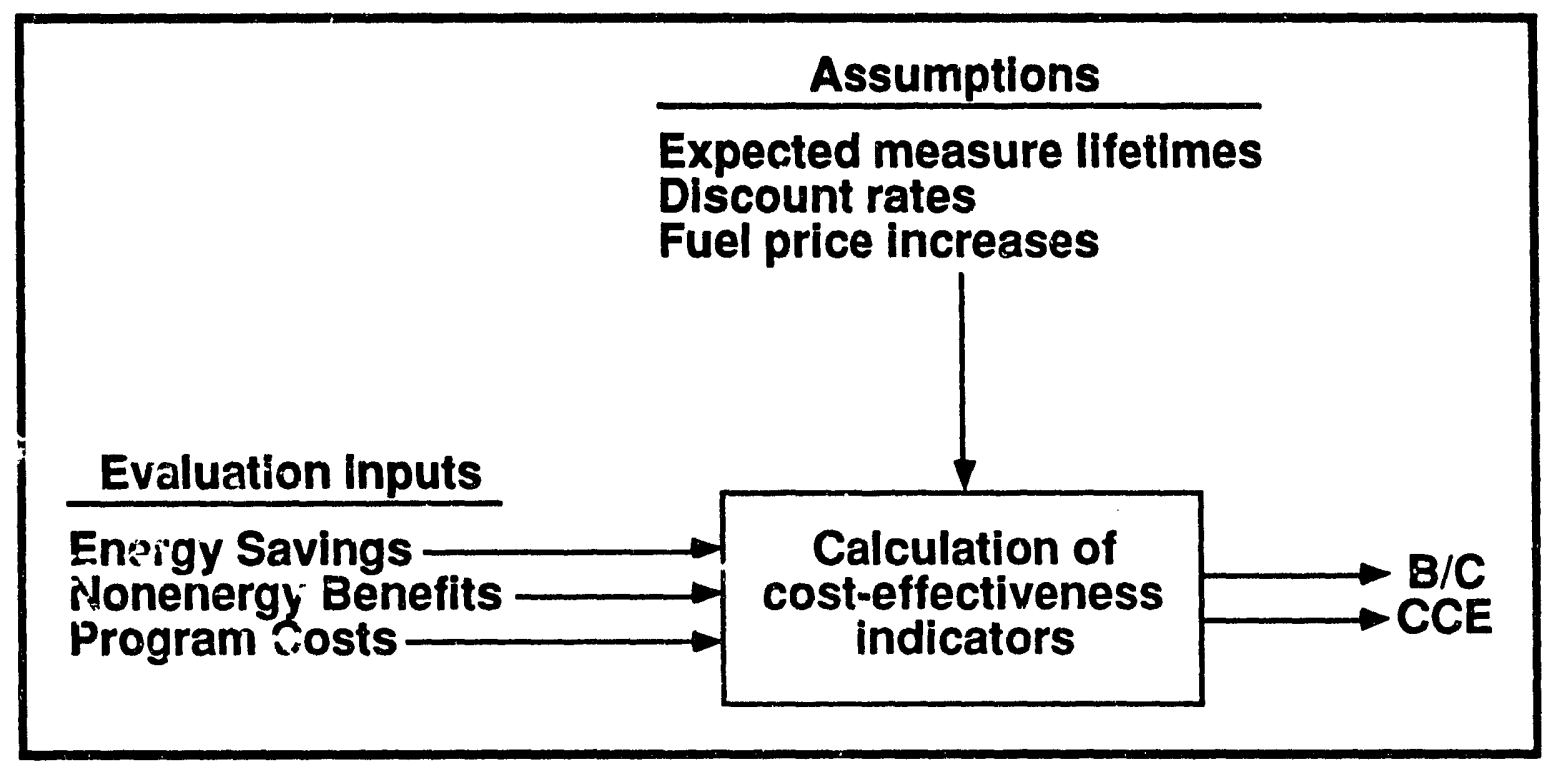

Fig. 8.1 Assumptions, Evaluation Inputs, and Indicators for Cost-Effectiveness Analysis 
This chapter examines the cost effectiveness of the Program from three major perspectives (Fig. 8.2). The first perspective includes only energy savings benefits and on-site installation costs. In this installation perspective, which follows the usual procedure in previous low-income weatherization program evaluations, the only benefit that is valued is energy savings and the only costs included are expenditures for materials and on-site installation labor. The second perspective, the progrart perspective, includes only energy savings benefits, but compares these benefits to total costs (i.e., on-site installation costs plus management and overhead costs). The third perspective, the societal, includes the most comprehensive set of benefits and costs: both energy and selected nonenergy benefits (as valued in Chapter 6), and all costs (as developed in Chapter 7).

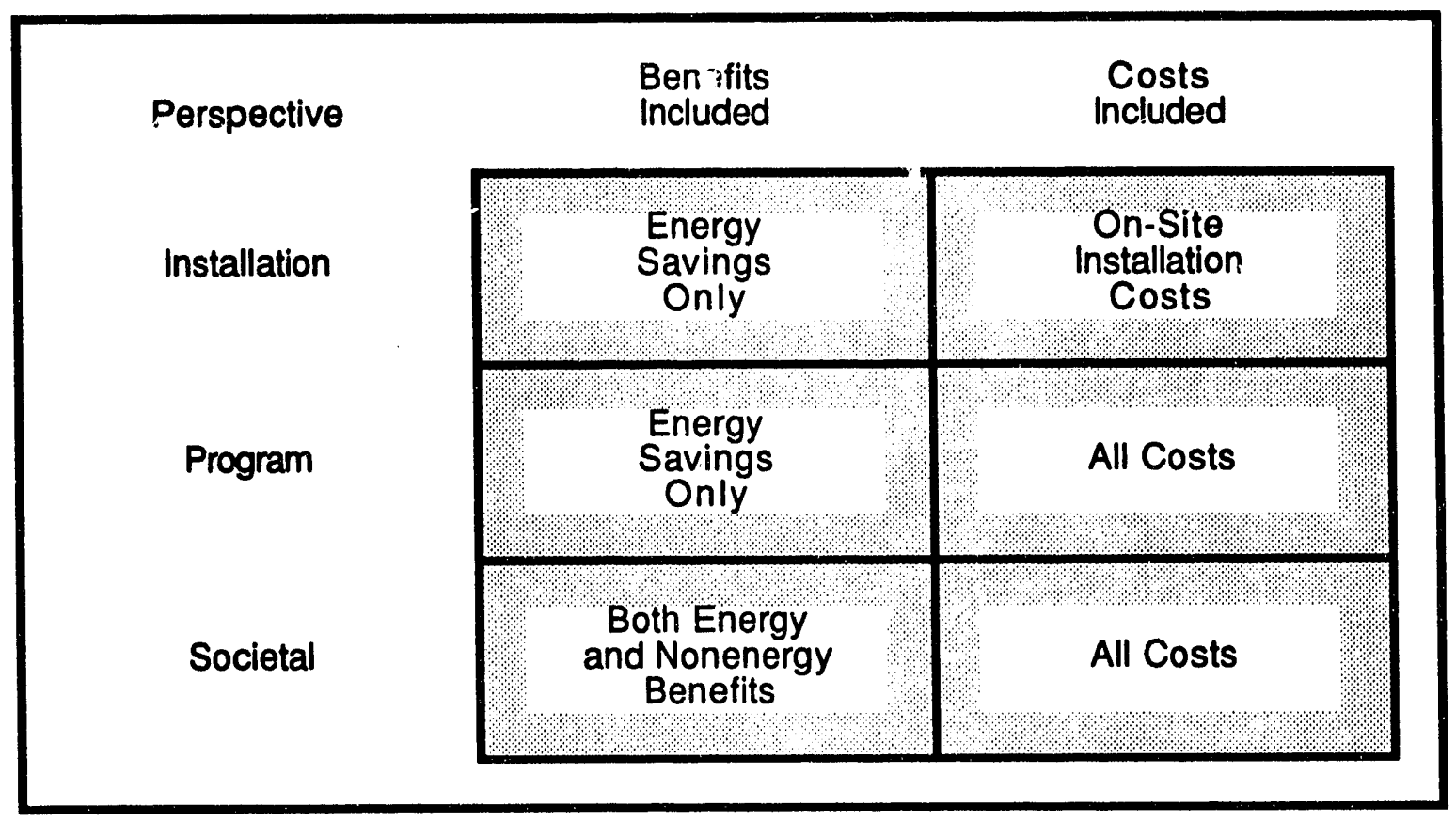

Fig. 8.2 Three Approaches Used to Calculate Cost Effectiveness.

Each of these approaches is valuable for different purposes. The first perspective, which determines on-site installation benefits and costs is best for comparing this study's results to those of previous evaluations of low-income weatherization programs. The second approach, the program perspective, offers the most conservative estimate of program cost effectiveness. If the program is cost effective from this perspective, it will be from the others as well. The third approach, which uses a broad, societal perspective, is best for valuing a mure complete set of program impacts and for comparisons with altemative uses of government funds.

A focus on cost effectiveness is, in theory, superior to a focus on energy savings for the purpose of assessing weatherization measurcs, service delivery procedures, and other program options. Comparisons by climate region, type of heating fuel and divelling type based on cost- 
effectiveness results may offer better guidance for allocating program resources than comparisons based only on energy savings. For example, if submarket $A$ achieves higher energy savings than submarket B, this fact alone does not mean that more resources should be invested in submarket A. Cost con jerations also must be included in such decisions. To continue the example, it may be that submarket B achieves $80 \%$ of the energy savings of submarket $A$ at half the cost, making it a more cost-effective investment option. In practice, however, the average costs per dwelling do not vary much by suogroup, while the energy savings fluctuate markedly. As a result, the findings of the costeffectiveness analysis closely mirror those of the energy savings analysis in Chapter 5.

Nevertheless, it is important to examine the cost effectiveness of the Program to determine its value both to low-income households and to the larger society. In addition, the Program cannot be accurately compared to low-income utility programs by examining only energy savings. Utility lowincome weatherization programs have a very broad range of investment levels from lows of less than $\$ 100$ per dwelling to highs of over $\$ 4,000$ in the Hood River Conservation Project (Brown and Keating, 1989). Cost-effectiveness comparisons are essential for ranking the success of programs with such disparate investment : $:$ vels.

Analysis with each of the three perspectives (installation, program, and societal) used the same baseline assumptions: a real discount rate of $4.7 \%^{1}$ and measure lifetimes of 20 years. Sensitivity analyses were conducted by varying the discount rates (2\% to $10 \%)$, measure lifetimes (10 years to 25 years), and other inputs. Examples of the sensitivity results are shown in Section 8.2.5.

A justification for the baseline assumption of a 20 -year measure lifetime was developed by taking : to account the following information:

- the frequency of installation of various packages of measures,

- the average lifetime of the weatherization measures included in each package, and

- the measured savings by package.

The development of a realistic assumed average lifetime (which was weighted both by the frequency of installation of packages of weatherization measures and by their measured savings) for the PY 1989 program required several steps which are explained in Appendix H-1.

The national gas and electricity prices for 1989 were developed by using average State prices (EIA, 1989 and EIA, 1991a) and weighting them according to the proportions of PY 1989 weatherized dwellings located in each State. The resulting weighted average national prices were $\$ 0.588$ per ccf of natural gas and $\$ 0.069$ per $\mathrm{kWh}$ of electricity. Price escalation rates are based on

1 This discount rate was recommended (for evaluating the cost effectiveness of the WAP) by DOE in the Federal Register, 1991, October 23 Proposed Rule. The results presented in most of this Chapter are based on a discount rate of $4.7 \%$ and a lifetime of 20 years. Examples of results based on $10 \%$ and $2 \%$ discount rates and various lifetimes are shown in Section 8.2.5. 
Energy Information Administration reference case projections to the year 2010 (EIA, 1991b). Prices for other fuels also were obtained from the EIA document (EIA, 1991a, p. 20).

Net energy savings (rather than gross energy savings) are used in all the cost-effectiveness calculations, because we consider this a better indicator of program impacts (Chapter 5). Two indicators are used for the installation and program perspectives: benefit/cost ratios and the cost of conserved energy (CCE). For the societal perspective, only benefit/cost ratios are used because a CCE does not reflect nonenergy benefits.

\subsection{COST EFFECTIVENESS IN GAS-HEATED DWELLINGS}

\subsubsection{Installation Perspective}

The results of the cost-effectiveness calculations, based on the instaliation perspective, for gasheated dwellings are shown in Fig. 8.3. These national results indicate a benefit/cost ratio of 1.58. For an average expenditure, in gas-heated dwellings, of $\$ 1,015$ the Program produced energy-savings benefits of $\$ 1,605$.

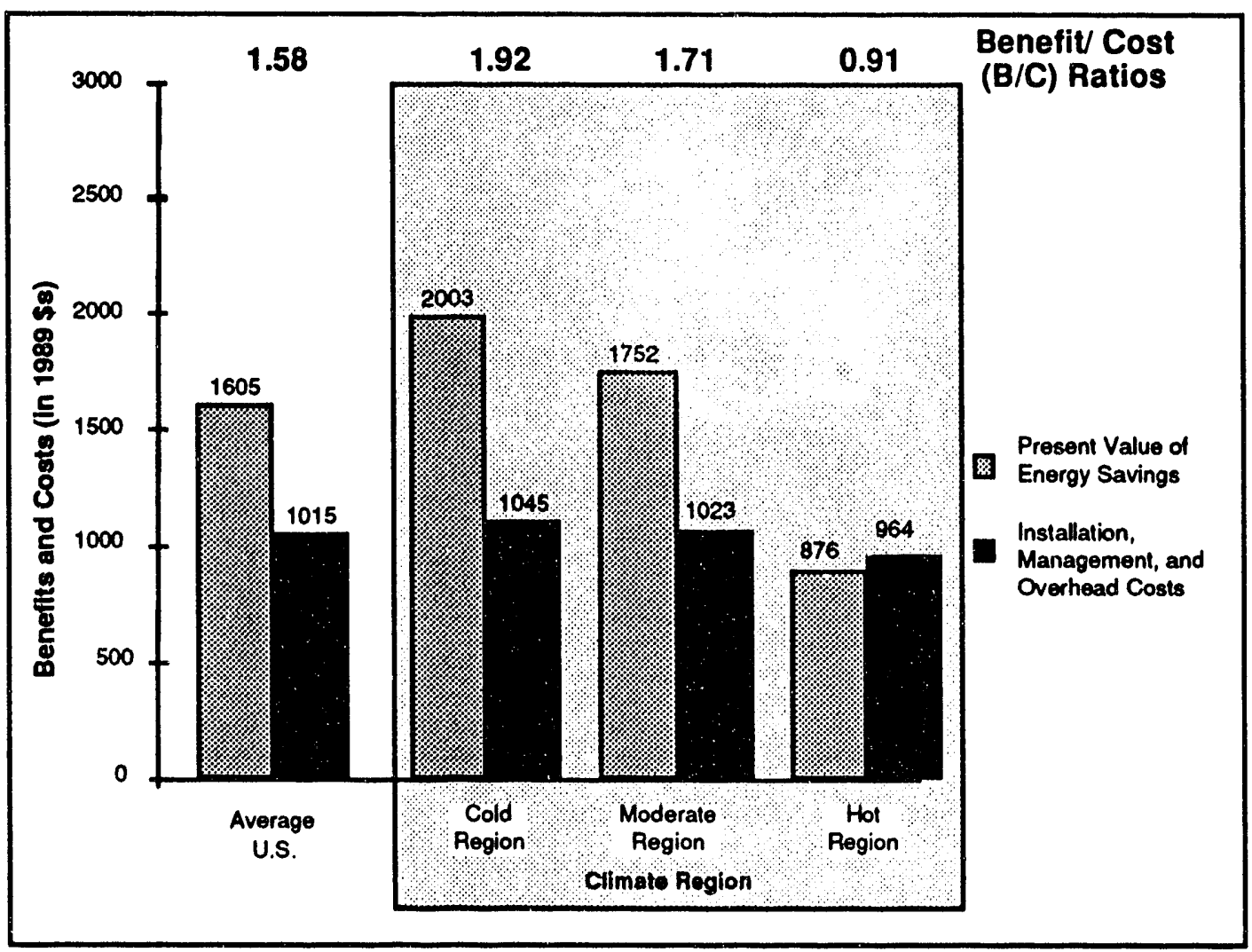

Fig. 8.3 Installation Benefits and Costs by Climate Region for Gas-Heated Dwellings. 
The results for each climate region (based on net savings) show the Program to be cost effective in the cold and moderate regions, with benefit/cost ratios of 1.92 and 1.71 , respectively (Fig. 8.3). Because the energy savings were much lower in the hot climate region, while the average installation costs were only slightly lower there, its benefit/cost ratio was 0.91 .

Comparisons by dwelling type (Fig. 8.4) indicate that the prevailing methods of weatherizing mobile homes in PY 1989 were the least cost effective $(b / c=1.23)$. This is not surprising because mobile homes had the lowest savings of any dwelling type. Weatherization of all other dwelling types was more cost effective, with single-family detached dwellings (which account for $64 \%$ of all dwellings weatherized) having the highest benefit/cost ratio (Fig. 8.4).

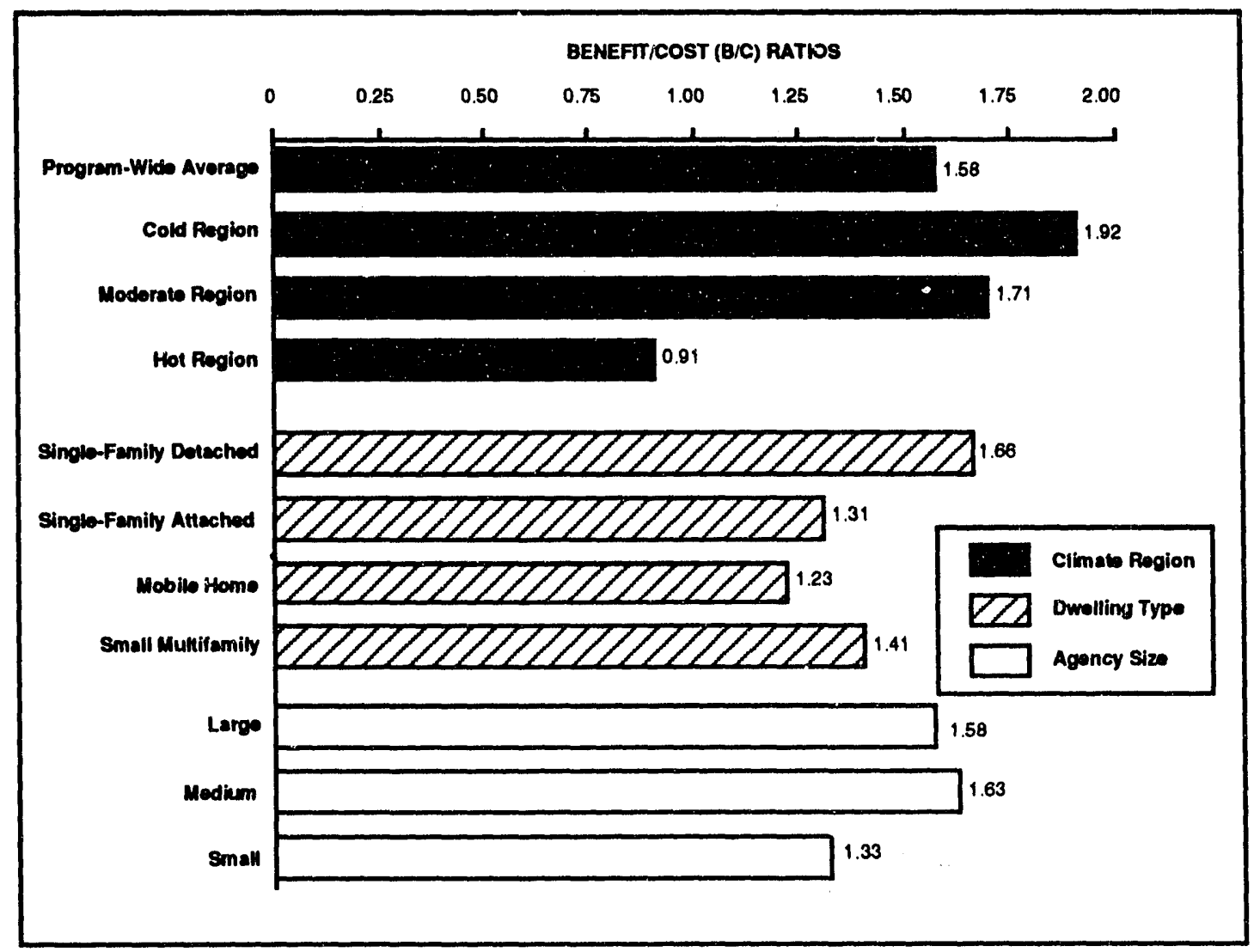

Fig. 8.4 Installation Benefit/Cost Ratios by Climate Region, Dwelling Type, and Agency Size for Gas-Heated Dwellings.

Medium-sized agencies did the most cost-effective work, followed by large agencies. Weatherizations completed by small agencies (which had the lowest savings and highest costs) were the least cost effective, although their benefit/cost ratio was still above 1.30. The relative performance of each subgroup is summarized in Fig. 8.5. Only the hot region falls below the threshold for cost effectiveness. 


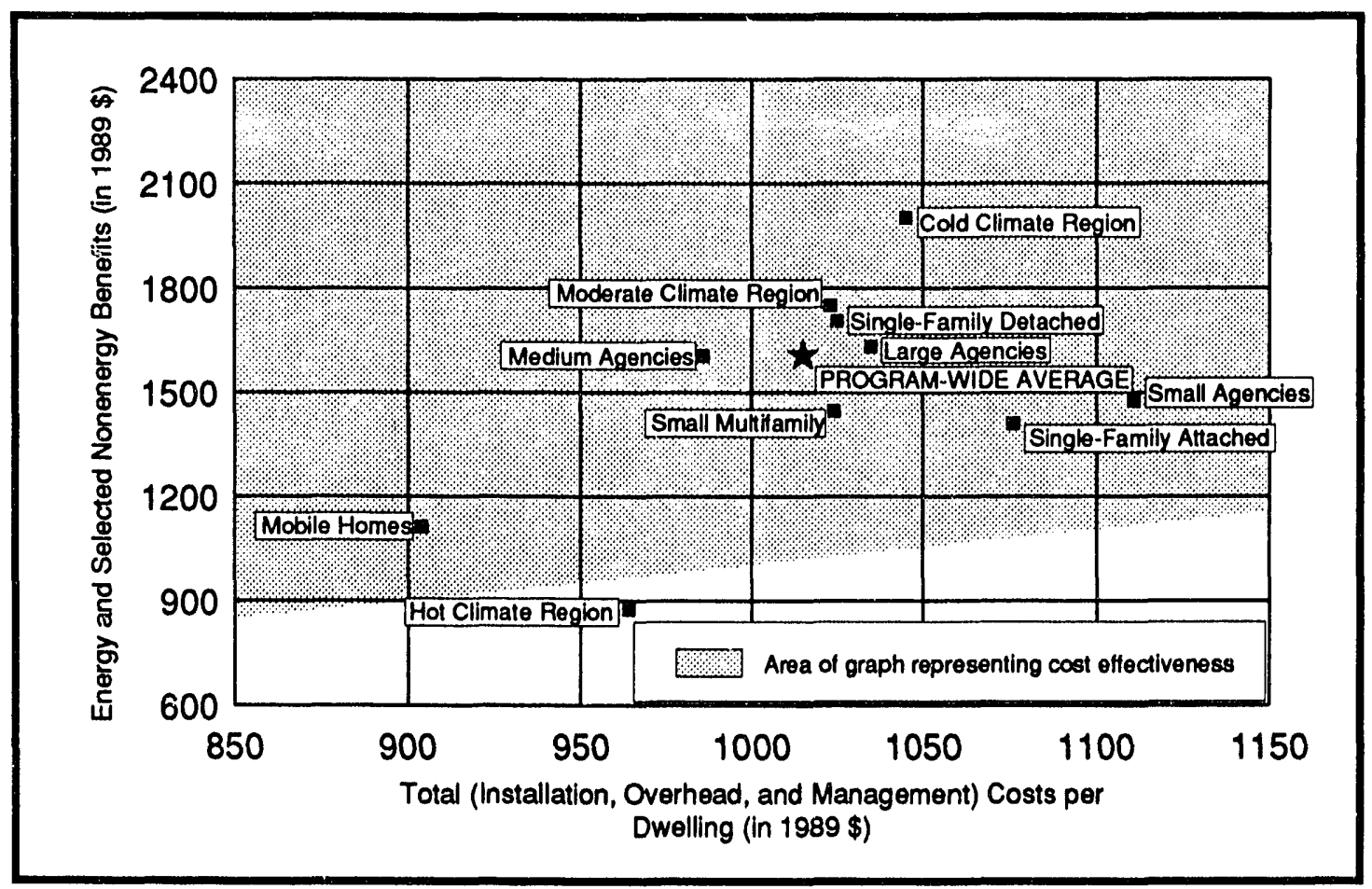

Fig. 8.5 Installation Perspective: Energy Benefits vs. Installation Costs for Gas-Heated Dwellings

The national cost of conserved energy (calculated with a discount rate of $4.7 \%$, net savings of $173 \mathrm{ccf}$, installation costs of $\$ 1,015$, and a 20 year measure lifetime) was $\$ 0.46 /$ ccf (or $\$ 4.60$ per $\mathrm{MBtu}$ ) for the gas-heated dwellings. This cost of conserved energy (CCE) is less than the weighted national price of natural gas for $1990(\$ 0.59 / \mathrm{ccf})$, which is another indication that the Program is cost effective. The cold $(\$ 0.35 / \mathrm{ccf})$ region had a CCE well below the 1990 price, while the hot region $(\$ 0.83 / \mathrm{ccf})$ had costs of conserved energy that were well above the 1990 weighted price. The moderate region $(\$ 0.44 / \mathrm{ccf})$ had a CCE that was somewhat lower than the 1990 price.

\subsubsection{Program Perspective}

From the program perspective, which compares only energy savings benefits to all costs, the national program was cost effective, with a benefit/cost ratio of 1.06 . The cold and moderate region had higher $b / c$ ratios than the national average, while the hot region had a ratio of 0.60 (Fig. 8.6). Only single-family detached homes had b/c ratios above 1.00 with this perspective (Fig. 8.7). Large and medium-sized agencies had cost-effective results, while small agencies did not. The relative performance of each subgroup is summarized in Fig. 8.8. 


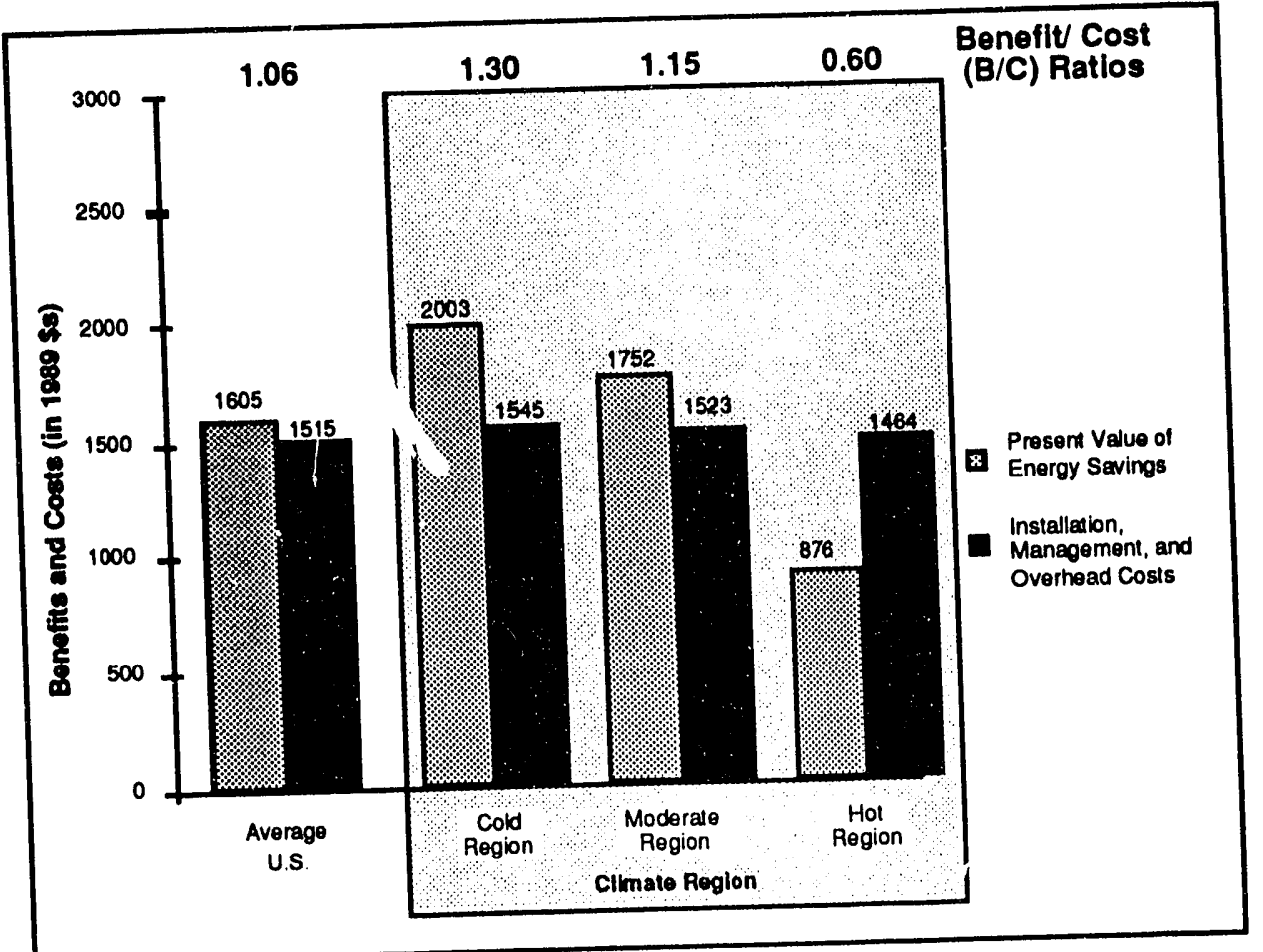

Fig. 8.6 Program Benefits and Costs by Climate Region for Gas-Heated Dwellings

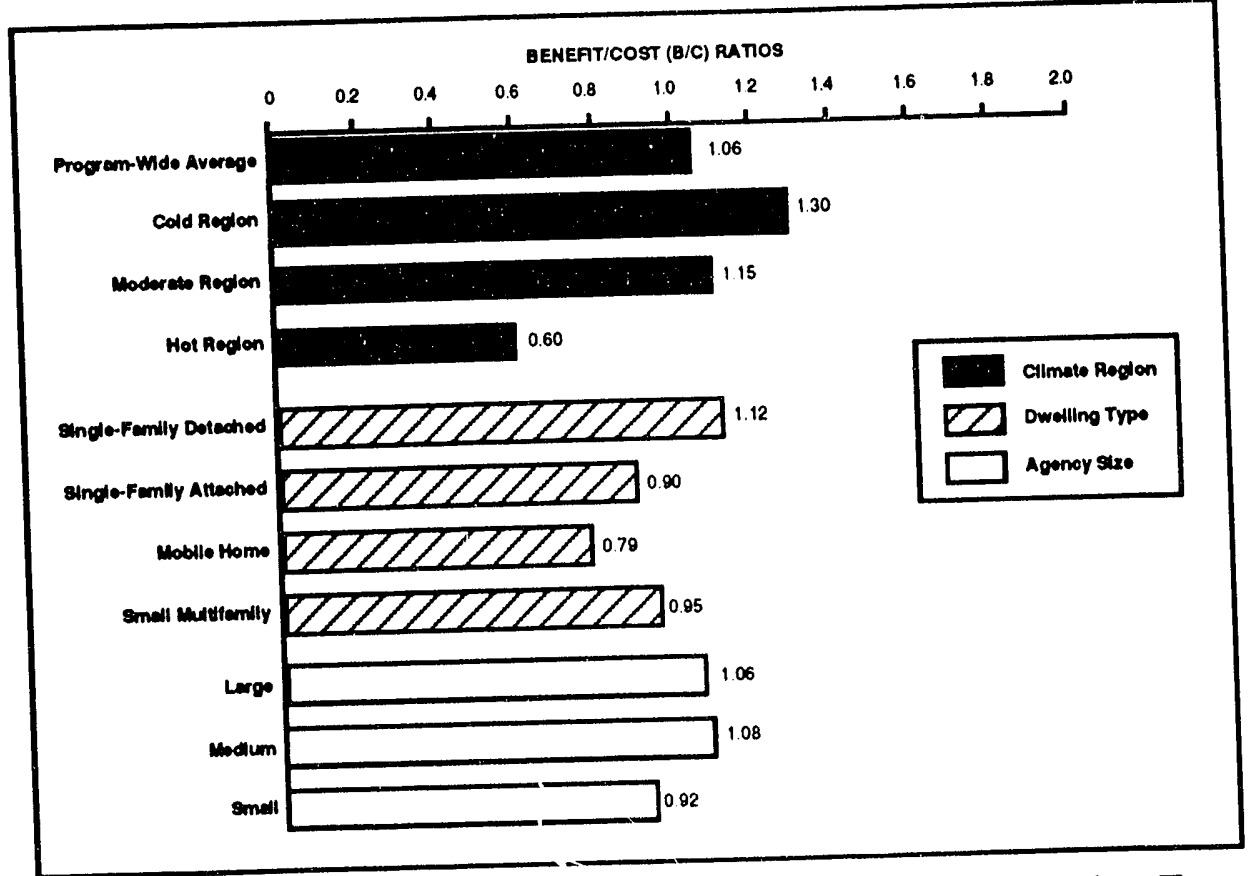

Fig. 8.7 Program Benefit/Cost Ratios by Climate Region, Dwelling Type, and Agency Size for Gas-Heated Dwellings 


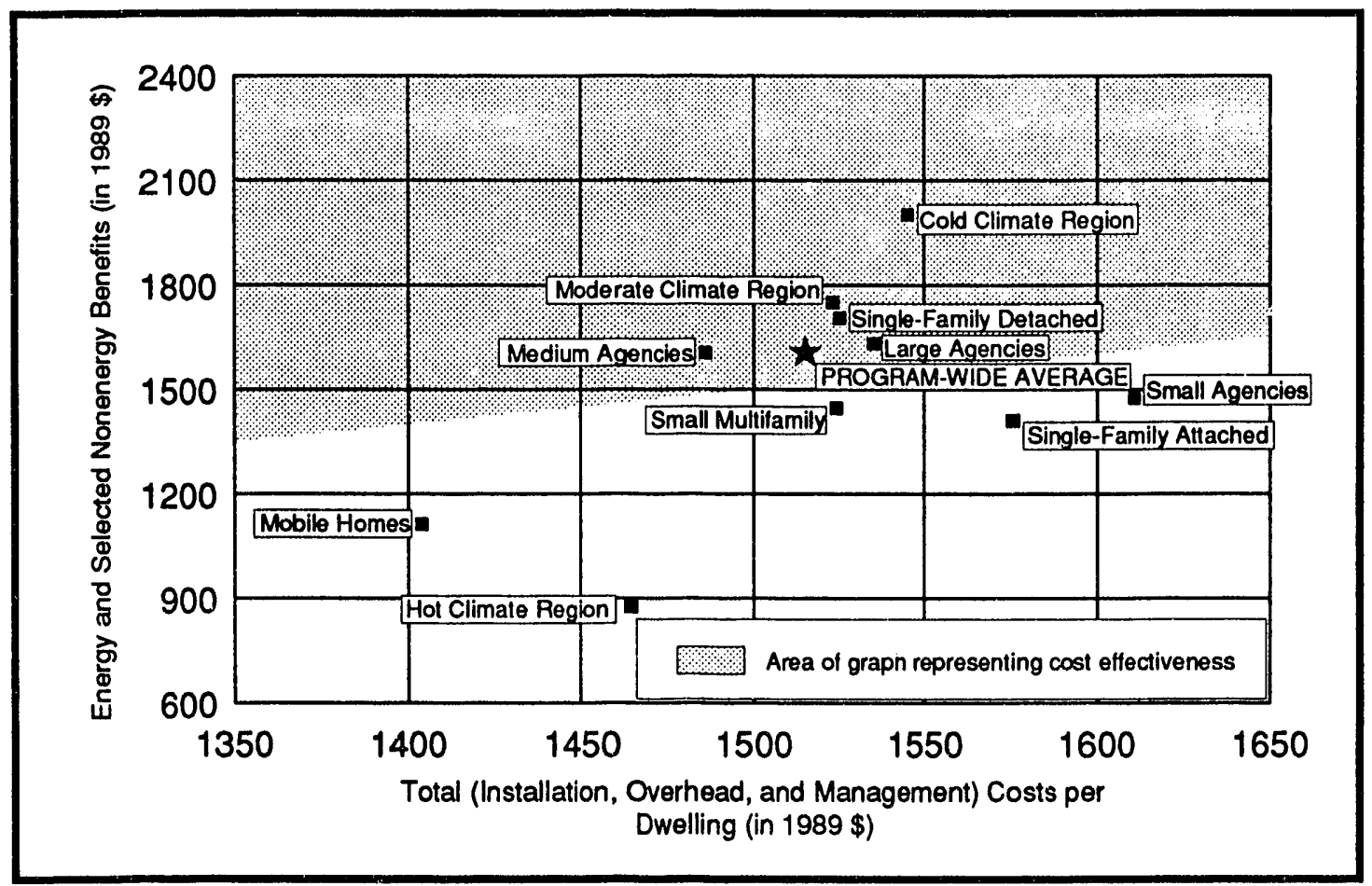

Fig. 8.8 Program Perspective: Energy Benefits Only vs. Total Costs for Gas-Heated Dwellings

\subsubsection{Societal Perspective}

From the societal perspective, which includes both energy and nonenergy (e.g., employment and environmental) benefits and both installation and noninstallation (i.e., overhead and management) costs for the gas-heated dwcllings, the Program in PY 1989 was cost effective, with a national benefit/cost ratio of 1.61 (Fig. 8.9). The societal perspective produces somewhat higher benefit/cost ratios than the installation perspective because management and overhead costs were assumed to add $\$ 500$ to the costs, while the discounted employment and environmental benefits increased benefits by over $\$ 900$. The relative performance of subgroups does not change as the perspectives change because the societal perspective simply adds a constant to both the benefits and the costs of the installation perspective.

With the societal perspective, climate region ratios ranged from 1.17 for the hot region to 1.84 for the cold region. All dwelling types had a benefit/cost ratio above 1.00. Weatherization of mobile homes was the least cost-effective (Fig. 8.10). Medium-sized agencies had the highest benefit/cost ratios, while small agencies had a benefit/cost ratio of 1.43 . The relative performance of each subgroup is summarized in Fig. 8.11. All subgroups exceed the cost-effectiveness threshold. 


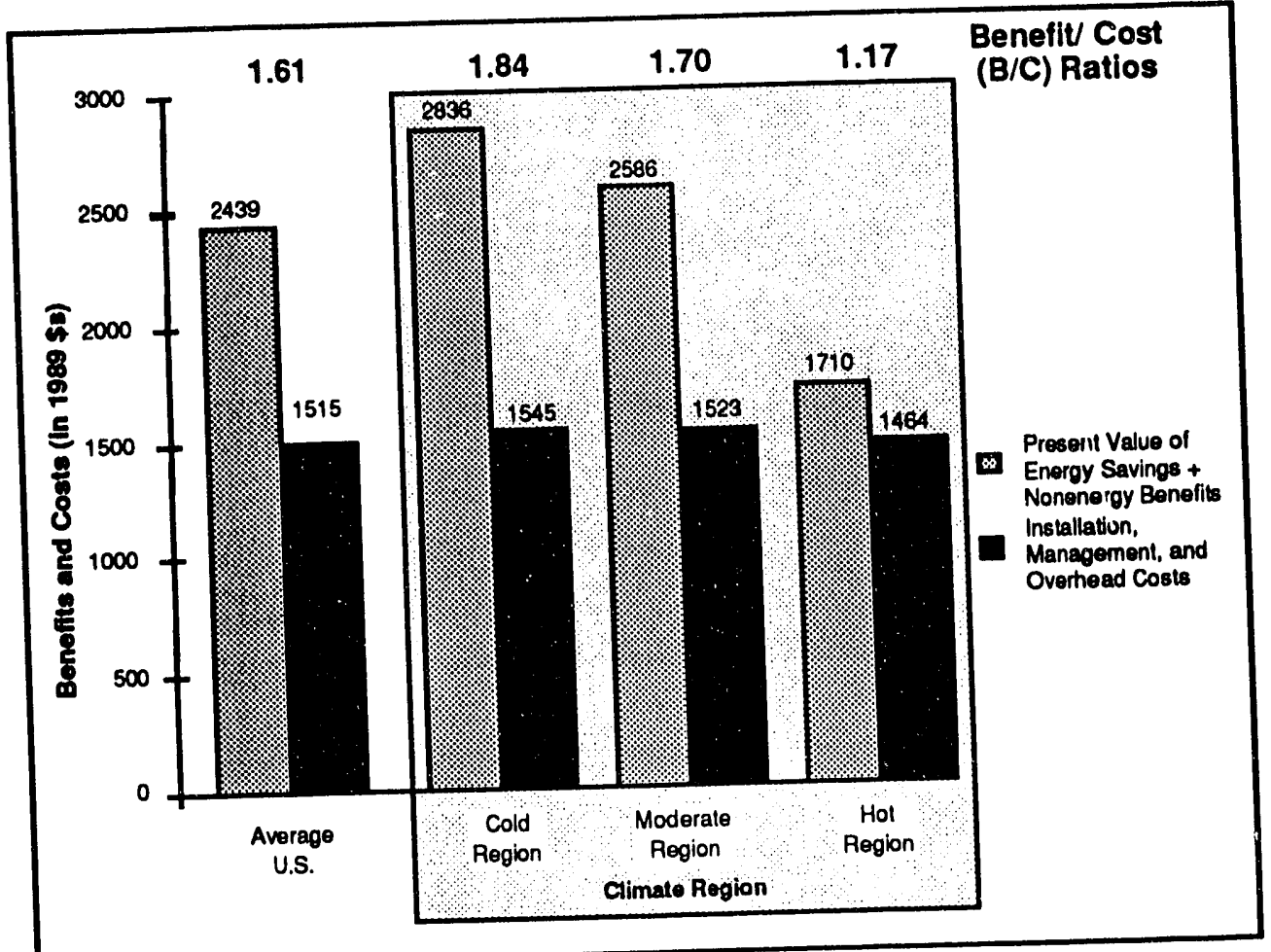

Fig. 8.9 Societal Benefits and Total Costs by Climate Region for Gas-Heated Dwellings.

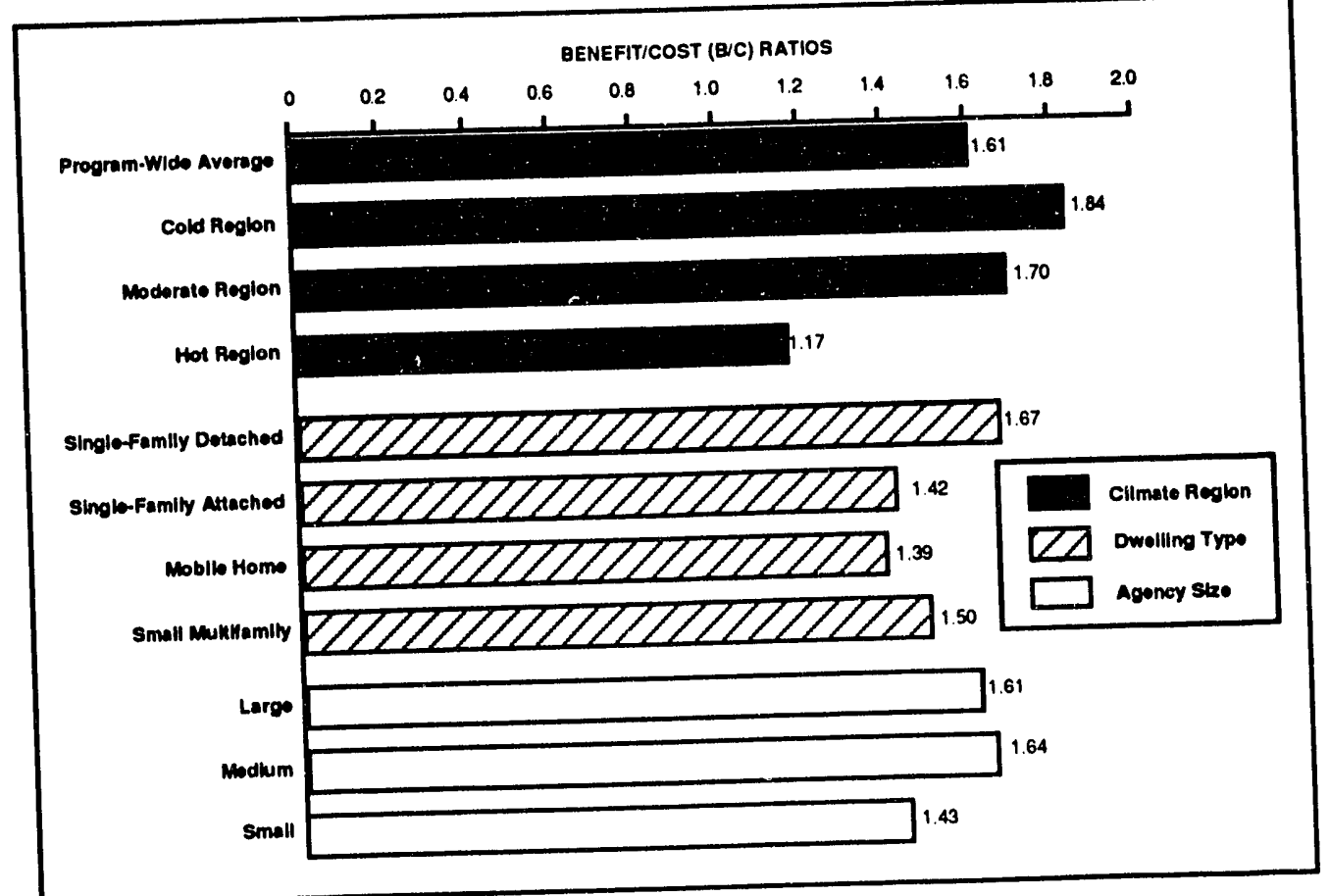

Fig. 8.10 Societal Benefit/Cost Ratios by Climate Region, Dwelling Type, and Agency Size for Gas-Heated Dwellings 


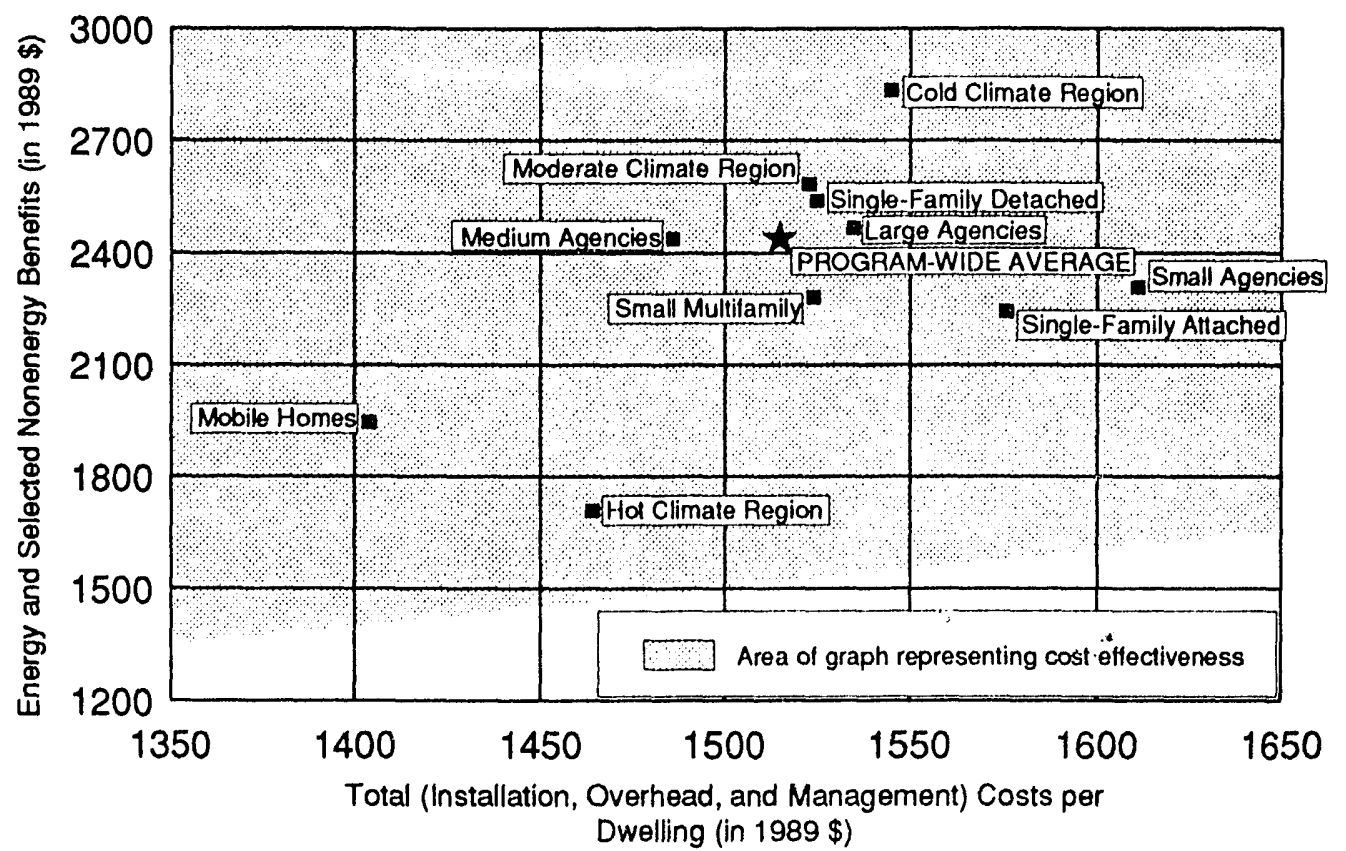

Fig. 8.11 Societal Perspective: Energy and Selected Nonenergy Benefits vs. Total Costs for Gas-Heated Dwellings

\subsubsection{Excluding Utility Funding and Structural Measures Costs}

Nine percent of the funds expended by the Program in PY 1989 were leveraged funds provided by utilities (Mihlmester, et al., 1992, p.11). One could argue that it is inappropriate to include these leveraged funds in the benefit/cost ratio that characterizes the DOE program. In some cases, these utility funds would not have been spent on low-income weatherization, if it were not for the existence of the Program infrastructure of local agencies. Also, the utility funds are sometimes spent on measures that reduce electricity demand (such as compact fluorescent bulbs) in homes that heat with fuels other than electricity. Thus, the energy savings of such utility investments would not be captured by our study. In addition, some utility funds are spent on budget counseling, which again would not lead to energy-savings benefits in our study.

The inclusion of costs associated with structural measures (such as replacing broken windows and doors, or fixing roof leaks) can also be debated. Some structural measures, although necessary for the effective performance of other energy-efficiency measures, may add more to the costs than they produce in energy savings. Major investments in structural measures are not intended to be supported by DOE funds because the Weatherization Program is primarily an energy-efficiency program, and not a housing rehabilitation program. In addition, a significant portion of the money invested in structural measures is likely to come from non-DOE sources, such as federal (e.g., HUD), State or local housing rehabilitation programs. 
Because of the arguments (discussed above) for excluding utility funds and the costs of structural measures from the analysis of the cost effectiveness of the Program, we examined the impact on the cost-effectiveness results of these exclusions. Table 8.1 shows the results of excluding these costs with the installation perspective, and Table 8.2 shows the results with the program and societal perspectives. All of the combinations examined show the program to be cost effective. When all costs (including utility funds, structural measures, installation overhead, and management costs) and only energy-savings benefits are included, the national benefit/cost ratio is 1.06 . Of course, as more costs are excluded and more benefits are included the benefit/cost ratios increase. Because all of the other combinations in Tables 8.1 and 8.2 either include more benefits, or exclude more costs, they produce benefit/cost ratios that are noticeably higher than the minimum of 1.06 .

Table 8.1 Benefit/Cost Ratios Using Installation Costs Only for Gas-Heated Dwellings Weatherized in 1989 Program Year

\begin{tabular}{|c|c|c|c|c|}
\hline \multirow[b]{3}{*}{ Beneits. } & \multicolumn{4}{|c|}{ Installation Costs } \\
\hline & \multicolumn{2}{|c|}{ DOE \$ only } & \multicolumn{2}{|c|}{ DOE \& Utility S } \\
\hline & $\begin{array}{l}\text { With } \\
\text { Structural } \\
\text { Measures }\end{array}$ & $\begin{array}{l}\text { Without } \\
\text { Structural } \\
\text { Measures }\end{array}$ & $\begin{array}{l}\text { With } \\
\text { Structural } \\
\text { Measures }\end{array}$ & $\begin{array}{l}\text { Without } \\
\text { Structural } \\
\text { Measures }\end{array}$ \\
\hline Energy Savings & 1.74 & 2.01 & $1.58^{\mathrm{c}}$ & 1.81 \\
\hline $\begin{array}{l}\text { Energy Savings and Selected } \\
\text { Nonenergy Benefits }\end{array}$ & 2.64 & 3.06 & 2.40 & 2.74 \\
\hline \multicolumn{5}{|c|}{$\begin{array}{l}\text { a Nine percent of total program expenditures were provided by utility companies. These funds are removed from } \\
\text { the benefit/cost ratios in this column. } \\
\text { b An average of } \$ 126 \text { per dwelling was spent on structural measures. These costs are removed in this column. } \\
\text { c This figure corresponds to the installation perspective used in the rest of the chapter. }\end{array}$} \\
\hline
\end{tabular}

\subsubsection{Sensitivity Analysis}

Because there is uncertainty about the inputs (e.g., measure lifetimes, fuel price escalation rates, discount rates) to the cost-effectiveness analysis, a simulation modeling approach was used to produce a distribution of likely outcomes. This simulation modeling was performed with @RISK software, which is a risk analysis method that allows the analyst to define uncertainty in model inputs by specifying probability distributions. 
Table 8.2 Benefit/Cost Ratios Using Total Costs for Gas-Heated Dwellings Weatherized in 1989 Program Year

\begin{tabular}{|c|c|c|c|c|}
\hline \multirow[b]{3}{*}{ Benefits } & \multicolumn{4}{|c|}{ Total Costs (Installation, Management and Overhead) } \\
\hline & \multicolumn{2}{|c|}{ DOE \$ only } & \multicolumn{2}{|c|}{ DOE \& Utility $\$$} \\
\hline & $\begin{array}{l}\text { With } \\
\text { Structural } \\
\text { Measures }\end{array}$ & $\begin{array}{l}\text { Without } \\
\text { Structural } \\
\text { Measures }\end{array}$ & $\begin{array}{l}\text { With } \\
\text { Structural } \\
\text { Measures }\end{array}$ & $\begin{array}{l}\text { Without } \\
\text { Structural } \\
\text { Measures }\end{array}$ \\
\hline Energy Savings & 1.13 & 1.24 & $1.06^{c}$ & 1.16 \\
\hline $\begin{array}{l}\text { Energy Savings and Selected } \\
\text { Nonenergy Benefits }\end{array}$ & 1.71 & 1.88 & $1.61^{\mathrm{d}}$ & 1.76 \\
\hline $\begin{array}{l}\text { a Nine percent of total program } \\
\text { the benefit/cost ratios in this c } \\
\text { b An average of } \$ 126 \text { per dwelli } \\
\text { c This figure corresponds to the } \\
\text { d This figure corresponds to the }\end{array}$ & $\begin{array}{l}\text { itures were } p \\
\text { spent on struc } \\
\text { perspective } \\
\text { perspective }\end{array}$ & $\begin{array}{l}\text { d by utility } \mathrm{cc} \\
\text { neasures. Th } \\
\text { the rest of th } \\
\text { the rest of the }\end{array}$ & $\begin{array}{l}\text { ies. These f } \\
\text { sts are remov } \\
\text { ter. } \\
\text { ter. }\end{array}$ & $\begin{array}{l}\text { removed from } \\
\text { lis column. }\end{array}$ \\
\hline
\end{tabular}

All of the input variables to the cost-effectiveness analysis were assigned a triangular probability distribution (Technical Appendix E, p. E-30, @RISK User's Guide). The triangular distribution is specified by a minimum, maximum, and modal value. For example, measure lifetimes were assumed to have a minimum, maximum, and mode of 15,25 and 20 years, respectively. In this case, as in all others where the mode is halfway between the minimum and the maximum, the mean is the same as the mode (20 years). The savings distribution was defined as the $90 \%$ confidence interval around the net savings, with a minimum of $151 \mathrm{ccf}$, a maximum of $193 \mathrm{ccf}$ and a modal value of 173 ccf. The distribution of discount rates was assigned a minimum of $2 \%$, a maximum of $10 \%$, and a modal value of $4.7 \%$.

After all the input distributions were defined, the @RISK simulation program was used to select one thousand samples of points from the input distributions in order to calculate benefit/cost ratios for each combination. The 1,000 possible outcomes were then used to produce a probability distribution of likely benefit/cost ratios. One thousand cases were run to produce each of the output distributions shown in Fig. 8.12, for the program perspective, and Fig. 8.13, for the societal perspective. 
Expected Value $=1.02$

\section{Program Perspective}

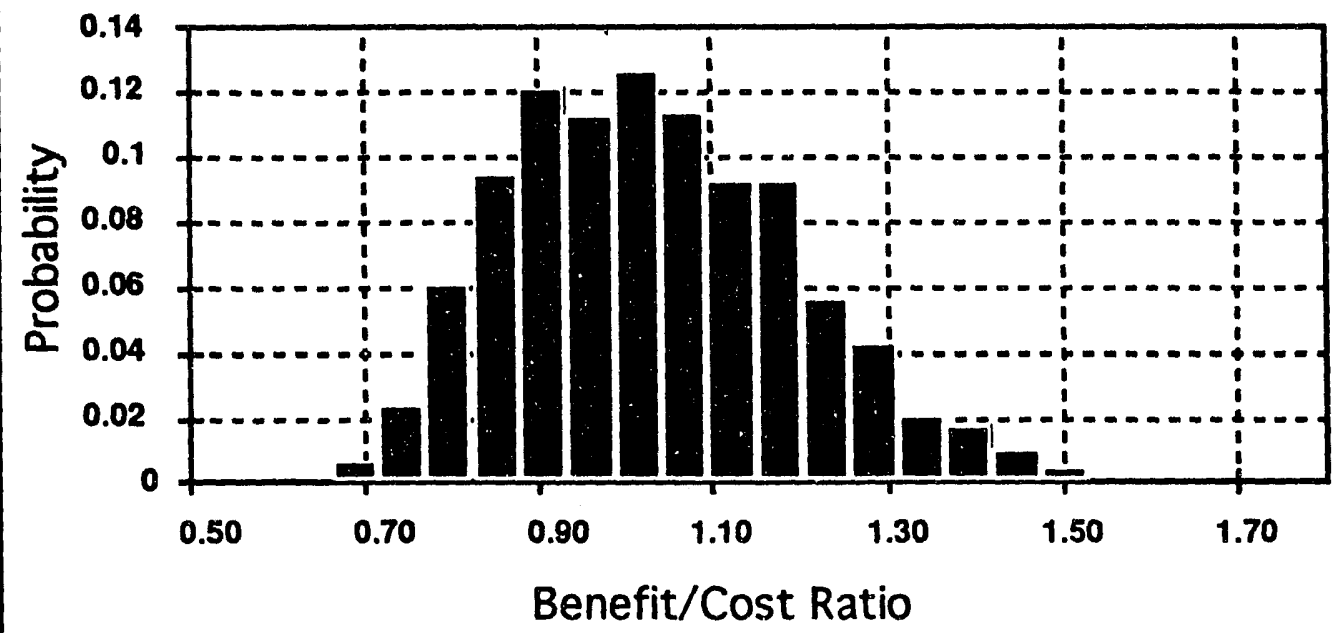

Fig. 8.12 Distribution of Program Benefit/Cost Ratios with Input Distributions for Assumptions

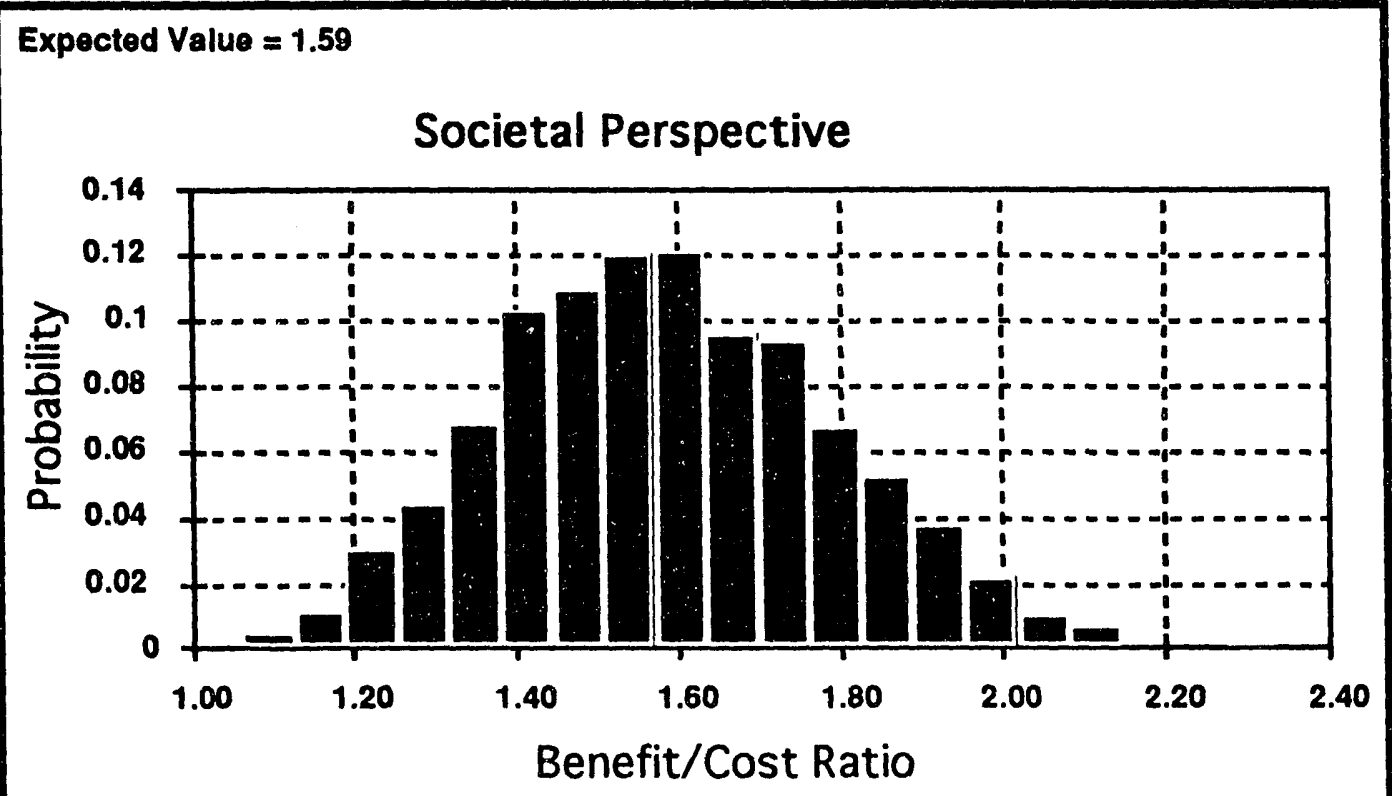

Fig. 8.13 Distribution of Societal Benefit/Cost Ratios with Input Distributions for Assumptions 
The output distribution for the program perspective (Fig. 8.12) shows that only the more favorable combinations of assumptions produce a cost-effective result, while less favorable ones do not. Nevertheless, the mean of the distribution was 1.02 and slightly more than $50 \%$ of the cases produced a $\mathrm{b} / \mathrm{c}$ ratio above 1.00 . With the societal perspective, in contrast, the Program is cost effective for all of the specified input distributions and is cost effective in $100 \%$ of the cases sampled (Fig. 8.13).

The program perspective results are particularly sensitive to the shoice of discount rates as illustrated in Figure 8.14. With the program perspective, a fixed discount rate of $2 \%$, and distributions for the other inputs, the Program is cost effective with all combinations of inputs. With a fixed discount rate of $4.7 \%$, it is cost-effective only for the more favorable parts of the input distributions, and with a discount rate of $10 \%$ or higher it is never cost effective. With the societal perspective, even discount rates as high as $10 \%$ always produce cost-effective results (Table 8.3).

Benefit/cost results are sensitive, not only to the choice of discount rate, but also to the assumed lifetime of the measures. The effects of varying both assumed discount rates and lifetimes are summarized in Table 8.3 and Fig. 8.15.

\subsection{COST EFFECTIVENESS IN ELECTRICALLY HEATED DWELLINGS}

Because electricity prices are higher than gas prices, energy savings benefits in electricaily heated dwellings are worth more than those in gas-heated dwellings (Chapter 5). On the cost side, electrically heateu dwellings had slightly lower-than-average weatherization costs (Chapter 7). Costeffectiveness results, therefore, were generally more favorable for the electrically heated dwellings. For the electrically heated dwellings, net savings at the site were used for all of the benefit/cost ratio:

\subsubsection{Installation Perspective}

The detailed results of the cost-effectiveness calculations for electrically heated dwellings are shown in Appendix $\mathbf{H}-2$. The national b/c ratio, with t'e installation perspective, was 1.69 .

The pattern of results by subgroups was very similar to the results for the gas-heated dwellings (Section 8.2). Fur the electrically heated dwellings, with the installation perspective, only the hot region and mobile homes had b/c ratios of less than 1.00. Comparisons by dwelling type indicate that single-family detached and small multifamily dwellings had benefit/cost ratios of 1.82 and 1.64, respectively (Appendix $\mathrm{H}-2$ ). ${ }^{2}$

2 Weatherization of single-family attached dwellings was not evaluated for cost effectiveness, because only five homes were available in this category. 

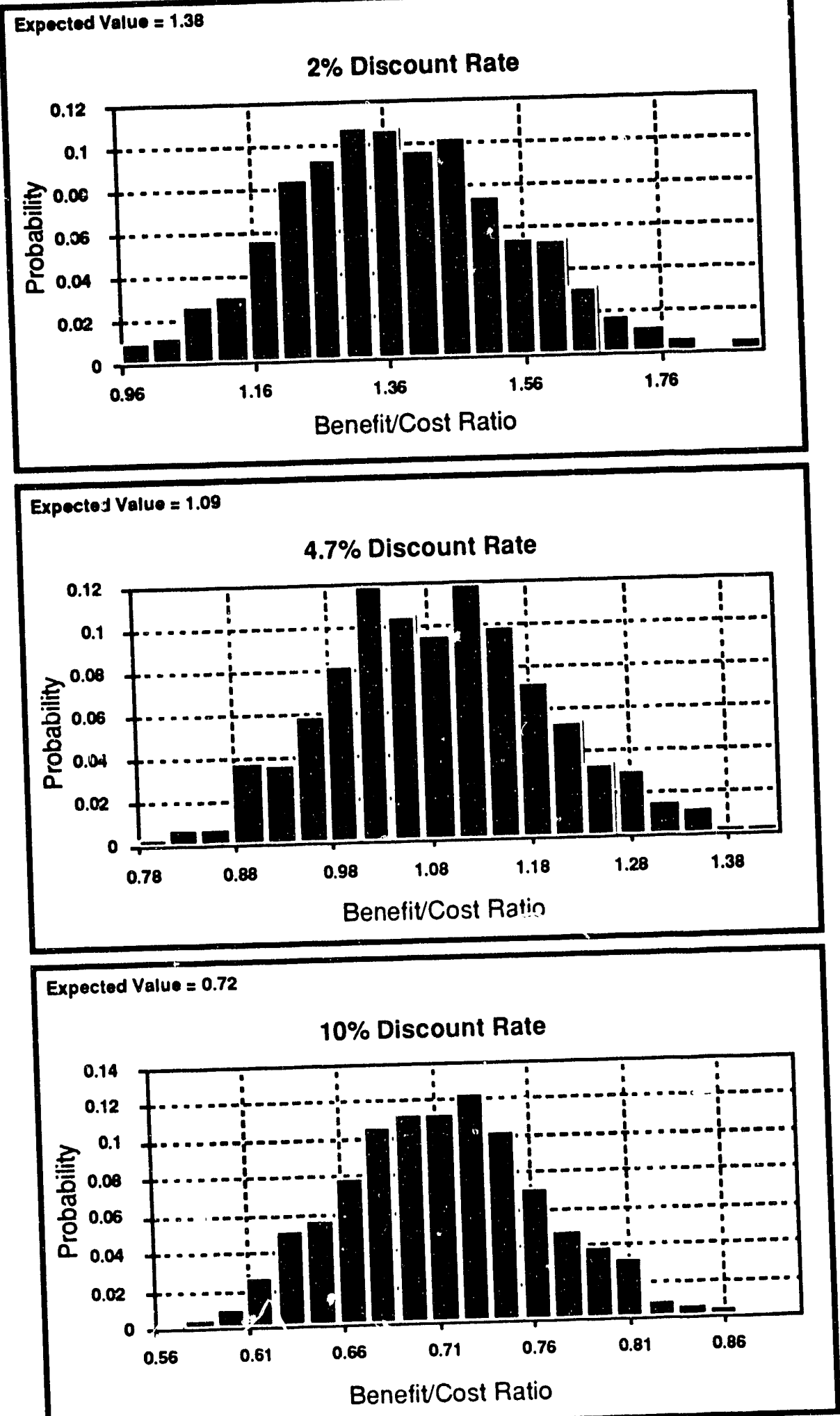

Fig. 8.14 Sensitivity of Program Perspective Results to Choice of Discount Rates 
Table 8.3 Sensitivity of Benefit/Cost Ratios to Discount Rates and Lifetimes

\begin{tabular}{|c|c|c|c|}
\hline \multirow[b]{2}{*}{ biefne (qears) } & \multicolumn{3}{|c|}{ Discount Rate } \\
\hline & $2 \%$ & $4.7 \%$ & $10 \%$ \\
\hline Instailation Perspectice & \multirow[b]{2}{*}{$\begin{array}{l}1.20 \\
1.50 \\
2.00 \\
2.51\end{array}$} & \multirow[b]{2}{*}{$\begin{array}{l}0.89 \\
1.26 \\
1.58 \\
1.86 \\
\end{array}$} & \multirow[b]{2}{*}{$\begin{array}{l}0.73 \\
0.93 \\
1.07 \\
1.17 \\
\end{array}$} \\
\hline 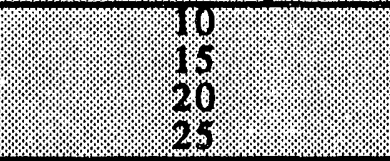 & & & \\
\hline Program Perspective & \multirow[b]{2}{*}{$\begin{array}{l}0.67 \\
1.01 \\
1.34 \\
1.68 \\
\end{array}$} & \multirow[b]{2}{*}{$\begin{array}{l}0.59 \\
0.84 \\
1.06 \\
1.25\end{array}$} & \multirow[b]{2}{*}{$\begin{array}{l}0.49 \\
0.63 \\
0.72 \\
0.78\end{array}$} \\
\hline - & & & \\
\hline Societal Perspective & \multirow[b]{2}{*}{$\begin{array}{l}1.22 \\
1.56 \\
1.90 \\
2.24\end{array}$} & \multirow[b]{2}{*}{$\begin{array}{l}1.14 \\
1.39 \\
1.61 \\
1.80\end{array}$} & \multirow[b]{2}{*}{$\begin{array}{l}1.03 \\
1.17 \\
1.26 \\
1.33\end{array}$} \\
\hline 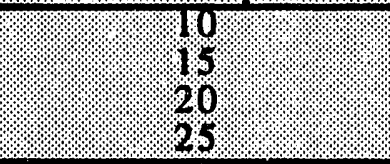 & & & \\
\hline
\end{tabular}

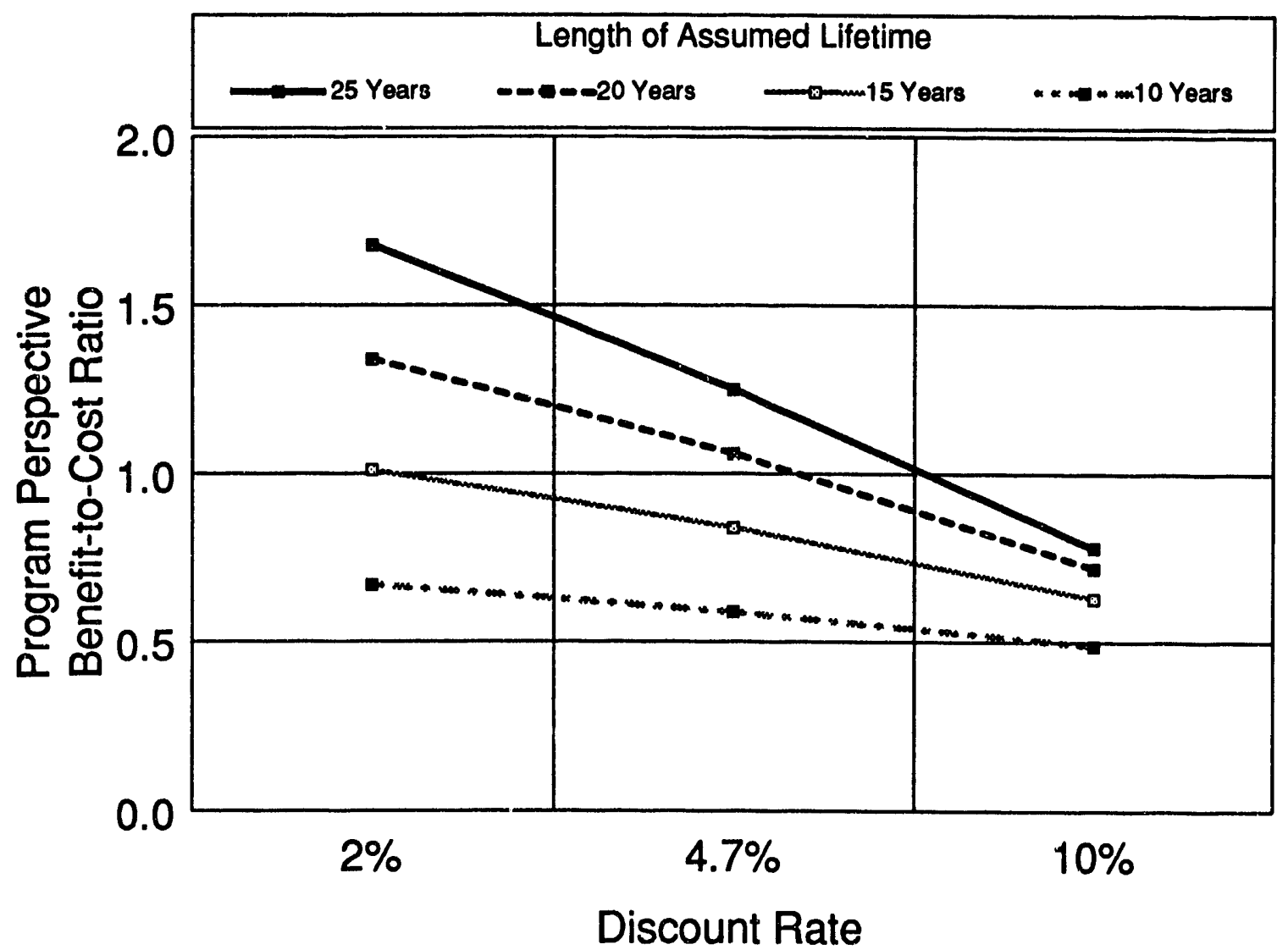

Fig. 8.15 Sensitivity of Benefit/Cost Ratios to Assumed Discount Rates and Measure Lifetimes 
Examination of the correlation between agency size and $b / c$ ratios for electrically heated dwellings showed a different pattern from the results for gas dwellings (Appendix $\mathbf{H}-2$ ). In electrically heated dwellings, large agencies had the highest benefit/cost ratios. In contrast, medium agencies had the highest $b / c$ ratios for gas-heated homes. Because the sample size for electrically heated homes in large agencies was small $(n=39)$ (compared with the gas-heated sample of 1,477 dwellings weatherized by large agencies), the electric results for large agencies are less reliable than the gas findings. Small agencies had the lowest b/c ratios for both gas- and electrically heated dwellings.

\subsubsection{Program Perspective}

From the program perspective, the national Program and most subgroups achieved cost effectiveness. The subgroups with b/c ratios below 1.00 were: hot climate region, mobile homes, and small agencies (Appendix H-2). All other subgroups had b/c ratios greater than 1.00 .

\subsubsection{Societal Perspective}

From the societal perspective, which includes both energy and selected nonenergy benefits and both installation and noninstallation costs, the weatherization of electrically heated dwellings was cost effective, with a national benefit/cost ratio of 2.33 . The cold and moderate climate regions had ratios of 2.86 and 2.73, respectively (Fig. 8.16). The hot region was less cost effective (1.57). With this perspective, all dwelling types, except mobile homes (1.47), had benefit/cost ratios greater then 2.00. Large and medium-sized agencies also had benefit/cost ratios above 2.00 , while small agencies (1.89) did not.

\subsection{OTHER FUELS}

Although the energy savings for dwellings that heat with fuels other than gas, electricity, and fuel oil were not measured directly in this evaluation, estimates of savings in MBtu's for other fuels were presented in Chapter 5 (Tables 5.5 and 5.6). To assign a dollar value to the assumed savings for other fuels we used the national prices given in the EIA State Energy Price and Expenditure Report 1989 (EIA, 1991a, p. 20). The assumed values are shown in Appendix F-2.

\subsection{PROGRAM-WIDE COST EFFECTIVENESS}

To estimate program-wide cost effectiveness our results for gas and electrically heated dwellings, and the results from the Fuel-Oil Study (Temes and Levins, 1992), were combined with the assumed annual dollar savings for other fuels. The annual dollar savings for each fuel were weighted 


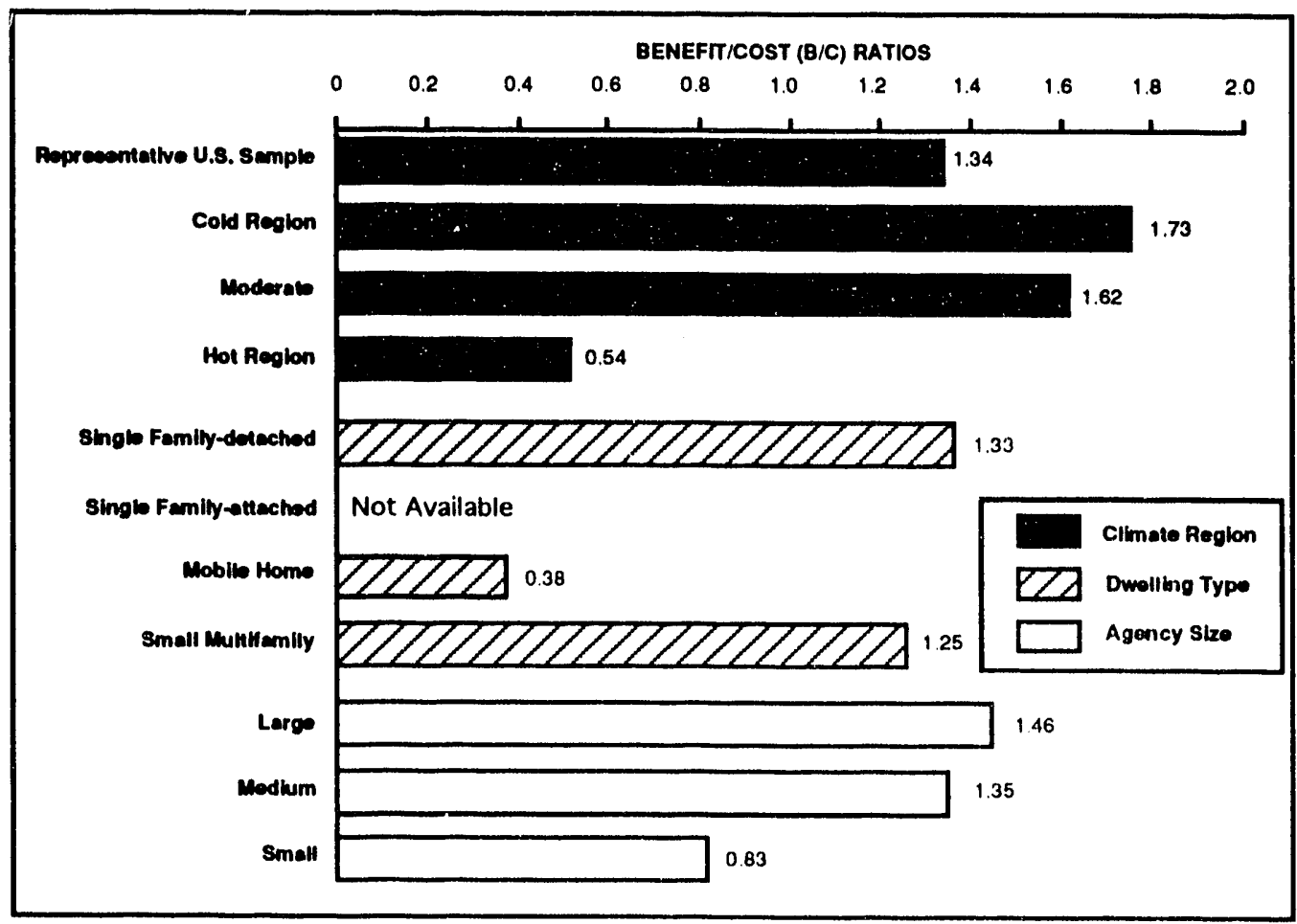

Fig. 8.16 Societal Benefit/Cost Ratios by Climate Region, Dwelling Type, and Agency Size for Electrically Heated Dwellings.

by the proportion of dwellings in the Program population that heat with that fuel to obtain an average annual dollar savings for all fucl types (Appendix F-2). Using this procedure, we estimated that average annual dollar savings for all fuel types was $\$ 115.55$ per dwelling. Using our baseline assumptions of 20-year lifetimes and a $4.7 \%$ discount ratc, this amount of annual dollar savings along with the weighted average national installation cost of $\$ 1,050$ for all fucl types yielded a benefit/cost Iatio of 1.61 . With the program perspective the b/c ratio for all fucls was 1.09 . With the societal perspective, the benefit/cost ratio for all fucls was 1.72 .

\subsection{COMPARISONS WITH PREVIOUS COST EFFECTIVENESS RESULTS}

The results of cost-effectiveness analyses in previous evaluations of low-income weatherization programs were reviewed in Chapter 1 (Section 1.4.2). Pcabody (1984) did not report the cost of conserved energy for the 1981 Program. Schlegel and Pigg (1990), in their review of nine evaluations of cold climate programs serving gas-heated dwellings, reported CCE's that, when recalculated with our bascline assumptions (4.7\% discount ratc, 20-year lifetime, only on-site installation costs), averaged $\$ 6.08 / \mathrm{MBtu}$, with a range of $\$ 2.69$ to $\$ 17.33$. Cohen, et al. (1990), in their review of 12 evaluations of cold climate programs serving gas-heated dwellings, reported a 
median CCE, recalculated with our assumptions, of $\$ 5.07 / \mathrm{MBtu}$. Thus, our cold climate region results for gas-heated dwellings ( $\$ 3.50$ per $\mathrm{MBtu}$ ) compare very favorably to the results of previous studies, as do the national gas results ( $\$ 4.60$ per MBtu). This suggests that for gas-heated dwellings the 1989 Program improved upon the average performance of programs included in previous low-income weatherization evaluations (Fig. 8.17). Comparisons with utility low-income programs (for gasheated dwellings) also show the 1989 Program to be more cost effective (Fig. 8.18). Similarly, the results for electrically heated dwellings indicated a national CCE ( $\$ 0.04$ per $\mathrm{kWh}$ ) that was lower than the average national price of $\$ 0.069$ per $\mathbf{k W h}$.

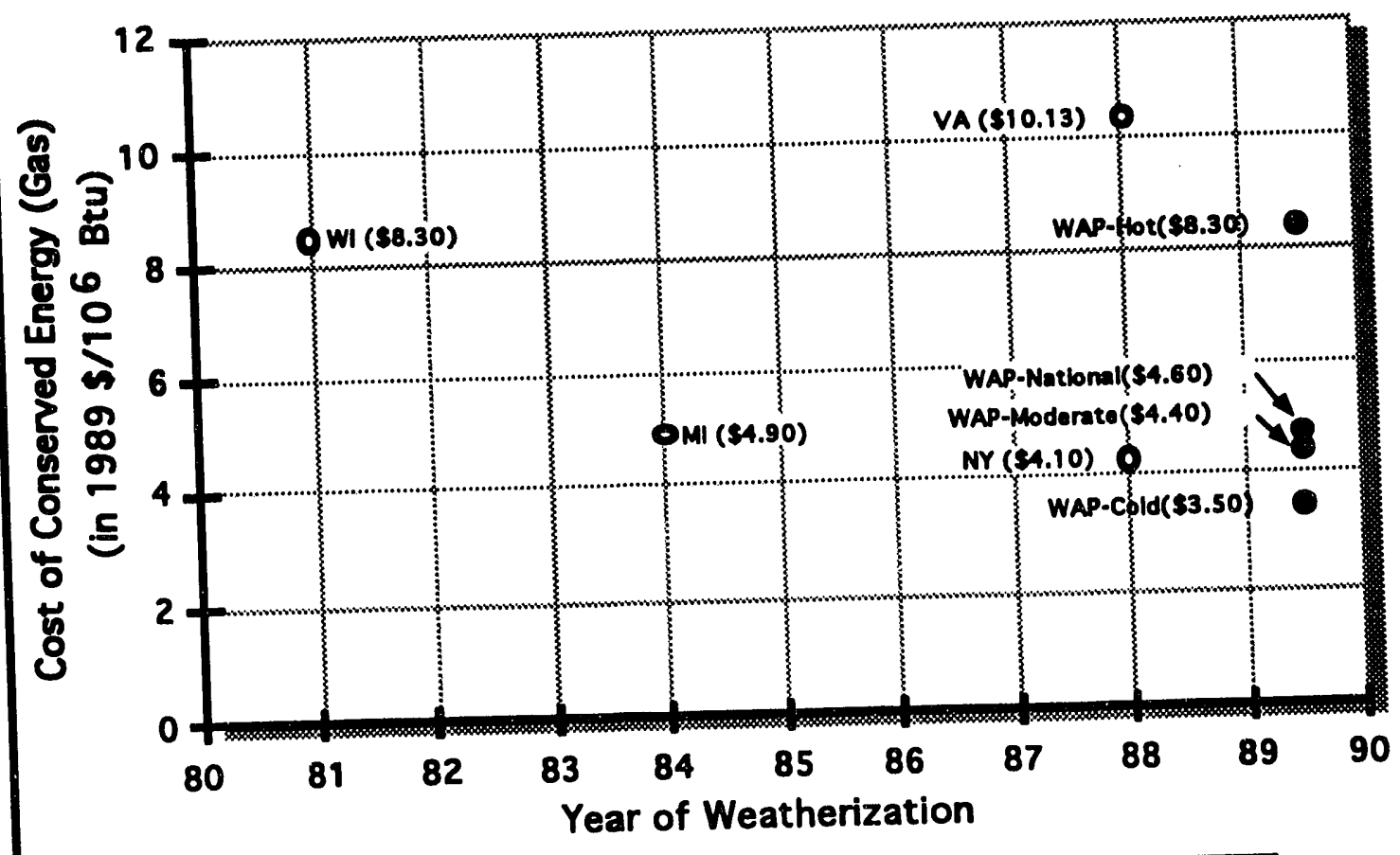

WI 81: Wisconsin State Weatherization Assistance Program M 84: Michigan State Weatherization Assistance Program NY 88: New York State Weatherization Assistance Program VA 88: Virginia State Weatherization Assistanue Program

Fig. 8.17 Cost of Conserved Energy for the Weatherization Assistance Program and Low-Income Utility Programs in Gas-Heated Dwellings. 


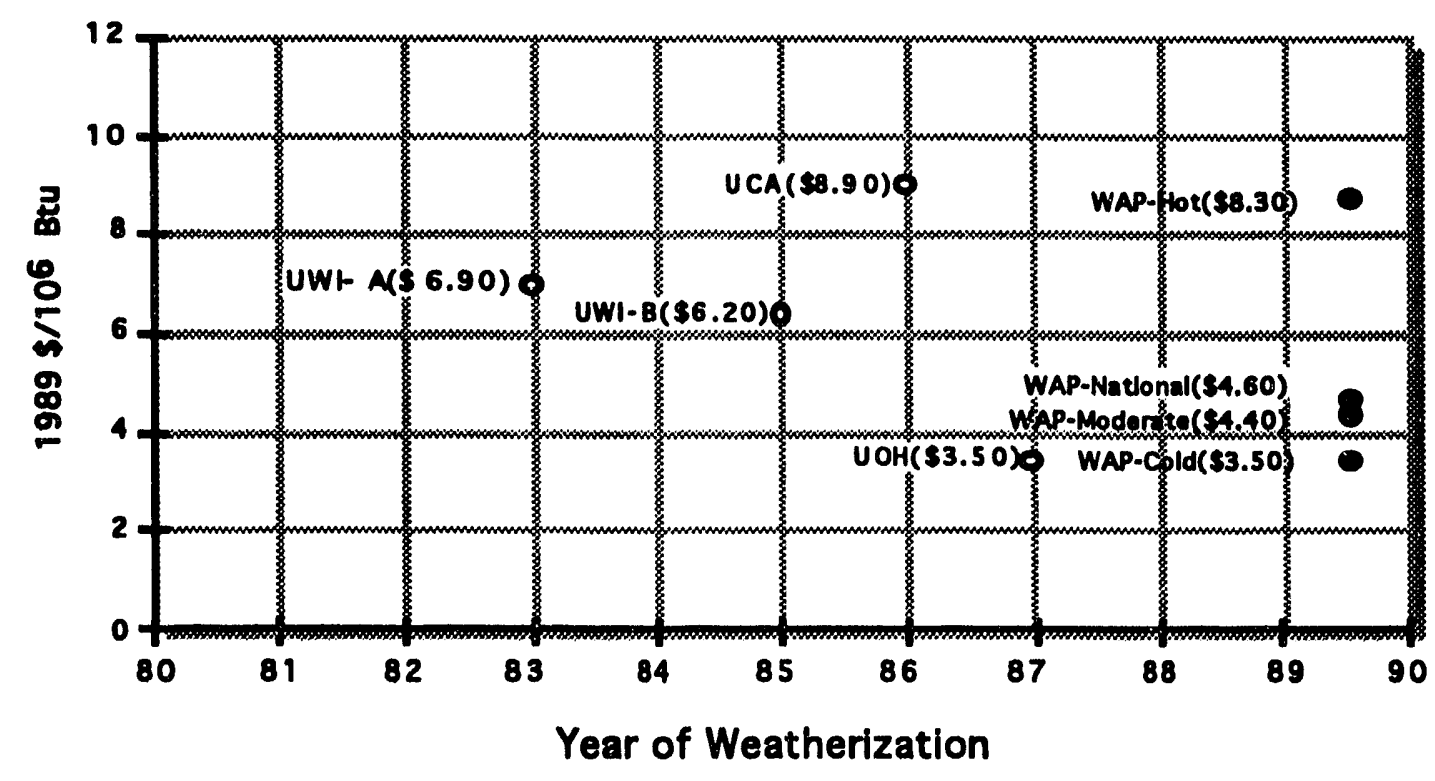

UWI-A: Wisconsin utilities initiating low-income programs in 1982

UWI-B: Wisconsin utillties initiating low-income programs in 1983

UCA: Pacific Gas and Elactric's low-income program

UOH: Ohio Utility low-income pillot program

Fig. 8.18 Cost of Conserved Energy for the PY 1989 Weatherization Assistance Program vs. Low-Income Utility Programs in Gas-Heated Dwellings

\subsection{SUMMARY}

This chapter examined the cost-effectiveness of the Program from three perspectives. With the installation perspective, which follows the usual procedure in previous low-income weatherization program evaluations, the only benefit valued is energy savings and the only costs included are expenditures for materials and installation labor. The program perspective also includes only energy benefits, but compares these benefits to total costs. With the societal perspective, benefits include both energy and selected nonenergy benefits, and total costs (including installation, overhead and management expenditures) are used.

\subsubsection{Gas and Electric Cost Effectiveness}

For gas-heated dwellings, the national Program was cost effective from all three perspectives, with $\mathrm{b} / \mathrm{c}$ ratios ranging from 1.06 to 1.61 . The cold and moderate regions had higher $\mathrm{b} / \mathrm{c}$ ratios than the national average, while the hot region had $b / c$ ratios of less than 1.00 with the installation and 
program perspectives, and of 1.17 with the societal perspective. Only single-family detached homes (which account for $64 \%$ of weatherized homes) had $b / c$ ratios above 1.00 with the program perspective. All dwelling types had $b / c$ ratios of 1.23 or higher with the other two perspectives. Large and medium-sized agencies had cost-effective results with all three perspectives, while small agencies fell below 1.00 with the program perspective.

Because electricity prices are higher than gas prices, energy savings in electrically heated dwellings are worth more. Therefore, cost-effectiveness results were consistently more favorable. The national benefit/cost ratio was 1.13 with the program perspective, and higher with the other two perspectives. All climate regions had $\mathrm{b} / \mathrm{c}$ ratios of 1.57 or higher with the societal perspective. With the program and installation perspectives, the Program was cost effective in the cold and moderate regions, but not in the hot region. Comparisons by dwelling type, with the program and installation perspectives, indicate that weatherizations of single-family detached and small multifamily dwellings were cost-effective, while those of mobile homes were not. From the societal perspective, the weatherization of electrically heated dwellings was highly cost effective, with a national benefit/cost ratio of 2.33. All of the subgroups showed cost-effective results with the societal perspective.

\subsubsection{Program-wide Cost Effectiveness}

Both the gas and electric results compare favorably to those of previous evaluations. The CCE for our study was less than the CCE's reported in previous studies of gas-heated dwellings in cold climate regions. The CCE for electricity also was well below prevailing prices. When all fuel types were combined, the national program benefit/cost ratio was estimated at 1.09 , the installation b/c ratio at 1.61 , and the societal at 1.72 . Thus, our analyses show that the Program is cost effective nationally, and for nearly all subgroups. When utility co-funding and the cost of structural measures are excluded, the bottom line is even more favorable. 


\section{FACTORS ASSOCIATED WITH PROGRAM PERFORMANCE}

Previous studies suggest that many factors influence the energy savings and cost effectiveness of weatherization, including:

- occupant characteristics, e.g., household income and demographics;

- dwelling unit characteristics, e.g., energy consumption prior to weatherization, age and size of dwelling;

- weatherization measures installed, e.g., type of insulation, air leakage control, space heating system retrofits;

- service delivery differences, e.g., method of client selection, use of diagnostic and audit procedures, client education;

- weatherization costs, e.g., total materials costs; and

- agency characteristics, e.g., use of contractors vs. in-house crews.

Section 9.1 examines the relationship of energy savings to each of these factors, using a dwelling-level analysis. Two approaches are taken. First, we present the average energy savings of dwellings that are associated with a particular factor (for instance, dwellings that are owner-occupied or dwellings that received high-density wall insulation). Because of the important role of climate, average energy savings is presented by region and for the national program.' Second, we identify the characteristics that distinguish high energy savers from low energy savers. ${ }^{2}$

The dwelling-level analysis described in Section 9.1 is hindered by the wide variability in energy savings, which reflects the many factors that influence residential energy consumption. This variation is less troublesome when the results for individual dwellings are aggregated: hence the value of an agency-level analysis.

Section 9.2 examines factors that influence energy savings on an agency-by-agency basis. Because of the small sample of electrically heated dwellings with consumption data, the agency-level analysis is limited to gas-heated dwellings. Our sample contains 97 agencies for which dwelling specific data and gas savings estimates are available for at least 10 dwellings they weatherized in PY 1989. Three measures of agency performance are examined: absolute gas savings, percent gas

1 The regional analysis is limited to gas-heated dwellings because the sample of electrically heated homes is too small to enable a region-by-region analysis. A two-way analysis of variance (ANOVA) is used to test the significance of each factor, after the influence of climate region is controlled. The interaction between climate region and each factor also is tested.

2 For gas-heated dwellings, this analysis is conducted individually for each of the three climate regions. High gas savers are those dwellings with savings in the upper quartile of gas-heated dwellings in the respective region. Low gas savers are dwellings with savings in the lowest quartile. For electrically heated dwellings, the small sample size can only support a program-wide analysis. Thus, high electricity savers are those dwellings with savings in the upper quartile of all electrically heated dwellings, and low electricity savers are those in the lowest. 
savings, and benefit/cost ratios. ${ }^{3}$ Mean values of the full range of predictors also are calculated for each agency. Multivariate regression analysis then is used to identify correlates and models of agency performance.

The chapter ends with a summary of its findings (Section 9.3). It underscores that more analysis is needed to understand the findings reported in this chapter and to employ them as a basis for policy and program recommendations. The results reported in this chapter are "correlational" in nature and cannot identify "causes" of high energy savings. A more thorough and detailed analysis of factors influencing energy savings and cost effectiveness will result from the field work portion (Phase 2) of the Single-Family Study.

\subsection{DWELLING-LEVEL ANALYSIS}

\subsubsection{Occupant Characteristics}

All of the occupant characteristics discussed in Chapter 3 were examined as possible correlates of energy savings, including family income, household size, the presence of elderly or handicapped occupants, change of occupancy, and household tenure (i.e., owners or renters). None of these characteristics correlates with energy savings when examined across the entire national sample of dwellings, based on a 0.05 level of significance. Further, the two-way ANOVA indicates that none of these characteristics is significant after controlling for climate region, nor are any interactions with climate region significant. The only characteristic that is nearly significant (at the 0.11 level) is change of occupancy. Dwellings with a change of occupancy after weatherization saved more than any other dwellings. Turnover in occupants during the year before and after weatherization is associated with the least gas savings, and dwellings with one or more occupancy changes before weatherization saved less than average. Since household turnover is often associated with periods of vacancy, the relationship described above may simply reflect the low level of gas consumption that occurs when dwellings are unoccupied. The low level of savings experiunced by dwellings that had turnover in occupants both before and after weatherization suggests that dwellings with greater transiency offer less opportunity for savings. Certainly, client education efforts will not reduce a dwelling's consumption if the clients who are educated move out. Instead, some of these households will apply their new knowledge about energy efficiency to their new dwelling. Unfortunately, any such effects cannot be traced with the evaluation's existing data.

When high and low gas savers are compared on a region-by-region basis, owner occupancy in the cold region and the presence of one or more handicapped persons in the hot region are

3 The benefit/cost ratio used here is based on the program perspective: all costs are included, but the benefits are limited to the net present value of the energy savings. The benefit/cost ratio is estimated individually for each dwelling, then the mean value for each agency is calculated. 
characteristic of low savers. Recall that in the hot region, a higher than average proportion of weatherized dwellings are occupied by handicapped clients, compared with the Program nationwide (Table 3.1). Thus, weatherizing dwellings with this targeted population may reduce the savings that local agencies in the hot region are able to generate. On the other hand, the of the Weatherization Assistance Program in PY 1989 calls for special attention to the needs of this group. The extension of this mandate in 1991 to include families with children may direct agencies to households that offer greater energy-savings potential. Similarly, the DOE allocation formula directs more resources towards States with more owner-occupied low-income dwellings. Our findings do not provide any evidence that this preference enhances program performance.

Table 9.1 Factors Distinguishing High from Low Energy Savers: Occupant and Dwelling Characteristics

\begin{tabular}{|c|c|c|c|c|}
\hline & \multicolumn{3}{|c|}{ Gasoneated Dwellings. } & \\
\hline 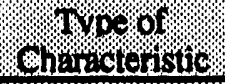 & $\begin{array}{l}001 \mathrm{~d} \\
\text { Qtínatereston }\end{array}$ & 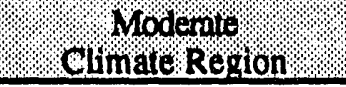 & climaterestion & pweilins \\
\hline \%, & Owner-occupied (-) & $\begin{array}{l}\text { Pre-weatherization } \\
\text { occupancy change (-) }\end{array}$ & $\begin{array}{l}\text { Presence of } \\
\text { handicapped } \\
\text { occupant }(-)\end{array}$ & \\
\hline 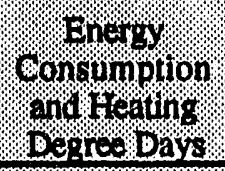 & $\begin{array}{l}\text { Pre-weatherization gas } \\
\text { consumption }\end{array}$ & $\begin{array}{l}\text { Pre-weatherization gas } \\
\text { consumption } \\
\text { Heating degree days }\end{array}$ & $\begin{array}{l}\text { Pre-weatherization } \\
\text { gas } \\
\text { consumption }\end{array}$ & $\begin{array}{l}\text { Pre-weatherization } \\
\text { electricity } \\
\text { consumption } \\
\text { Heating degree days }\end{array}$ \\
\hline onopeterists & $\begin{array}{l}\text { Mobile homes (-) } \\
\text { Single-family detached } \\
\text { dwellings } \\
\text { Small multifamily } \\
\text { dwellings } \\
\text { Area of conditioned } \\
\text { dwelling space } \\
\text { Age of dwelling } \\
\text { Supplemental fuel use (-) } \\
\text { Air conditioning (-) }\end{array}$ & $\begin{array}{l}\text { Mobile home (-) } \\
\text { Single-family detached } \\
\text { dwellings } \\
\text { Area of conditioned } \\
\text { dwelling space } \\
\text { Air conditioning } \\
\text { equipment (-) }\end{array}$ & & \\
\hline
\end{tabular}

(-) Indicates a negative relationship between high savers and presence of the characteristic.

\subsubsection{Dwelling Characteristics}

All of the dwelling characteristics shown in Fig. 9.1 are associated with energy savings, both nationwide and within the three climate regions. ${ }^{4}$ Recall that dwelling type also is a significant correlate, as discussed in Chapter 5.

4 Statistics associated with Figures 9.1 through 9.12 are presented in Appendix I. 


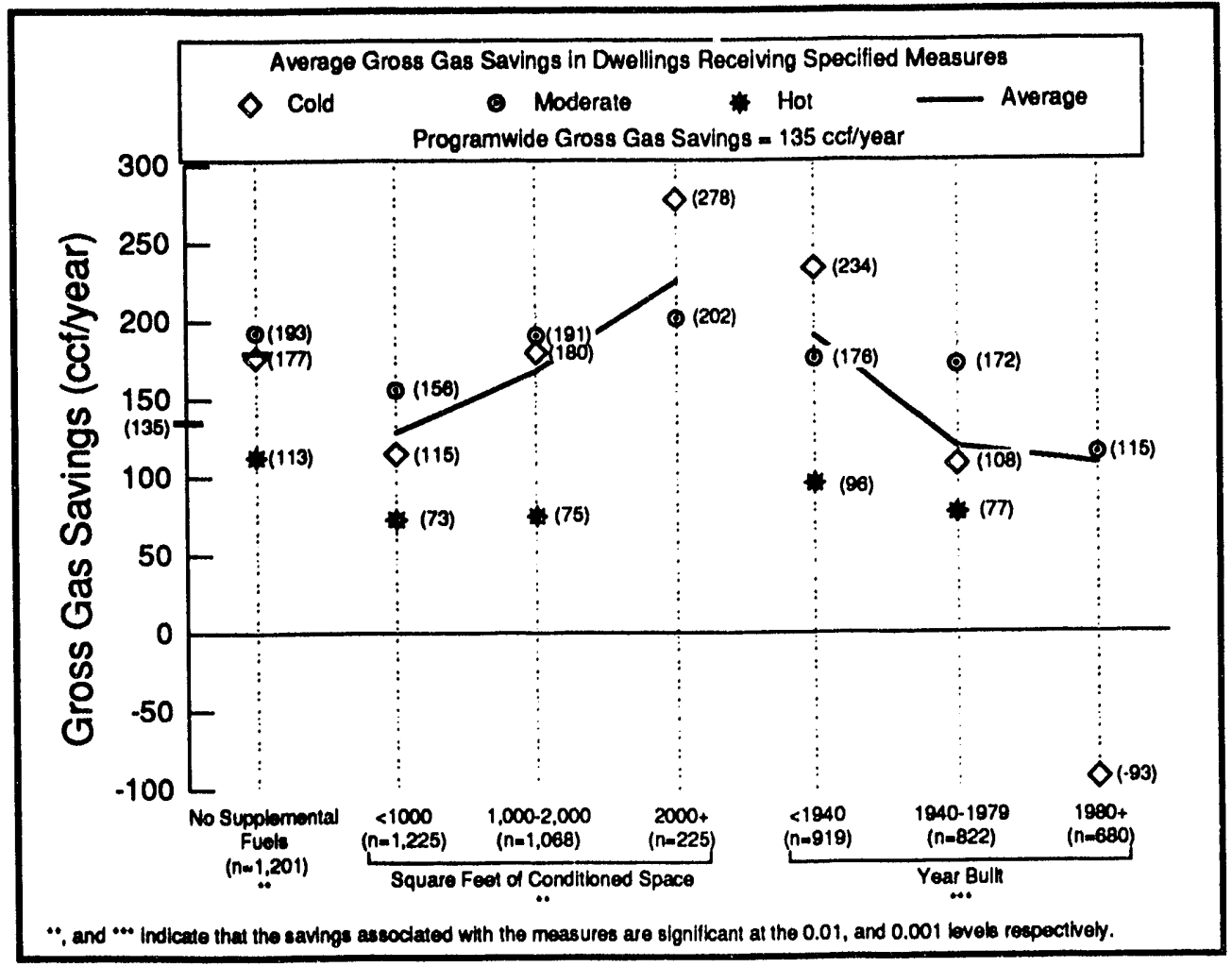

Fig. 9.1 Gas Savings of Dwellings With Different Dwelling Characteristics

Supplemental Heating Fuels, Central Heating Systems, and Air Conditioning. Dwellings with supplemental heating fuels saved $64 \mathrm{ccf} / \mathrm{dwelling}$ less gas than dwellings that had only a primary heating fuel (Table 1.2 in Appendix 1). This has significant implications for our estimate of the energy saved by gas-heated homes. Supplemental heating fucls characterize $25.9 \%$ of the gas-heated dwellings weatherized in PY 1989 for which gas data are available. It is reasonable to assume that dwellings with gas and one or more supplemental heating fucls saved as much energy as dwellings with only gas heat, except that they saved an equivalent of 64 ccf by reducing the consumption of their supplemental fuels. Thus, our estimated energy savings of gas-heated homes should be increased by $16.6 \mathrm{ccf} / \mathrm{d}$ welling (i.e., $0.259 \times$ 64). This would result in a net savings of $190 \mathrm{ccf} / \mathrm{year}$.

Gas-heated dwellings with central heating systems saved more gas than homes with other types of gas-heating equipment such as space heaters. However, this pattern is due entirely to the 
greater incidence of central heating systems in the cold and moderate climate regions, which produce greater energy savings (Fig. 9.1). The two-way ANOVA indicates that there is no significant correlation between central heating systems and gas savings, once the climate region effect is taken into account. The analysis of high and low gas savers, by region, corroborates the lack of correlation.

The presence of air conditioning equipment is characteristic of low gas savers within both the cold and moderate climate regions (Table 9.1). This is probably due, at least in part, to the prevalence of air conditioning in the warmer parts of these climate regions where gas savings are lower. When climate region is incorporated into the two-way ANOVA, the presence of air conditioning does not correlate significantly with gas savings.

Size and Age of Dwelling. Larger and older dwellings have significantly higher-thanaverage gas savings. Older homes also have higher electricity savings. Dwellings with 2,000 or more square feet of conditioned living space saved nearly twice as much gas as dwellings with less than 1,000 square footage, and dwellings built before 1940 saved nearly twice as much gas as dwellings built in 1980 or more recently. Older and bigger dwellings are more common in the cold and moderate regions, which partly explains this phenomenon. However, there also is evidence of the importance of these two factors in the region-specific analysis of high and low gas savers located in the cold and moderate regions (Table 9.1), and in the two-way analysis of variance (Fig. 9.1).

Pre-Weatherization Energy Consumption. By far, the most influential predictor of a dwelling's potential for energy savings is its level of pre-weatherization encrgy consumption: dwellings that consume more energy before weatherization, save more energy after weatherization. Figure 9.2 vividly illustrates the relationship between pre-NAC energy use and savings - for both gas- and electrically heated dwellings. Pre-weatherization energy consumption reflects occupant characteristics (e.g., the appliances purchased by a houschold and the houschold's management of its thermostat), dwelling characteristics (c.g., size of dwelling, the leakiness of a house and the efficiency of its heating system), climate (harsher conditions leading to greater consumption), and a host of other influences. The correspondence between high energy use and high potential savings has been recognized by many local weatherization agencies (for instance, it is a feature of New York's TIPS audit). It is also built into many utility DSM programs, which frequently give priority to weatherizing this subset of potential clients. More widespread use of pre-weatherization energy use to prioritize clients would increase the Program's energy savings.

\subsubsection{Weatherization Measures}

All of the weatherization measures discussed in Chapter 4 were examined as possible correlates of energy savings. The results of the analysis of high versus low energy savers are 


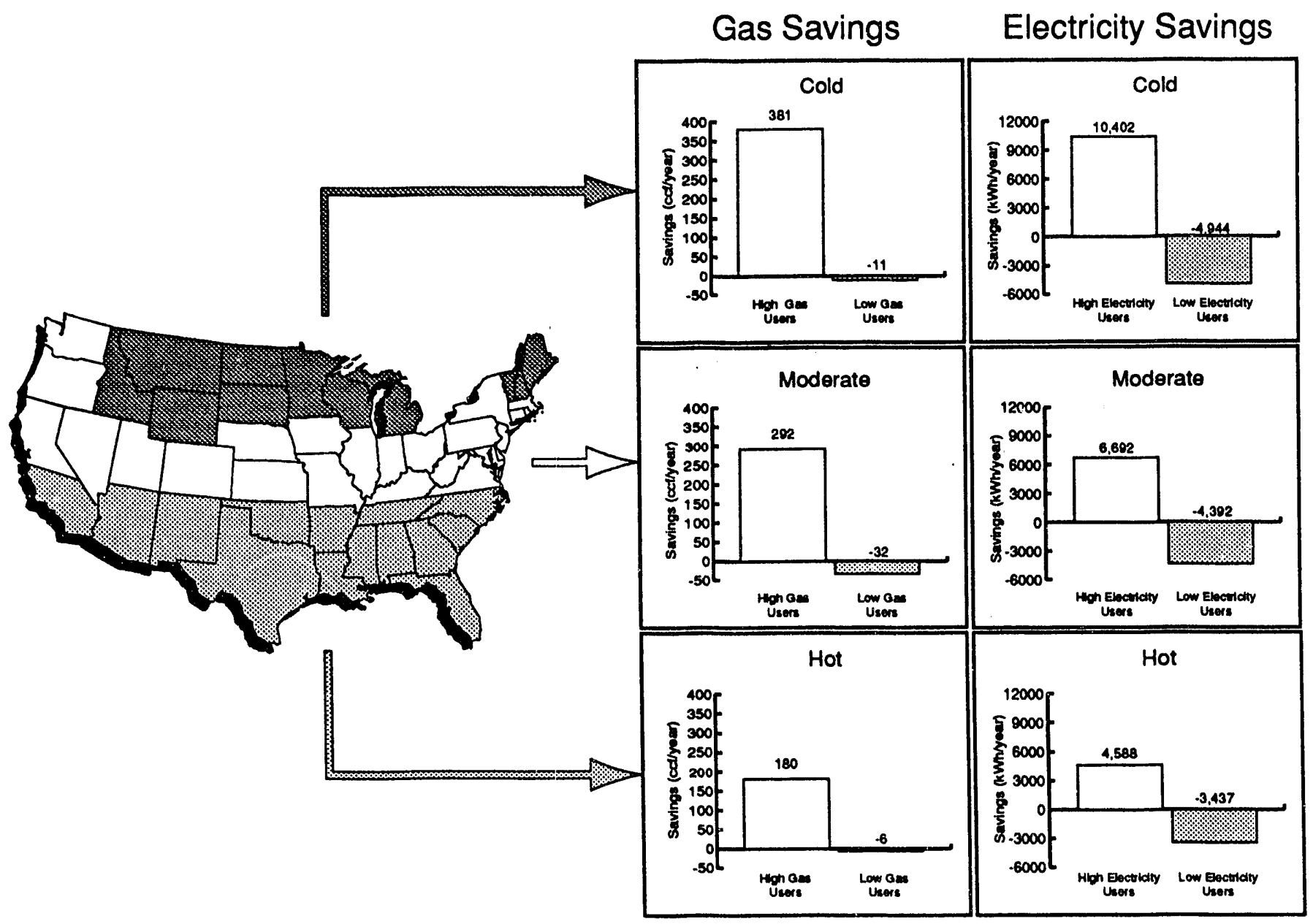

Fig. 9.2 Gross Energy Savings of High Versus Low Energy Users

summarized in Table 9.2. In addition, Figures 9.3 through 9.8 illustrate the energy saved by dwellings that received each of the individual weatherization measures, both nationwide, and by region. Since dwellings usually received other measures besides the one in question, it is not possible to estimate precisely how much energy is saved by a single measure, based on the analysis presented here. Rather, the mean savings associated with installation of a particular measure reflect the savings achieved by weatherization jobs that include the meas!nre. 


\section{Table 9.2. Factors Dir.anguishing High from Low Energy Savers: Weatherization Measures}

\begin{tabular}{|c|c|c|c|c|}
\hline & \multicolumn{3}{|c|}{ CasnHeated Dwellings } & \multirow{2}{*}{$\begin{array}{l}\text { Electrically } \\
\text { Heated } \\
\text { Dwellings }\end{array}$} \\
\hline $\begin{array}{l}\text { Troe of } \\
\text { Measure }\end{array}$ & Climate foegrion & $\begin{array}{l}\text { Moderate } \\
\text { Climate Region }\end{array}$ & $\begin{array}{l}\text { Hot Climate } \\
\text { Region }\end{array}$ & \\
\hline $\begin{array}{l}\text { Ar Leakage } \\
\text { Control }\end{array}$ & $\begin{array}{l}\text { Caulking/ } \\
\text { weatherstripping (-) }\end{array}$ & $\begin{array}{l}\text { Air sealing without } \\
\text { blower doors } \\
\text { Distribution system }\end{array}$ & & \\
\hline Insulation & $\begin{array}{l}\text { Attic first time } \\
\text { Attic added } \\
\text { Wall "normal" } \\
\text { Wall "high density" } \\
\text { Rim or band joint }\end{array}$ & $\begin{array}{l}\text { Attic first time } \\
\text { Attic added } \\
\text { Wall "normal" } \\
\text { Wall "high density" } \\
\text { Floor } \\
\text { Gher envelope } \\
\text { insulation }\end{array}$ & $\begin{array}{l}\text { Attic first time } \\
\text { Floor }\end{array}$ & $\begin{array}{l}\text { Wall "normal" } \\
\text { Rim or band } \\
\text { joint }\end{array}$ \\
\hline $\begin{array}{l}\text { Water Heater } \\
\text { Measiures }\end{array}$ & $\begin{array}{l}\text { Water hester tank } \\
\text { insulation } \\
\text { Pipe insulation } \\
\text { Low floy showerhead }\end{array}$ & $\begin{array}{l}\text { Entire system } \\
\text { replacement (-) } \\
\text { Pipe insulation } \\
\text { Temperature reduction }\end{array}$ & $\begin{array}{l}\text { Other water heater } \\
\text { measures }\end{array}$ & \\
\hline $\begin{array}{l}\text { Heating System } \\
\text { Measures }\end{array}$ & $\begin{array}{l}\text { Ent:re heating system } \\
\text { replacement }\end{array}$ & $\begin{array}{l}\text { Entire heating system } \\
\text { replacement } \\
\text { System component } \\
\text { retrofit } \\
\text { Other heating system } \\
\text { modifications }\end{array}$ & & \\
\hline Windows and Doors & Storm windows (-) & & & \\
\hline
\end{tabular}

(-) Indicates a negative relationship between high savers and factor.

Air Leakage Control. Of ail of the air leakage control measures, sealing the distribution system of gas heating systems is assisciated with the highest savings. The two-way ANOVA indicates that this measure has a nearly-significant effect on gas savings nationwide $(p=0.069)$, and within the moderate region, the measure is highly significant at distinguishing high from low savers.

Air sealing without the aid of a blower door is associated w.ih slightly above-average gas savings that are statistically significant. Fig. 9.3 indicates that air sei.ing without blower doors is correlated with high savings in the cold and moderate regions, and that the association with savings is quite significant. Air sealisg without blower doors also characterizes high savers in the moderate region (Table 9.2) Iii contrast, sealing with blower doors is not correlated with significantly greaterthan-average savir.$s^{5}$

5 In addition, an analysis of weatherization costs indicates that they are nof lower for blower door-assisted air sealing than for unaided air seaiing. Thus, there are no discemitic energy savings or cost reductions. 


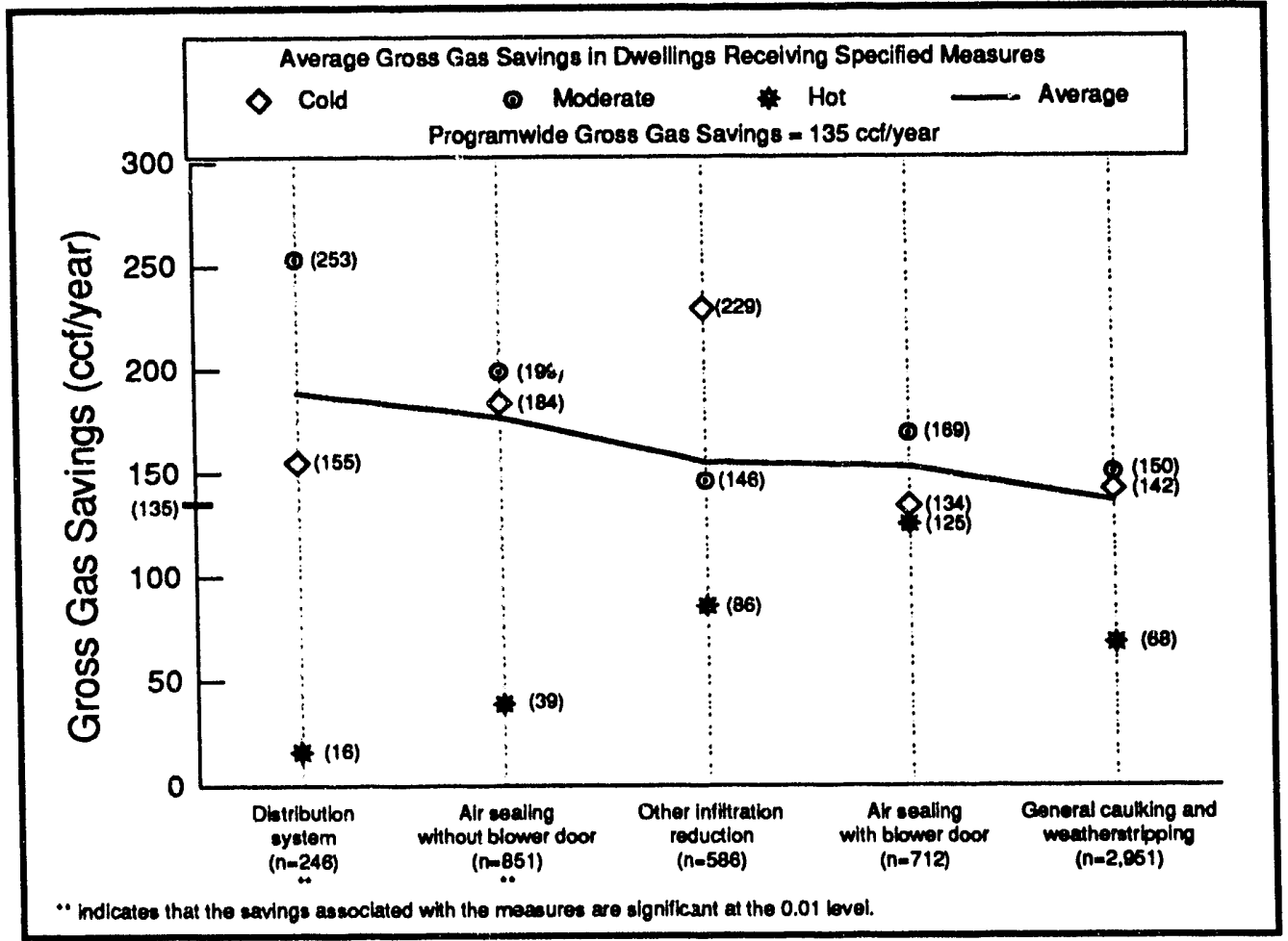

Fig. 9.3 Gas Savings of Dwellings that Received Air Leakage Control Measures

This finding is somewhat surprising. Ai. sealing with the assistance of a blower door is generally viewed as a cost-effective measure (Coher., Goldman, and Harris, 1990). However, it must be remembered that blower doors were just being introduced into local agency procedures in 1989 90. Crew members were being trained and an initial base of experience was being established. There is some indication from recent DOE monitoring that blower door testing has sometimes been used to exhaustively detect and plug every exfiltration point rather than to concentrate upon the major leaks that can be cost effectively sealed (U.S. Department of Energy, 1992, page 6-31). While blower doors may have been ineffectively applied or unnecessarily used during PY 1989, these problems are probably less characteristic of today's Pregram.

Finally, general caulking and weatherstripping is not correlated with gas or electricity savings nationwide, nor is it significant in the two-way ANOVA. However, in the cold region, general caulking and weatherstripping is characteristic of low gas savers (Table 9.2). This is consistent with a growing consensus among building scientists that general caulking and weatherstripping saves little energy. 
Insulation. The installation of most types of insulation is associated with higher-than-average gas savings (Fig. 9.4). ${ }^{6}$ Of particular note is the extremely high savings achieved by dwellings that received either high-density cellulose wall insulation (293 ccf/year savings) or normal wall insulation (265 ccf/year savings). High-density cellulose has been found to be a powerful technique for installing insulation and achieving air sealing at the same time. Many crews find that the infiltration rates of some houses can be cut in half without using a tube of caulk. The secret is careful installing of high-density cellulose in wall cavities and other places where it really counts. In PY 1989, few agencies were using high-density cellulose, but the numbers have been increasing since then. Results from the Fuel-Oil Study corroborate the high energy-savings potential of this new measure.

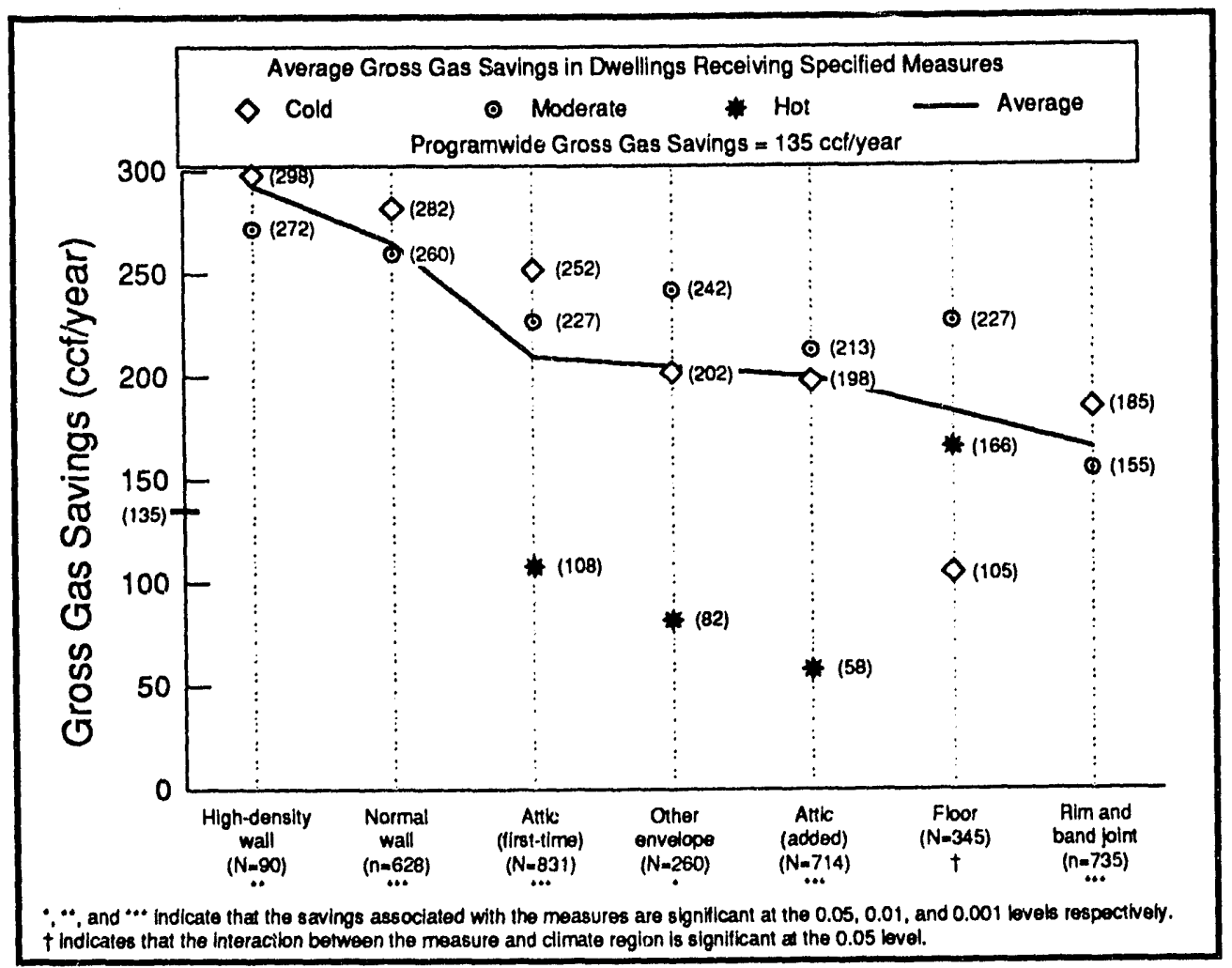

Fig. 9.4 Gas Savings of Dwellings that Received Insulation

Attic, floor, rim/band joint, and other envelope insulation are also associated with significantly higher-than-average gas savings. These high savings are significant even after climate region differences are coritrolled in the two-way ANOVA.

These same patterns are found within each of the climate regions in the analysis of high vs low savers (Table 9.2). Most types of insulation are characteristic of high gas savers in the cold and

6 The average savings for the hot climate region are not shown for wall and rim/band joint insulation, due to low installation rates which produced sample sizes of less than 10 dwellings. 
moderate regions. In the hot region, floor and first-time attic insulation are particularly common among high gas savers. Normal wall insulation and rim and band joint insulation also are characteristic of high electricity savers.

Water Heater Measures. Each of the wate- heater measures shown in Fig. 9.5, except water heater system replacement, is associated with higher-than-average gas savings. However, when the climate region effect is isolated by the two-way ANOVA, only three of these measures significantly correlate with gas savings: pipe insulation, other water heater measures, and waterheater temperature reduction. Most studies indicate that these measures produce relatively low (but cost-effective) savings (Brown, Rurucher, and White, 1989). The results shown in Fig. 9.5 may simply reflect the fact that water-iteating measures are included in the repertoire of highperforming agencies, which extends beyond building envelope measures.

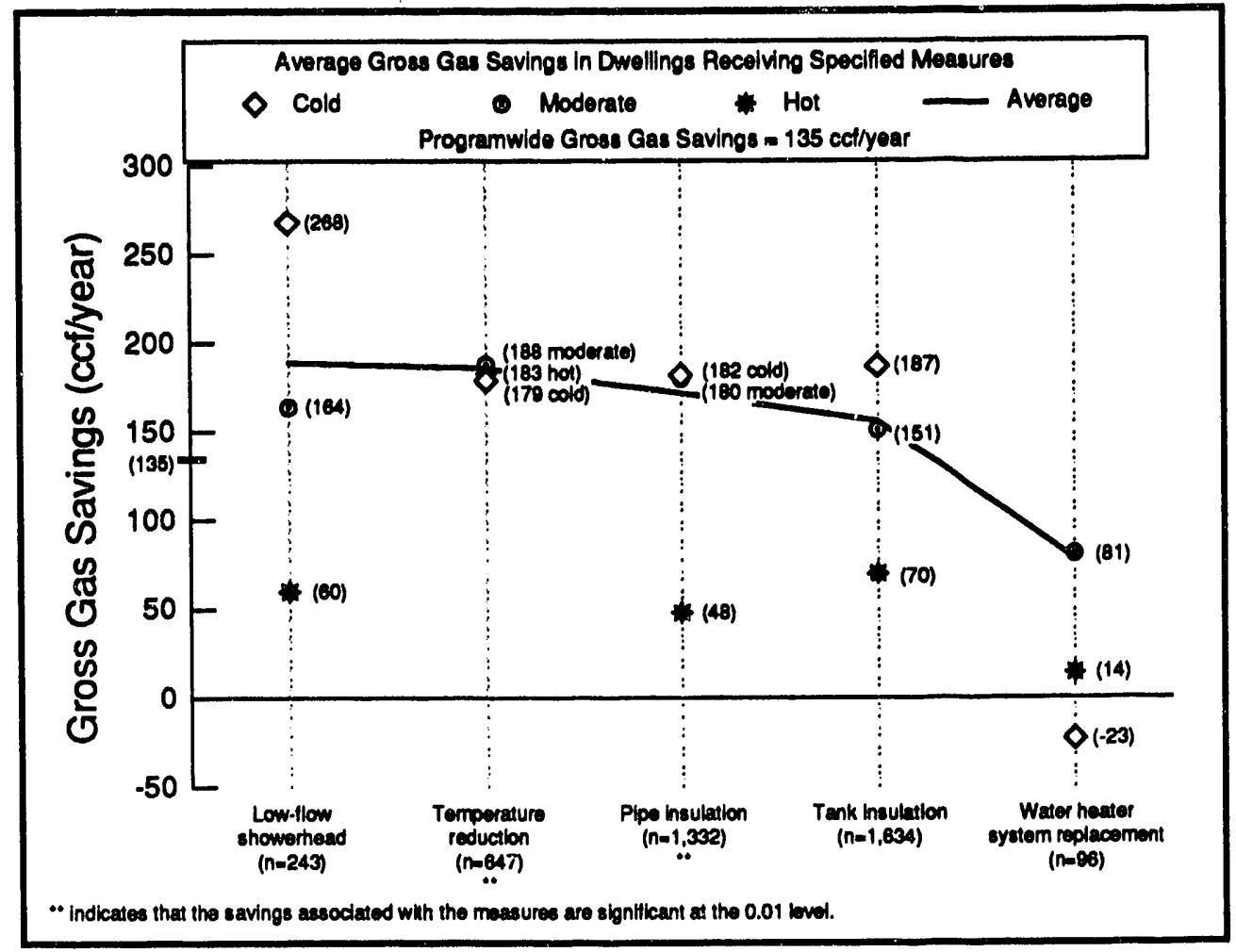

Fig. 9.5 Gas Savings of Dwellings that Received Water Heater Measures

Water heaters are replaced infrequently by local weatherization agencies, which makes it difficult to detect any associated differences between pre- and post-weatherization consumption. The mean values shown in Fig. 9.5, however, indicate an overall increase in gas $r$ se following the replacement of water heaters. This may reflect the installation of gas water heaters in place of faulty 
or inefficient electric models, resulting perhaps in lower overall energy use but higher gas consumption.

The region-by-region analysis indicates a preponderance of water-heater measures among high gas savers, both in the cold and moderate regions (Table 9.2). Within the hot climate region, water-'ieater measures are not characteristic of high gas savings, perhaps because in PY 1989 waterheater 1.:easures were rarely installed by local weatherization agencies in that region (Table 4.1).

Water-heater measures do not characterize high electricity savers (Table 9.2), even though more than half of the electrically heated dwellings weatherized in PY 1989 received at least one such measure (Table 4.2).

Windows and Doors. None of the window or door treatments shown in Fig. 9.6 are associated with significantly higher-than-average gas or electricity savings. The most common measure in this category is storm windows, which were installed in more than one-third of all dwellings weatherized in PY 1989 (Table 4.1). Nationwide, gas-heated dwellings that received storm windows averaged savings of only $131 \mathrm{ccf}$ during their first year after weatherization, compared with $143 \mathrm{ccf} / \mathrm{year}$ savings for dwellings that did not receive storm windows. Indeed, in the cold region, the differential is even greater: $109 \mathrm{ccf} /$ year for the $616 \mathrm{dwellings}$ that received storms, and $172 \mathrm{ccf} / \mathrm{year}$ for the 305 dwellings that did not. As Table 9.2 indicates, storm windows are characteristic of low

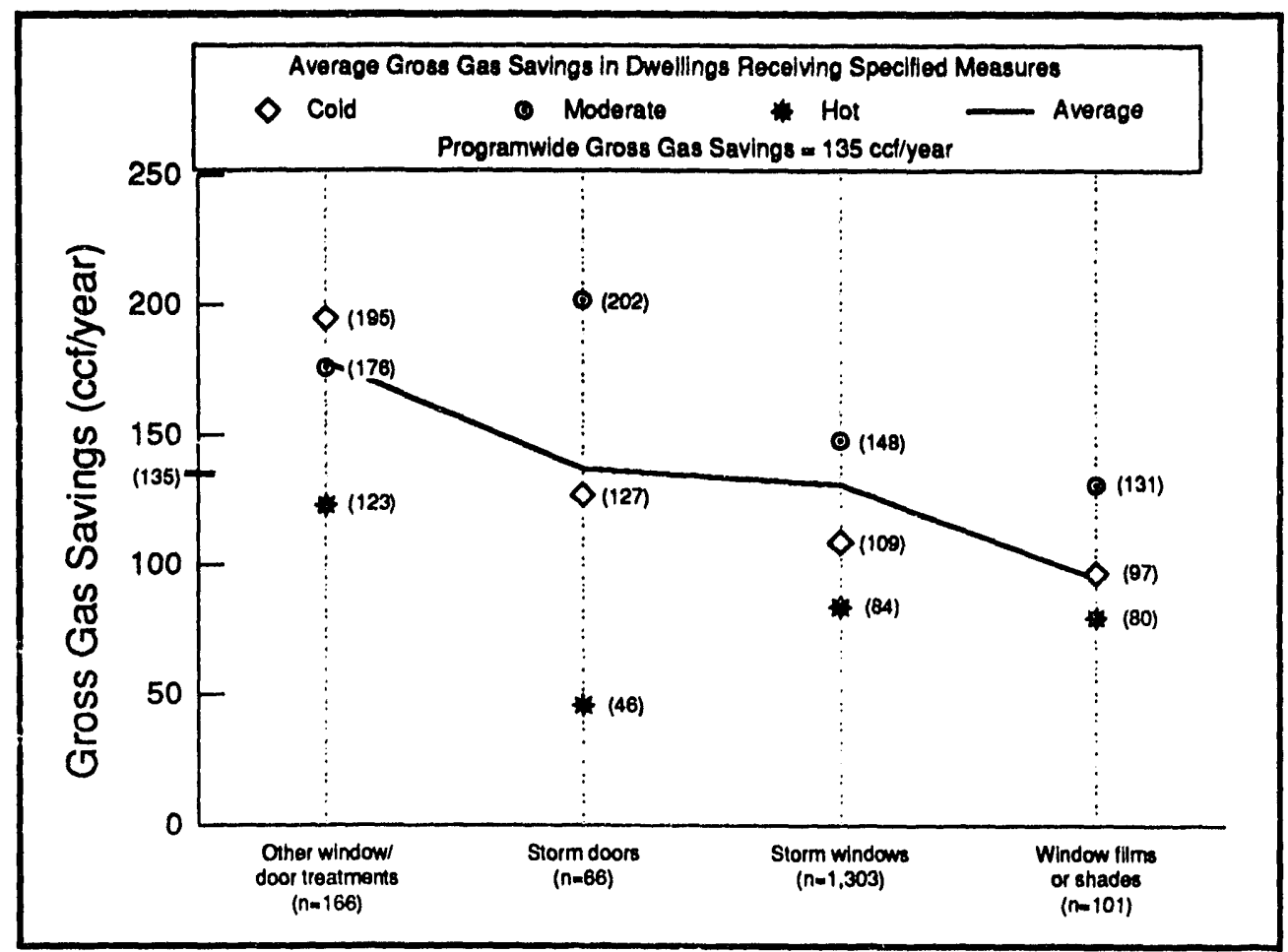

Fig. 9.6 Gas Savings of Dwellings that Received Window and Door Measures 
savers in the cold region. The overall pattern of savings associated with storm doors is similar, although the sample sizes are much smaller.

The average savings of dwellings that received window film or shades is even less - only 95 ccf during their initial post-weatherization year. Window film and shades are installed most frequently in the hot climate region primarily to save on electricity costs; thus, reduced gas use is not to be expected. Unfortunately, the sample sizes are too small to test for any significant association with electricity savings in the hot climate region.

Space-Heating System Measures. Many of the space-heating system measures examined in this evaluation are associated with higher-than-average gas savings (Fig. 9.7). In particular, dwellings that received system replacements, heating system repairs, or "other space-heating measures" had savings in excess of $190 \mathrm{ccf} / \mathrm{year}$. The region-by-region analysis corroborates the importance of space-heating measures: heating system replacements are associated with high gas savings in the cold region; and heating system replacements, system component retrofits, and "other heating system modifications" are characteristic of high gas savers in the moderate region.

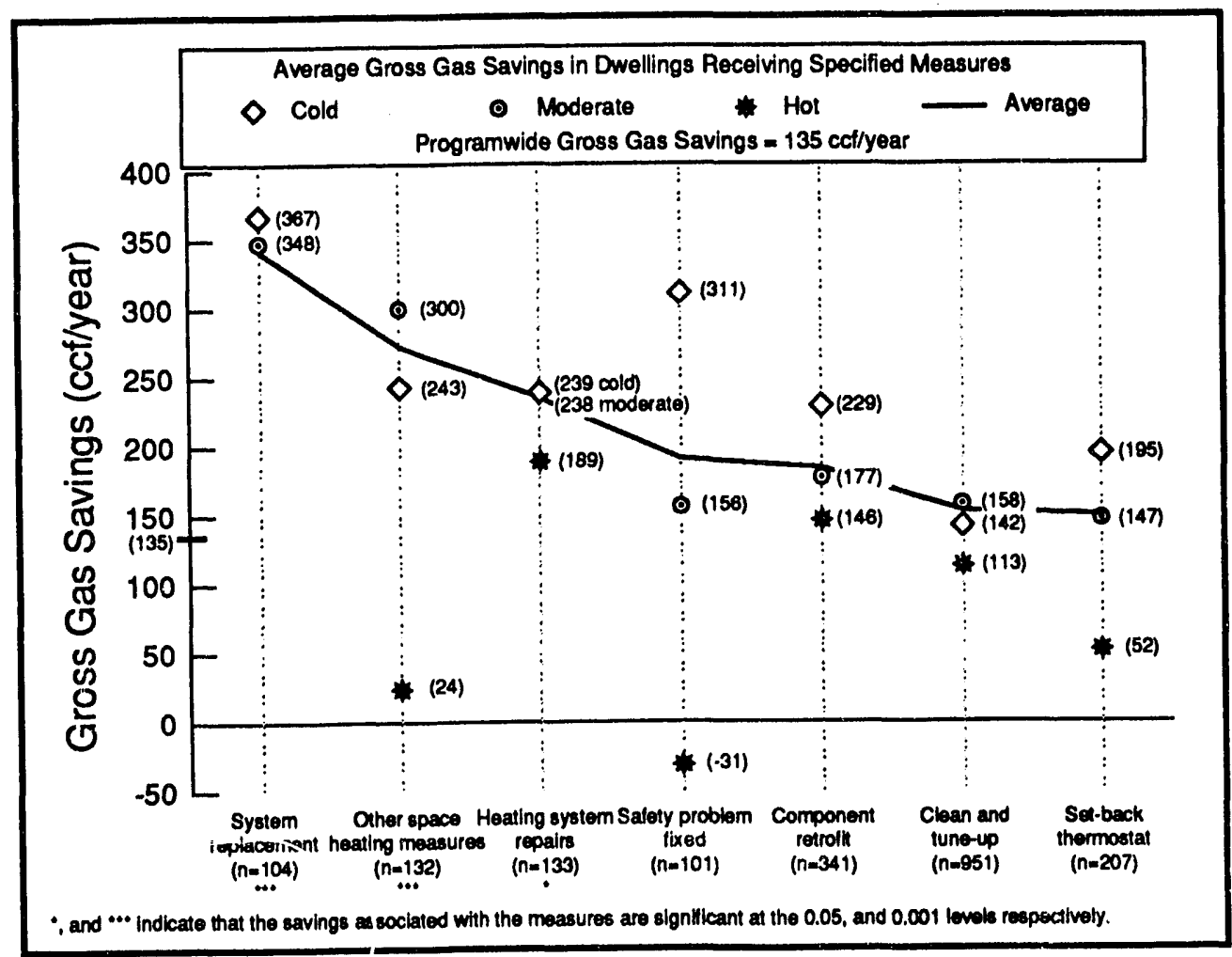

Fig. 9.7 Gas Savings of Dwellings that Received Space-Heating System Measures 
None of these measures emerge as significant in the analysis of the hot region, in part because only $2 \%$ of the dwellings weatherized in that region received a heating-system measure of any type from local weatherization agencies in PY 1989. The most common space-heating system measure in the hot region is the "clean and tune." While the sample size is too small to indicate significance, it is nonetheless interesting that the 36 systems in the hot region that were cleaned and tuned are associated with savings that are $77 \%$ higher than the 399 dwellings in the same region that did not receive this measure.

Heating-system measures are seldom installed in electrically heated dwellings, and as a result they do not correlate with high savings in these homes.

Mobile Home Measures. None of the mobile-home measures shown in Fig. 9.8 are associated with significantly greater-than-average savings. This is consistent with the minimal gas and electricity savings achieved by mobile homes, in general. It must also be noted, however, that the mobile-home measures examined here are used infrequently. As a result, our sample sizes are limited, and statistical significance is difficult to achieve. Recall that the two most common measures applied by local weatherization agencies to mobile homes during PY 1989 are general caulking and weatherstripping, and storm windows (Table 4.1). These measures are associated with average, or below average, savings.

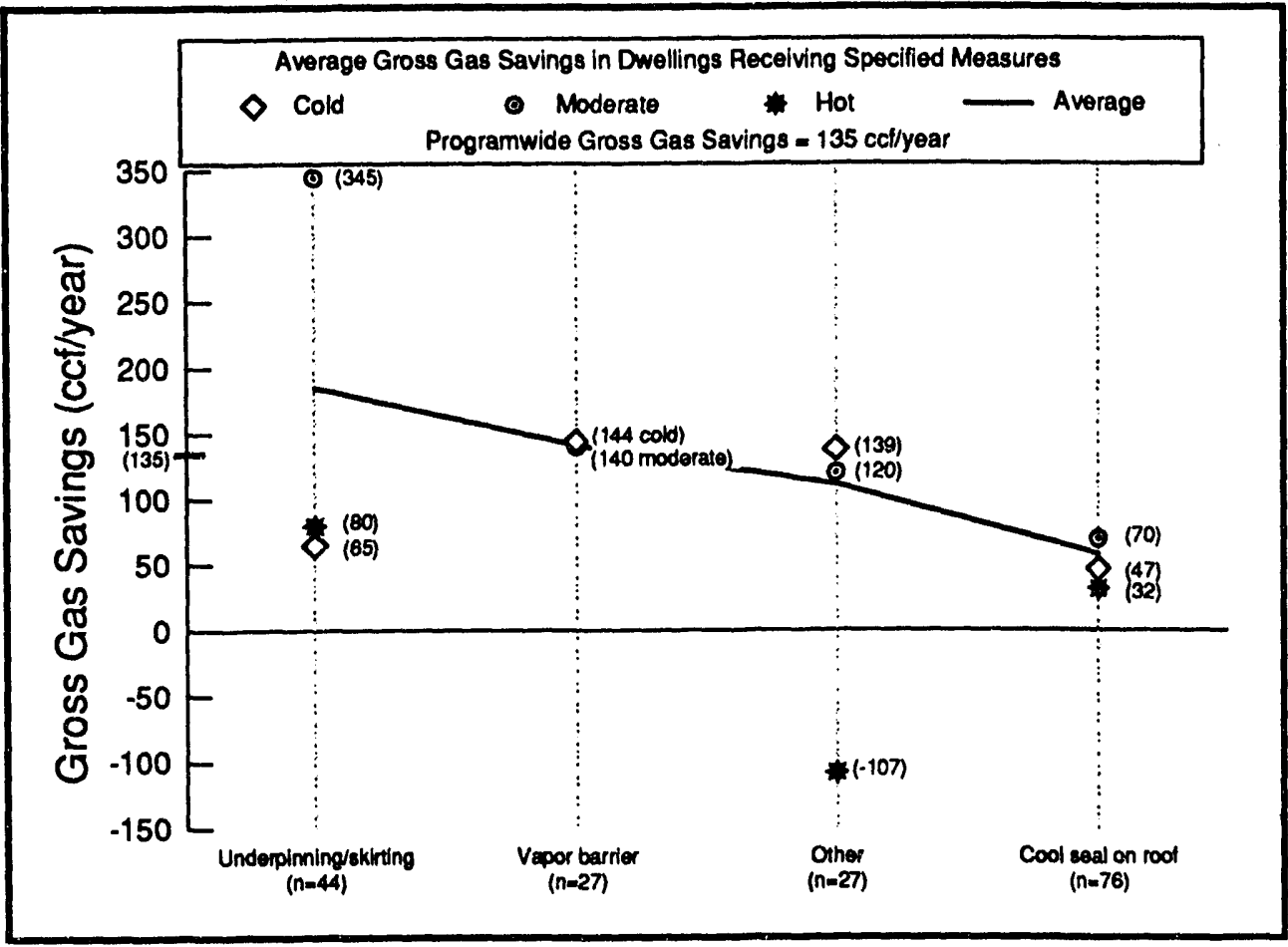

Fig. 9.8 Gas Savings of Dwellings that Received Mobile Home Measures 
A larger sample and more refined data collection might have identified a positive savings impact from adding underbelly insulation to mobile homes. Of the 44 mobile homes that received underpinning or skirting, the average gas savings was $185 \mathrm{ccf} / \mathrm{d}$ welling. Interviews with program managers of the agencies that weatherized these dwellings indicate that underbelly insulation (which was checked on the survey form as a type of "underpinning") was added to a majority of these dwellings. Indeed, the agency-level analysis (discussed in Section 9.2) suggests that mobile home underpinning/skirting is correlated significantly with agency savings.

\subsubsection{Service Delivery Procedures}

Just as the use of particular weatherization measures corresponds with high gas savings, so do many service delivery procedures. None of the service delivery procedures studied here, however, correlate significantly with electricity savings (Table 9.3). As a result, the following discussion focuses entirely on gas-heated dwellings.

Client Selection, Investment Criteria, and Measure Selection. None of the methods of selecting clients or determining investment levels is associated with higher-than-average gas savings nationwide (Fig. 9.9). However, determining investment levels based on energy use or estimated savings is almost a significant characteristic of high savers in the moderate region $(p=0.08)$. This method of directing resources takes advantage of the fact that high energy users offer the greatest potential for saving energy.

Among the different audit approaches, dwellings that received an integrated envelope/heating system audit saved significantly more gas - averaging $176 \mathrm{ccf} / \mathrm{d}$ welling. Thus, even though less than $10 \%$ of the dwellings employed this method of selecting weatherization measures in PY 1989, the integrated audit was associated with a significantly high level of savings. This finding supports the value of DOE's decision to develop a national weatherization audit, which features an integrated approach to selecting envelope and space-heating system measures, and DOE's new weatherization rules, which allow the 60-40 rule to be relaxed if an integrated audit is used. It is also consistent with field studies that have documented high savings when an integrated audit is employed (Sharp, 1993; Termes, 1990).

Diagnostic Procedures. The use of several diagnostic procedures is consistently associated with high gas savings. In contrast, use of these diagnostic s has no discernible relationship to electricity savings, in part because many of the diagnostic procedures are not relevant to electric heating systems (see Table 9.3 and Fig. 9.10). 


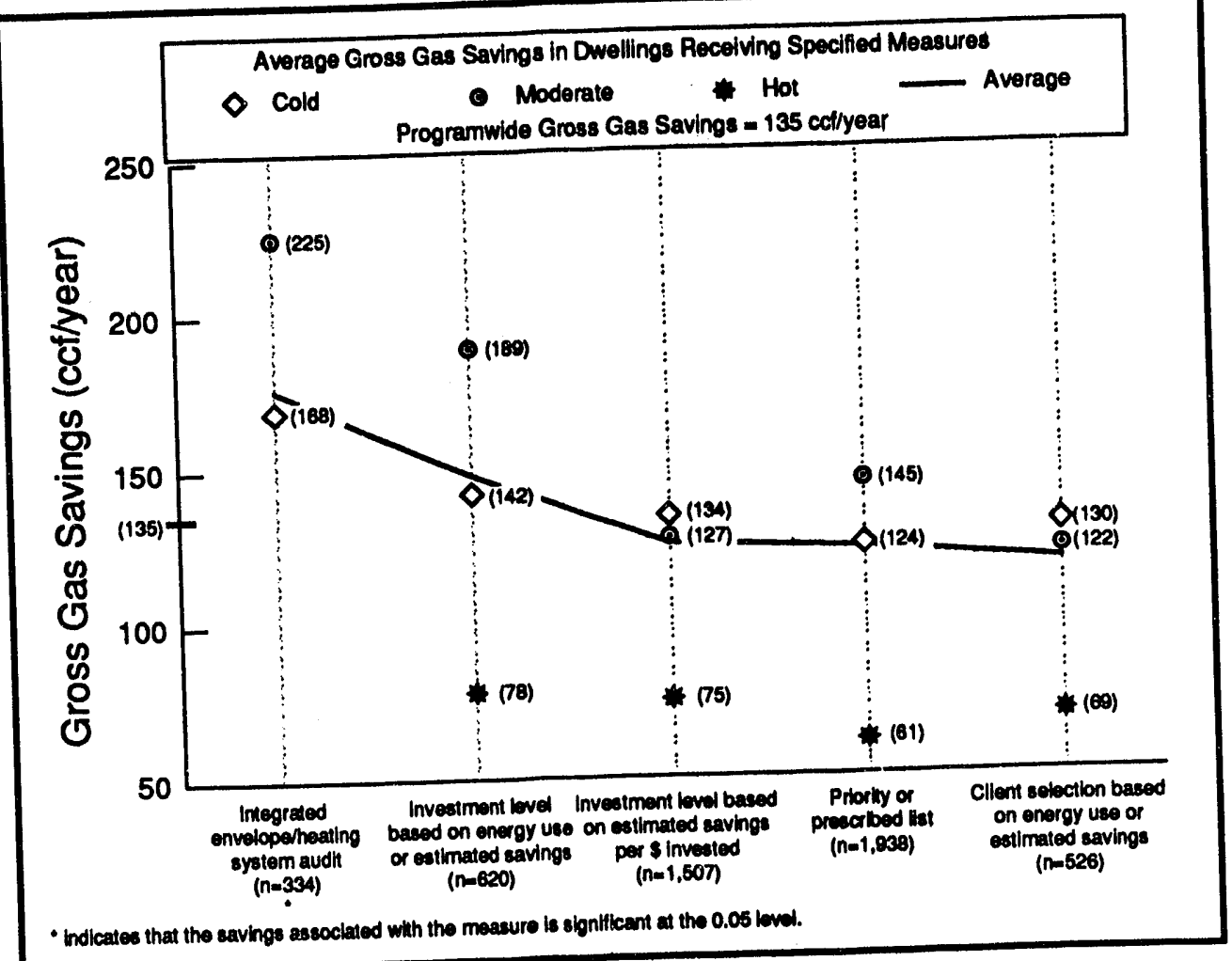

Fig. 9.9 Gas Savings of Dwellings Based on Client Selection, Investment Criteria, and Measure Selection

Distribution system diagnostics for system balancing and to find leaks for sealing are conducted in dwellings with significantly high gas savings of $190 \mathrm{ccf} / \mathrm{year}$. Heating system efficiency tests also are associated with significantly higher-than-average gas savings (152 ccf/year). Since these diagnostics are most common in the cold and moderate climate regions, one would expect the savings of dwellings that receive them to be high. The two-way ANOVA indicates that above and beyond any climate region effect, these three measures are significantly correlated with high savings. In addition, two of these diagnostic procedures are characteristic of high gas savers in the separate analyses of the moderate and cold regions (Table 9.3). (Distribution system diagnostics for system balancing is not significant in the analysis of high/low savers, perhaps because only 129 dwellings received this measures, in total.) Obviously, the application of these diagnostic tools, by themselves, does not save energy. Rather, their use is indicative of agencies that employ advanced procedures for determining the best weatherization measures for individual dwellings.

As occurred in the analysis of blower door-assisted air sealing, the use of blcwer doors for envelope diagnostics is generally associated with average savings. Since blower doors are rarely used as diagnostic tools in the hot region, ceteris paribus, the national analysis of gas savings should have uncovered a correspondence between blower door diagnostics and higher savings, but this is not the case. Further, the two-way ANOVA does not detect any significant correlation with savings after accounting for climate region differentials (Table 9.3). 


\section{Table 9.3 Factors Associated with High Gas and Electricity Savings: Service Delivery Procedures}

\begin{tabular}{|c|c|c|c|c|}
\hline \multirow[b]{2}{*}{$\begin{array}{l}\text { Tyoe of Service } \\
\text { Delivery } \\
\text { Procedures }\end{array}$} & \multicolumn{3}{|c|}{ Cas-Heated Dwellings } & \multirow{2}{*}{$\begin{array}{l}\text { Electrically } \\
\text { oweated }\end{array}$} \\
\hline & clingle Region & $\begin{array}{l}\text { Moderate } \\
\text { Climate Region }\end{array}$ & $\begin{array}{l}\text { Hot Climate } \\
\text { Region }\end{array}$ & \\
\hline $\begin{array}{l}\text { Local Agency } \\
\text { Factors }\end{array}$ & $\begin{array}{l}\text { Small agency (-) } \\
\text { Large Agency } \\
\end{array}$ & $\begin{array}{l}\text { Small agency } \\
\text { Medium agency } \\
\text { Large agency }(-) \\
\text { Contractors-only (-) } \\
\text { Mixed in-house crews } \\
\text { and contractors }\end{array}$ & & \\
\hline Use of Diagnostics & $\begin{array}{l}\text { Heating system } \\
\text { efficiency tests } \\
\text { Heating system safety } \\
\text { test }\end{array}$ & $\begin{array}{l}\text { Distribution system } \\
\text { diagnostics to find } \\
\text { leaks for sealing } \\
\text { Heating system } \\
\text { efficiency tests }\end{array}$ & & \\
\hline Measure Selection & Integrated audit & & & \\
\hline Client Education & & $\begin{array}{l}\text { Client education using } \\
\text { literature }\end{array}$ & & $\begin{array}{l}\text { Client education } \\
\text { using literature (-) }\end{array}$ \\
\hline Cost & $\begin{array}{l}\text { Total direct costs } \\
\text { Total materials costs }\end{array}$ & $\begin{array}{l}\text { Total direct costs } \\
\text { Total materials costs }\end{array}$ & Total direct costs & $\begin{array}{l}\text { Total direct costs } \\
\text { Total materials costs }\end{array}$ \\
\hline
\end{tabular}

(-) Indicates a negative relationship between high savers and service delivery procedure.

Client Education. Approximately two-thirds of the weatherization jobs during PY 1989 included the provision of energy-conservation literature to the low-income client (Table 4.5). Clients who received literature saved an equivalent amount of gas as clients who did not (Fig. 9.11). The significance of the interaction term in the two-way ANOVA, however, suggests that there are different relationships across climate regions. Indeed, high gas savers in the moderate region are distinguished by their more frequent use of energy-conservation literature to help educate clients (Table 9.3). In contrast, the 526 cold climate clients that received literature saved only $108 \mathrm{ccf} / \mathrm{year}$, while the 267 cold climate clients that did not receive literature saved much more (186 ccf/year). Similarly, the delivery of client education using literature is characteristic of low electricity savings (Table 9.3). 


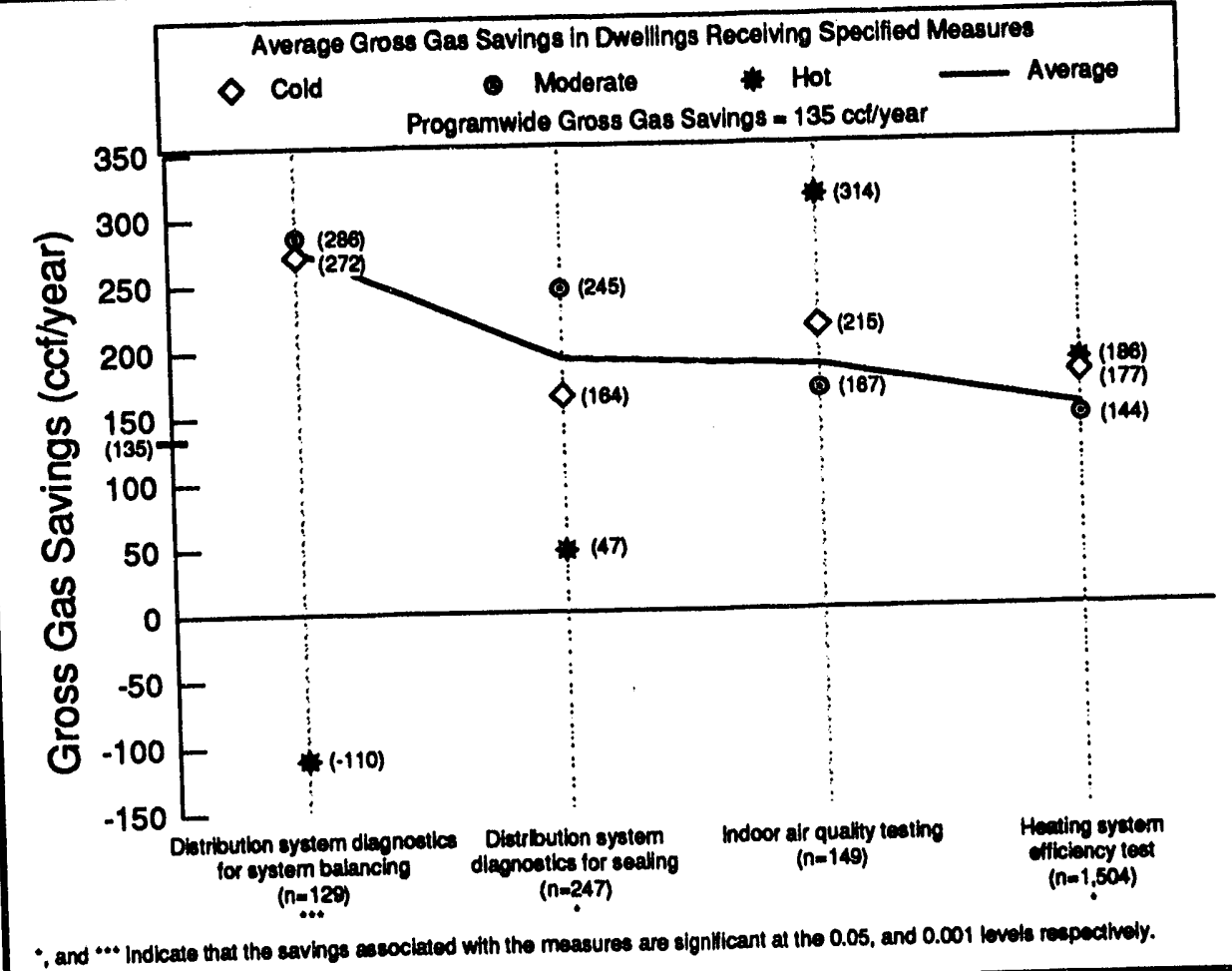

Fig. 9.10a Gas Savings of Dwellings that Used Particular Diagnostic Procedures

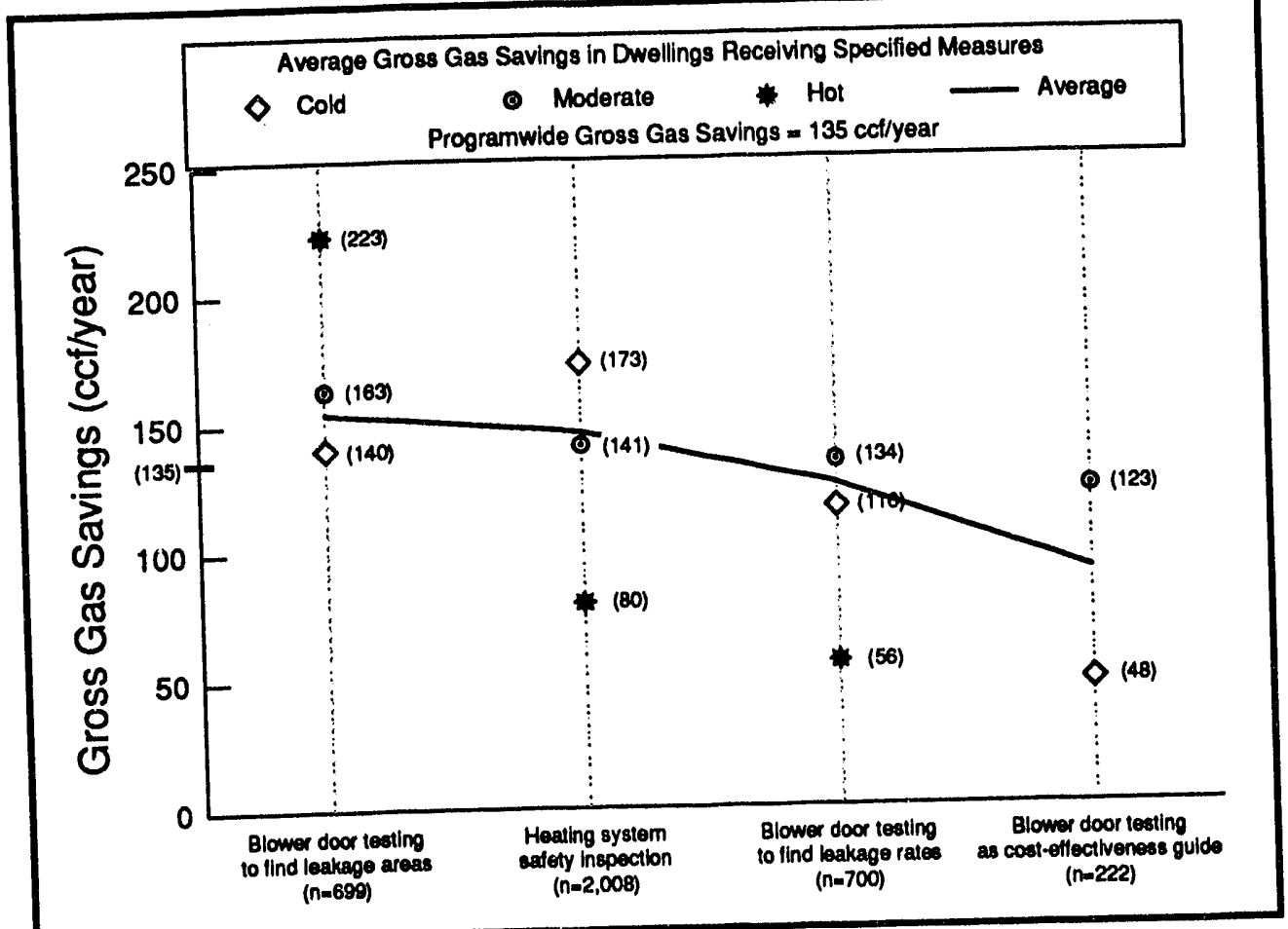

Fig. 9.10b Gas Savings of Dwellings that Used Particular Diagnostic Procedures 


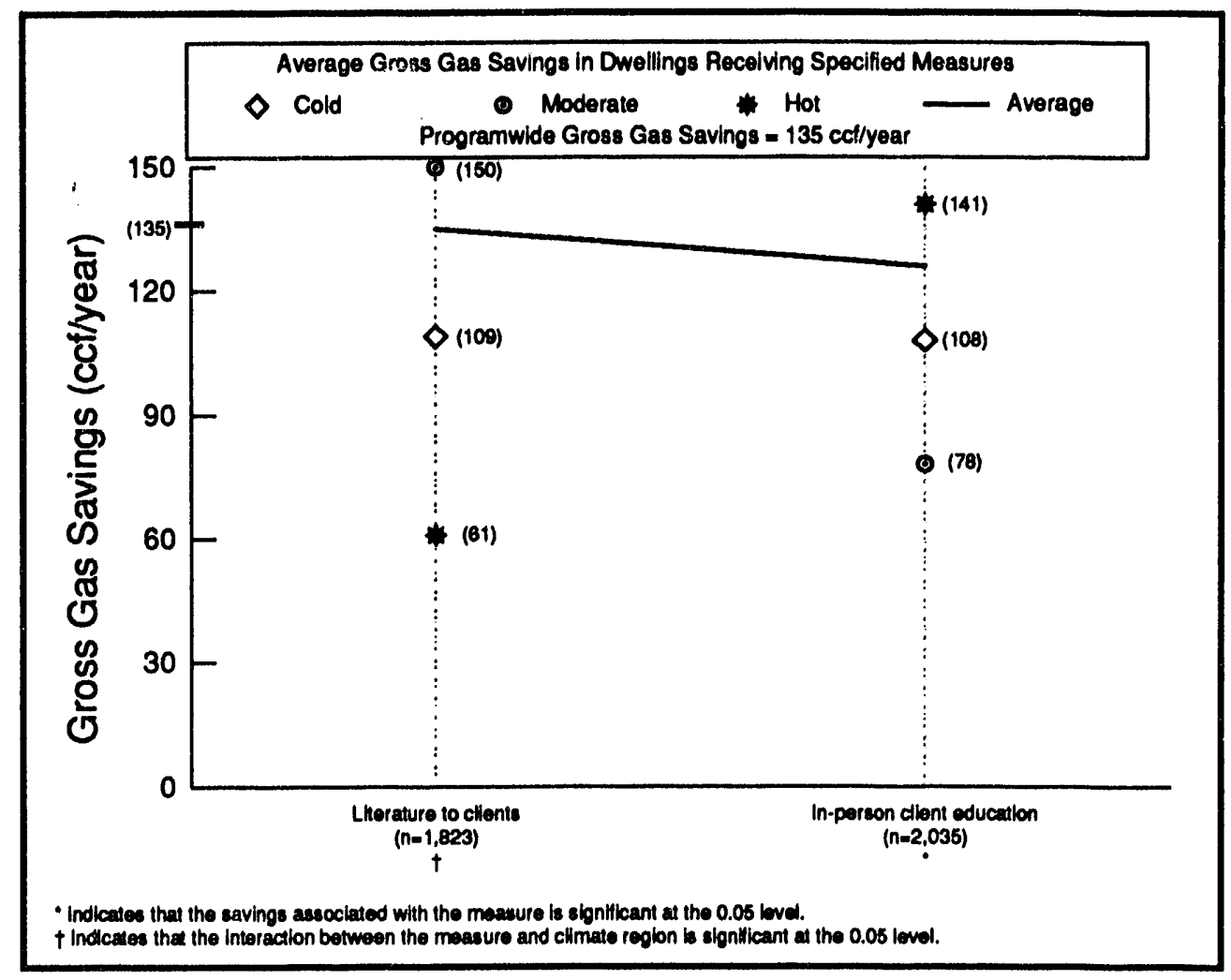

Fig. 9.11 Gas Savings of Dwellings that Used Client Education Procedures

More than three-quarters of the dwellings that were weatherized during PY 1989 received inperson client education (76\%). The 2,035 houscholds that received in-person client education saved $126 \mathrm{ccf} /$ year, while the 567 households that did not, saved significantly more (169 ccf/year). The two-way ANOVA indicates that the negative correlation remains after controlling for any climate region differentials. This finding suggests that local agencies may not be fully exploiting the potential of client education, or that is too confounded with other factors to see any effect.

Weatherization Costs. There is a strong relationship between savings and weatherization costs - both total direct costs and total materials costs (Fig. 9.12). Total direct costs of $\$ 1,500$ or greater are associated with savings that exceed $250 \mathrm{ccf} / \mathrm{year}$, and the same level of savings is associated with total materials costs of $\$ 1,000$ or greater. Interestingly, total direct costs between $\$ 1,000$ and $\$ 1,500$ are associated with approximately the same savings (120 to $130 \mathrm{ccf} / \mathrm{year})$ as dwellings with considerably lower costs. In contrast, the four increasing calcgories of material costs shown in Fig. 9.12 are each associated with increasing gas savings.

The close association between weatherization costs and savings is corroborated by the comparison of high and low energy savers (Table 9.3). High gas savers are characterized by high 
weatherization expenditures within each of the three climate regions. High expenditures are also characteristic of high electricity savers.

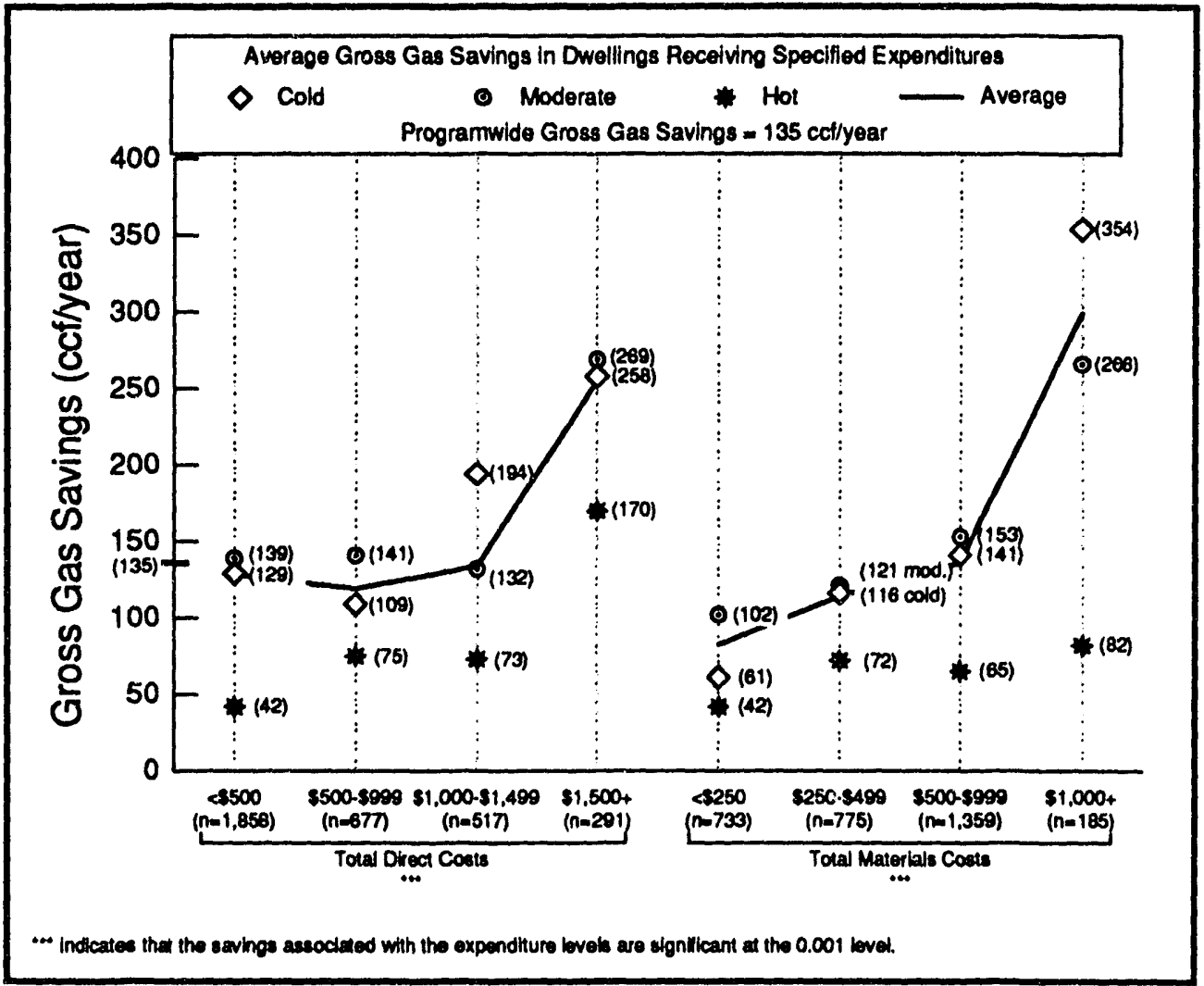

Fig. 9.12 Gas Savings of Dwellings with Different Levels of Weatherization Costs

\subsection{AGENCY-LEVEL ANALYSIS}

The agency-level analysis is based on 97 agencies for which gross gas savings are available for at least 10 dwellings they weatherized in PY 1989. These 97 agencies include 32 local agencies from the cold region, 49 from the moderate region, and 16 from the hot region. Consistent with the dwelling-level analysis, agencies from the hot region are disproportionately represented by the lower end of the savings scale (Fig. 9.13). The total number of dwellings involved in this analysis is 2,921.

The average gross savings of these agencies ranges from $-118 \mathrm{ccf} / y e a r$ to $530 \mathrm{ccf} / \mathrm{year}$, with a mean value of $141 \mathrm{ccf} /$ year (Fig. 9.13). The median is somewhat smaller (125 ccf/year) reflecting the distribution's positive skewness -3 agencies have extremely high average savings, ranging from 400 to $530 \mathrm{ccf} /$ year, while 12 agencies have modestly negative average savings, ranging from -1 to -118 ccf/year. 


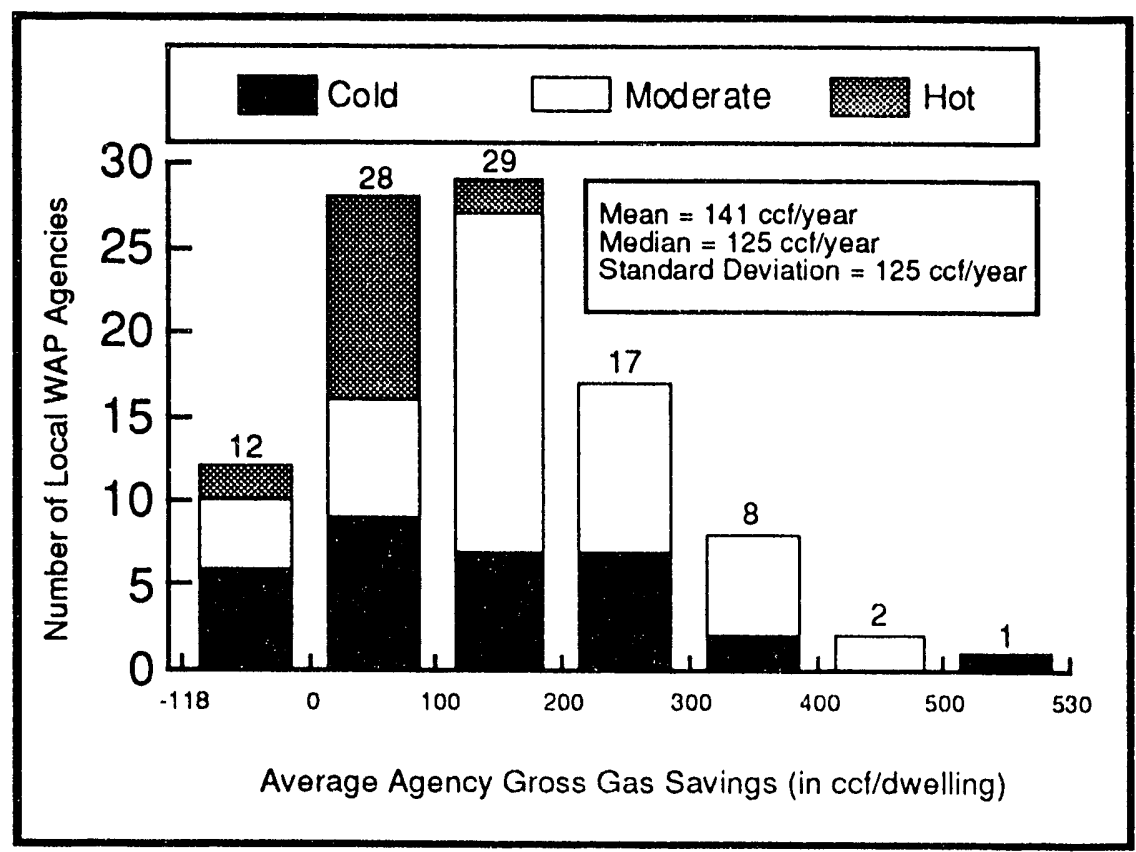

Fig. 9.13 Average Gas Savings of 97 Local Weatherization Agencies

Figure 9.14 shows the distribution of pereent gross gas savings for the same 97 agencies. Gross gas savings as a percent of pre-weatherization gas consumplion range from $-7.8 \%$ to $32.2 \%$, with a mean and median of $10.9 \%$. Agencies from the three climate regions are distributed quite evenly across the full range of percent savings, unlike the histogram of gross savings in ccf/year. This reflects the lower levels of pre-weatherization gas consumption in the hot region.

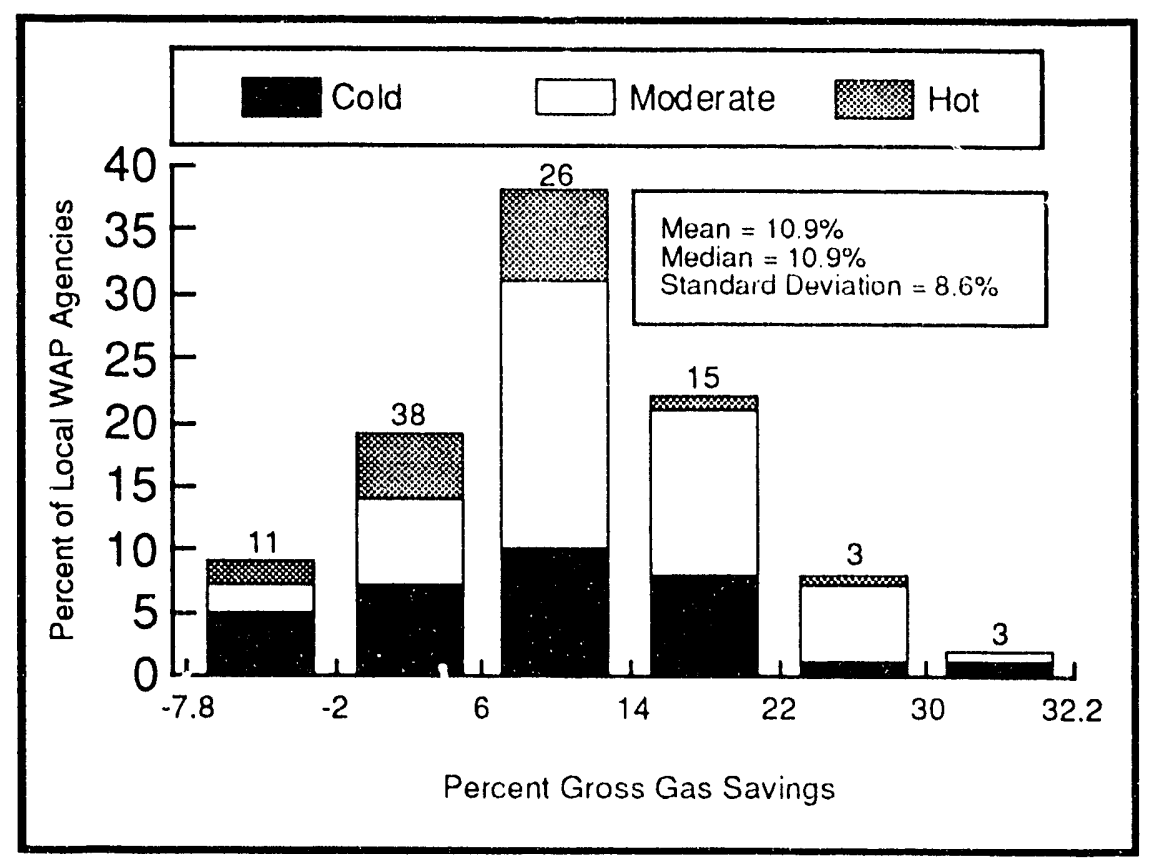

Fig. 9.14 Average Percent Gas Savings of 97 Local Weatheriation Agencies 
Figure 9.15 presents the benefit/cost ratios of the same 97 local agencies. Benefit/cost ratios range from -0.61 to 4.45 , with a mean of 0.99 and a median of 0.77 .7

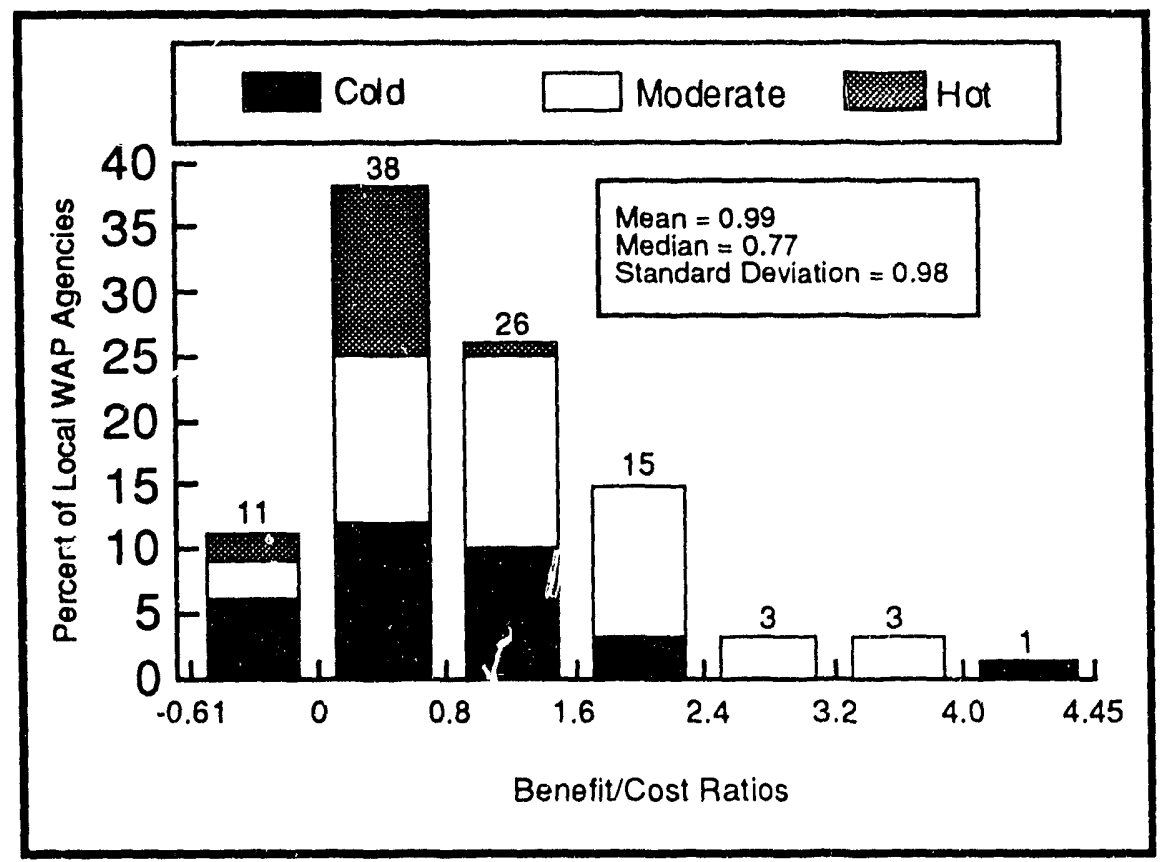

Fig. 9.15 Average Benefit/Cost Ratio of 97 Local Weatherization Agencies

Agency-level mean values were calculated for the full range of possible predictors of energy savings discussed in Section 9.1. Multiple regression analysis was then used to predict each of the three measures of program performance: mean gas savings, percent gas savings, and benefit/cost ratio.

As we have noted above and throughout this report, interpreting the role of individual predictors of savings is complicated by the fact that these predictors tend to occur in clusters. For instance, interpreting the role of the size and age of dwellings is confused by the fact that the colder climates (with higher savings) tend to have older and larger dwellings. Similarly, interpreting the impact of houschold composition on savings is complicated by the fact that the hot climate region (with lower savings) tends to serve more handicapped and elderly clients.

One way to sort out the impact of individual predictors is through multivariate regression analysis. Ordinary least-squares regression modeling was decmed appropriate, with forward stepwise inclusion of independent variables with partial F-statistics that are significant at the 0.05 level. The agency-level data appear to meet all of the modeling requirements of ordinary least-squares

? Recail uiai these distributions are unweighted tand are not the best estimate of programwide cost effectiveness, which for gas dwellings weatherized in PY 1989 is estimated to be 1.06, using the program perspective. 
regression. The results are presented in Table 9.5 (for gas savings), Table 9.6 (for percent gas savings), and Table 9.7 (for cost effectiveness).

Table 9.5 Regression Analysis of Average Agency Gas Savings Per Weatherized Dwelling

\begin{tabular}{|c|c|c|c|c|}
\hline \multicolumn{5}{|l|}{$\begin{array}{l}\text { Dependent Variable-Average } \\
\text { Agency Gross Gas Savings (in } \\
\text { ccf/year per weatherized dwelling) }\end{array}$} \\
\hline Predictor: & $\begin{array}{l}\text { Unstandardized } \\
\text { Regression } \\
\text { Coefficient }\end{array}$ & $\begin{array}{l}\text { Standard } \\
\text { Error }\end{array}$ & $\mathrm{T}$-value & $\begin{array}{l}\text { Standardized } \\
\text { Regression } \\
\text { Coefficient }\end{array}$ \\
\hline Intercept & -177 & 36.9 & $-4.81 * * *$ & 0.000 \\
\hline Pre-NAC & 0.156 & $0 . v 24$ & $6.42 * * *$ & 0.176 \\
\hline Normal wall insulation & 155 & 33.6 & $4.61 * * *$ & 0.303 \\
\hline $\begin{array}{l}\text { Distribution system diagnostics for } \\
\text { system balancing }\end{array}$ & 235 & 42.0 & $5.60 * * *$ & 0.342 \\
\hline Other envelope insulation & 228 & 54.9 & $4.16 * * *$ & 0.251 \\
\hline Underpinning/skirting & 371 & 135.7 & $2.74 * *$ & 0.160 \\
\hline Structural repairs to walls & 288 & 66.4 & $4.34 * * *$ & 0.265 \\
\hline Low-flow showerhead & 144 & 42.8 & $3.35 * *$ & 0.197 \\
\hline Large agency & -48 & 21.4 & $-2.22 *$ & -0.145 \\
\hline $\begin{array}{l}\text { Blower door testing to determine } \\
\text { cost effectiveness }\end{array}$ & -146 & 37.4 & $-3.89 * * *$ & -0.284 \\
\hline $\begin{array}{l}\text { Blower door testing to measure } \\
\text { air leakage }\end{array}$ & 78 & 26.2 & $2.97 *$ & 0.234 \\
\hline Package of measures $\# 3^{a}$ & -577 & 1,917 & $-3.01 *$ & -0.189 \\
\hline Attic insulation-first time & 105 & 38.9 & $2.69 * *$ & 0.176 \\
\hline Mobile home & 166 & 48.5 & $3.42 * * *$ & 0.228 \\
\hline Package of measures \#6 $\mathrm{b}$ & -163 & 64.7 & $-2.52 *$ & -0.164 \\
\hline $\begin{array}{l}\text { Coefficient of Determination }\left(R^{2}\right. \\
\text { Adjusted Coefficient of Determin } \\
\text { F-Value }=16.7^{* * *} \\
\text { Sample Size }=97\end{array}$ & $\left(R^{2}\right)=0.70$ & & & \\
\hline
\end{tabular}

$*, * *$, and $* * *$ indicate significance at a $0.05,0.01$, or 0.001 level, respectively.

a Includes only air leakage control.

b Includes the following: air leakage control, water heater measures, and windows and doors. 
Each of the regression analyses is able to explain between one-half and three-quarters of the variance in its dependent variable, and is therefore very powerful. The models are also highly significant (at 0.001 ) and include between 7 and 14 significant predictors.

Table 9.6 Regression Analysis of Average Agency Percent Gas Savings

\begin{tabular}{|c|c|c|c|c|}
\hline \multicolumn{5}{|l|}{$\begin{array}{l}\text { Dependent Variable= Average } \\
\text { Agency Percent Gas Savings }\end{array}$} \\
\hline 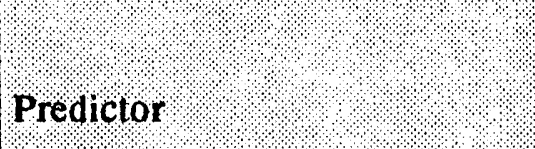 & $\begin{array}{l}\text { Unstandardized } \\
\text { Regression } \\
\text { Coefficient }\end{array}$ & Standard & T-value & $\begin{array}{l}\text { Standardized } \\
\text { Regression } \\
\text { Coefficient }\end{array}$ \\
\hline Intercept & -3.4 & 2.22 & -1.51 & 0.00 \\
\hline Nomial wall insulation & 13.6 & 2.54 & $5.34 * * *$ & 0.388 \\
\hline Other envelope insulation & 17.3 & 5.05 & $3.42 * * *$ & 0.277 \\
\hline Low flow showertheads & 13.3 & 3.70 & $3.59 * * *$ & 0.266 \\
\hline Other structural repairs & 16.9 & 6.77 & $2.50 *$ & 0.184 \\
\hline Vapor barrier & 28.0 & 12.70 & $2.21 *$ & 0.159 \\
\hline Underpinning/skirting & 56.9 & 11.45 & $4.97 * * *$ & 0.357 \\
\hline Clean and tune-up & 7.4 & 2.16 & $3.43 * * *$ & 0.263 \\
\hline Prionity or prescribed list & -14.8 & 7.07 & -2.10 & -0.170 \\
\hline $\begin{array}{l}\text { Blower door testing to measure } \\
\text { air leakage rates }\end{array}$ & -8.0 & 2.73 & $-2.94 * *$ & -0.228 \\
\hline $\begin{array}{l}\text { Distribution system diagnostics } \\
\text { for system balancing }\end{array}$ & 12.7 & 3.37 & $3.76 * * *$ & 0.269 \\
\hline No change of occupancy & 6.2 & 2.31 & $2.70 * * *$ & 0.200 \\
\hline $\begin{array}{l}\text { Coefficient of Determination } \\
\text { Adjusted Coefficient of Deter } \\
\text { F.Value }=1.07 * * * \\
\text { Sample Size }=97\end{array}$ & $\left(\mathbf{R}^{2}\right)=0.53$ & & & \\
\hline
\end{tabular}

$*, * *$, and $* * *$ indicate significance at a $0.05,0.01$, or 0.001 level, respectively.

The first predictor that entered into the stepwise regression analysis of average agency gas savings is pre-NAC, emphasizing once again the overwhelming importance of this factor. Its regression coefficient suggests that for every increase of $1 \mathrm{ccl} / \mathrm{ycar}$ in pre-weatherization gas use, gas savings increases by $0.156 \mathrm{ccf} /$ year. Pre-NAC is also a significant predictor of cost effectiveness (Table 9.7). 
Table 9.7 Regression Analysis of Average Agency Percent Cost Effectiveness

\begin{tabular}{|c|c|c|c|c|}
\hline \multirow{2}{*}{$\begin{array}{l}\text { Dependent Variable=Average } \\
\text { Agency BenefiuCost Ratio (Societal) }\end{array}$} & \multirow{2}{*}{\multicolumn{2}{|c|}{$\begin{array}{l}\text { Unstandardized } \\
\text { Regression } \\
\text { Coefficient }\end{array}$}} & \multirow[b]{2}{*}{$\mathrm{T}$-value } & \multirow[b]{2}{*}{$\begin{array}{l}\text { Standardized } \\
\text { Regression } \\
\text { Coefficient }\end{array}$} \\
\hline & & & & \\
\hline Intercept & -1.52 & 0.28 & $-5.48 * * *$ & 0.000 \\
\hline Attic insulation-first time & 1.49 & 0.31 & $4.79 * * *$ & 0.318 \\
\hline Norrial wail insulation & 1.12 & 0.28 & $4.02 * * *$ & 0.279 \\
\hline Setback thermostat & 2.28 & 0.88 & $2.59 *$ & 0.190 \\
\hline Other heating system modifications & 1.39 & 0.49 & $2.82 *$ & 0.185 \\
\hline Integrated audit & 0.58 & 0.21 & $2.73 * *$ & 0.177 \\
\hline Pre-NAC & 0.00070 & 0.00020 & $3.52 * * *$ & 0.249 \\
\hline Package of measures \# Ia & 1.15 & 0.25 & $4.59 * * *$ & 0.336 \\
\hline Total materials cost & 0.00101 & 0.00031 & $3.25 * *$ & 0.210 \\
\hline \multicolumn{5}{|c|}{$\begin{array}{l}\text { Coefficient of Deternination }\left(R^{2}\right)=0.66 \\
\text { Adjusted Coefficient of Determination }\left(R^{2}\right)=0.63 \\
\text { F Value }=21,0 * * * \\
\text { Sample Size }=97\end{array}$} \\
\hline
\end{tabular}

$*, * *$, and $* * *$ indicate significance at a $0.05,0.01$, or 0.001 level, respectively.

a This is a miscellaneous package of relatively uncommon combinations of measures that did not receive insulation. Eighty-five percent of the households receiving this package had some combination of the following installed: air lcakage control, insulation, water heater measure, windows and doors, and space-heating system measure.

Once the impact of pre-NAC on savings is taken into account in the model described in Table 9.5, large agencies tend to save less, and agencies that serve high percentages of mobile homes achieve higher-than-average gas savings. Agencies that scrve dwellings with low rates of household turnover also save more.

The regression models include many of the weatherization measures that have been highlighted already as contributing to high gas savings, in particular:

- attic insulation (first time) and wall insulation

- low-flow showerheads

- mobile home underpinning/skirting

- distribution system diagnostics for system balancing 
- integrated audits.

In contrast, blower door testing to determine cost effectiveness and the use of priority or prescribed lists to select clients enter the regression model with negative coefficients, indicating that agencies that use either of these measures in a high proportion of their weatherized dwellings consistently experience lower-than-average savings.

\subsection{SUMMARY}

This chapter's analysis of factors influencing energy savings was multifaceted: (1) it examined the savings of individual dwellings and the average savings of different agencies; (2) it examined absolute savings as well as percent savings and benefit/cost ratios; (3) it employed both bivariate and multivariate analytic techniques; and (4) it examined the predictors of performance in each of three climate regions and nationwide. The different approaches produced a consistent portrayal of the major predictors of energy savings.

The analysis indicates that energy savings per dwelling are largest in the Program's dominant submarkets, where weatherization activity is concentrated. These include:

- cold and moderate climate regions; and

- single-family detached homes.

Partly because of small sample sizes, few additional predictors of clectricit savings were identified. These include pre-NAC and first-time attic insulation. In contrast, our analy:sis identified numerous predictors of gas savings.

Certain service delivery procedures correspond with higher-than-average gas savings, including:

- weatherization of high energy users;

- integrated envelope/heating system audit;

- distribution system diagnostics; and

- heating system efficiency tests.

In contrast, the energy-savings benefits of blower-door assisted air sealing and client education were not discernible.

Certain weatherization measures correspond with higher-than-average gas savings, including:

- distribution system air leakage control;

- air sealing without blower doors;

- heating system replacement;

- attic insulation (particularly first-time); 
- wall insulation (particularly high density);

- floor insulation;

- water heater tank insulation, pipe insulation and temperature reduction;

- furnace replacements; and

- mobile home underpinning or skirting.

In contrast, the energy-savings benefits of storm windows could not be detected.

Many of these findings are consistent with the results of previous research. The two findings that are least substantiated by other research are the apparent key role of distribution system diagnostics and air leakage control, and the questionable energy-savings benefits of blower-door assisted air sealing.

Clearly, more analysis is needed to understand these findings and to employ them as a basis for policy and program recommendations. This will be the subject of the Single-Family Study's onsite field work. 


\section{SUMMARY AND CONCLUSIONS}

This chapter summarizes the findings of the Single-Family Report (Sections 10.1 through 10.7) and offers several recommendations for future operation of the Weatherization Assistance Program (Section 10.8).

\subsection{DESCRIPTION AND CHARACTERIZATION OF THE SAMPLE 10.1.1 Characteristics of Weatherized Dwellings and Key Subgroups}

The analysis of weatherized dwellings underscores the existence of great diversity in the types of occupants and single-family and small multifamily buildings that received DOE weatherization services during PY 1989. The dominant markets are clear: most weatherized dwellings are singlefamily detached $(64 \%)$, owner-occupied $(66 \%)$, are located in the moderate climate region (59\%), have central heating systems (68\%), and heat with natural gas (51\%). On the other hand, the PY 1989 weatherized dwellings also include mobile homes $(20 \%)$, dwellings that heat primarily with non-utility fuels such as liquid propane gas (13\%) and wood (6\%), and households with elderly occupants (36\%) and persons with disabilities (24\%).

There are significant geographic differences in the demographic and housing characteristics of the Program's clients. Key differences by climate region are:

- Cold Climate: highest household incomes, highest incidence of central heating and owner-occupancy.

- Moderate Climate: predominantly heated by natural gas, highest percentage of small multifamily homes.

- Hot Climate: highest percentage of mobile homes, smaller and newer homes, relatively few central heating systems, more supplemental fuels, high percentage of homes with elderly or handicapped occupants.

Similarly, dwelling and occupant traits vary markedly across primary heating fuels.

- Dwellings Heated by Natural Gas: vast majority have central heating systems, older homes than average, many small multifamily dwellings, few mobile homes.

- Dwellings Heated by Electricity: relatively few central heating systems, more air conditioning equipment, newer than average.

- Dwellings Heated by "Other" Fuels: about half have central heating systems, high percentage use supplemental heating fuels, many mobile homes.

Dwelling and occupant traits also vary by type of dwelling.

- Single-family Detached Dwellings: largest household sizes, highest incidence of elderly and handicapped occupants, more reliance on supplemental fuels. 
- Single-family Attached Dwellings: high incidence of central heating, limited use of supplemental fuels, oldest dwellings, highest income occupants.

- Mobile Homes: smallest and newest dwellings, greatest home ownership, limited gas heat.

- Small Multifamily Dwellings: heat primarily with natural gas, largest dwellings, lowest level of home ownership, fewest elderly.

These differences are key to understanding the performance, challenges, and opportunities of the Program.

\subsubsection{Comparison of Weatherized and Eligible Populations}

Definitions of income eligibility for the Program vary among the States, but generally range from $125 \%$ to $150 \%$ of the federal poverty level. ${ }^{1}$ Program participants and the eligible population have somewhat different profiles when eligibility is defined as $125 \%$ of poverty. Because the Program tends to serve the needier part of the low-income sector, these differences are more pronounced when eligibility is defined as $150 \%$ of poverty.

Participants in PY 1989 typically had a lower average income than the Program-eligible population (Fig. 10.1) They also resided in smaller and older homes. In addition, weatherized dwellings had fewer electric heating systems and relied more on non-utility fucls, such as fuel oil, propane, kerosene, wood, and coal, than the eligible population. These findings characterize a program that directs its resources towards the more economically disadvaniaged portion of the lowincome population.

Participants in PY 1989 were more concentrated in the cold and moderate climate regions than the eligible population, reflecting the higher funding levels of States with colder climates. The weatherized dwellings also included higher proportions of mobile homes and lower proportions of single-family attached and small multifamily dwellings than the eligible population. This is the case even though (1) mobile homes are most prevalent in the hot region (which receives disproportionately less funding relative to its low-income population), and (2) single-family attached and small multifamily dwellings are most prevalent in the moderate and cold climate regions (which receive disproportionately more funding). Thus, there appears to be a programwide tendency to serve mobile homes at higher rates, and small multifamily and attached single-family dwellings at lower rates than their proportions in the eligible population.

1 Some States use $125 \%$ of the federal poverty level as the Program eligibility threshold, while others use $150 \%$ of the poverty level. Other definitions, such as $60 \%$ of the State's median income, also may be used. Because of the varying State definitions, the Program-eligible population actually has a mean income that is somewhere between $125 \%$ and $150 \%$ of the poverty level. 


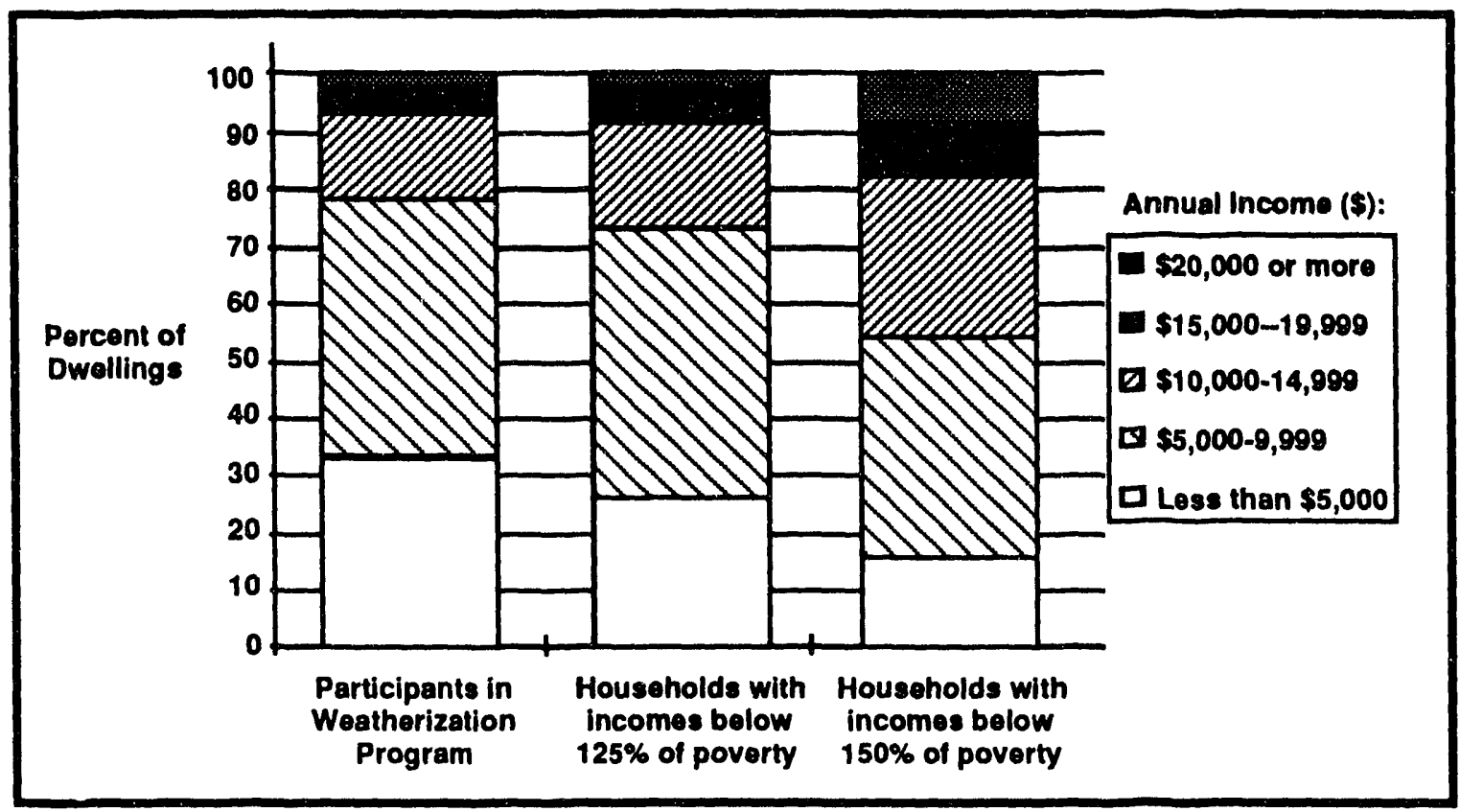

Fig. 10.1 Income Distribution of Program Participants and Eligible Households.

In general, the average proportion of dwellings with an elderly occupant is about the same in the two populations. Weatherization agencies located in the hot climate region, however, served a disproportionately large number of elderly clients.

\subsection{DESCRIPTION OF WEATHERIZATION ACTIVITIES}

\subsubsection{National Program Trends over Time}

The cost effectiveness of the Program depends upon selecting the most appropriate measures for each participating house and installing them properly so that each dollar spent on weatherization generates the maximum energy savings. In the early years of the Program, emergency and temporary measures were emphasized, including caulking, weatherstripping, and low-cost/no-cost measures such as plastic window sheets. By the time of the Encrgy Information Administration's evaluation of the 1981 weatherization program, the emphasis had changed to more permanent and effective building envelope measures, such as storm windows and attic insulation. By 1989, spaceheating system measures (such as tune-ups and component retrofits, which were not part of the 1981 Program) were installed in $30 \%$ of the weatherized dwellings (Fig. 10.2). In PY 1989, another new measure - blower door-assisted air sealing - was used in $18 \%$ of weatherization jobs. Storm windows, on the other hand, were installed in a majority of weatherized dwellings in 1981, but were installed in only $36 \%$ of the dwellings weatherized in PY 1989. Insulation was installed in $62 \%$ of the dwellings weatherized in PY 1989 (down slightly from 81\% in 1981), but in PY 1989 it included 
much more sidewall, floor, and duct insulation as opposed to just attic insulation. These trends are consistent with a growing body of research emphasizing the cost effectiveness of furnace retrofits, blower door diagnostics, and insulation; and questioning the ability of storm windows to save energy cost effectively.

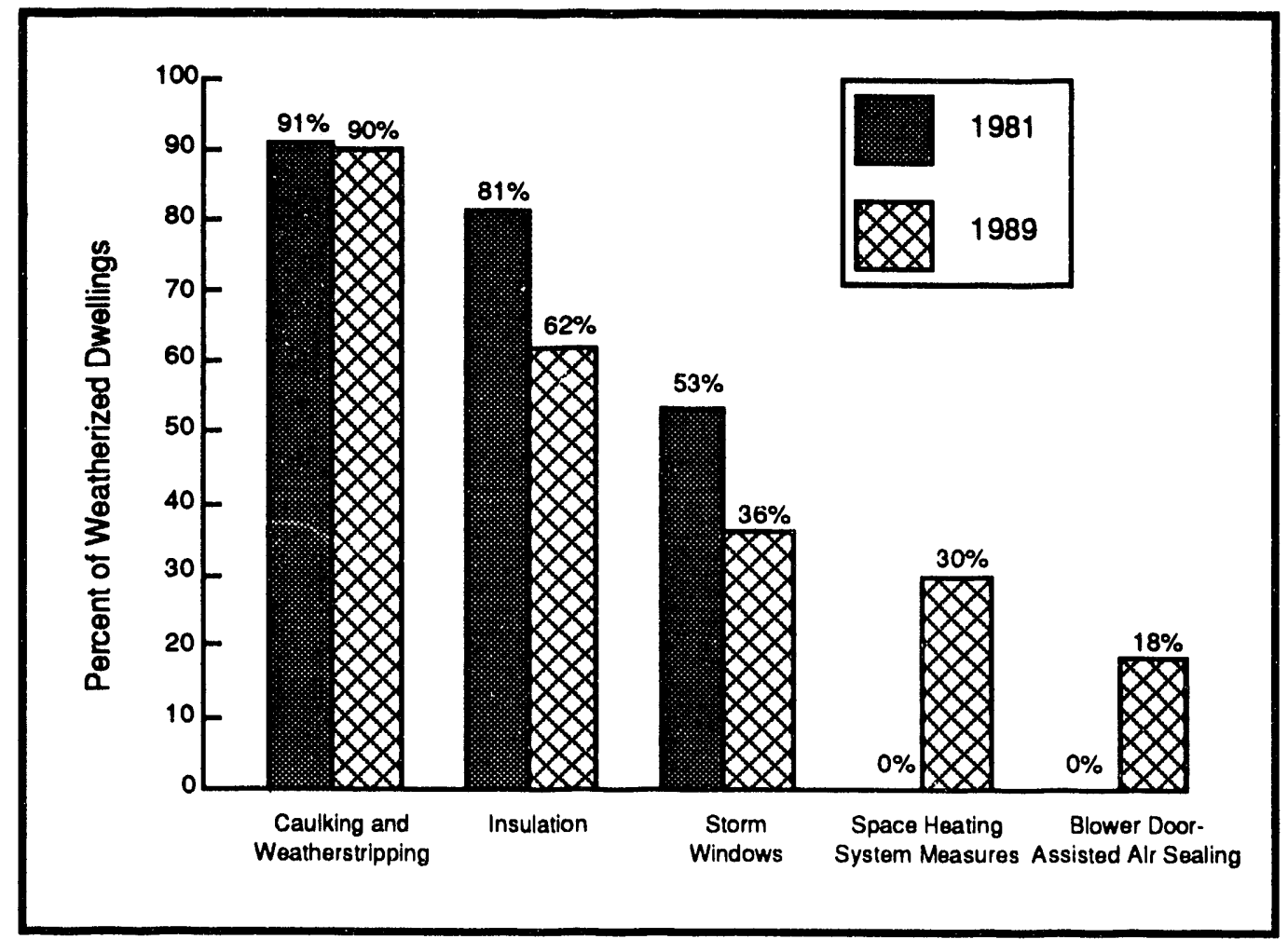

Fig. 10.2 Installation Rates for Selected Weatherization Measures: 1981 and 1989.

The diversity and complexity of weatherization procedures has increased dramatically over the past decade. While many agencies still select their clients on a first come-first served basis, others target clients with greater-than-average potential for cost-effective energy savings. Similarly, investment criteria have been developed that deviate from uniform expenditures per house to allow larger investments in dwellings that offer greater energy-savings opportunities. Program implementers now have a large menu of diagnostic tools to help guide their weatherization. In addition, the Program permits the use of a variety of methods for selecting weatherization measures, which allow measures to be better targeted to the specific needs of individual dwellings than occurs when priority or prescribed lists are used. Recognizing the impact of occupant behavior upon energy consumption, client education has become an integral part of many State and local weatherization programs. Finally, quality control has gone beyond visual inspections during monitoring visits, to include sophisticated measurement and diagnostic procedures. 
Despite the increased use of more sophisticated measures and diagnostic techniques, many advanced measures and service delivery techniques are still not practiced very widely. For example, in 1989, few weatherized dwellings received high-density wall insulation $(2 \%)$, an integrated envelope/heating system audit $(8 \%)$, or distribution system diagnostics to find leakage areas for air sealing (8\%).

\subsubsection{Differences Across Regions, Heating Fuels, and Housing Types}

There was great diversity in the weatherization measures installed and the procedures used during the 1989 Program. Differences across climate regions are particularly pronounced.

- Cold climate region: high installation rates for insulation, water heating, and space heating measures; low installation rates for storm and replacement windows and doors; most frequent use of integrated audits and blower door testing; more space heating diagnostics.

- Moderate climate region: high installation rates for storm windows, space-heating measures, and air leakage control; most heating system diagnostics and dissemination of energy literature.

- Hot climate region: low installation rates for wall insulation and space- and water-heating measures; high installation rates for replacement windows and doors; least frequent use of integrated audits, blower door testing, and space heating diagnostics.

Local weatherization agencies in the cold climate region emphasize many of the measures and procedures that recent literature suggests will produce the best results (such as integrated audits, insulation, space heating and water-heating measures). In contrast, housing rehabilitation measures, which cannot be expected to significantly lower energy usage, are emphasized most by agencies in the hot region, reflecting the more dilapidated condition of the South's housing stock.

Differences in measures installed and procedures used by fuel type were less dramatic, but still significant.

- Gas-heated dwellings: high installation rates for insulation, space- and water-heating measures; low installation rates for mobile home measures; and most frequent use of distribution system diagnostics and air sealing, heating system efficiency tests, and integrated audits.

- Electrically heated dwellings: high installation rates for storm windows; low installation rates for other types of weatherization measures; infrequent use of space-heating diagnostics and integrated audits; and greatest emphasis on client education.

- Dwellings heated by "other" fuels: high installation rates for mobile home measures; low installation rate for water-heater measures; and most frequent use of blower door testing for envelope diagnostics and as a cost-effectiveness guide.

In part, these differences reflect the fact that measures and procedures are in some cases appropriate for certain fuel types but not for others. For example, the most common heating system measures 
and diagnostics are not applicable to electric heating systems. Profiles of weatherization measures and procedures also differ across primary heating fuels because reliance on these fuels differs geographically (e.g., the hot region relies more on "other fuels") and by housing type (e.g., mobile homes are rarely heated by natural gas).

Finally, differences across dwelling types are also apparent.

- Single-family detached homes: high installation rates for insulation, storm windows and doors, and air leakage control; low installation rates for space-heating measures; and most blower door testing.

- Mobile homes: high installation rates for storm windows, underpinning/skirting, and cool seals on roofs; and low installation rates for insulation.

- Single-family attached dwellings: high installation rates for space-heating system improvements, storm windows, and attic insulation; and low installation rates for wall insulation.

- Small multifamily dwellings: high installation rates for water-heater measures and storm windows and doors; greater use of heating system diagnostics, distribution system diagnostics, and integrated audits; and less blower door testing.

Like the cold climate region and gas-heated dwellings, two dwelling types had a high concentration of advanced diagnostic procedures: single-family detached homes and small multifamily dwellings.

The above profiles indicate that there are systematic variations in the diagnostics and measures used to weatherize different types of dwellings. These differences are key to understanding the performance of the Program in its various submarkets.

\subsection{ENERGY SAVINGS}

For both gas- and electrically heated dwellings, the estimation of heating and cooling energy savings involved several steps. First, normalized annual consumption (NAC), which is the amount of energy that would have been consumed in a year with typical weather, was estimated for a preweatherization year (pre-NAC), and a post-weatherization year (post-NAC), for each dwelling with complete consumption data. ${ }^{2}$ Gross savings were estimated by subtracting the average post-NAC from the average pre-NAC for weatherized homes. Net savings were estimated by subtracting the average gross savings for control homes from the average gross savings for weatherized homes. The gross or net percentage savings were calculated by dividing the average gross or net savings by the average pre-NAC.

The energy saved by weatherizing fuel-oil heated homes was based on the results of the FuelOil Study. The energy saved in homes heated by other fuels was based on the analysis of gas-heated homes, with a correction for their different geographic distributions.

2 The Princeton Scorekeeping Method (PRISM) was used to calculate Normalized Annual Consumption. 


\subsubsection{The 1989 Program Results}

Estimates of programwide energy savings are summarized in Table 10.1. On average, each dwelling weatherized in PY 1989 saved an estimated 17.6 MBtu's during its first year after weatherization, ${ }^{3}$ resulting in a $13.5 \%$ reduction in total energy use, an $18.2 \%$ reduction in the energy used for space heating, and an annual decrease of $\$ 116$ in the low-income participant's energy burden.

Table 10.1 1st and 20-Year Energy Savings of Housing Units Weatherized in PY 1989

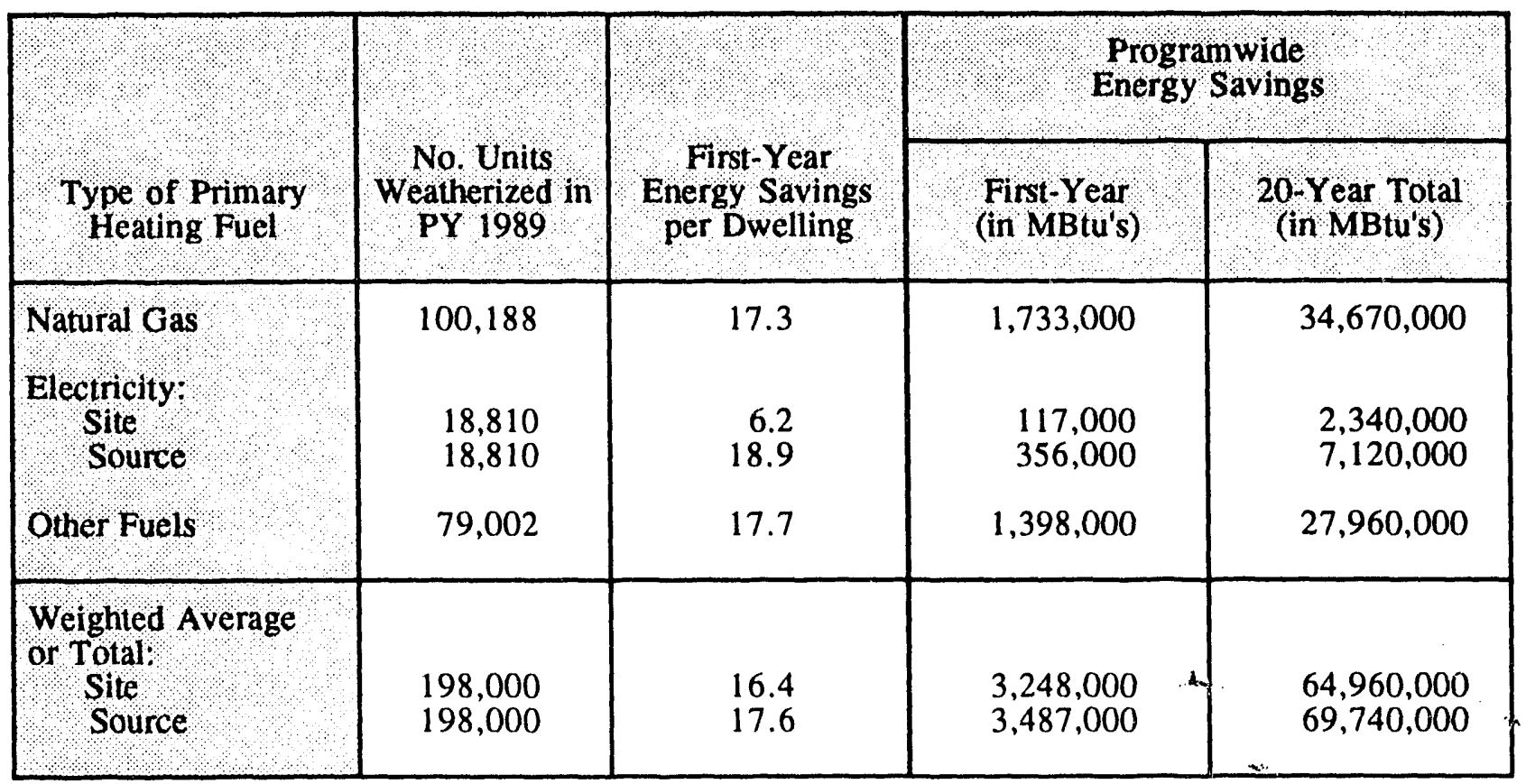

Nationwide, the 1989 Program resulted in annual energy savings of 3,487,000 MBtu's. At an equivalence of 5.8 MBtu's per barrel of oil, this represents 601,000 barrels of oil during 1990-91, or 1,650 barrels of oil per day. Over the 20-year lifetime of the weatherization measures installed in PY 1989,4 it is estimated that the savings from this one year of weatherization will amount to $69,740,000$ MBtu's, or 12 million barrels of oil. This is approximately equal to the amount of oil that was added to the emergency Strategic Petroleum Reserve in 1992.

3 MBtu refers to one million British thermal units.

4 The assumption of an average lifetime of 20 years for all weatherization measures installed in PY 1989 was based on an analysis of: (1) the frequency of installation of various packages of measures, (2) the average lifetime of the energy conservation measures included in each package, aild (3) the measured gas savings of each package. 


\subsubsection{Gas-Heated Dwellings}

Gas-heated dwellings account for $90 \%$ of the 4,299 weatherized dwellings for which fuel consumption records were available, and represent half of the dwellings weatherized by the Program in PY 1989. Thus, their performance dominates the outcome of this evaluation.

This study's weighted estimate of net savings in gas-heated homes is $173 \mathrm{ccf}$ 's or $17.3 \mathrm{MBtu}$ 's. This represents $13.0 \%$ of pre-weatherization gas consumption (Table 10.2). The savings are higher when calculated as a percentage of the gas used for space-heating purposes during the year preceding weatherization. Using this as the denominator for estimating percent net savings, the Program saved an average of $18.3 \%$ of the gas used for space heating.

Table 10.2 Gas Savings in Gas-Heated Dwellings

\begin{tabular}{|l|c|c|c||c|}
\hline $\begin{array}{l}\text { Number of Dwellings } \\
\text { Cold Region }\end{array}$ & $\begin{array}{c}\text { Moderate } \\
\text { Region }\end{array}$ & Hot Region & $\begin{array}{c}\text { Program-wide } \\
\text { Average }\end{array}$ \\
\hline $\begin{array}{l}\text { First-year Gross Savings (in } \\
\text { ccf/dwelling) }\end{array}$ & 1,040 & 2.243 & 590 & 3,873 \\
\hline $\begin{array}{l}\text { First-year Net Savings (in } \\
\text { ccf/dwelling) }\end{array}$ & 235 & 137 & 102 & 135 \\
\hline $\begin{array}{l}\text { Net Savings as Percent of Total } \\
\text { Cas Use }\end{array}$ & $17.7 \%$ & $12.4 \%$ & $10.9 \%$ & 173 \\
\hline $\begin{array}{l}\text { Net Savings as Percent of Gas } \\
\text { Used for Space Heating }\end{array}$ & $24.9 \%$ & $17.5 \%$ & $15.4 \%$ & $18.0 \%$ \\
\hline
\end{tabular}

Net gas savings are highest in the cold region ( $235 \mathrm{ccf} s)$, somewhat lower in the moderate region (182 ccf's), and much lower in the hot region (91 ccf's). Because pre-weatherization gas use is highest in the moderate climate region, net savings as a percent of total gas use for this region $(12.4 \%)$ is much less than in the cold region $(17.7 \%)$. Due to the low level of gas use in the hot region, percent net savings for this region (10.9\%) is only slightly less than in the moderate region. Variations in savings by dwelling type are large and significant for gas-heated dwellings: singlefamily detached dwellings (the dominant dwelling type served by the Program) saved over 50\% more than mobile homes.

\subsubsection{Electrically Heated Dwellings}

Electrically heated dwellings represent $10 \%$ of the dwellings weatherized by the Program during 1989. Thus, they account for a small, but significant fraction of the Program's clients. 
The weighced net savings estimate for the Program nationwide is $1,830 \mathrm{kWh} / \mathrm{year}$ or 6.2 MBtu's/year (at the site) (Table 10.3).5 This represents a $12.2 \%$ reduction in total electricity, a $29.7 \%$ reduction in electricity used for space heating and air conditioning, and a $35.9 \%$ reduction in electricity used for space heating.

Table 10.3 Electricity Savings in Electrically Heated Dwellings

\begin{tabular}{|c|c|c|c|c|}
\hline & Cold Region & Moderate: & 110. Region & Program widerage \\
\hline Number of Dwellings & 35 & 260 & 131 & 426 \\
\hline $\begin{array}{l}\text { First year Gross Savings (in } \\
\text { kWh/dwelling) }\end{array}$ & 1,933 & 939 & 307 & 867 \\
\hline $\begin{array}{l}\text { Finst year Net Savings (in } \\
\text { LWhydwe"'ing) }\end{array}$ & 2,686 & 2,479 & 595 & 1,830 \\
\hline Net Savirigs as Percent of Total & $14.4 \%$ & $14.9 \%$ & $5.4 \%$ & $12.2 \%$ \\
\hline $\begin{array}{l}\text { Net Savings as Percent of } \\
\text { Electricity Used for Space Heating }\end{array}$ & $42.4 \%$ & $43.8 \%$ & $15.9 \%$ & $35.9 \%$ \\
\hline
\end{tabular}

The energy saved by electrically heated homes varies markedly across key subgroups. Perient net savings range from $5.4 \%$ in the hot region to $14.9 \%$ in the moderate region. As with gasheated homes, single-family detached and small multifamily dwellings saved more electricity after weatherization than mobile homes.

\subsubsection{Dwellings Heated by Other Fuels}

An indirect estimation approach was used to estimate the energy saved by dwellings heated by fuels other than natural gas and electricity. The approach emphasized the similarity between gasheated homes and dwellings heated primarily by these other fuels, but recognized that the two types of dwellings have different regional distributions. I'c also incorporated the results of the National Weatherization Evaluation's Fuel-Oil Study. The result is an estimate of $17.7 \mathrm{MBtu}$ 's saved per weatherized dwelling heated with other fuels. This value is slightly more than the estimated energy savings for gas-heated homes (17.3 MBtu's per year), because of the high savings of the fuel-oil heated homes located in the nine northeastem states (22.4 MBtu's per year).

The estimated energy saved by different types of "other" fuels suggests that fuel oil has contributed :-: ;re than any of the others. It is the most common "other" fuel among homes weatherized in PY 1989, and it is used primarily in the cold and moderate regions. Liquid propane

5 Additional energy savings occur at the source of clcctricity generation, because energy (e.g., coal or gas) so typically consumed to produce electricity. 
gas is the next most common "other" fuel, but because it is used primarily in the hot region, it contributes much less to the Program's total energy savings.

\subsubsection{Trends and Comparisons}

The estimated Program savings in PY 1989 are higher than the estimate of 13.8 MBtu's per dwelling resulting from EIA's evaluation of the 1981 Program (Peabody, 1984). In addition to the general increase in savings over time, our findings differ in other ways from the earlier evaluation. Peabody (1984) found very little variation in energy savings by climate region, reporting only slightly lower savings in warmer climates. The Single-Family Study documents much higher savings in the moderate and cold regions compared with the hot region. Peabody (1984) found lower savings for electrically heated dwellings than for dwellings heated by natural gas, but our results show comparability, particularly when considering percent savings. Finally, our estimate of energy savings for homes heating primarily with fuel oil is the highest of any fuel type, while fuel-oil energy savings were more like the average in the assessment of the earlier program.

The estimated savings of the 1989 Program compare favorably with the results of evaluations of utility-operated low-income weatherization programs and evaluations of individual State weatherization programs.

\subsection{NONENERGY IMPACTS}

The various nonenergy impacts of low-income weatherization programs are numerous. However, much of the research addressing these benefits has been qualitative $i_{i}$, nature, presenting only anecdotal evidence. A consensus on how to quantify the value of many nonenergy benefits has not been reached.

Table 10.4 lists the nonenergy benefits that were monetized in this study. Additional benefits that have not been assigned a dollar value include: thermal comfort improvements, indoor air quality, benefits of increased nonenergy expenditures, and savings associated with fewer residential moves. Thus, the dollar value used here for nonenergy benefits $(\$ 976)$ is conservative.

The methods used here to estimate the value of nonenergy impacts varied. Estimates of environmental benefits relied on a literature review and on information from this study about the proportions of weatherized dwellings using various fuel types and about the average savings by fuel type. The analysis of environmental impacts was limited to the costs associated with $\mathrm{SO}_{2}, \mathrm{NO}_{\mathrm{X}}$, and $\mathrm{CO}_{2}$. Estimates of employment benefits combined a literature review with data from this study on the number of employees directly supported by DOE's weatherization program, the skill level of workers, and managers' judgments concerning the structure of the job market for weatherization workers. 
Table 10.4 Net Present Value of Nonenergy Impacts of the Weatherization Assistance Program

\begin{tabular}{|l|c|}
\hline $\begin{array}{l}\text { Type of Nonenergy Impact } \\
\text { Enhanced Property Value and Extended Lifetime of } \\
\text { Dwelling }\end{array}$ & $\begin{array}{c}\text { Net Present Value of the } \\
\text { Impact per Dwelling } \\
(1989 \$)\end{array}$ \\
\hline $\begin{array}{l}\text { Reduced Fires } \\
\text { Reduced Arrearages }\end{array}$ & $\$ 126$ \\
\hline Federal Taxes Generated from Direct Employment & $\$ 3$ \\
\hline $\begin{array}{l}\text { Lncorne Generated from Indirect Employment } \\
\text { Avoided Costs of Unemployment Benefits }\end{array}$ & $\$ 32$ \\
\hline $\begin{array}{l}\text { Environmental Externalities } \\
\text { Total Net Present Value of Nonenergy Impacts }\end{array}$ & $\$ 506$ \\
\hline $\begin{array}{l}\text { The net present value of the environmental benefits was calculated assuming a } 4.7 \% \text { discount } \\
\text { rate and a 20-year lifetime. The other nonenergy bencfits occur only in the year (1989) in } \\
\text { which weatherization occurred and, therefore, do not require discounting. }\end{array}$ \\
\hline
\end{tabular}

Direct and indirect, but not induced, employment benefits are included in the estimate. Data from this study on weatherization expenditures for home repairs are used to quantify the benefits associated with maintaining or enhancing property values and extending the lifetime of dwellings. Our estimate of reductions in arrearages is based on a literature review and data on payment histories that were collected on the dwellings included in this study.

\subsection{COSTS}

In PY 1989, the programwide average total installation cost (i.e., materials and on-site labor) per dwelling was $\$ 1,050$. Expenditures for individual dwellings, however, often varied substantially from this average. In particular:

- Eighty-five percent of dwellings had total installation expenditures of less than $\$ 1,500$, with $45 \%$ of dwellings in the $\$ 600$ to $\$ 1,200$ range. About $8 \%$ had expenditures of less than $\$ 300$ and about $9 \%$ had expenditures of more than $\$ 1,800$.

- There were no significant differences by climatc region in total materials costs, but differences in labor costs and total installed cosis were significant. The largest installation expenditures were in the moderate and cold climate regions, while the hot region spent about $10 \%$ less. 
- Total installation costs, total materials costs, and labor costs differed significantly by fuel type with the highest expenditures for dwellings that heat with other fuels.

- Total installation costs, total materials costs, and labor costs differed significantly by dwelling type with the highest total installation expenditures for single-family attached and single-family detached dwellings, and the highest materials costs for multifamily.

Although total materials costs did not vary significantly by climate region, the proportion of the expenditures invested in various types of measures did differ significantly (Fig. 10.3). In the cold region, investments were highest for insulation. In the moderate region, the highest expenditures were for windows and doors. In the hot region, structural repairs had the highest investment level, and windows and doors consumed nearly as high an amount. Thus, the cold region puts more resources into the measures most likely to save energy. Differences in materials costs by fuel type also were significant with the most being spent on homes heated with other fuels.

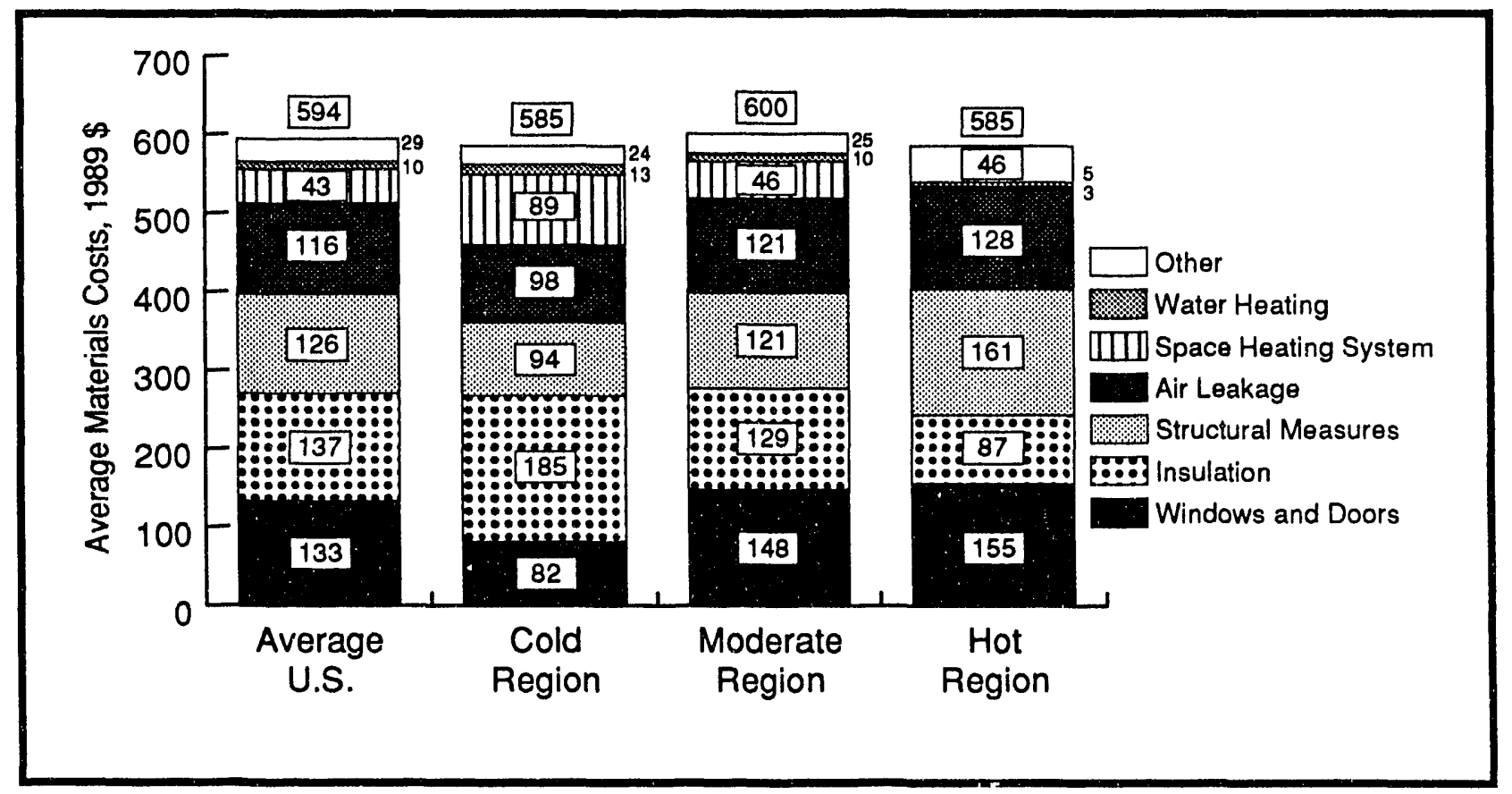

Fig. 10.3 Average Material Costs (in 1989 dollars), by Climate Region.

Labor cost data were collected and calculated with different methods for crew-only, contractor-only, and mixed (crew and contractor) weatherization jobs. This was necessary because the way agencies track costs for crew and contractor labor differs. Among the representative dwellings that could be classified by labor type, approximately one-third fell into each of the three types: crew-only, 33\%; contractor-only, 38\%; and mixed crew and contractor, $29 \%$. Generally, 
agencies tend to use one labor type on all, or at least most, of their weatherization jobs. Nationally, labor costs averaged about $\$ 433$ per dwelling out of a total installation cost of $\$ 1,050$.

Previous studies suggest that management and overhead costs (all costs other than materials and on-site-installation labor) range from $\$ 300$ to $\$ 600$ per house. In spite of the magnitude of management and overhead costs, most previous evaluations of weatherization programs have not reported them and have not included them in their cost-effectiveness calculations. In part, this reflects the difficulty of obtaining accurate information on management and overhead costs. An estimate of management and overhead costs $(\$ 500)$, consistent with findings of previous studies, was developed and used in this evaluation.

\subsection{COST EFFECTIVENESS}

The cost effectiveness of the Program was examined from many perspectives, but only three are presented in detail, by subgroup. With the installation perspective, which follows the usual procedure in previous low-income weatherization program evaluations, the only benefit valued is energy savings and the only costs included are installation expenditures (i.e., on-site-installation labor and materials costs). With the program perspective, the only benefit valued is energy savings, while costs include installation and management and overhead costs (i.e., the "worst" case). With the societal perspective, benefits include both energy and nonenergy benefits, and costs include installation and management and overhead costs. Net energy savings (rather than gross energy savings) are used in all the cost-effectiveness calculations, because we consider this a better indicator of program impacts. In addition, the same baseline assumptions are used (4.7\% discount rate and 20 year lifetime of measures), although sensitivity analyses are conducted using alternatives.

\subsubsection{The 1989 Program Results}

All of the perspectives that were examined show the 1989 national program to be cost effective. Benefit/cost (b/c) ratios range from 1.09 (for the program perspective) to 1.72 (for the

societal perspective). With the installation perspective, the $b / c$ ratio is 1.61 . Thus, the value of the energy saved by the Program slightly exceeds the cost of operating the Program. When nonenergy benefits are also included, the Program returns $\$ 1.72$ for every $\$ 1.00$ invested.

\subsubsection{Gas-Heated Dwellings}

For gas-heated dwellings, the national Program was cost effective from all three perspectives, with b/c ratios ranging from 1.06 to 1.61 . Fig. 10.4 presents the results for the societal perspective. The cold and moderate regions had higher $b / c$ ratios than the national average, while the hot region had $\mathrm{b} / \mathrm{c}$ ratios of less than 1.00 with the installation and program perspectives, and of 1.17 with the 
societal perspective. Only single-family detached homes (which account for $63 \%$ of weatherized homes) had $\mathrm{b} / \mathrm{c}$ ratios above 1.00 with the program perspective. All dwelling types had $\mathrm{b} / \mathrm{c}$ ratios of 1.23 or higher with the other two perspectives. Large and medium-sized agencies had cost-effective results with all three perspectives, while small agencies fell below 1.00 with the program perspective.

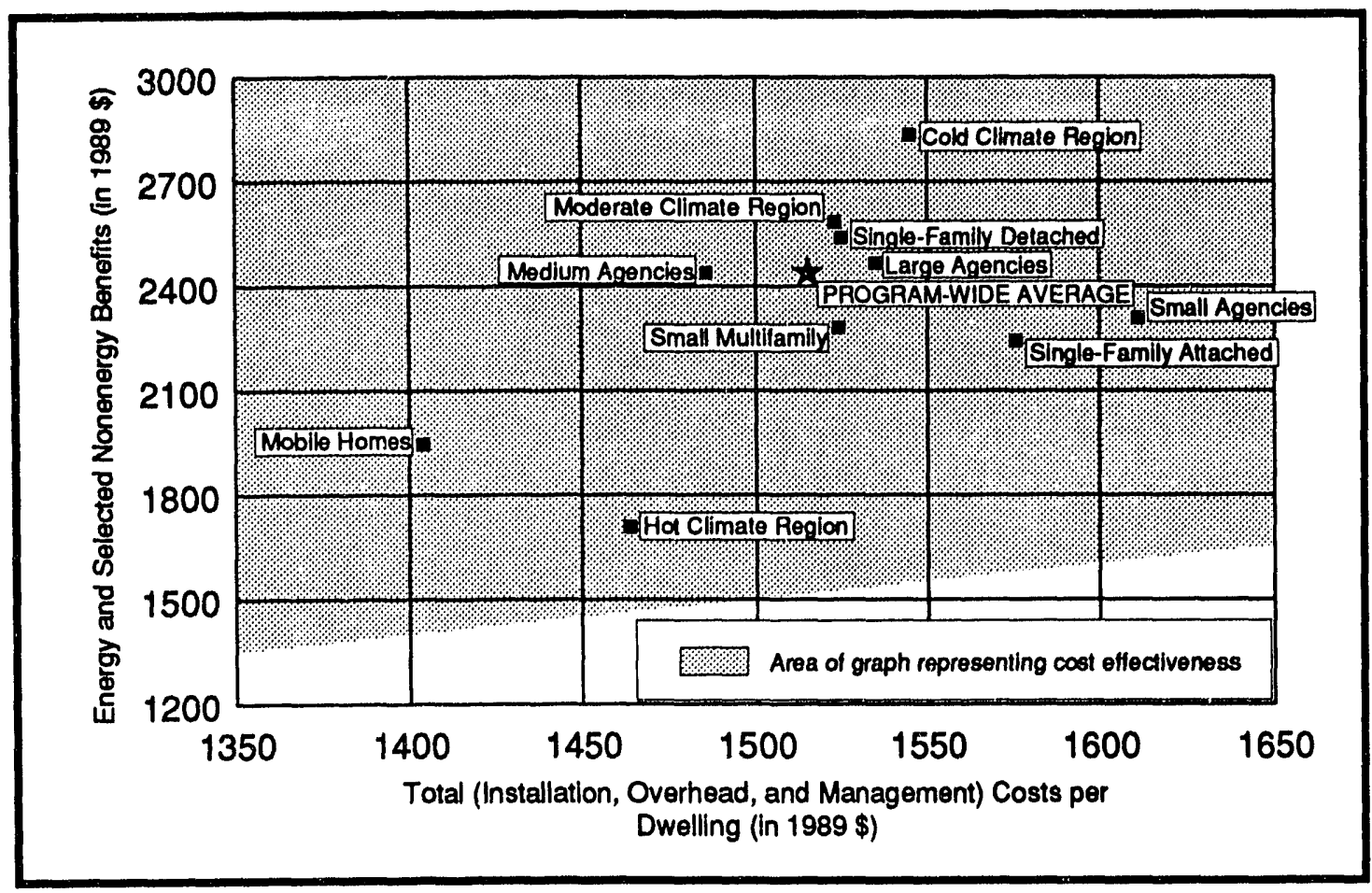

Fig. 10.4 Societal Perspective: Energy and Nonenergy Benefits vs. Total Costs for Gas-Heated Dwellings.

\subsubsection{Electrically Heated Dwellings}

Because electricity prices are higher than gas prices, energy savings in electrically heated dwellings are worth more. Therefore, cost-effectiveness results were consistently more favorable. The national benefit/cost ratio was 1.13 with the program perspective, and higher with the other two perspectives. The results by climate region show that the Program was cost effective in the cold and moderate regions, but not in the hot region. All climate regions had $b / c$ ratios of 1.17 or higher with the societal perspective. Comparisons by dwelling type indicate that weatherizations of single-family detached and small multifamily dwellings were cost-effective, while those of mobile homes were not. From the societal perspective, the weatherization of electrically heated dwellings was highly cost 
effective, with a national benefit/cost ratio of 2.33. All of the subgroups showed cost-effective results with this perspective.

\subsubsection{Trends and Comparisons}

The results of cost-effectiveness analyses in previous evaluations suggest that for gas-heated dwellings the 1989 Program improved upon the average performance of similar programs. Schlegel and Pigg (1990), in their review of nine evaluations of cold climate programs serving gas-heated dwellings, reported costs of conserved energy (CCE) that, when recalculated with our baseline assumptions (4.7\% discount rate, 20-year lifetime, only on-site installation labor and materials costs), averaged $\$ 6.08 / \mathrm{MBtu}$, with a range of $\$ 2.69$ to $\$ 17.33$. Cohen, et al. (1990), in their review of 12 evaluations of cold climate programs serving gas-heated dwellings, reported a median CCE recalculated with our assumptions, of $\$ 5.07 / \mathrm{MBtu}$. Thus, our cold climate region results for gasheated dwellings ( $\$ 3.50$ per $\mathrm{MBtu}$ ) compare favorably to the results of previous studies, as do the national results $(\$ 4.60$ per MBtu). Comparisons with utility low-income programs (for gas-heated dwellings) also show the 1989 Program to be more cost effective. The results for electrically heated dwellings indicated a national CCE $(\$ 0.04$ per $\mathrm{kWh})$ that was lower than the average national price of $\$ 0.07$ per $\mathrm{kWh}$.

\subsection{FACTORS ASSOCIATED WITH PERFORMANCE}

The analysis of factors associated with energy savings was multifaceted: (1) it examined the savings of individual dwellings and the average savings of different agencies; (2) it examined absolute savings as well as percent savings and benefit/cost ratios; (3) it employed both bivariate and multivariate analytic techniques; and (4) it examined the predictors of performance in each of three climate regions and nationwide. The different approaches produced a consistent portrayal of the major predictors of energy savings.

The analysis indicates that energy savings per dwelling are largest in the Program's dominant submarkets, where weatherization activity is concentrated. These include:

- cold and moderate climate regions; and

- single-family detached homes.

Partly because of small sample sizes, few additional predictors of electricity savings were identified. These include high electricity consumption prior to weatherization and the installation of first-time attic insulation. In contrast, numerous factors were significantly associated with gas savings.

Certain service delivery procedures correspond with higher-than-average gas savings, including:

- weatherization of households with high gas consumption (Fig. 10.5);

- integrated envelope/heating system audit; 
- distribution system diagnostics; and

- heating system efficiency tests.

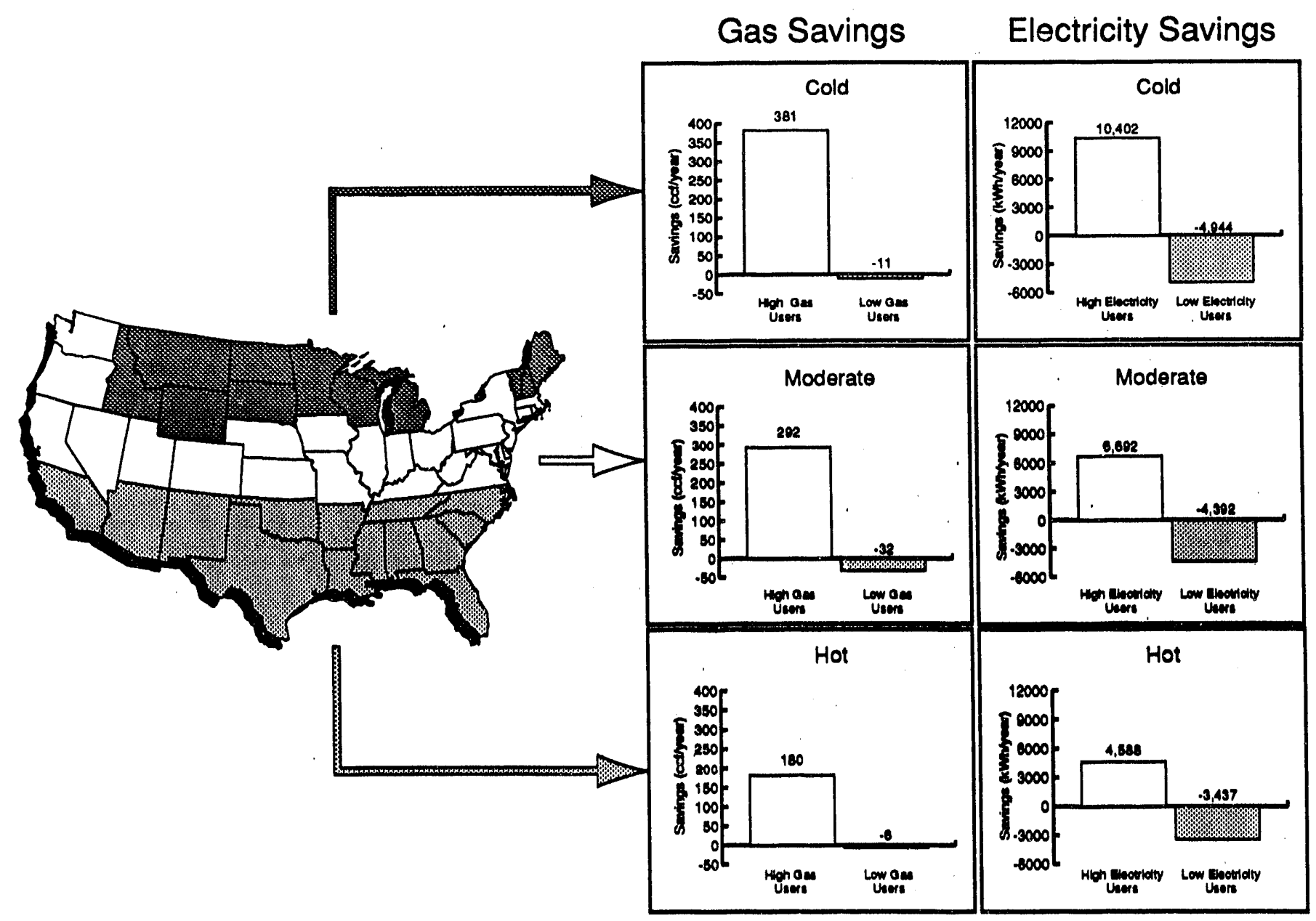

Fig. 10.5 Energy Saved by High vs. Low Energy Users in the Three Climate Regions.

In contrast, the energy-savings benefits of blower-door assisted air sealing and client education were not discernible.

Certain weatherization measures correspond with higher-than-average gas savings, including:

- distribution system air leakage control;

- air sealing without blower doors;

- attic insulation (particularly first-time);

- wall insulation (particularly high density);

- floor insulation;

- water heater tank insulation, pipe insulation and temperature reduction;

- furnace replacements; and 
- mobile home underpinning/skirting.

Many of these findings are consistent with the results of previous research. The two findings that are least substantiated by other research are the apparent key role of distribution system diagnostics and air leakage control, and the questionable energy-savings benefits of blower-door assisted air sealing.

Clearly, more analysis is needed to test these findings before employing them as a basis for policy and program recommendations. The results reported here are "correlational" in nature and cannot identify "causes" of high energy savings. More definitive information on factors influencing savings will result from the Single-Family Study's on-site field work (i.e., phase two).

\subsection{CONCLUSIONS AND RECOMMENDATIONS}

During PY 1989, the Weatherization Assistance Program weatherized 198,000 single-family or small multifamily homes. On average, each weatherized dwelling saved an estimated 17.7 MBtu's during its first year after weatherization, resulting in an annual decrease, in 1989 dollars, of $\$ 116$ in the low-income participant's energy burden. Nationwide, the 1989 Program resulted in annual energy savings of 3,487,000 MBtu's. At an equivalence of 5.8 MBtu's per barrel of oil, this represents 601,000 barrels of oil during $1990-91$, or 1,650 barrels of oil per day. Over the 20-year lifetime of the weatherization measures installed in PY 1989, it is estimated that the savings from this one year of weatherization will amount to $69,740,000 \mathrm{MBtu}$ s, or 12 million barrels of oil. This is approximately equal to the amount of oil that was added to the emergency Strategic Petroleum Reserve in 1992.

Total costs (including materials, installation-related labor, installation-related overhead, and program management) averaged $\$ 1,550$ per weatherized dwelling in PY 1989. From the societal perspective, which includes both energy and nonenergy benefits and total costs for all single-family and small multifamily dwellings, the Program in PY 1989 was cost effective, with a benefit/cost ratio of 1.72 . Table 10.5 presents some of these key statistics.

The Program proved most cost effective in the submarkets (including cold and moderate climate regions and single-family detached homes) where weatherization activity is concentrated. The hot climate region and mobile homes, on the other hand, represent submarkets where program improvements are needed. Service delivery procedures that correspond with higher-than-average energy savings include high priority for high energy users and integrated envelope/heating system audits. Weatherization measures associated with higher-than-average savings include heating system replacements and attic, wall, and floor insulation. More widespread adoption of these measures and procedures represent some of the many promising opportunities for the future. 
Table 10.5 Energy Savings and Cost Effectiveness of the Weatherization Assistance Program

\begin{tabular}{|c|c|}
\hline Indicator & Program-Wide Value \\
\hline $\begin{array}{c}\text { First-Year Energy Savings per Dwelling } \\
\text { (in Million Btu's ) }\end{array}$ & $\begin{array}{c}16.4 \text { (site) } \\
17.6 \text { (source) }\end{array}$ \\
\hline Energy Savings as a Percent of Total Energy Use & $13.5 \%$ \\
\hline Energy Savings as a Percent of Energy Used for Space Heating & $18.2 \%$ \\
\hline First-Year Dollars Saved per Dwelling & $\$ 116$ \\
\hline Installation-Related Costs per Dwelling & $\$ 1,050$ \\
\hline Total Weatherization Costs per Dwelling & $\$ 1,550$ \\
\hline Program Benefit/Cost Ratio & 1.09 \\
\hline Installation Benefit/Cost Ratio & 1.61 \\
\hline Societal Benefit/Cost Ratio \\
\hline Cost per Million Btu's of Conserved Natural Gas \\
\hline Cost per kWh of Conserved Electricity \\
\hline Number of Single-Family and Small Multifamily Dwellings \\
Weatherized in PY 1989 \\
\hline
\end{tabular}

Based on energy consumption one year after weatherization in 1989-90.

2 Estimated at an average cost of $\$ 6.89$ per MBtu's.

3 Based on energy-savings benefits and total weatherization costs.

4 Based on energy-savings benefits and installation-related costs.

5 Based on energy-savings, employment, environmental and other nonenergy benefits and total weatherization costs.

6 The weighted average retail price for natural gas is $\$ 5.90$ per MBtu.

7 The weighted average retail price for electricity is $\$ 0.07 \mathrm{per} \mathrm{kWh}$.

\subsubsection{Diversity and the Need for Technology Transfer}

Perhaps the most striking result of this Single-Family Study is the tremendous diversity among local agencies. Some agencies weatherize 15 homes in a year, while others weatherize thousands. Some achicve savings of more than $400 \mathrm{ccf} / \mathrm{ycar}$, as much as $40 \%$ of pre-weatherization consumption, while others produce no savings. Some employ state-of-the-art procedures, leverage a wide variety of financial and technical resources, and perform sophisticated self-evaluations designed to constantly improve their performance. Others follow the same procedures year after year, do not evaluate their impacts, and rely only on DOE funding. Phase 2 of the Single-Family Study, which is now underway, will describe and analyze the practices used by ten high-performing agencies selected 
from each major geographical region on the basis of measured energy savings. Phase 2 also will involve comparing and contrasting the characteristics of high and low saving agencies and dwellings.

Although the Phase 2 study is still in progress, it is already clear that there is no single formula for success. Each of the ten successful agencies employs a variety of useful approaches. Some target high energy consumers, who have a greater potential for savings, and who bear a greater energy burden. Some use more advanced audit procedures, such as the Targeted Investment Program (TIPS) audit. Most employ advanced diagnostics and understand how to use them effectively. Some use very effective client education techniques. Some leverage funds from other federal and State programs, and from utilities so that more complete home repair and weatherization. can be offered to clients. Some employ methods of controlling costs, such as bulk purchasing of insulation or high-efficiency furnaces at substantial discounts, so that more complete retrofits can be accomplished within budget constraints. The feature that most clearly distinguishes the high performers is a management style that strives for improvement in energy savings and cost effectiveness. Some high-performing agencies, for example, continuously evaluate their programs by monitoring the energy saved by samples of the homes they weatherize. Others implement pilot programs to test new ideas and approaches. All are cager to learn about and implement improvements in their programs.

Agencies that are less successful, in contrast, implement few changes in procedures. Their focus is on producing the expected number of completed units. They continue to use priority lists which may be out-of-date, do not employ advanced diagnostic techniques, do not explore ways to leverage funds, and do not seek out or implement technical innovations. More of their weatherization dollars are invested in replacement and storm windows. They do not target client subgroups with the highest potential for energy savings. They offer services on a first-come-first-served basis, and make no efforts to measure or improve energy savings and cost effectiveness.

The challenge for federal, regional and State managers of the Program is to encourage and assist the less innovative agencies in the adoption of the procedures used by the most effective agencies. This process should take place at each management level. State pilot programs such as a recent one in Virginia (Greely, Randolph and Hill, 1992) could be implemented in many States to demonstrate how to improve savings and cost effectiveness. The encouragement of State peer networking and mentoring relationships could also be an effective mechanism. Regional and federal support for technology transfer might include supporting the development of the State demonstrations and networking, as well as supporting the development of guidebooks, and focused hands-on training sessions that could be offered in a number of States. 


\subsubsection{Targeted Research and Technology Transfer}

This Single-Family Study identified several submarkets and technologies that need management attention. The hot climate region and mobile homes are submarkets where program improvements are clearly needed. Savings in both of these submarkets could probably increase substantially and be made cost effective with the implementation of state-of-the-art procedures.

Hot Climate Weatherization. Greely, Randolph and Hill (1992) demonstrated that lowincome homes in Virginia offer as great a potential for savings as homes in colder climates. Although Virginia is classified as a moderate climate State in the National Evaluation, it borders the hot region and, therefore, provides some indication of the potential there, especially in States such as Tennessee, Arkansas, Oklahoma and the northern parts of Georgia, Alabama and Mississippi, where heating loads are substantial. Demonstration studies of this type should be conducted in States with predominantly cooling climates (such as Florida, California, Texas, and Arizona) to determine the potential for savings there. Currently there are few published demonstration studies of weatherization's potential for savings in such cooling dominated climates.

The Virginia study concluded that realizing higher savings requires:

- a strong emphasis on the installation of high-density cellulose sidewall insulation and on the use of advanced air sealing techniques,

- a decreased emphasis on conventional caulking, and

- less investment in replacement and storm windows.

The Single-Family Study's findings support all of the Virginia study's recommendations except the one about the use of advanced air scaling techniques. However, since most experimental studies of these techniques have shown them to be of significant value, as did the Fuel-Oil Study, we believe that the potential of blower doors as a weatherization tool should continue to be explored. Clearly results from correlational studies are not as conclusive as experimental results in determining the value of specific techniques. In addition, we believe that the small percentage of agencies using these techniques in PY 1989 may have been at the beginning of the learning curve at that time. DOE might consider supporting the development of a guidebook on advanced air sealing by a committee of experts, to promote the effective use of blower doors. In addition, research on the current use of blower doors by local weatherization agencies is needed to determine whether or not blower doors are being employed effectively today.

The Single-Family Study's results also suggest some related recommendations:

- an increased emphasis on attic, wall and floor insulation,

- extensive use of integrated heating system/envelope audits,

- an increased emphasis on heating system replacements, and

- targeting of the highest energy users. 
The last recommendation, targeting of the highest energy users, deserves strong emphasis because pre-weatherization energy use was by far the best predictor of savings in the Single-Family Study.

Mobile Home Weatherization. Demonstration studies on mobile homes have shown the potential for much higher savings in this subgroup as well. Because DOE recognized this potential for higher savings, it initiated a testing program at the Solar Energy Research Institute (now the National Renewable Energy Laboratory) in 1988 to investigate cost-effective ways to weatherize mobile homes. The research showed that the most cost-effective measures for mobile homes located in cold climates are: blower-door-directed air sealing and duct repair, furnace tune-up, blown-in belly and roof insulation, and interior storm panels (Judkoff, 1991). Research still needs to be conducted to determine cost-effective mobile home weatherization strategies in hot climates.

\subsubsection{Recordkeeping and Future Evaluations}

A final set of recommendations concerns recordkeeping and future program evaluation. Cost records were extremely difficult to use in this evaluation. The current DOE categories for collecting cost data are too aggregate to answer questions about the cost-effectiveness of various weatherization activities. Data on total materials costs were maintained by all of the local agencies in our sample. In contrast, data on costs for specific types of materials and labor were often unavailable and used different breakdowns across agencies. The consistent estimation of management and overhead costs was nearly impossible. Because of variations in terminology and accounting systems, the frequent integration of functions among various programs offered by the same Community Action Agency, and the diversity of funding sources, we concluded that a rigorous study of costs would require sending audit teams to work directly on-site with program staff. Because there is little understanding of how agencies control their costs, this issue may offer important levers for improving program verformance. Implementation of a management information system to collect consistent and more detailed cost data, supported by user-friendly software, would facilitate future evaluation work.

Obtaining fuel consumption records for the Single-Family Study also was extremely difficult, expensive, and time consuming. Many utilities refused to cooperate. If local agencies would routinely collect consumption records from utilities for the year before weatherization, at the time of weatherization, much of the difficulty in collecting fuel records could be avoided. Utilities typically keep about one year of records in casily accessible computer files. Obtaining fuel consumption records that are more than a year old, however, usually requires special programming, labor intensive searches for microfiche or hard copies, or may even be impossible to accomplish.

All local agencies should be required to have applicants authorize the release of one year of pre- and post-weatherization fuel records. The application forms used in many States already require signed authorizations. However, this is not done universally, and some existing authorization 
statements are inadequate (e.g., only authorizing the collection of consumption data for the main heating fuel). If local agencies would obtain authorizations for the release of the previous year's fuel consumption records when clients apply for weatherization, it would greatly facilitate both in-house and external evaluations of their programs. In addition, local agencies could use consumption data to target clients with the highest potential for savings, and to guide weatherization investment levels. 


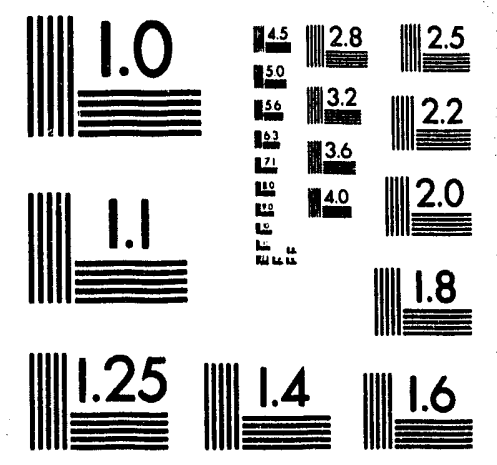



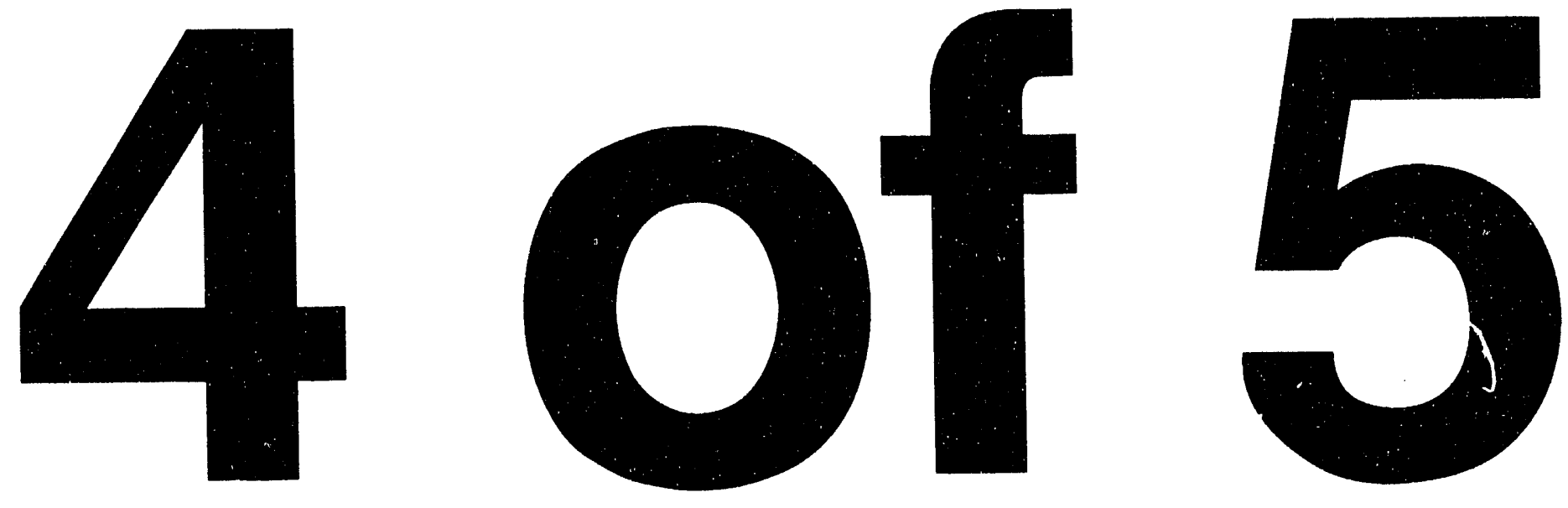


\title{
Department of Energy
}

Washington, DC 20585

September 24, 1990

Dear State WAP Program Manager:

Implementation of the National Evaluation of the Weatherization Assistance Program (WAP) has begun, and DOE is now in need of some assistance from you. In particular, I have three requests.

First, I would like you to review the most recent draft of the subgrantee questionnaire for the Characterization of the WAP Network study. The evaluation project's Working Groups have helped to develop the questionnaire to this stage, and it is now being finalized. Should you have significant comments, we would appreciate receiving them by October 1 , 1990. Please send your comments to Marilyn Brown who will be compiling them for DOE's review:

\author{
Marilyn A. Brown \\ Oak Ridge National Laboratory \\ P.O. Box 2008 \\ Oak Ridge, Tennessee 37831-6206 \\ Telephone: 615-576-8152 \\ FAX 615-576-2912
}

Second, please transmit a letter to your WAP subgrantees announcing the forthcoming questionnaire for the Characterization of the WAP Network study. I have enclosed a draft letter to serve as a model. Please feel free to modify it as appropriate. The letter alerts subgrantees that a questionnaire is coming and encourages their prompt response. We plan to mail this questionnaire directly to subgrantees in early October, 1990. Thus, you should mail your letter by October 1 .

Finally, we need some information on the subgrantees in your state. In particular, we need a list of your subgrantees, including a contact name, agency name, address, and telephone number, and the approximate number of homes weatherized by each subgrantee during Program Year 1989 (April 1, 1989 through March 31, 1990). Please return this information directly to Marilyn Brown by October 12,1990. The information on homes weatherized in 1989 will be used to develop a representative sample of the weatherized homes for the Single-Family and High-Density Multifamily studies.

Should you have any comments or questions concerning these requests, please feel free to call Darrell Beschen at DOE (202-586-1732) or Marilyn. 
State WAP Program Manager

Page 2

September 24, 1990

On behalf of the Department of Energy, I would like to thank you for your cooperation. The results of the national weatherization evaluation will provide valuable insights into the current capabilities and future potential of the WAP.

Sincerely,

Mary E. Fouler

Mary E. Fowler, Director

Weatherization Assistance

Program Division

Enclosures (3)

1) Model Letter to Subgrantees with Enclosures

2) Draft Subgrantee Questionnaire for Characterization of the WAP Network study

3) List of Subgrantees

cc/enc: Governor Designated Grantees

Support Office Directors

DOE WAP Program Managers

B-2.2 


\section{Department of Energy \\ Washington, DC 20585}

December 17, 1990

\section{Dear WAP Director:}

As you know, the U.S. Department of Energy (DOE) is conducting a National Evaluation of the Weatherization Assistance Program with the assistance of Oak Ridge National Laboratory. You should have already received an information package about the National Evaluation (in September) and a questionnaire to fill out that provides information for characterizing the WAP network of service providers (in October).

Implementation of another part of the National Evaluation is now beginning. The SingleFamily Study, a three-year effort, will estimate the energy savings, nonenergy impacts, and cost-effectiveness of the weatherization measures installed by the WAP during the 1989 program year (PY89). It also will identify factors influencing savings and cost effectiveness and will examine the persistence of energy savings over time. A sample of 400 subgrantees across the nation was randomly selected to participate in the Single-Family Study. Your agency is included in this sample and thus will play an important role in representing the Weatherization Assistance Program nationwide. A successful evaluation will provide all of us with the up-to-date, credible, and reliable information needed for effective decision making and operations. Your assistance and cooperation in this study are critical to its success. It can't be done without you. In particular, we need you to provide us with five items by January 14, 1991.

First, we need a list of names, addresses, and job numbers or some other unique identifiers (whatever your agency uses) for clients whose dwellings were weatherized by your agency's DOE program in PY89. This list should include all homes that your agency weatherized, entirely or in part, with DOE funds or with funds from other sources, such as state monies, that were used according to DOE regulations. Homes that received services solely from funding sources that did not follow DOE regulations, such as LIHEAP funding that was not combined with DOE funding, should not be on the list. The list will be used to select a nationally representative sample of homes weatherized by the DOE program in PY89. From your list, we will draw a $5 \%$ to $20 \%$ sample of homes for subsequent, detailed analysis.

Second, we would like you to provide the names of the gas and electric utilities serving your weatherization service area, and if readily available, the names and telephone numbers of contacts at these utilities who can provide billing data for clients you have served. We will be contacting these utilities to collect pre- and post-weatherization energy consumption data for the $5 \%$ to $20 \%$ sample of homes your agency weatherized in PY89.

Third, if your agency obtains written permission from clients to access their utility records, please send us a sample of one of the signed forms. We will use this form to seek utility billing data for the $5 \%$ to $20 \%$ sample of homes your agency weatherized in PY89. We are hoping that the utilities in your area will not require a copy of the consent form for each sampled household, but will proceed knowing that you have them in your files. Please let us know if you did not collect these forms in PY89.

Fourth, if it is readily available, we would like to know two things about each dwelling unit on the PY89 list: (1) type of primary heating fuel and (2) whether or not the dwelling unit is in a building with 5 or more units. (These larger buildings will be the subject of the evaluation's Multifamily Study. ) 
Finally, as the study progresses, information on the measures installed in specific dwellings and on the materials and labor costs of these installations will be needed. We will be contacting you later this winter to ask for specific dara on the $5 \%$ to $20 \%$ sample of dwellings your agency weatherized in PY89. If possible, it would be helpful to have an example of the type of information that is available in your reconds for dwellings weatherized in PY89. A xerox or computer printout of a typical record would do the job.

In sum, we need five items from you by January 14, 1991:

- a list (with names, addresses and identification numbers) of all the dwellings weatherized by your agency in PY89,

- information on the utilities serving these dvellings,

- a sample utility bill waiver,

- housing and fuel type data (if it can be obtained easily) for dwellings weatherized in PY89, and

- a sample of the information your agency maintains on each dwelling weatherized in PY89.

Please send this information to:

Marilyn A. Brown

Oak Ridge National Laboratory

P.O. Box 2008

Oak Ridge, Tennessee 37831-6206

Telephone: 615-576-8152

FAX: 615-576-2912

A self-addressed envelope and two forms are enclosed. We thought you might find them useful in responding to our request for information. However, we'll take the information in whatever form is most convenient to you.

Thank you very much for your assistance. Should you have any questions, please feel free to call Darrell Beschen at DOE (202-586-1732) or Marilyn Brown at the phone number
listed above.

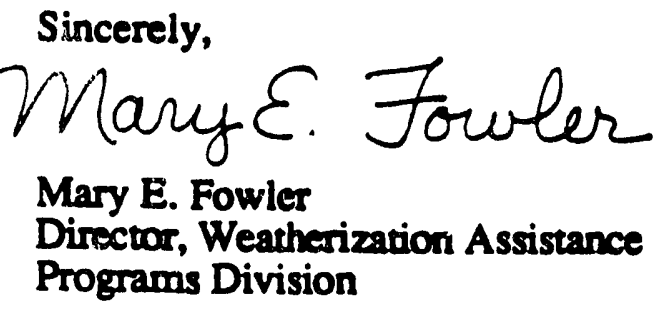

Enclosures

cc: State WAP Program Manager 
March 28, 1991

Dear WAP Director:

Recently, your agency sent a package of information to Oak Ridge National Laboratory (ORNL) to support the Single-Family Study which is part of the U.S. Department of Energy's National Evaluation of the Weatherization Assistance Program. Thank you. Your assistance and cooperation are greatly appreciated. The primary goal of the Single-Family Study is to estimate the national energy savings, nonenergy impacts, and cost-effectiveness of the WAP in the 1989 Program Year. The Single-Family Study also will identify factors influencing savings and cost effectiveness, and will assess the persistence of energy savings over time. The information you are providing makes it possible to achieve these goals.

We now need your help in compiling data for the Single-Family Study on:

- a sample of dwellings weatherized in PY 1989,

- a control group, and

- your agency's average installation-related overhead and program management costs.

Compiling data on each of these topics will take some time, but this is the last request firr data you will receive this year. Information on these topics should be sent to ORNi by May 3, 1991. The details of what is needed on each of the topics are discussed below.

\section{Data on Weatherized Buildings}

The first step in compiling a national database on dwellings weatherized in the 1989 Program Year (PY), is to select a random sample of homes weatherized in PY 1989. Using your agency's list of PY 1989 completions, ORNL selected a random sample of weatherized dwellings. A list of the dwellings selected is enclosed, along with a dwelling-specific data collection form for compiling information on each dwelling in the sample. The requested information needed for each dwelling covers:

- dwelling characteristics and equipment,

- occupant characteristics,

- weatherization measures installed,

- service delivery procedures, and

- costs.

The dwelling-specific form was developed by examining the examples of forms and records that many agencies sent to ORNL along with their lists of weatherized homes. This form was reviewed by weatherization experts and pretested by six local agencies. We realize that different agencies keep records in different ways. Please just use your best judgement in completing the forms. We will contact you if we have questions about your responses. The items on the enclosed form were selected to reflect the content of typical recordkeeping systems. Most agencies will have most of this information in their records. Please provide as 
much of the requested data as you can. If there are items that you do not have in your records, please indicate this on the form. If you keep some of the requested information in cumputer data bases, electronic transfer of the information may be most convenient for you. If you send electronic files, please be sure to provide the information needed to read and interpret the data.

\section{Control Group Data}

At this time, we also need your help in identifying a control group for the Single-Family Study. A credible evaluation must have a control group so that the study can show that measured effects, such as reductions in energy consumption, did not occur in dwellings that did not receive program services. The control group should consist of applicants for weatherization services who are currently on your waiting list. Because we need to study the fuel consumption of the control group, it should include only dwellings that heat primarily with electricity or natural gas. We would like to have approximately the same number of control group dwellings as ne number of weatherized dwellings that heat mainly with gas and electricity that are on the enclosed list.

A control group form is enclosed for listing job numbers, names, addresses, utility companies, and utility account numbers for the control group of applicants waiting for services. Please begin by listing applicants that have already been income qualified. If there are not enough applicants whose income eligibility has been determined, please add applicants who are waiting for their eligibility to be determined. If it is more converilent for you, the list of control group dwellings can be sent as an electronic file.

\section{Data on Costs}

In addition to the data on the weatherized and control group dwellings, we need some information on your agency's average installation-related overhead and program management costs in PY 1989. This information will be used to determine the total cost of delivering services and as input to the cost-effectiveness analysis. The enclosed agency information form defines the cost terms, explains the categories of costs, and asks for the required cost data.

Filling out the enclosed forms will take some time (about 20 minutes per sampled dwelling, according to our pretesters), but this is the last request for data on the PY 1989 weatherized dwellings that you will receive this year.

The only other assistance we may need with data collection for the weatherized and control group homes concerns the process of obtaining fuel consumption records from gas or electric utilities. Since you indicated that your agency does not routinely obtain permission to examine client fuel consumption records, some additional effort may be required to access fuel consumption records from the utility companies. Sometimes LowIncome Home Energy Assistance (LIHEAP) Programs collect bill waivers as part of their application process. To the extent that your clients also receive LIHEAP services, bill waivers for them may be available from LIHEAP.

Some weatherization program managers have told us that the utilities in their service areas will provide fuel consumption information to them without first insisting on having 
bill waivers. If you have been able to obtain fuel consumption data without bill waivers, please let us know about this. If a utility in your area insists on bill waivers, it may be necessary to contact some of your clients directly and ask them to sign a waiver. We may need your help in settling on the best way to handle the process of collecting gas and electric utility fuel consumption records in your service area. ORNL will ask the utilities for the fuel records first and ask for your assistance only if problems occur.

The information you are providing is vital to the success of the Single-Family Study being conducted by DOE with assistance from ORNL. A successful evaluation will provide all of us with the up-to-date, credible, and reliable information needed for effective decision making and operations. Your assistance and cooperation are important and greatly appreciated.

In sum, we need three items from you by May 3, 1991:

- a completed form on each weatherized dwelling in the random sample,

- a list of dwellings for the control group, and

- one completed agency information form on costs.

Please send the completed forms to:

Marilyn A. Brown

Oak Ridge National Laboratory

P.O. Box 2008

Oak Ridge, Tennessee 37831-6206

Telephone: $615-576-8152$

FAX: 615-576-2912

Enclosed is a self-addressed stamped envelope for your use. Thank you for your assistance. Should you have further questions, please feel free to call Darrell Beschen, the DOE project manager, at (202-586-1732) or Marilyn Brown, the ORNL project manager, at the phone number listed above.

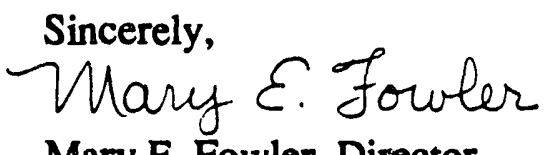

Mary E. Fowler, Director

Weatherization Assistance Programs Division

\section{Enclosures}

1. List of Sampled Weatherized Dwellings Heated Mainly by Gas or Electricity

2. List of Sampled Weatherized Dwellings Heated Mainly by Other Fuels

3. Dwelling-Specific Forms (one form per sampled dwelling)

4. Control Group Form

5. Agency Information Form (for recording agency cost data)

\section{cc: State WAP Program Manager}


Dear WAP Director.

Several months ago, DOE requested information on a sample of homes your agency weatherized in Program Year 1989 and information on homes waiting to be weatherized. The data request was part of the National WAP Evaluation's Single-Family Study. This study is the principal means by which the cost effectiveness of DOE's Weatherization Assistance Program will be assessed. To be accurate, data must be collected from a nationwide sample of local weatherization providers. For this reason your participation is essential.

Over the past few months, Oak Ridge National Laboratory has telephoned you on DOE's behalf, to encourage you to provide the data we need. DOE has also contacted State WAP Program Managers to notify them of the burden we have placed on their local agencies, and to ask for their assistance in helping you respond. We understand that in most cases State agencies took this action.

Our records indicate that we still have not received the requested data. Thus, we are writing to you directly to encourage your participation. Because the project has progressed several stages, we no longer need the list of homes waitine to be weatherized. However, we still need the other information (the "House-Specific Forms" and the "Agency Information Form"). We are asking that you please provide this information by Monday, September 30. The necessary forms were previously mailed to you; all but the waiting list form should be completed and retumed to:

\section{Marilyn A. Brown}

Oak Ridge National Laboratory

P.O. Box 2008

BId $4500 \mathrm{~N}, \mathrm{MS} 6206$

Oak Ridge, TN $37831-6206$

If you cannot locate the forms or if you have already retumed them, please call Marilyn and she will forwand another set to you.

If you have any questions about the Single-Family Study or any other aspect of the National WAP Evaluation, please feel free to call Darrell Beschen at DOE (202-586-2238) or Marilyn Brown at ORNL (615-576-8152). We appreciate your assistance, which is so critical to an accurate and informative evaluation.

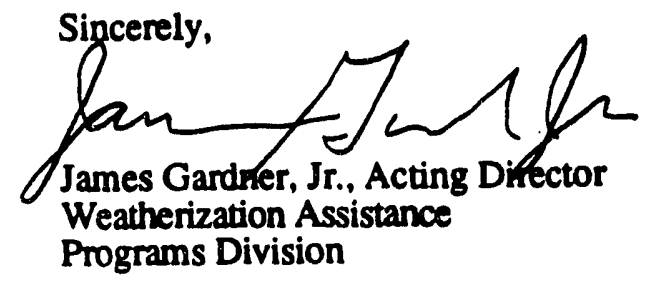

$\propto$ State WAP Manager DOE Support Office

File - RC 
Washington, DC 20585

April 26, 1991

Dear Utility Company Manager.

In 1990 the U.S. Department of Energy (DOE) initiated an in-depth national evaluation of the low-income Weatherization Assistance Program. A description of the National Weatherization Evaluation is enclosed (Attachment 1) along with a list of some of the many agencies, utility associations, and regulatory associations that support the evaluation (Attachment 2). The people on the enclosed list (Attachment 2) are part of the Working Group for the National Weatherization Evaluation. These Working Group members offer DOE recommendations for planning and implementing the evaluation. They represent the constituencies that will use the evaluation results.

This nationally important evaluation has five parts which are being implemented over a three-year period. One of these studies is documenting the extent of utility sector activity in low-income residential weatherization. Your utility may have received a survey form about its low-income weatherization activities earlier this year. Now we need your assistance with the Single-Family Study, the largest part of the evaluation. A primary goal of this study is to estimate program energy savings. Your assistance is vital to the achievement of this goal. Specifically, we will need information on a sample of DOE. program homes served by your utility, including fuel consumption records for the period of January 1988 to April 1991.

The names and addresses of the sample of your clients that are included in the study will be sent to your utility within the next several months. We have requested utility account numbers for each of these households from the local weatherization agencies that have served them, but they may not be available for everyone. It is not possible to tell you at this point exactly how many of your clients will be on our list, but it is likely to range between 5 and 100 households. In a few cases, for utilities that serve most of a State or a large metropolitan area, several hundred houscholds may be in the study. The purpose of this letter is simply to inform you of the importance of the study and to ask for your help and cooperation in responding to our upcoming data request.

Please use the enclosed reply form and retum envelope to let us know who at your utility can best respond to our data request. We recognize that in some cases, all billing records will be kept at a central location. In other cases, local branch offices must be contacted for information on the houses in their service area. Please provide names, addresses, and telephone numbers for the necessary contacts, at headquarters and/or branch offices. Also, please indicate whether or not you anticipate any problems in providing the data, and, if so, how to resolve these problems. We would appreciate receiving this reply form by May 20, 1991.

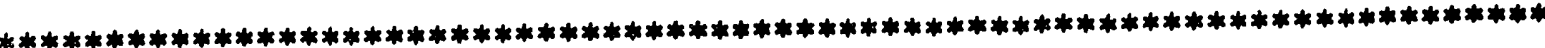

The National Weatherization Evaluation is supported by many organizations including:

NARUC AGA APPA EEI NRECA NCAF NASCSP U.S. HHS/LIHEAP 
As you may already know, most households weatherized by the DOE program sign bill waivers as part of their application for weatherization services, allowing the federal government access to their energy bills. Further, all data on fuel consumption that you provide to DOE will be presented only in aggregate statistical summaries, and information about specific households will be kept confidential in accordance with the Privacy Act of 1974. DOE and ORNL have conducted many studies of this type in the past and are familiar with the responsibilities for careful management of such data.

Please note that we will be collecting energy billing data from natural gas and electric utilities only. If your organization does not distribute natural gas or electricity, please indicate this on the enclosed form.

If you have any problems or concerns about this data request, please contact the project managers at DOE or ORNL, who are:

Darrell A. Beschen

U.S. Department of Energy

CE-532

1000 Independence Ave., SW

Washington, DC 20585

Telephone (202) 586-1732
Marilyn A. Brown

Oak Ridge National Laboratory

P.O. Box 2008

Oak Ridge, Tennessee 37831-6206

Telephone: (615) 576-8152

FAX: 615-576-2912

We greatly appreciate your assistance with this important project.

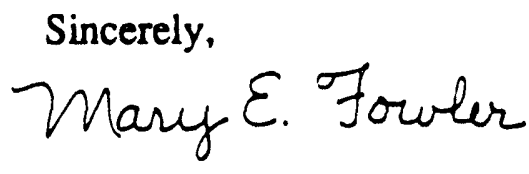

Mary E. Fowler, Director

Weatherization Assistance

Programs Division

Attachments/Enclosures

1: Attachment One: Description of the Evaluation

2: Attachment Two: Organizations Supporting the Evaluation

3. Reply Form and Return Envelope

$œ:$ State WAP Program Manager

State Public Utility Commission

DOE Support Office WAP Program Manager

File - RC 


\section{Department of Energy \\ Washington, DC 20585}

July 16,1991

Dear Utility Manager.

In April of 1991 your utility received a letter from the the U.S. Department of Energy (DOE) concerning the National Evaluation of its Weatherization Assistance Program. A copy of this letter, which explains the purposes and national importance of this evaluation, is enclosed (Attachment 1). In response to this letter, many utilities returned a reply form to us describing the availability of their data. We greatly appreciate the high level of cooperation we have experienced thus far.

As explained in the letter of April 26, we need your help to determine program energy savings. Specifically, we need monthly residential customer utility billing recc:ds from January 1988 to the present for a sample of dwellings in your service area that are in the DOE weatherization program. The name, address, and telephone number of your State's weatherization program manager is in Attachment 2.

Data requirements for the study of energy savings are explained in Attachment 3 which is printed on blue paper. The entire blue attachment should be forwarded to your data processing staff. For each address printed in Attachment 3 we need billing records covering the time period of January 1988 through the most recent billing period (May or June 1991). At a minimum, we need the following for each record:

- a unique customer account number.

- the consumption for each billing period (e.g., $2150 \mathrm{kWh}$, or $120 \mathrm{ccf}$, or, 200 therms),

- the amount billed for consumption during each billing period,

- the meter reading date for each billing period,

- an indication of whether a reading is actual or estimated, and

- an explanation of billing codes.

In this study, we need to track consumption for a given address or dwelling even if the occupants change. Please include the dwelling's billing records for the entire time period (January 1988 through the present) even if the occupants of the dwelling have changed. Since the account also may have changed, please include all applicable account numbers too.

If at all possible, we also would like to collect information on the effects of weatherization on arrearages and fuel cutoffs. To analyze such impacts, we need the types of data discussed in Attachment 3. These data include information on:

- customer payment records,

- fuel assistance payments,

- fuel cutoffs, and

- participation in forgiveness programs.

We realize that you may not have all of the data discussed in Attachment 3. If you would provide as much of it as you can, some analysis of impacts on arrearages will often be possible. The data essential for the analysis of energy savings is, of course, the most critical information for our study. 
Although we can accept the transfer of these records on any medium, it would be most convenient if you can transfer the records by computer tape or diskette. If convenient, we would prefer that the data be sent in ASCII or EBCDIC format. If the data are on tape or cartridge, please provide a labeled medium. A file transfer media form is enclosed as part of Attachment 3; be sure to use this form when transferring electronic records. In addition, please provide the record format for your data. To meet our project's deadlines, we need to receive the requested information by August 26, 1991. The data should be sent to Marilyn Brown of Oak Ridge National Laboratory at the address in the box below.

Please include as much of the information shown in Attachment 3 as possible for the enclosed list of dwellings. We will analyze the data you provide and send you reports that document the results. These reports should be useful to you in planning programs for your low-income customers. They also will provide guidance for the DOE's energy policymakers and Weatherization Assistance Program staff.

The National Weatherization Evaluation includes a study of the persistence of energy savings for up to three years after a dwelling is weatherized. We will, therefore, make a second request for billing records for the enclosed list of residential accounts in 1993 for the period of May 1991 to April 1993.

If you have any questions, or foresee any obstacles to meeting our August 26, 1991 deadline, please contact either the DOE or the Oak Ridge National Laboratory Project Manager. Please send the data to Oak Ridge at the address below.

Darrell A. Beschen U.S. Department of Energy CE-532 1000 Independence Ave., SW Washington, DC 20585 Telephone (202) 586-1732
Marilyn A. Brown

Oak Ridge National Laboratory

P.O. Box 2008

Oak Ridge, Tennessee 37831-6206

Telephone: (615) 576-8152

FAX: 615-574-4747

We greatly appreciate your assistance with this important project.

Sincerely,

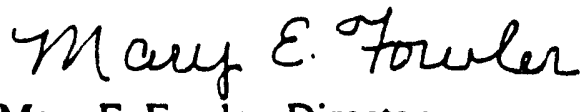

Mary E. Fowler, Director

Weatherization Assistance Programs Division

Enclosure 1. Attachment One: Introductory Letter of April 26

2. Attachment Two: State Program Manager Informatic $\pi$

3. Attachment Three: Data Requirements (3A), Consumption Record Sample Format (3B), '.ist of Dwellings (3C), Reply Form (3D) and File Transfer Media Form (3E)

File - RC 


\section{Department of Energy}

Washington. DC 20585

November 20, 1991

FL0010

Vice President, Customer Relations

Florida Power Corporation

P.O. Box 158

Crawfordville, FL 32327

Dear Vice President, Customer Relations:

RE: Your Help Obtaining Data for the DOE National Weatherization Evaluation

Your help is needed to obtain fuel consumption data for the most comprehensive national study ever conducted of the effectiveness of the U.S. Department of Energy's Weatherization Assistance Program (WAP). The national evaluation of the WAP is being conducted by DOE with the assistance of Oak Ridge National Laboratory (ORNL). An executive overview of the National Weatherization Evaluation is enclosed (Attachment 1) along with a list of several of the agencies, utility associations, and regulatory associations that support the evaluation and advised us to solicit your help (Attachment 2). The evaluation is being conducted to provide utilities and government agencies with information that they need to plan and implement effective energyefficiency programs for low-income residential markets. We believe the evaluation will be useful to many groups, including the utility industry.

The evaluation is being implemented with the assistance of many key national associations serving the utility industry. The Working Group members (listed in Attachment 2) have provided advice to us over the past 18 months to ensure that the evaluation meets the needs of their constituencies. Successful completion of the project now depends greatly upon your assistance. and we hope that you, like your colleagues in the national associations, will provide support for this effort.

In July, DOE wrote to at your utility requesting fuel consumption information on a sample of about 18 homes weatherized between April 1, 1989 and March 31, 1990. At this time we have not received a response to our data request. Would you please look into this matter for me? If the data already have been sent, please convey our thanks to $\cdots \ldots \ldots$ If the data have not yet been sent to ORNL, would you please expedite a response. In the event that the data request package sent in July has been misplaced, please have someone contact the ORNL Project Manager, Dr. Marilyn Brown, at (615) 576-8152 (FAX: 615-574-4747) for a replacement. We need to have the requested data by December 6 to avoid a major delay in the three-year study.

The data your utility provides us will be kept in strictest confidence. Access to the "raw" data which identifies the resident will be limited to staff working on the evaluation for the DOE 
and ORNL. Both facilities have restricted public access. Data shared with those conducting further analysis will be stripped of all identifiers of individuals and specific homes to ensure their anonymity. No information regarding specific utilities, individuals, or dwelling units will be published in any of the evaluation's reports. The only data we will publish will be aggregate statistics that do not allow utilities, individuals, or dwelling units to be singled out. While the payment history information would make the study's conclusions more useful to policymakers. it is not vital to the study and need not be provided if the utility feels it is privileged information (See Attachment 3).

Please call me if you have any questions. I can be reached at 202-586-2238. Since we had hoped to receive the data from your utility in October, would you please urge your staff to provide the information to ORNL by December i? Your utility's assistance is vital to the success of this important national study. Your support will make it possible to provide the DOE and the utility community with information about the most cost-effective approaches to providing energy-efficiency services to low-income residential markets. If you have any questions, or foresee any obstacles to meeting our December 6 deadline, please contact me (at 202-586-2238 or Marilyn Brown at ORNL (at 615-576-8152). We greatly appreciate your assistance with this important project.

$$
\begin{aligned}
& \text { Sincerely, } \\
& \text { Darrell A. Beschen } \\
& \text { Darrell A. Beschen } \\
& \text { Evaluation Project Manager }
\end{aligned}
$$

\section{$\mathrm{DAB} / \mathrm{MAB} / \mathrm{dpb}$}

\section{Attachments}

1: Overview of the National Weatherization Evaluation

2: Key Organizations Supporting the Evaluation

3: Example of Fuel Consumption Sample Format

cc: Marilyn Brown (ORNL)

File - RC 


\title{
State of Wisconsin \ PUBLIC SERVICE COMMISSION
}

\author{
December 11, 1991
}

\author{
CHARLES H. THOMPSON, CHAMMAN \\ JOHN T. COUGHLN, COMMISSIONEA \\ CHERYL L PARAINO, COMMIBSIONEA \\ 4802 Shoboygan Avenue \\ P. O. Box 7854 \\ Madison, Wisconsin 53707-7854
}

\section{Subject: Your Urgent Assistance to Obtain Data for Important National Study}

Dear Commission Chair:

Your help is urgently needed to obtain missing data for the most comprehensive national study ever conducted of the effectiveness of low-income weatherization programs. Your agency is represented in this study by the participation of two NARUC delegates. The study's managers have requested crucial data from utilities in your state, but some of this information has not been received. This data must be obtained by December 30 to avoid a major delay in the three-year study.

In May of this year you received a copy of the correspondence that was sent to gas and electric utilities in your State describing the U.S. Department of Energy's national evaluation of the Weatherization Assistance Program (WAP). The evaluation is being conducted by DOE with the assistance of Oak Ridge National Laboratory (ORNL). A description of the National Weatherization Evaluation is enclosed (Attachment 1) along with a list of some of the many agencies, utility associations, and regulatory representatives that support the evaluation (Attachment 2).

This nationally significant evaluation will provide utilities, regulators, and government agencies with information that will help them to plan and implement effective energy-efficiency programs for low-income residential markets. It is the largest (48 states, 400 local agencies, 500 utilities, and 10,000 dwellings) and most comprehensive evaluation of this nationwide residential energy conservation program ever conducted, and we believe that it will be very useful to many of its constituents, including the regulatory community. As your NARUC representatives for this study, we strongly urge you to support this important study by encouraging the utilities in your State to supply the missing energy consumption data. The data the utilities provide will make it possible to develop information about cost-effective and innovative approaches to providing energy-efficiency services to low-income residential markets.

In July, DOE/ORNL contacted some of the utilities in your State to request fuel consumption information on a sample of homes weatherized with WAP funding between April 1, 1989 and March 31, 1990. DOE/ORNL has received data from some of these utilities, but others have not yet responded or have provided incomplete data (See Attachment 3).

The assistance of these utilities is vital to the success of this important national study. Would you please encourage the nonresponding utilities in your State to provide the data that were requested? A suggested letter to the President, CEO, or General Manager of nonresponding utilities is enclosed as Attachment 4. We hope you will send a letter like this to the utilities that have not yet responded to the DOE/ORNL data request. The appropriate label from Attachment 3 should be placed on this letter before sending it to each 
nonresponding utility. In addition to the letter, a telephone call to the large utilities might help to expedite data collection. It also would be helpful to DOE/ORNL to be able to track your correspondence with the utility managers so that they can refer to it in future contacts. It would, therefore, be useful if you would see that the letters you send are copied to the ORNL Project Manager, Dr. Marilyn A. Brown. Her address is P.O. Box 2008, Bldg. 4500N, MS-6206, Oak Ridge, Tennessee 37831-6206 (FAX 615-574-4747). Alternatively, if you wish, you may call and ask Marilyn for assistance in preparing a mailing to the nonresponding vitilities in your state.

The data that utilities provide to DOE/ORNL will be kept in absolute confidence. Access to the "raw" data which identifies the resident will be strictly limited to staff working on the evaluation for DOE and ORNL. Both facilitics have restricted public access. Data shared with those conducting further analysis will be stripped of all identifiers of individuals and specific dwellings to ensure their anonymity. No individuals or dwelling units will be specifically identified in any of the evaluation's reports. The only data to be published will be condensed statistics that do not allow individuals or dwelling units to be singled out. In addition, the most sensitive information on payment histories is not vital to the study if you or the utility contacts consider it privileged information. Although only the fuel consumption information is essential to the study's major goals, it would greatly help the study's usefulness to policymakers if the payment histories were included. Again, such data will be kept absolutely confidential.

Please call Darrell Beschen at DOE (202-586-2238) or Marilyn Brown at ORNL (615-576-8152) if you have questions. It is important that you consider acting on this request as soon as possible. Thank you, in advance, for encouraging the utilities in your State to participate in this important project.

Sincerely,

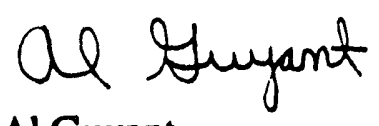

Al Guyant

Consumer Programs Manager

Public Service Commission

Wisconsin

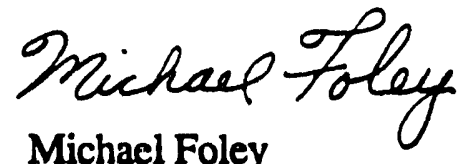

Director of Financial Analysis

National Association of Regulatory Utility of Commissioners
cc: Darrell A. Beschen (DOE)
Marilyn A. Brown (ORNL)
File - RC

Attachment 1: Overview of the National Weatherization Evaluation

Attachment 2: Key Organizations Supporting the Evaluation

Attachment 3: List of Nonresponding Utilities

Attachment 4: Suggested Letter to Utility Contacts 


\section{APPENDIX B-3 \\ EXAMPLES OF DATA COLLECTION FORMS}


OMB Approval No.: 1910-1400

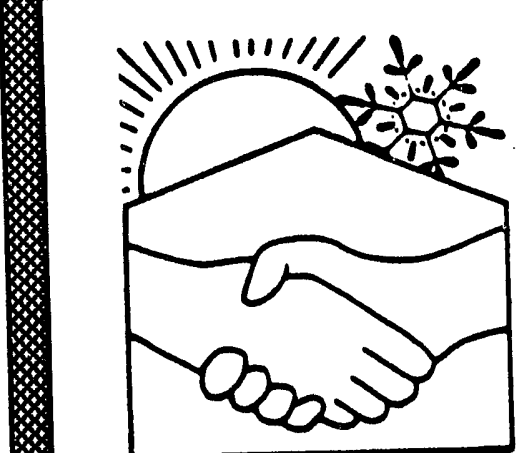

\section{NATIONAL WEATHERIZATION EVALUATION}

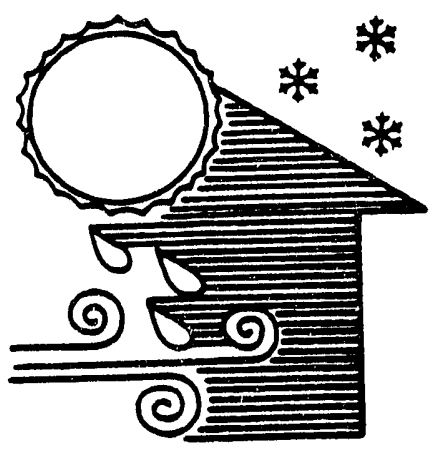

\section{DWELLING-SPECIFIC FORM}

\section{DWELLING AND OCCUPANT CHARACTERISTICS, WEATHERIZATION MEASURES AND COSTS FOR DWELLINGS WEATHERIZED IN THE 1989 PROGRAM YEAR}

Agency contact, address, and telephone number

(please complete or correct, as necessary):

Name, address, and identification number of dwelling (please complete or correct, as necessary): 


\section{A. DWELLING CHARACTERISTICS AND EQUIPMENT}

A1. When was the weatherization completed on this dwelling?

Month (CIRCLE YEAR) 1989 1990*

*If this house was not we.therized between April 1, 1989 and March 31, 1990, it should not be in the sample and no further information is needed. Please return this form along with the others.

A2. Is this dwelling a. .. ?** (MARK ONE)

[] Mobile/manufactured home

[] Single-family detached

[] Single-family attached (townhouse or rowhouse)

[] Small multifamily (2-4 units)

[] Large multifamily (5 or more units) ${ }^{* * *}$

**Our definitions of single-family and small (2-4 unit) multifamily dwelling units are the same as those used by DOE's Residential Energy Consumption Survey (RECS). The RECS definitions are given on the accompanying agency information form.

***If this dwelling is part of a large multifamily building, it should not be in the sample and no further information is needed. Please return this form along with the others.

A3. At the time of weatherization, what was the conditioned (heated or cooled) square footage of this dwelling? (include the basement only if it is conditioned) conditioned square feet

A4. At the time of weatherization, did members of this household own this home or did they rent? (MARK ONE)

[ ] Own (buying)

[] Rent

[] Occupied without payment 
A5. At the time of weatherization, what was the one main heating fuel used for heating this home? (MARK ONLY ONE FUEL IN COLUMN A5)

A6. What supplemental fuels were used to heat the home -- including those used to provide heat just occasionally? Include fuels that ran portable heaters if they were used. MARK ALL THAT APPLY (If none, mark "No supplemental fuels used" in Column "A6" below.)

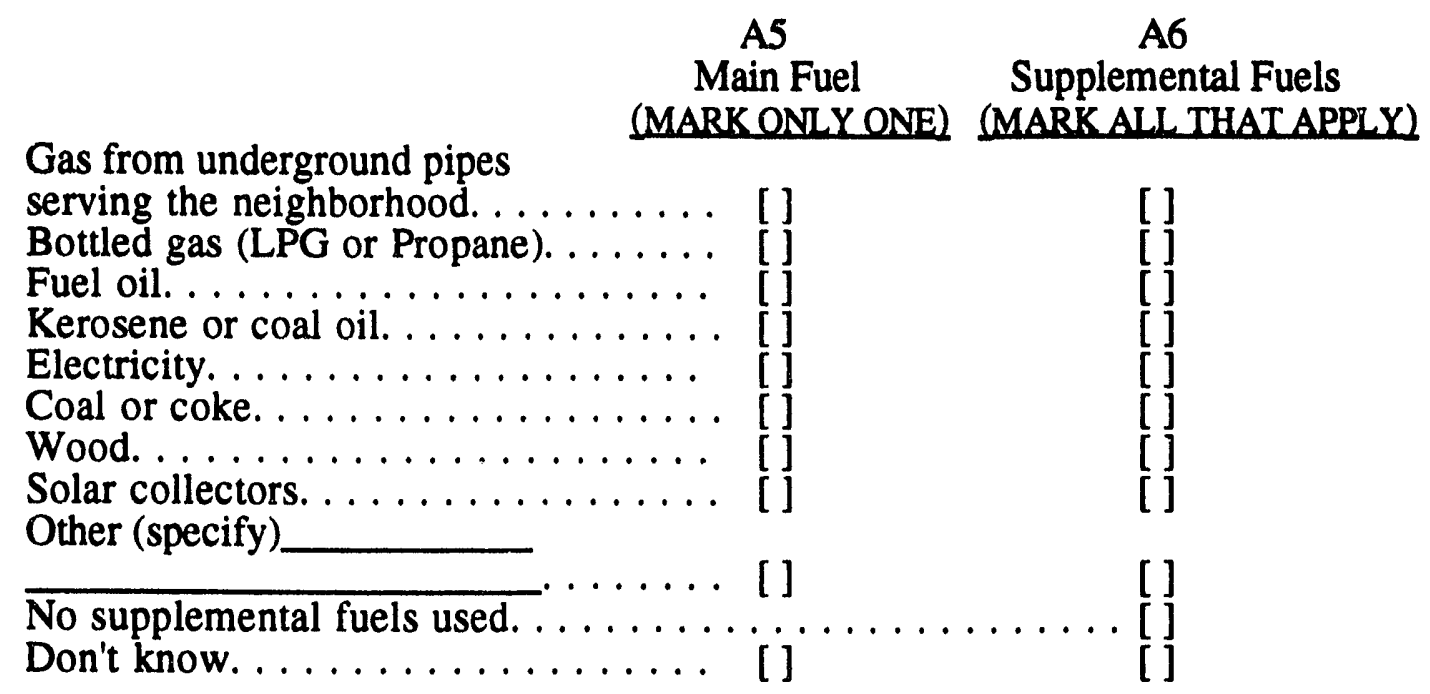

A7. If this household's main fuel is gas or electricity, please provide the name of the gas (if any) and electric utility companies that provide service to this dwelling and the household's utility account numbers.

Electric Utility

Gas Utility

\begin{tabular}{c}
\hline Account Number \\
\hline Account Number
\end{tabular}

A8. Which heating system types were used in this home? (MARK ALL THAT APPLY)

[ ] Central systems (e.g., forced air furnace, central gravity furnace, steam boiler, hot water boiler, heat pump)

[ ] Fossil fueled in-space heaters (e.g., wall furnaces, floor funaces, wood, coal, kerosene or gas stoves)

[ ] Electric in-space heaters (e.g., wall, floor, baseboard, imbedded cable, portable [cord connected])

[ ] Both central and in-space

[ ] Other (specify)

[ ] Don't know 
A9. About when was this dwelling originally built? (MARK ONE)
[] Before 1900
[] $1900-1909$
[1] 1910-1919
[1] 1920-1929
[] 1930-1939
[ ] 1940-1949
[] 1950-1959
[] 1960-1969
[] 1970-1979
[] 1980-1984
[] 1985 or later

A10. Does this dwelling have central air conditioning equipment ? (MARK ONE)
[ ] Yes
[] No
[] Don't know

A11. How many wall or window unit air conditioners does it have? (MARK ONE)
[ ] None
[] 1
[1 2
[] 3
[] 4 or more
[] Don't know

\section{B. OCCUPANT CHARACTERISTICS}

B1. Please indicate the total number of persons living in this house at the time of weatherization and the number who were elderly or handicapped.

Total number:

Number of elderly:

Number of handicapped:

B2. What was the household's income on the application form at the time when its eligibility was verified for the services it received in the 1989 program year?

$\$$ 


\section{WEATHERIZATION MEASURES INSTALLED}

Please check any of the measures listed that were installed in this dwelling. Indicate whether they were installed by in-house crew or contractor. If measures that are not listed were installed, please describe them in the appropriate "Other" category.

C1. Insulation

$$
\begin{aligned}
& \text { Installed by: } \\
& \text { In-house Contractor } \\
& \text { crew }
\end{aligned}
$$

Attic Insulation (installed for the first time)....... [ ]

Attic Insulation (added to existing insulation). ..... [ ]

*Wall Insulation (normal technique). . . . . . . []

*Wall Insulation (high-density technique)....... [ ]

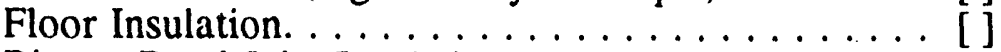

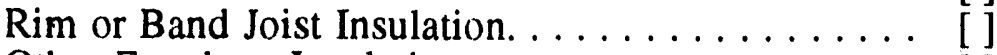

Other Envelope Insulation. . . . . . . . . . [ ]

(Specify:

*The "normal technique" for installing wall insulation is characterized by blowing cellulose or fiberglass insulation into exterior wall cavitites to average densities using a two-hole, gravity-blow installation method. The "high-density technique" is characterized by blowing cellulose insulation into exterior wall cavities to high densities using a one-hole, tube-fill installation method. Under the "high-density technique," special attention is focused on sealing air leakage sites while insulating the walls; air bypasses are identified during the installation process and sealed by plugging the airleakage pathways with cellulose.

C2. Air Leakage Control

General Caulking and Weatherstripping........ [ ] [ ] (door and window)

Air Sealing, emphasizing bypasses with ....... [ ] [ ]

Air Sealing, emphasizing bypasses without ...... [ ] [ ]

Distribution System. $\ldots \ldots \ldots \ldots \ldots \ldots \ldots \ldots \ldots \ldots \ldots \ldots$
Other Infiltration Reduction. $\ldots \ldots \ldots \ldots \ldots$

(Specify: 
C3. Water Heating System

$$
\begin{aligned}
& \text { Installed by: } \\
& \text { In-house Contractor } \\
& \text { crew }
\end{aligned}
$$

Water Heater Tank Insulation. ............. [ ]

Entire Water Heating System Replacement. ....... [ ]

Pipe Insulation. . . . . . . . . . . . . . [ ]

Low Flow Shower Heads. . . . . . . . . . . . [ ]

Temperature Reduction. ................ []

Other Water Heater Measures.

(Specify:

C4. Structural Repairs (full or partial)

Attic Ventilation. ................ [ ]

Roof...................... []

Doors. . . . . . . . . . . . . . . . . . . []

Replacement of Doors. ............... []

Windows/Glazing. . . . . . . . . . . . . []

Replacement of Windows. . . . . . . . . . []

Walls. . . . ...................... []

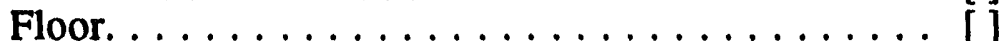

Other Structural Repairs.

(Specify:

C5. Windows and Doors

Storm Windows (How many?

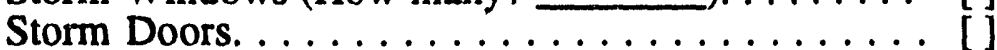

Window Films or Shades. . . . . . . . . . . []

Other Window or Door Treatments.

[]
[]
[]

(Specify:

\section{)}

C6. Mobile Home Measures

Vapor Barrier. . . . . . . . . . . . . . . [ ]

Underpinning/Skirting. . . . . . . . . . . . [ ]

Cool Seal (on roof) . . . . . . . . . . . . . [ ]

Other.

(Specify: 
C7. Space Heating System

$$
\begin{aligned}
& \text { Installed by: } \\
& \text { In-house Contractor } \\
& \text { crew }
\end{aligned}
$$

Clean and Tune-up. ................. [ ]

Entire Heating System Replacement. . . . . . . . . . . [ ]

Set-back Thermostat. ................. [ ]

Heating System Component Retrofits.

[]
[]
[]

(Specify:

Safety Problem Fixed. . . . . . . . . . . . [ ]

(Specify:

Repairs...................... []

(Specify:

Other Heating System Modifications. .......... [ ]

(Specify:

C8. Space Cooling System

Tune-up. .................... [ ]

(e.g., cleaning, controls adjustment, filter replaced)

Entire Air-conditioning System Replacement ....... [ ]

Fans Installed or Replaced. . . . . . . . . . . . . . []

Set-back Thermostat. . . . . . . . . . . . . . . []

Other Cooling System Modifications. .......... []

(Specify:

C9. Other Health and Safety Repairs or Improvements

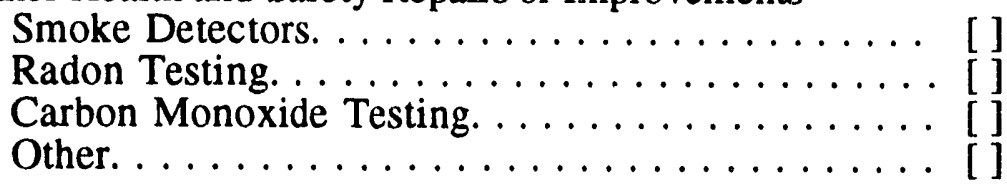

[]
[]
[]

(Specify: 


\section{SERVICE DELIVERY PROCEDURES}

\section{Selection of Measures}

D1. Please check the type of procedure that was used to select the measures that were installed in this dwelling in the 1989 program year. (CHECK ALL THA'T APPLY)

[] Envelope measures were selected using a priority or prescribed list of measures

[ ] Envelope measures were selected using a decision approach or scoring (calculation) developed for each house

[] Envelope measures were selected based on an analysis of energy savings per \$ invested

[ ] Space-heating system measures were selected based on physical characteristics or a standard approach

[ ] Space-heating system measures were selected using a decision approach or scoring (calculations) based on cperating performance

[ ] Space-heating system measures were selected based on an analysis of energy savings per $\$$ invested

[] Selection of envelope and space-heating system measures was made simultaneously under one approach rather than separately using two distinct procedures.

[] Other measure selection procedures. Specify:

Use of Diagnostics

D2. Please check the type of diagnostic procedures that were used in this dwelling in the 1989 program year. (CHECK ALL THAT APPLY)

[ ] Blower door testing was used to find leakage areas for sealing

[ ] Blower door testing to measure air leakage rates

[] Blower door testing was used to determine when to stop work using cost-effectiveness guidelines (not minimum ventilation guidelines)

[ ] Distribution system diagnostics were used to find leakage areas for sealing

[ ] Distribution system diagnostics were used to determine system balancing

[ ] Infrared scanning was used

[] Indoor air quality testing was used

[] Heating system efficiency testing was used

[ ] A heating system safety inspection was conducted

[] Other diagnostic procedures. Specify:

Ouality Control

D3. Please indicate the type of quality control inspection this house received in the 1989 program year. (CHECK ALL THAT APPLY)

[ ] A visual quality control inspection after weatherization for envelope measures

[] A quality control inspection after weatherization for envelope measures that used blower door testing as a diagnostic tool

[ ] A quality control inspection after weatherization for envelope measures that used infrared scanning as a diagnostic tool

[ ] A visual quality control inspection after weatherization for heating system measures

[] A quality control inspection after weatherization for heating system measures that used diagnostic tools such as combustion efficiency testing

[ ] Other quality control procedures. Specify: 


\section{E. COSTS: MATERIALS, LABOR, INSTALLATION OVERHEAD AND PROGRAM MANAGEMENT}

\section{Definitions and Instructions}

If a job is crew-based, supply the materials costs (Question E1) and calculate the direct labor costs (Question E2). If a job is contractor-based, supply the materials costs (Question E1) and the total installed costs (Question E3). If both crews and contractors worked on a house, complete all three questions (Questions E1, E2, and E3). If you need further instructions, please see the instructions in the agency information form.

Figure 1. Program Cost Categories

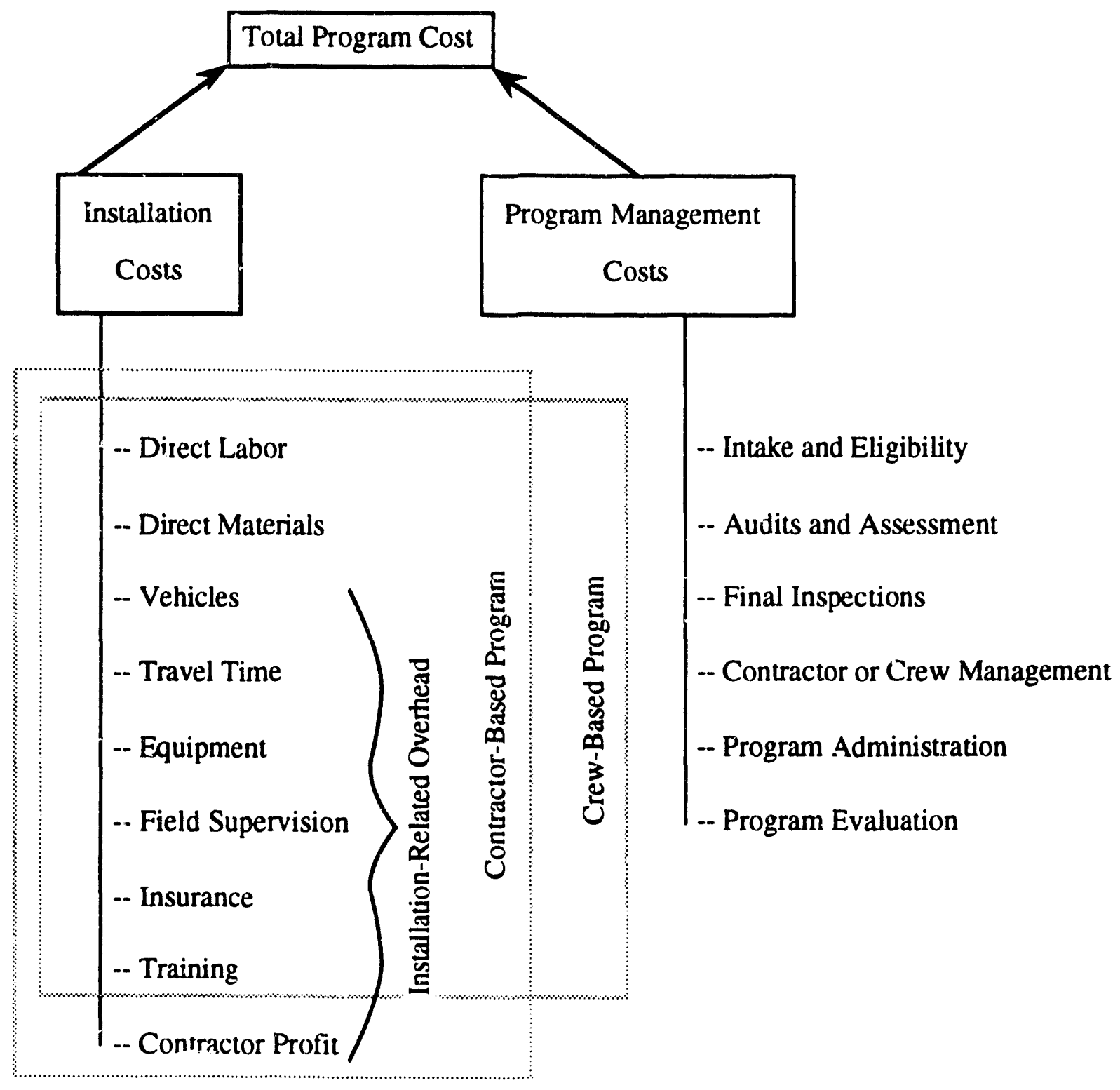




\section{E1: BREAKDOWN OF MATERIALS COSTS}

In the chart below please fill in the crew-based and/or contractor-based materials cost of the measures that were installed in this dwelling in the 1989 program year. Do not include labor, administrative or program support costs here. Do include costs covered by all sources of funding (i.e., PVE, LIHEAP, or utilities). If you cannot provide the costs by measure, just enter the total materials cost in the box at the bottom.

Insulation

Crew-Based

Materials

Costs
Contractor-Based

Materials

Costs

attic

$$
\$
$$

wall

other

Air Leakage Control

Water Heating System Measures

Structural Repairs

Winciows and Doors

$$
\$
$$

$\$$

$\$$

$\$$

$\$$

$\$$

Space Heating System

retrofit

replacement

$\$$

$\$$

Space Cooling System

retrofit

replacement

Other

$\$$

$\$$

$\$$

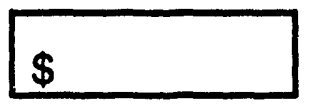

Crew-Based

Total Materials Costs
$\$$

$\$$

$\$$

$\$$

$\$$

$\$$

$\$$

$\$$

$\$$

$\$$

$\$$

$\$$

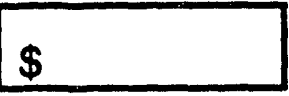

Contractor-Based

Tota! Materials

Costs 


\section{E2: CREW-BASED INSTALLATION COSTS}

Directions: Please fill in the number of crew hours for this house from information in your files. Provide your best estimate of the average hourly rate for your crew and multiply this by the number of hours to produce an estimate of the direct labor costs.

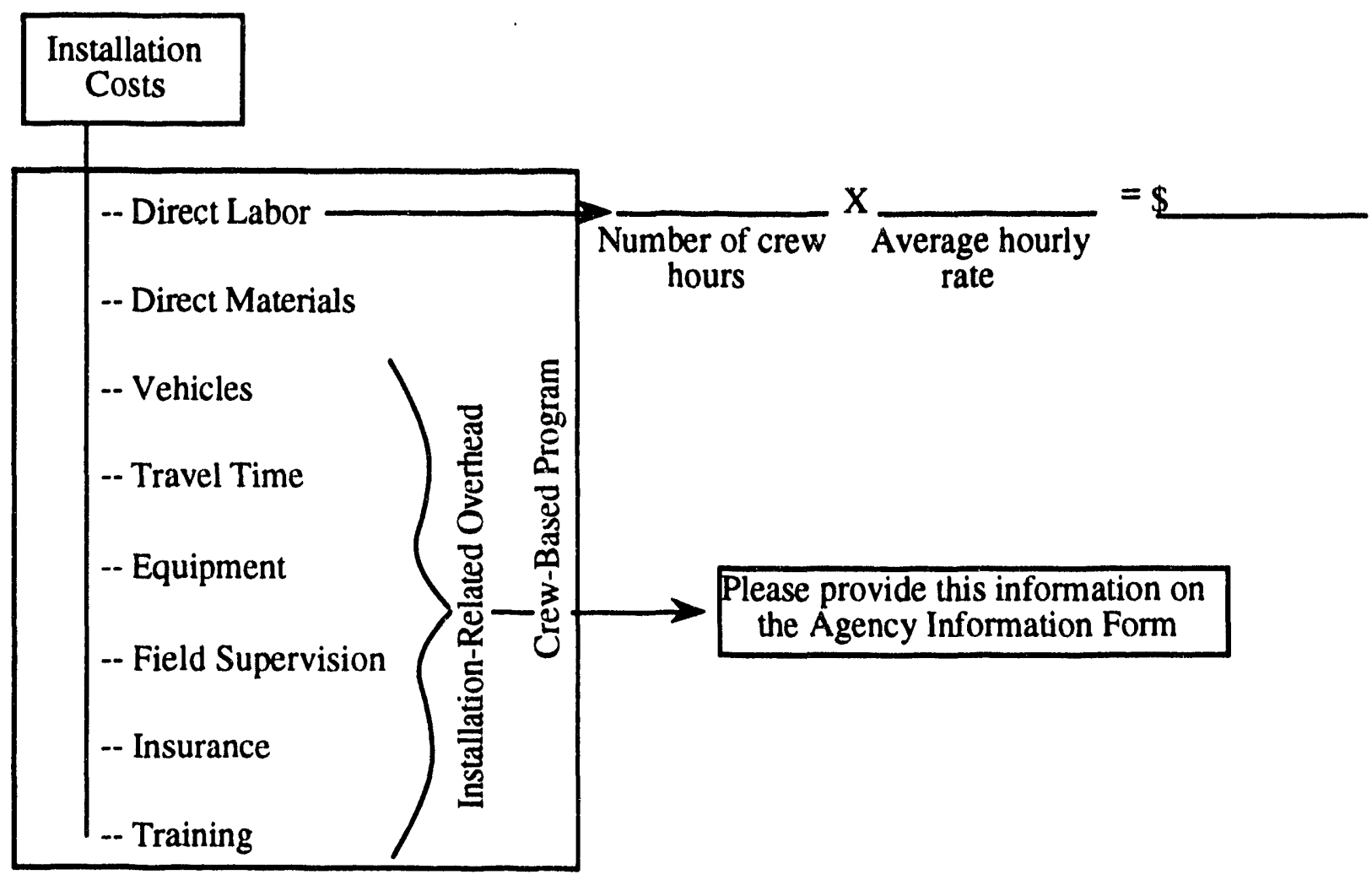

\section{E3: CONTRACTOR-BASED INSTALLATION COSTS}

Directions: Please fill in the total installation costs* billed by contractors for this house. This should include all the cost categories listed above plus the contractor's profit. Total Installed Cost $\$$ *Include the materials costs (reported on p.9) in this total, as well as labor costs and installation-related overhead.

\section{F. FUNDING SOURCES}

F1. What percentage of the funds spent on this house were funds from DOE's WAP? $\%$

F2. If funds from non-DOE sources were used, were they all used according to DOE guidelines?

[] Yes

[] No 


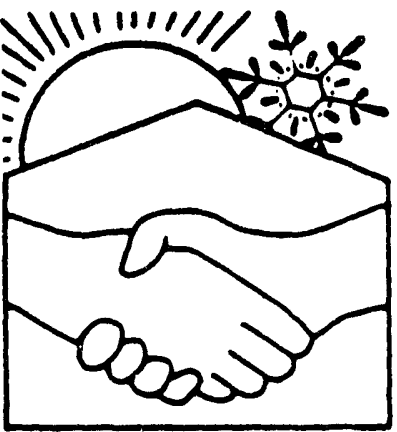

\section{NATIONAL WEATHERIZATION EVALUATION}

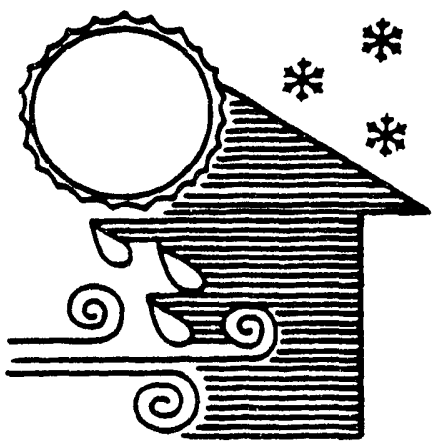

AGENCY INFORMATION FORM

Agency id \#, contact, address, and telephone number:

When you finish filling out this form, the dwelling-specific forms, and the waiting list forms, please estimate the amount of staff time it took to complete them. hours 


\section{AGENCY INFORMATION FORM}

A. Please provide the name(s) and telephone numbers of staff member(s) completing these forms, just in case we have any questions about the answers.

Name:

Phone \#:

\section{B. COST DEFINITIONS AND INSTRUCTIONS}

There are two types of forms included in this package: this form (the Agency Information Form) and a Dwelling-Specific Form for each dwelling in the random sample.

Figure 1 on page 2 provides background information for completing questions E1 to E3 of the Dwelling-Specific Form and for completing the information on installationrelated overhead and program management costs on pages 3 and 4 of this form.

The total cost of a program can be divided into installation costs and program management costs (Fig.1). Total installation costs include the costs of materials, direct labor and overhead expenses that are directly related to the installation process, such as the costs of vehicles, travel, equipment, insurance, field supervision, and training. When contractors deliver services, these installation overhead expenses are included, along with a profit, in the charges made for a job. When agency crews do the work, some of the installation overhead expenses may not be tracked directly on a per-house basis. As a result, there are separate questions for crew vs. contractor installation costs on both of the forms.

If a job is crew-based, supply the materials costs (Question E1 of the DwellingSpecific Form) and calculate the direct labor costs (Question E2 of the Dwelling-Specific Form). If a job is contractor-based, supply the materials costs (Question E1) and the total installed costs (Question E3). If both crews and contractors worked on a house, complete all three questions (Questions E1, E2, and E3 of the Dwelling-Specific Form).

Both crew-based and contractor-based programs should estimate an average program management cost per house weatherized (Question $\mathrm{Cl}$ on this Agency Information Form). The program management cost should be calculated by subtracting the total installation costs (labor + materials + installation-related overhead) for all houses weatherized in PY 1989 from the total agency budget (in PY 1989). The total program management cost should then be divided by the number of houses weatherized (in PY 1989) to produce an average per-house program management cost (Question C1). This estimate only needs to be recorded on the Agency Information Form because it will be the same for all houses.

If your agency has any crew-based jobs, the average per-house cost of installationrelated overhead expenses should be estimated (Question C 3 on this Agency Information Form). To do this estimate, your agency's costs for vehicles, equipment, liability insurance, training, travel time, field supervision and any other installation-related expenses in the 1989 program year (PY) should be summed and then divided by the number of homes weatherized in the 1989 program year. You only need to record your estimait uf the 
average per-house cost of installation-related overhead expenses once on the Agency Information Form because it will be the same for all houses.

We realize that different agencies track costs in different ways. Please just use your best judgement in estimating the average installation-related overhead and the average p. ogram management expenses. The dwelling-specific records of materials costs, crewbased labor hours, and contractor's total installed costs that are in your files should be coded onto a Dwelling-Specific Form for each house in the sample.

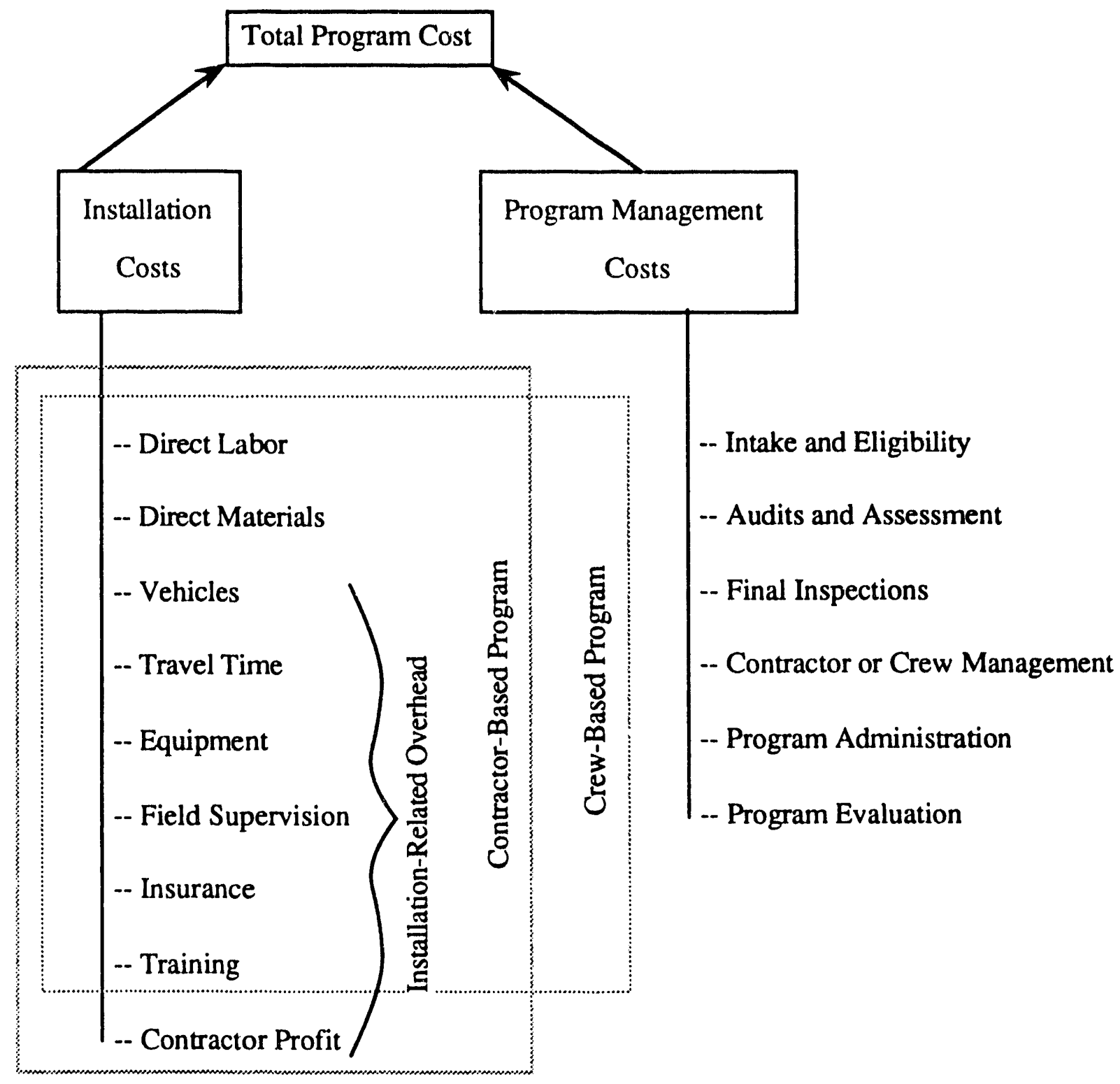

Figure 1. Cost Categories 


\section{AVERAGE AGENCY PROGRAM MANAGEMENT COSTS AND INSTALLATION-RELATED OVERHEAD}

\section{C1. AVERAGE PROGRAM MANAGEMENT COSTS}

Total Program Costs for PY 1989

$\$$

- Total Installation Costs* for All Houses Weatherized in PY 1989

$\$$

*Add all direct materials costs, labor costs, and installationrelated overhead together to obtain this cost figure.

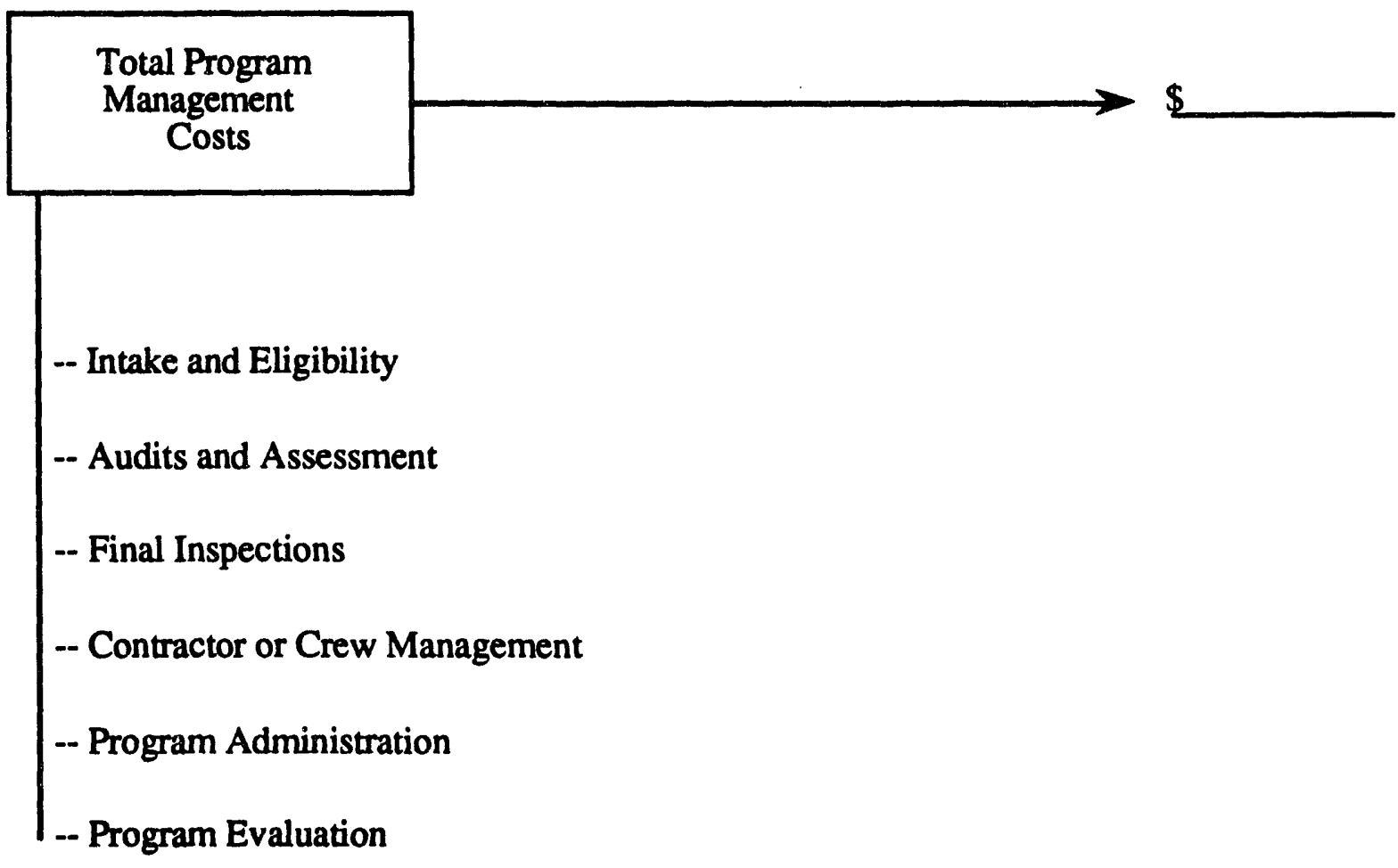
program management cost

**Divide the total program management costs for PY 1989 by the number of houses weatherized in PY 1989.

C2. Some program management costs (such as client intake and eligibility checks, or office space and expenses) may be absorbed by other programs or agencies (e.g., LIHEAP, Councils on Aging). What percentage of your program management costs would you estimate are absorbed by other programs or agencies?

$\%$ 
C3. CREW-BASED INSTALLATION-RELATED OVERHEAD

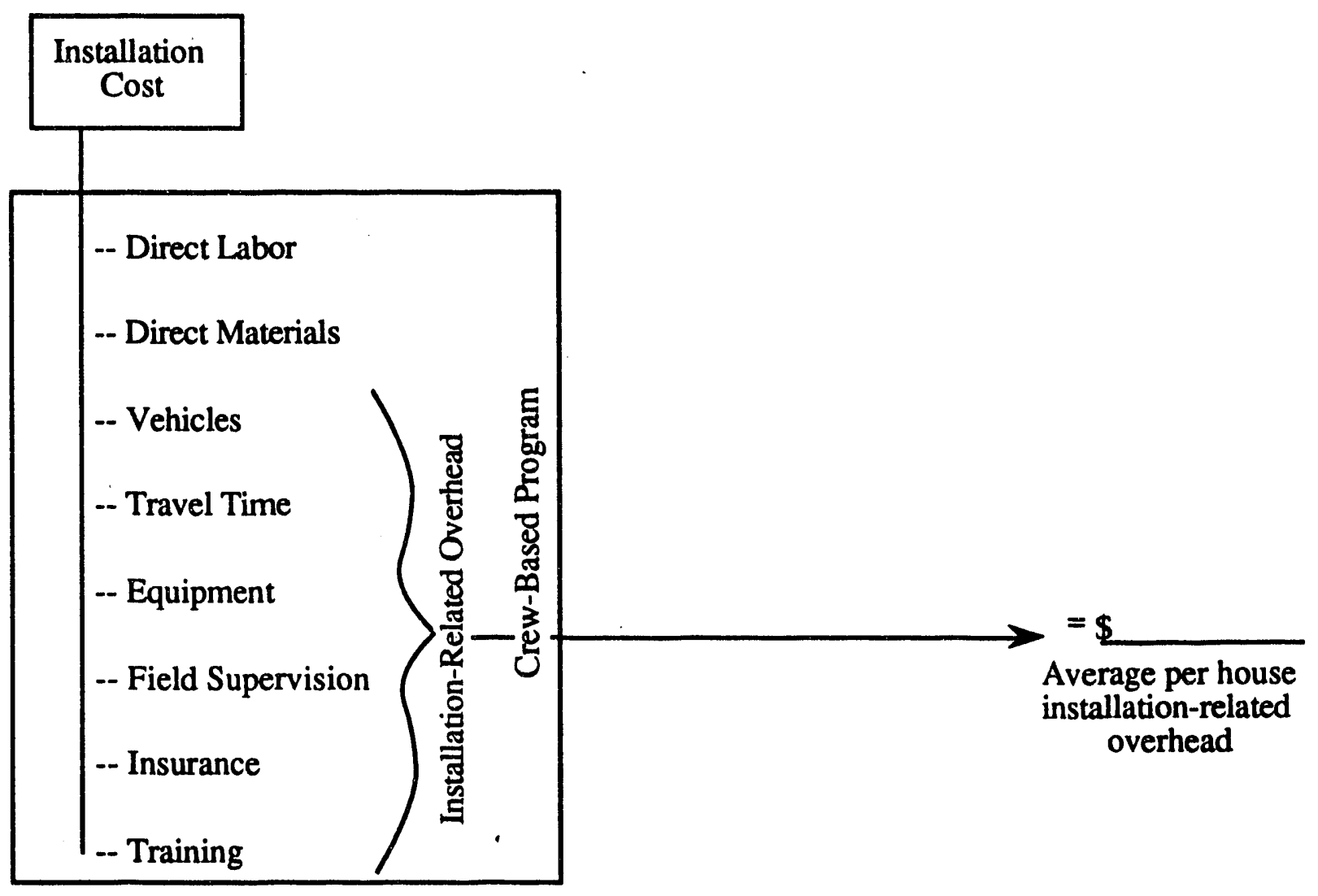

\section{HOUSING TYPE DEFINITIONS}

Definitions of single-family and small multifamily housing units for Question A2 on page 1 of the Dwelling-Specific Form:

[A] single-family housing unit [is] a structure that provides living space for one household or family. The structure may be detached, attached on one side (semidetached), or attached on two sides. Attached houses are considered single-family houses as long as the house itself is not divided into more than one housing unit and has an independent outside entrance. A single-family house is contained within walls that go from the basement (or ground floor, if there is no basement) to the roof.

[A] house or building with two to four housing units is a structure that is divided into living quarters for two, three, or four families or households. This category also includes houses originally intended for occupancy by one family (or for some other use) that have since been converted to separate dwellings for two to four families. Typical arrangements in these types of living quarters are separate apartments downstairs and upstairs, or one apartment on each of three or four floors. 
APPENDIX B-4

PROCEDURES FOR MATCHING WEATHER STATIONS TO HOUSING UNITS 


\section{PROCEDURE FOR MATCHING WEATHER STATIONS}

The ORNL approach to matching weather stations to housing units is based on three assumptions:

1. Considering only NOAA primary weather stations would not be sufficient for the purposes of the Weatherization Assistance Program evaluation, and the use of NOAA secondary weather stations would enable a more precise description of local weather conditions.

2. Proximity of a housing unit to a weather station plays an important role in the assignment process.

3. The assignment process must reflect the fact that climate varies at a greater degree in the north-south direction than in the east-west direction.

Using these assumptions, ORNL staff developed the following protocol for matching housing units to weather stations.

The first step involved identifying the geographic location of both the housing units to be studied and the potential weather stations (both primary and secondary). These locations were denoted in longitude and latitude.

Next, the weighted distance (D) between each housing unit and each weather station was calculated as:

$$
D=\sqrt{\left(\text { Lat }_{\text {IIU }}-\text { Lat }_{W S}{ }^{2}+(0.5)\left(\text { Long }_{H U}-\text { Long }_{w S}\right)^{2}\right.}
$$

where:

Lat $_{\text {Hu }}=$ The latitude of the housing unit
Lat $_{w s}=\quad$ The latitude of the weather station
Long $_{\text {HU }}=$ The longitude of the housing unit
Long

This is a weighted distance calculation in that distance in the west-east longitude contributes half of its actual distance to the total distance computed.

In circumstances where one or more days of temperature data are missing or considered questionable from a weather station data file, replacement of the daily values is done using the nearest NOAA primary weather station. 


\section{APPENDIX B-5}

SAMPLE WEIGHTING PROCEDURES 


\section{COMPUTATIONS FOR WAP \\ SINGLE FAMILY SAMPLING WEIGHTS \\ AND ESTIMATORS OF TOTALS AND MEANS}

This note gives a brief description of details for construction of sampling weights (or expansion factors) and estimators of totals and means for the WAP Single-Family sample data.

There are 60 ( = 10 Subregions X 6 CAP Categories) strata. What follows is a brief description of the computation of sampling weights (or expansion factors) for stratum 11 (i.e.. Subregion $=1$ and CAP Category $=1$ ) sample data.

The number of CAPs in stratum 11 is $N_{11}=10$.

The number of responding CAPs in stratum 11 selected for the random sample of CAPs is $n_{11}=5$.

Now, each of the responding $n_{11}=5$ CAPs selected for the sample has three types of houses of interest:

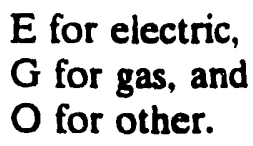

For the $i^{\text {th }}$ CAP selected for the sample where $i=1,2,3,4,5\left(=n_{11}\right)$, let

$M_{\text {HIiE }}=\quad$ the total number of "electric" houses in the th sample CAP from stratum 11,

$M_{\text {IIiG }}=$ the total number of "gas" houses in the $i^{\text {th }}$ sample CAP from stratum 11, and

$M_{11 i 0}=$ the total number of "other" houses in the $i^{\text {th }}$ sample CAP from stratum 11.

Thus each sample CAP has three types of houses and independent simple random samples were selected from each type. Let

$r_{\text {liiE }}=$ the number of sample "electric" houses in the $i^{\text {th }}$ sample CAP for stratum 11 for which we have reported data,

$r_{\text {lliG }}=$ the number of sample "gas" houses in the $i^{\text {th }}$ sample CAP for stratum 11 for which we have reported data, and

$r_{11 i 0}=$ the number of sample "other" houses in the $i^{\text {th }}$ sample CAP for stratum 11 for which we have reported data.

The following sample weights are suggested for the houses in stratum 11. 


\section{Type of House Heating System}

Stratum 11

Sample CAP

1

2

3

Electric

Gas

Other

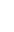

$\frac{N_{11}}{n_{11}} \cdot \frac{M_{111}}{r_{11 E}}$

$\frac{N_{11}}{n_{11}} \cdot \frac{M_{1116}}{r_{1116}}$

$\frac{N_{11}}{n_{11}} \cdot \frac{M_{1110}}{r_{1110}}$

$\frac{N_{11}}{n_{11}} \cdot \frac{M_{112 E}}{r_{112 \Sigma}}$

$\frac{N_{11}}{n_{11}} \cdot \frac{M_{112 G}}{r_{112 G}}$

$\frac{N_{11}}{n_{11}} \cdot \frac{M_{1120}}{r_{1120}}$

$\frac{N_{11}}{n_{11}} \cdot \frac{M_{113 Z}}{r_{113 \delta}}$

$\frac{N_{11}}{n_{11}} \cdot \frac{M_{113 G}}{r_{113 G}}$

$\frac{N_{11}}{n_{11}} \cdot \frac{M_{1130}}{r_{1130}}$

4

$\frac{N_{11}}{n_{11}} \cdot \frac{M_{114 E}}{r_{114 E}}$

$\frac{N_{11}}{n_{11}} \cdot \frac{M_{114 G}}{r_{114 G}}$

$\frac{N_{11}}{n_{11}} \cdot \frac{M_{1140}}{r_{1140}}$

$5\left(=n_{11}\right)$

$\frac{N_{11}}{n_{11}} \cdot \frac{M_{115 E}}{r_{115 E}}$

$\frac{N_{11}}{n_{11}} \cdot \frac{M_{1150}}{r_{1150}}$

$\frac{N_{11}}{n_{11}} \cdot \frac{M_{1150}}{r_{1150}}$

The above steps leading to the sampling weights in the table for stratum 11 are to be repeated for each of the remaining 59 strata.

NOTES: (i) The weights reflect the way in which the sample of houses was selected and lead to unbiased estimators of totals and means, assuming that the nonrespondent houses are similar to the responding houses. First a simple random sample of CAPs, then a simple random sample of houses from each type of houses in the sample CAPs is selected. In general, the form of the sampling weight is

$$
w=\frac{N}{n} \cdot \frac{M}{r}
$$

where $\frac{M}{r}$ raises the reported house data to the sample CAP level and $\frac{N}{n}$ raises the data from the sample CAP level to the stratum universe level.

(ii) The sampling weights are adjusted for nonresponre, and they also reflect different sampling rates.

(iii) One set of weights is needed for the data supplied by the CAPs, and another set of weights is needed for the data supplied by the utilities.

Estimates of totals and means can be easily obtained. Let $Y$ be a variable for which we want estimates of the total of the $Y s$, denoted by $Y_{Y_{c}}$, and/or the mean of the $Y s$, denoted by $\bar{Y}_{c}$ for the houses in the entire universe with a certain characteristic, say $C$. 
1. To estimate the number of houses in the entire universe with characteristic $C$, we sum the sampling weights of all the sample houses with the characteristic $\mathrm{C}$.

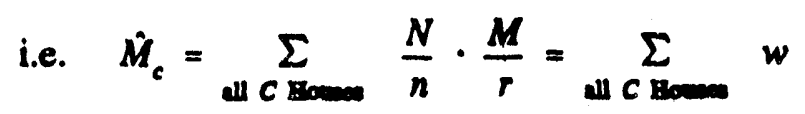

2. To estimate the total value of $Y_{T_{c}}$ for the houses in the entire universe with characteristic $C$, we use

$$
Y_{T_{c}}=\sum_{\text {all }} \sum_{\text {Honom }} Y \cdot\left(\frac{N}{n} \cdot \frac{M}{r}\right)=\sum_{c \text { Hlomen }} Y \cdot W
$$

3. To estimate the mean value $\bar{Y}_{c}$ for the units in the entire population with characteristic $\mathrm{C}$, we use

$$
\hat{\bar{Y}}_{c}=\frac{\hat{Y}_{T_{c}}}{\hat{M}_{c}}=\frac{\sum_{C \text { Howe }} Y \cdot W}{\sum_{C \text { Hown }} w}
$$

Examples of $\mathrm{C}$ include:

(i) $\mathrm{C}=$ all gas houses

(ii) $\mathrm{C}-$ all electric houses in Subregion 1.

(iii) $\mathrm{C}=$ all houses in Region 2.

(iv) $\mathrm{C}=$ all gas houses in CAP Category 3.

T. Wright (6-2523)

Mathematical Sciences Section

Oak Ridge National Laboratory

January 20, 1992 


\section{APPENDIX C}

\section{SUPPLEMENTAL TABLES FOR CHAPTER 3}




\section{Table C.1 Definition of Terms for Developing Weights for the Dwelling-Specific Data}

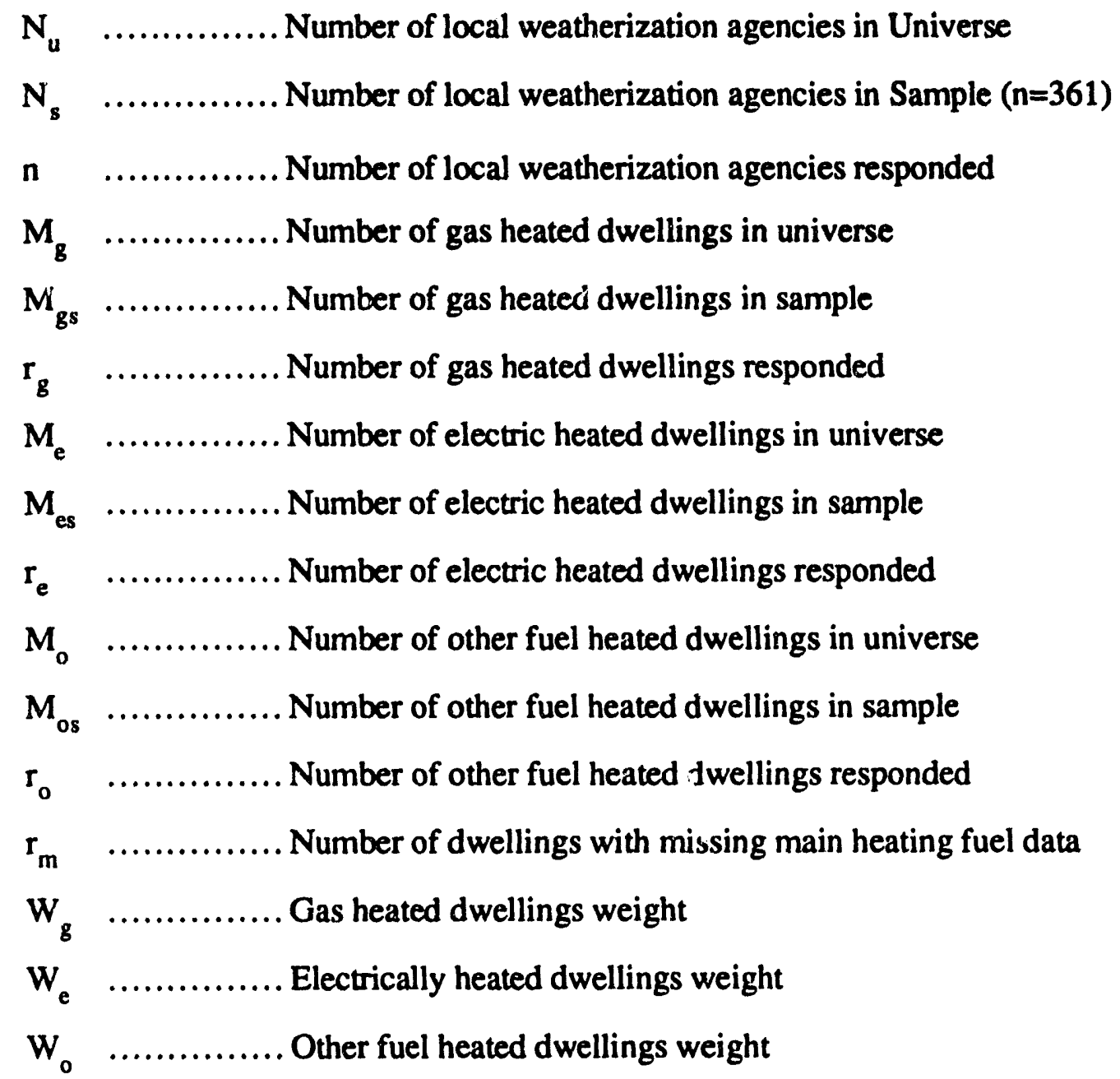




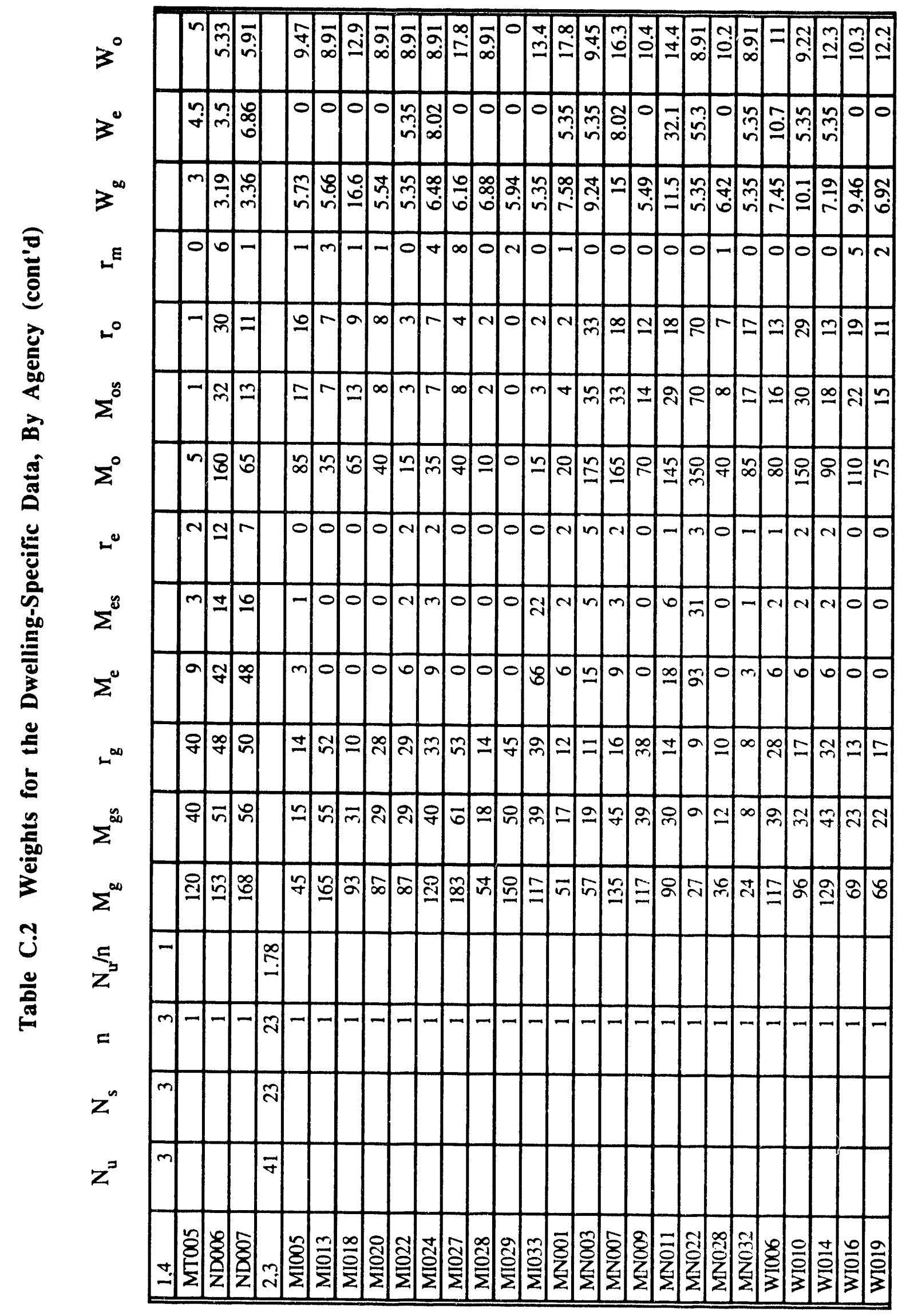




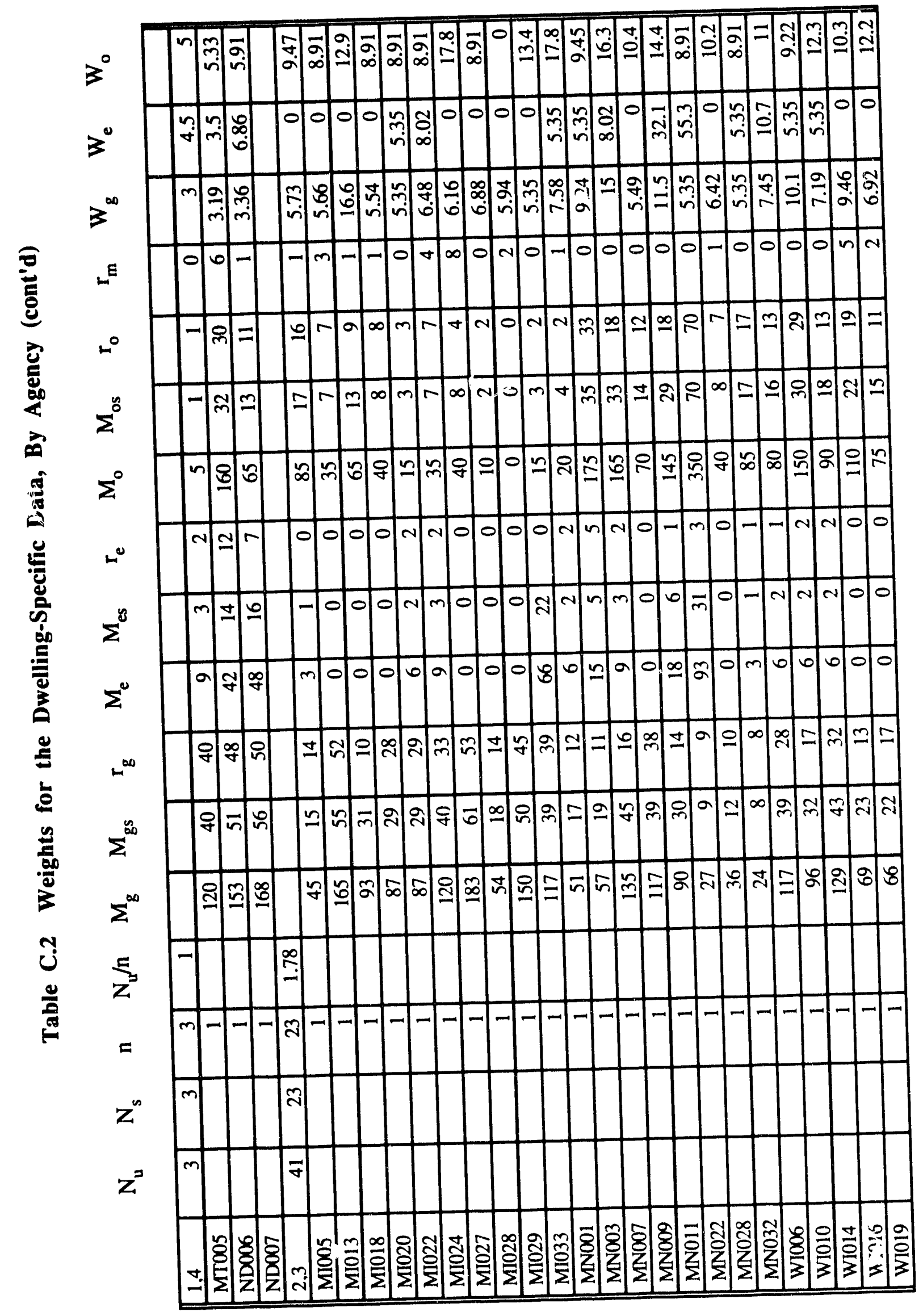




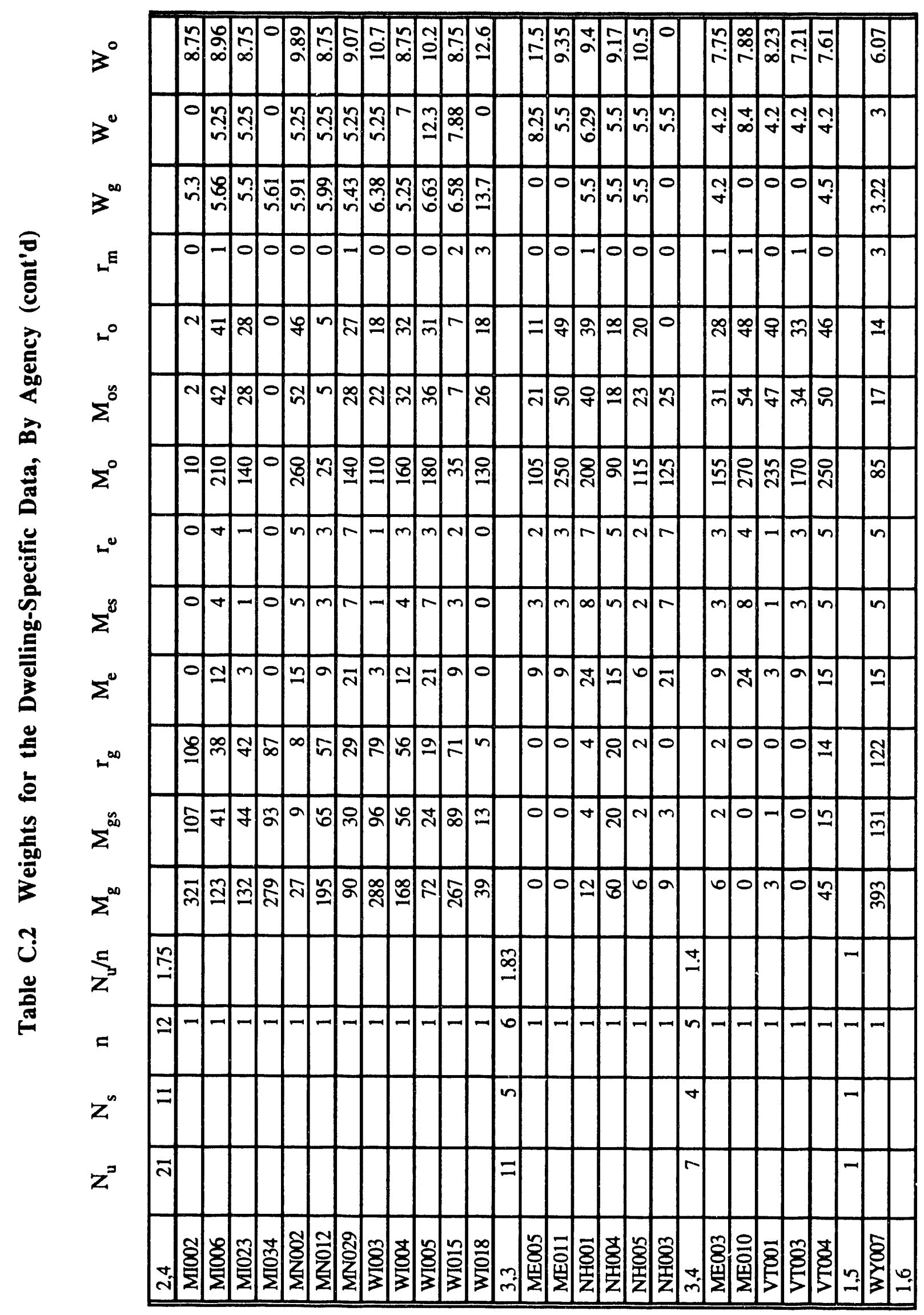




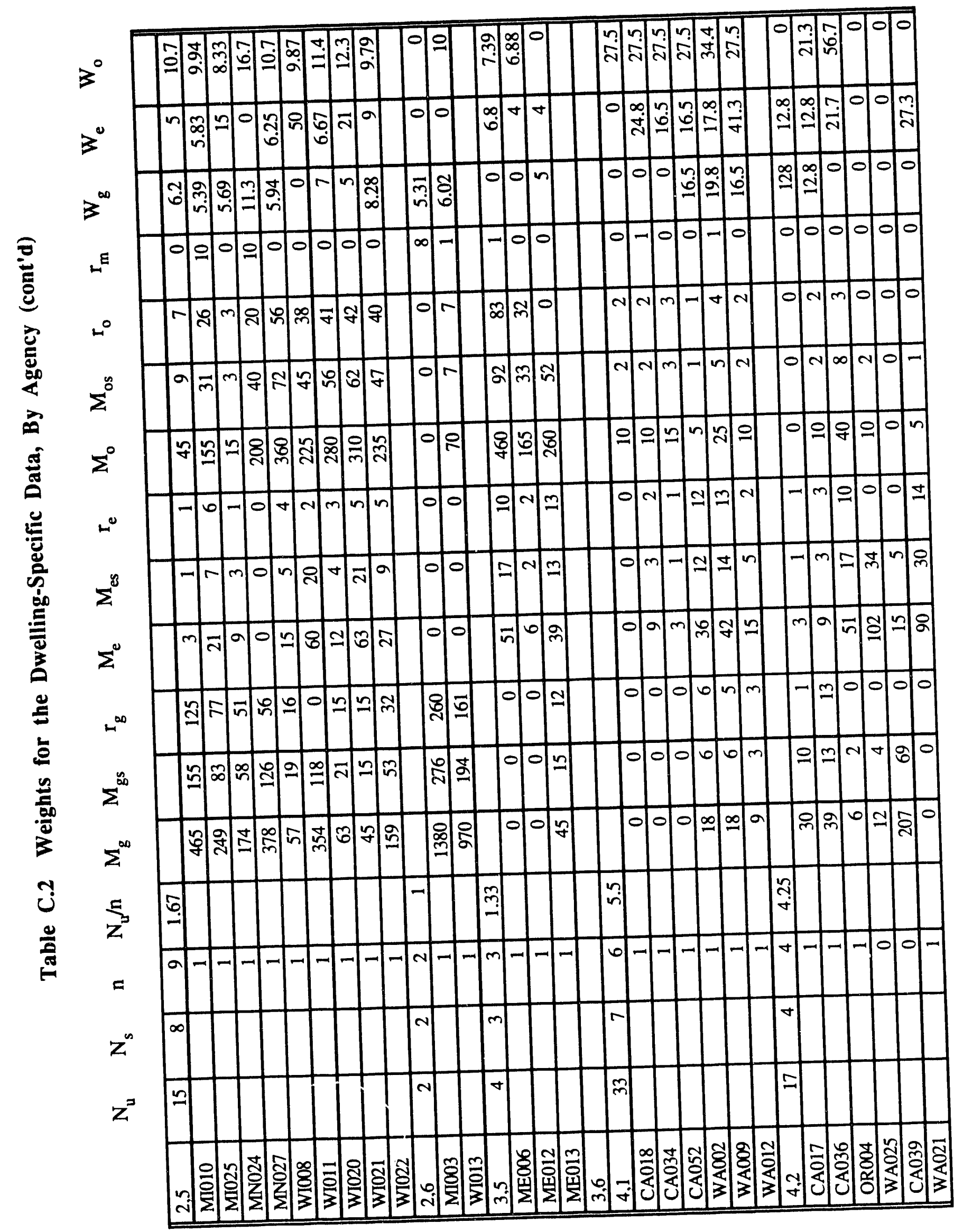




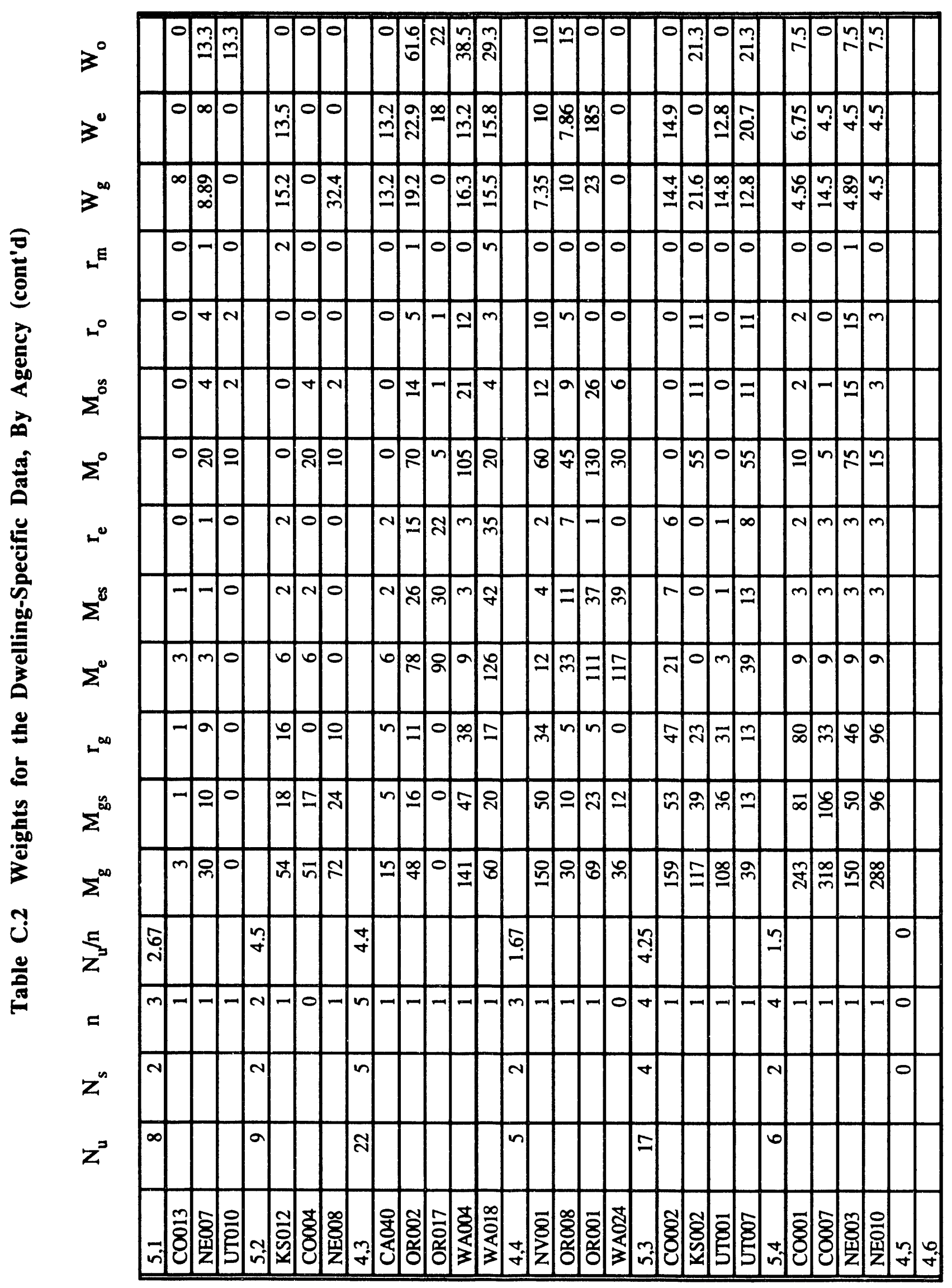




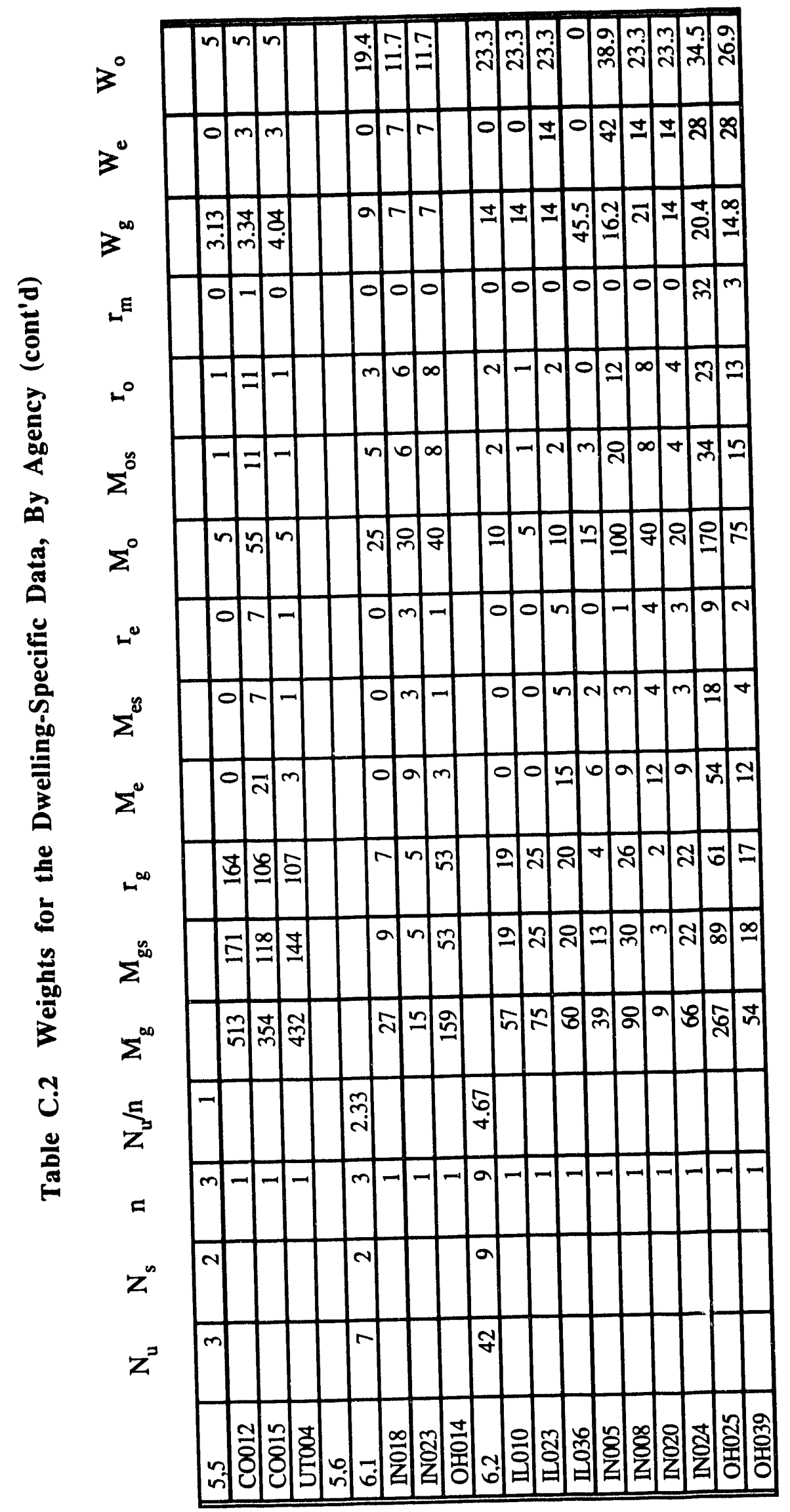




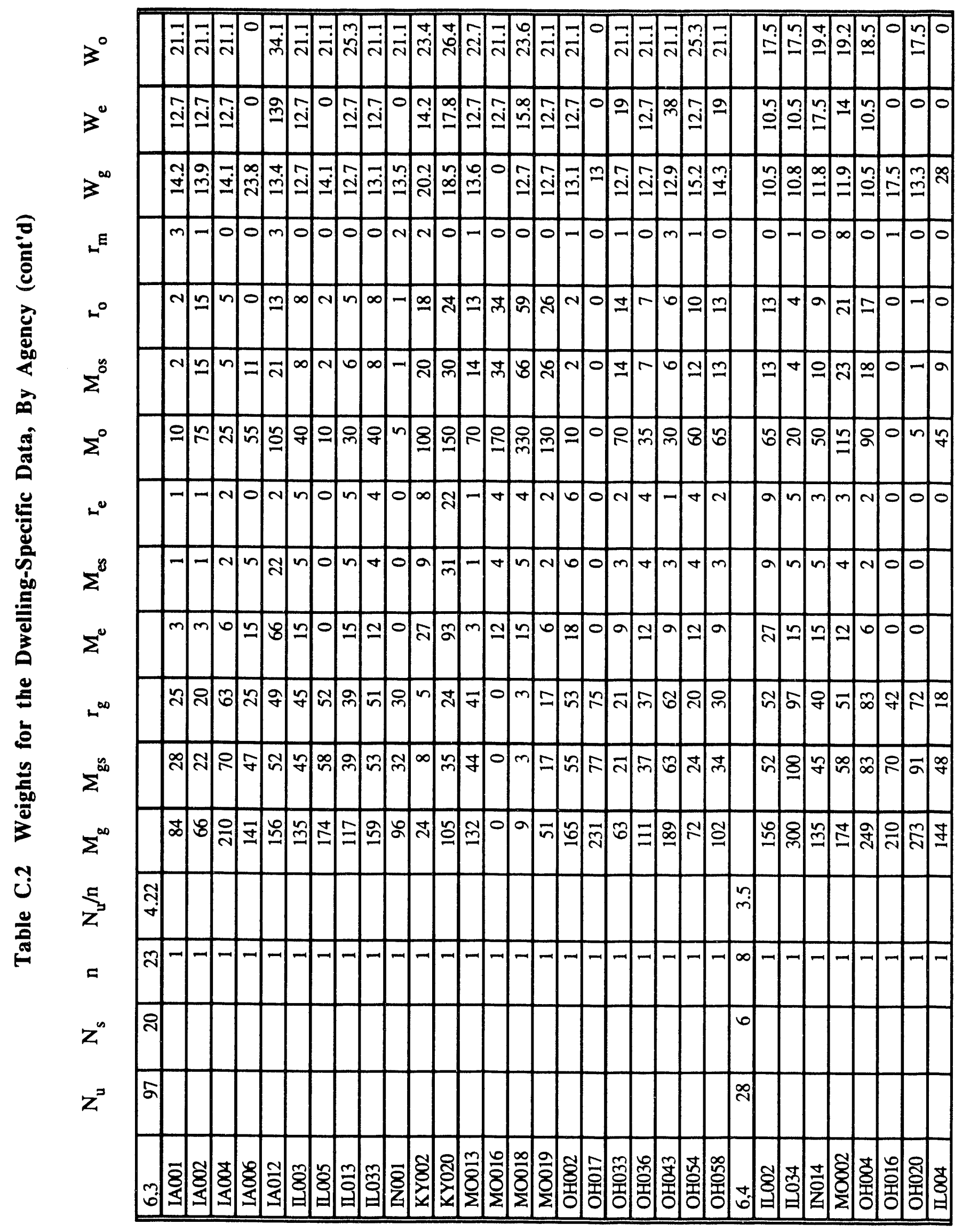




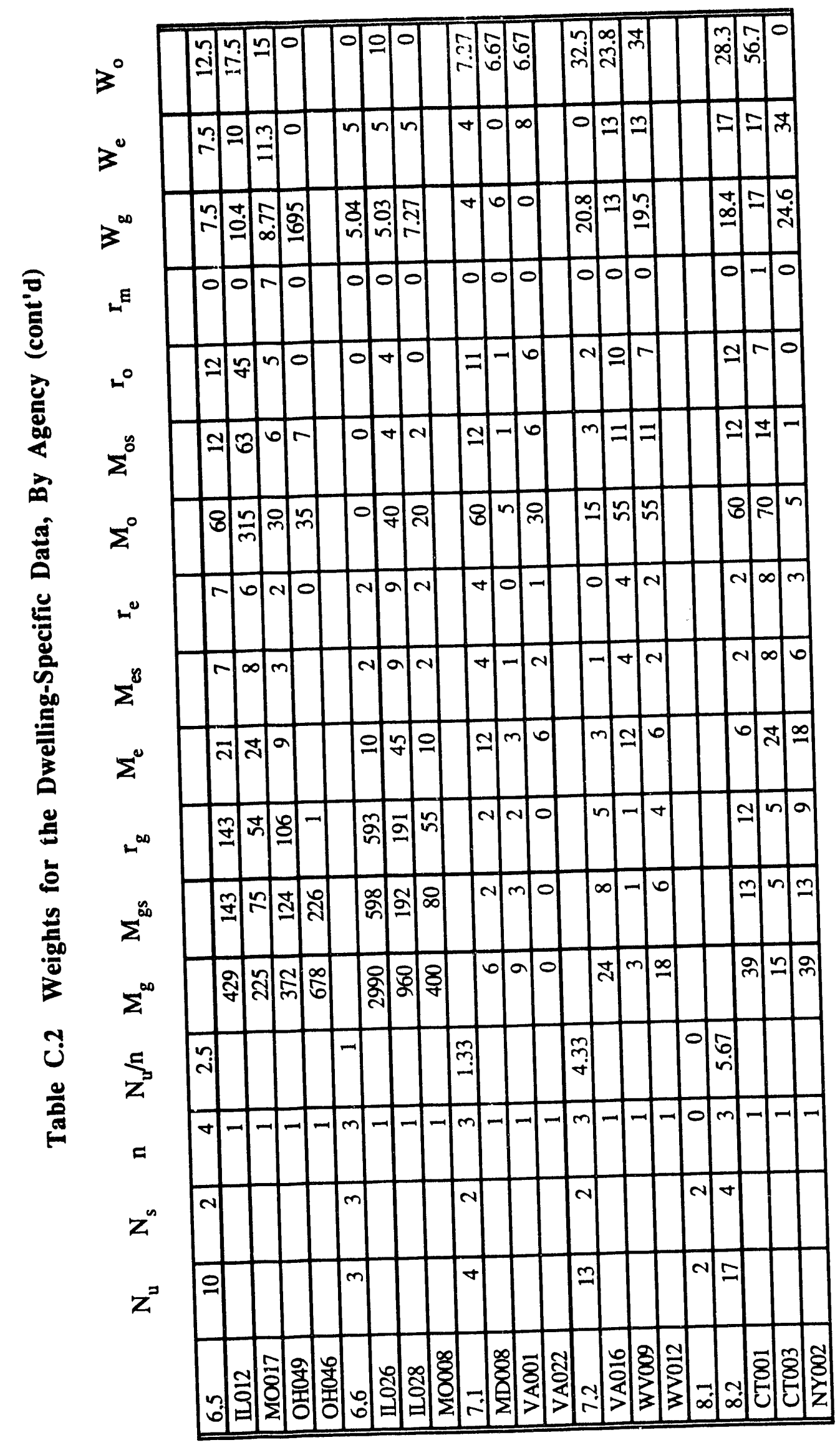

C. 9 


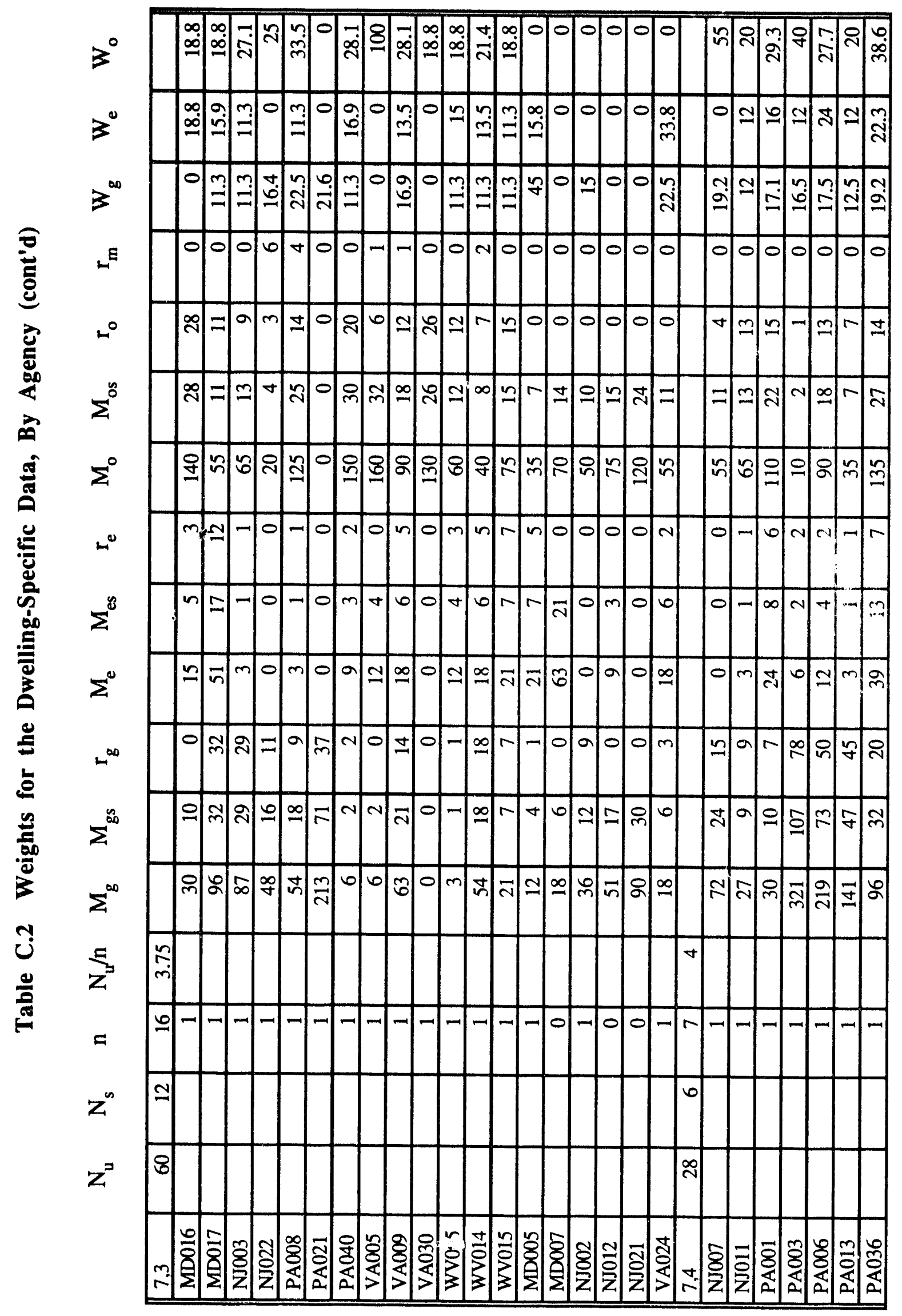




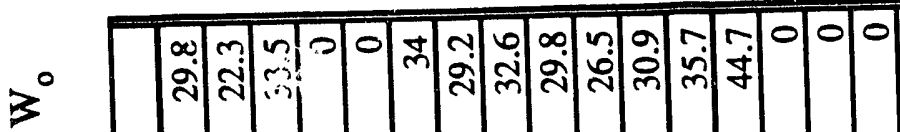

3

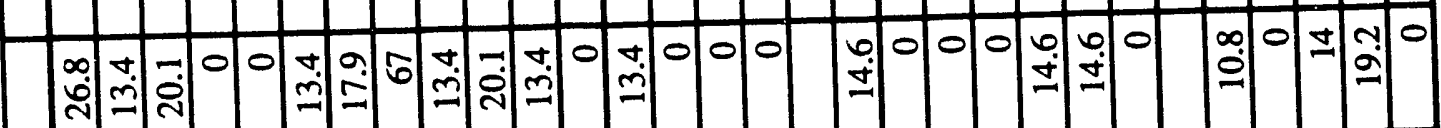

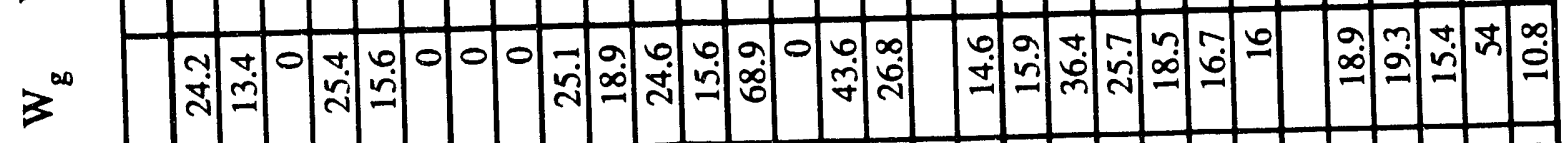

폰

-

है

$\rightarrow$

0

a m

기

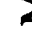

$\sum$

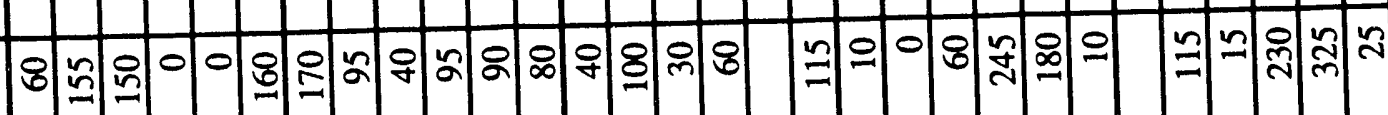

(2)

$\stackrel{2}{2}$

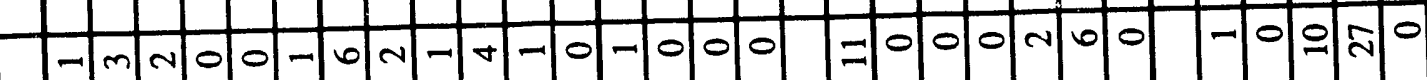

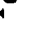

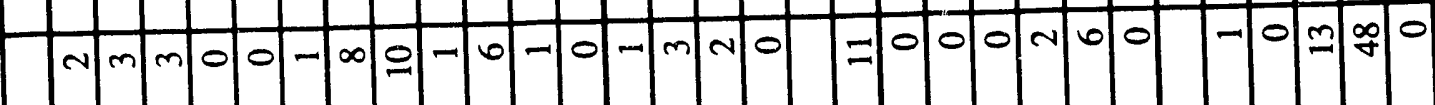

$\Sigma$

$\sum$

- a a 0 o m

-10

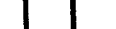

$\infty$

m 0 0

$\stackrel{0}{\infty} \Sigma$

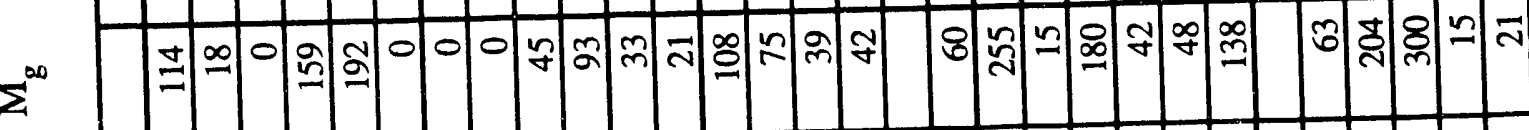

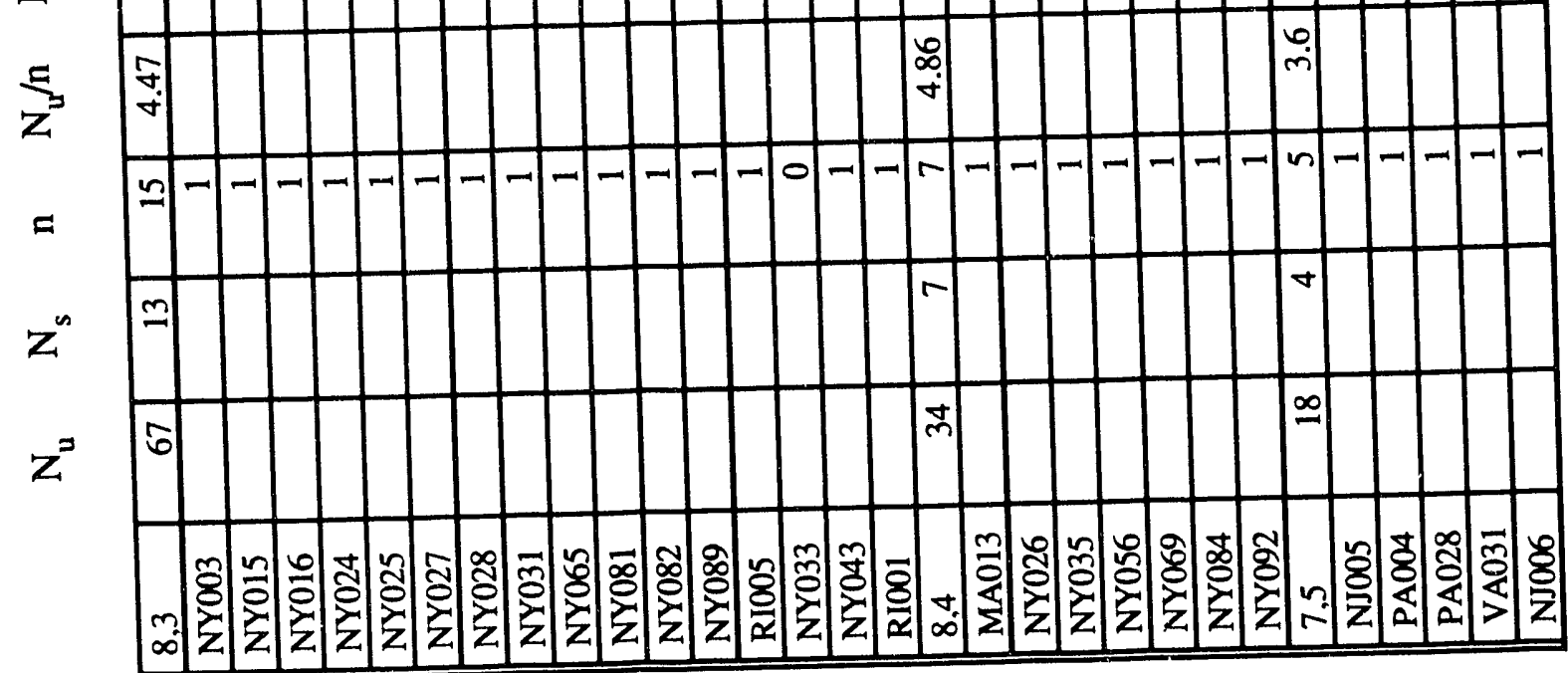




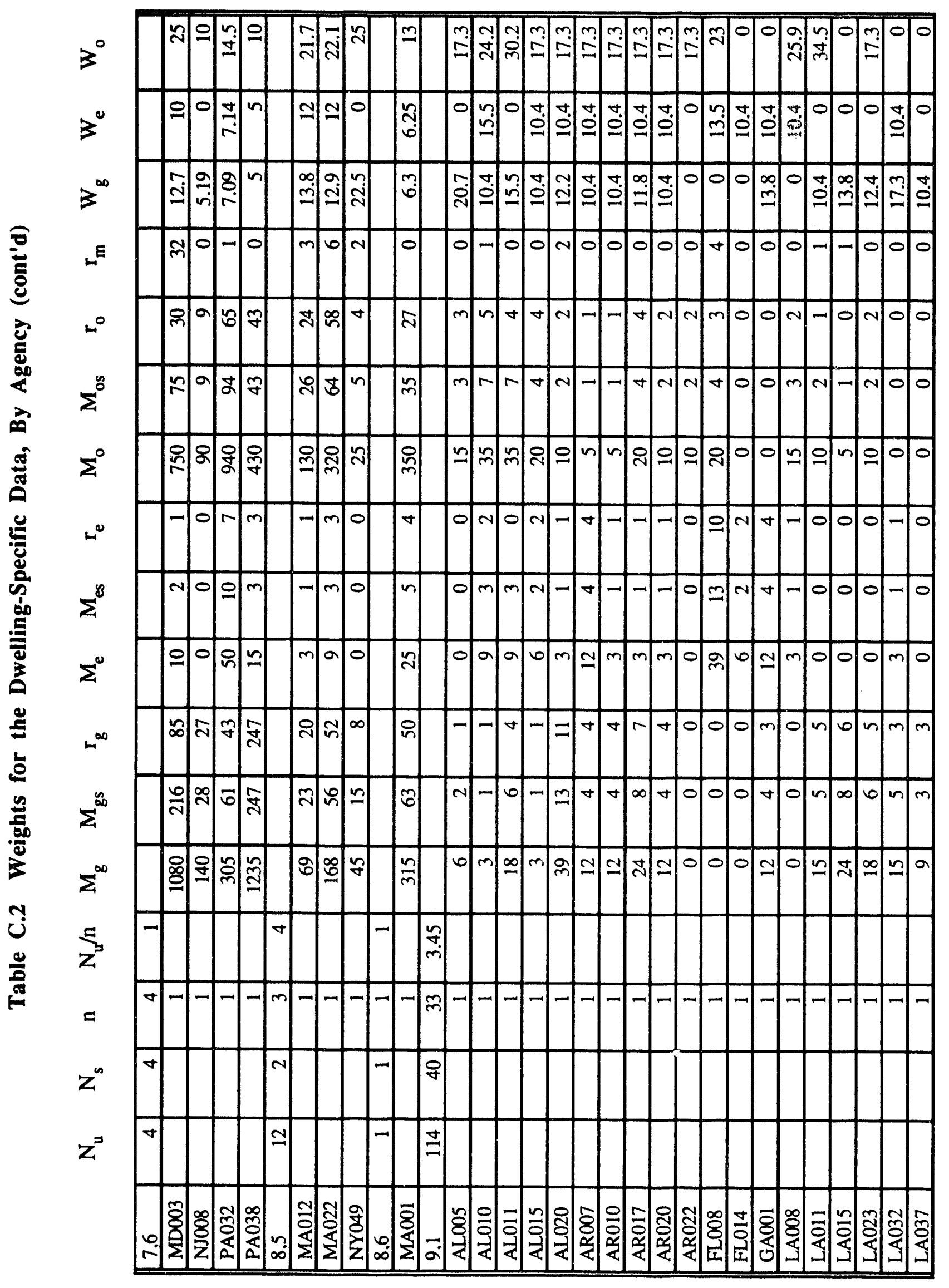




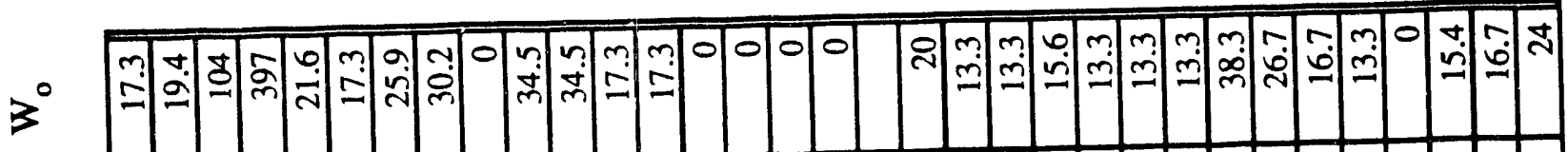

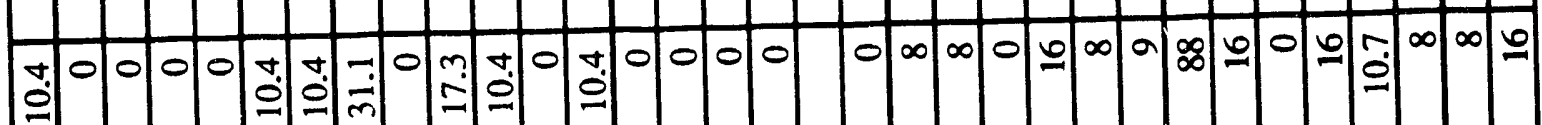
30

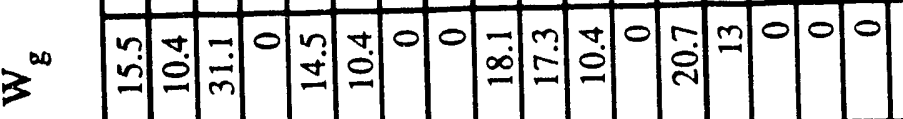

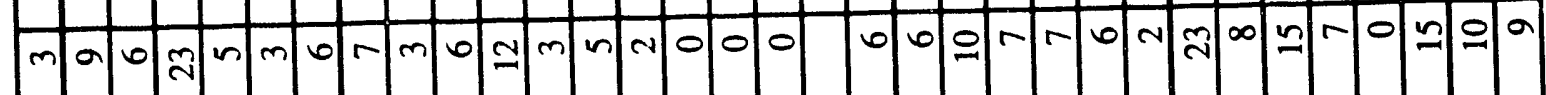

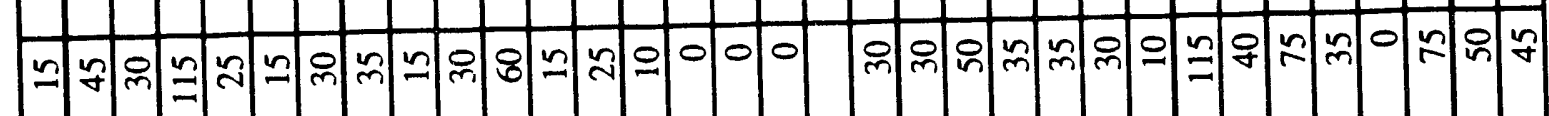

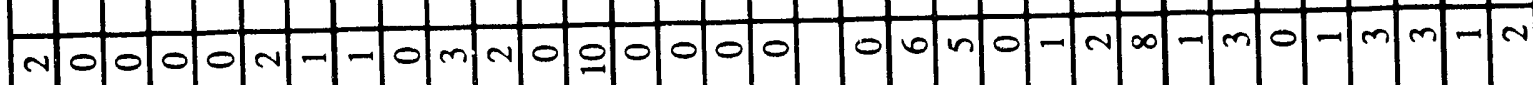

$\Sigma$ 


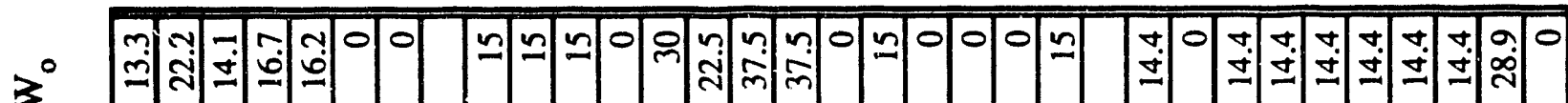
0 $\vec{z}$

$3^{\infty}$

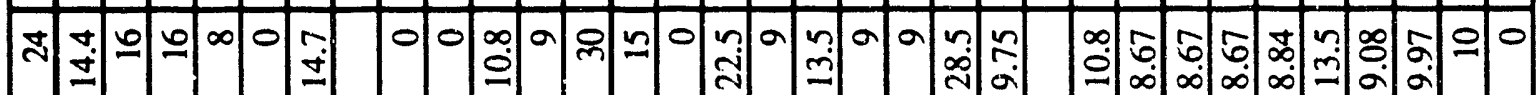
0-00000 0000000-0000-0 m-000-0

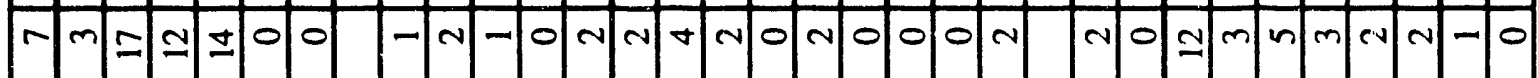

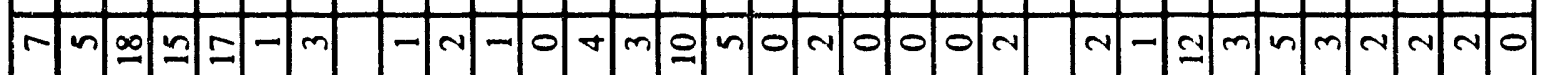

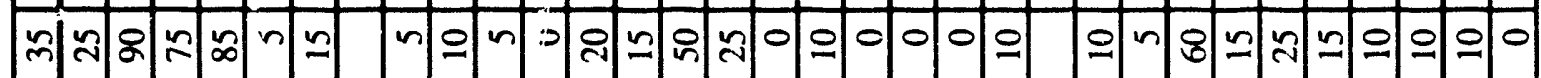

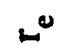
-0잉ㅇ -0이이-

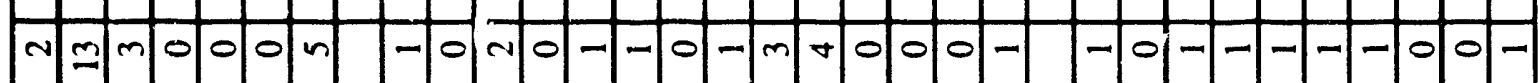
$\sum^{0}$

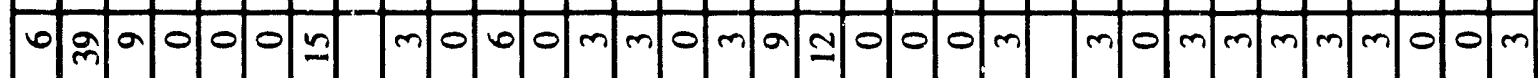
nn- -

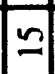

ษ
으

누

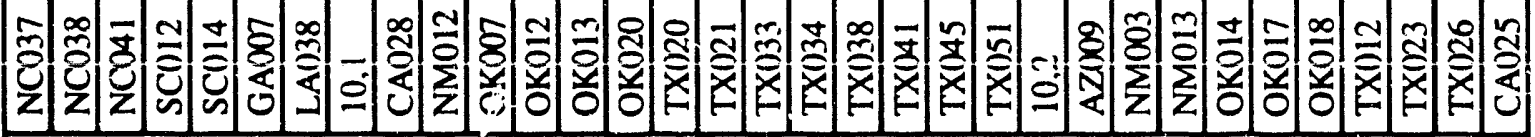




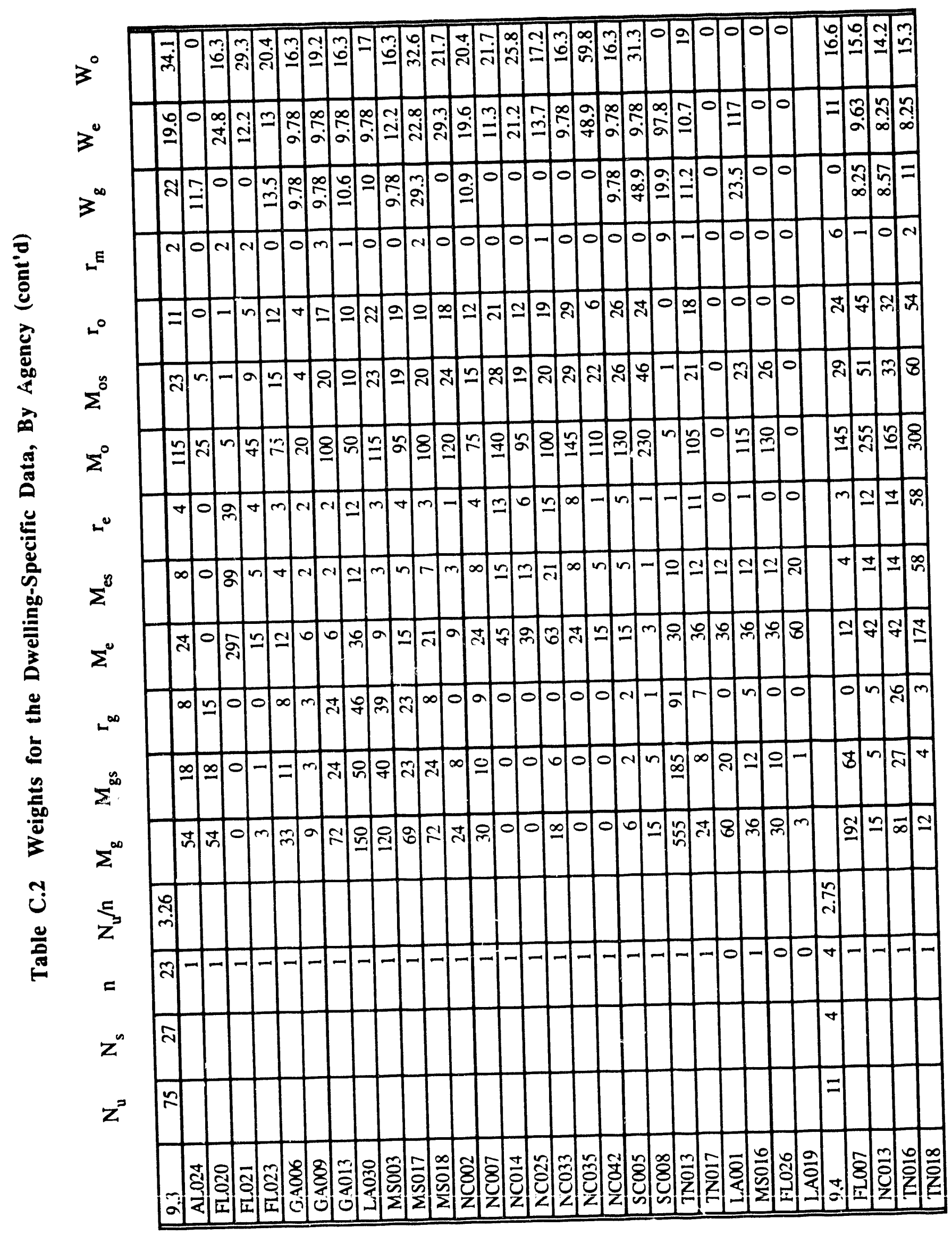




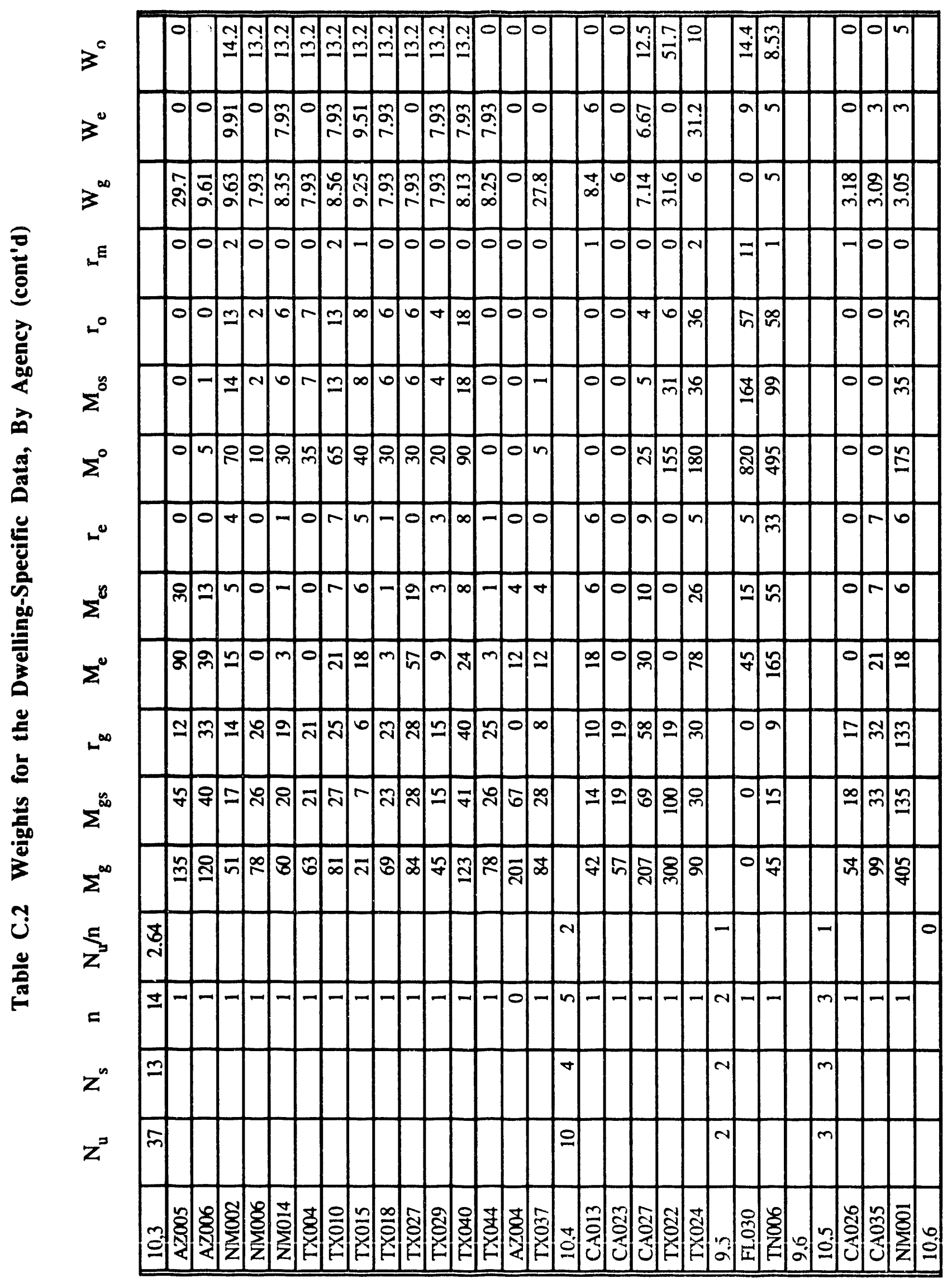




\section{Table C.3 Distribution of WAP-Participant Homes and WAP-Eligible Homes by Climate Region}

\begin{tabular}{|l|c|c|}
\hline Climate Region & WAP-Participant Dwellings & WAP-Eligible Dwellings' \\
Cold & 19.3 & 12.2 \\
\hline Moderate & 58.4 & 42.7 \\
\hline Hot & 22.1 & 45.0 \\
\hline
\end{tabular}

1 These figures were provided by Response Analysis from the 1990 Residential Energy Consumption Survey (RECS). Eligibility for WAP was defined as $125 \%$ of the federal poverty income guidelines. Table C.4 Age of Dwelling and Square Footage of WAP.Participant Homes
and WAP.Eligible Homes in the U.S.

\begin{tabular}{|c|c|c|}
\hline & WAP Participant Dwellings & WAP-Eligible Dwellings' \\
\hline \multicolumn{3}{|c|}{ Year Dwelling was Built } \\
\hline Before 1940 & 38.6 & 31.4 \\
\hline $1940-49,, 4$ & 11.3 & 10.7 \\
\hline $1950-59,8$ & 10.5 & 13.8 \\
\hline $1960-69$ & 11.9 & 13.8 \\
\hline $1970-79$ & 14.7 & 18.5 \\
\hline After 1980 & 13.1 & 11.7 \\
\hline \multicolumn{3}{|c|}{ Square Footage } \\
\hline Less than 800 & 30.1 & 25.9 \\
\hline $800-999$ & 23.8 & 19.3 \\
\hline $1000-1299$ & 23.0 & 21.2 \\
\hline $1300-1599$ & 10.5 & 11.6 \\
\hline Over 1600 & 12.7 & 22.0 \\
\hline
\end{tabular}

1 These figures were provided by Response Analysis from the 1990 Residential Energy Consumption Survey (RECS). Eligibility for WAP was defined as $125 \%$ of the federal poverty income guidelines. Square footage is defined by RECS to include "heated" square feet of living space, while the Single-Family Study defined it as "conditioned" square feet of living space. The former would not include cooled space, while the latter would. 


\section{Table C.5 Income Distribution of WAP-Participant and WAP-Eligible Households in the U.S.}

\begin{tabular}{|c|c|c|}
\hline Income $(\$)$ & $\begin{array}{l}\text { WAP-Participant } \\
\text { Households (weighted) }\end{array}$ & WAP-Eligible Dwellings \\
\hline Less than 5,000 & 32.5 & 25.3 \\
\hline $5,000-9,999$ & 46.4 & 48.3 \\
\hline $10,000 \cdot 14,999$ & 15.1 & 18.2 \\
\hline $15,000-19,999$ & 4.5 & 6.8 \\
\hline 20,000 or more & 1.6 & 1.5 \\
\hline
\end{tabular}

1 These figures were provided by Response Analysis from tie 1990 Residential Energy Consumption Survey (RECS). Eligibility for WAP was de ined as $125 \%$ of the federal poverty income guidelines. 


\section{APPENDIX E}

SUPPLEMENTAL TABLES FOR CHAPTER 5 
Table E.1 Definition of Terms for Developing Weights

for the Energy Consumption Data

$\mathrm{N}_{\mathrm{u}} \quad \ldots \ldots \ldots \ldots$...... Number of local weatherization agencies in Universe

$\mathrm{N}_{\mathrm{s}} \quad \ldots \ldots \ldots \ldots$ Number of local weatherization agencies in Sample $(\mathrm{n}=361)$

$\mathrm{n}_{\mathrm{wx}} \quad \ldots \ldots \ldots \ldots . .$. Number of local weatherization agencies with weatherized dwelling responses

$\mathrm{n}_{\mathrm{np}} \quad \ldots \ldots \ldots \ldots . .$. Number of local weatherization agencies with non-participant dwelling responses

$M_{g} \quad \ldots \ldots \ldots \ldots . .$. Number of gas heated dwellings in universe

$M_{s} \quad \ldots \ldots \ldots \ldots . . .$. Number of gas heated dwellings in sample

$r_{w x} \quad \ldots \ldots \ldots \ldots . .$. Number of responding weatherized dwellings

$r_{n p} \quad \ldots \ldots \ldots \ldots . . .$. Number of responding non-participant dwellings

$\mathrm{W}_{\mathrm{wx}} \ldots \ldots \ldots \ldots . .$. Weight for weatherized dwellings

$\mathrm{W}_{\mathrm{np}} \ldots \ldots \ldots \ldots \ldots$ Weight for non-participant dwellings 
Table E.2 Weights for the Energy Consumption Data, by Agency

$\begin{array}{llllllllllll}N_{u} & N_{s} & n_{w x} & N_{w} / N_{w x} & n_{n p} & N_{w} / n_{n p} & M_{g} & M_{s} & r_{w x} & r_{n p} & W_{w x} & W_{n p}\end{array}$

\begin{tabular}{|c|c|c|c|c|c|c|c|c|c|c|c|c|}
\hline 1,1 & 10 & 5 & 1 & 10 & 1 & 10 & & & & & 0 & 0 \\
\hline MT015 & & & 0 & & 0 & & 3 & 1 & 0 & 0 & 0 & 0 \\
\hline WY001 & & & 1 & & 1 & & 33 & 11 & 9 & 1 & 14.7 & 211 \\
\hline 1,2 & 7 & 4 & 4 & 1.75 & 0 & 0 & & & & & 0 & 0 \\
\hline ID001 & & & 1 & & 0 & & 75 & 25 & 16 & 0 & 18.8 & 0 \\
\hline ID005 & & & 1 & & 0 & & 9 & 3 & 3 & 0 & 12 & 0 \\
\hline MT004 & & & 0 & & 0 & & 39 & 13 & 0 & 0 & 0 & 0 \\
\hline WY002 & & & 1 & & 0 & & 27 & 9 & 3 & 0 & 36 & 0 \\
\hline WY004 & & & 1 & & 0 & & 66 & 22 & 13 & & 20.3 & 0 \\
\hline 2,1 & 10 & 5 & 1 & 10 & 1 & 10 & & & & & 0 & 0 \\
\hline MN033 & & & 1 & & 1 & & 33 & 11 & 7 & 3 & 18.9 & 70.4 \\
\hline MN034 & & & 0 & & 0 & & 0 & 0 & 0 & 0 & 0 & 0 \\
\hline 2,2 & 5 & 3 & 2 & 2.5 & 3 & 1.67 & & & & & 0 & 0 \\
\hline MN006 & & & 1 & & 1 & & 75 & 25 & 12 & 17 & 25 & 28.2 \\
\hline MN021 & & & 0 & & 1 & & 3 & 1 & 0 & 1 & 0 & 19.2 \\
\hline MN026 & & & 1 & & 1 & & 75 & 25 & 20 & 28 & 15 & 17.1 \\
\hline 3,1 & & & 0 & 0 & 0 & & & & & & 0 & 0 \\
\hline 3,2 & & & 0 & 0 & 0 & & & & & & 0 & 0 \\
\hline 1,3 & 23 & 12 & 9 & 2.56 & 9 & 2.56 & & & & & 0 & 0 \\
\hline ID004 & & & 1 & & 0 & & 132 & 44 & 32 & 0 & 11.7 & 0 \\
\hline ID007 & & & 1 & & 1 & & 45 & 15 & 12 & 10 & 10.6 & 13.3 \\
\hline ID008 & & & 1 & & 1 & & 57 & 19 & 13 & 12 & 12.4 & 14 \\
\hline MT008 & & & 0 & & 0 & & 42 & 14 & 0 & 0 & 0 & 0 \\
\hline MT009 & & & 0 & & 0 & & 93 & 31 & 0 & 0 & 0 & 0 \\
\hline MT010 & & & 0 & & 0 & & 105 & 35 & 0 & 0 & 0 & 0 \\
\hline ND001 & & & 1 & & 1 & & 132 & 44 & 20 & 20 & 18.7 & 19.5 \\
\hline ND002 & & & 1 & & 1 & & 54 & 18 & 12 & 16 & 12.7 & 9.97 \\
\hline ND003 & & & 1 & & 1 & & 33 & 11 & 8 & 18 & 11.7 & 5.42 \\
\hline NDO04 & & & 1 & & 1 & & 57 & 19 & 13 & 4 & 12.4 & 42.1 \\
\hline ND005 & & & 1 & & 1 & & 45 & 15 & 9 & 9 & 14.1 & 14.8 \\
\hline SD002 & & & 1 & & 1 & & 69 & 23 & 13 & 16 & 15 & 12.7 \\
\hline SD003 & & & 0 & & 1 & & 39 & 13 & 0 & 4 & 0 & 28.8 \\
\hline SD004 & & & 0 & & 0 & & 0 & 0 & 0 & 0 & 0 & 0 \\
\hline 1.4 & 3 & 3 & 3 & 1 & 2 & 1.5 & & & & & 0 & 0 \\
\hline MT005 & & & 1 & & 0 & & 120 & 40 & 21 & 0 & 16.1 & 0 \\
\hline ND006 & & & 1 & & 1 & & 153 & 51 & 27 & 14 & 16 & 32.3 \\
\hline ND007 & & & 1 & & 1 & & 168 & 56 & 29 & 14 & 16.4 & 35.5 \\
\hline 2,3 & 41 & 23 & 16 & 2.56 & 15 & 2.73 & & & & & 0 & 0 \\
\hline Ml005 & & & 1 & & 1 & & 45 & 15 & 2 & 3 & 63.6 & 44.3 \\
\hline $\mathrm{MI013}$ & & & 1 & & 1 & & 165 & 55 & 38 & 28 & 12.3 & 17.4 \\
\hline MI018 & & & 0 & & 1 & & 93 & 31 & 0 & 3 & 0 & 91.6 \\
\hline $\mathrm{MIO20}$ & & & 0 & & 0 & & 87 & 29 & 0 & 0 & 0 & 0 \\
\hline $\mathrm{Ml022}$ & & & 1 & & 1 & & 87 & 29 & 22 & 22 & 11.2 & 11.7 \\
\hline $\mathrm{MIO} 24$ & & & 1 & & 1 & & 120 & 40 & 29 & 33 & 11.7 & 10.7 \\
\hline $\mathrm{MIO27}$ & & & 0 & & 0 & & 183 & 61 & 0 & 0 & 0 & 0 \\
\hline $\mathrm{Ml028}$ & & & 0 & & 0 & & 54 & 18 & 0 & 0 & 0 & 0 \\
\hline $\mathrm{MI029}$ & & & 0 & & 0 & & 150 & 50 & 0 & 0 & 0 & 0 \\
\hline MI033 & & & 0 & & 0 & & 117 & 39 & 0 & 0 & 0 & 0 \\
\hline
\end{tabular}

E.2 
Table E.2 Weights for the Energy Consumption Data, by Agency

\begin{tabular}{|c|c|c|c|c|c|c|c|c|c|c|c|c|}
\hline & $\mathrm{N}_{\mathrm{u}}$ & $\mathbf{N}_{\mathbf{s}}$ & $\mathrm{n}_{\mathrm{wx}}$ & $N_{u} / N_{W X}$ & $n_{n p}$ & $\mathrm{~N}_{\mathrm{u}} / \mathrm{n}_{\mathrm{np}}$ & $\mathbf{M}_{\mathrm{g}}$ & $\mathbf{M}_{\mathbf{s}}$ & $r_{w x}$ & $r_{n p}$ & $W_{w x}$ & $W_{n p}$ \\
\hline MN001 & & & 1 & & 1 & & 51 & 17 & 13 & 27 & 11.1 & 5.58 \\
\hline $\mathrm{MNO03}$ & & & 1 & & 1 & & 57 & 19 & 4 & 10 & 40.3 & 16.8 \\
\hline MN007 & & & 1 & & 1 & & 135 & 45 & 20 & 36 & 19.1 & 11.1 \\
\hline MN009 & & & 1 & & 1 & & 117 & 39 & 10 & 7 & 33.1 & 49.4 \\
\hline MN011 & & & 1 & & 0 & & 90 & 30 & 9 & 0 & 28.3 & 0 \\
\hline MN022 & & & 1 & & 1 & & 27 & 9 & 3 & 54 & 25.4 & 1.48 \\
\hline MN028 & & & 1 & & 1 & & 36 & 12 & 6 & 4 & 17 & 26.6 \\
\hline MN032 & & & 1 & & 1 & & 24 & 8 & 7 & 3 & 9.69 & 23.6 \\
\hline W1006 & & & 1 & & 1 & & 117 & 39 & 27 & 31 & 12.2 & 11.2 \\
\hline WI010 & & & 1 & & 0 & & 96 & 32 & 1 & 0 & 271 & 0 \\
\hline WI014 & & & 1 & & 1 & & 129 & 43 & 23 & 20 & 15.9 & 19.1 \\
\hline WI016 & & & 1 & & 1 & & 69 & 23 & 12 & 17 & 16.3 & 12 \\
\hline W1019 & & & 0 & & 0 & & 66 & 22 & 0 & 0 & 0 & 0 \\
\hline 2,4 & 21 & 11 & 7 & 3 & 7 & 3 & & & & & 0 & 0 \\
\hline $\mathrm{MIO02}$ & & & 0 & & 0 & & 321 & 107 & 0 & 0 & 0 & 0 \\
\hline MI006 & & & 0 & & 0 & & 123 & 41 & 0 & 0 & 0 & 0 \\
\hline $\mathrm{MIO} 23$ & & & 0 & & 0 & & 132 & 44 & 0 & 0 & 0 & 0 \\
\hline MI034 & & & 0 & & 0 & & 279 & 93 & 0 & 0 & 0 & 0 \\
\hline $\mathrm{MNO02}$ & & & 1 & & 1 & & 27 & 9 & 4 & 5 & 19.1 & 16 \\
\hline MN012 & & & 1 & & 1 & & 195 & 65 & 53 & 50 & 10.4 & 11.5 \\
\hline MN029 & & & 1 & & 1 & & 90 & 30 & 11 & 4 & 23.1 & 66.5 \\
\hline WI003 & & & 0 & & 0 & & 288 & 96 & 0 & 0 & 0 & 0 \\
\hline WI004 & & & 1 & & 1 & & 168 & 56 & 28 & 31 & 17 & 16 \\
\hline WI005 & & & 1 & & 1 & & 72 & 24 & 16 & 28 & 12.7 & 7.6 \\
\hline W1015 & & & 1 & & 1 & & 267 & 89 & 3 & 4 & 252 & 197 \\
\hline W1018 & & & 1 & & 1 & & 39 & 13 & 3 & 15 & 36.7 & 7.68 \\
\hline 3,3 & 11 & 5 & 2 & 5.5 & 2 & 5.5 & & & & & 0 & 0 \\
\hline ME005 & & & 0 & & 0 & & 0 & 0 & 0 & 0 & 0 & 0 \\
\hline ME011 & & & 0 & & 0 & & 0 & 0 & 0 & 0 & 0 & 0 \\
\hline $\mathrm{NHOO1}$ & & & 1 & & 1 & & 12 & 4 & 3 & 2 & 11.3 & 17.7 \\
\hline $\mathrm{NH} 004$ & & & 1 & & 1 & & 60 & 20 & 20 & 21 & 8.48 & 8.44 \\
\hline $\mathrm{NH} 005$ & & & 0 & & 0 & & 6 & 2 & 0 & 0 & 0 & 0 \\
\hline $\mathrm{NH} 003$ & & & 0 & & 0 & & 9 & 3 & & & 0 & 0 \\
\hline 3,4 & 7 & 4 & 1 & 7 & 1 & 7 & & & & & 0 & 0 \\
\hline $\mathrm{ME} 003$ & & & 0 & & 0 & & 6 & 2 & 0 & 0 & 0 & 0 \\
\hline ME010 & & & 0 & & 0 & & 0 & 0 & 0 & 0 & 0 & 0 \\
\hline VT001 & & & 0 & & 0 & & 3 & 1 & 0 & 0 & 0 & 0 \\
\hline VTO03 & & & 0 & & 0 & & 0 & 0 & 0 & 0 & 0 & 0 \\
\hline VT004 & & & 1 & & 1 & & 45 & 15 & 12 & 16 & 10.6 & 8.31 \\
\hline 1,5 & 1 & 1 & 1 & 1 & 1 & 1 & & & & & 0 & 0 \\
\hline WY007 & & & 1 & & 1 & & 393 & 131 & 83 & 95 & 10.4 & 11.4 \\
\hline 1,6 & & & & & 0 & 0 & & & & & 0 & 0 \\
\hline 2.5 & 15 & 8 & 7 & 2.14 & 6 & 2.5 & & & & & 0 & 0 \\
\hline MI010 & & & 0 & & 0 & & 465 & 155 & 0 & 0 & 0 & 0 \\
\hline $\mathrm{MIO25}$ & & & 1 & & 1 & & 249 & 83 & 60 & 43 & 9.13 & 15.9 \\
\hline MN024 & & & 1 & & 0 & & 174 & 58 & 7 & 0 & 54.7 & 0 \\
\hline MNO27 & & & 1 & & 1 & & 378 & 126 & 45 & 66 & 18.5 & 15.8 \\
\hline WI008 & & & 1 & & 1 & & 57 & 19 & 7 & 6 & 17.9 & 26.1 \\
\hline
\end{tabular}


Table E.2 Weights for the Energy Consumption Data, by Agency

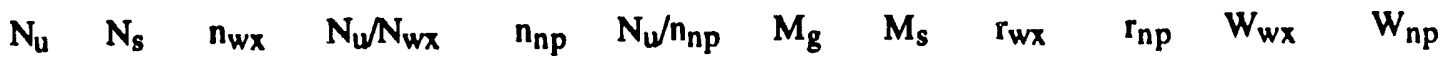

\begin{tabular}{|c|c|c|c|c|c|c|c|c|c|c|c|c|}
\hline W1011 & & & 1 & & 0 & & 354 & 118 & 6 & 0 & 130 & 0 \\
\hline W1020 & & & 0 & & 1 & & 63 & 21 & 0 & 9 & 0 & 19.3 \\
\hline W1021 & & & 1 & & 1 & & 45 & 15 & 3 & 7 & 33 & 17.7 \\
\hline W1022 & & & 1 & & 1 & & 159 & 53 & 6 & 14 & 58.3 & 31.2 \\
\hline 2,6 & 2 & 2 & 1 & 2 & 0 & 0 & & & & & 0 & 0 \\
\hline Ml003 & & & 0 & & 0 & & 1380 & 276 & 0 & 0 & 0 & 0 \\
\hline W1013 & & & 1 & & 0 & & 970 & 194 & 141 & 0 & 15.1 & 0 \\
\hline 3,5 & 4 & 3 & 1 & 4 & 1 & 4 & & & & & 0 & 0 \\
\hline ME006 & & & 0 & & 0 & & 0 & 0 & 0 & 0 & 0 & 0 \\
\hline ME012 & & & 0 & & 0 & & 0 & 0 & 0 & 0 & 0 & 0 \\
\hline ME013 & & & 1 & & 1 & & 45 & 15 & 11 & 1 & 9 & 124 \\
\hline 3,6 & & & & & 0 & 0 & & & & & 0 & 0 \\
\hline 4,1 & 33 & 7 & 2 & 16.5 & 1 & 33 & & & & & 0 & 0 \\
\hline CA018 & & & 0 & & 0 & & 0 & 0 & 0 & 0 & 0 & 0 \\
\hline CA034 & & & 0 & & 0 & & 0 & 0 & 0 & 0 & 0 & 0 \\
\hline $\mathrm{CA052}$ & & & 0 & & 0 & & 0 & 0 & 0 & 0 & 0 & 0 \\
\hline WA002 & & & 1 & & 1 & & 18 & 6 & 6 & 7 & 40.2 & 34.5 \\
\hline WA009 & & & 0 & & 0 & & 18 & 6 & 0 & 0 & 0 & 0 \\
\hline WA012 & & & 1 & & 0 & & 9 & 3 & 3 & 0 & 40.2 & 0 \\
\hline 4,2 & 17 & 4 & 1 & 17 & 3 & 5.67 & & & & & 0 & 0 \\
\hline $\mathrm{CA017}$ & & & 0 & & 0 & & 30 & 10 & 0 & 0 & 0 & 0 \\
\hline CA036 & & & 0 & & 1 & & 39 & 13 & 0 & 4 & 0 & 131 \\
\hline OR004 & & & 0 & & 1 & & 6 & 2 & 0 & 7 & 0 & 11.5 \\
\hline WA025 & & & 1 & & 1 & & 12 & 4 & 4 & 4 & 40.2 & 40.2 \\
\hline CA039 & & & 0 & & 0 & & 207 & 69 & 0 & 0 & 0 & 0 \\
\hline WA021 & & & 0 & & 0 & & 0 & 0 & 0 & 0 & 0 & 0 \\
\hline 5,1 & 8 & 2 & 0 & 0 & 0 & 0 & & - & & & 0 & 0 \\
\hline $\mathrm{COO13}$ & & & 0 & & 0 & & 3 & 1 & 0 & 0 & 0 & 0 \\
\hline NE007 & & & 0 & & 0 & & 30 & 10 & 0 & 0 & 0 & 0 \\
\hline UTO10 & & & 0 & & 0 & & 0 & 0 & 0 & 0 & 0 & 0 \\
\hline 5,2 & 9 & 2 & 2 & 4.5 & 1 & 9 & & & & & 0 & 0 \\
\hline KS012 & & & 0 & & 0 & & 54 & 18 & 0 & 0 & 0 & 0 \\
\hline $\mathrm{COOO4}$ & & & 1 & & 0 & & 51 & 17 & 13 & 0 & 52.6 & 0 \\
\hline NE008 & & & 1 & & 1 & & 72 & 24 & 10 & 9 & 96.5 & 107 \\
\hline 4,3 & 22 & 5 & 3 & 7.33 & 1 & 22 & & & & & 0 & 0 \\
\hline CA040 & & & 0 & & 0 & & 15 & 5 & 0 & 0 & 0 & 0 \\
\hline OR002 & & & 1 & & 0 & & 48 & 16 & 13 & 0 & 15.4 & 0 \\
\hline OR017 & & & 0 & & 1 & & 0 & 0 & 0 & 3 & 0 & 0 \\
\hline WA004 & & & 1 & & 0 & & 141 & 47 & 11 & 0 & 53.4 & 0 \\
\hline WA018 & & & 1 & & 0 & & 60 & 20 & 8 & 0 & 31.3 & 0 \\
\hline 4,4 & 5 & 2 & 3 & 1.67 & 2 & 2.5 & & & & & 0 & 0 \\
\hline NV001 & & & 1 & & 1 & & 150 & 50 & 21 & 13 & 29.8 & 64.1 \\
\hline OR008 & & & 1 & & 1 & & 30 & 10 & 10 & 6 & 12.5 & 27.8 \\
\hline OR001 & & & 1 & & 0 & & 69 & 23 & 5 & 0 & 57.5 & 0 \\
\hline WA024 & & & 0 & & 0 & & 36 & 12 & 0 & 0 & 0 & 0 \\
\hline 5,3 & 17 & 4 & 2 & 8.5 & 3 & 5.67 & & & & & 0 & 0 \\
\hline $\mathrm{COOO2}$ & & & 0 & & 0 & & 159 & 53 & 0 & 0 & 0 & 0 \\
\hline $\mathrm{KSO02}$ & & & 0 & & 1 & & 117 & 39 & 0 & 4 & 0 & 163 \\
\hline
\end{tabular}

E.4 
Table E.2 Weights for the Energy Consumption Data, by Agency

\begin{tabular}{|c|c|c|c|c|c|c|c|c|c|c|c|c|}
\hline & $\mathrm{N}_{\mathrm{u}}$ & $\mathbf{N}_{\mathbf{s}}$ & $\mathrm{n}_{\mathrm{wX}}$ & $N_{u} / N_{w x}$ & $n_{n p}$ & $N_{w} / n_{n p}$ & $\mathbf{M}_{\mathbf{g}}$ & $\mathbf{M}_{\mathbf{s}}$ & $r_{w x}$ & $r_{n p}$ & $w_{w x}$ & $W_{n p}$ \\
\hline UTO01 & & & 1 & & 1 & & 108 & 36 & 33 & 29 & 13.6 & 20.7 \\
\hline UT007 & & & 1 & & 1 & & 39 & 13 & 2 & 1 & 81.3 & 217 \\
\hline 5,4 & 6 & 2 & 4 & 1.5 & 3 & 2 & & & & & 0 & 0 \\
\hline con1 & & & 1 & & 1 & & 243 & 81 & 23 & 26 & 44 & 51.9 \\
\hline $\mathrm{CO} 007$ & & & 1 & & 1 & & 318 & 106 & 33 & 23 & 40.2 & 76.8 \\
\hline $\mathrm{NE} 003$ & & & 1 & & 1 & & 150 & 50 & 41 & 22 & 15.2 & 37.9 \\
\hline NE010 & & & 1 & & 0 & & 288 & 96 & 35 & 0 & 34.3 & 0 \\
\hline 4,5 & & 0 & 0 & 0 & 0 & 0 & & & & & 0 & 0 \\
\hline 4,6 & & & & & 0 & 0 & & & & & 0 & 0 \\
\hline 5,5 & 3 & 2 & 3 & 1 & 2 & 1.5 & & & & & 0 & 0 \\
\hline $\mathrm{CO012}$ & & & 1 & & 0 & & 513 & 171 & 47 & 0 & 10.9 & 0 \\
\hline $\mathrm{CO015}$ & & & 1 & & 1 & & 354 & 118 & 1 & 1 & 354 & 531 \\
\hline UT004 & & & 1 & & 1 & & 432 & 144 & 114 & 63 & 3.79 & 10.3 \\
\hline 5,6 & & & & & 0 & 0 & & & & & 0 & 0 \\
\hline 6,1 & 7 & 2 & 2 & 3.5 & 3 & 2.33 & & & & & 0 & 0 \\
\hline IN018 & & & 0 & & 1 & & 27 & 9 & 0 & 1 & 0 & 189 \\
\hline IN023 & & & 1 & & 1 & & 15 & 5 & 3 & 5 & 30.6 & 21 \\
\hline $\mathrm{OHO14}$ & & & 1 & & 1 & & 159 & 53 & 30 & 10 & 32.5 & 111 \\
\hline 6,2 & 42 & 9 & 6 & 7 & 4 & 10.5 & & & & & 0 & 0 \\
\hline IL010 & & & 1 & & 1 & & 57 & 19 & 17 & 9 & 20.5 & 44.3 \\
\hline IL 023 & & & 0 & & 0 & & 75 & 25 & 0 & 0 & 0 & 0 \\
\hline IL 036 & & & 1 & & 1 & & 60 & 20 & 5 & 6 & 73.5 & 70 \\
\hline IN005 & & & 0 & & 0 & & 39 & 13 & 0 & 0 & 0 & 0 \\
\hline IN008 & & & 0 & & 0 & & 90 & 30 & 0 & 0 & 0 & 0 \\
\hline IN020 & & & 1 & & 1 & & 9 & 3 & 2 & 1 & 27.6 & 63 \\
\hline IN024 & & & 1 & & 1 & & 66 & 22 & 6 & 14 & 67.4 & 33 \\
\hline $\mathrm{OH} 025$ & & & 1 & & 0 & & 267 & 89 & 15 & 0 & 109 & 0 \\
\hline OH039 & & & 1 & & 0 & & 54 & 18 & 4 & 0 & 82.7 & 0 \\
\hline 6,3 & 97 & 20 & 14 & 6.93 & 12 & 8.08 & & & & & 0 & 0 \\
\hline IA001 & & & 1 & & 1 & & 84 & 28 & 23 & 18 & 26.9 & 41.7 \\
\hline IA002 & & & 0 & & 1 & & 66 & 22 & 0 & 14 & 0 & 42.1 \\
\hline IA004 & & & 1 & & 1 & & 210 & 70 & 13 & 21 & 119 & 89.3 \\
\hline IA006 & & & 1 & & 1 & & 141 & 47 & 25 & 6 & 41.5 & 210 \\
\hline IA012 & & & 1 & & 0 & & 156 & 52 & 48 & 0 & 23.9 & 0 \\
\hline IL003 & & & 1 & & 0 & & 135 & 45 & 25 & 0 & 39.7 & 0 \\
\hline IL005 & & & 1 & & 0 & & 174 & 58 & 2 & 0 & 640 & 0 \\
\hline IL013 & & & 1 & & 1 & & 117 & 39 & 10 & 15 & 86 & 69.6 \\
\hline ILn23 & & & 1 & & 1 & & 159 & 53 & 18 & 24 & 65 & 59.2 \\
\hline INGO1 & & & 0 & & 0 & & 96 & 32 & 0 & 0 & 0 & 0 \\
\hline $\mathrm{KYO02}$ & & & 1 & & 1 & & 24 & 8 & 5 & 1 & 35.3 & 214 \\
\hline KY020 & & & 1 & & $i$ & & 105 & 35 & 5 & 1 & 154 & 938 \\
\hline $\mathrm{MO012}$ & & & 0 & & 0 & & 132 & 44 & 0 & 0 & 0 & 0 \\
\hline $\mathrm{MO016}$ & & & 0 & & 0 & & 0 & 0 & 0 & 0 & 0 & 0 \\
\hline $\mathrm{MO} 18$ & & & 0 & & 0 & & 9 & 3 & 0 & 0 & 0 & 0 \\
\hline MO019 & & & 0 & & 1 & & 51 & 17 & 0 & 1 & 0 & 455 \\
\hline $\mathrm{OH} 002$ & & & 0 & & 0 & & 165 & 55 & 0 & 0 & 0 & 0 \\
\hline $\mathrm{OH} 017$ & & & 0 & & 0 & & 231 & 77 & 0 & 0 & 0 & 0 \\
\hline $\mathrm{OH} 033$ & & & 1 & & 1 & & 63 & 21 & 11 & 3 & 42.1 & 188 \\
\hline
\end{tabular}


Table E.2 Weights for the Energy Consumption Data, by Agency

$\begin{array}{llllllllllll}N_{u} & N_{s} & n_{W x} & N_{u} / N_{w x} & n_{n p} & N_{u} / n_{n p} & M_{g} & M_{s} & r_{w x} & r_{n p} & W_{w x} & W_{n p}\end{array}$

\begin{tabular}{|c|c|c|c|c|c|c|c|c|c|c|c|c|}
\hline $\mathrm{OH} 036$ & & & 0 & & 0 & & 111 & 37 & 0 & 0 & 0 & 0 \\
\hline $\mathrm{OH} 043$ & & & 1 & & 0 & & 189 & 63 & 35 & 0 & 39.7 & 0 \\
\hline OH054 & & & 1 & & 1 & & 72 & 24 & 8 & 1 & 66.2 & 643 \\
\hline OH058 & & & 1 & & 1 & & 102 & 34 & 17 & 1 & 44.1 & 911 \\
\hline 6,4 & 28 & 6 & 3 & 9.33 & 2 & 14 & & & & & 0 & 0 \\
\hline IL002 & & & 0 & & 0 & & 156 & 52 & 0 & 0 & 0 & 0 \\
\hline IL034 & & & 1 & & 0 & & 300 & 100 & 71 & 0 & 31.1 & 0 \\
\hline IN014 & & & 1 & & 1 & & 135 & 45 & 10 & 12 & 99.3 & 100 \\
\hline $\mathrm{MO002}$ & & & 0 & & 0 & & 174 & 58 & 0 & 0 & 0 & 0 \\
\hline $\mathrm{OH} 004$ & & & 0 & & 0 & & 249 & 83 & 0 & 0 & 0 & 0 \\
\hline OH016 & & & 0 & & 0 & & 210 & 70 & 0 & 0 & 0 & 0 \\
\hline $\mathrm{OH} 020$ & & & 0 & & 0 & & 273 & 91 & 0 & 0 & 0 & 0 \\
\hline ILO04 & & & 1 & & 1 & & 144 & 48 & 18 & 25 & 58.8 & 51.4 \\
\hline 6,5 & 10 & 2 & 1 & 10 & 2 & 5 & & & & & 0 & 0 \\
\hline IL012 & & & 1 & & 1 & & 429 & 143 & 30 & 8 & 46.5 & 174 \\
\hline $\mathrm{MO017}$ & & & 0 & & 1 & & 225 & 75 & 0 & 35 & 0 & 20.9 \\
\hline $\mathrm{OH} 049$ & & & 0 & & 0 & & 372 & 124 & 0 & 0 & 0 & 0 \\
\hline $\mathrm{OH} 046$ & & & 0 & & 0 & & 678 & 226 & 0 & 0 & 0 & 0 \\
\hline 6.6 & 3 & 3 & 3 & 1 & 2 & 1.5 & & & & & 0 & 0 \\
\hline IL026 & & & 1 & & 1 & & 2990 & 598 & 392 & 167 & 24.8 & 58.2 \\
\hline IL028 & & & 1 & & 1 & & 960 & 192 & 67 & 56 & 46.6 & 55.7 \\
\hline $\mathrm{MO008}$ & & & 1 & & 0 & & 400 & 80 & 69 & 0 & 18.8 & 0 \\
\hline 7,1 & 4 & 2 & 1 & 4 & 0 & 0 & & & & & 0 & 0 \\
\hline MD008 & & & 0 & & 0 & & 6 & 2 & 0 & 0 & 0 & 0 \\
\hline VA001 & & & 1 & & 0 & & 9 & 3 & 2 & 0 & 54 & 0 \\
\hline VA022 & & & 0 & & 0 & & 0 & 0 & 0 & 0 & 0 & 0 \\
\hline 7,2 & 13 & 2 & 0 & 0 & 0 & 0 & & & & & 0 & 0 \\
\hline VA016 & & & 0 & & 0 & & 24 & 8 & 0 & 0 & 0 & 0 \\
\hline WV009 & & & 0 & & 0 & & 3 & 1 & 0 & 0 & 0 & 0 \\
\hline WV012 & & & 0 & & 0 & & 18 & 6 & 0 & 0 & 0 & 0 \\
\hline 8,1 & 2 & 2 & 0 & 0 & 0 & 0 & & & & & 0 & 0 \\
\hline 8,2 & 17 & 4 & 2 & 8.5 & 2 & 8.5 & & & & & 0 & 0 \\
\hline CT001 & & & 1 & & 1 & & 39 & 13 & 12 & 12 & 39 & 58.5 \\
\hline CT003 & & & 0 & & 0 & & 15 & 5 & 0 & 0 & 0 & 0 \\
\hline NY002 & & & 1 & & 1 & & 39 & 13 & 9 & 34 & 52 & 20.6 \\
\hline 7,3 & 60 & 12 & 13 & 4.62 & 7 & 8.57 & & & & & 0 & 0 \\
\hline MD016 & & & 0 & & 0 & & 30 & 10 & 0 & 0 & 0 & 0 \\
\hline MD017 & & & 1 & & 1 & & 96 & 32 & 5 & 9 & 101 & 74.7 \\
\hline NJ003 & & & 1 & & 1 & & 87 & 29 & 12 & 5 & 381 & 12 \\
\hline NJ022 & & & 1 & & 1 & & 48 & 16 & 1 & 4 & 253 & 84 \\
\hline PA008 & & & 1 & & 0 & & 54 & 18 & 13 & 0 & 21.8 & 0 \\
\hline PA021 & & & 1 & & 0 & & 213 & 71 & 48 & 0 & 23.3 & 0 \\
\hline PA040 & & & 0 & & 0 & & 6 & 2 & 0 & 1 & 0 & 0 \\
\hline VA005 & & & 0 & & 0 & & 6 & 2 & 0 & 0 & 0 & 0 \\
\hline VA009 & & & 0 & & 0 & & 63 & 21 & 0 & 0 & 0 & 0 \\
\hline VA030 & & & 0 & & 0 & & 0 & 0 & 0 & 0 & 0 & 0 \\
\hline WV005 & & & 1 & & 0 & & 3 & 1 & 1 & 0 & 15.8 & 0 \\
\hline WV014 & & & 1 & & 1 & & 54 & 18 & 2 & 4 & 142 & 94.5 \\
\hline
\end{tabular}


Table E.2 Weights for the Energy Consumption Data, by Agency

$\begin{array}{llllllllllll}N_{u} & N_{s} & n_{w x} & N_{u} / N_{w x} & n_{n p} & N_{u} / n_{n p} & M_{g} & M_{s} & r_{w x} & r_{n p} & W_{w x} & W_{n p}\end{array}$

\begin{tabular}{|c|c|c|c|c|c|c|c|c|c|c|c|c|}
\hline WV015 & & & 0 & & 0 & & 21 & 7 & 0 & 0 & 0 & 0 \\
\hline MD005 & & & 1 & & 0 & & 12 & 4 & 1 & 0 & 63 & 0 \\
\hline MD007 & & & 1 & & 1 & & 18 & 6 & 1 & 5 & 94.5 & 25.2 \\
\hline $\mathrm{NJO02}$ & & & 1 & & 1 & & 36 & 12 & 9 & 9 & 21 & 28 \\
\hline NJ012 & & & 1 & & 1 & & 51 & 17 & 15 & 1 & 17.9 & 357 \\
\hline NJ021 & & & 1 & & 0 & & 90 & 30 & 5 & 0 & 94.5 & 0 \\
\hline VA024 & & & 1 & & 0 & & 18 & 6 & 3 & 0 & 31.5 & 0 \\
\hline 7,4 & 28 & 6 & 5 & 5.6 & 5 & 5.6 & & & & & 0 & 0 \\
\hline NJ007 & & & 1 & & 1 & & 72 & 24 & 10 & 9 & 37.8 & _56 \\
\hline NJ011 & & & 0 & & 1 & & 27 & 9 & 0 & 10 & 0 & 18.9 \\
\hline PA001 & & & 1 & & 1 & & 30 & 10 & 1 & 2 & 158 & 105 \\
\hline $\mathrm{PA} 003$ & & & 1 & & 0 & & 321 & 107 & 41 & 0 & 41.1 & 0 \\
\hline PA006 & & & 0 & & 1 & & 219 & 73 & 0 & 26 & 0 & 59 \\
\hline $\mathrm{PA013}$ & & & 1 & & 1 & & 141 & 47 & 16 & 24 & 46.3 & 41.1 \\
\hline $\mathrm{PA036}$ & & & 1 & & 0 & & 96 & 32 & 3 & 0 & 168 & 0 \\
\hline 8,3 & 67 & 13 & 11 & 6.09 & 8 & 8.38 & & & & & 0 & 0 \\
\hline $\mathrm{NYO03}$ & & & 1 & & 1 & & 114 & 38 & 19 & 29 & 31.5 & 27.5 \\
\hline NY015 & & & 0 & & 0 & & 18 & 6 & 0 & 0 & 0 & 0 \\
\hline NY016 & & & 0 & & 0 & & 0 & 0 & 0 & 0 & 0 & 0 \\
\hline NY024 & & & 1 & & 1 & & 159 & 53 & 46 & 30 & 18.1 & 37.1 \\
\hline NY025 & & & 1 & & 1 & & 192 & 64 & 21 & 36 & 48 & 37.3 \\
\hline NY027 & & & 0 & & 0 & & 0 & 0 & 0 & 0 & 0 & 0 \\
\hline NY028 & & & 0 & & 0 & & 0 & 0 & 0 & 0 & 0 & 0 \\
\hline NY031 & & & 0 & & 0 & & 0 & 0 & 0 & 0 & 0 & 0 \\
\hline NY065 & & & 1 & & 1 & & 45 & 15 & 9 & 6 & 26.3 & 52.5 \\
\hline NY081 & & & 1 & & 0 & & 93 & 31 & 1 & 0 & 488 & 0 \\
\hline NY082 & & & 1 & & 1 & & 33 & 11 & 9 & 2 & 19.3 & 116 \\
\hline NY089 & & & 1 & & 0 & & 21 & 7 & 1 & 0 & 110 & 0 \\
\hline RI005 & & & 1 & & 1 & & 108 & 36 & 8 & 3 & 70.9 & 2.52 \\
\hline NY033 & & & 1 & & 0 & & 75 & 25 & 18 & 0 & 21.9 & 0 \\
\hline NY043 & & & 1 & & 1 & & 39 & 13 & 4 & 5 & 51.2 & 54.6 \\
\hline RI001 & & & 1 & & 1 & & 42 & 14 & 7 & 4 & 31.5 & 73.5 \\
\hline 8.4 & 34 & 7 & 7 & 4.86 & 7 & 4.86 & & & & & 0 & 0 \\
\hline $\mathrm{MA} 013$ & & & 1 & & 1 & & 60 & 20 & 13 & 12 & 24.2 & 35 \\
\hline NY026 & & & 1 & & 1 & & 255 & 85 & 57 & 9 & 23.5 & 198 \\
\hline NY035 & & & 1 & & 1 & & 15 & 5 & 4 & 1 & 19.7 & 105 \\
\hline NY056 & & & 1 & & 1 & & 180 & 60 & 7 & 6 & 135 & 210 \\
\hline NY069 & & & 1 & & 1 & & 42 & 14 & 12 & 10 & 18.4 & 29.4 \\
\hline NY084 & & & 1 & & 1 & & 48 & 16 & 12 & 10 & 21 & 33.6 \\
\hline NY092 & & & 1 & & 1 & & 138 & 46 & 25 & 13 & 29 & 74.3 \\
\hline 7.5 & 18 & 4 & 4 & 4.5 & 3 & 6 & & & & & 0 & 0 \\
\hline $\mathrm{NJ}(005$ & & & 1 & & 1 & & 63 & 21 & 12 & 18 & 20.4 & 13.6 \\
\hline $\mathrm{PA004}$ & & & 1 & & 0 & & 204 & 68 & 28 & 0 & 28.3 & 0 \\
\hline $\mathrm{PA} 028$ & & & 1 & & 1 & & 300 & 100 & 77 & 47 & 1.5 .2 & 24.8 \\
\hline VA031 & & & 0 & & 0 & & 15 & 5 & 0 & 0 & 0 & 0 \\
\hline NJ006 & & & 1 & & 1 & & 21 & 7 & 7 & 96 & 11.7 & 0.85 \\
\hline 7,6 & 4 & 4 & 2 & 2 & 3 & 1.33 & & & & & 0 & 0 \\
\hline $\mathrm{MD} 003$ & & & 0 & & 1 & & 1080 & 216 & 0 & 37 & 0 & 114 \\
\hline
\end{tabular}


Table E.2 Weights for the Energy Consumption Data, by Agency

$\begin{array}{llllllllllll}N_{u} & N_{s} & n_{W x} & N_{u} / N_{w x} & n_{n p} & N_{u} / n_{n p} & M_{g} & M_{s} & r_{w x} & r_{n p} & W_{W x} & W_{n p}\end{array}$

\begin{tabular}{|c|c|c|c|c|c|c|c|c|c|c|c|c|}
\hline $\mathrm{NJ} 008$ & & & 1 & & 1 & & 140 & 28 & 7 & 13 & 77.8 & 41.9 \\
\hline PA032 & & & 0 & & 1 & & 305 & 61 & 0 & 70 & 0 & 16.9 \\
\hline PA038 & & & 1 & & 0 & & 1235 & 247 & 164 & 0 & 29.3 & 0 \\
\hline 8,5 & 12 & 2 & 3 & 4 & 3 & 4 & & & & & 0 & 0 \\
\hline $\mathrm{MA012}$ & & & 1 & & 1 & & 69 & 23 & 10 & 8 & 26.8 & 33.5 \\
\hline $\mathrm{MA022}$ & & & 1 & & 1 & & 168 & 56 & 28 & 27 & 23.3 & 24.2 \\
\hline NY049 & & & 1 & & 1 & & 45 & 15 & 10 & 1 & 17.5 & 175 \\
\hline 8,6 & 1 & 1 & 0 & 0 & 0 & 0 & & & & & 0 & 0 \\
\hline MA001 & & & 0 & & 0 & & 315 & 63 & 0 & 0 & 0 & 0 \\
\hline 9,1 & $\begin{array}{r}11 \\
4 \\
\end{array}$ & 40 & 12 & 9.5 & 12 & 9.5 & & & & & 0 & 0 \\
\hline AL005 & & & 1 & & 1 & & 6 & 2 & 2 & 1 & 22.3 & 49.2 \\
\hline AL010 & & & 1 & & 0 & & 3 & 1 & 1 & 0 & 22.3 & 0 \\
\hline AL011 & & & 1 & & 1 & & 18 & 6 & 4 & 4 & 33.5 & 36.9 \\
\hline AL015 & & & 1 & & 0 & & 3 & 1 & 1 & 0 & 22.3 & 0 \\
\hline $\mathrm{ALO20}$ & & & 1 & & 0 & & 39 & 13 & 9 & 0 & 32.2 & 0 \\
\hline AR007 & & & 0 & & 0 & & 12 & 4 & 0 & 0 & 0 & 0 \\
\hline AR010 & & & 0 & & 0 & & 12 & 4 & 0 & 0 & 0 & 0 \\
\hline AR017 & & & 0 & & 0 & & 24 & 8 & 0 & 0 & 0 & 0 \\
\hline AR020 & & & 0 & & 0 & & 12 & 4 & 0 & 0 & 0 & 0 \\
\hline AR022 & & & 0 & & 0 & & 0 & 0 & 0 & 0 & 0 & 0 \\
\hline FL008 & & & 0 & & 0 & & 0 & 0 & 0 & 0 & 0 & 0 \\
\hline FL014 & & & 0 & & 0 & & 0 & 0 & 0 & 0 & 0 & 0 \\
\hline GA001 & & & 0 & & 1 & & 12 & 4 & 0 & 2 & 0 & 49.2 \\
\hline LA008 & & & 0 & & 1 & & 2 & 0 & 0 & 2 & 0 & 0 \\
\hline LA011 & & & 0 & & 0 & & 15 & 5 & 0 & 0 & 0 & 0 \\
\hline LA015 & & & 0 & & 0 & & 24 & 8 & 0 & 0 & 0 & 0 \\
\hline LA023 & & & 0 & & 0 & & 18. & 6 & 0 & 0 & 0 & 0 \\
\hline $\mathrm{LA} 032$ & & & 0 & & 0 & & 15 & 5 & 0 & 0 & 0 & 0 \\
\hline LA037 & & & 0 & & 0 & & 9 & 3 & 0 & 0 & 0 & 0 \\
\hline LA044 & & & 0 & & 0 & & 18 & 6 & 0 & 0 & 0 & 0 \\
\hline $\mathrm{MS} 002$ & & & 0 & & 1 & & 18 & 6 & 0 & 6 & 0 & 24.6 \\
\hline MS008 & & & 1 & & 1 & & 9 & 3 & 1 & 1 & 66.9 & 73.9 \\
\hline MS010 & & & 0 & & 1 & & 0 & 0 & 0 & 4 & 0 & 0 \\
\hline MS011 & & & 1 & & 1 & & 21 & 7 & 3 & 2 & 52.1 & 86.2 \\
\hline MSO15 & & & 0 & & 0 & & 24 & 8 & 0 & 0 & 0 & 0 \\
\hline $\mathrm{NCOO4}$ & & & 0 & & 0 & & 0 & 0 & 0 & 0 & 0 & 0 \\
\hline $\mathrm{NCO} 10$ & & & 0 & & 0 & & 0 & 0 & 0 & 0 & 0 & 0 \\
\hline $\mathrm{NCO} 18$ & & & 1 & & 1 & & 21 & 7 & 1 & 5 & 156 & 34.5 \\
\hline $\mathrm{NCO} 31$ & & & 1 & & 1 & & 15 & 5 & 3 & 1 & 37.2 & 123 \\
\hline $\mathrm{NCO36}$ & & & 0 & & 0 & & 3 & 1 & 0 & 0 & 0 & 0 \\
\hline $\mathrm{SCO} 07$ & & & 0 & & 0 & & 0 & 0 & 0 & 0 & 0 & 0 \\
\hline TNO02 & & & $\mathrm{c}$ & & 0 & & 6 & 2 & 0 & 0 & 0 & 0 \\
\hline $\mathrm{ARO09}$ & & & 1 & & 0 & & 15 & 5 & 4 & 0 & 27.9 & 0 \\
\hline LA007 & & & 1 & & 0 & & 54 & 18 & 12 & 0 & 33.5 & 0 \\
\hline LA0.35 & & & 1 & & 1 & & 3 & 1 & 1 & 1 & 22.3 & 24.6 \\
\hline AL021 & & & 0 & & 1 & & 0 & 0 & 0 & 12 & 0 & 0 \\
\hline 9,2 & 56 & 20 & 11 & 5.09 & 10 & 5.6 & & & & & 0 & 0 \\
\hline
\end{tabular}


Table E.2 Weights for the Energy Consumption Data, by Agency

$\begin{array}{llllllllllll}N_{u} & N_{s} & n_{w x} & N_{u} / N_{w x} & n_{n p} & N_{u} / n_{n p} & M_{g} & M_{s} & r_{w x} & r_{n p} & W_{w x} & W_{n p}\end{array}$

\begin{tabular}{|c|c|c|c|c|c|c|c|c|c|c|c|c|}
\hline $\mathrm{ALO03}$ & & & 1 & & 1 & & 39 & 13 & 4 & 5 & 72.5 & 64 \\
\hline ALO06 & & & 1 & & 1 & & 12 & 4 & 2 & 2 & 44.6 & 49.2 \\
\hline Al.022 & & & 0 & & 0 & & 6 & 2 & 0 & 0 & 0 & 0 \\
\hline AR001 & & & 0 & & 0 & & 24 & 8 & 0 & 0 & 0 & 0 \\
\hline AR003 & & & 0 & & 0 & & 24 & 8 & 0 & 0 & 0 & 0 \\
\hline AR005 & & & 0 & & 0 & & 33 & 11 & 0 & 0 & 0 & 0 \\
\hline AR013 & & & 1 & & 1 & & 21 & 7 & 5 & 14 & 31.2 & 12.3 \\
\hline FL025 & & & 0 & & 0 & & 0 & 3 & 0 & 0 & 0 & 0 \\
\hline FL027 & & & 1 & & 1 & & 30 & 10 & 6 & 5 & 37.2 & 49.2 \\
\hline FL033 & & & 0 & & 0 & & 51 & 17 & 0 & 0 & 0 & 0 \\
\hline GA004 & & & 1 & & 1 & & 87 & 29 & 17 & 10 & 38.1 & 71.4 \\
\hline GA012 & & & 0 & & 0 & & 102 & 34 & 0 & 0 & 0 & 0 \\
\hline MS012 & & & 0 & & 1 & & 135 & 45 & 0 & 16 & 0 & 69.2 \\
\hline MSO21 & & & -1 & & 1 & & 30 & 10 & 10 & 4 & 22.3 & 61.6 \\
\hline NC019 & & & 1 & & 1 & & 39 & 13 & 7 & 8 & 41.4 & 40 \\
\hline $\mathrm{NCO}^{7}$ & & & 0 & & 0 & & 45 & 15 & 0 & 0 & 0 & 0 \\
\hline $\mathrm{NCO} 38$ & & & 0 & & 0 & & 27 & 9 & 0 & 0 & 0 & 0 \\
\hline $\mathrm{NCO}_{1}$ & & & 1 & & 0 & & 6 & 2 & 1 & 0 & 44.6 & 0 \\
\hline $\mathrm{SC} \cup 12$ & & & 0 & & 0 & & 6 & 2 & 0 & 0 & 0 & 0 \\
\hline SC014 & & & 1 & & 1 & & 12 & 4 & 2 & 5 & 44.6 & 19.7 \\
\hline GA007 & & & 1 & & 0 & & 36 & 12 & 2 & 0 & 134 & 0 \\
\hline 1. A038 & & & 1 & & 1 & & 33 & 11 & 6 & 9 & 40.9 & 30.1 \\
\hline 10,1 & 42 & 15 & 4 & 10.5 & 3 & 14 & & & & & 0 & 0 \\
\hline A028 & & & 0 & & 0 & & 0 & 0 & 0 & 0 & 0 & 0 \\
\hline NM012 & & & 0 & & 0 & & 0 & $c$ & 0 & 0 & 0 & 0 \\
\hline $0 \mathrm{KO07}$ & & & 0 & & 0 & & 18 & 6 & 0 & 0 & 0 & 0 \\
\hline $\mathrm{OKO12}$ & & & 1 & & 0 & & 30 & 10 & 6 & 0 & 37.2 & 0 \\
\hline OK013 & & & 0 & & 0 & & 30 & 10 & 0 & 0 & 0 & 0 \\
\hline OK020 & & & 1 & & 0 & & 15 & 5 & 4 & 0 & 27.9 & 0 \\
\hline TX020 & & & 0 & & 1 & & 0 & 0 & 0 & 1 & 0 & 0 \\
\hline TX021 & & & 0 & & 0 & & 30 & 10 & 0 & 0 & 0 & 0 \\
\hline TX033 & & & 1 & & 1 & & 6 & 2 & 2 & 4 & 22.3 & 12.3 \\
\hline TX034 & & & 0 & & 1 & & 27 & 9 & 0 & 0 & 0 & 0 \\
\hline TX038 & & & 0 & & 0 & & 9 & 3 & 0 & 0 & 0 & 0 \\
\hline TX041 & & & 0 & & 0 & & 33 & 11 & 0 & 0 & 0 & 0 \\
\hline TX045 & & & 1 & & 1 & & 57 & 19 & 11 & 8 & 38.5 & 58.5 \\
\hline TX051 & & & 0 & & 0 & & 39 & 13 & 0 & 0 & 0 & 0 \\
\hline 10.2 & 26 & 10 & 5 & 5.2 & 4 & 6.5 & & & & & 0 & 0 \\
\hline AZO09 & & & -1 & & 0 & & 60 & 20 & 10 & 0 & 44.6 & 0 \\
\hline NM003 & & & 1 & & 1 & & 69 & 23 & 16 & 10 & 32.1 & 56.6 \\
\hline NM013 & & & 0 & & 0 & & 9 & 3 & 0 & 0 & 0 & 0 \\
\hline OK014 & & & 1 & & 1 & & 57 & 19 & 11 & 6 & 38.5 & 78 \\
\hline OK017 & & & 1 & & 1 & & 153 & 51 & 14 & 17 & 81.3 & 73.9 \\
\hline OK018 & & & 0 & & 1 & & 84 & 28 & 0 & 13 & 0 & 53 \\
\hline $\mathrm{TX} 012$ & & & 0 & & 0 & & 66 & 22 & 0 & 0 & 0 & 0 \\
\hline TX023 & & & 0 & & 0 & & 69 & 23 & 0 & 0 & 0 & 0 \\
\hline TX026 & & & 0 & & 0 & & 66 & 22 & 0 & 0 & 0 & 0 \\
\hline CA025 & & & 1 & & 0 & & 30 & 10 & 9 & 0 & 24.8 & 0 \\
\hline
\end{tabular}

E.9 
Table E.2 Weights for the Energy Consumption Data, by Agency

$\begin{array}{llllllllllll}N_{u} & N_{s} & n_{W x} & N_{u} / N_{W x} & n_{n p} & N_{u} / n_{n p} & M_{g} & M_{s} & r_{w x} & r_{n p} & W_{w x} & W_{n p}\end{array}$

\begin{tabular}{|c|c|c|c|c|c|c|c|c|c|c|c|c|}
\hline 9,3 & 75 & 27 & 12 & 6.25 & 10 & 7.5 & & & & & 0 & 0 \\
\hline $\mathrm{AL024}$ & & & 1 & & 1 & & 54 & 18 & 8 & 1 & 26.1 & 348 \\
\hline FL020 & & & 0 & & 1 & & 54 & 18 & 0 & 10 & 0 & 34.8 \\
\hline FL021 & & & 0 & & 0 & & 0 & 0 & 0 & 0 & 0 & 0 \\
\hline FLO23 & & & 0 & & 0 & & 3 & 1 & 0 & 0 & -0 & 0 \\
\hline GA006 & & & 1 & & 1 & & 33 & 11 & 3 & 2 & 42.5 & 106 \\
\hline GA009 & & & 0 & & 0 & & 9 & 3 & 0 & 0 & 0 & 0 \\
\hline $\mathrm{GA} 013$ & & & 1 & & 0 & & 72 & 24 & 1 & 0 & 278 & 0 \\
\hline LA030 & & & 0 & & 0 & & 150 & 50 & 0 & 0 & 0 & 0 \\
\hline $\mathrm{MSOO3}$ & & & 1 & & 1 & & 120 & 40 & 39 & 7 & 11.9 & 110 \\
\hline MS017 & & & 1 & & 0 & & 69 & 23 & 5 & 0 & 53.4 & 0 \\
\hline $\mathrm{MS} 018$ & & & 1 & & 1 & & 72 & 24 & 16 & 23 & 17.4 & 20.2 \\
\hline $\mathrm{NCOO} 2$ & & & 0 & & 0 & & 24 & 8 & 0 & 0 & 0 & 0 \\
\hline $\mathrm{NC} 007$ & & & 1 & & 0 & & 30 & 10 & 3 & 0 & 38.7 & 0 \\
\hline $\mathrm{NCO} 14$ & & & 0 & & 0 & & 0 & 0 & 0 & 0 & 0 & 0 \\
\hline $\mathrm{NC} 025$ & & & 0 & & 0 & & 0 & 0 & 0 & 0 & 0 & 0 \\
\hline $\mathrm{NC} 033$ & & & 0 & & 0 & & 18 & 6 & 0 & 0 & 0 & 0 \\
\hline $\mathrm{NC} 035$ & & & 0 & & 1 & & 0 & 0 & 0 & 1 & 0 & 0 \\
\hline $\mathrm{NC}, 4$ ? & & & 0 & & 0 & & 0 & 0 & 0 & 0 & 0 & 0 \\
\hline $\mathrm{SC} 005$ & & & 1 & & 1 & & 6 & 2 & 1 & 15 & 23.2 & 2.58 \\
\hline SC008 & & & 0 & & 0 & & 15 & 5 & 0 & 0 & 0 & 0 \\
\hline TN013 & & & 1 & & 1 & & 555 & 185 & 31 & 17 & 69.2 & 210 \\
\hline TN017 & & & 0 & & 0 & & 24 & 8 & 0 & 0 & 0 & 0 \\
\hline LAOO1 & & & 1 & & 1 & & 60 & 20 & 12 & 22 & 19.3 & 17.6 \\
\hline MS016 & & & 1 & & 1 & & 36 & 12 & 5 & 6 & 27.8 & 38.7 \\
\hline FL026 & & & 1 & & 0 & & 30 & 10 & 4 & 0 & 29 & 0 \\
\hline LA019 & & & 0 & & 0 & & 3 & 1 & 0 & 0 & 0 & 0 \\
\hline 9.4 & 11 & 4 & 2 & 5.5 & 1 & 11 & & & & & 0 & 0 \\
\hline FLO0)7 & & & 0 & & 0 & & 192 & 64 & 0 & 0 & 0 & 0 \\
\hline $\mathrm{NC} 013$ & & & 1 & & 0 & & 15 & 5 & 2 & 0 & 29 & 0 \\
\hline TN016 & & & 1 & & 1 & & 81 & 27 & 13 & 2 & 24.1 & 261 \\
\hline TN018 & & & 0 & & 0 & & 12 & 4 & 0 & 0 & 0 & 0 \\
\hline 10,3 & 37 & 13 & 10 & 3.7 & 6 & 6.17 & & & & & 0 & 0 \\
\hline $\mathrm{AZOO} 5$ & & & 1 & & 0 & & 135 & 45 & 34 & 0 & 15.4 & 0 \\
\hline $\mathrm{AZ} 006$ & & & 1 & & 1 & & 120 & 40 & 33 & 20 & 14.1 & 38.7 \\
\hline $\mathrm{NM} 002$ & & & 1 & & 1 & & 51 & 17 & 7 & 6 & 28.2 & 54.8 \\
\hline NM006 & & & 0 & & 0 & & 78 & 26 & 0 & 0 & 0 & 0 \\
\hline $\mathrm{NMO} 14$ & & & 0 & & 0 & & 60 & 20 & 0 & 0 & 0 & 0 \\
\hline $\mathrm{TX}(0) 4$ & & & 1 & & 0 & & 63 & 21 & 4 & 0 & 60.9 & 0 \\
\hline $\mathrm{TX} 010$ & & & 1 & & 0 & & 81 & 27 & 13 & 0 & 24.1 & 0 \\
\hline TX015 & & & 1 & & 1 & & 21 & 7 & 2 & 8 & 40.6 & 16.9 \\
\hline TX018 & & & 0 & & 0 & & 69 & 23 & 0 & 0 & 0 & 0 \\
\hline TX027 & & & 0 & & 0 & & 84 & 28 & 0 & 0 & 0 & 0 \\
\hline TX029 & & & 0 & & 0 & & 45 & 15 & 0 & 0 & 0 & 0 \\
\hline $\mathrm{TX}(040$ & & & 1 & & 1 & & 123 & 41 & 16 & 3 & 29.7 & 264 \\
\hline TX144 & & & 1 & & 1 & & 78 & 26 & $2 !$ & 21 & $! 1.4$ & 23.9 \\
\hline $\mathrm{AZOO}) 4$ & & & 1 & & 0 & & 201 & 67 & 54 & 0 & 14.4 & 0 \\
\hline $\mathrm{TX037}$ & & & 1 & & 1 & & 84 & 28 & 10 & 6 & 32. & 90.2 \\
\hline
\end{tabular}


Table E.2 Weights for the Energy Consumption Data, by Agency

\begin{tabular}{|c|c|c|c|c|c|c|c|c|c|c|c|c|}
\hline & $\mathbf{N}_{\mathbf{u}}$ & $\mathbf{N}_{\mathbf{s}}$ & $n_{w x}$ & $N_{u} / N_{w x}$ & $\mathrm{n}_{\mathrm{np}}$ & $N_{u} / n_{n p}$ & $\mathrm{M}_{\mathrm{g}}$ & $\mathbf{M}_{\mathbf{s}}$ & $r_{w X}$ & $r_{n p}$ & $W_{w x}$ & $W_{n p}$ \\
\hline 10,4 & 10 & 4 & 3 & 3.33 & 1 & 10 & & & & & 0 & 0 \\
\hline $\mathrm{CA013}$ & & & 1 & & 1 & & 42 & 14 & 8 & 56 & 20.3 & 4.83 \\
\hline $\mathrm{CAO23}$ & & & 0 & & 0 & & 57 & 19 & 0 & 0 & 0 & 0 \\
\hline $\mathrm{CA027}$ & & & 0 & & 0 & & 207 & 69 & 0 & 0 & 0 & 0 \\
\hline $\mathrm{TX} 022$ & & & 1 & & 0 & & 300 & 100 & 4 & 0 & 290 & 0 \\
\hline TX024 & & & 1 & & 0 & & 90 & 30 & 16 & 0 & 21.8 & 0 \\
\hline 9,5 & 2 & 2 & 0 & 0 & 0 & 0 & & & & & 0 & 0 \\
\hline FLO30 & & & 0 & & 0 & & 0 & 0 & 0 & 0 & $\because \quad 0$ & 0 \\
\hline TN006 & & & 0 & & 0 & & 45 & 15 & 0 & 0 & 0 & 0 \\
\hline 9,6 & & & & & 0 & 0 & & & & & 0 & 0 \\
\hline 10,5 & 3 & 3 & 3 & 1 & 1 & 3 & & & & & 0 & 0 \\
\hline CA026 & & & 1 & & 0 & & 54 & 18 & 9 & 0 & 10 & 0 \\
\hline CA035 & & & 1 & & 0 & & 99 & 33 & 25 & 0 & 6.6 & 0 \\
\hline NM001 & & & 1 & & 1 & & 405 & 135 & 4 & 3 & 169 & 675 \\
\hline 10,6 & & & & 0 & & 0 & & & & & 0 & 0 \\
\hline
\end{tabular}




\section{ATTRITION ANALYSIS}

Attrition bias was analyzed by comparing the characteristics of dwellings for which energy savings estimates were available with dwellings for which there were no savings estimates. Characteristics were chosen which tend to be correlated with energy savings. These pertain to dwelling features and rates of installation of weatherization measures.

Gas- and electrically heated dwellings were examined separately, and the dwelling-specific data weights for each fuel type were used. The results are provided in Table E.3. Several significant differences between dwellings with and without consumption data are identified, indicating the existence of systematic differences in response rates. While many differences are statistically significant, they are generally small in magnitude. In addition, consumption weights were created to correct for differential response rates across climate regions and agency size; thus, some of the differences identified in Table E. 3 may not lead to bias in the final energy savings estimates.

Table E.3 shows that gas-heated dwellings with savings estimates tend to be newer, with more central heating, and more supplemental heating fuels. There is also a higher proportion of small multifamily dwellings among this group, and a slightly smaller proportion of mobile homes. Overall, the gas-heated dwellings with savings estimates tended to receive fewer weatherization measures (including air leakage measures, insulation, and water-heater measures) than the other dwellings. On the other hand, they received more windows and doors.

Electrically heated dwellings with savings estimates tend to be older, with fewer central heating systems, and less air conditioning. As with the gas-heated dwellings, there is a higher proportion of small multifamily dwellings among this group, and a smaller proportion of mobile homes. Unlike the gas-heated dwellings, electrically heated dwellings with savings estimates tended to receive more weatherization measures than the other dwellings. The only exception is mobile home measures and space-heating system measures, which were installed at a lower rate among the electrically heated dwellings with consumption data. 
Table E.3 Attrition Analysis ${ }^{1}$

\begin{tabular}{|c|c|c|c|c|}
\hline \multirow[b]{2}{*}{ Characteristic } & \multicolumn{2}{|c|}{$\begin{array}{l}\text { Gas-heated } \\
\text { Dwellings }\end{array}$} & \multicolumn{2}{|c|}{$\begin{array}{l}\text { Electrically } \\
\text { Heated Dwellings }\end{array}$} \\
\hline & $\begin{array}{l}\text { No Savings } \\
\text { Estimate }\end{array}$ & $\begin{array}{l}\text { With Savings } \\
\text { Estimate }\end{array}$ & $\begin{array}{c}\text { No Savings } \\
\text { Estimate }\end{array}$ & $\begin{array}{l}\text { With Savings } \\
\text { Estimate }\end{array}$ \\
\hline $\begin{array}{l}\text { Type of Dwelling } \\
\text { Single-family detached } \\
\text { Single-family attached } \\
\text { Mobile home } \\
\text { Small multifamily }\end{array}$ & $\begin{array}{r}67.7 * * * \\
3.7 * * * \\
11.7 * * * \\
16.9 * * *\end{array}$ & $\begin{array}{r}64.9 \\
4.5 \\
9.0 \\
21.6\end{array}$ & $\begin{array}{r}55.6 * * * \\
1.5 * * * \\
33.5 * * * \\
9.2 * * *\end{array}$ & $\begin{array}{r}61.3 \\
1.8 \\
18.6 \\
18.0\end{array}$ \\
\hline Supplemental Heating Fuels & $23.0^{* * *}$ & 31.3 & 31.7 & 33.4 \\
\hline Central Heating Systems & $80.6 *$ & 81.3 & $39.7^{* * *}$ & 30.4 \\
\hline $\begin{array}{l}\text { Air Conditioning (window and } \\
\text { central) }\end{array}$ & 30.6 & 30.1 & $44.3^{* * *}$ & 32.5 \\
\hline $\begin{array}{l}\text { Square Footage } \\
\text { Less than } 900 \\
1,000 \text { to } 1,999 \\
2,000 \text { or more }\end{array}$ & $\begin{array}{l}49.2^{* * *} \\
43.2^{* * * *} \\
7.6\end{array}$ & $\begin{array}{r}50.5 \\
42.5 \\
7.0\end{array}$ & $\begin{array}{r}58.6^{*} \\
38.2^{*} \\
3.1^{*}\end{array}$ & $\begin{array}{r}58.8 \\
36.9 \\
4.2\end{array}$ \\
\hline $\begin{array}{l}\text { Year of Construction } \\
1939 \text { or before } \\
1940 \text { to } 1979 \\
1980 \text { or after }\end{array}$ & $\begin{array}{l}46.4^{* * *} \\
38.6^{* * *} \\
15.0^{* * *}\end{array}$ & $\begin{array}{l}44.7 \\
35.6 \\
19.7\end{array}$ & $\begin{array}{l}15.0^{* * *} \\
63.9^{* * *} \\
21.1 * * *\end{array}$ & $\begin{array}{l}21.5 \\
60.6 \\
17.8\end{array}$ \\
\hline Air Leakage Control & $96.6^{* * *}$ & 96.1 & $87.6 * * *$ & 93.4 \\
\hline Insulation & $68.8^{* * *}$ & 64.5 & $46.6 * * *$ & 56.6 \\
\hline Water Heater Measure & $64.4^{* * *}$ & 59.3 & $50.8^{* * *}$ & 54.4 \\
\hline Windows and Doors & $37.0 * * *$ & 44.3 & $35.6 * * *$ & 48.5 \\
\hline Space Heating System & 36.2 & 35.8 & $8.5 * * *$ & 6.4 \\
\hline Mobile Home Measure & $7.4^{* * *}$ & 4.7 & $21.0 * * *$ & 14.4 \\
\hline
\end{tabular}

1 Chi-square statistics were used to test the significance of differences between dwellings with energy consumption data and dwellings without consumption data. The numbers in each column represent the percentage of dwellings with the characteristic, using the dwelling-specific weights shown in Table E.2.

* and *** indicate that the two groups of dweilings are significant different, at the 0.05 and 0.001 level. respectively. 
Table E.4 Mean Values of PRISM Model Parameters
for Gas Heated Dwellings ${ }^{\mathrm{a}}$

\begin{tabular}{|c|c|c|c|c|c|}
\hline & $\begin{array}{l}\text { Intercept } \\
\text { (ccf/Day) }\end{array}$ & $\begin{array}{l}\text { Heating } \\
\text { Slope } \\
\text { (ccf/ }{ }^{\circ} \text { F Day) }\end{array}$ & $\begin{array}{c}\text { Temperature } \\
\text { Dependent } \\
\text { Gas Use } \\
\text { (ccf/Year) }\end{array}$ & $\mathrm{R}^{2}$ & $\begin{array}{c}\text { Reference } \\
\text { Temperature } \\
\left({ }^{\circ} \mathrm{F}\right)\end{array}$ \\
\hline \multicolumn{6}{|l|}{$\begin{array}{l}\text { Weatherized Group } \\
(\mathrm{N}=3873)\end{array}$} \\
\hline $\begin{array}{c}\text { Pre- } \\
\text { Weatherization }\end{array}$ & $\begin{array}{c}0.93 \\
(0.68)\end{array}$ & $\begin{array}{c}0.20 \\
(0.04)\end{array}$ & $\begin{array}{l}1032 \\
(275)\end{array}$ & $\begin{array}{c}0.83 \\
(0.003)\end{array}$ & $\begin{array}{l}63.2 \\
(9.4)\end{array}$ \\
\hline $\begin{array}{c}\text { Post- } \\
\text { Weatherization }\end{array}$ & $\begin{array}{c}0.86 \\
(0.57)\end{array}$ & $\begin{array}{c}0.17 \\
(0.03)\end{array}$ & $\begin{array}{c}924 \\
(247)\end{array}$ & $\begin{array}{c}0.84 \\
(0.003)\end{array}$ & $\begin{array}{c}63.3 \\
(30.8)\end{array}$ \\
\hline \multicolumn{6}{|l|}{$\begin{array}{c}\text { Control Group } \\
(\mathrm{N}=2611)\end{array}$} \\
\hline $\begin{array}{c}\text { Pre- } \\
\text { Weatherization }\end{array}$ & $\begin{array}{c}0.75 \\
(0.53)\end{array}$ & $\begin{array}{c}0.16 \\
(0.03)\end{array}$ & $\begin{array}{c}856 \\
(200)\end{array}$ & $\begin{array}{c}0.84 \\
(0.004)\end{array}$ & $\begin{array}{l}63.4 \\
(8.2)\end{array}$ \\
\hline $\begin{array}{c}\text { Post- } \\
\text { Weatherization }\end{array}$ & $\begin{array}{c}0.74 \\
(0.54)\end{array}$ & $\begin{array}{c}0.16 \\
(0.03)\end{array}$ & $\begin{array}{c}871 \\
(202)\end{array}$ & $\begin{array}{c}0.85 \\
(0.004)\end{array}$ & $\begin{array}{l}63.2 \\
(8.6)\end{array}$ \\
\hline
\end{tabular}

a Numbers in parentheses are standard errors. 

Table E.5 Mean Values for Heating-Only PRISM Parameters
for Electrically Heated Dwellings ${ }^{\mathrm{a}}$

\begin{tabular}{|c|c|c|c|c|c|}
\hline & $\begin{array}{c}\text { Intercept } \\
\text { (kWh/Day) }\end{array}$ & $\begin{array}{l}\text { Heating Slope } \\
\text { (kWh/ } /^{\circ} \text { F Day) }\end{array}$ & $\begin{array}{l}\text { Electricity Use } \\
\text { For Space } \\
\text { Heating } \\
\text { (kWh/Year) }\end{array}$ & $\mathbf{R}^{2}$ & $\begin{array}{c}\text { Reference } \\
\text { Temperature } \\
\left(^{\circ} \mathrm{F}\right)\end{array}$ \\
\hline \multicolumn{6}{|l|}{ Weatherized Group } \\
\hline $\begin{array}{c}\text { Pre- } \\
\text { Weatherization }\end{array}$ & $\begin{array}{c}4.9 \\
(3.5)\end{array}$ & $\begin{array}{c}1.9 \\
(0.5)\end{array}$ & $\begin{array}{c}4538 \\
(3806)\end{array}$ & $\begin{array}{l}0.65 \\
(.32)\end{array}$ & $\begin{array}{c}62.7 \\
(12.9)\end{array}$ \\
\hline $\begin{array}{c}\text { Post- } \\
\text { Weatherization }\end{array}$ & $\begin{array}{c}4.9 \\
(3.3)\end{array}$ & $\begin{array}{l}1.7 \\
(0.5)\end{array}$ & $\begin{array}{c}4683 \\
(2893)\end{array}$ & $\begin{array}{l}0.67 \\
(.32)\end{array}$ & $\begin{array}{c}62.0 \\
(41.6)\end{array}$ \\
\hline \multicolumn{6}{|l|}{$\begin{array}{l}\text { Control Group } \\
(\mathrm{N}=418)\end{array}$} \\
\hline $\begin{array}{c}\text { Pre- } \\
\text { Weatherization }\end{array}$ & $\begin{array}{c}5.2 \\
(3.5)\end{array}$ & $\begin{array}{c}1.7 \\
(0.6)\end{array}$ & $\begin{array}{c}4295 \\
(4136)\end{array}$ & $\begin{array}{c}0.59 \\
(0.32)\end{array}$ & $\begin{array}{c}62.8 \\
(32.8)\end{array}$ \\
\hline $\begin{array}{c}\text { Post- } \\
\text { Weatherization }\end{array}$ & $\begin{array}{c}4.9 \\
(3.4)\end{array}$ & $\begin{array}{c}1.7 \\
(0.5)\end{array}$ & $\begin{array}{c}4331 \\
(4487)\end{array}$ & $\begin{array}{c}0.64 \\
(0.32)\end{array}$ & $\begin{array}{c}63.8 \\
(27.1)\end{array}$ \\
\hline
\end{tabular}

a Numbers in parentheses are standard errors, except in the column of $\mathrm{R}^{2} \mathrm{~s}$ where the numbers in parentheses are standard deviations. 


\section{Table E.6 Mean Values for Cooling-Only PRISM Parameters for Electrically Cooled Dwellingsa}

\begin{tabular}{|c|c|c|c|c|c|}
\hline & $\begin{array}{c}\text { Intercept } \\
(\mathrm{kWh} / \text { Day })\end{array}$ & $\begin{array}{l}\text { Cooling Slope } \\
\text { (kWh/'F Day) }\end{array}$ & $\begin{array}{l}\text { Electricity Use } \\
\text { For Space } \\
\text { Cooling } \\
\text { (kWh/Year) }\end{array}$ & $\mathrm{R}^{2}$ & $\begin{array}{c}\text { Reference } \\
\text { Temperature } \\
\left({ }^{\circ} \mathrm{F}\right)\end{array}$ \\
\hline \multicolumn{6}{|c|}{$\begin{array}{l}\text { Weatherized Group } \\
(\mathrm{N}=22)\end{array}$} \\
\hline $\begin{array}{c}\text { Pre- } \\
\text { Weatherization }\end{array}$ & $\begin{array}{c}5.1 \\
(1.8)\end{array}$ & $\begin{array}{c}2.6 \\
(1.4)\end{array}$ & $\begin{array}{l}2933 \\
(467)\end{array}$ & $\begin{array}{c}0.69 \\
(0.35)\end{array}$ & $\begin{array}{l}73.8 \\
(3.0)\end{array}$ \\
\hline $\begin{array}{c}\text { Post- } \\
\text { Weatherization }\end{array}$ & $\begin{array}{l}5.8 \\
(2.1)\end{array}$ & $\begin{array}{l}2.8 \\
(1.5)\end{array}$ & $\begin{array}{l}3134 \\
(523)\end{array}$ & $\begin{array}{l}0.77 \\
(.27)\end{array}$ & $\begin{array}{l}75.2 \\
(4.0)\end{array}$ \\
\hline \multicolumn{6}{|l|}{$\begin{array}{c}\text { Control Group } \\
(\mathrm{N}=41)\end{array}$} \\
\hline $\begin{array}{c}\text { Pre- } \\
\text { Weatherization }\end{array}$ & $\begin{array}{c}4.7 \\
(1.9)\end{array}$ & $\begin{array}{c}2.4 \\
(1.7)\end{array}$ & $\begin{array}{l}2460 \\
(623)\end{array}$ & $\begin{array}{l}0.67 \\
(.28)\end{array}$ & $\begin{array}{l}74.0 \\
(6.2)\end{array}$ \\
\hline $\begin{array}{c}\text { Post- } \\
\text { Weatherization }\end{array}$ & $\begin{array}{c}4.9 \\
(2.1)\end{array}$ & $\begin{array}{c}2.7 \\
(2.1)\end{array}$ & $\begin{array}{l}2240 \\
(636)\end{array}$ & $\begin{array}{l}0.71 \\
(.27)\end{array}$ & $\begin{array}{l}76.4 \\
(4.5)\end{array}$ \\
\hline
\end{tabular}

a Numbers in parentheses are standard errors, except in the column of $\mathrm{R}^{2} \mathrm{~s}$ where the numbers in parentheses are standard deviations. 
Table E.7 Mean Values for Heating-and-Cooling PRISM Parameters for Electrically Heated and Cooled Dwellings ${ }^{a}$

\begin{tabular}{|c|c|c|c|c|c|c|c|c|}
\hline & $\begin{array}{c}\text { Intercept } \\
\text { (kWh/Day) }\end{array}$ & $\begin{array}{l}\text { Heating } \\
\text { Slope } \\
\text { (kWh/ }{ }^{\circ} \mathrm{F} \\
\text { Day) }\end{array}$ & $\begin{array}{c}\text { Cooling } \\
\text { Slope } \\
\text { (kWh/'F } \\
\text { Day) }\end{array}$ & $\begin{array}{c}\text { kWh Use } \\
\text { For Space } \\
\text { Heating } \\
\text { (kWh/ } \\
\text { Year) }\end{array}$ & $\begin{array}{c}\text { kWh Use } \\
\text { For Space } \\
\text { Cooling } \\
\text { (kWh/ } \\
\text { Year) }\end{array}$ & $\mathbf{R}^{2}$ & $\begin{array}{c}\text { Heating } \\
\text { Reference } \\
\text { Temperature } \\
\text { ('F) }\end{array}$ & $\begin{array}{c}\text { Cooling } \\
\text { Reference } \\
\text { Temperature } \\
\text { ('F) }\end{array}$ \\
\hline \multicolumn{9}{|c|}{$\begin{array}{l}\text { Weatherized Group } \\
(\mathrm{N}=19)\end{array}$} \\
\hline $\begin{array}{c}\text { Pre- } \\
\text { Weatherization }\end{array}$ & $\begin{array}{c}7.5 \\
(9.1)\end{array}$ & $\begin{array}{l}21.2 \\
(7.7)\end{array}$ & $\begin{array}{c}4.9 \\
(7.7)\end{array}$ & $\begin{array}{c}4732 \\
(5199)\end{array}$ & $\begin{array}{c}2159 \\
(1835)\end{array}$ & $\begin{array}{l}0.64 \\
(.64)\end{array}$ & $\begin{array}{l}61.0 \\
(27.9)\end{array}$ & $\begin{array}{l}71.3 \\
(8.2)\end{array}$ \\
\hline $\begin{array}{c}\text { Post- } \\
\text { Weatherization }\end{array}$ & $\begin{array}{c}4.2 \\
(6.2)\end{array}$ & $\begin{array}{c}18.6 \\
(14.3)\end{array}$ & $\begin{array}{c}6.5 \\
(2.6)\end{array}$ & $\begin{array}{c}4888 \\
(3282)\end{array}$ & $\begin{array}{c}3078 \\
(1978)\end{array}$ & $\begin{array}{l}0.79 \\
(.17)\end{array}$ & $\begin{array}{c}56.2 \\
(19.7)\end{array}$ & $\begin{array}{l}67.8 \\
(8.8)\end{array}$ \\
\hline \multicolumn{9}{|c|}{$\begin{array}{l}\text { Control Group } \\
(\mathrm{N}=33)\end{array}$} \\
\hline $\begin{array}{c}\text { Pre- } \\
\text { Weatherization }\end{array}$ & $\begin{array}{c}2.7 \\
(5.0)\end{array}$ & $\begin{array}{c}23.0 \\
(26.3)\end{array}$ & $\begin{array}{c}4.5 \\
(26.3)\end{array}$ & $\begin{array}{c}3234 \\
(5283)\end{array}$ & $\begin{array}{c}2303 \\
(2251)\end{array}$ & $\begin{array}{l}0.65 \\
(.21)\end{array}$ & $\begin{array}{c}61.6 \\
(56.2)\end{array}$ & $\begin{array}{l}70.9 \\
(9.4)\end{array}$ \\
\hline $\begin{array}{c}\text { Post- } \\
\text { Weatherization }\end{array}$ & $\begin{array}{c}6.5 \\
(15.4)\end{array}$ & $\begin{array}{c}19.5 \\
(39.4)\end{array}$ & $\begin{array}{c}2.7 \\
(3.5)\end{array}$ & $\begin{array}{c}3952 \\
(9273)\end{array}$ & $\begin{array}{c}3939 \\
(5037)\end{array}$ & $\begin{array}{l}0.67 \\
(.26)\end{array}$ & $\begin{array}{c}62.1 \\
(41.4)\end{array}$ & $\begin{array}{l}70.8 \\
(8 . \dot{6})\end{array}$ \\
\hline
\end{tabular}

a Numbers in parentheses are standard errors, except in the column of $\mathrm{R}^{2} \mathrm{~S}$ where the numbers in parentheses are standard deviations. 


\section{APPENDIX $F$ SUPPLEMENTAL TABLES FOR CHAPTER 6}


Table F.1 Incidental Repairs, Structural, Health, and Safety Measures,
by Climate Region (weighted) ${ }^{1}$

\begin{tabular}{|c|c|c|c|c|}
\hline & $\begin{array}{l}\text { Total } \\
\text { Sample } \\
(\mathrm{N}=14,971)\end{array}$ & $\begin{array}{l}\text { Cold : } \\
\text { Climate } \\
\text { Region } \\
(\mathrm{N}=4,690)\end{array}$ & $\begin{array}{l}\text { Moderate } \\
\text { Climate } \\
\text { Region } \\
(\mathrm{N}=7,238)\end{array}$ & $\begin{array}{l}\text { Climat } \\
\text { Region, } \\
\text { N-3,043) }\end{array}$ \\
\hline 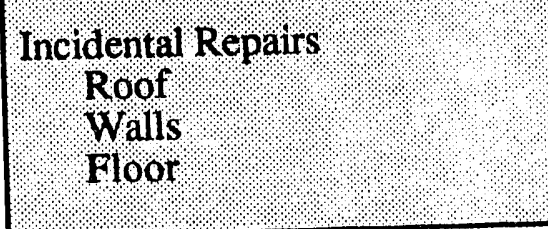 & $\begin{array}{r}16.3 \\
8.8 \\
6.4 \\
4.5\end{array}$ & $\begin{array}{r}13.7 \\
6.7 \\
6.0 \\
2.5\end{array}$ & $\begin{array}{r}13.0 \\
7.2 \\
4.8 \\
3.4\end{array}$ & $\begin{array}{r}27.2 \\
15.0 \\
10.9 \\
8.9\end{array}$ \\
\hline $\begin{array}{l}\text { Structural Measures } \\
\text { Windows glazing } \\
\text { Replacement of doors } \\
\text { Replacement of windows } \\
\text { A ttic ventilation } \\
\text { Door repairs } \\
\text { Other }\end{array}$ & $\begin{array}{l}86.1 \\
47.2 \\
37.8 \\
36.9 \\
34.2 \\
23.2 \\
16.2\end{array}$ & $\begin{array}{l}81.7 \\
41.7 \\
25.3 \\
26.1 \\
36.0 \\
19.4 \\
17.5\end{array}$ & $\begin{array}{l}86.8 \\
48.1 \\
34.4 \\
37.0 \\
38.0 \\
21.6 \\
16.2\end{array}$ & $\begin{array}{l}87.8 \\
49.8 \\
57.8 \\
46.3 \\
22.7 \\
31.1 \\
15.1\end{array}$ \\
\hline $\begin{array}{l}\text { Health and Safety Measures } \\
\text { Carbon monoxide test } \\
\text { Window and door locks } \\
\text { Smoke detectors }\end{array}$ & $\begin{array}{r}26.5 \\
22.9 \\
3.5 \\
3.2\end{array}$ & $\begin{array}{r}20.4 \\
18.3 \\
1.5 \\
1.4\end{array}$ & $\begin{array}{r}36.3 \\
32.4 \\
5.5 \\
3.2\end{array}$ & $\begin{array}{l}5.9 \\
1.8 \\
0.0 \\
4.6\end{array}$ \\
\hline $\begin{array}{l}\text { Heating System } \\
\text { Repairs } \\
\text { Safety measures }\end{array}$ & $\begin{array}{l}6.9 \\
5.3 \\
2.3\end{array}$ & $\begin{array}{l}6.2 \\
4.3 \\
2.4\end{array}$ & $\begin{array}{l}9.4 \\
7.5 \\
3.0\end{array}$ & $\begin{array}{l}0.5 \\
0.3 \\
0.2\end{array}$ \\
\hline
\end{tabular}

1 Values in the table are the percent of dwellings in which a measure was installed. All of the measures differ significantly across climate regions at the 0.001 level, based on Chi-square tests. The table is limited to measures that were installed in at least $2 \%$ of the homes weatherized during PY 1989. 
Table F.2 Incidental Repairs, Structural, Health, and Safety Measures, by Primary Heating Fuel (weighted)

\begin{tabular}{|c|c|c|c|}
\hline & $\begin{array}{l}\text { Natural Gas } \\
(\mathrm{N}=9,161)\end{array}$ & $\begin{array}{l}\text { Electricity } \\
(\mathrm{N}=1,325)\end{array}$ & $\begin{array}{l}\text { Other } \\
(\mathrm{N}=4,113)\end{array}$ \\
\hline $\begin{array}{l}\text { Incidental Repairs } \\
\text { Roof } \\
\text { Walls } \\
\text { Floor }\end{array}$ & $\begin{array}{r}15.2 \\
7.8 \\
7.1 \\
3.6\end{array}$ & $\begin{array}{r}15.1 \\
7.4 \\
4.9 \\
5.7\end{array}$ & $\begin{array}{r}17.9 \\
10.5 \\
5.8 \\
5.2\end{array}$ \\
\hline $\begin{array}{l}\text { Structural Measures } \\
\text { Windows/glazing } \\
\text { Replacement of doors } \\
\text { Replacement of windows } \\
\text { Attic ventilation } \\
\text { Door repairs } \\
\text { Other }\end{array}$ & $\begin{array}{l}87.9 \\
54.1 \\
35.5 \\
34.8 \\
38.5 \\
25.0 \\
17.3\end{array}$ & $\begin{array}{l}76.9 \\
28.5 \\
34.4 \\
35.1 \\
23.4 \\
20.6 \\
13.1\end{array}$ & $\begin{array}{l}85.9 \\
43.1 \\
41.6 \\
40.1 \\
31.5 \\
21.7 \\
15.7\end{array}$ \\
\hline $\begin{array}{l}\text { Health and Safety Measures } \\
\text { Carbon monoxide test } \\
\text { Window and door locks } \\
\text { Smoke detectors }\end{array}$ & $\begin{array}{r}36.6 \\
33.7 \\
4.6 \\
2.6\end{array}$ & $\begin{array}{r}12.1 \\
6.6 \\
3.9 \\
2.6\end{array}$ & $\begin{array}{r}17.2 \\
13.2 \\
2.0 \\
3.9\end{array}$ \\
\hline $\begin{array}{l}\text { Heating System } \\
\text { Repairs } \\
\text { Safety measures }\end{array}$ & $\begin{array}{l}8.9 \\
6.8 \\
3.1\end{array}$ & $\begin{array}{l}1.8 \\
1.3 \\
0.6\end{array}$ & $\begin{array}{l}5.5 \\
4.4 \\
1.7\end{array}$ \\
\hline
\end{tabular}

1 Values in the table are the percent of dwellings in which a measure was installed. All of the measures differ significantly across fuel types at the 0.001 level, based on Chi-square tests. The table is limited to measures that were installed in at least $2 \%$ of the homes weatherized during PY 1989. There are 372 missing observations. 
Table F.3 Incidental Repairs, Structural, Health, and Safety Measures,

\begin{tabular}{|c|c|c|c|c|}
\hline & $\begin{array}{c}\text { Single-family } \\
\text { Detached } \\
(\mathrm{N}=9,445)\end{array}$ & $\begin{array}{l}\text { Mobile } \\
\text { Home } \\
(\mathrm{N}=2,760)\end{array}$ & $\begin{array}{c}\text { Single-family } \\
\text { Attached } \\
(\mathrm{N}=570)\end{array}$ & $\begin{array}{l}\text { Small } \\
\text { Multifamily } \\
(\mathrm{N}=2,074)\end{array}$ \\
\hline $\begin{array}{l}\text { Incidental Repairs } \\
\text { Roof } \\
\text { Walls } \\
\text { Floor }\end{array}$ & $\begin{array}{r}17.7 \\
9.9 \\
8.0 \\
3.7\end{array}$ & $\begin{array}{r}18.2 \\
9.2 \\
3.4 \\
8.9\end{array}$ & $\begin{array}{r}16.3 \\
13.0 \\
6.4 \\
0.1\end{array}$ & $\begin{array}{l}6.1 \\
2.2 \\
3.1 \\
2.3\end{array}$ \\
\hline $\begin{array}{l}\text { Structural Measures } \\
\text { Windows/glazing } \\
\text { Replacement of doors } \\
\text { Replacement of windows } \\
\text { Attic ventilation } \\
\text { Door repairss } \\
\text { Other }\end{array}$ & $\begin{array}{l}89.2 \\
54.1 \\
35.3 \\
35.1 \\
45.3 \\
27.7 \\
18.9\end{array}$ & $\begin{array}{r}82.7 \\
25.2 \\
60.5 \\
48.9 \\
4.9 \\
18.2 \\
11.3\end{array}$ & $\begin{array}{r}69.9 \\
38.5 \\
15.0 \\
20.6 \\
33.9 \\
3.5 \\
11.8\end{array}$ & $\begin{array}{l}81.2 \\
51.6 \\
21.2 \\
32.2 \\
26.0 \\
14.5 \\
12.2\end{array}$ \\
\hline $\begin{array}{l}\text { Health and Safety Measures } \\
\text { Carbon monoxide test } \\
\text { Window and door locks } \\
\text { Smoke detectors }\end{array}$ & $\begin{array}{r}27.6 \\
23.9 \\
2.9 \\
3.0\end{array}$ & $\begin{array}{r}20.7 \\
16.6 \\
2.2 \\
4.4\end{array}$ & $\begin{array}{r}42.6 \\
39.0 \\
32.4 \\
0.7\end{array}$ & $\begin{array}{r}26.7 \\
24.3 \\
1.3 \\
2.2\end{array}$ \\
\hline $\begin{array}{l}\text { Heating System } \\
\text { Repairs } \\
\text { Safety measures }\end{array}$ & $\begin{array}{l}7.4 \\
5.7 \\
2.4\end{array}$ & $\begin{array}{l}5.5 \\
4.2 \\
1.6\end{array}$ & $\begin{array}{r}16.1 \\
13.5 \\
6.4\end{array}$ & $\begin{array}{l}4.2 \\
3.1 \\
1.6\end{array}$ \\
\hline
\end{tabular}

1 Values in the table are the percent of dwellings in which a measure was installed. All of the measures differ significantly across dwelling types at the 0.001 level, based on Chi-square tests. The table is limited to measures that were installed in at least $2 \%$ of the homes weatherized during PY 1989. There are 122 missing observations. 
Table F.4 Incidental Repairs, Structural, Health, and Safety Measures, by Agency Size (weighted) ${ }^{1}$

\begin{tabular}{|c|c|c|c|}
\hline 2.27. & $\begin{array}{c}\text { Small } \\
(\mathrm{N}=1,870)\end{array}$ & $\begin{array}{c}\text { Medium } \\
(\mathrm{N}=8,494)\end{array}$ & $\begin{array}{c}\text { Large } \\
(\mathrm{N}=4,607)\end{array}$ \\
\hline $\begin{array}{l}\text { Incidental Repairs } \\
\text { Roof } \\
\text { Walls } \\
\text { Floor }\end{array}$ & $\begin{array}{r}18.6 \\
10.4 \\
6.9 \\
5.3\end{array}$ & $\begin{array}{r}17.8 \\
9.6 \\
7.0 \\
5.1\end{array}$ & $\begin{array}{r}10.2 \\
5.5 \\
4.2 \\
1.8\end{array}$ \\
\hline $\begin{array}{l}\text { Structural Measures } \\
\text { Windows glazing } \\
\text { Replacentent of doors } \\
\text { Replacement of windows } \\
\text { Attic ventilation } \\
\text { Door repairs } \\
\text { Other }\end{array}$ & $\begin{array}{l}83.8 \\
42.9 \\
45.1 \\
37.6 \\
29.9 \\
24.6 \\
15.1\end{array}$ & $\begin{array}{l}87.4 \\
49.1 \\
39.6 \\
38.5 \\
34.7 \\
26.1 \\
15.1\end{array}$ & $\begin{array}{l}83.7 \\
45.1 \\
27.4 \\
32.0 \\
35.9 \\
14.1 \\
18.8\end{array}$ \\
\hline $\begin{array}{l}\text { Health and Safety Measures } \\
\text { Carbon monoxide test } \\
\text { Window and door locks (other) } \\
\text { Smoke detectors }\end{array}$ & $\begin{array}{r}28.1 \\
20.6 \\
1.0 \\
9.4\end{array}$ & $\begin{array}{r}26.3 \\
23.2 \\
2.8 \\
2.4\end{array}$ & $\begin{array}{r}25.7 \\
23.7 \\
7.3 \\
0.4\end{array}$ \\
\hline $\begin{array}{l}\text { Heating System } \\
\text { Repairs } \\
\text { Safety measures }\end{array}$ & $\begin{array}{l}4.6 \\
3.5 \\
1.4\end{array}$ & $\begin{array}{l}6.4 \\
4.7 \\
2.5\end{array}$ & $\begin{array}{l}9.6 \\
8.4 \\
2.2\end{array}$ \\
\hline
\end{tabular}

1 Values in the table are the percent of dwellings in which a measure was installed. All of the measures differ significantly across fuel types at the 0.001 level, based on Chi-square tests. The table is limited to measures that were installed in at least $2 \%$ of the homes weatherized during PY 1989. 
APPENDIX F-2

WEIGHTED ANNUAL DOLLAR VALUE OF ENERGY SAVINGS FOR ALL FUEL TYPES

\begin{tabular}{|c|c|c|c|c|c|}
\hline Fuel & $\begin{array}{c}\text { Weatherized } \\
\text { Dwel'́ings }\end{array}$ & $\begin{array}{c}\text { MBtu's } \\
\text { per } \\
\text { Dwelling }\end{array}$ & $\begin{array}{c}\text { \$ Value } \\
\text { of Savings } \\
\text { per } \\
\text { Dwelling }\end{array}$ & $\begin{array}{c}\text { Weighted } \\
\text { Value \$ }\end{array}$ \\
\hline $\begin{array}{c}\text { Natural Gas } \\
\text { Fuel Oil-Nine }\end{array}$ & 50.5 & 17.3 & 5.90 & 102.07 & 51.65 \\
\hline Fuel Oil-Other & 7.0 & 19.0 & 6.76 & 128.44 & 8.99 \\
\hline LPG & 13.3 & 15.4 & 10.29 & 158.47 & 21.08 \\
\hline Electricity & 9.5 & 6.2 & 22.41 & 138.94 & 13.20 \\
\hline Wood & 5.8 & 16.2 & 2.67 & 43.25 & 2.51 \\
\hline Kerosene & 3.2 & 15.9 & 7.24 & 115.12 & 3.68 \\
\hline Coal or Coke & 1.4 & 16.9 & 2.67 & 45.12 & 0.63 \\
\hline Other & 0.2 & 15.3 & 5.92 & 90.58 & 0.18 \\
\hline Weighted Mean & & & 6.89 & & 115.55 \\
\hline
\end{tabular}

* Source of fuel prices: EIA (1001a). 


\section{APPENDIX G}

SUPPLEMENTAL TABLES FOR CHAPTER 7 
Table G.1 Average Materials Costs ${ }^{a}$ of Weatherization Measures, by Climate Region (weighted)

\begin{tabular}{|c|c|c|c|c|c|c|c|c|}
\hline & \multicolumn{2}{|c|}{ Total Sample } & \multicolumn{2}{|c|}{$\begin{array}{l}\text { Cold } \\
\text { Climate Region }\end{array}$} & \multicolumn{2}{|c|}{$\begin{array}{l}\text { Moderate } \\
\text { Climate Region }\end{array}$} & \multicolumn{2}{|c|}{ Climate Region } \\
\hline & $(\$-1989)$ & $\begin{array}{l}\% \text { of } \\
\text { Total }\end{array}$ & $\begin{array}{c}\text { Cost } \\
(\$-1989)\end{array}$ & $\begin{array}{l}\% \text { of } \\
\text { Total }\end{array}$ & $\begin{array}{c}\text { Cost } \\
(\$-1989)\end{array}$ & $\begin{array}{l}\% \text { of } \\
\text { Total }\end{array}$ & $\begin{array}{c}\text { Cost } \\
(\$-1989)\end{array}$ & $\%$ of \\
\hline $\begin{array}{l}\text { Average Total } \\
\text { Materials Costs }\end{array}$ & 594 & & 585 & & 600 & & 585 & \\
\hline $\begin{array}{l}\text { Windows and } \\
\text { Doors }\end{array}$ & 133 & 22 & 82 & 14 & 148 & 25 & 155 & 26 \\
\hline Insulation & 137 & 23 & 185 & 32 & 129 & 22 & 87 & 15 \\
\hline $\begin{array}{l}\text { Structural } \\
\text { Measures }\end{array}$ & 126 & 21 & 94 & 16 & 121 & 20 & 161 & 28 \\
\hline Air Leakage & 116 & 20 & 98 & 17 & 121 & 20 & 128 & 22 \\
\hline $\begin{array}{l}\text { Space Heating } \\
\text { Systemb }\end{array}$ & 43 & 7 & 89 & 15 & 46 & 8 & 3 & 1 \\
\hline Water Heating & 10 & 2 & 13 & 2 & 10 & 2 & 5 & 1 \\
\hline Other & 29 & 5 & 24 & 4 & 25 & 4 & 46 & 8 \\
\hline $\begin{array}{l}\text { a Includes cost } \\
\text { b Includes spac }\end{array}$ & zero whe & the $m$ & $\begin{array}{l}\text { sure is no } \\
\text { and retro }\end{array}$ & $\begin{array}{l}\text { installe } \\
\text { its. }\end{array}$ & & & & \\
\hline
\end{tabular}


Table G.2 Average Materials Costs ${ }^{a}$ of Weatherization Measures Installed, by Primary Heating Fuel (weighted)

\begin{tabular}{|c|c|c|c|c|c|c|}
\hline & \multicolumn{2}{|c|}{ Nạtural Gas } & \multicolumn{2}{|c|}{ Electricity } & \multicolumn{2}{|c|}{ Other } \\
\hline & $\begin{array}{l}\text { Cost } \\
(\$-1989)\end{array}$ & $\begin{array}{l}\% \text { of } \\
\text { Total }\end{array}$ & $\begin{array}{c}\text { Cost } \\
(\$-1989)\end{array}$ & $\begin{array}{l}\% \text { of } \\
\text { Total }\end{array}$ & $\begin{array}{l}\text { Cost } \\
(\$-1989)\end{array}$ & \% of \\
\hline $\begin{array}{l}\text { Average Total } \\
\text { Materials Costs }\end{array}$ & 559 & & 592 & & 639 & \\
\hline Windows and Doors & 120 & 22 & 152 & 26 & 147 & 23 \\
\hline Insulation & 146 & 26 & 147 & 25 & 127 & 20 \\
\hline Structural Measures & 103 & 18 & 168 & 28 & 143 & 22 \\
\hline Air Leakage & 120 & 22 & 81 & 14 & 117 & 18 \\
\hline Space Heating Systemb & 40 & 7 & 7 & 1 & 56 & 9 \\
\hline Water Heating & 9 & 2 & 14 & 2 & 9 & 1 \\
\hline Other & 20 & 3 & 23 & 4 & 41 & 6 \\
\hline $\begin{array}{l}\text { a Includes costs of zero } \\
\text { b Includes space-heatin }\end{array}$ & $\begin{array}{l}\text { n the meas } \\
\text { lacements : }\end{array}$ & $\begin{array}{l}\text { e was no } \\
\text { d retrofi }\end{array}$ & installed. & & & \\
\hline
\end{tabular}


Table G.3 Average Materials Costs ${ }^{a}$ of Weatherization Measures Installed, by Type of Dwelling (weighted)

\begin{tabular}{|c|c|c|c|c|c|c|c|c|}
\hline & \multicolumn{2}{|c|}{$\begin{array}{l}\text { Single-family } \\
\text { Detached }\end{array}$} & \multicolumn{2}{|c|}{ Mobile Home } & \multicolumn{2}{|c|}{$\begin{array}{l}\text { Single-family } \\
\text { Attached }\end{array}$} & \multicolumn{2}{|c|}{$\begin{array}{c}\text { Small } \\
\text { Multifamilyb }\end{array}$} \\
\hline & $\begin{array}{c}\text { Cost } \\
(\$-1989)\end{array}$ & $\begin{array}{l}\% \text { of } \\
\text { Total }\end{array}$ & $\begin{array}{c}\text { Cost } \\
(\$-1989)\end{array}$ & $\begin{array}{l}\% \text { of } \\
\text { Total }\end{array}$ & $\begin{array}{c}\text { Cost } \\
(\$-1989)\end{array}$ & $\begin{array}{l}\% \text { of } \\
\text { Total }\end{array}$ & $\begin{array}{c}\text { Cost } \\
(\$-1989)\end{array}$ & $\begin{array}{l}\text { \% of } \\
\text { Total }\end{array}$ \\
\hline $\begin{array}{l}\text { Average Total } \\
\text { Materials Costs }\end{array}$ & 597 & & 594 & & 457 & & 603 & \\
\hline $\begin{array}{l}\text { Windows and } \\
\text { Doors }\end{array}$ & 112 & 19 & 200 & 34 & 123 & 27 & 138 & 23 \\
\hline Insulation & 179 & 30 & 28 & 5 & 36 & 8 & 138 & 23 \\
\hline $\begin{array}{l}\text { Structural } \\
\text { Measures }\end{array}$ & 117 & 20 & 173 & 29 & 95 & 21 & 106 & 18 \\
\hline Air Leakage & 120 & 20 & 94 & 16 & 53 & 12 & 131 & 22 \\
\hline $\begin{array}{l}\text { Space Heating } \\
\text { Systemc }\end{array}$ & 36 & 6 & 30 & 5 & 141 & 31 & 68 & 11 \\
\hline Water Heating & 9 & 2 & 7 & 1 & 6 & 1 & 11 & 2 \\
\hline Other & 24 & 4 & 62 & 10 & 2 & 1 & 10 & 2 \\
\hline $\begin{array}{l}\text { a Includes cost } \\
\text { b Dwellings in } \\
\text { c Includes spac }\end{array}$ & $\begin{array}{l}\text { of zero wh } \\
\text { wo- to four } \\
\text {-heating re }\end{array}$ & $\begin{array}{l}\text { en the } n \\
\text { unit bu } \\
\text { laceme }\end{array}$ & $\begin{array}{l}\text { easure was } \\
\text { Idings. } \\
\text { its and retr }\end{array}$ & not inst & & & & \\
\hline
\end{tabular}


Table G.4 Average Materials Costs ${ }^{\mathrm{a}}$ of Weatherization Measures Installed, by Size of Agencyb (weighted)

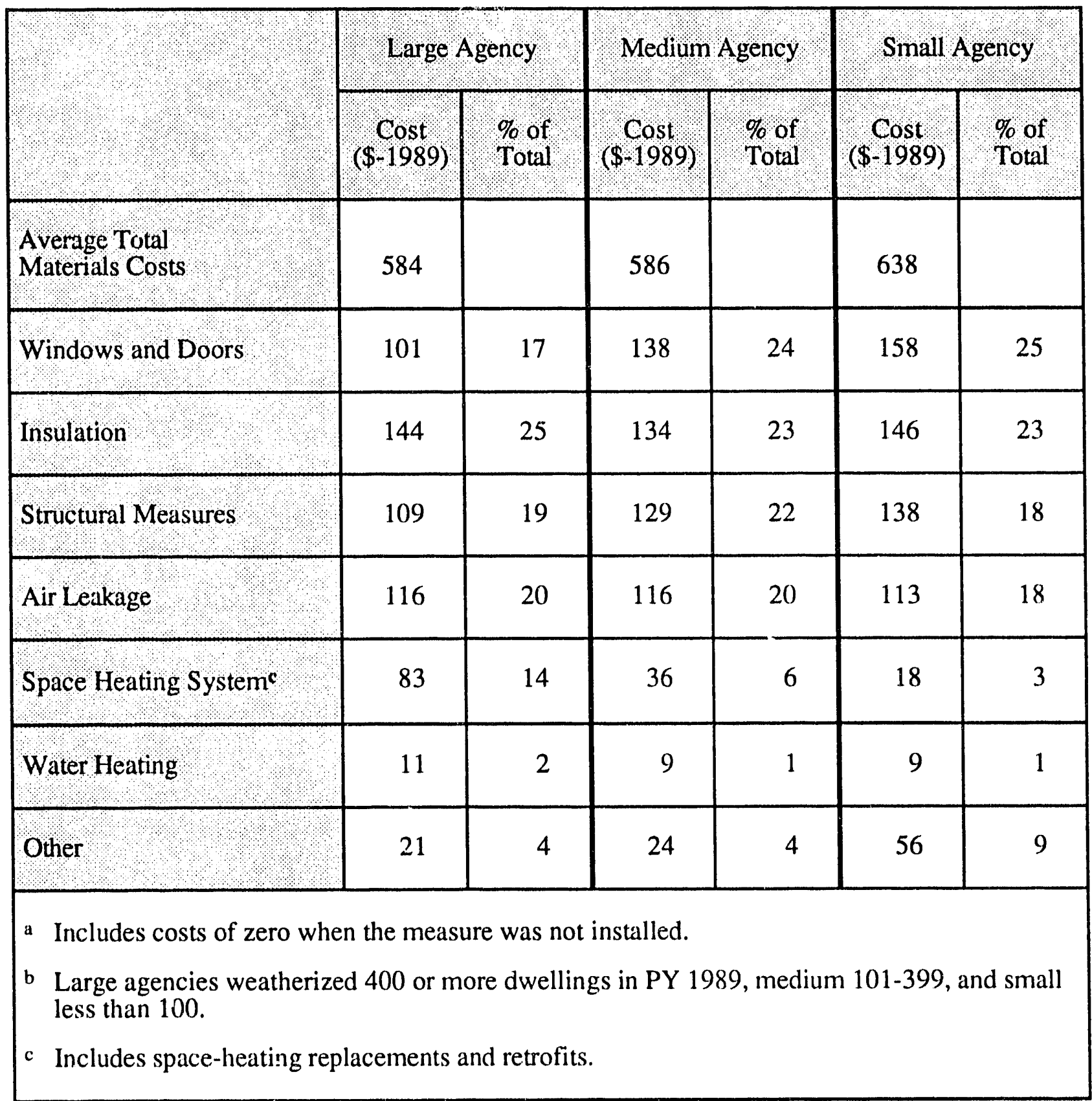


Table G.5 Indicators of Substandard Housing, by Census Region

\begin{tabular}{|c|c|c|c|c|}
\hline & Northeast ${ }^{t}$ & Midwest? & Soith'th & West" \\
\hline Lacking some plumbing facilities'? & 0.15 & 0.09 & 0.24 & 0.12 \\
\hline Water leakage from inside structure' & 8.32 & 8.44 & 10.99 & 10.71 \\
\hline Holes in floors ${ }^{2}$ & 0.56 & 0.54 & 1.03 & 0.68 \\
\hline Open cracks or holes (interior) ${ }^{2}$ & 2.63 & 3.04 & 3.75 & 3.74 \\
\hline Exposed wiring? & 1.15 & 1.22 & 1.18 & 1.24 \\
\hline $\begin{array}{l}\text { Lowest rating of overall opinion of structure } \\
\text { (i.e, received a score of t on a } 10 \text { point } \\
\text { scale) }\end{array}$ & 0.10 & 0.39 & 0.41 & 0.08 \\
\hline $\begin{array}{l}\text { Severe or moderate physical problem } \\
\text { (plumbing, heating, upkeep, hallways, or } \\
\text { kitchen) }\end{array}$ & 4.34 & 4.37 & 8.93 & 4.22 \\
\hline Percent of households below poverty? & 10.91 & 12.76 & 15.95 & 11.57 \\
\hline \multicolumn{5}{|c|}{$\begin{array}{l}\text { Source: American Housing Survey for the United States in } 1989 \text { (U.S. Department of } \\
\text { Commerce), H150/89, July } 1991 \text {. } \\
1 \text { Table 3-4. } \\
2 \text { Table 3-7. } \\
3 \text { Table 2-1. } \\
4 \text { Numbers are percentages based on the entire sample of dwellings surveyed by the } 1989 \\
\text { American Housing Survey. Similar statistics are not available for the subset of dwellings } \\
\text { occupied by low-income persons. }\end{array}$} \\
\hline
\end{tabular}


Table G.8 Average Total Installation and Labor Costs per Dwelling, by Dwelling Type

\begin{tabular}{|c|c|c|c|c|}
\hline & $\begin{array}{l}\text { Single- } \\
\text { Family } \\
\text { Detached }\end{array}$ & $\begin{array}{l}\text { Mobile } \\
\text { Home }\end{array}$ & $\begin{array}{l}\text { Single- } \\
\text { Family. } \\
\text { Attached }\end{array}$ & $\begin{array}{l}\text { Small } \\
\text { Multifamily }\end{array}$ \\
\hline Crev Only & $(n=2,258)$ & $(n=990)$ & $(n=71)$ & $(n=445)$ \\
\hline $\begin{array}{l}\text { Average total installed cost" } \\
\text { (\$/dwelling) }\end{array}$ & 841 & 817 & 760 & 777 \\
\hline Average hourly rate $(\$ / h$.) & 10 & 10 & 10 & 12 \\
\hline $\begin{array}{l}\text { Average crew labor cost } \\
\text { (\$/dwelling) }\end{array}$ & 338 & 266 & 194 & 335 \\
\hline Contrictoris only. & $(n=2,719)$ & $(n=677)$ & $(n=85)$ & $(n=518)$ \\
\hline $\begin{array}{l}\text { Aycrag totil installed cost? } \\
\text { (Sfdwelling) }\end{array}$ & 1,188 & 1,036 & 1,486 & 1,186 \\
\hline Avernge contractor labor cosis? & 536 & 451 & 638 & 528 \\
\hline Mixed (crey \& contractor) & $(\mathrm{n}=1,361)$ & $(n=376)$ & $(n=19)$ & $(n=209)$ \\
\hline $\begin{array}{l}\text { Average total installed cost }{ }^{b} \\
\text { (\$/dwelling) }\end{array}$ & 1,283 & 1,169 & 1,105 & 1,133 \\
\hline Average labor cost (\$/dwelling) & 566 & 442 & 349 & 517 \\
\hline \multicolumn{5}{|c|}{$\begin{array}{l}\text { a includes materials and labor } \\
\text { b includes materials, labor, contractor profit, and installation-related overhead } \\
\text { c includes labor, contrac or profit, and installation-related overhead } \\
\text { d This is calculated as the difference between the average total installec cost for mixed labor jobs } \\
\text { and the average materials cost (Table 7.1). It includes installation- }- \text { lated overhead costs and } \\
\text { contractor profit. }\end{array}$} \\
\hline
\end{tabular}




\section{Table G.9 Average Installation and Labor Custs per Dwelling, by Size of Agency}

\begin{tabular}{|c|c|c|c|}
\hline & Large & Medium & Small \\
\hline 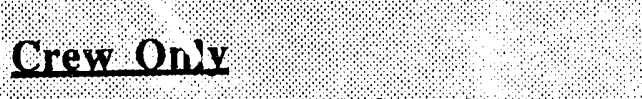 & $(n=1,272)$ & $(n=2,886)$ & $(n=723)$ \\
\hline $\begin{array}{l}\text { Average total installed cost }{ }^{\mathrm{a}} \\
(\$ \text { ddwelling) }\end{array}$ & 894 & 813 & 801 \\
\hline Average hourly rate $(\$ / \mathrm{hr}$.) & 10 & 11 & 9 \\
\hline Average crew labor cost (\$/dwelling) & 287 & 323 & 319 \\
\hline Contractor Only : : & $(n=1,796)$ & $(n=3,085)$ & $(n=651)$ \\
\hline $\begin{array}{l}\text { Average total installed cost'b } \\
\text { (\$) }\end{array}$ & 1,189 & 1,172 & 1,147 \\
\hline Average contractor labor costsc. & 558 & 518 & 495 \\
\hline Mixed (crevi: \& : contractor) & $(n=1,531)$ & $(n=2,319)$ & $(n=464)$ \\
\hline (\$) dqueling) & 1,142 & 1,208 & 1,539 \\
\hline Average labor d cost $(\$ / d w e l l i n g)$ & 495 & 527 & 608 \\
\hline \multicolumn{3}{|l|}{ a includes materials and labor } & \\
\hline \multicolumn{4}{|c|}{ b includes materials, labor, contractor profit, and installation-related overhead } \\
\hline \multicolumn{4}{|c|}{ c includes labor, contractor profit, and installation-related overhead } \\
\hline \multicolumn{4}{|c|}{$\begin{array}{l}\text { This is calculated as the difference between the average total installed cost for mixed labor } \\
\text { jobs and the average materials cost (Table 7.1). It includes insiallation-related overhead costs } \\
\text { and cringactor profit. }\end{array}$} \\
\hline
\end{tabular}




\section{APPENDIX H-1 \\ BENEFIT/COST ANALYSIS BASED ON WEIGHTED ESTIMATES OF THE LIFETIMES OF MEASURES}




\section{APPENDIX H-1}

\section{BENEFIT/COST ANALYSIS BASED ON WEIGHTED ESTIMATES OF THE LIFETIMES OF MEASURES}

Some energy conservation measures (ECMs) produce savings for only a few years (e.g., caulking around window frames, or furnace cleaning and tune-ups), while others (e.g., insulation or furnace replacements) may save energy for 20 or more years. For convenience, benefit/cost ratios are typically calculated by assuming an average lifetime for all weatherization measures installed by a program. The question of what average lifetime to assume in a benefit/cost calculation for the measures installed by the WAP in PY 1989 was resolved by taking into account the following information:

- the frequency of installation of various packages of measures,

- the average lifetime of the ECMs included in each package, and

- the measured gas savings of each package.

The development of a realistic assume average lifetime (which was weighted both by the frequency of installation of packages of ECMs and by their measured savings) for the PY 1989 program required several steps:

Available literature was consulted about the expected lifetimes of the ECMs included in the WAP. For the most part, the sources consulted closely agreed on the expected lifetimes of specific measures. When the sources did not agree, a simple average was calculated for that measures (Table H.1).

A weighted average lifetime estimate was developed for each of the five major categories of measures on the Dwelling-Specific Form ( $\mathrm{C1}-\mathrm{C} 3$, and $\mathrm{C5}-\mathrm{C} 7$, Appendix B-3). These estimates were developed by combining the expected lifetimes for ECMs supplied by the literature with the proportions of the subcategories of measures installed in this study's sample of dwellings. For example, water heater tank insulation (Table H.1) produces savings for 13 years, while water heater temperature reduction is expected to produce savings for about three years. Since $44 \%$ of the homes in our sample received water heater tank insulation while $13 \%$ received water heater temperature reduction, the 13-year lifetime for tank insulation was weighted about three times more heavily than the three-year lifetime for water heater temperature refuction in calculating a weighted average lifetime estimate of 11 years for category $\because:$

3) Assumptions concerning the proportions of total savings due to each subcategory of weatherization measures were developed within each of the five major categories of measures. These assumptions were based on an inspection of the patterns of savings in the ten most common packages of measures installed in the dwellings in our data set (Fig. H.1 and 'Table H.2), and on the reported ranges of savings from the BECA data set (Cohen, et al., 1991).

The assumptions used were that air leakage, and water heater measures each account for between 4 and $25 \mathrm{ccf}$ of the total savings within a package, that space heating measures account for 
between 32 and 41 ccf of the total savings, that insulation measures account for between 79 and 197 ccf of the total savings within a package, and that windows and doors account for between 13 and $43 \mathrm{ccf}$. The assumed savings for a subcategory of measures vary across packages because the savings for all included subcategories were required to sum to the measured total savings for the package. In addition, the assumed savings per subcategory was required to stay as close as possible to the ranges shown in Table H.3.

The savings weighted lifetimes (calculated by weighting each of the subcategories average lifetime by its assumed savings) for the ten most common packages of measures varied from 10 to 24 years. When all of the packages' lifetimes (any dwelling not included in the ten most common packages was placed in either package 11, which included all other combinations of ECMs that included insulation, or in package 12, which included all other combinations of ECMs that did not include insulation) were weighted by the savings per package, the savings weighted lifetime for the national program was 20 years (Table H.4). Therefore, this figure was used for the assumed lifetime of measures in the benefit/cost calculations in Chapter 8. 


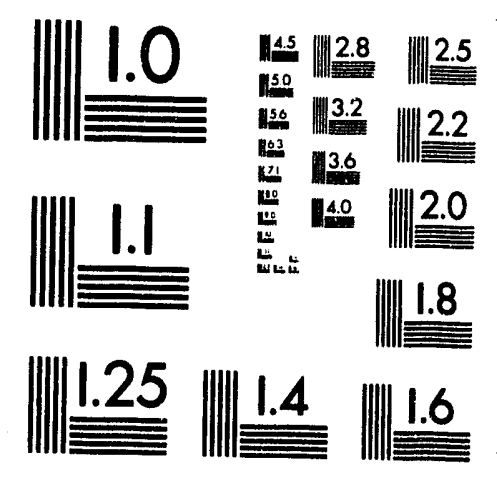



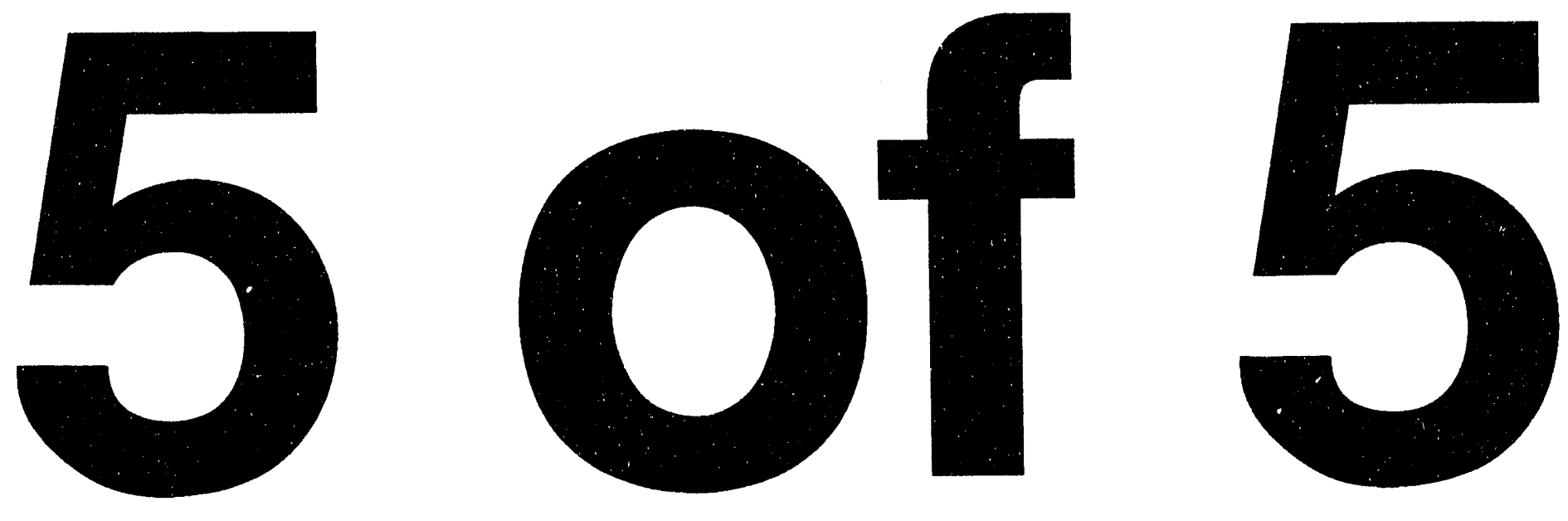
Table H.1

\section{Expected Lifetimes for Conservation Measures on the Dwelling-Specific Form}

\begin{tabular}{|c|c|c|c|c|c|c|}
\hline \multirow{2}{*}{\multicolumn{2}{|c|}{ Measure Type }} & \multicolumn{3}{|c|}{ Source' } & \multirow{3}{*}{$\begin{array}{c}\text { Average } \\
\underline{25^{3}} \\
\end{array}$} & \multirow{3}{*}{ Weights ${ }^{2}$} \\
\hline & & 1 & 2 & 3 & & \\
\hline \multirow[t]{2}{*}{$\mathrm{C} 1$} & \multirow{2}{*}{$\begin{array}{l}\text { Insulation } \\
\text { Attic insulation } \\
\text { Wall insulation } \\
\text { Floor insulation }\end{array}$} & & & & & \\
\hline & & $\begin{array}{l}20 \\
20 \\
20\end{array}$ & $\begin{array}{l}25 \\
25 \\
25\end{array}$ & $\begin{array}{l}30 \\
30 \\
30\end{array}$ & $\begin{array}{l}25 \\
25 \\
25\end{array}$ & $\mathrm{~N} / \mathrm{A}^{4}$ \\
\hline $\mathrm{C} 2$ & Air Leakage Control & 10 & 10 & - & 10 & $\mathrm{~N} / \mathrm{A}^{4}$ \\
\hline \multirow[t]{2}{*}{ C3 } & \multirow{2}{*}{$\begin{array}{l}\text { Water Heating System } \\
\text { Water Heater Tank Insulation } \\
\text { Entire Water Heating System } \\
\text { Replacement } \\
\text { Pipe Insulation } \\
\text { Low Flow Shower Heads } \\
\text { Temperature Reduction } \\
\end{array}$} & & & & 11 & $\mathrm{~N} / \mathrm{A}^{4}$ \\
\hline & & $\begin{array}{r}- \\
10 \\
10 \\
3 \\
\end{array}$ & $\begin{array}{l}13 \\
10 \\
\cdots\end{array}$ & $\begin{array}{l}13 \\
-- \\
-- \\
-- \\
\end{array}$ & $\begin{array}{r}13 \\
10 \\
10 \\
3 \\
\end{array}$ & $\begin{array}{r}44 \% \\
1 \% \\
35 \% \\
9 \% \\
13 \% \\
\end{array}$ \\
\hline C5 & Windows and Doors & 15 & 15 & - & 15 & $\mathrm{~N} / \mathrm{A}^{4}$ \\
\hline \multirow[t]{2}{*}{ C6 } & \multirow{2}{*}{$\begin{array}{l}\text { Space Heating System } \\
\text { Clean and Tune-up } \\
\text { Entire Heating System Replacement } \\
\text { Set-back Thermostat } \\
\text { Heating System Component } \\
\text { Retrofits }\end{array}$} & & & & $\underline{8.5}$ & \\
\hline & & $\begin{array}{r}2 \\
15 \\
-- \\
10 \\
\end{array}$ & $\begin{array}{c}-- \\
23 \\
-- \\
-- \\
\end{array}$ & $\begin{array}{l}-- \\
20 \\
15\end{array}$ & $\begin{array}{r}2 \\
19 \\
15 \\
10 \\
\end{array}$ & $\begin{array}{r}16 \% \\
3 \% \\
4 \% \\
8 \% \\
\end{array}$ \\
\hline
\end{tabular}

1 The three sources used were:

(1) M.P. Ternes, P.S. Hu, L.S. Williams, and P. Gocwey, The National Fuel End-Use Efficiency Field Test: Energy Savings and Performance of an Improved Energy Conservation Measure Selection Technique, ORNL/CON-303, Oak Ridge National Laboratory, January 1991.

(2) An Energy Efficiency Blueprint for California, Appendix A: Mcasurement Protocols for DSM Programs Eligible for Shareholder Incentives, Report of the Statewide Collaborative Process. January 1991.

(3) Koomey, J.G., et al. 1991, The Potential for Electricity Efficiency Improvements in the U.S. Residential Sector, LBL-30477, UC-350, Lawrence Berkeley Laboratory, Berkeley, CA.

2 Weights are based on the proportion of FY 1989 dwellings receiving the measures.

3 Underlined figures indicate the weighted average for the five major categories of measures.

$4 \mathrm{~N} / \mathrm{A}=$ not applicable, either because all expected lifetimes for subcategories in the major category were the same, or because expected lifetimes were missing for some or all of the subcategories. 
Fig. H.1

\section{Ten Most Common Packages of Weatherization Measures in Gas-Heated Dwellings}

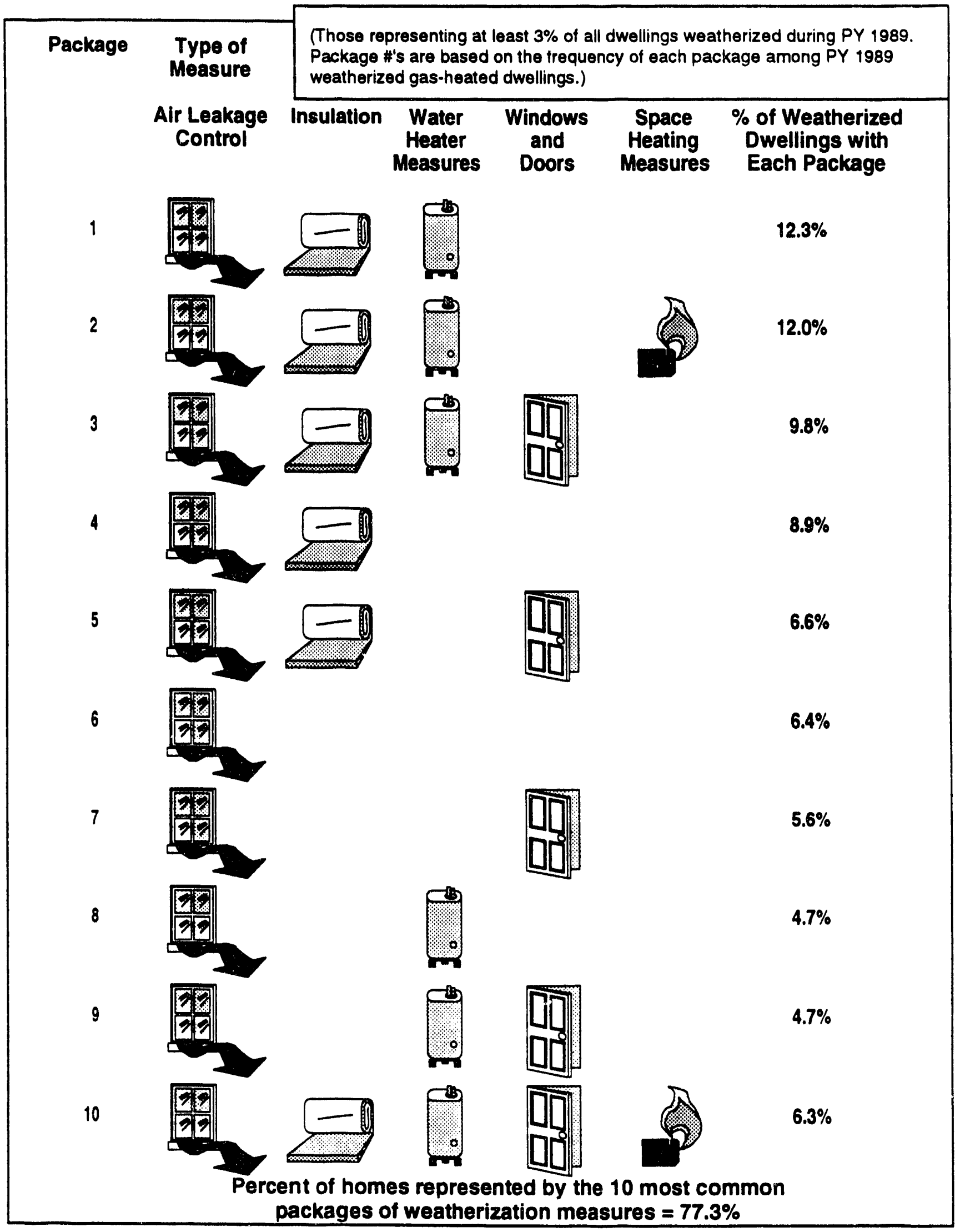

H.1.4 
Table H.2

Rank Order of Savings for the Ten Most
Common Packages of Measures

\begin{tabular}{|c|c|c|c|c|c|c|}
\hline $\begin{array}{c}\text { Package } \\
\text { Number }\end{array}$ & $\begin{array}{c}\text { Leakage } \\
\text { Control }\end{array}$ & $\begin{array}{c}\text { Air. } \\
\text { Insulation }\end{array}$ & $\begin{array}{c}\text { Water } \\
\text { Heating }\end{array}$ & $\begin{array}{c}\text { Windows } \\
\text { and Doors }\end{array}$ & $\begin{array}{c}\text { Space } \\
\text { Heating } \\
\text { System }\end{array}$ & $\begin{array}{c}\text { CCF } \\
\text { Savings }\end{array}$ \\
\hline 2 & $\mathrm{X}$ & $\mathrm{X}$ & $\mathrm{X}$ & & $\mathrm{X}$ & 259 \\
\hline 10 & $\mathrm{X}$ & $\mathrm{X}$ & $\mathrm{X}$ & $\mathrm{X}$ & $\mathrm{X}$ & 216 \\
\hline 1 & $\mathrm{X}$ & $\mathrm{X}$ & $\mathrm{X}$ & & & 185 \\
\hline 4 & $\mathrm{X}$ & $\mathrm{X}$ & & & & 165 \\
\hline 3 & $\mathrm{X}$ & $\mathrm{X}$ & $\mathrm{X}$ & $\mathrm{X}$ & & 157 \\
\hline 5 & $\mathrm{X}$ & $\mathrm{X}$ & & $\mathrm{X}$ & & 100 \\
\hline 7 & $\mathrm{X}$ & & & $\mathrm{X}$ & & 57 \\
\hline 9 & $\mathrm{X}$ & & $\mathrm{X}$ & $\mathrm{X}$ & & 32 \\
\hline 6 & $\mathrm{X}$ & & & & & 25 \\
\hline 8 & $\mathrm{X}$ & & $\mathrm{X}$ & & & -9 \\
\hline
\end{tabular}

Table H.3

Ranges of Savings Suggested by Single-Family Study and by BECA Findings

\begin{tabular}{|c|c|c|}
\hline Measure Type & $\begin{array}{l}\text { Single-Family } \\
\text { Study }\end{array}$ & $\mathrm{BECA}$ \\
\hline Air Leakage Control & $5-25$ & -- \\
\hline Windows and Doors & $0-40$ & $20-50$ \\
\hline Water Heating System & $0-10$ & -- \\
\hline Insulation & $80-200$ & $130-440$ \\
\hline Space Heating System & $30-70$ & $70-320^{1}$ \\
\hline
\end{tabular}

1 Excludes tune-ups. 


\section{APPENDIX H-2}

\section{COST-EFFECTIVENESS RESULTS FOR \\ ELECTRICALLY HEATED DWELLINGS}




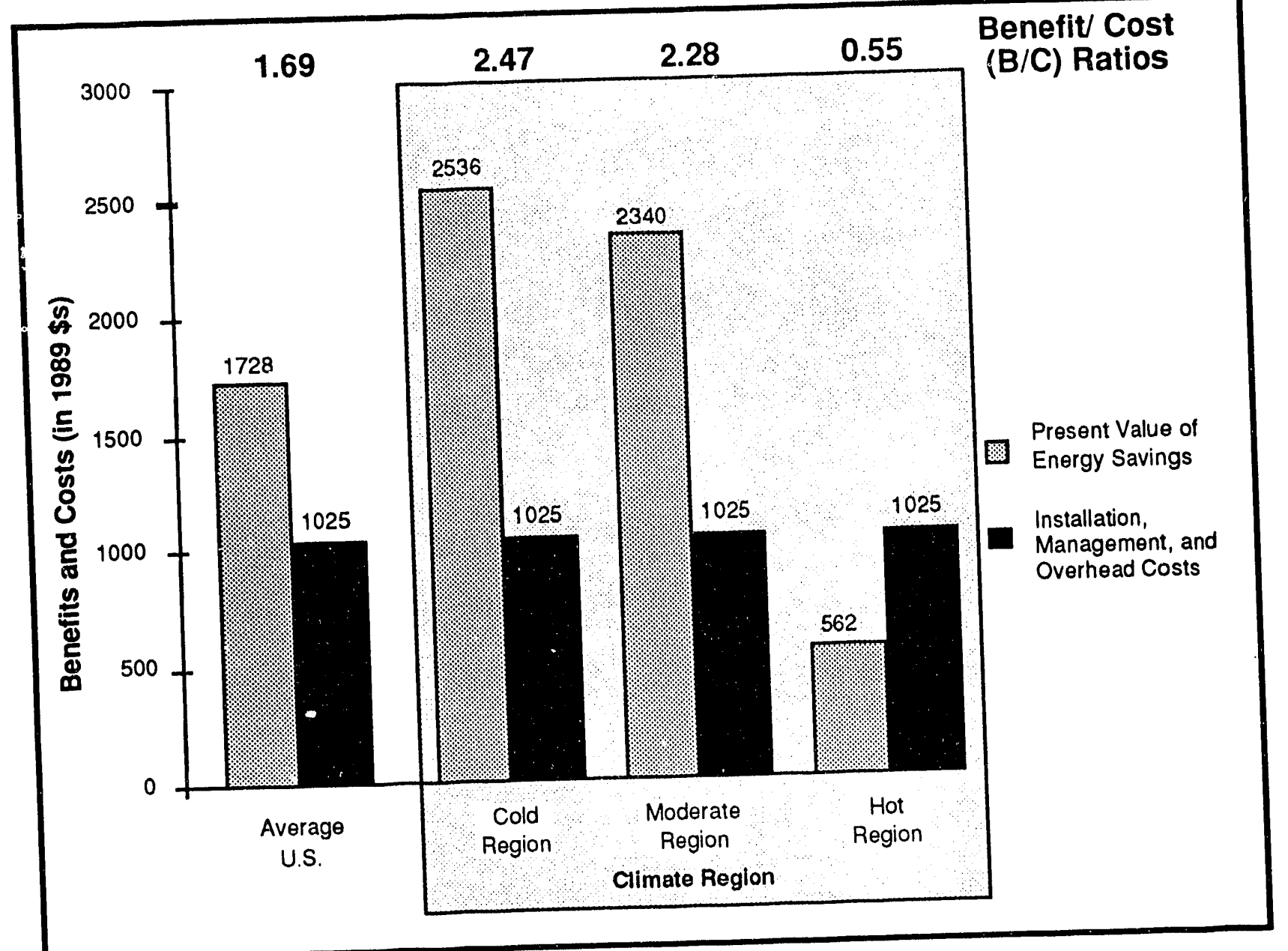

Fig. H-2.1 Installation Benefits and Costs by Climate Region for Electrically Heated Dwellings. 


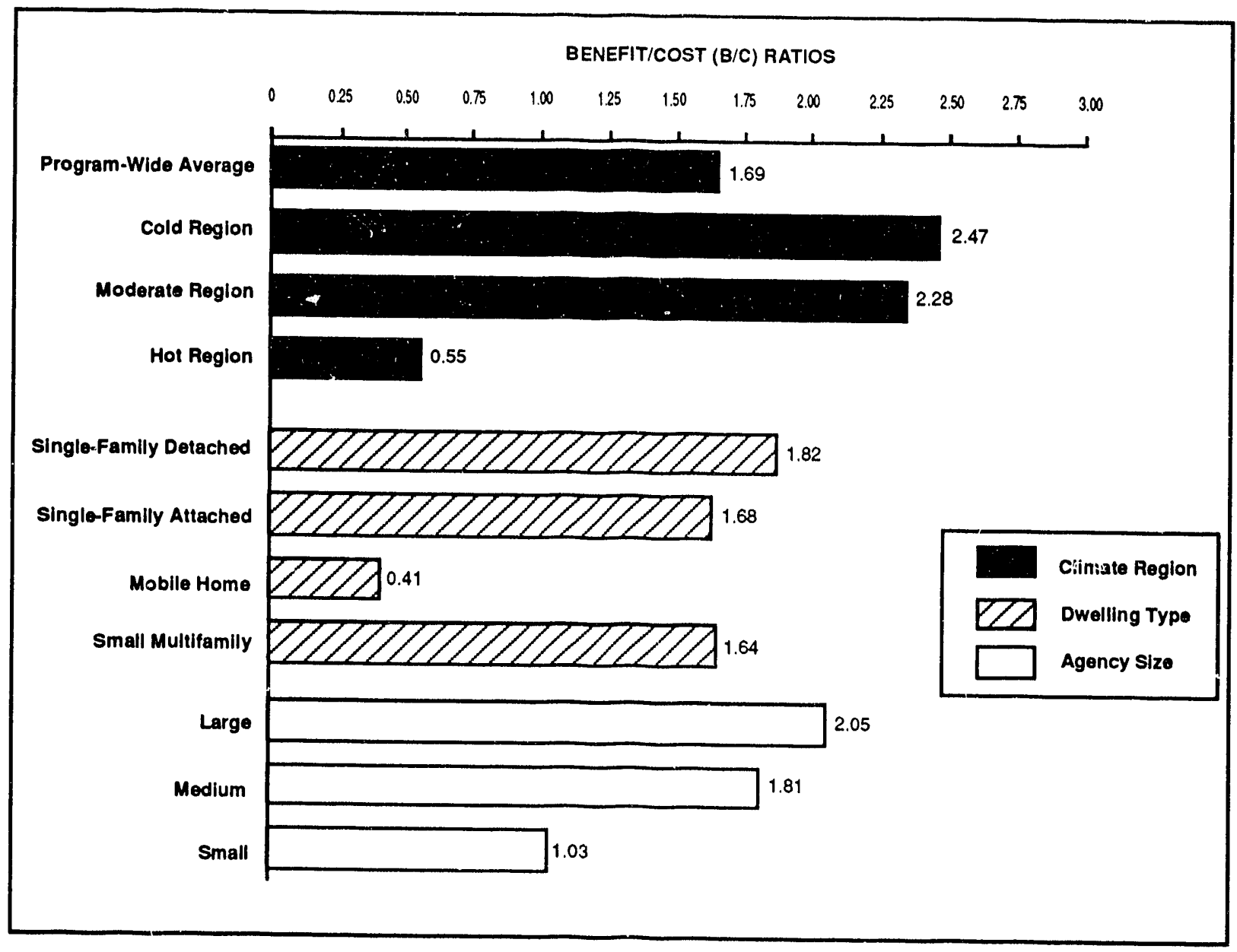

Fig. H-2.2 Installation Benefit/Cost Ratios by Climate Region, Dwelling Type, and Agency Size for Electrically Heated Dwellings. 


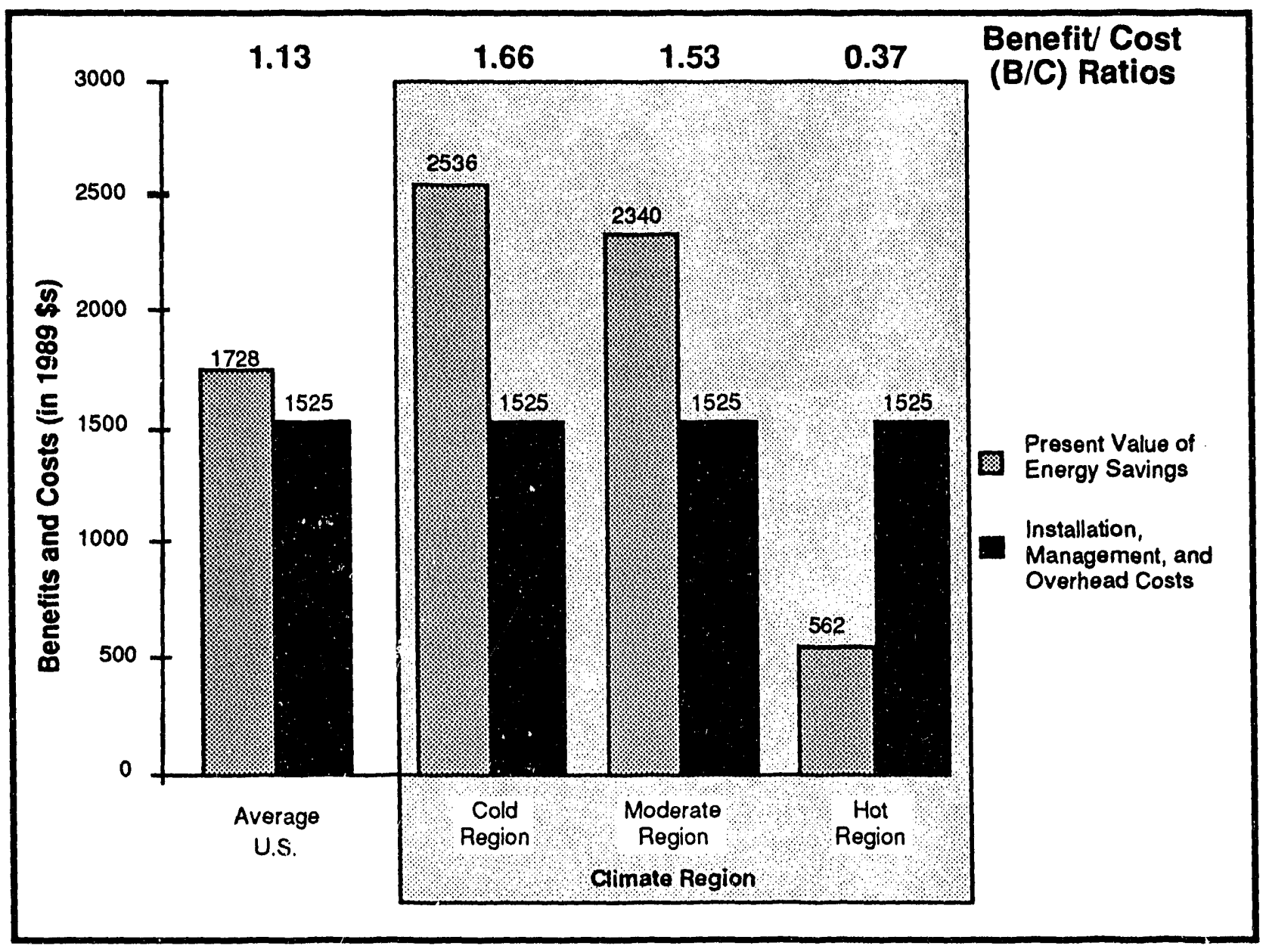

Fig. H-2.3 Program Benefits and Costs by Climate Region for Electrically Heated Dwellings 


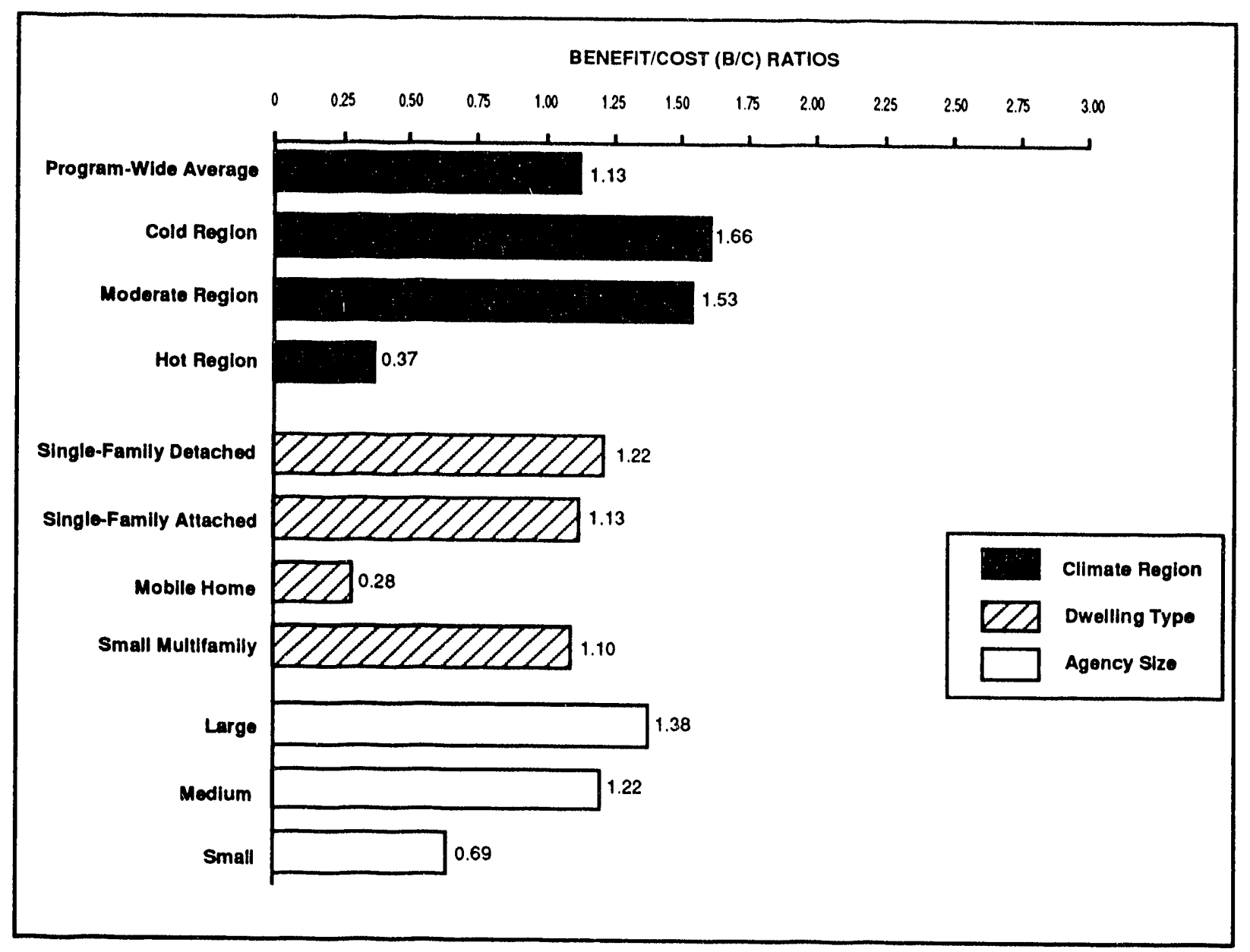

Fig. H-2.4 Program Benefit/Cost Ratios by Climate Region, Dwelling Type, and Agency Size for Electrically Heated Dwellings 


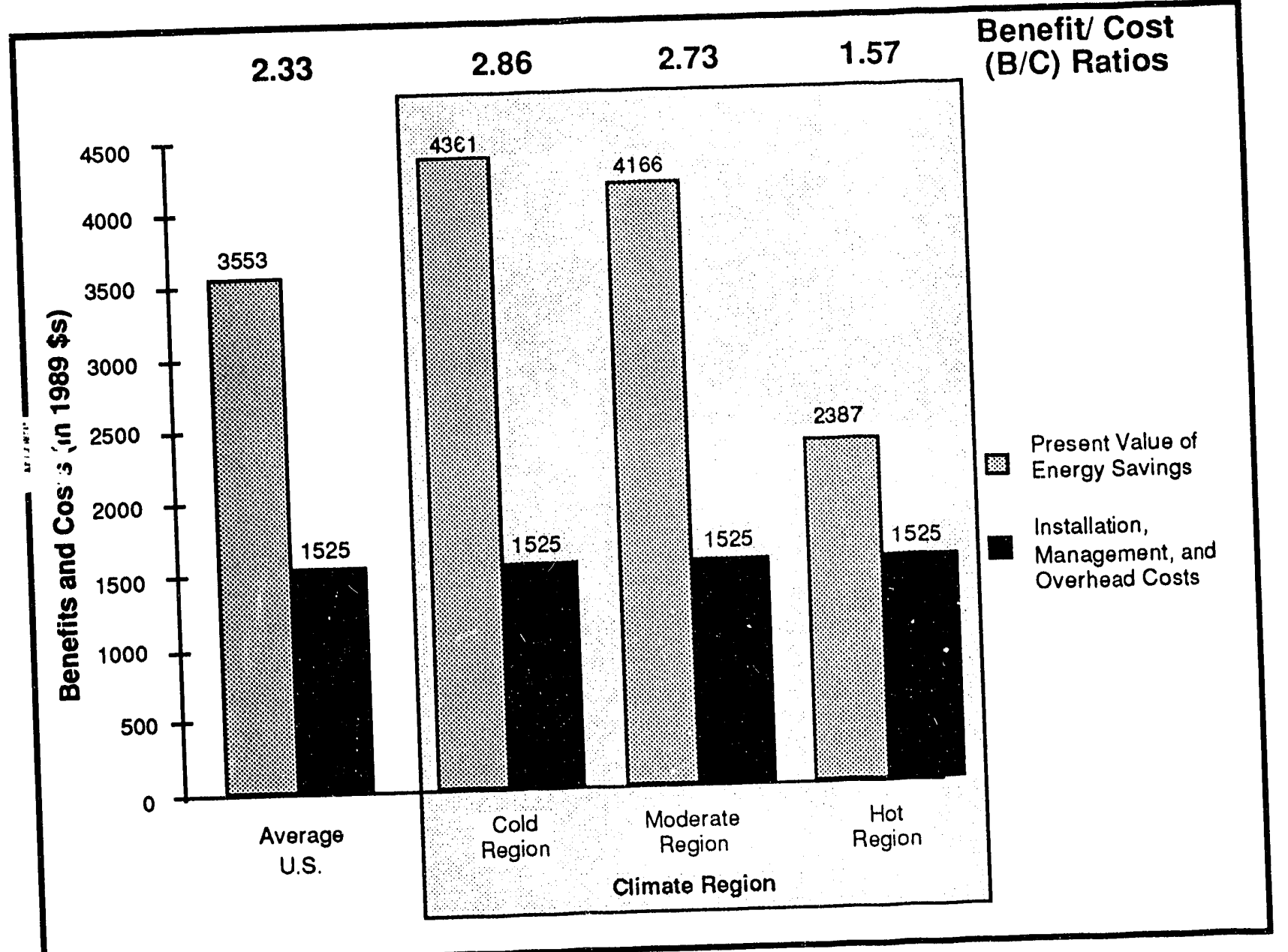

Fig. H-2.5 Societal Benefits and Costs by Climate Region for Electrically Heated Dwellings. 


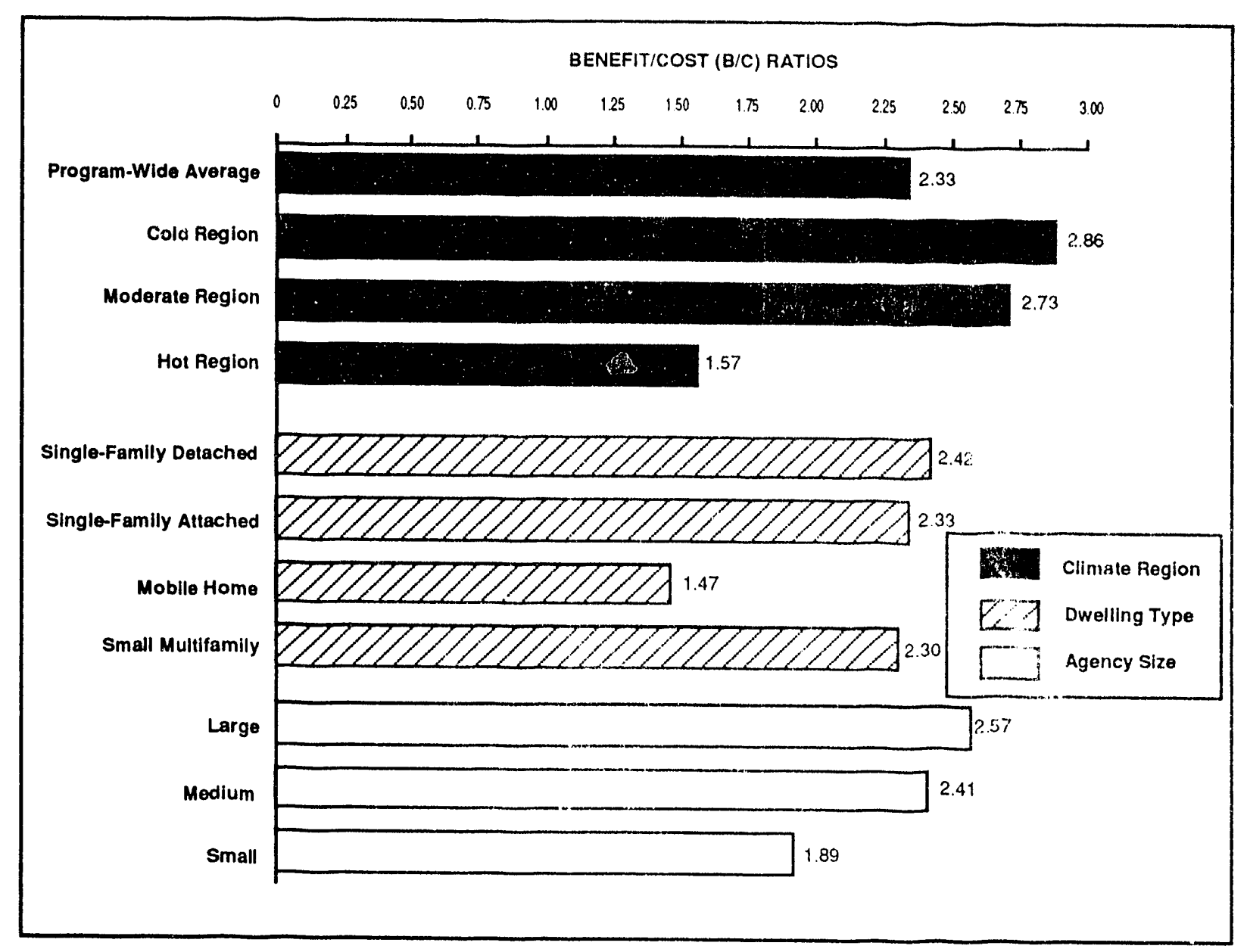

Fig. H-2.6 Societal Benefits and Costs by Climate Region, Dwelling Type, and Agency Size for Electrically Heated Dwellings. 


\section{APPENDIX I SUPPLEMENTAL TABLES FOR CHAPTER 9}


Table I.1 Energy Savings by Occupant Characteristics'

\begin{tabular}{|c|c|c|c|c|}
\hline & \multicolumn{2}{|c|}{ Gas-Heated Dwellings } & \multicolumn{2}{|c|}{$\begin{array}{l}\text { Electrically-Heated } \\
\text { Dwellings }\end{array}$} \\
\hline & $\begin{array}{l}\text { Gas Savings } \\
\text { (ccf/year) }\end{array}$ & $\begin{array}{l}\text { Number of } \\
\text { Dwellings. }\end{array}$ & $\begin{array}{l}\text { Electricity } \\
\text { Savings: } \\
(\mathrm{kWh} / \mathrm{y} \text {.ar) }\end{array}$ & $\begin{array}{l}\text { Number of } \\
\text { Dwellings }\end{array}$ \\
\hline $\begin{array}{l}\text { Owners/Renters } \\
\text { Owned } \\
\text { Rented }\end{array}$ & $\begin{array}{l}133 \\
152\end{array}$ & $\begin{array}{l}2,049 \\
1,242\end{array}$ & $\begin{array}{l}726 \\
711\end{array}$ & $\begin{array}{l}191 \\
136\end{array}$ \\
\hline $\begin{array}{l}\text { Number of Occupants } \\
1 \text { or } 2 \text { persons } \\
3 \text { to } 5 \text { persons } \\
6 \text { or more persons }\end{array}$ & $\begin{array}{l}154 \\
124 \\
149\end{array}$ & $\begin{array}{r}1,621 \\
1,449 \\
253\end{array}$ & $\begin{array}{r}294 \\
919 \\
1,917\end{array}$ & $\begin{array}{r}165 \\
133 \\
27\end{array}$ \\
\hline $\begin{array}{l}\text { Change of Occupants } \\
1 \text { or more before weatherization } \\
1 \text { or more after weatherization } \\
\text { No change of occupants } \\
\text { Both before and after }\end{array}$ & $\begin{array}{r}128 \\
193 \\
139 \\
38\end{array}$ & $\begin{array}{r}215 \\
97 \\
2,540 \\
76\end{array}$ & $\begin{array}{r}-226 \\
892 \\
883 \\
-604\end{array}$ & $\begin{array}{r}23 \\
16 \\
260 \\
14\end{array}$ \\
\hline $\begin{array}{l}\text { Elderly Occupant } \\
1 \text { or more } \\
\text { None }\end{array}$ & $\begin{array}{l}137 \\
142\end{array}$ & $\begin{array}{r}949 \\
2,373\end{array}$ & $\begin{array}{l}607 \\
777\end{array}$ & $\begin{array}{l}111 \\
216\end{array}$ \\
\hline $\begin{array}{l}\text { Handicapped Occupant } \\
1 \text { or more } \\
\text { None }\end{array}$ & $\begin{array}{l}149 \\
138\end{array}$ & $\begin{array}{r}735 \\
2,588\end{array}$ & $\begin{array}{r}1,093 \\
606\end{array}$ & $\begin{array}{r}76 \\
251\end{array}$ \\
\hline $\begin{array}{l}1989 \text { Family Income } \\
\text { Less than } \$ 5,000 \\
\$ 5,000 \text { to } \$ 14,999 \\
\$ 15,000 \text { or more }\end{array}$ & $\begin{array}{l}141 \\
150 \\
148\end{array}$ & $\begin{array}{r}698 \\
1,585 \\
178\end{array}$ & $\begin{array}{r}1,042 \\
471 \\
1,059\end{array}$ & $\begin{array}{r}126 \\
185 \\
16\end{array}$ \\
\hline
\end{tabular}

1 Significant tests for gas-heated dwellings were based on an F-test from a two-way analysis of variance, controlling for climate region. Significant tests for electrically heated dwellings used a T-test for bi-level factors and a F-test for multi-level factors.

$*, * *$, and $* * *$ indicate that energy savings are significantly greater than zero at the $0.05,0.01$, or 0.001 level, respectively. 
Table I.2 Energy Savings by Dwelling Characteristics ${ }^{1}$

\begin{tabular}{|c|c|c|c|c|}
\hline & Gas-Heated & Dwellings & $\begin{array}{l}\text { Electrice } \\
\text { D we }\end{array}$ & $\begin{array}{l}\text { Heated } \\
\text { ngs }\end{array}$ \\
\hline & $\begin{array}{l}\text { Gas Savings } \\
\text { (ccf/year) }\end{array}$ & $\begin{array}{l}\text { Number of } \\
\text { Dwellings }\end{array}$ & $\begin{array}{l}\text { Electricity } \\
\text { Savings } \\
(\mathrm{kWh} / \mathrm{y} \text { ear })\end{array}$ & $\begin{array}{l}\text { Number of } \\
\text { Dwellings }\end{array}$ \\
\hline $\begin{array}{l}\text { Type of Dwelling } \\
\text { Single-family detached } \\
\text { Single-family attached } \\
\text { Mobile home } \\
\text { Small multifamily }\end{array}$ & $\begin{array}{r}147 * * \\
120^{* *} \\
68^{* *} \\
147^{* *}\end{array}$ & $\begin{array}{r}2,119 \\
205 \\
346 \\
656\end{array}$ & $\begin{array}{r}1,046 \\
-283 \\
-399 \\
872\end{array}$ & $\begin{array}{r}195 \\
7 \\
59 \\
62\end{array}$ \\
\hline $\begin{array}{l}\text { Supplemental Heating Fuel } \\
\text { Yes } \\
\text { No }\end{array}$ & $\begin{array}{l}117^{* *} \\
180^{* *}\end{array}$ & $\begin{array}{r}675 \\
1,201\end{array}$ & $\begin{array}{r}1,316 \\
951\end{array}$ & $\begin{array}{r}60 \\
108\end{array}$ \\
\hline $\begin{array}{l}\text { Central Heating System } \\
\text { Central heating system } \\
\text { Other }\end{array}$ & $\begin{array}{r}158 \\
94\end{array}$ & $\begin{array}{r}2,503 \\
431\end{array}$ & $\begin{array}{r}190 \\
1,004\end{array}$ & $\begin{array}{r}99 \\
215\end{array}$ \\
\hline $\begin{array}{l}\text { Air-Conditioning Equipment } \\
\text { Yes } \\
\text { No }\end{array}$ & $\begin{array}{l}124 \\
174\end{array}$ & $\begin{array}{c}660 \\
1332\end{array}$ & $\begin{array}{l}250 \\
947\end{array}$ & $\begin{array}{r}79 \\
129\end{array}$ \\
\hline $\begin{array}{l}\text { Square Footage } \\
\text { Less than } 999 \\
1,000 \text { to } 1,999 \\
2,000 \text { or more }\end{array}$ & $\begin{array}{l}129^{* *} \\
168^{* *} \\
226^{* *}\end{array}$ & $\begin{array}{r}1,225 \\
1,068 \\
225\end{array}$ & $\begin{array}{r}496 \\
864 \\
3,181\end{array}$ & $\begin{array}{r}164 \\
111 \\
23\end{array}$ \\
\hline $\begin{array}{l}\text { Year of Construction } \\
1939 \text { or before } \\
1940 \text { to } 1974 \\
1975 \text { or after }\end{array}$ & $\begin{array}{l}191 * * * \\
119 * * * \\
108 * * *\end{array}$ & $\begin{array}{l}919 \\
822 \\
680\end{array}$ & $\begin{array}{l}894 \\
895 \\
-60\end{array}$ & $\begin{array}{r}51 \\
147 \\
51\end{array}$ \\
\hline $\begin{array}{l}\text { Climate Region } \\
\text { Cold region } \\
\text { Moderate region } \\
\text { Hot region }\end{array}$ & $\begin{array}{r}151^{* *} \\
148^{* *} \\
68^{* *}\end{array}$ & $\begin{array}{r}921 \\
1,987 \\
435\end{array}$ & $\begin{array}{r}1,933 \\
602 \\
262\end{array}$ & $\begin{array}{r}35 \\
268 \\
24\end{array}$ \\
\hline
\end{tabular}

1 Significant tests for gas-heated dwellings were based on an F-test from a two-way analysis of variance, controlling for climate region. Significant tests for electrically heated dwellings used a T-test for bi-level factors and a F-test for multi-level factors.

$*^{*}, * *$ and $* * *$ indicate that energy savings are significantly greater than zero at the $0.05,0.01$, or 0.001 level, respectively. 
Table I.3 Energy Savings by Weatherization Measures ${ }^{1}$

\begin{tabular}{|l|l|c|c|c|}
\hline & & & \\
Electrically. Heated \\
Dwellings
\end{tabular}

: Significant tests for gas-heated dwellings were based on an F-test from a two-way analysis of variance, controlling for climate region. Significant tests for electrically heated dwellings used a T-test for bi-level factors and a F-test for multi-level factors.

$*^{* * *}$, and $* * *$ indicate that energy savings are significantly greater than zero at the $0.05,0.01$, or 0.001 level, respectively. 
Table I.4 Energy Savings by Service Delivery Procedures ${ }^{1}$

\begin{tabular}{|c|c|c|c|c|}
\hline & $\begin{array}{l}\text { Gas: } \\
\text { Dwe }\end{array}$ & $\begin{array}{l}\text { leated } \\
\text { lings. }\end{array}$ & Electrica & fings? \\
\hline & $\begin{array}{l}\text { Gass } \\
\text { (cavings: }\end{array}$ & $\begin{array}{l}\text { Number of } \\
\text { Dwellings }\end{array}$ & $\begin{array}{l}\text { Electicity } \\
\text { Savings: } \\
\text { (kWhyear) }\end{array}$ & $\begin{array}{l}\text { Number of } \\
\text { Dwellings }\end{array}$ \\
\hline 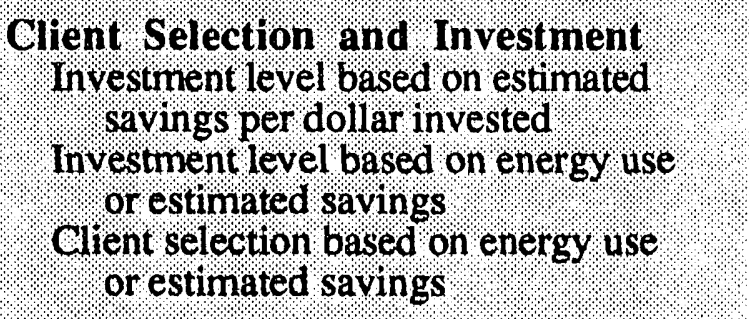 & $\begin{array}{l}125^{*} \\
148 \\
118^{*}\end{array}$ & $\begin{array}{r}1,507 \\
620 \\
526\end{array}$ & $\begin{array}{r}638 \\
430 \\
1,327\end{array}$ & $\begin{array}{r}106 \\
58 \\
61\end{array}$ \\
\hline 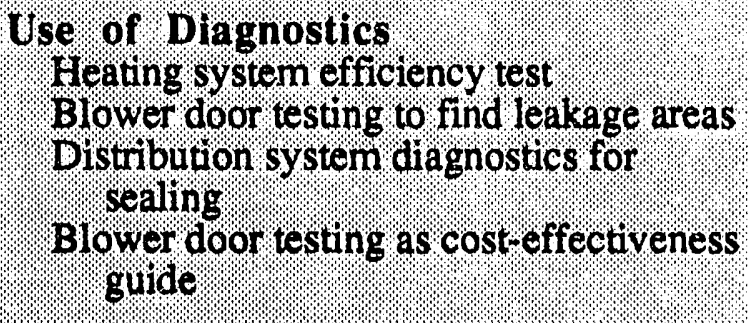 & $\begin{array}{l}152 * * \\
154 \\
192 * * \\
90\end{array}$ & $\begin{array}{r}1,504 \\
699 \\
247\end{array}$ & $\begin{array}{r}184 \\
1,836 \\
748 \\
1,835\end{array}$ & $\begin{array}{l}52 \\
59 \\
22 \\
15\end{array}$ \\
\hline 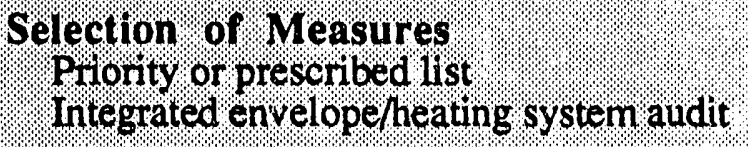 & $\begin{array}{l}123 \\
176^{*}\end{array}$ & $\begin{array}{r}1,938 \\
334\end{array}$ & $\begin{array}{l}714 \\
161\end{array}$ & $\begin{array}{r}284 \\
19\end{array}$ \\
\hline $\begin{array}{l}\text { Client Education } \\
\text { In person education } \\
\text { Literature to client? }\end{array}$ & $\begin{array}{l}126^{*} \\
135^{* *}\end{array}$ & $\begin{array}{l}2,035 \\
1,823\end{array}$ & $\begin{array}{l}256 \\
-89\end{array}$ & $\begin{array}{l}161 \\
142\end{array}$ \\
\hline $\begin{array}{l}\text { Quality Control } \\
\text { Visual inspection of heating system } \\
\text { Beating system diagnostics }\end{array}$ & $\begin{array}{l}131 \\
128 \\
109\end{array}$ & $\begin{array}{r}1,370 \\
1,079 \\
270\end{array}$ & $\begin{array}{r}347 \\
96 \\
1,663\end{array}$ & $\begin{array}{l}57 \\
43 \\
29\end{array}$ \\
\hline
\end{tabular}

1 Significant tests for gas-heated dwellings were based on an F-test from a two-way analysis of variance, controlling for climate region. Significant tests for electrically heated dwellings used a T-test for bi-level factors and a F-test for multi-level factors.

$*, * *$, and $* * *$ indicate that energy savings are significantly greater than zero at the $0.05,0.01$, or 0.001 level, respectively. 
Table I.5 Energy Sayings by Weatherization Costs and Agency Characteristics ${ }^{1}$

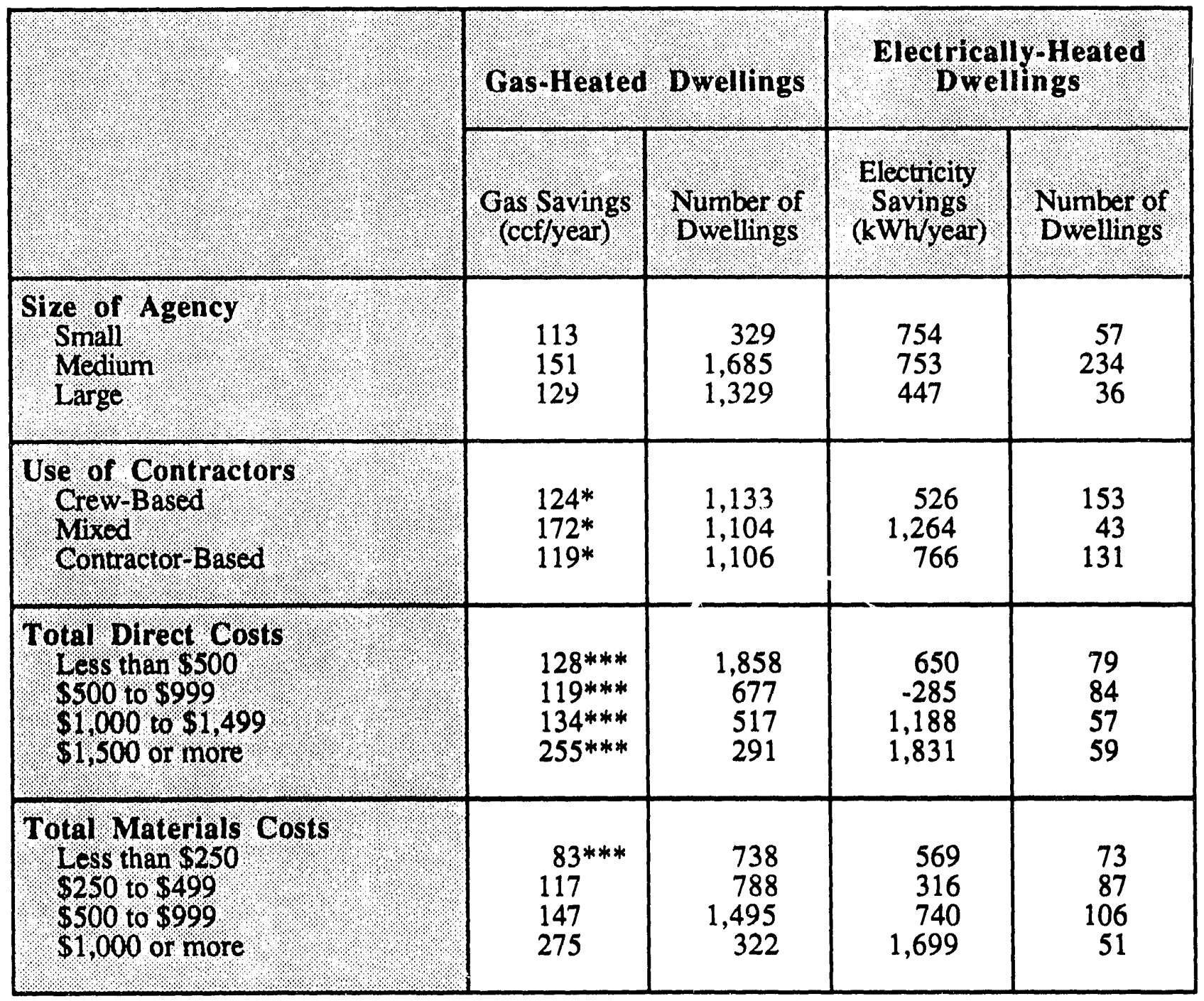

1 Significant tests for gas-heated dwellings were based on an F-test from a two-way analysis of variance, controlling for climate region. Significant tests for electrically heated dwellings used a T-test for bi-level factors and a F-test for multi-level factors.

$*, * *$, and $* * *$ indicate that energy savings are significantly greater than zero at the $0.05,0.01$, or 0.001 level, respectively. 



\section{INTERNAL DISTRIBUTION}

1 R.A. Balzer, 4500N, MS 6206

2 D.C. Bauer, 4500N, MS 6206

3 L.G. Berry, 4500N, MS 6206

4 M.A. Brown, 4500N, MS 6206

5 R.S. Carlsmith, 4500 N, MS 6188

6 C.V. Chester, 4500 N, MS 6190

7 S.M. Cohn, 4500N, MS 6205

8 J.W. Cooke, 4500N, MS 6269

9 G.E. Courville, 3147, MS 6070

10 T.R. Curlee, 4500 N, MS 6205

11 S. Das, 4500N, MS 6205

12 W. Fulkerson, 4500N, MS 6247

13 M.B. Gettings, 3147, MS 6070

14 S.W. Hadley, 4500N, MS 6206

15 L.J. Hill, 4500N, MS 6205

16 E.L. Hillsman, 4500N, MS 6206

17 E. Hirst, 4500N, MS 6206

18 R.B. Honea, 4500N, MS 6179

19 P.J. Hughes, 3147, MS 6070

20 M.A. Kamitz, 4515, MS 6065

21 C.R. Kerley, 4500N, MS 6205

22 J.O. Kolb, 3147, MS 6070
23 M.A. Kuliasha, 4500N, MS 6189

24 W.P. Levins, 3147, MS 6070

25 H.A. McLain, 3147, MS 6070

26 J.M. MacDonald, 3147, MS 6070

27 W.R. Mixon, 3147, MS 6070

28 R.L. Noe, 4500N, MS 6206

29 D.E. Reichle, 4500 N, MS 6253

30 A.C. Schaffhauser, 4500 N, MS 6186

31 M. Schweitzer, 4500N, MS 6206

32 T.R. Sharp, 3147, MS 6070

33 R.B. Shelton, 4500N, MS 6187

34 B.M. Sorensen, 4500N, MS 6190

35-534 S.A. Surdam, 4500N, Room H11-D

535 M.P. Ternes, 3147, MS 6070

536 B.E. Tonn, 4500N, MS 6207

537 D.L. White, 4500N, MS 6206

538 T.J. Wilbanks, 4500N, MS 6184

539 ORNL Patent Office

540 Central Research Library

541 Document Reference Section

542-544 Laboratory Records (3)

545 Laboratory Records - RC

\section{EXTERNAL DISTRIBUTION}

546 D.A. Beschen, U.S. Department of Energy, 5G-023, EE-70, 1000 Independence Ave., S.W., Washington, DC 20585

547 D.R. Bohi, Director, Energy and Natural Resources Division, Resources for the Future, 1616 P Street, N.W., Washington, DC 20036

548 P. Brandis, Office of Energy Resources, Bonneville Power Administration, P.O. Box 3621, Portland, OR 97208

549 T.E. Drabek, Professor, Department of Sociology, University of Denver, Denver, Colorado 80208-0209 


\section{EXTERNAL DISTRIBUTION (cont'd)}

550 M.A. Fowler, U.S. Department of Energy, 5G-023, EE-532, 1000 Independence Avenue, S.W., Washington, DC 20585

551 C.D. MacCracken, President, Calmac Manufacturing Corporation, 101 West Sheffield Ave., P.O. Box 710, Englewood, NJ 07631

552 Ralph Nader, Post Office Box 19367, Washington, DC 20036

553 Office of Assistant Manager for Energy Research and Development, DOE Oak Ridge Field Office, P.O. Box 2008, Oak Ridge, TN 37831-6269

554 OSTI, U.S. Department of Energy, P.O. Box 62, Oak Ridge, TN 37831

555 J.B. Shrago, Director, Office of Technology Transfer, Vanderbilt University, 405 Kirkland Hall, Nashville, TN 37240

556 G.F. Sowers, P.E., Senior Vice President, Law Companies Group, Inc., 114 Townpark Drive, Suite 250, Kennesaw, Georgia 30144-5599

557 J. Van Vlandren, U.S. Department of Energy, EE-532, 1000 Independence Ave., S.W., Washington, DC 20585

558 C.M. Walton, Paul D. and Betty Robertson Meek Centennial Professor and Chairman, Department of Civil Engineering, College of Engineering, The University of Texas at Austin, Cockrell Hall, Suite 4.2, Austin, Texas 78712 

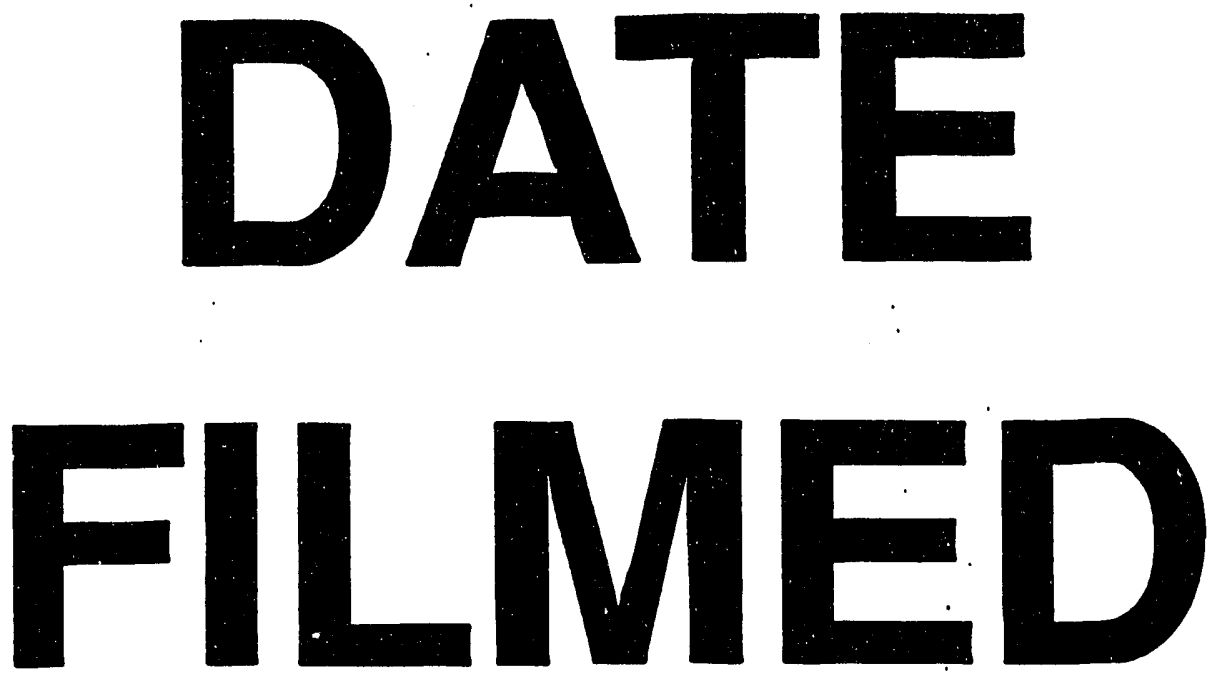

$10 / 7 / 93$
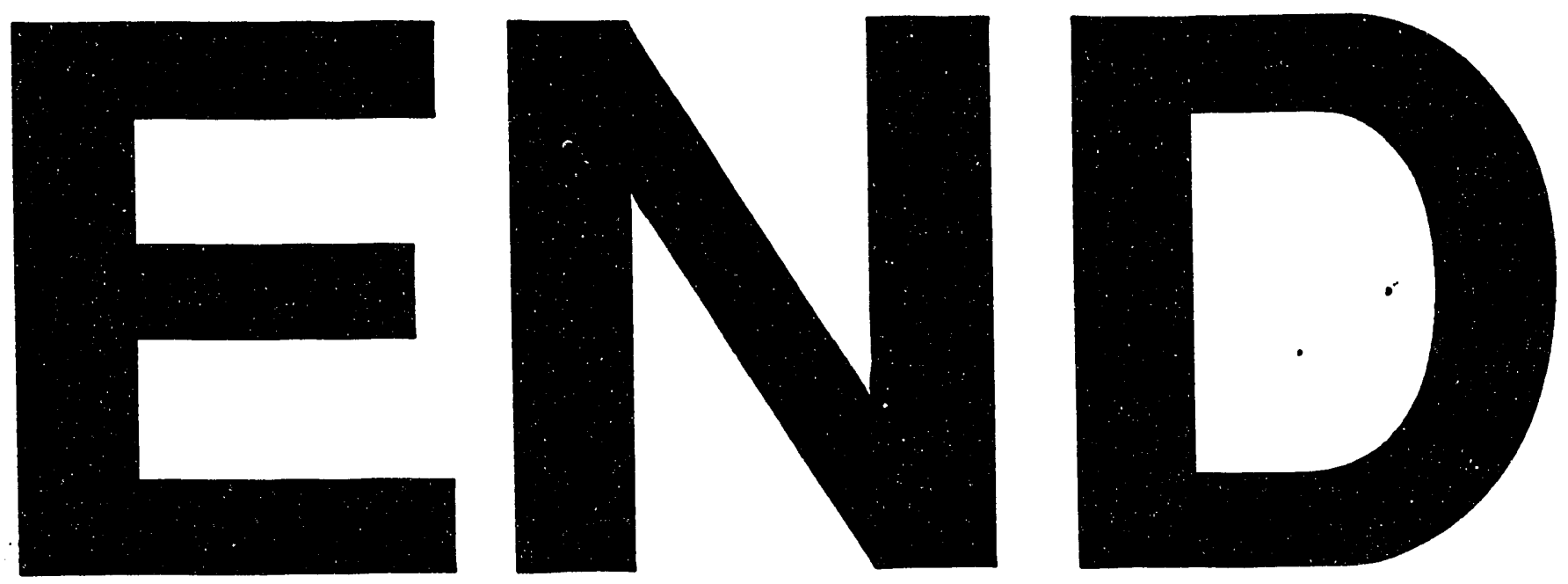
